\title{
EARTH SCIENCES DIVISION RESEARCH SUMMARIES 2002-2003
}

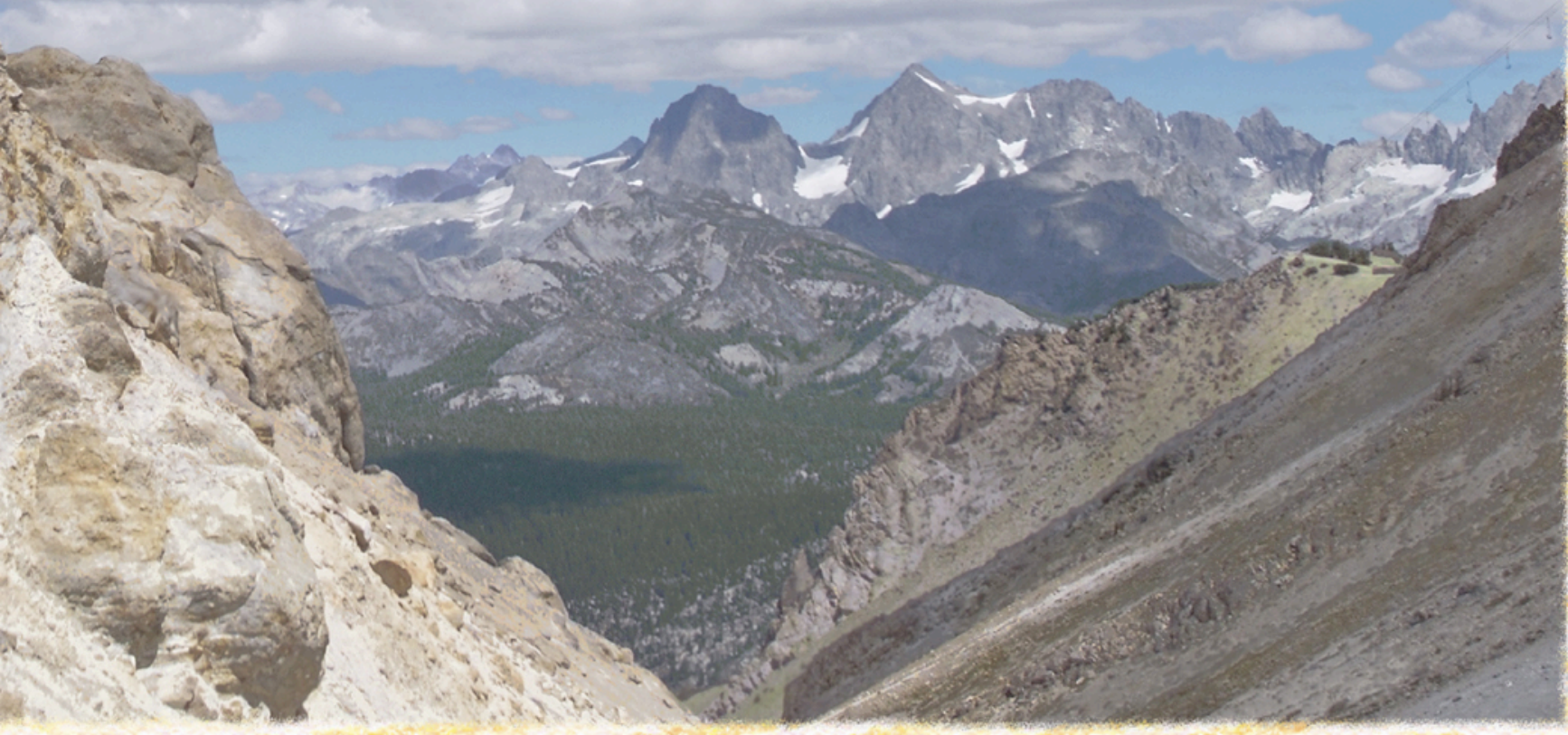


Disclaimer

This document was prepared as an account of work sponsored by the United States Government. While this document is believed to contain correct information, neither the United States Government nor any agency thereof, nor The Regents of the University of California, nor any of their employees, makes any warranty, express or implied, or assumes any legal responsibility for the accuracy, completeness, or usefulness of any information, apparatus, product, or process disclosed, or represents that its use would not infringe privately owned rights. Reference herein to any specific commercial product, process, or service by its trade name, trademark, manufacturer, or otherwise, does not necessarily constitute or imply its endorsement, recommendation, or favoring by the United States Government or any agency thereof, or The Regents of the University of California. The views and opinions of authors expressed herein do not necessarily state or reflect those of the United States Government or any agency thereof, or The Regents of the University of California.

Ernest Orlando Lawrence Berkeley National Laboratory is an equal opportunity employer. 
LBNL-53859

\section{Earth SCIENCES Division}

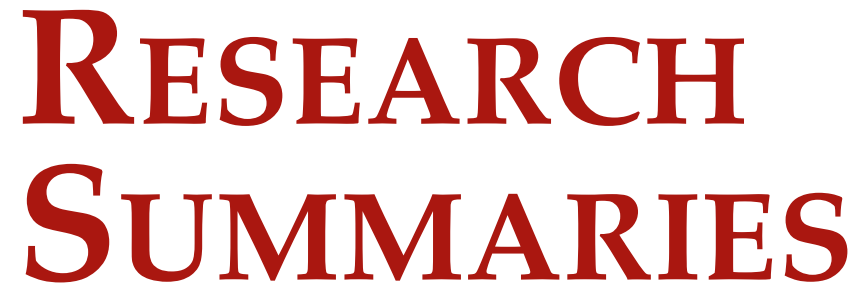

\section{2-2003}

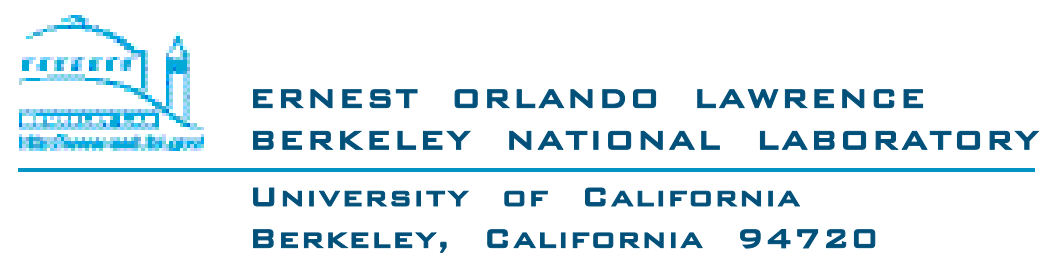

Prepared for the U.S. Department of Energy under Contract No. DE-AC03-76SF00098 


\section{EARTH SCIENCES Division ORganization ChaRT}

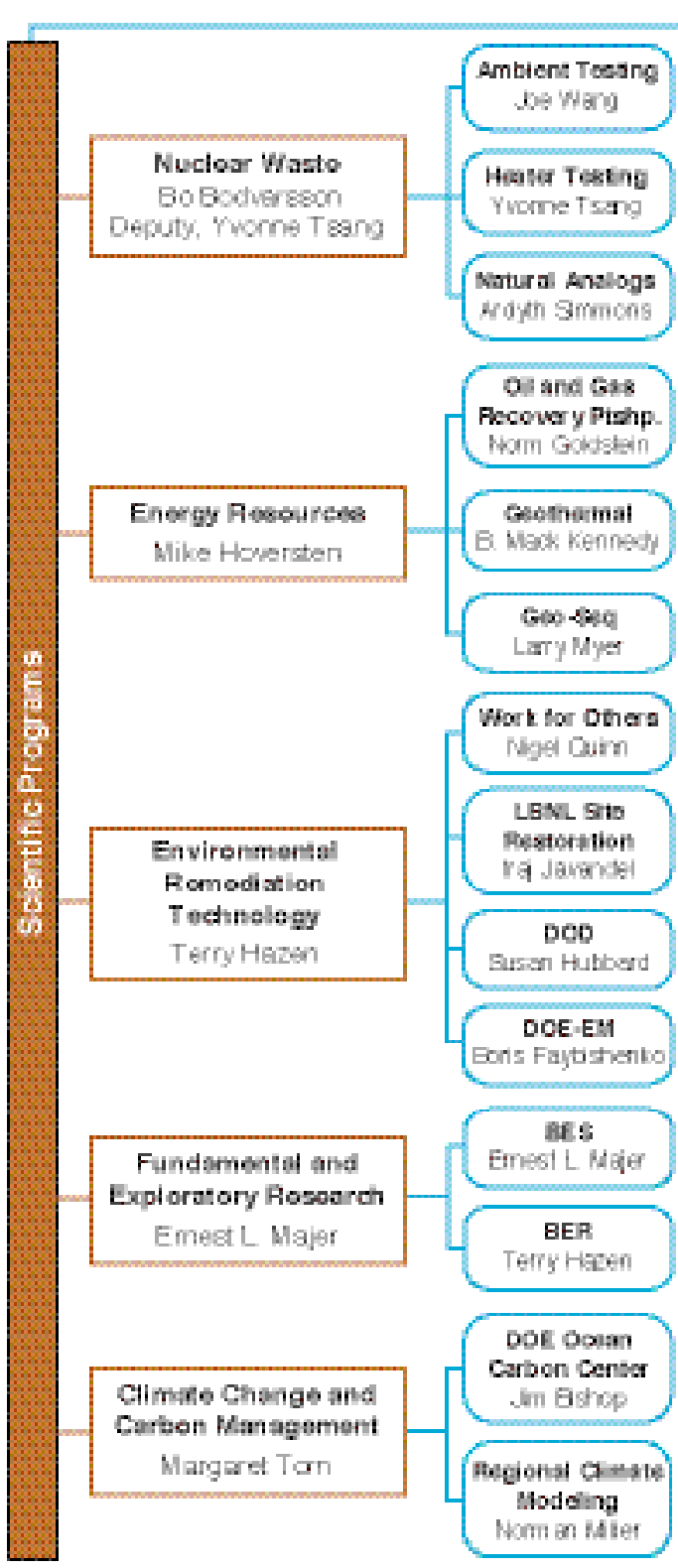

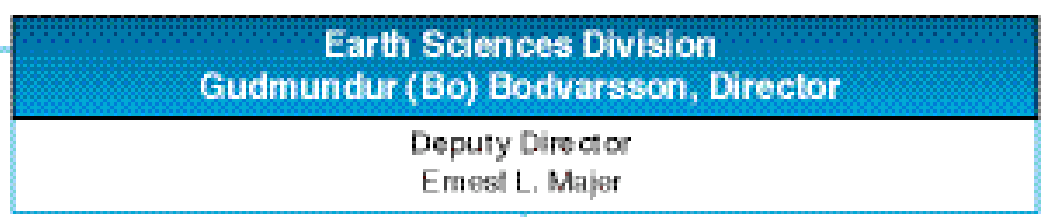

Division Staff and Administration Linda Wury

Technicad Support Department Ywonne Trang

\section{Division Council}

Bo Bodversson, Chai

Profesaional Staf Committee

Wonne Teang, Chair

Environment, Hesith \& Safety

Peter Persom iRandall Hedegasard

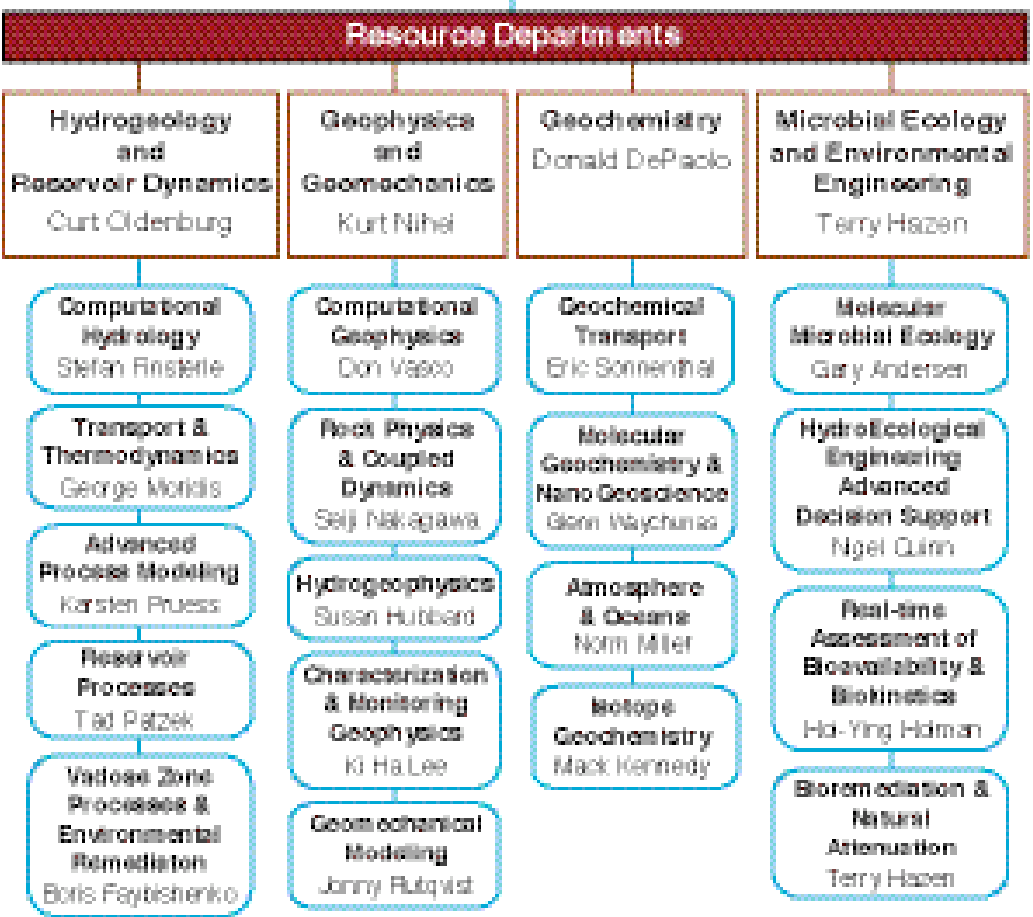

megrae is
Hydrology
Chin-Pu Tsang

coupled

Processes a

Mochassic

Hydrotoly

Jas Britioliser

Charectertzation

a. Itontioning

kenz kar beati 


\section{TABLE OF CONTENTS}

A Perspective from the Division Director

Hydrogeology and Reservoir Dynamics 25

$\begin{array}{ll}\text { GEOPHYSICS AND GEOMECHANICS } & 7\end{array}$

$\begin{array}{lr}\text { GEOCHEMISTRY } & 9\end{array}$

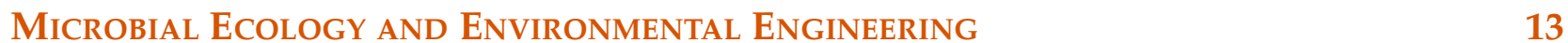

RESEARCH PROGRAMS 15

$\begin{array}{ll}\text { FUNDAMENTAL AND EXPLORATORY RESEARCH } & 17\end{array}$

U-Th/He Age Determinations on Volcanic Rocks: A New Tool for Quaternary Geochronology

Kinetic Fractionation of Lithium Isotopes by Diffusion in Water

John N. Christensen, Frank Richter, and Ruslan Mendybaev

Film Flow along Tunnel Walls

Teamrat A. Ghezzehei and Stefan Finsterle

Air-derived Noble Gases In Sediments: Implications for Basin-Scale Hydrogeology

B. Mack Kennedy, Tom Torgersen, and Thijs van Soest

Noble Gas Isotope Studies of Geothermal Systems

B. Mack Kennedy and Matthijs C. van Soest

Synthesis, Characterization, and Reactivity of Nanoparticulate Goethite

Christopher S. Kim, Jill F. Banfield, and Glenn A. Waychunas

Fault Zone Imaging Using Guided Waves

Valeri Korneev and Robert Nadeau

Joint Inversion for Mapping Subsurface Hydrological Parameters

Ki Ha Lee and Hung-Wen Tseng

Use of ${ }^{234} \mathrm{U} /{ }^{238} \mathrm{U}$ Ratios to Measure In Situ Weathering Rates in the Hanford Vadose Zone

Katharine Maher, Donald J. DePaolo, and John N. Christensen 


\section{Fundamental AND EXPLORATORY RESEARCH (CONTINUED)}

Detection and Identification of Unexploded Ordnance

Frank Morrison, Alex Becker, Erika Gasperikova, and Torquil Smith

Seismic Wave Scattering by Hetergenous Fractures and Faults

Seiji Nakagawa, Aoife C. Toomey, and Larry R. Myer

Imaging Attenuation in Rock with Heterogeneous Multiphase Fluids

Kurt T. Nihei, S. Nakagawa, and T. Watanabe

Clay Mineral Surface Geochemistry: Structure of Water Adsorbed on a Mica Surface

Sung-Ho Park and Garrison Sposito

Intercomparison of Simulation Codes for Geologic Sequestration of $\mathrm{CO}_{2}$

Karsten Pruess

Investigation of the Effects of Evaporation and Infiltration

on Vadose Zone Pore-Fluid $\delta^{18} \mathrm{O}$ Values at Hanford, Using TOUGHREACT

Michael J. Singleton, Eric L. Sonnenthal, Donald J. DePaolo, and Mark E. Conrad

Uranium Diffusion

Tetsu K. Tokunaga, Jiamin Wan, Jasquelin Pena, Stephen R. Sutton, and Matt Newville

Vanishing of Capillary Hysteresis in Porous Media

Tetsu K. Tokunaga, Keith R. Olson, and Jiamin Wan

Helium Isotope Ratios in South Sister Volcano Vicinity, Cold Springs

Jiamin Wan, Guilin Han, Jasquelin Pena, Xiang-Yun Song, and Tetsu Tokunaga

Comparison of the Wet Hematite and Corundum (0001) Surface Structures

Determined by Synchrotron X-Ray CTR Analysis

Glenn Waychunas, Thomas Trainor, Peter Eng, and Gordon Brown

Manganese Valence and Mineral Surface Structure Determined with In Situ Soft X-Ray Spectroscopy 


\section{Nuclear Waste (CONTINUED)}

Investigating How the Multiscale Heterogeneity of Hydrogeologic Properties Affects

Flow and Transport at Yucca Mountain, Nevada

Paul Cook and Joe Wang

Geothermal Systems as Natural Analogues for Yucca Mountain Coupled Processes

Patrick Dobson and Timothy Kneafsey

Development of Numerical Grids for Unsaturated Zone Flow and Transport Modeling

Patrick Dobson, Lehua Pan, Yu-Shu Wu, and Randy Hedegaard

Scaling and Hierarchy of Models for Flow Processes in Unsaturated Fractured Rock

Boris Faybishenko, G.S. Bodvarsson, Jennifer Hinds, and Paul A. Witherspoon

Evaporation from a Seepage Face

Stefan Finsterle, Teamrat A. Ghezzehei, Rob C. Trautz, C.F. (Rick) Ahlers, and Paul J. Cook

Effects of Induced Convection on Far-Field Groundwater Flow

Kazumasa Ito and Kenzi Karasaki

Investigation of Uncertainty in Hydrogeologic Modeling of Flow and Transport in a

Large, Saturated Granitic Rock Mass

Kenzi Karasaki, Christine Doughty, and Kazumasa Ito

Fracture Sealing by Mineral Dissolution and Precipitation at Yucca Mountain

Timothy J. Kneafsey, Patrick F. Dobson, Eric L. Sonnenthal, John A. Apps, and Nicolas Spycher

Scale Dependency of the Effective Matrix Diffusion Coefficient

Hui-Hai Liu, Gudmundur S. Bodvarsson, and Guoxiang Zhang

The Active Fracture Model and Fractal Flow Behavior

Hui-Hai Liu, Guoxiang Zhang, and Gudmundur S. Bodvarsson

Implications of Halide Leaching on Chlorine-36 Studies at Yucca Mountain

Guoping Lu, Eric L. Sonnenthal, and Gudmundur S. Bodvarsson

3-D Studies of Mountain-Scale Radionuclide Transport in the

Unsaturated Zone at Yucca Mountain, Nevada

George J. Moridis, Yonkoo Seol, and Yu-Shu Wu

A Modeling Study of Flow Diversion and Focusing in Unsaturated Fractured Rocks

New Improvements to Wingridder: An Interactive Grid Generator For TOUGH2

Lehua Pan

Coupled Thermal-Hydrological-Mechanical Analysis with TOUGH-FLAC 


\section{Nuclear Waste (CONTINUED)}

Flow and Transport Through a Fault Embedded in Fractured Rock

Rohit Salve, Hui-Hai Liu, Paul Cook, Atlantis Czarnomski, and Joseph S.Y. Wang

A Numerical Study of Unsaturated Flow and Transport

Through a Fractured Meter-sized Rock Block

Yongkoo Seol, Timothy J. Kneafsey, Kazumasa Ito, and Stefan Finsterle

Effects of Water-Rock Interaction of Unsaturated Flow in Heterogeneous Fractured Rock

Eric Sonnenthal, Nicolas Spycher, Charles Haukwa, and Tianfu Xu

Yucca Mountain Heater Test Cooling Phase

Yvonne Tsang, Sumit Mukhopadhyay, Jonny Rutqvist, Eric Sonnenthal, and Nicolas Spycher

A Mountain-Scale Flow Model for the Unsaturated Zone of Yucca Mountain, Nevada

A Numerical Investigation of Flow Focusing in Unsaturated Fracture Networks

Keni Zhang, Yu-Shu Wu, G. S. Bodvarsson, and Hui-Hai Liu

Multiscale Heterogeneity Effects at Yucca Mountain

Quanlin Zhou, Hui-Hai Liu, Gudmundur S. Bodvarsson, and Curtis M. Oldenburg

Fractured Reservoir Modeling: Coupled Seismic and Fluid Response

Thomas M. Daley, Michael Schoenberg, Jonny Rutqvist, and Kurt Nihei

A Portable X-Ray Computed Tomography Sysytem

Barry M. Freifeld, Timothy J. Kneafsey, Jacob Pruess, and Liviu Tomutsa

Joint Crosswell and Single-Well Seismic Studies of

$\mathrm{CO}_{2}$ Injection in an Oil Reservoir at Lost Hills, California

Roland Gritto, Thomas M. Daley, and Larry R. Myer

Joint Geophysical Imaging

Gas-Hydrate Imaging Using X-Ray Computed Tomography

Fracture Quantification in Naturally Fractured Gas Reservoirs

Ernest L. Majer

Classification of Gas Hydrate Deposits and Corresponding Production Strategies 


\section{ENERGy Resources (CONTINUED)}

Simulation of Partitioning Tracers

Chao Shan and Karsten Pruess

Physics-Based Reconstruction of Sedimentary Rocks

Dmitriy Silin and Tad Patzek

Nanoscale Three-Dimensional Rock Imaging Using Focussed Ion Beam

Liviu Tomutsa (ESD) and Velimir Radmilovic (NCEM)

Finite-Difference Modeling of 3-D Anisotropic Wave Propagation Using Variable Grid Spacing

Aoife Toomey and G. M. Hoversten

Changes in Noncondensable Gases in Steam from the Cerro Prieto Geothermal Field

Alfred H. Truesdale, Marcelo J. Lippmann, M. H. Rodriguez, and A. Perez

3-D Resistivity Imaging of Single-Hole EM Data

Hung-Wen (Ocean) Tseng and Ki Ha Lee

Rapid Imaging of Interwell Fluid Saturations Using Seismic and Multiphase Production Data

Don Vasco and Akhil Datta-Gupta

ENVIRONMENTAL REMEDiATION TECHNOLOGY

DNA Microarrays for Characterization of Microbial Backgrounds

Gary Andersen, Todd DeSantis, and Sonya Murray

Smart Storage of Landfilled Waste

Sharon E. Borglin, Terry C. Hazen, Curtis M. Oldenburg, and Peter T. Zawislanski

Real-time Sensor to Monitor Suspended Sediment Loads in Streams

Chris G. Campbell

A Stochastic Integrated Approach to Parameter Estimation Using Geophysical Data

Jinsong Chen, Susan Hubbard, Michael G. Hoversten, and Ernest Majer

Identifying the Sources of Subsurface Uranium Contamination at the Hanford Site, Washington

John N. Christensen, P. Evan Dresel, Mark Conrad, Kate Maher, and Donald J. DePaolo

Estimation of Natural Biodegradation Rates of Organics in Buried Waste at INEEL

Mark Conrad and Donald J. DePaolo

DOE Environmental Management International Projects Highlights

Boris Faybishenko

NAPL Contaminant Location with High-Frequency Crosswell Seismic Methods

Jil T. Geller, Ernest L. Majer, Jonathan Ajo-Franklin, Kenneth H. Williams, and John E. Peterson 


\section{Environmental Remediation Technology (CONTINUed)}

Biological Treatment of Irrigation Drainage for Selenium Removal

Franklin Bailey Green, Sharon E. Borglin, Clement Hsieh, Rick Y.C. Huang, Tryg J. Lundquist,

Nigel W.T. Quinn, Archana Sudame, Mathew G. Takata, and William J. Oswald

Accelerated Biodegradation of Organic Contaminants by Humic Acid

Hoi-Ying Holman, K. Nieman, D.L. Sorenson, C.D. Miller, and R.C. Sims

Application of Thermally Enhanced Vapor Extraction at Berkeley Lab

Iraj Javandel and Barry Freifeld

High-Frequency Electromagnetic Impedance Measurements for

Ki Ha Lee, Alex Becker, and Hung-Wen Tseng

The Role of Biogeochemical Dynamics in the Formation of U(VI) Solid Phases

Tracy E. Letain, Terry C. Hazen, and Heino Nitsche

Use of Sr Isotopes to Determine Long-Term Average Vadose Zone Infiltration Flux at Hanford 200W Area

Katharine Maher, Donald J. DePaolo, and Mark S. Conrad

Simulating Landfill Biodegradation Processes with T2LBM

101

Curtis M. Oldenburg, Sharon E. Borglin, and Terry C. Hazen

TMVOC, A Simulator for Multiple Volatile Organic Chemicals

Karsten Pruess and Alfredo Battistelli

Real-Time Management of Dissolved Oxygen in the San Joaquin River Deep-Water Ship Channel

Nigel W.T. Quinn, William T. Stringfellow, and Jeremy Hanlon

Biological Treatment of Mixed Wastes: A Safer Alternative to Incineration

William T. Stringfellow, Tatsuyuki Komada, and Li-Yang Chang

Estimates of Hydraulic Conductivities Along the Russian River Using Groundwater Temperature Profiles

Grace W. Su, James Jasperse, Donald Seymour, and Jim Constantz

Unsaturated Hydraulic Properties of Gravels

Tetsu K. Tokunaga, Keith R. Olson, and Jiamin Wan

Bioprospecting in Extreme Environments

Robert C. Trautz, Iraj Javandel, and Preston D. Jordan 


\section{Environmental ReMediation Technology (CONTINUed)}

Uranium Transformations in Contaminated Sediments

Jiamin Wan, Tetsu K. Tokunaga, Terry Hazen, Mary Firestone, Zuoping Zheng,

Jasquelin Pena, Joern Larsen, and Eoin Brodie

Geochemical Evolution of Highly Alkaline and Saline Tank Waste Plumes

During Seepage Through Vadose Zone Sedments

Jiamin Wan, Tetsu K. Tokunaga, Joern T. Larsen, and Zuoping Zheng

Modeling Geochemical Reactive Transport of Concentrated Aqueous Solutions in Variably Saturated Media 112

Guoxiang Zhang, Zuoping Zheng, and Jiamin Wan

Berkeley Lab Site Modeling

Quanlin Zhou, Jens T. Birkholzer, Iraj Javandel, and Preston D. Jordan

\section{Climate Variability and Carbon Management}

Understanding and Assessing Global Ocean Carbon Sequestration

James K. Bishop

Modeling Supercritical $\mathrm{CO}_{2}$ Injection in Brine-Bearing Formations

Christine Doughty, Karsten Pruess, and Sally M. Benson

Tracking Stable Isotopes In a Regional Climate Model

Prudence N. Foster, Norman L. Miller, and Don DePaolo

Performance Requirements for Geological Storage of $\mathrm{CO}_{2}$

Robert P. Hepple and Sally M. Benson

A Mesoscale Analysis of the Impact of Snowpack on Climate Variability in the Sierra Nevada Region

Jiming Jin and Norman L. Miller

Impact of the ENSO Snowpack on the Western United States: A Global Climate Model Study

Jiming Jin and Norman L. Miller

Geostatistical Modeling of Climate Variables at Regional Scales

Phaedon C. Kyriakidis and Norman L. Miller

Isotopic Variations in Atmospheric Moisture in the Great Plains Region

Madhav V. Machavaram, Mark E. Conrad, and Norman L. Miller

Crosswell and Vertical Seismic Imaging at the Weyburn $\mathrm{CO}_{2}$ Project

Ernest L. Majer, Dale Cox, Roland Gritto, and Thomas M. Daley

Uncertainty Analysis of California Streamflow Using Multiple Climate Change Scenarios 


\section{Climate Variability and Carbon Management (continued)}

The California Water Resources Research and Applications Center

Norman L. Miller, K.E. Bashford, G. Brimhall, W.E. Dietrich, J.A. Dracup,

J. Jin, J. Kim, P. C. Kyriakidis, X. Liang, and N.W.T. Quinn

The DOE Water Cycle Pilot Study:

Modeling and Analysis of Seasonal and Event Variability at the Walnut River Watershed

Norman L. Miller, Kathy E. Bashford, Mark S. Conrad, Prudence N. Foster, and Madhav V. Machavaram

The GEO-SEQ Project

Larry R. Myer and Sally M. Benson

Carbon Dioxide for Enhanced Gas Recovery and as Cushion Gas

Coupled Model for $\mathrm{CO}_{2}$ Leakage and Seepage

Curtis M. Oldenburg and André J.A. Unger

Nonisothermal Effects During $\mathrm{CO}_{2}$ Leakage from a Geologic Disposal Reservoir

Karsten Pruess

Effect of Wheat Harvest on Regional Clmate: Experiments with the Coupled MM5-ISOLSM Model

William Riley, Heather S. Cooley, and Margaret S. Torn

Using ${ }^{18} \mathrm{O}$ to Partition Ecosystem Carbon Exchanges:

Impact of the Near-Surface $\delta^{18} \mathrm{O}$ Value of Soil Water on the $\delta^{18} \mathrm{O}$ Value of the Soil-Surface $\mathrm{CO}_{2}$ Flux

William J. Riley

A Noniterative Model to Compute $\mathrm{CO}_{2}-\mathrm{H}_{2} \mathrm{O}$ Mutual Solubilities at $12-100^{\circ} \mathrm{C}$ and up to $600 \mathrm{Bar}$

Nicolas Spycher and Karsten Pruess

Carbon Cycling in the Southern Great Plains: The ARM/LBNL Carbon Project

Margaret S. Torn, M.L. Fischer, William J. Riley, I. Pesenson, and J. Berry

The Importance of Belowground Plant Allocation for Terrestrial Carbon Sequestration

Margaret S. Torn, T.E. Dawson, J.A. Bird, J. Gaudinski, and D.E. Williard

A Whole-Forest Pulse-Label Study of Microbial Dynamics and Root Turnover

Margaret S. Torn, J. Gaudinski, K. Treseder, J. Westbrook, D. Joslin, and C. Swanston

TOUGHREACT Simulation Studies for Mineral Trapping Following $\mathrm{CO}_{2}$ Disposal in Deep Saline Aquifers

Tianfu Xu, John A. Apps, and Karsten Pruess 


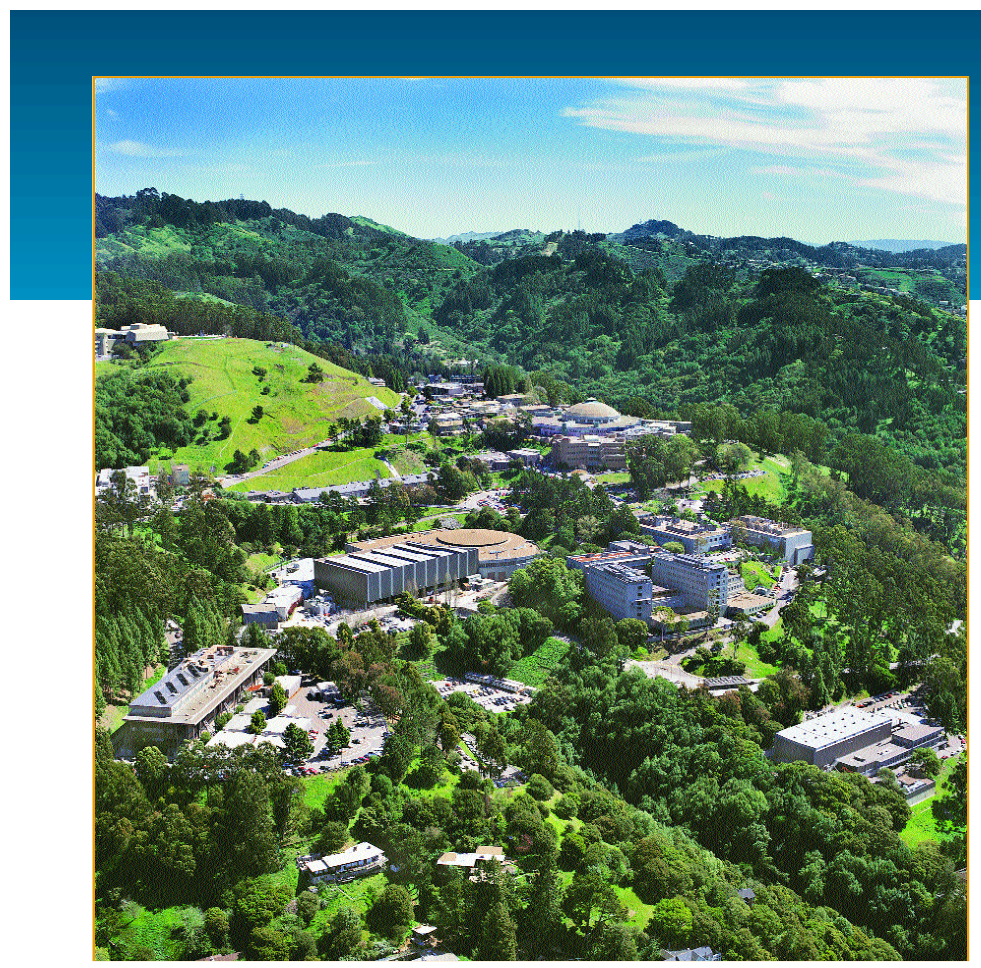

Research in earth and atmospheric sciences is becoming increasingly important in light of the energy, climate change, and environmental issues facing the United States and the world. The development of new energy resources other than hydrocarbons and the safe disposal of nuclear waste and greenhouse gases (such as carbon dioxide and methane) are critical to the future energy needs and environmental safety of this planet. In addition, the cleanup of many contaminated sites in the U.S., along with the preservation and management of our water supply, remain key challenges for us as well as future generations.

Addressing these energy, climate change, and environmental issues requires the timely integration of earth sciences' disciplines (such as geology, hydrology, oceanography, climatology, geophysics, geochemistry, geomechanics, ecology, and environmental sciences). This integration will involve focusing on fundamental crosscutting concerns that are common to many of these issues. A primary focus will be the characterization, imaging, and manipulation of fluids in the earth. Such capabilities are critical to many DOE applications, from environmental restoration to energy extraction and optimization.

The Earth Sciences Division (ESD) of the Ernest Orlando Lawrence Berkeley National Laboratory (Berkeley Lab) is currently addressing many of the key technical issues described above.
Ernest Orlando Lawrence Berkeley National Laboratory EARTH SCIENCES DIVISION RESEARCH SUMMARIES 2002-2003

\section{A Perspective from the Division Director}

Gudmundur S. Bodvarsson

510/486-4789 gsbodvarsson@lbl.gov

Our total staff of over 200 scientists, UC Berkeley faculty, support staff and guests-performing world-acclaimed fundamental research in hydrogeology and reservoir engineering, geophysics and geomechanics, geochemistry, microbial ecology, and environmental engineering-provide the foundation for all of our programs. Building on this scientific foundation, we perform applied earth science research and technology development to support the Department of Energy in a number of its program areas, namely:

- Fundamental and Exploratory Research--fundamental research to provide a basis for new and improved energy and environmental technologies

- Nuclear Waste Management-theoretical, experimental and simulation studies of the unsaturated zone at Yucca Mountain, Nevada

- Energy Resources-collaborative projects with industry to develop or improve technologies for the exploration and production of oil, gas, and geothermal reservoirs

- Environmental Remediation Technology-innovative technologies for locating, containing, and remediating metals, radionuclides, chlorinated solvents, and energyrelated contaminants in soils and groundwaters

- Climate Change and Carbon Management-geologic sequestration of carbon dioxide, carbon cycling in the oceans and terrestrial biosphere, and regional climate modeling, which are the cornerstones of a major new divisional research thrust related to understanding and mitigating the effects of increased greenhouse gas concentrations in the atmosphere. 
In this document, we present summaries of many of our current research projects. While it is not a complete accounting, it is representative of the nature and breadth of our research effort. We are proud of our scientific efforts, and we hope that you will find our research useful and exciting. Any comments on our research are appreciated and can be sent to me personally.

This report is divided into five sections that correspond to the major research programs in the Earth Sciences Division:

- Fundamental and Exploratory Research

- Nuclear Waste

- Energy Resources

- Environmental Remediation Technology

- Climate Variability and Carbon Management

These programs draw from each of ESD's disciplinary departments: Microbial Ecology and Environmental Engineering, Geophysics and Geomechanics, Geochemistry, and Hydrogeology and Reservoir Dynamics. Short descriptions of these departments are provided as introductory material. A list of publications for the period from January 2002 to June 2003, along with a listing of our personnel, are appended to the end of this report.

\section{ACKNOWLEDGMENTS}

We gratefully acknowledge the support of our major sponsors in the Department of Energy, which include the Office of Science, the Office of Fossil Energy, the Office of Energy Efficiency and Renewable Energy, the Office of Civilian Radioactive Waste Management, and the Office of Environmental Management. We also appreciate the support received from other federal agencies such as the Bureau of Reclamation, the Department of Defense, the Environmental Protection Agency, and NASA. Lastly, we must also acknowledge and thank our industrial collaborators, who provide both financial and in-kind support through various partnership projects, and who bring additional ideas, data, and experience to ESD. 


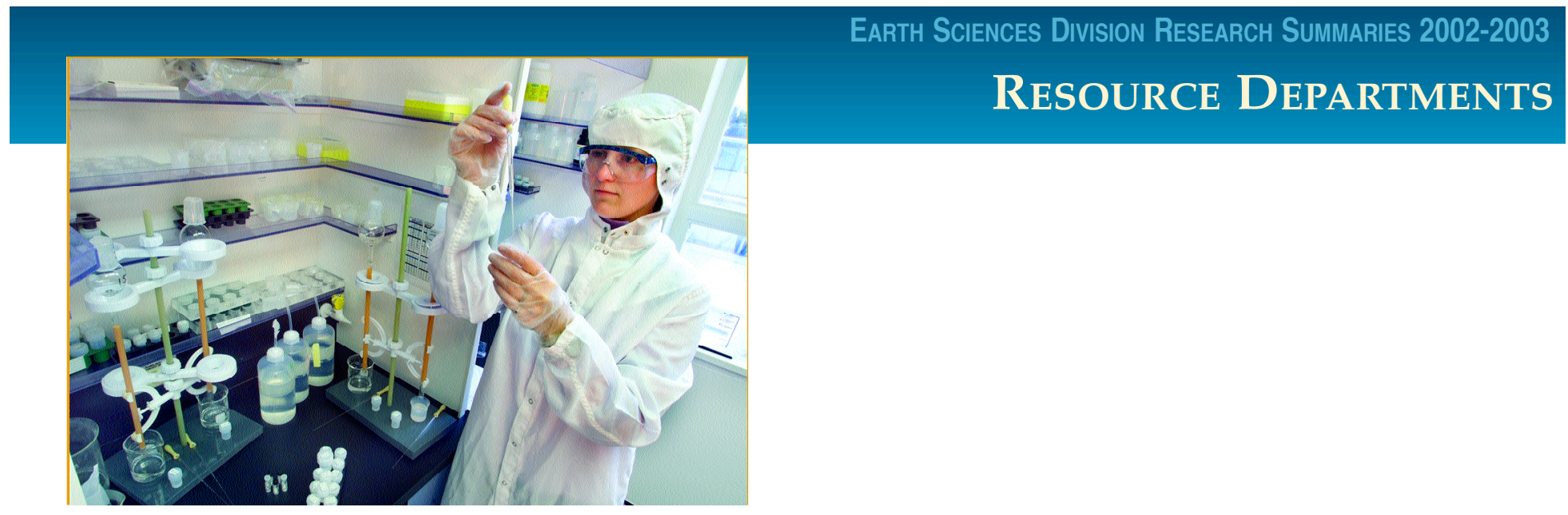

\section{Hydrogeology and Reservoir Dynamics}

GeOPHYSICS AND GeOMECHANICS

GEOCHEMISTRY

Microbial ECOLOGY AND ENVIRONMENTAL ENGINEERING 



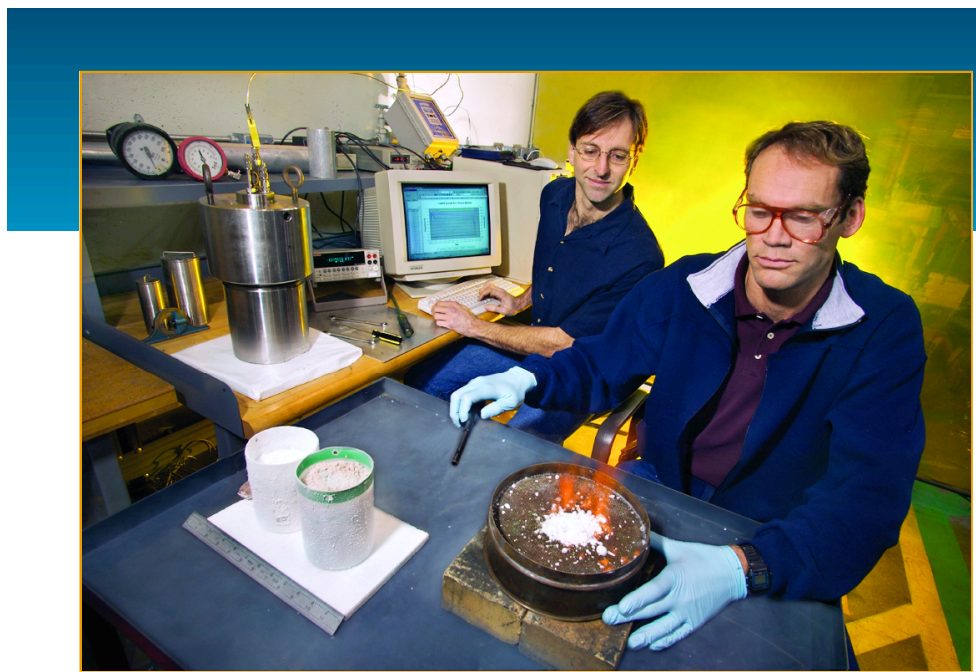

The Hydrogeology and Reservoir Dynamics (HRD) department consists of more than 60 scientists, postdocs, research associates, and graduate students carrying out a broad range of cutting-edge research in fundamental and applied hydrology. HRD has expertise in theoretical, experimental, field, and modeling approaches in a variety of research areas, among which are unsaturated zone hydrology (including fracture flow and transport), reservoir engineering (including pore-level modeling and gas hydrate studies), contaminant hydrology (including reactive and colloid-assisted transport), and coupled nonisothermal, geochemical, and geomechanical processes. The HRD department addresses national needs in the areas of subsurface energy resource recovery, contaminant hydrology, geologic $\mathrm{CO}_{2}$ storage, and nuclear waste disposal. Highlights of research efforts in these areas over the last two years include the following:

\section{SUBSURFACE ENERGY RESOURCE RECOVERY}

Researchers in HRD are studying ways to enhance production of energy from subsurface reservoirs containing geothermal energ $y$, oil and gas, and methane gas hydrates. Continuing the long tradition of geothermal researdh in the Earth Sciences Division, staff members in HRD are investigating geothermal reservoir dynamics using natural tracers as indicators of boiling, recharge, and mixing in liquid-dominated systems. Applications and development of ESD's reservoir simulator TOUGH2, for phase-partitioning tracer studies using noble gases in vapor-dominated systems, are also carried out for characterizing fracture systems and fracture matrix interactionwith the ultimate goal of optimizing energy production. Imaging of oil reservoir rock and highly detailed mathematical models of pore structure are used by HRD scientists to derive relative permeability curves to improve oil recovery from rocks such as diatomite.
Resource Department

HYDROGEOLOGY AND RESERVOIR DYNAMICS

Curt Oldenburg

510/486-7419

cmoldenburg@lbl.gov
The vast potential of gas-hydrate deposits in permafrost, coupled with practical barriers to hydrate gas production, has motivated HRD's development of the world's leading gashydrate reservoir simulator. This extension of TOUGH2 has been used to predict gas production from a permafrost reservoir for various types of hydrate deposits. In a parallel effort, HRD researchers have developed the first-ever portable computed tomography (CT) scanner for imaging gas hydrates in rock cores that are brought to the surface during exploration drilling. This innovation has allowed researchers to quantify gas-hydrate deposits on site before dissociation of the hydrates occurs due to depressurization and heating. Laboratory experiments using CT scanning of manufactured hydrates in rock cores are allowing ESD researchers to track hydrate dissociation fronts over time while controlling pressure and temperature. This work will lead to better understanding of hydrate dynamics and gashydrate methane production strategies. Integrating scientific observations of gas hydrates from the field and lab, coupled with unique numerical simulation capabilities, creates an effective approach to gas hydrate science.

\section{CONTAMINANT HYDROLOGY}

HRD researchers address the national need for subsurface contaminant characterization and remediation across the spectrum of approaches. In the lab, HRD researchers are investigating some of the nation's most critical subsurface contamination issues, including the chemical evolution of highly alkaline Hanford tank waste, reduction and re-oxidation of mobile Uranium VI in sediments, hydraulic properties of unsaturated gravels, and the natural production of transport-enhancing mobile nanoparticles in the subsurface. In the field, HRD investigators lead the Berkeley Lab site restoration effort to remediate groundwater plumes containing dissolved chlorinated solvent and fuel contaminants. A pressurized constant-head water-injection system has been developed and used to measure hydraulic conductivity in low-conductivity systems typical of the Berkeley Lab site. Soil heating with vapor extraction was used in a lowpermeability and heterogeneous setting to remove over $500 \mathrm{~kg}$ of chlorinated solvent. In addition, TOUGH2 modeling of groundwater flow at the Berkeley Lab site is being carried out to improve understanding of contaminant transport. HRD's work

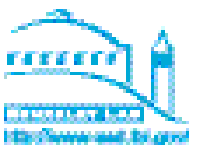


in surface water is growing: field work is being done to investigate the hydraulic conductivity of river gravels for recharge studies, and to develop and test a fiber-optic turbidity meter. Collaboration with scientists in other ESD departments and Berkeley Lab divisions is currently under way, with a focus on the coupled water-energy system in California. On the theoretical and modeling side, new TOUGH2 modules for multiple volatile organic compounds (TMVOC) and landfill biodegradation and gas production processes (T2LBM) have been developed. The pumping rates and pressures in deep well injection of hazardous waste have been analyzed with a new approach to obtain formation hydraulic properties. Finally, HRD maintains an international program to develop and test advanced technologies at sites worldwide, which can then be used domestically to help with our nation's most difficult contamination problems.

\section{GEOLOGIC $\mathrm{CO}_{2}$ STORAGE}

A relatively new area in which HRD is making significant advances (with national and international impact) is geologic $\mathrm{CO}_{2}$ storage. Because geologic $\mathrm{CO}_{2}$ storage is a new concept, there are broad basic research needs. For example, HRD researchers are developing methods for predicting $\mathrm{CO}_{2}-\mathrm{H}_{2} \mathrm{O}$ mutual solubilities. These methods are then incorporated into new modules of TOUGH2 that are applied to a variety of $\mathrm{CO}_{2}$ storage problems, including $\mathrm{CO}_{2}$ injection into deep brine formations, injection into depleted gas reservoirs, leakage upward through faults and fractures, and leakage and seepage of $\mathrm{CO}_{2}$ in the near-surface environment. The effects of geochemical processes, including mineral precipitation and dissolution associated with $\mathrm{CO}_{2}$ storage, are being studied using TOUGHREACT, the coupled geochemistry and reservoir simulator. By analogy, mechanical effects associated with $\mathrm{CO}_{2}$ storage are being studied using TOUGH-FLAC, a coupled geomechanical reservoir simulator. An international code intercomparison study led by HRD researchers provided confidence that $\mathrm{CO}_{2}$ reservoir processes can be accurately modeled. Laboratory work in this area has included efforts to image $\mathrm{CO}_{2}$ flow and measure relative permeability parameters such as residual gas saturation, a key property for saturated zone $\mathrm{CO}_{2}$ storage.

\section{NUCLEAR WASTE DISPOSAL IN THE UNSATURATED ZONE}

The motivation for HRD's extensive effort in unsaturated zone hydrology and coupled processes is stimulated by the need to understand flow and transport in the unsaturated zone at Yucca Mountain, Nevada. Research by HRD scientists in this prominent area is both broad and focused. Starting with research underground, HRD scientists have run a wide program of experiments and testing in the Exploratory Studies Facility (ESF) at Yucca Mountain. Field experiments range from the large multiyear Drift Scale Test, to smaller-scale liquid releases in boreholes. The practical difficulties of running tests underground at a remote site have motivated the development of sophisticated remote monitoring and operation capabilities, whereby instrument adjustments, liquid releases, and data collection can be controlled remotely by scientists on site at Berkeley Lab. In addition, a large block of fractured tuff (1 cubic meter) was extracted from the ESF and transported to Berkeley Lab for laboratory experiments and testing. This effort complements smaller-scale lab experiments focused on mineral precipitation and dissolution in fractured tuff by hot aqueous fluids. The heater testing, seepage experiments, and fault and fracture flow testing (among other tests) have been designed and run by teams that include members with numerical modeling expertise.

The coupled approach of field experiment and modeling analysis has served to advance understanding of the coupled flow and transport properties of Yucca Mountain. Field data are used to constrain and calibrate numerical models of flow and transport developed over a wide range of scales for Yucca Mountain. These efforts involve the use of the inverse modeling version of TOUGH2 called iTOUGH2, also developed by HRD personnel. On the mountain scale, a large three-dimensional TOUGH2 model has been developed, the flow fields from which are used with advanced transport modules that consider colloidassisted transport and diffusion to model radionuclide transport. The details of seepage into drifts, flow diversion, and flow focusing are modeled on appropriate scales, as are processes of waterrock interaction and geomechanical effects.

A considerable amount of general unsaturated zone hydrology knowledge and understanding is generated by HRD researchers. For example, new conceptualizations of fracturematrix interaction, scale dependence, and effects of multiscale heterogeneity have been investigated. Work in this area also extends to saturated systems in Japan, where free convection simulations and uncertainty studies associated with potential nuclear waste repositories are being carried out. The large effort in HRD on a broad range of hydrologic processes related to nuclear waste disposal typifies the strong integration of field, laboratory, and modeling analyses characteristic of ESD scientific investigations.

\section{FUNDING}

Funding for HRD comes primarily from the U.S. Department of Energy, including: the Director, Office of Science, Office of Basic Energy Sciences, Division of Chemical Sciences, Geosciences, and Biosciences; the Director, Office of Science, Office of Biological and Environmental Research; the Assistant Secretary for Energy Efficiency and Renewable Energy, Office of Technology Development, Office of Geothermal Technologies; the Assistant Secretary for Fossil Energy, Office of Coal and Power Systems and Office of Natural Gas and Petroleum Technology, through the National Energy Technology Laboratory; the Director, Office of Civilian Radioactive Waste Management; and the Assistant Secretary of the Office of Environmental Management, Office of Science and Technology, Environmental Management Science Program. The department also receives funding support from the U.S. Environmental Protection Agency. Other funding is provided through the Laboratory Directed Research and Development Program at Berkeley Lab.

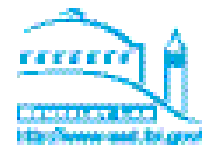




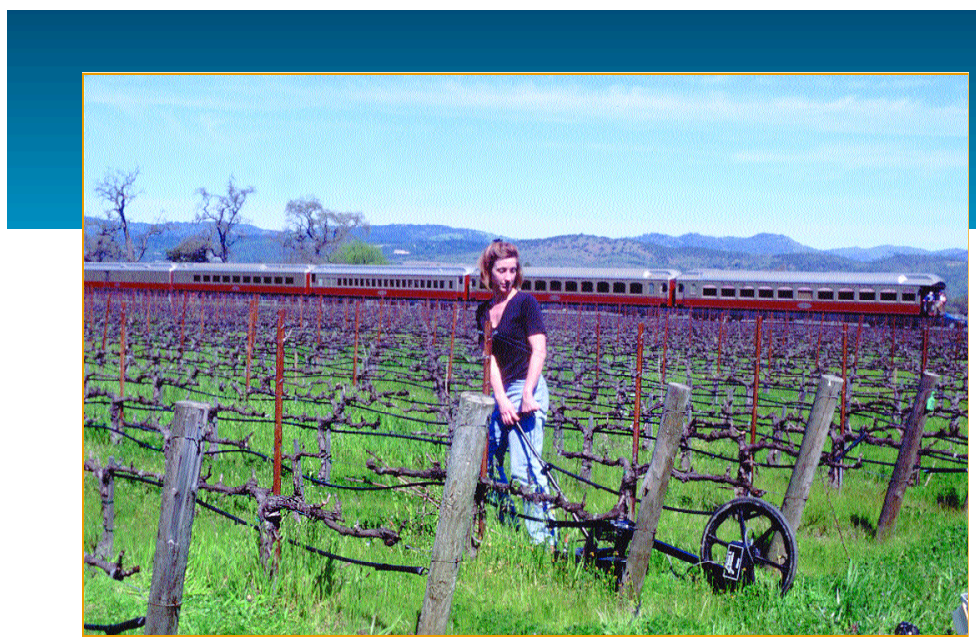

The primary focus of the Geophysics and Geomechanics Department is to develop new methodologies for extracting subsurface properties, including fluid properties, saturation, porosity, pore pressure, permeability, and in situ stress, and apply these methodologies to field data. These new methodologies incorporate a variety of data, including geophysical (seismic, electromagnetic (EM), electrical, seismo-electric, gravity, ground-penetrating radar (GPR), geomechanical (displacement, tilt), and fluid flow (pressure). Fundamental and applied research carried out in support of this objective includes laboratory rock physics and pore-scale imaging studies, field geophysics surface and borehole studies, field geophysical-imaging hardware development, theory development, computational geophysics and geomechanics modeling, and imaging and inversion (deterministic and stochastic) algorithm development. The driver for this research is the increasing need to directly image fluid saturations, pore pressures, and permeability in the subsurface for energy production, environmental remediation, carbon management, and nuclear waste disposal purposes, and to do so in the presence of anisotropy and multiscale heterogeneities.

\section{SCIENTIFIC RESEARCH AREAS}

The department is organized into five scientific research areas, led by the indicated Research Area Leaders:

- Computational Geophysics (Don Vasco)

- Rock Physics and Coupled Dynamics (Seiji Nakagawa)

- Hydrogeophysics (Susan Hubbard)

- Characterization and Monitoring Geophysical Instrumentation ( $\mathrm{Ki}-\mathrm{Ha} \mathrm{Lee})$

- Computational Geomechanics (Jonny Rutqvist)

The primary purpose of these research areas is to advance the science supporting high-resolution methods for extracting subsurface properties and process information from geophysical, geomechanical, and fluid flow data.
Resource Department

GEOPHYSICS AND GEOMECHANICS

Kurt T. Nihei

510/486-5349 ktnihei@lbl.gov

\section{COMPUTATIONAL GEOPHYSICS}

The focus of this research area is to develop efficient, 3D numerical codes for modeling seismic wave propagation and electromagnetic wave propagation and diffusion. The challenge is to develop accurate and efficient computer codes capable of modeling the seismic and electromagnetic response of complex geologic structures (i.e., structures that may contain anisotropy or multiscale heterogeneities in the form of fractures, faults, folds, layers, or patchy saturation). A variety of methods, including boundary integral equation, global matrix, finite difference, spectral element, discrete element, and asymptotic ray methods, are in the process of being developed for high-performance parallel computing frameworks. These codes will serve as the computational engines for the next generation of modeling-based deterministic and stochastic inversion algorithms. This research is performed using the supercomputers at the National Energy Research Scientific Computing Center (NERSC) at Berkeley Lab, and the PC cluster maintained by the Center for Computational Seismology (CCS), within Berkeley Lab's Earth Sciences Division.

\section{ROCK PHYSICS AND COUPLED DYNAMICS}

The connections between a geophysical observable, such as seismic velocities and attenuation, electrical conductivity, and dielectric constant, and rock properties, such as porosity, permeability, and fluid saturation, are provided by rock-physics measurements and/or theories. Rock-properties measurement efforts are carried out at the Rock and Soil Physics Lab. This facility has the electronic instrumentation and mechanical equipment to perform a variety of geophysical measurements, including seismic, electrical, electromagnetic, and fluid flow, under low to moderate confining pressures. Experiments that require detailed information about the porous microstructure and fluid saturations at the pore level are carried out using the $\mathrm{x}$-ray computed tomography (CT) scanner in the Rock Imaging

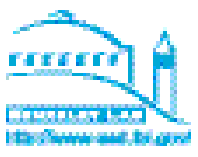


Lab and the recently completed high-resolution x-ray microtomography station located at Berkeley Lab's Advanced Light Source, and using the focused ion beam (fib) located at Berkeley Lab's National Center for Electron Microscopy. The primary focus of our laboratory efforts is towards the understanding of the geophysical properties of rock and sediments that are either not well described by conventional rock physics theories (e.g., poorly consolidated sands and clays, gas hydrates, fractured rock) or that have yet to be fully exploited (e.g., seismic attenuation, seismo-electric response). Complementary theoretical efforts are also under way to explore the dynamics of poroelastic and seismoelectric response of rocks that contain multiple fluid phases.

\section{HYDROGEOPHYSICS}

Research in the area of hydrogeophysics combines the disciplines of geophysics and hydrogeology to develop new approaches for characterizing the shallow subsurface over a range of scales for subsurface properties (such as hydraulic conductivity, geochemical heterogeneity, lithology, and moisture movement over time). This interdisciplinary field is unique in the level of fusion between hydrogeological and geophysical data sets, the incorporation of complex petrophysical models, and the application of emerging stochastic inversion techniques. In this area, new research is also being carried out to investigate the role of biogeochemical changes associated with bioremediation in the hydrological and geophysical responses resulting from processes such as dissolution/precipitation of minerals, gas evolution, and biofilm generation.

\section{CHARACTERIZATION AND MONITORING GEOPHYSICAL INSTRUMENTATION}

The focus of this research area is the development of innovative geophysical instrumentation, including sensors, sources, and analysis software, for subsurface imaging and monitoring. Efforts that are currently under way include the development of an optimum electromagnetic system for detecting and identifying unexploded ordnance, a novel electromagnetic imaging system (for environmental applications) that operates in the frequency band between electromagnetic diffusion and wave propagation, and a miniature rotary shear source for crosswell and single-well seismic imaging applications.

\section{COMPUTATIONAL GEOMECHANICS}

This research area is concerned with the development of new computational tools for predicting stress-induced changes in transport properties, fracturing, and fault slip resulting from fluid injection, fluid withdrawal, and thermal loading. Of particular interest is the development of new computational geomechanics-based inverse methods for estimating subsurface fracturing and fluid movement, and for predicting the seismic response resulting from fluid injection into fractured rock.

\section{FUNDING}

The Geophysics and Geomechanics Department derives its funding from a variety of U.S. Department of Energy (DOE) and non-DOE sources. The primary sources of DOE funding are the Director, Office of Science (Basic Energy Sciences and Biological and Environmental Research), Office of Environmental Management, Fossil Energy, Office of Geothermal Technologies, Office of Civilian Radioactive Waste Management, and the Berkeley Lab Laboratory Directed Research and Development Program. Non-DOE funding sources include the U.S. Department of Defense (SERDP), the Environmental Protection Agency (EPA), Shell Oil Company, and ChevronTexaco Energy Research and Technology. 


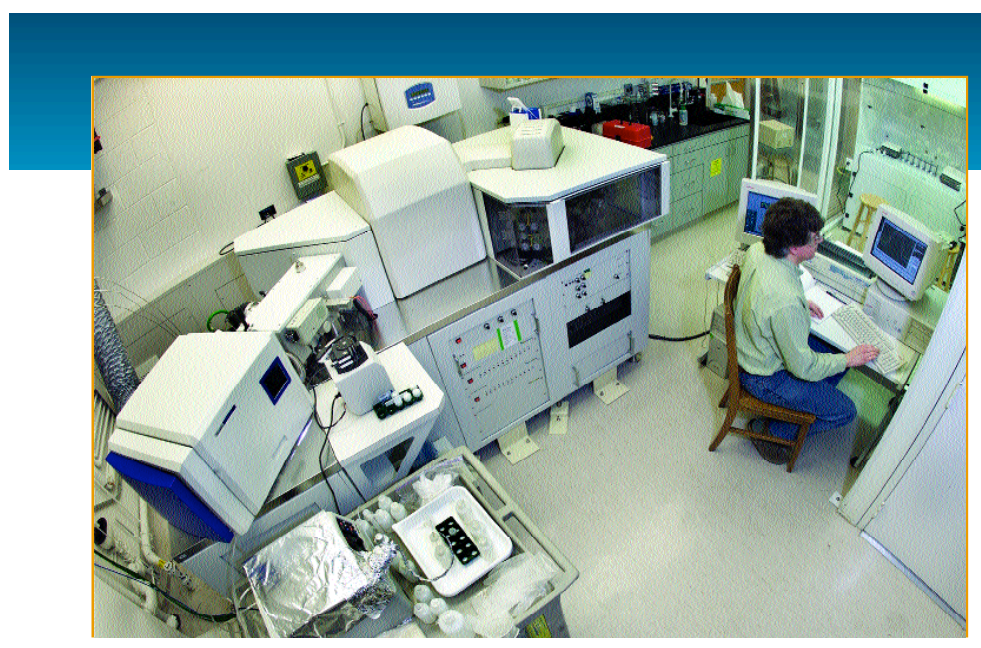

The Earth Sciences Division's Geochemistry Department combines expertise in chemical and isotopic analysis, molecular geochemistry and nanogeoscience, mineralogy, and multiscale data-gathering methodology to enable geochemical characterization of earth systems from the macroscopic to the molecular. The department comprises four groups with complementary interests and capabilities.

\section{MOLECULAR GEOCHEMISTRY AND NANOGEOSCIENCE}

Studies in this group address issues of contaminant sequestration and migration in the environment, mineral-fluid reactions, and various aspects of aqueous solution chemistry. Fundamental studies on the nature of the aqueous solution/mineral interface and on the structure of (near-aqueous) solvated ions and colloids down to the nanometer regime are also being performed. The aim of the latter studies is to provide improved modeling capability for contaminant migration, weathering, sediment transfer, ion exchange, and nutrient cycles. Current work includes: molecular-dynamics modeling of the interlayer-solvated cations in clays and the aggregation dynamics of nanoparticle iron oxides; studies of the solvation environment of contaminant and nutrient molecules in aqueous solution; determination of the molecular identity of initial iron oxide precipitates on quartz surfaces; and characterization of the surface chemistry and structure of environmentally important minerals via simulation, $x$-ray scattering, and $x$-ray spectroscopy methods. Many of these efforts involve newly developed capabilities utilizing synchrotron $x$-ray sources. Important new work on the aqueous behavior of humic and fulvic acids, hydroxyl speciation near cations in water, and the nature of organic contaminants on mineral surfaces has been carried out recently at Berkeley Lab's Advanced Light Source. The group also does extensive collaboratory research utilizing the NCEM at Berkeley Lab, and takes advantage of the NSERC facility at Berkeley Lab for large-scale molecular dynamics simulations.
Resource Department GEOCHEMISTRY Donald J. DePaolo

510/643-7686 djdepaolo@lbl.gov

\section{ISOTOPE GEOCHEMISTRY}

The Isotope Geochemistry group operates the Center for Isotope Geochemistry, which was established in 1988 and includes six important analytical facilities: stable isotope and noble gas isotope laboratories; a soil carbon laboratory; an analytical chemistry laboratory; the Inductively Coupled Plasma Multi-Collector Magnetic Sector mass spectrometry laboratory, and a thermal-ionization mass spectrometry laboratory located on the UC Berkeley campus. We also have an affiliation with the cosmogenic isotope laboratory in UC Berkeley's Space Sciences Laboratory. These facilities provide state-of-the-art characterization of all types of earth materials for research throughout the department and elsewhere in the division. Further, they support the Center's goals of finding new ways to utilize isotopic ratio methods to study earth processes, and applying isotopic and chemical analysis procedures to specific environmental and energy problems of national interest.

Current research programs include: (1) the development of models that use isotopic composition data from element pairs in fluids to constrain fluid flow rates, water-mineral reaction rates, and the geometry and spacing of fractures in rock matrices; (2) the development and application of noble gas isotopes as natural tracers for fluid source and movement in hydrocarbon and geothermal systems; (3) development of techniques for dating Quaternary geological events using uranium-thorium-helium systematics; (4) the geochemical monitoring and analysis of large-scale experiments simulating the effects of nuclear waste heat generation within the proposed repository in Yucca Mountain, Nevada; (5) the application of helium and neodymium isotopes to determine magma-chamber recharge rates in areas having possible volcanic hazards or the potential for geothermal energy extraction; (6) the development of carbon, nitrogen, and oxygen isotope techniques for quantifying in situ bioremediation and environmental restoration; (7) the use of carbon isotopes to quantify rates of organic carbon cycling and storage efficiency in soils, the impact of climate

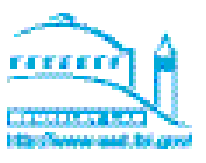


change on carbon cycling, and linkages between carbon, water, and nitrogen cycles, (8) application of natural isotopic tracers to follow the movement of water and contaminates through the vadose zone and in groundwater, and (9) applications of hydrogen and oxygen isotopes to issues concerning the water cycle. A new program is under way to study iron isotope variations as a tracer in the oceanic and terrestrial iron cycles.

\section{ATMOSPHERE AND OCEAN SCIENCES}

The focus of this group is on the characterization of conditions and chemical components in the oceans and atmosphere, and on the development of process models using these inputs (combined with other hydrospheric data) to explain and predict climatic change.

The California Water Resources Research and Applications Center maintains a suite of research and operational tools for weather forecasts, climate prediction, and basic research. Ongoing collaborations include: streamflow simulations with the National Oceanic \& Atmospheric Administration's California Nevada River Forecast Center; runoff contaminant monitoring and management with the U.S. Bureau of Reclamation; development of landslide-hazard prediction models with faculty at UC Berkeley; development of snow-cover and snow-water equivalent maps for California with UC Santa Barbara; and development of a shared information distribution system with the U.S. Department of Energy's Accelerated Climate Prediction Initiative (DOE/ACPI) collaborators. Outreach activities for this year have included a scientific exchange program with AmazonTech.

The central motivation for ocean science research in this group is to better understand the biological and physical processes governing carbon in the ocean, how these processes affect the balance of $\mathrm{CO}_{2}$ between atmosphere and ocean, and the efficacy of using the oceans to sequester carbon. The issues are technologically challenging because of the rapidity of ocean biological processes-the entire carbon biomass in the ocean is replaced every one or two weeks.
The Berkeley Lab team collaborates with other scientists to deploy Carbon Explorers-robotic floats with telemetry capability and special sensors that can measure the distribution and fate of ocean carbon, as well as temperature, salinity, and pressure. In the laboratory, work is directed at expanding the sensor suite carried by Carbon Explorers. The latest innovation is an imaging optical sensor designed to simultaneously quantify the sedimentation of both inorganic and organic particulate carbon. The first Explorers documented the response of marine biota to iron deposited in the Pacific Ocean by a massive dust storm that had originated in Asia. In the Southern Ocean, Carbon Explorers have quantified biomass enhancement in response to deliberate iron addition to the ocean. A large-volume in situ filtration system is also used to collect size-fractionated particulate samples from surface to kilometer depths in the oceans.

\section{GEOCHEMICAL TRANSPORT}

A major effort of this group is the simulation and study of coupled mineral-water-gas reactive transport in unsaturated porous media. The work covers a wide range of processes under differing geologic environments, including infiltration/ evaporation processes in the soil zone, reactive transport processes in fractured rock under boiling conditions, injection of $\mathrm{CO}_{2}$ in deep aquifers, and hydrothermal alteration in geothermal systems. Although reactive transport modeling and code development are the predominant activities, the group is also active in planning the analysis and drilling activities for underground thermal experiments, laboratory experiments, and field studies of geothermal systems and natural analogues for nuclear waste isolation.

Much of the work is focused on predicting thermally driven processes accompanying the proposed emplacement of high-level nuclear waste at Yucca Mountain, Nevada, and on understanding the evolution of the natural hydrogeochemical system. The group has expanded its efforts to studies of geothermal systems, $\mathrm{CO}_{2}$ sequestration, and modeling of stable isotope variations in the vadose zone. Collaboration among 
others in the division brings together essential pieces of the problem, including hydrological processes in the unsaturated zone, thermodynamics and kinetics of geochemical processes, and isotopic effects.

Current projects include:

- Simulation and analysis of an ongoing large-scale underground thermal test, and planning of future drilling and sampling efforts

- Prediction of coupled thermal-hydrological-chemical processes around potential waste emplacement tunnels to evaluate changes in water and gas chemistry, mineralogy, and flow

- Analysis of geochemical and isotopic data from Yucca Mountain, including ${ }^{36} \mathrm{Cl}$ as a bomb-pulse tracer, to constrain models of flow and transport in the unsaturated zone

- Development of models for reactive transport in unsaturated systems and co-developers of the reactive transport code TOUGHREACT

- Evaluation and development of improved thermodynamic and kinetic databases for water-rock interaction modeling, including new relations for $\mathrm{CO}_{2}$ solubility to model $\mathrm{CO}_{2}$ sequestration

- Research on natural analogue sites, including (a) analysis and modeling of continuously cored intervals from the Yellowstone geothermal system to assess effects of mineral alteration on fracture and matrix permeability; (b) study of flow, transport, and secondary mineralization at Peña Blanca, Mexico; and (c) study of anthropogenic analogues, such as those at the Idaho National Engineering and Environmental Laboratory

- Modeling of $\mathrm{CO}_{2}$ sequestration in saline aquifers, including the impact of acid gas components, $\mathrm{H}_{2} \mathrm{~S}$ and $\mathrm{SO}_{2}$, and interactions with shale confining beds
- Modeling hydrothermal alteration in geothermal systems.

- Simulation of the effects of scaling and acidization on permeability in geothermal injection wells at the Tiwi geothermal field, Philippines

- Study of chemical interaction between formation waters, injected waste fluids, and host rock during deep well injection

- Development of a Pitzer-type geochemical reactive transport model and simulation of high-ionic-strength groundwater contamination

\section{FUNDING}

Funding for the Geochemistry Department comes from a variety of sources within the U.S. Department of Energy, including: the Director, Office of Science, Office of Basic Energy Sciences, Divisions of Materials Sciences, Engineering and Geosciences; Office of Environmental Management, O ffice of Science and Technology; Office of Energy Efficiency and Renewable Energy, Office of Utility Technologies, Office of Geothermal Technologies; Office of Biological and Environmental Research; and the Office of Civilian Radioactive Waste Management. Additional funding is provided by the U.S. Environmental Protection Agency; U.S. Navy; National Aeronautics and Space Administration, Office of Space Science and NASA Earth Enterprise; National Science Foundation, Office of Polar Programs; the University of California Campus-Laboratory Collaboration Hydrology Project; National Oceanographic Partnership Program (administered by the Office of Naval Research); National Oceanic and Atmospheric Administration, Office of Global Programs of the U.S. Department of Commerce, and the Laboratory-Directed Research and Development (LDRD) Program at Berkeley Lab. 



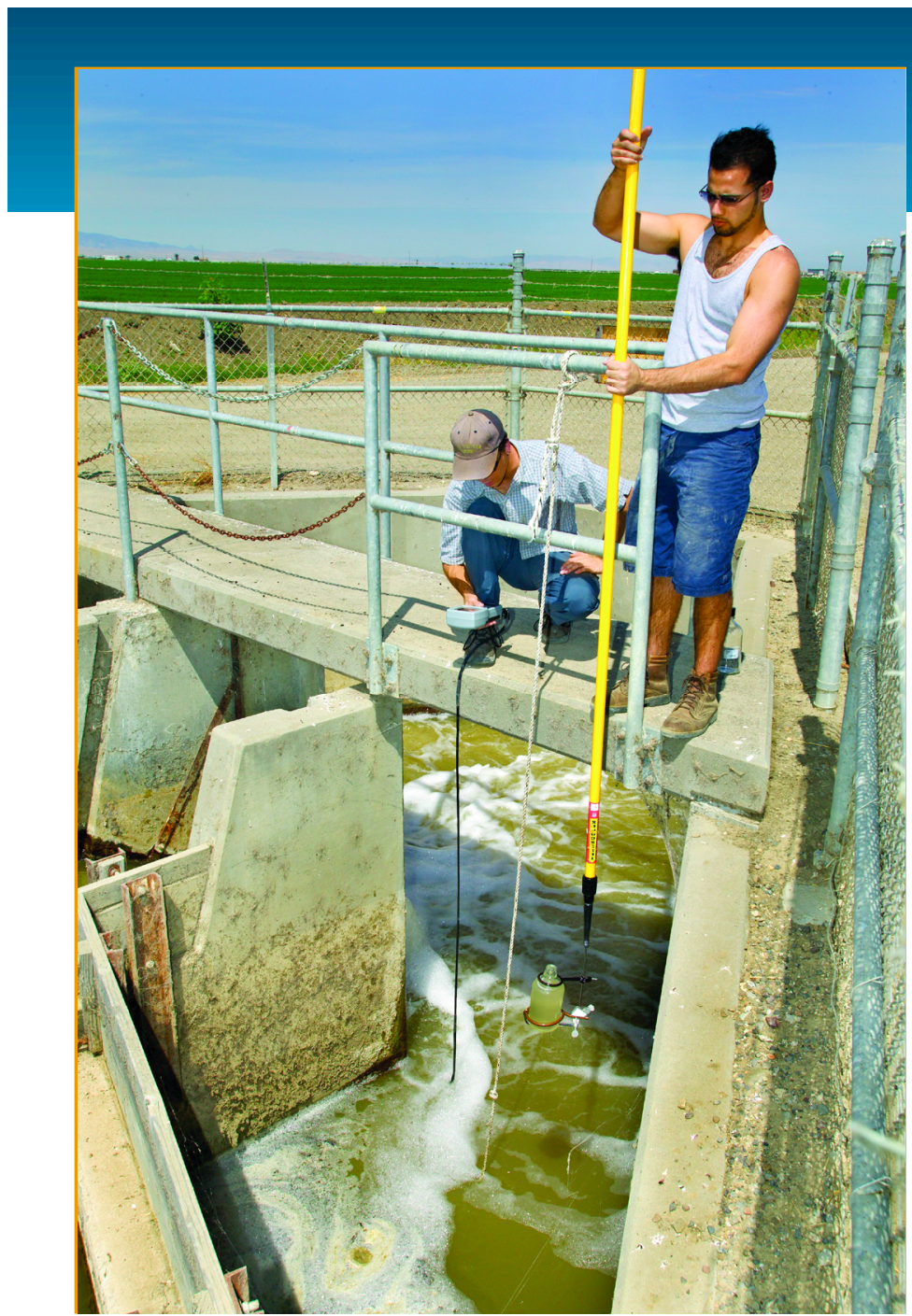

Resource Department

\title{
Microbial ECOLOGY AND
} ENVIRONMENTAL ENGINEERING

\author{
Terry C. Hazen \\ 510/486-6223 \\ tchazen@lbl.gov
}

\section{HYDROECOLOGICAL ENGINEERING ADVANCED DECISION SUPPORT (HEADS)}

The HEADS research group has established a strong track record in the rapidly growing, new subject area of Ecological Engineering. The term hydroecological engineering signifies the group's concentration on water resources and wastewater engineering. Recognizing the growth in the field of environmental informatics and the application of computer-based models in the development of decision support systems, the group is active in this niche area. Interest in decision support interfaces well with the group's expertise in the deployment of real-time flow and water quality sensors, rapid laboratory assessment techniques, and mathematical models to develop an early warning system for contaminant management and containment.

\section{MOLECULAR MICROBIAL ECOLOGY (MME)}

Understanding microbial interactions is key to the study of global warming, biodegradation of harmful compounds, and the exploration of complex microbial communities in their natural environment. The DOE has placed an increased emphasis on the role microbes play in modifying their environment and their impact on energy security. The MME group has responded to these needs by aggressively seeking out new projects and expanding its staff to develop new core capabilities. One of the key challenges has been to harness the explosion of microbial DNA sequence information to accurately measure the microbial dynamics in extreme environments. Since less than one percent of the microbial species can be cultured from these environments, our knowledge of what these organisms may be doing is limited to where they are observed and the similarity of their genomes to studied organisms. By understanding the ecological structure of microbial communities and the fine-scale dynamics resulting from subtle perturbations, it may be possible to identify novel functional pathways and use the diverse microbial capabilities to assist in key DOE missions. The molecular tools being developed in the ESD's Center for Environmental Biotechnology will position us to be leaders in this area. 
REAL-TIME ASSESSMENT OF BIOAVAILABILITY AND BIOKINETICS (RABB)

Interactions between environmental pollutants and ecological receptors begin when the pollutants become available to the target sites of a live ecological receptor. The ability to characterize the dynamics of the bioavailability of pollutants, their transformation kinetics, and the subsequent ecological response is a keystone to advancing the science in relevant DOE areas, including biogeochemistry, bioremediation, and exposure and risk assessment. Since 1999, the RABB research group at MEEED has pioneered the development and application of several cutting-edge technologies, such as synchrotron radiation-based spectromicroscopy, in vitro human gastrointestinal mimetic reactors, and in vivo mouse protocols that allow for the real-time assessment of bioavailability and biokinetics of environmental pollutants. The RABB group intends to establish this capability further by seeking out new projects and new collaborators, as well as expanding our staff, to position us as leaders in the areas of biological and environmental sciences.

\section{BIOREMEDIATION AND}

NATURAL ATTENUATION

Bioremediation and natural attenuation have been rapidly growing areas of science over the past decade. The acceptance of natural attenuation as a solution for cleaning up contaminated sites, and DOE's recognition that they will have long-term stewardship issues that they must address at the most contaminated sites, have greatly increased the urgency for basic and applied research related to microbial ecology and biogeochemistry. This type of research is truly enabling for natural attenuation, since characterization, predictions, and verification monitoring require a strong scientific basis. Natural attenuation is viewed as the best solution for cleaning up many waste sites and will save billions of dollars in cleanup costs.

MEEED scientists and engineers are recognized leaders in the field of bioremediation and natural attenuation. The Center for Environmental Biotechnology provides the primary facilities used by MEEED, including state-of-the-art equipment for microbiology and environmental engineering.
MEEED investigators have extensive experience in both water treatment and bioremediation, especially co-metabolic biodegradation and the treatment of inhibitory compounds. In addition to basic research, MEEED investigators have been involved in various aspects of more than 60 field demonstrations and deployments, and have five patents in this area that are licensed to more than 30 companies. The types of contaminants in which MEEED investigators have expertise include chlorinated solvents, petroleum hydrocarbons, polynuclear a romatic hydrocarbons, ketones, methyl tert-butyl ether (MTBE), TNT, inorganic nitrogen $\left(\mathrm{NO}_{3}, \mathrm{NH}_{4}\right)$, tritium, plutonium, neptunium, chromium, and uranium. The Bioremediation and Natural Attenuation area has both basic research and field application foci for the MEEED. The basic research foci are co-metabolism, biotreatability, biotransformation kinetics, and modeling of biogeochemical processes. Field-application foci are co-metabolic techniques, biogeochemical assessment techniques, and modeling of attenuation and environmental fate.

\section{FUNDING}

MEEED personnel are funded by DOE programs in (1) the Office of Science, Office of Biological and Environmental Research (OBER) (Natural and Accelerated Bioremediation Research Program); (2) the Office of Environmental Management, Offices of Science and Technology and Environmental Restoration Program; (3) the Office of Fossil Research, the Petroleum Environmental Research Forum; and (4) the National Nuclear Security Administration, Office of Nonproliferation Research and Engineering (NN20). In addition, support is provided by the U.S. Department of Homeland Security, the Department of Agriculture; the Department of the Interior, Bureau of Land Management, and Bureau of Reclamation under the CALFED program, for bioreactor treatment of groundwater containing MTBE obtained from a remediation company, as well as several projects with remediation companies using DOE-patented technologies for in situ bioremediation. MEEED personnel are also funded by Berkeley Lab's Laboratory Directed Research and Development (LDRD) Program in the area of aerobic bioreactor studies of landfills. 


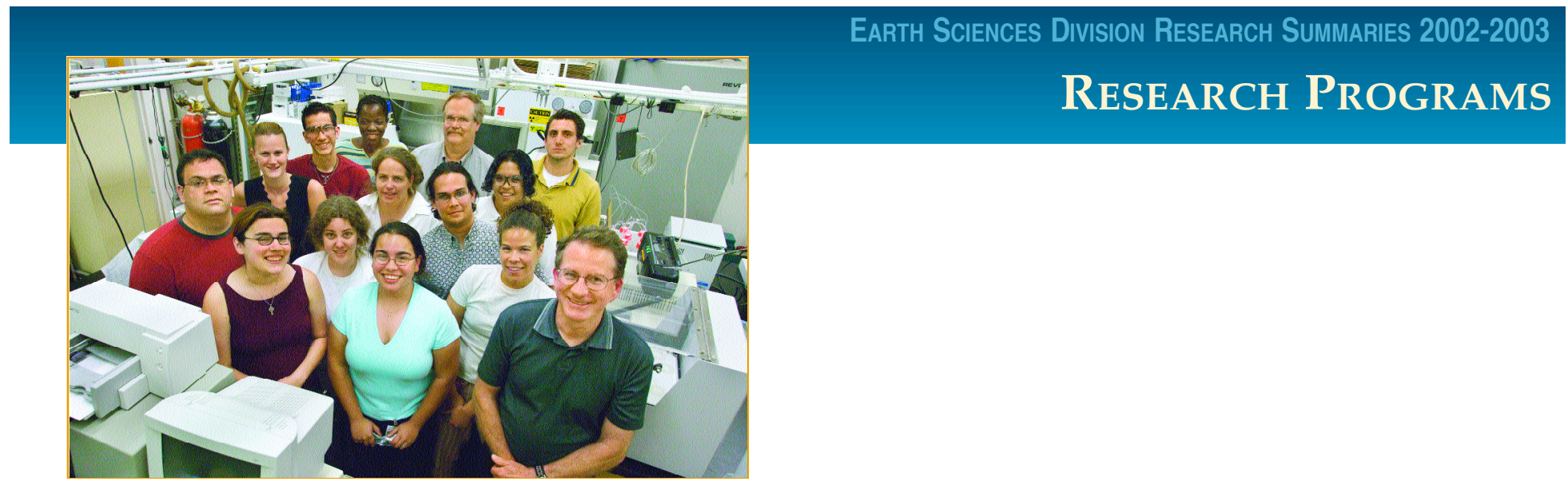

FundaMental AND EXPloratory RESEARCH

Nuclear WAste

ENERGy RESOURCES

ENVIRONMENTAl ReMEdiation TeCHNOlOGY

Climate Variability and Carbon Management 



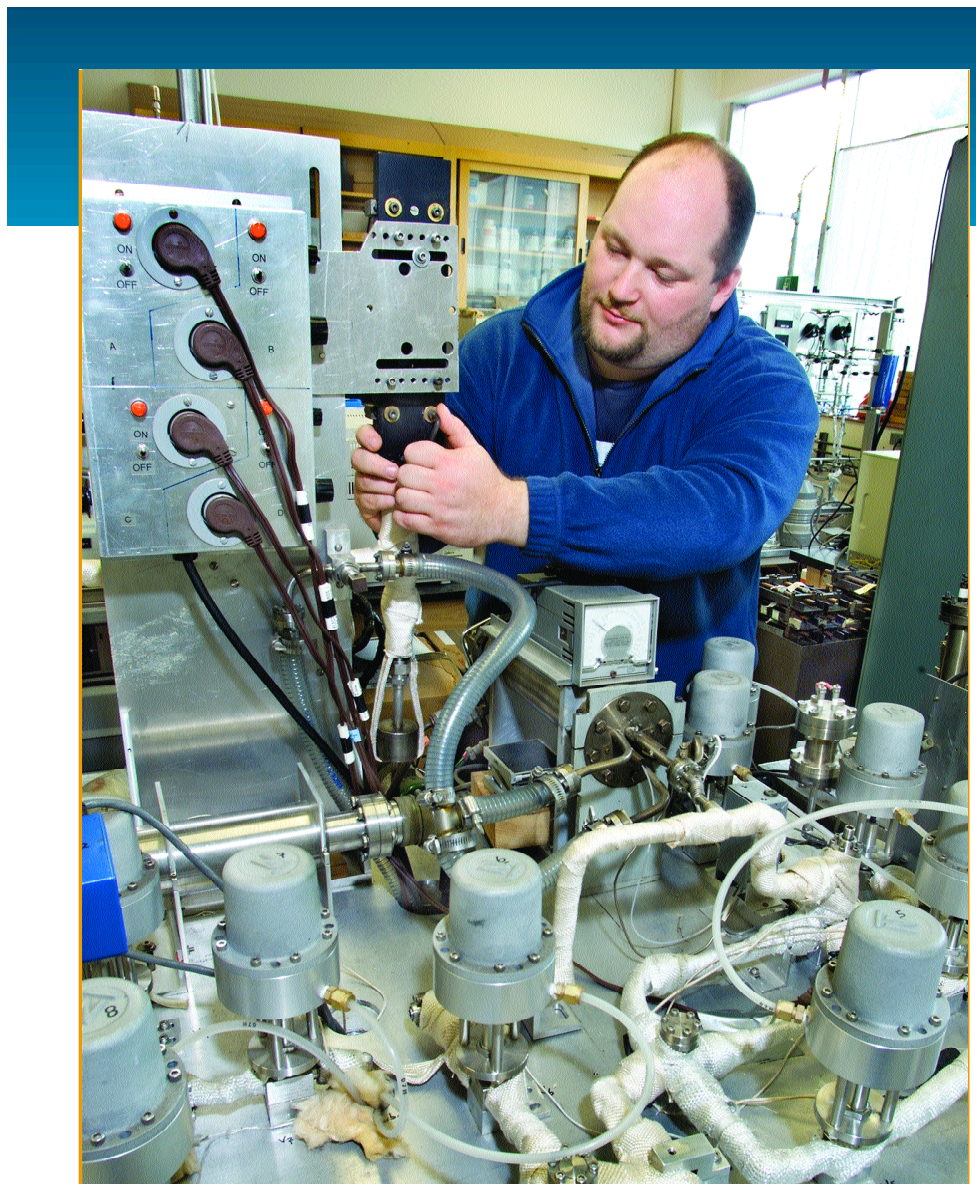

The Fundamental and Exploratory Research Program (FERP) covers fundamental earth sciences research conducted in support of the Department of Energy's science mission. This mission includes research in the natural sciences to provide a basis for new and improved energy technologies and for understanding and mitigating the environmental impacts of energy development and use. FERP also includes exploratory research in important new energy and environmental topics conducted under the Laboratory Directed Research and Development (LDRD) program. The scientific insights and breakthroughs achieved in FERP often become the underpinnings for projects that support DOE's applied research and development program offices.

Over the years, the basic earth sciences research program at Berkeley Lab has focused on three broad earth sciences problems:

1. Fundamental studies of chemical and mass transport in geologic media, with special reference to predictive modeling of multiphase, multicomponent, nonisothermal fluid flow in saturated and unsaturated fractured rocks

2. The development of new isotopic techniques for understanding the nature of a broad range of global processesfrom the relatively short-term effects of natural fluid migration in the crust to longer-term (i.e., 10-20 thousand years) global climate variations
Research Program

\section{FUNDAMENTAL AND EXPLORATORY RESEARCH}

Ernest L. Majer

510/486-6709 elmajer@lbl.gov
3. Fundamental studies in the propagation of seismic/acoustic and broadband electromagnetic waves through geologic media, with emphasis on new computational techniques for high-resolution imaging of near-surface and crustal structures (such as possible fracture flow paths) and for inferring the types of fluids present in pores and fractures

Results from these research endeavors have had a major impact on applied energy, carbon management/ climate change, environmental, and radioactive waste management programs. Current researh projects are briefly described here.

\section{CHEMICAL AND MASS TRANSPORT INVESTIGATIONS}

Current research in this area is focused on colloid transport in unsaturated porous media and rock fractures, chemical transport in structured porous media, unsaturated fast flow in fractured rock, and production and evaluation of coupled processes for $\mathrm{CO}_{2}$ in aquifers. Our recent colloid research has been focused on quantifying the partitioning of surface-active colloids at the air-water interfaces. Much effort has been devoted to characterizing surface accumulations of colloids. We have recently developed a simple dynamic method to quantify colloid-surface excesses at air-water interfaces without requiring assumptions concerning the thickness of interfacial regions.

The studies of chemical transport in structured porous media have focused on $\mathrm{Cr}(\mathrm{VI})$ diffusion and reduction to $\mathrm{Cr}$ (III) within natural soil aggregates, to test the validity of our previously reported results from synthetic soil aggregates. Experiments were conducted on intact aggregates of Altamont clay. Work on unsaturated fast flow in fractured rock concerns water films on fracture surfaces under near-zero (negative) matric potentials and examines the possibility of fast, unsaturated flow under "tension." We showed that at matric potentials greater than that needed to saturate the rock matrix, transmissive water films can develop on fracture surfaces. 
In the work on prediction and evaluation of coupled processes for $\mathrm{CO}_{2}$ disposal in aquifers, the accuracy of published data and correlations for thermophysical properties of $\mathrm{CO}_{2}$ (density, viscosity, enthalpy) is being evaluated for the range of pressure and temperature conditions of interest in aquifer disposal. Suitable correlations were implemented in our multipurpose simulator TOUGH2. Pre-existing models for $\mathrm{CO}_{2}$ dissolution in aqueous fluids were enhanced by incorporating salinity and fugacity effects. Special techniques were developed for describing the movement of sharp $\mathrm{CO}_{2}$-water interfaces during immiscible displacement of saline brines by $\mathrm{CO}_{2}$.

\section{ISOTOPE GEOCHEMISTRY}

The Center for Isotope Geochemistry (CIG) is a state-ofthe-art analytical facility established in 1988 to measure the concentrations and isotopic compositions of elements in rocks, minerals, and fluids in the earth's crust, atmosphere, and oceans. Fundamental research conducted at this center is directed at finding new ways to use isotopic information to study earth processes, such as long-term climate changes, and at predicting the chemical transport of mantle-derived or deep crustal fluids as they move through the crust.

One of the major problems being studied at CIG is how to estimate fluid-solid reaction rates in natural-groundwater higher-temperature geothermal conditions, particularly as these rates affect mineral dissolution and secondary mineral precipitation. ESD researchers are developing novel ways of estimating reaction rates by using isotopic tracers (primarily strontium, but also uranium and neodymium) to determine solid-fluid exchange rates in various natural situations. Scientists are able to derive the "reaction length," a parameter that depends on the ratio of isotope transport by diffusion and advection to the reaction rate. The ultimate objective is to understand the microscopic (as well as pore-scale and mesoscale) characteristics of natural systems that have been characterized in terms of "field scale" reactionrate measures. An intermediate goal is to establish empirically the natural range of fluid-solid reaction rates.

\section{ADVANCED COMPUTATION \\ FOR EARTH IMAGING}

The Center for Computational Seismology (CCS) was created in 1983 as the Berkeley Lab and UC Berkeley nucleus for seismic research related to data processing, advanced imaging, and visualization. In recent years, a great deal of cross-fertilization between seismologists and other geophysicists and hydrogeologists has developed within the division, resulting in collaborations on a wide variety of fundamental imaging problems. A primary thrust in this research has been to jointly develop seismic and electrical methods for understanding fluid flow and p roperties within the subsurface. In addition, fundamental studies on improved inversion and modeling of complex media in 3D are being carried out to analyze such effects as matrix heterogeneity fluid flow and anisotropy. Applications range from small-scale environmental problems to oil and gas reservoirs.

\section{ROCK PHYSICS}

A variety of rock and soil science experiments are being conducted through ESD's Geoscience Measurements Facility, which supports both field and laboratory work. In one new laboratory project, researchers are studying the compaction and fracturing of weakly cemented granular rocks. This study examines the effect of micromechanical properties of weak granular rock on macroscopic properties such as load-displacement response, ultimate strength, and failure mode. In a second study, a fundamental investigation of scattering and intrinsic attenuation of seismic waves in rock with heterogeneous distributions of fluids and gas is being conducted. This research represents a departure from past rock-physics studies on seismic attenuation, in that the emphasis here is not a detailed study of a specific attenuation mechanism, but rather to investigate theoretical and laboratory methods for obtaining separate estimates of scattering and intrinsic attenuation in rock with heterogeneous pore-fluid distributions.

\section{FUNDING}

Funding for research in the Fundamental and Exploratory Research Program comes from a variety of sources. These include (primarily) the U.S. Department of Energy, through the Director, Office of Science, Office of Basic Energy Sciences, Division of Chemical Sciences, Geosciences, and Biosciences; the Office of Biological and Environmental Research; the Assistant Secretary for Fossil Energy, Office of Natural Gas and Petroleum Technology, National Petroleum Technology Office, Natural Gas and Oil Technology Partnership; and the Office of Environmental Management Science Program. Funding is also provided by the Laboratory Directed Research and Development Program (LDRD) at Berkeley Lab. 


\title{
U-Th/He Age Determinations on Volcanic Rocks: A New Tool for QUATERNARY GEOCHRONOLOGY
}

\author{
Sarah M. Aciego, B. Mack Kennedy, John N. Christensen, Donald J. DePaolo, and Ian Hutcheon ${ }^{1}$ \\ ${ }^{1}$ Lawrence Livermore National Laboratory \\ Contact: Sarah M. Aciego, 510/486-4975, smaciego@lbl.gov
}

\section{RESEARCH OBJECTIVES}

Determining the age or time scale of events that have occurred within the past million years is still a challenge to geoscientists and an invaluable tool in evaluating hazards on the time scale of human life. Both radiocarbon and argonargon (Ar-Ar) dating can be restricted due to a lack of appropriate phases or materials associated with the event. The uranium-thorium/helium (U-Th/He) system, which has been used successfully for thermochronology on zircon and apatite, has potential for dating young volcanic rocks. Our goal is to investigate the viability of applying the $\mathrm{U}-\mathrm{Th} / \mathrm{He}$ dating method to late Quaternary volcanic rocks containing relatively common minerals, such as garnet and olivine, that are not viable for Ar-Ar and radiocarbon dating.

\section{APPROACH}

The U-Th/He dating method is based on the radiogenic production of ${ }^{4} \mathrm{He}$ from the alpha decay of $\mathrm{U}$ and Th. An age is calculated for the accumulated ${ }^{4} \mathrm{He} / \mathrm{U}-\mathrm{Th}$ ratio measured in the sample. The accuracy of the age can be compromised by the high mobility of helium in most minerals, gain or loss of ${ }^{4} \mathrm{He}$ by alpha recoil, and isotopic disequilibrium in the U-Th$\mathrm{Pb}$ decay chains. Therefore, to evaluate the viability of the method, we conducted a study of garnet phenocrysts from the 79 A.D. eruption of Vesuvius collected at the Villa of Poppea in Pompeii.

\section{ACCOMPLISHMENTS}

To thoroughly test the validity of this method for dating young samples, we had to address several issues: diffusive loss, trapped helium, loss or gain of ${ }^{4} \mathrm{He}$ from alpha recoil, and changing production of ${ }^{4} \mathrm{He}$ because of isotopic disequilibrium in the $\mathrm{U}$ and $\mathrm{Th}$ decay chains. Crushing and step-heating experiments were done to determine the amount of helium trapped and lost by diffusion. The distribution of $U$ and Th was determined by ion microprobe techniques, and then applied to a simple model to determine loss and gain of helium by alpha recoil. Measurement of the isotopic ratios within the U-Th-Pb decay chains allowed us to correct the calculated age for radioactive equilibrium. Given these considerations, the resultant age of $1,866 \pm 243$ years indicates that the U$\mathrm{Th} / \mathrm{He}$ method is applicable to dating Holocene volcanic samples with accuracy and precision of $\pm 13 \%$ on samples with 20 ppm U.

\section{SIGNIFICANCE OF FINDINGS}

The calculated age of the Vesuvius lava validates the U$\mathrm{Th} / \mathrm{He}$ method for the dating of young volcanic systems. The age of the Vesuvius samples is extremely small compared to the 1.8 million year age range covered by the Quaternary epoch. Older samples should contain much larger amounts of radiogenic helium for the same amount of $U$ and $T h$ or similar amounts of helium for smaller concentrations of $U$ and $T h$. The method can now be applied to a range of young lavas that contain fewer mineral phases and were previously not datable using existing $\mathrm{Ar}-\mathrm{Ar}$ and radiocarbon techniques.

\section{RELATED PUBLICATION}

Aciego, S.M., B.M. Kennedy, D.J. DePaolo, J.N. Christensen, and

I. Hutcheon, U-Th/He age of phenocrystic garnet from the 79 A.D. eruption of Mt. Vesuvius. Earth and Planetary Science Letters, 2003 (in press).

Renne, P.R., et al., Ar-40 / Ar-39 dating into the historical realm, Calibration against Pliny the Younger. Science, 277, 12791280, 1997.

\section{ACKNOWLEDGMENTS}

This research was supported by the Director, Office of Science, Office of Basic Energy Sciences, Division of Chemical Sciences, Geosciences, and Biosciences, of the U.S. Department of Energy under Contract No. DE-AC03-76SF00098. We would like to thank Paul Renne for providing the Vesuvius pumice sample.

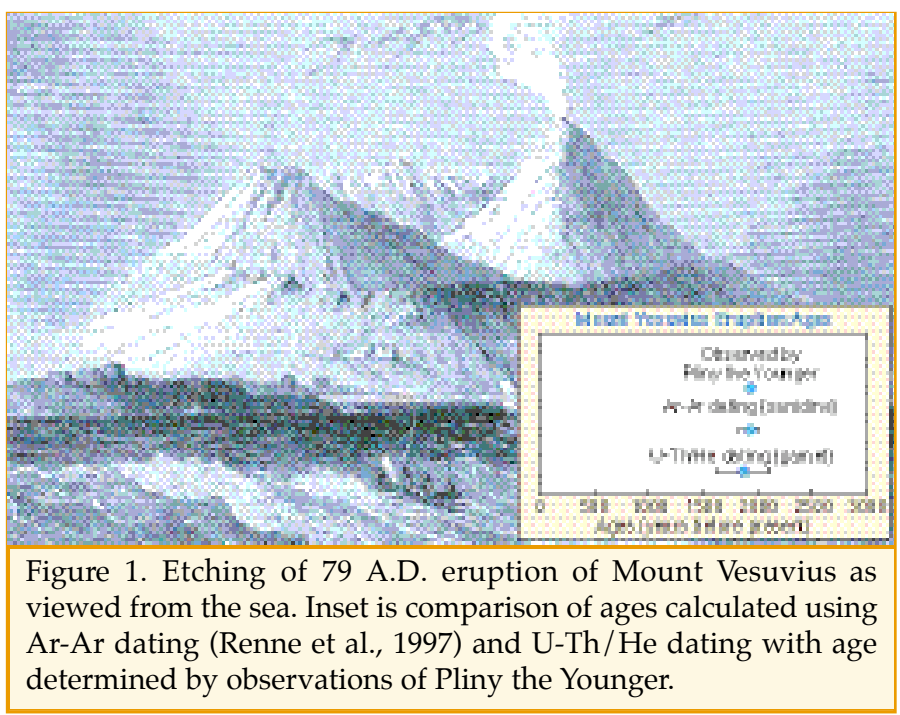

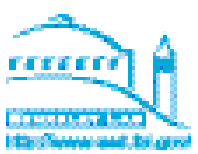




\title{
Kinetic Fractionation of LITHIUM Isotopes by Diffusion IN WATER
}

\author{
John N. Christensen, Frank Richter ${ }^{1}$, and Ruslan Mendybaev ${ }^{1}$ \\ ${ }^{1}$ Department of Geophysical Sciences, University of Chicago \\ Contact: John N. Christensen, 510/486-6735, jnchristensen@lbl.gov
}

\section{RESEARCH OBJECTIVES}

The mass-dependent fractionation of stable isotopes can occur during a number of physical processes, only some of which are well understood theoretically and well investigated experimentally. In particular, the kinetic fractionation of isotopes during diffusion, though understood for gaseous systems, is not well characterized and understood for condensed systems such as liquid water or silicate melts. In the simple case of diffusion of a monatomic gaseous species in an isothermal gas, the ratio of the diffusivities for two isotopes of an element is proportional to the square root of the inverse ratio of the isotope masses. This arises from the equivalence in kinetic energy for molecules in an isothermal gas. In condensed systems such as silicate melts, this simple relationship does not appear to hold. We undertook experiments in aqueous solutions to better understand the phenomenon of kinetic fractionation during diffusion. Results could provide a signature for diffusion in geochemical systems, as well as add to fundamental understanding of the structure and behavior of ion complexes in aqueous solutions.

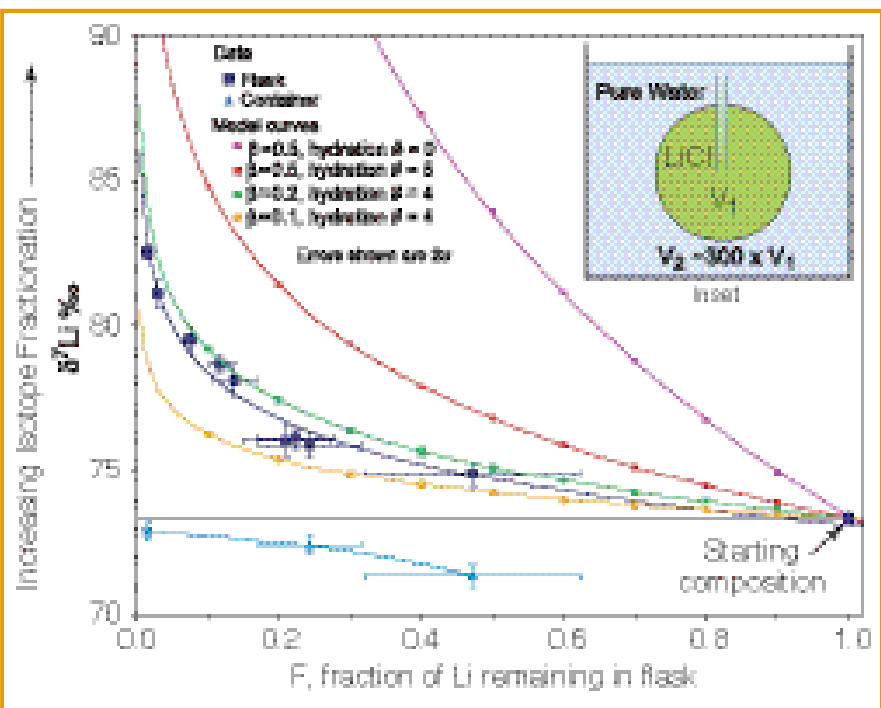

Figure 1. Plot of $\mathrm{F}$, the fraction of $\mathrm{Li}$ remaining in the flask, vs. ${ }^{7} \mathrm{Li}$, a measure of the $\mathrm{Li}$ isotopic composition. Large black squares = data for flasks, blue triangles $=$ data for containers. Model curves are shown for different hydration numbers (\# of waters in the hydration sphere) and exponential factors $(=\beta)$. The inset shows the experimental setup, a flask of Li solution immersed and communicating with a larger volume of pure water.

\section{APPROACH}

The experimental setup consists of a $0.7 \mathrm{~mL}$ glass flask immersed in a larger $(\sim 300 x)$ volume container (see inset,
Figure 1). The flask is filled with a solution of the element of interest and communicates with the larger container via a thin tube. The experiments reported here used a $\sim 700 \mathrm{ppm}$ lithium chloride $(\mathrm{LiCl})$ solution in the flask and high purity water in the surrounding container. Pairs of flasks and containers were set up and allowed to exchange for periods ranging from 31 days to 99 days. At the end of an experiment, we measured the concentrations of Li remaining in the flask and built up in the container. Lithium isotopic compositions $\left({ }^{7} \mathrm{Li} /{ }^{6} \mathrm{Li}\right.$ ratios) were measured by multiple-collector ICP mass spectrometry (MCICPMS).

\section{ACCOMPLISHMENTS}

The results of nine experimental runs with durations ranging from 31 to 99 days are displayed in Figure 1, where F, the fraction of the original $\mathrm{Li}$ remaining in the bulb, is plotted against $\delta^{7} \mathrm{Li}$, a measure of $\mathrm{Li}$ isotopic composition. The longest duration experiment left only $1.5 \%$ of the original amount of $\mathrm{Li}$ in the flask, the balance having diffused into the container volume. As F decreases and Li diffuses from the flask, the isotopic composition of the Li in the flask is fractionated, with more of the heavier ${ }^{7} \mathrm{Li}$ left in the flask than the lighter ${ }^{6} \mathrm{Li}$. This demonstrates that kinetic fractionation of $\mathrm{Li}$ isotopes does occur, in contrast to similar experiments involving magnesium that failed to resolve a fractionation effect.

\section{SIGNIFICANCE OF FINDINGS}

Though fractionation was observed, it was not as great as would be predicted by the theory for gaseous diffusion. A portion of the discrepancy may result from $\mathrm{Li}^{+}$diffusing as a hydrated complex, diluting the ${ }^{6} \mathrm{Li}-{ }^{7} \mathrm{Li}$ mass difference. Models and observations suggest that a sphere of four to six water molecules surrounds $\mathrm{Li}^{+}$ions. But for an exponent of 0.5 , as for a gas, it would require a sphere of 11 waters, an improbable number. If the hydration sphere consists of four waters, then an exponential factor of $\sim 0.2$ reproduces the data. This may reflect the inelastic nature of interactions between water molecules and the $\mathrm{Li}^{+}$hydrated complex. Further experiments are being conducted to better understand and independently constrain the exponential factor and the hydration number.

\section{ACKNOWLEDGMENTS}

This work was supported by the Director, Office of Science, Office of Basic Energy Sciences, Division of Chemical Sciences, Geosciences, and Biosciences, of the U.S. Department of Energy under Contract No. DE-AC03-76SF00098.

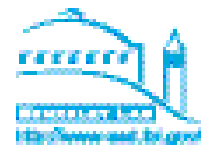




\section{Film Flow along TunNel Walls}

Teamrat A. Ghezzehei and Stefan Finsterle

Contact: Teamrat A. Ghezzehei, 510/486-5688, taghezzehei@lbl.gov

\section{RESEARCH OBJECTIVES}

Dripping of liquid water into tunnels or caves affects natural processes (such as formation of speleothems) and is important to engineering applications (such as mining and geologic disposal of nuclear wastes). Current computer models of these processes assume that liquid water drips immediately after entering the tunnel. In contrast, recent field observations showed that film flow and wetting of tunnel walls result in a temporal and spatial lag between liquid emergence and subsequent dripping. The objective of this research is to assess the impact on seepage of film flow along rough tunnel walls and provide a framework for realistic modeling of seepage and evaporation.

\section{APPROACH}

In this research, conceptual models are developed by capitalizing on recent advances in our understanding and modeling of (1) unsaturated flow near and around tunnels, (2) characterization of unsaturated flow on rough surfaces, and (3) dripping from pendant rivulets. To provide better insight into these hitherto poorly understood phenomena, the research favors analytical models that use simplified geometries and flow conditions.

\section{ACCOMPLISHMENTS}

The conceptual model developed thus far is schematically described in Figure 1. Liquid water enters subsurface tunnels at regions where the near-ceiling pores or fractures are fully saturated. Subsequently, the rough tunnel walls intercept the liquid, and film flow occurs, mediated by the capil lary roughness, which is generally on the order of one millimeter. Flow along the unsaturated wall is driven by capillary and gravitational gradients, as described by the BuckinghamDarcy law. In the unsaturated portions of the tunnel wall, re latively strong capillary adhesion prevents dripping. Dripping occurs at any location on the ceiling where sufficient positive pressu res develop with aerial extent equivalent to the base area of a pendant drop. To facilitate derivation of an analytical solution, we developed a one-dimensional steady-state model for a cylindrical tunnel, as shown in the right panel of Figure 1.

\section{SIGNIFICANCE OF FINDINGS}

Typical capillary pressure $(\psi)$ profiles for several tunnel sizes are shown in Figure 1. Generally, the wetness of the crown region increases with tunnel size because of reduced gravitational forces that are insufficient to drive the liquid away. Consequently, larger tunnels are more prone to dripping. The variable wetness of tunnel walls can be used for physically based estimation of evaporation losses into the tunnel air.

\section{RELATED PUBLICATION}

Ghezzehei, T.A., and S. Finsterle, Film flow on tunnel walls and its role in decreasing seepage. Vadose Zone Journal, 2003 (submitted).

\section{ACKNOWLEDGMENTS}

This work was supported by the Director, Office of Science, Office of Basic Energy Sciences, Division of Chemical Sciences, Geosciences, and Biosciences, of the U.S. Department of Energy under Contract No. DE-AC03-76SF00098.

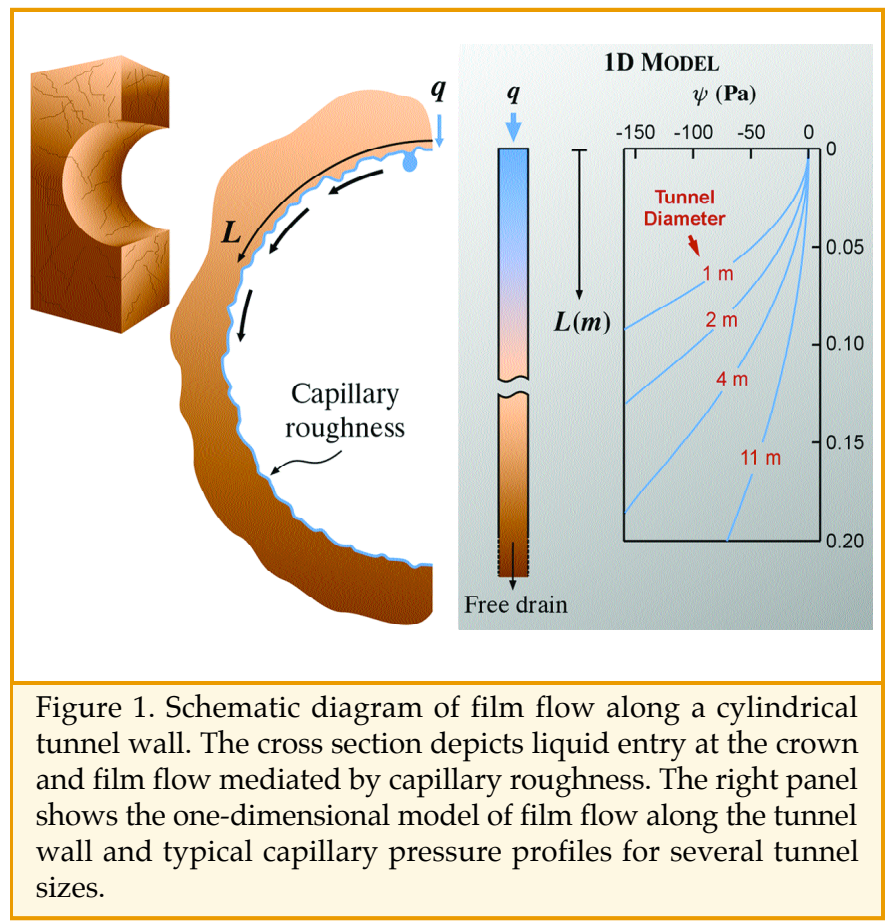

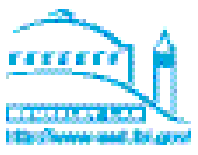




\title{
Air-Derived Noble Gases In Sediments: IMPLICATIONS FOR BASIN-SCALE HYDROGEOLOGY
}

\author{
B. Mack Kennedy, Tom Torgersen ${ }^{1}$, and Matthijs C. van Soest \\ ${ }^{1}$ Department of Marine Sciences, University of Connecticut \\ Contact: B. Mack Kennedy, 510/486-6451, bmkennedy@lbl.gov
}

\section{RESEARCH OBJECTIVES}

The goal of this project is to isolate and identify the various air-derived noble gas components in sediments, particularly (but not exclusively) those sediments associated with hydrocarbon systems. This project is designed to address how noble gas elemental patterns are acquired and retained in rocks and minerals and how they are transferred to the fluid phases in which they have been measured.

\section{APPROACH}

Laboratory and theoretical studies are carried out to (1) identify and isolate the carrier phases of the various air-derived noble gas components in sedimentary rocks and minerals, (2) investigate the process(es) responsible for acquisition and subsequent trapping of the components in their sedimentary carrier phases, and (3) evaluate the mechanisms that release these noble gas components to the ambient hydrological system

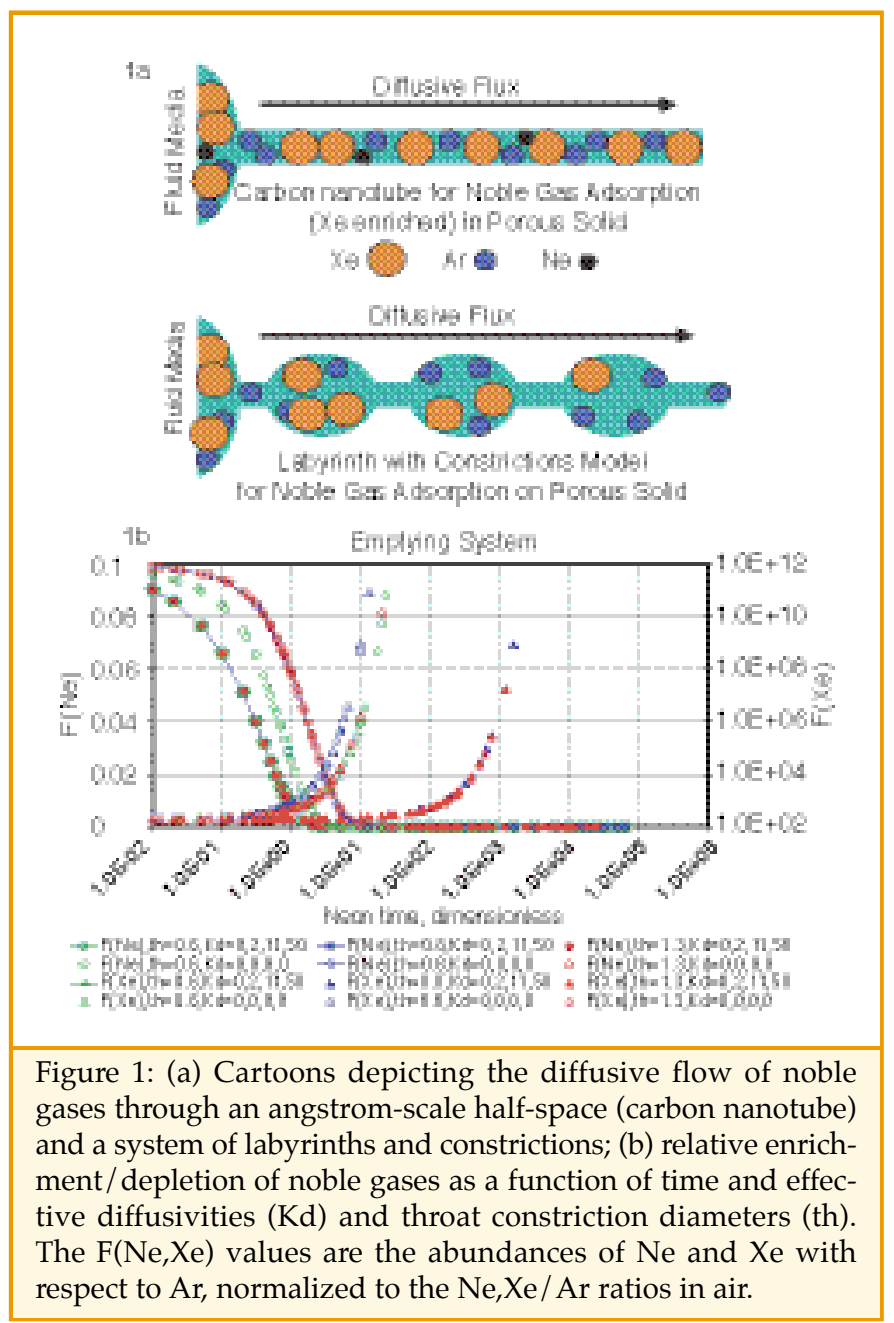

under temperatures and pressures encountered in natural basin processes.

\section{ACCOMPLISHMENTS}

We have examined adsorption and diffusion-controlled fractionation of noble gases as an explanation for the absolute and relative abundances observed in sedimentary rocks. The model uses diffusive filling and emptying of (1) angstromscale half spaces and (2) a system of labyrinths-with-constrictions on the order of the diffusing species' atomic diameter (Figure 1a). Since physical properties of the noble gases are strong functions of atomic mass, the individual diffusion coefficients, adsorption coefficients, and atomic diameters combine to enhance the transport of neon $(\mathrm{Ne})$ while impeding xenon $(\mathrm{Xe})$ (Figure 1b).

\section{SIGNIFICANCE OF FINDINGS}

The model results compare favorably with literature data for noble gas concentrations and relative abundances in terrestrial rocks. It is generally assumed that the source for all atmospheric noble gases in subsurface fluids is air-saturated water. Evidence for water-derived noble gases in hydrocarbon systems is extensive and provides strong support that water plays an important role in hydrocarbon systems. However, excesses of atmospheric xenon and neon recently identified in hydrocarbon systems may be derived from the source and reservoir rocks associated with the system (Torgersen and Kennedy, 1999; Kennedy et al., 2002). If so, future noble gas studies of fluid sources and flow will have to consider sediments as potential sources for atmospheric noble gases, which up till now have been mostly ignored.

\section{RELATED PUBLICATIONS}

Torgersen, T., and B.M. Kennedy., Air-Xe enrichments in Elk Hills oil field gases: Role of water in migration and storage. Earth Planet. Sci. Lett., 167, 239-253, 1999.

Kennedy, B.M., T. Torgersen, and M.C. van Soest, Multiple atmospheric noble gas components in hydrocarbon reservoirs: A study of the Northwest Shelf, Delaware Basin, SE New Mexico. Geochim Cosmochim Acta., 66, 2807-2822, 2002.

\section{ACKNOWLEDGMENTS}

This work was supported by the Director, Office of Science, Office of Basic Energy Sciences, Division of Chemical Sciences, Geosciences, and Biosciences, of the U.S. Department of Energy under Contract No. DE-AC03-76SF00098.

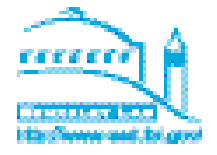




\title{
Noble Gas Isotope Studies of Geothermal Systems
}

\author{
B. Mack Kennedy and Matthijs C. van Soest \\ Contact: B. Mack Kennedy, 510/486-6451, bmkennedy@lbl.gov
}

\section{RESEARCH OBJECTIVES}

This project develops isotope tracers for identifying fluid and heat sources and studying fluid processes in geothermal systems. Recently, we have concentrated on identifying geochemical and / or isotopic signals that can be used to locate geothermal systems in regions lacking recent volcanic activity and surface manifestations of deep hot fluids.

\section{APPROACH}

Fluids within the earth's crust contain noble gases (helium $[\mathrm{He}]$, neon [Ne], argon [Ar], krypton [Kr], and xenon [Xe]) from a variety of sources, each characterized by a unique composition, and therefore contributions from different sources can be easily identified. For instance, geothermal fluids that acquire heat from active magma systems are strongly enriched in ${ }^{3} \mathrm{He}$, with ${ }^{3} \mathrm{He} /{ }^{4} \mathrm{He}$ ratios up to 9 times the ratio in air (R/Ra $\sim 9$ ); those that acquire heat from the natural thermal gradient are depleted in ${ }^{3} \mathrm{He}(\mathrm{R} / \mathrm{Ra} \sim 0.02)$. This vast difference provides a sensitive quantitative measure of fluid and heat source driving a geothermal system and fluid mixing within the system.

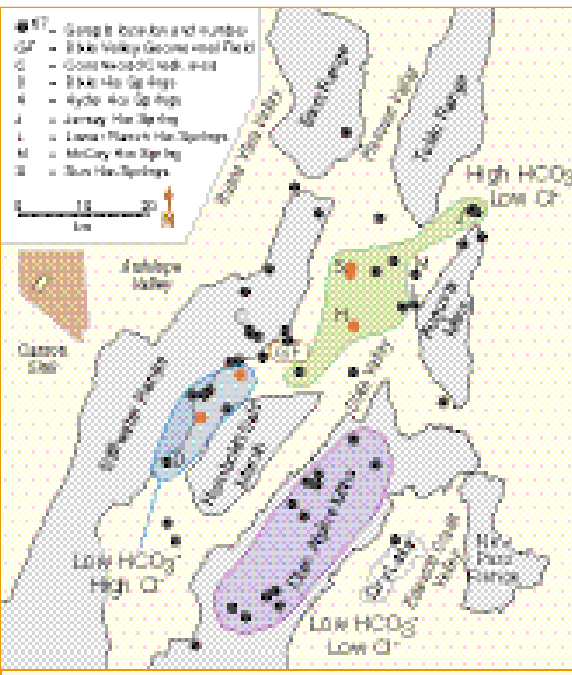

Figure 1a: Map showing the location of Dixie Valley wells, springs, fumaroles, and the Dixie Valley Geothermal Field. Features identified by letters (see Legend) were sampled for noble gas isotope analyses.

Figure 1b: Helium isotopic compositions $(\mathrm{R} / \mathrm{Ra})$ for the Dixie Valley samples are

\section{ACCOMPLISHMENTS}

The Dixie Valley Geothermal Field, Nevada, is considered a classic nonmagmatic geothermal system that acquires heat by deep fluid circulation. Similar systems occur throughout the Basin and Range Province of northern Nevada. Fluids sampled throughout Dixie Valley (Figure 1a) have a range in helium isotopic compositions $(\sim 0.3-0.8 \mathrm{Ra})$. The highest values $(0.7-0.8$ $\mathrm{Ra})$, found in fluids produced from the Dixie Valley Geothermal Field, suggest that the natural thermal gradient provides $\sim 85-90 \%$ of the reservoir heat. Co-variations between He isotopic composition and abundances (Figure $1 \mathrm{~b}$ ) require mixing of two fluids, and also require that all of the sampled features (except Well 66-21) contain a fluid component indistinguishable from that produced from the geothermal field.

\section{SIGNIFICANCE OF FINDINGS}

The observation of a common deep fluid throughout Dixie Valley suggests the presence of a larger exploitable geothermal resource than presently under production. This study also demonstrates the utility of noble gas isotopes for finding and evaluating the extent of hidden geothermal systems.

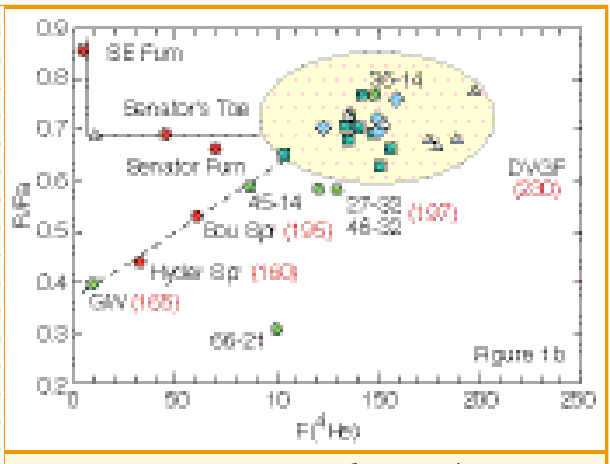

plotted as a function of the $4 \mathrm{He} / 36 \mathrm{Ar}$ ratio (normalized to the ratio in air). The $\mathrm{F}(4 \mathrm{He})$ values reflect the degree of helium enrichment relative to that expected for young meteoric waters $[\mathrm{F}(4 \mathrm{He}) \sim 0.2]$. The composition of Dixie Valley geothermal production wells plot within the ellipse. The dotted line emanating from the ellipse portrays the trajectory expected for either boiling (e.g., Senator's Toe and Fumarole) or air contamination (SE Fumarole). The dashed line depicts two fluids mixing. Numbers in parentheses are calculated chemical geothermometer temperatures.

\section{RELATED PUBLICATIONS}

Kennedy, B.M., M.C. van Soest, and S. Johnson, Helium isotopes in Dixie Valley wells, springs, and fumaroles: Heat and fluid sources; regional trends. Geothermics, 2003 (submitted).

Kennedy, B.M., T.P. Fischer, and D.L. Shuster, Heat and helium in geothermal systems. Proceedings, 25 th Workshop on Geothermal Reservoir Engineering, Stanford Geothermal Program Report SGP-TR-165, pp. 167-173, 2000.

\section{ACKNOWLEDGMENTS}

This work was supported by the Assistant Secretary for Energy Efficiency and Renewable Energy, Office of Technology Development, Office of Geothermal Technologies, of the U.S. Department of Energy under Contract No. DEAC03-76SF00098. 


\title{
SYNTHESIS, ChaRACTERIZATION, AND REACTIVITY OF NANOPARTICULATE GOETHITE
}

\author{
Christopher S. Kim, Jill F. Banfield, and Glenn A. Waychunas \\ Contact: Christopher S. Kim, 510/486-7709, cskim@lbl.gov
}

\section{RESEARCH OBJECTIVES}

Nanoparticles feature high surface areas, a tendency to remain in suspension, and differences in their chemical/physical properties relative to bulk phases. As a result, the reactivity of nanoparticles to metal contaminants (e.g., As, $\mathrm{Cu}, \mathrm{Hg}, \mathrm{Zn}$ ) may be greatly enhanced in inverse proportion to their size. The objectives of this research are to study the formation, growth, and reactivity of nanoparticulate goethite $(\alpha-\mathrm{FeOOH})$, one of the most common mineral phases in the environment and one of the most reactive in terms of metal-contaminant uptake.

\section{APPROACH}

Our approach involves the synthesis and characterization of nanoparticulate goethite over a range of sizes (from 10 to $100 \mathrm{~nm}$ ). Studies of goethite nanoparticle growth over time are then paired with metal uptake studies and analysis of metal speciation at the mineral-water interface to understand any changes in reactivity as a function of size. Transmission electron microscopy (TEM), surface area analysis, $x$-ray diffraction (XRD), and dynamic light scattering (DLS) are used to characterize the differently sized batches of nanoscale goethite and determine their size, morphology, surface area, and size distribution. The growth and structure of the nanoparticles are investigated through small- and wide-angle $\mathrm{x}$-ray scattering (SAXS/WAXS) spectroscopy, while metal uptake is studied using batch sorption experiments paired with inductively coupled plasma-atomic emission spectrometry (ICP-AES) and extended $x$-ray absorption fine structure (EXAFS) spectroscopy.

\section{ACCOMPLISHMENTS}

We have synthesized goethite over a range of $10-80 \mathrm{~nm}$ in diameter (surface areas $>250 \mathrm{~m}^{2} / \mathrm{g}$ ), using a microwave annealing process and aging at $90^{\circ} \mathrm{C}$. The size distribution of the nanogoethite has been characterized with DLS and TEM. Analyzing aged samples with DLS shows that the nanogoethite exhibits two stages of growth (Figure 1): relatively rapid growth from 0 to 4 days $(10-58 \mathrm{~nm})$ and much slower growth from 4 to 33 days $(58-78 \mathrm{~nm})$. This may represent initial evidence of (oriented) aggregation as a mechanism for nanoparticle growth, in agreement with recent studies indicating that growth through aggregation dominates over growth from solution. This distinction is important in predicting the eventual fate/sequestration of metals that may sorb to nanoparticles during their growth.

The SAXS / WAXS spectroscopy work has focused on the in situ growth of nanoparticulate goethite suspensions at $90^{\circ} \mathrm{C}$.
Batch uptake experiments and corresponding EXAFS analysis have shown differences in the mode of metal speciation between $10 \mathrm{~nm}$ and $73 \mathrm{~nm}$ batches of goethite, indicating that there is a particle-size dependency on the method of metal sorption, perhaps caused by varying densities or proportions of sorption sites as a function of size.

\section{SIGNIFICANCE OF FINDINGS}

This work has important, fundamental implications for our understanding of how the properties of nanoscale materials, including reactivity to metals, may deviate with decreasing particle size. In addition, this research has potential applications in remediation of abandoned mines or industrially polluted regions, where high-surface-area, hypersorbent phases such as nanoparticulate goethite may assist in the cleanup of heavy metals.

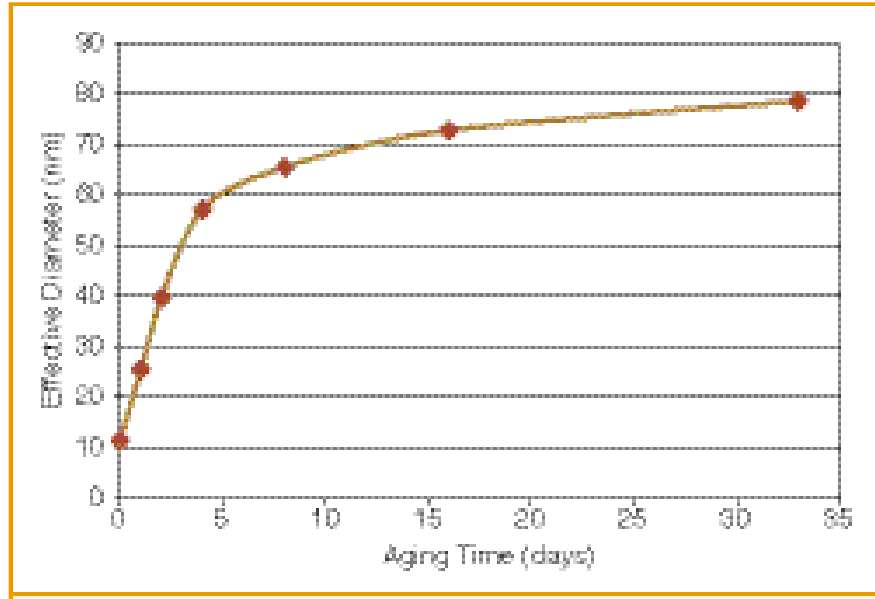

Figure 1. Dynamic light scattering (DLS) measurements tracking the growth of goethite nanoparticles as a function of aging time at $90^{\circ} \mathrm{C}$

\section{RELATED PUBLICATION}

Waychunas, G.A., Structure, aggregation, and characterization of nanoparticles. In Nanoparticles and the Environment (J.F. Banfield and A. Navrotsky, editors), Mineralogical Society of America, 2001.

\section{ACKNOWLEDGMENTS}

This work was supported by Laboratory Directed Research and Development (LDRD) funding from Berkeley Lab, provided by the Director, Office of Science, of the U.S. Department of Energy under Contract No. DE-AC0376SF00098.

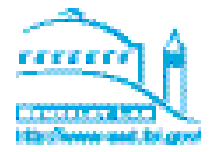




\section{Fault Zone Imaging Using Guided Waves \\ Valeri Korneev and Robert Nadeau \\ Contact: Valeri Korneev, 510/486-7214, vakorneev@lbl.gov}

\section{RESEARCH OBJECTIVES}

The main goal of this project is to develop new seismic image processing technologies. These technologies will improve the quality and resolution of seismic images for complex media, as well as increase our knowledge of the physical processes in rocks.

\section{APPROACH}

A significant part of the project involves furthering our understanding of seismic wave propagation in an active fault zone. Our method involves attributing specific features of recorded seismic waves to the structural and physical properties of the fault, which allow extraction of more detailed information from the data. Analysis and interpretation of the data enable extensive numerical modeling of seismic wave propagation in the fault zones. We use microearthquake data from Parkfield, California (located on the San Andreas fault) to apply the new forward modeling techniques we have developed for use on a crustal scale. These techniques are complemented by an innovative guided-wave tomography inversion scheme to obtain high-resolution images of the fault zone core.

Numerical modeling and a number of field observations have indicated the usefulness of propagating fault zone guided waves (FZGW) at Parkfield, which has a 20 to $40 \%$ lowvelocity fault zone 100 to $200 \mathrm{~m}$ wide.

\section{ACCOMPLISHMENTS}

Using amplitude guided-wave tomographic inversion, we obtained a unique image (Figure 1) of the inner structure of the San Andreas fault zone, with resolution exceeding travel-time P- and S- wave tomography by a factor of ten. The results show clearly that FZGW are most effectively generated within a well-defined region of the fault zone. This region plunges to the northwest through an area of extremely high seismicity, separating locked and slipping sections of the fault (as determined from both geodesy and microearthquake recurrence rates). We interpret this localized region of FZGW generation to be the northwest edge of the M6 asperity at Parkfield, the low attenuation most likely resulting from dewatering by fracture closure and/or fault-normal compression. Changes in fracture orientation, caused by a complex stress field in the boundary of creeping and locked zones of the fault, are also likely causes of the low attenuation.

\section{SIGNIFICANCE OF FINDINGS}

The obtained images indicate a high connectivity between various spatially dependent parameters (such as slip rate, stress change, and wave propagation velocities), which suggests their common origin. This study also shows that FZGW can be used for amplitude tomographic inversion, giving highresolution, robust images of the narrow low-velocity layers (faults). FZGW-generated images contain several significant features of the fault zone-the region of shallow velocity change in the Vibroseis monitoring, high seismicity, the largest earthquakes and associated high slip rate, the 1966 M6 hypocenter, and the transition from locked to creeping behavior. These results, and specifically the content and quality of the produced images, reinforce the importance of guided waves for fault zone studies.

\section{RELATED PUBLICATION}

Korneev, V.A., R.M. Nadeau, and T.V. McEvilly, Seismological studies at Parkfield IX: Fault zone imaging using guided wave attenuation. Bulletin of Seismological Society of America, 2003 (in press).

\section{ACKNOWLEDGMENTS}

This work was supported by the Director, Office of Science, Office of Basic Energy Sciences, Division of Chemical Sciences, Geosciences, and Biosciences, of the U.S. Department of Energy under Contract No. DE-AC03-76SF00098.

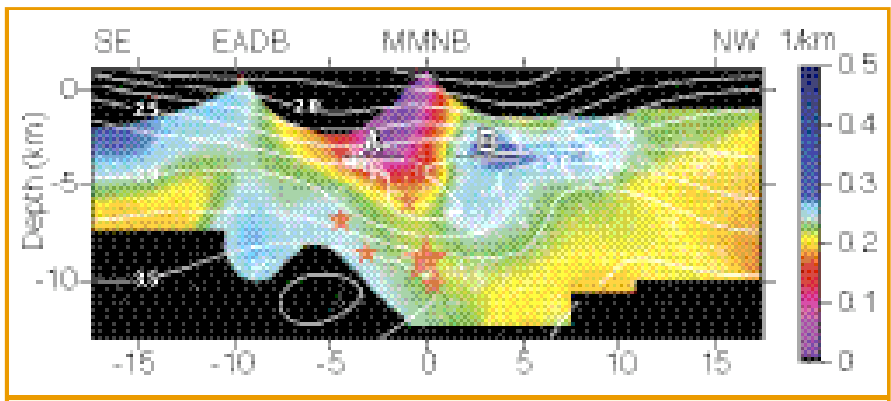

Figure 1. In-fault attenuation-coefficient image of the FZGW tomographic reconstruction, showing the northwest-plunging region of inferred strong fault zone guided-wave generation, Vs contours, 1987-1998 seismicity (small red stars for M>4 events), and the 1966 M6 hypocenter 


\section{Joint Inversion for Mapping Subsurface Hydrological Parameters \\ Ki Ha Lee and Hung-Wen Tseng \\ Contact: Ki Ha Lee, 510/486-7468, khlee@lbl.gov}

\section{RESEARCH OBJECTIVES}

One of the main objectives of geophysical inversion is to describe various subsurface processes involving fluid flow. Hydrological properties such as fluid electrical conductivity and rock porosity cannot be directly obtained with conventional inversion techniques. The electromagnetic (EM) field propagating in the subsurface is a function of bulk conductivity, which in turn may be empirically related to porosity, porefluid conductivity, saturation, and occasionally the temperature. Similarly, the amplitude, phase, and velocity of seismic waves depend on several factors (such as porosity, density, elastic constants, temperature, and pressure). The objective of this study was to develop methodologies for directly mapping hydrological parameters using joint analysis of different geophysical data, along with the empirical relationships between geophysical and hydrological parameters.

\section{APPROACH}

To assess the feasibility of deriving hydrological properties directly, we introduced a joint-inversion technique using electromagnetic (EM) and seismic travel-time data (Tseng and Lee, 2001). Because of the limited capability inherent to the inversion techniques used, we decided to investigate advanced inversion schemes for the improved joint inversion. Most of the EM inversion studies in the literature involve full waveform, but there is a lack of similar studies in the seismic area. Full-waveform inversion of seismic data is difficult, partly because of the lack of precise knowledge about the source. Since currently available approaches involve some form of source approximation, inversion results are subject to the quality and choice of the source information used.

\section{ACCOMPLISHMENTS}

A new full-waveform inversion scheme has been developed in this research program, exploiting the useful property of the normalized wavefield. A gather of seismic traces was first Fourier-transformed into the frequency domain, and a normalized wavefield was obtained for each trace in the frequency domain. Normalization was done with respect to the frequency response of a reference trace selected from the gather. The source spectrum was eliminated during the normalization procedure. With its source spectrum eliminated, the normalized wavefield allowed us to construct an inversion algorithm without the source information. The inversion algorithm minimized misfits between the measured normalized wavefield and the numerically computed normalized wavefield.

The validity of the scheme has been successfully demonstrated using a simple 2-D synthetic model (Lee and Kim, 2003).

\section{SIGNIFICANCE OF FINDINGS}

Normalized wavefields depend, for a given source, only on the subsurface model and the position of the source, and are independent of the source spectrum by construction. The significance of this is that full-waveform inversion of seismic data can be achieved without the source information. With the new method, potential inversion errors caused by source estimation (required by conventional full-waveform inversion methods) can be eliminated.

\section{RELATED PUBLICATIONS}

Lee, K.H., and H.J. Kim, Source-independent full waveform inversion of seismic data. Geophysics (in press), published electronically on May 20, 2003; Berkeley Lab Report LBNL49934.

Tseng, H.-W., and K.H. Lee, Joint inversion for mapping subsurface hydrological parameters. Expanded Abstracts, SEG International Exposition and 70th Annual Meeting, San Antonio, Texas, pp. 1341-1344, September 9-14, 2001.

\section{ACKNOWLEDGMENTS}

This work was supported by the Director, Office of Science, Office of Basic Energy Sciences, Division of Chemical Sciences, Geosciences, and Biosciences, of the U.S. Department of Energy under Contract No. DE-AC03-76SF00098. 


\title{
Use of 234U/238U Ratios to Measure IN Situ Weathering Rates in the HANFORD VADOSE ZONE
}

\author{
Katharine Maher, Donald J. DePaolo, and John N. Christensen \\ Contact: Katharine Maher, 510/642-9524, katem@eps.berkeley.edu
}

\section{RESEARCH OBJECTIVES}

Weathering rates of subsurface soil and rocks are difficult to quantify because of the difficulties in assessing the amount of reactive surface area and the thermodynamic potentials driving the chemical reactions. Mineral dissolution rates measured in the laboratory typically predict rates that are 2 to 4 orders of magnitude faster than estimates based on field measurements (White et al., 1996). Few field measurements are available, and most of those are on silicate soils. Almost no field measurements exist for deep vadose zone materials or for rocks in the saturated zone.

The uranium-series (U-series) isotope system can be used to measure reaction rates in aquifers and thick vadose zone environments. This approach is based on $\alpha$-recoil of ${ }^{234} \mathrm{Th}$ atoms across grain boundaries, which enriches the pore fluid in ${ }^{234} \mathrm{U}$. Dissolution of the solid phase releases mainly ${ }^{238} \mathrm{U}$ to the pore fluid, so that the ${ }^{234} \mathrm{U} / 238 \mathrm{U}$ ratio of the pore fluid is a measure of the local ratio of the dissolution uranium flux to the $\alpha$-recoil flux (Tricca et al., 2001; DePaolo et al., 2003 submitted). The in situ reaction rate can be calculated from measurements of the ${ }^{234} \mathrm{U} / 238 \mathrm{U}$ isotopic ratio of interstitial fluids and solid phases, if the $\alpha$-recoil flux can be estimated independently.

\section{APPROACH}

Uranium isotopes were measured for bulk sediment, sediment size fractions, pore fluids, the exchangeable fraction, and selected mineral phases of a $70 \mathrm{~m}$ vadose zone core at the Hanford Site, Washington, to estimate the mineral weathering rates and understand uranium distributions in the vadose zone. These measurements were performed using a Micromass IsoProbe multicollector ICP-MS at the Center for Isotope Geochemistry. A reactive transport model, aimed at comparing the U-series kinetics to those predicted by a multicomponent thermodynamic model, is being constructed to further evaluate the results.

\section{ACCOMPLISHMENTS}

The measured ${ }^{234} \mathrm{U} /{ }^{238} \mathrm{U}$ ratios for the vadose zone core yield weathering rates that are in general agreement with estimates based on other methods: approximately $10^{-6.4} \mathrm{yr}^{-1}$ (Figure 1). These are the first measurements of uranium isotope compositions of the vadose zone pore waters and solid phases, and the first attempt to use these measurements to estimate weathering rates in the vadose zone.

\section{SIGNIFICANCE OF FINDINGS}

This study is the first to quantify reaction kinetics in the vadose zone. Perhaps the most significant contribution of this work is the development of an in situ method for determining precipitation/dissolution rates that, when coupled with other geochemical data, may help to decipher the mechanisms that control weathering in natural systems.

\section{RELATED PUBLICATIONS}

DePaolo et al., Rate of diagenetic reactions in deep-sea sediment: In situ measurement using ${ }^{234} \mathrm{U} / 238 \mathrm{U}$ of pore fluids. Geochim. Cosmochim. Acta., 2003 (submitted).

Maher, K., D.J. DePaolo, M.E. Conrad, and R.J. Serne, Vadose zone infiltration rate at Hanford, Washington, inferred from Sr isotope measurements. Water Resour. Res., 39(8), 1204, 2003.

Tricca, A., G.J. Wasserburg, D. Porcelli, and M. Baskaran, The transport of $\mathrm{U}$ - and Th- series nuclides in a sandy unconfined aquifer. Geochim. Cosmochim. Acta, 65, 1187-1210, 2001.

White, A.F., A.E. Blum, M.S. Schulz, T.D. Bullen, J.W. Harden, and M.L. Peterson, Chemical weathering of a soil chronosequence on granitic alluvium 1. Reaction rates based on changes in soil mineralogy. Geochim. Cosmochim. Acta, 60, 2533-2550, 1996.

\section{ACKNOWLEDGMENTS}

This work was supported by the U.S. Department of Energy under Contract No. DE-AC06-76RL01830, through the Hanford Science and Technology Program, and by the Director, Office of Science, Office of Basic Energy Sciences, Division of Chemical Sciences, Geosciences, and Biosciences, of the U.S. Department of Energy under Contract No. DEAC03-76SF00098.

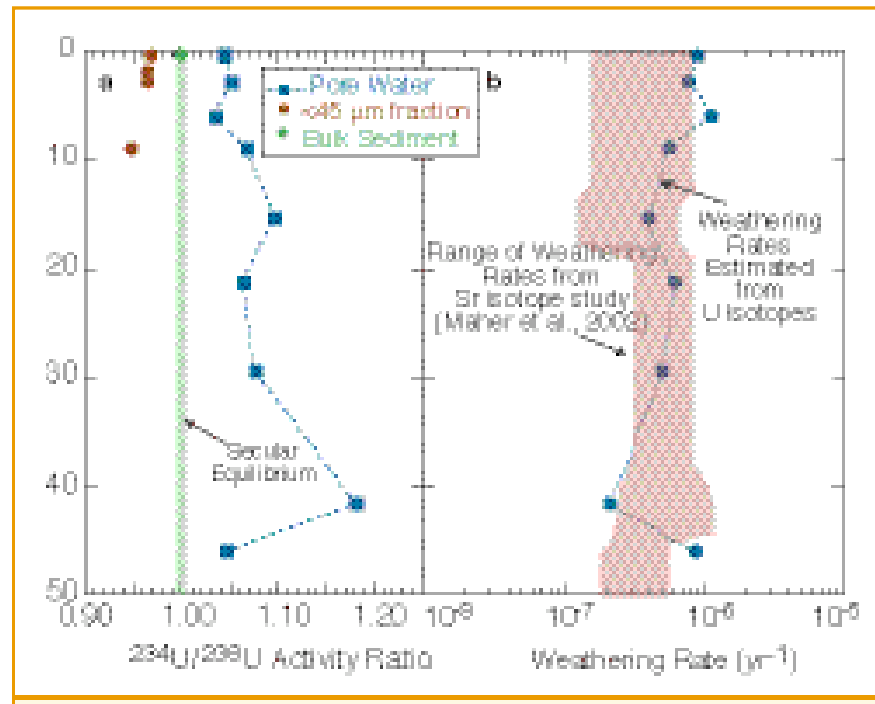

Figure 1. (a) U isotope data from the 299-W22-48 core, Hanford, Washington. (b) Comparison of estimated weathering rates derived from $\mathrm{Sr}$ and $\mathrm{U}$ isotope studies. 


\section{DETECTION AND IDENTIFICATION OF UNEXPLODED ORDNANCE \\ Frank Morrison, Alex Becker, Erika Gasperikova, and Torquil Smith \\ Contact: Erika Gasperikova, 510/486-4930, egasperikova@lbl.gov}

\section{RESEARCH OBJECTIVES}

A recent Task Force Report lists some 1,500 sites comprising approximately 15 million acres that potentially contain unexploded ordnance (UXO). In practice, the major costs in cleanup are excavation and removal, but at present, $90 \%$ of the objects detected are non-UXO, and $75 \%$ of the cost of excavation is for these non-UXO objects. Existing systems can detect metallic objects in the ground, but cannot discriminate between the generally cylindrical and symmetric intact UXO and the scraps or fragments of exploded UXO that are harmless (Figure 1). It is the objective of this research to design and fabricate an optimum active electromagnetic (AEM) system that can extract from the measurements the best possible estimates of the location, size, shape, and metal content of a buried metallic object-in the presence of interfering responses from the ground and non-UXO metallic objects.

\section{APPROACH}

These objectives are being realized through simulators: numerical models of the electromagnetic response, produced by an arbitrary target in the ground, to an arbitrary configuration of transmitters and receivers. The simulators are then used for the forward calculations required in inverse solutions for (a) the depth, size, and aspect ratio of a target and (b) the configuration of the transmitters and receivers to optimize the calculations in (a).

\section{ACCOMPLISHMENTS}

We have found that the depth, size, and principal moments (any target can be represented by three orthogonal principal dipole moments) can be derived from the response of a system consisting of three orthogonal transmitters and five sensitive induction-coil sensors mounted within a $1 \mathrm{~m} \times 1 \mathrm{~m}$ frame. Because of these findings, the project emphasis has shifted to making magnetic field sensors and instrumentation that can achieve measurement bandwidths (or time windows) that meet the specifications of the simulations. Since optimum determination of depth and orientation requires multiplepoint sensors (arrays of compact sensors), we have developed small induction sensors to replace the large open-loop sensors currently used in all AEM systems.

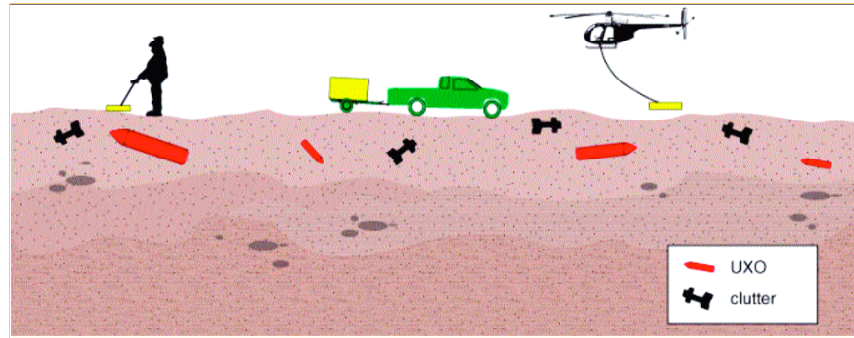

Figure 1. Conceptual representation of UXO in presence of clutter and geological noise

\section{SIGNIFICANCE OF FINDINGS}

We have designed a new generation of multisensor electromagnetic systems that can significantly extend the depth of UXO detection and, more importantly, determine key parameters of the object that will differentiate it from harmless scrap metal.

\section{ACKNOWLEDGMENTS}

This research has been funded by the U.S. Department of Defense, Department of the Army, under SERDP Project \#UX1225. 


\section{Seismic Wave Scattering by Hetergeneous Fractures and Faults \\ Seiji Nakagawa, Aoife C. Toomey, and Larry R. Myer \\ Contact: Seiji Nakagawa, 510/486-7894, snakagawa@lbl.gov}

\section{RESEARCH OBJECTIVES}

The conventional seismic displacement discontinuity (SDD) model for seismic wave scattering by single fractures and faults assumes a linear relationship between the wave-introduced, small relative displacement and the stress across a fracture. This relationship is represented by a material parameter called fracture compliance. Theoretical studies based upon the SDD model are usually limited to, or assume, fractures with a homogeneous distribution of fracture compliance on the fracture plane. Naturally occurring fractures and faults are, however, heterogeneous, with the microscale properties varying along the fracture plane. This variation gives rise to fracture compliance that is spatially heterogeneous and, possibly, auto-correlated. Since the heterogeneity of a fracture has a great impact on the hydraulic and mechanical properties of the fracture, understanding the effect of heterogeneity on the scattering of elastic waves can provide valuable tools for geophysical and nondestructive characterization of fracture properties.

\section{APPROACH}

The dynamic behavior of a real fracture and a fault can be modeled using an interface with a heterogeneous distribution of compliance, measured locally at some length scale much smaller than the seismic (elastic-wave) wavelengths. Analytical and numerical techniques to examine elastic-wave scattering by heterogeneous fractures and faults can be developed based on these "local" SDD boundary conditions and the plane-wave theory. This is achieved by simply applying a spatial Fourier transform to the conventional SDD conditions with the "local" fracture compliance. For this reason, this method is called the wavenumber-domain seismic-displacement-discontinuity (wd-SDD) method.

\section{ACCOMPLISHMENTS}

An analytical model of the wd-SDD method was developed, and a numerical algorithm was written to simulate elastic-wave scattering by heterogeneous fractures and faults. The heterogeneity is quantitatively represented as a spatially correlated, random distribution of the fracture compliance on a fracture or fault plane. Some of the advantages of this method are that (1) wave scattering for a wide range of frequencies can be examined, (2) all mode-converted waves can be modeled (Figure 1), and (3) only a small computer is needed for the numerical simulations.

\section{SIGNIFICANCE OF FINDINGS}

Using the developed method, we examined the scatteringinduced, frequency-dependent behavior of average fracture compliance determined from the scattered waves measured in the far field. Our results showed that, for a spatially correlated, heterogeneous fracture-compliance distribution with a finite correlation length, the average compliance increases as a function of frequency at low frequencies, and then decreases at high frequencies. The transition frequency between the low and high frequency regimes can be related to the correlation length of the distribution. In contrast, for a self-affine (fractal) compliance distribution that does not have characteristic length scale, the numerical simulations show little or no peak in the compliance spectra. Also, these frequency-dependent compliances have a complex value, which can be misinterpreted as the viscoelastic property of the fracture.

\section{RELATED PUBLICATION}

Nakagawa, S., K.T. Nihei, and L.R. Myer, Elastic wave scattering of a fracture with non-uniform stiffness distribution. EOS Trans., AGU, 83(47), Fall Meet. Suppl., Abstract S61B1141, 2002.

\section{ACKNOWLEDGMENTS}

This work was supported by the Director, Office of Science, Office of Basic Energy Sciences, Division of Chemical Sciences, Geosciences, and Biosciences, of the U.S. Department of Energy under Contract No. DE-AC03-76SF00098.

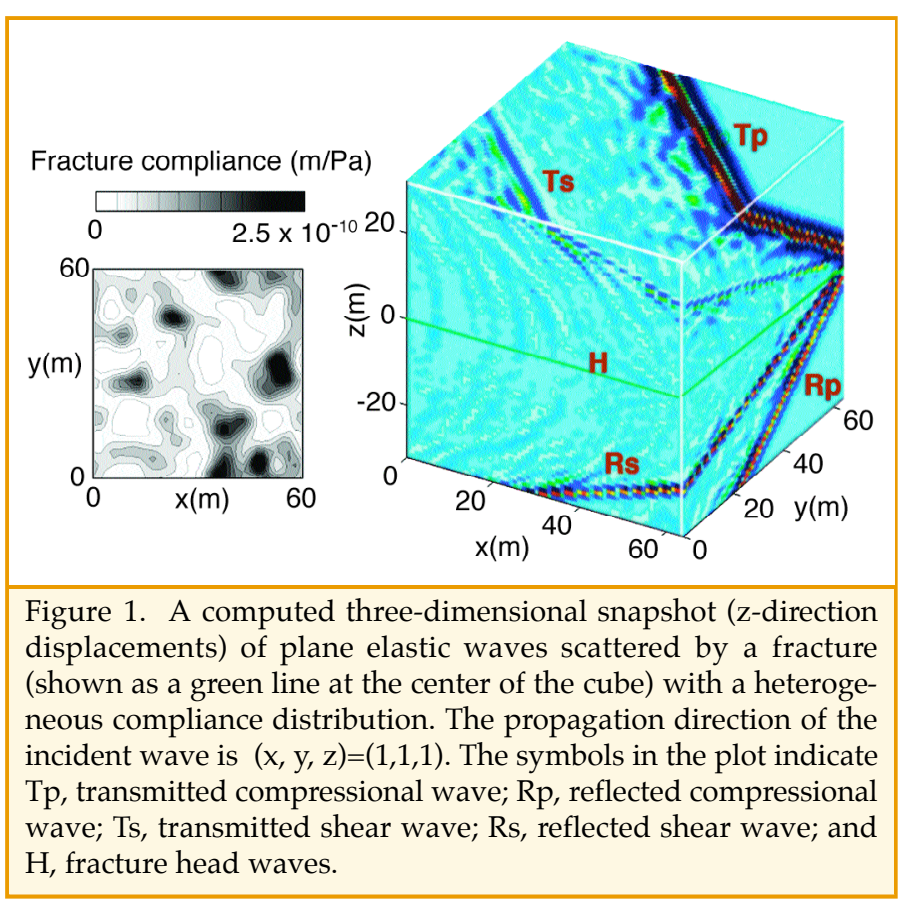




\title{
Imaging Attenuation in Rock with Heterogeneous Multiphase Fluids
}

\author{
Kurt T. Nihei, S. Nakagawa, and T. Watanabe
}

Contact: Kurt T. Nihei, 510/486-5349, ktnihei@lbl.gov

\section{RESEARCH OBJECTIVES}

At the center of this project is a fundamental investigation of scattering and intrinsic attenuation of seismic waves in rock with heterogeneous distributions of fluids and gas. This research represents a departure from past rock-physics studies on seismic attenuation, in that the emphasis here is not on a detailed study of a specific attenuation mechanism. Rather, the emphasis is on investigating theoretical and laboratory methods for obtaining separate estimates of scattering and intrinsic attenuation in rock with heterogeneous pore-fluid distributions. We anticipate that methods for obtaining separate estimates of intrinsic and scattering attenuation may lead to higher-resolution methods for monitoring the movement of fluids in the subsurface.

\section{APPROACH}

During the first two years of this project, we have adopted a deterministic approach to the problem of attenuation imaging. The approach is to use full-waveform viscoelastic nonlinear inversion to image the frequency-dependent viscoelastic properties of the subsurface. The complex moduli determined from this inversion provide estimates of the frequencydependent bulk and shear moduli and the P- and S-wave intrinsic attenuation. In principle, if the finite-difference modeling code used in the full-waveform inversion scheme correctly simulates wave propagation in a heterogeneous, viscoelastic medium, and the source-receiver coverage around the medium being probed is adequate, then the apparent attenuation caused by scattering off heterogeneities is removed in the inversion process. The attenuation estimated

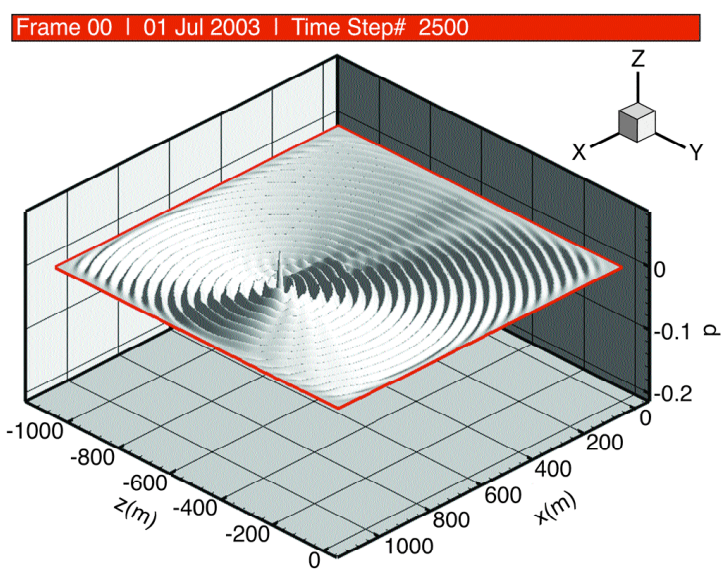

Figure1. Snapshot of the pressure field generated by a $100 \mathrm{~Hz}$ pressure source located in the lower left corner of a homogeneous medium with a single fracture, located in the middle of the model. An anisotropic, viscoelastic, time-domain staggered grid was used in this computation. from the inverted complex moduli will be the intrinsic attenuation. However, in practice, it is expected that cumulative scattering off subwavelength heterogeneities (e.g., layering) may also effectively remove energy from the dominant arrivals. This research will use numerical modeling with heterogeneity to investigate these issues.

\section{ACCOMPLISHMENTS}

One key component of full-waveform viscoelastic imaging is its efficient numerical algorithm for computing the seismic response at the receiver locations for multiple sources. We have found that a faster finite-difference solution for time harmonic problems can be computed with an explicit (i.e., time-domain) method rather than an iterative implicit (i.e., frequencydomain) method. In this time-domain approach to frequencydomain modeling, a time-domain finite-difference code is run with harmonic waves out to steady state (Figure 1). The magnitude and phase at each location $(x, z)$ are extracted from the time harmonic data using a phase-sensitive detection (PSD) algorithm. Tests performed using this algorithm demonstrate that it requires a simple summation over several cycles to obtain accurate magnitude and phase estimates. Tests have also shown that the algorithm works when multiple frequencies are present in the wavefield.

\section{SIGNIFICANCE OF FINDINGS}

Based on these results, a 2-D viscoelastic, anisotropic, frequency-domain, full-waveform inversion code is being built around a 2-D viscoelastic, anistropic, time-domain, staggeredgrid finite-difference code. We anticipate that this code will be significantly faster than, and capable of solving larger problems than, current viscoelastic frequency-domain inversion codes that utilize frequency-domain forward-modeling routines. We plan on completing and testing this inversion code later in 2003.

\section{RELATED PUBLICATION}

Watanabe, T., K.T. Nihei, S. Nakagawa, and L.R. Myer, Imaging of crosshole laboratory data using visco-acoustic waveform inversion and reverse-time imaging. Expanded Abstracts, 72nd Annual Meeting of the Society of Exploration Geophysics, Salt Lake City, Utah, pp. 870-873, 2002.

\section{ACKNOWLEDGMENTS}

This work was supported by the Director, Office of Science, Office of Basic Energy Sciences, Division of Chemical Sciences, Geosciences, and Biosciences, of the U.S. Department of Energy under Contract No. DE-AC03-76SF00098.

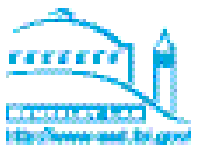




\section{Clay Mineral Surface Geochemistry: Structure of Water Adsorbed on a Mica Surface \\ Sung-Ho Park and Garrison Sposito \\ Contact: Sung-Ho Park, 510/643-372, sungho_park@lbl.gov}

\section{RESEARCH OBJECTIVES}

The objective of this project is to obtain the detailed structural properties of hydration water on a micaceous mineral surface.

\section{APPROACH}

Our approach uses Monte Carlo simulations as implemented in the program MONTE. The Muscovite model formula, $\mathrm{K}_{16} \mathrm{Al}_{23}\left(\mathrm{Al}_{16} \mathrm{Si}_{48}\right) \mathrm{O}_{160}(\mathrm{OH})_{32}$ was used with 256 water molecules in a simulation cell. This cell was then replicated infinitely in three dimensions to mimic a macroscopic mica-water interface system. The model potential functions used to represent water-water, counterion-water, counterion-counterion, counterion-mineral, and water-mineral interactions have been tested extensively and successfully for 2:1 clay-mineral hydrates. Our simulations were performed in a constant (NsT) ensemble, in which absolute temperature $(\mathrm{T})$ and pressure applied normal to the mineral layers (s) are maintained at 300 $\mathrm{K}$ and $100 \mathrm{kPa}$, respectively.

\section{ACCOMPLISHMENTS}

We have ascertained the detailed molecular structure of the mica-water interface. Figure 1 compares the water $\mathrm{O}$ (oxygen) density profile we obtained by Monte Carlo simulation with that derived from x-ray reflectivity measurements (Cheng et al., 2001). The match between their profile and ours (within 4 Å from the surface $\mathrm{O}$ ) is excellent, encouraging a direct interpretation of the two principal features in terms of adsorbed water species, as predicted by our simulation. The first peak in the $\mathrm{O}$ density profile describes the water molecules adsorbed near ditrigonal cavities, while the second peak corresponds to adsorbed water molecules distributed laterally at approximately 1.3 per surface cavity, as also reported by Cheng et al. (Figure 1). Visualization showed that most of these water molecules are oriented with one of their $\mathrm{OH}$ groups pointing toward the mineral-surface $\mathrm{O}$, which is consistent with hydrogen bond formation.

\section{SIGNIFICANCE OF FINDINGS}

Our simulation results were consistent with liquid-like disorder for the hydrate as a whole (Cheng et al., 2001) on the basis of their water $\mathrm{O}$ density profile tending to approach the bulk liquid limit after only a few oscillations (Figure 1). Overall, the structure of water adsorbed by micaceous minerals appears to be significantly more disordered than that of ice Ih. Our Monte Carlo results may also help to clarify the molecular interpretation of recent surface-force balance experiments involving hydration water between mica surfaces (Reviv et al., 2001). These experiments indicate that $\mathrm{K}+$ counterions are displaced into the hydration layers, in agreement with our simulation

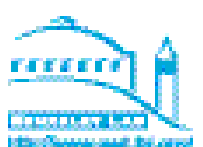
results; that a single layer of strongly adsorbed water may exist at the mica surface, in agreement with Figure 1; and that hydration water films thicker than about $4 \AA$ are liquidlike.

\section{RELATED PUBLICATIONS}

Cheng, L., P. Fenter, K.L. Nagy, M.L., Schlegel, and N.C. Sturchio, Molecular-scale density oscillations in water adjacent to a mica surface. Phys. Rev. Lett. 87, 156103, 2001.

Reviv, U., P. Laurat, and J. Klein, Fluidity of water confined to subnanometre films. Nature, 413, 51, 2001.

Park, S.-H. and G. Sposito, Do montmorillonite surfaces promote methane hydrate formation?: Monte Carlo and molecular dynamics simulations. J. Phys. Chem. B. 107, 2281, 2003.

Park, S.-H. and G. Sposito, Structure of water adsorbed on a mica surface. Phys. Rev. Lett. 89, 85501, 2001. URL: http:/ / esd.lbl.gov/GEO/aqueous_geochem/index.html.

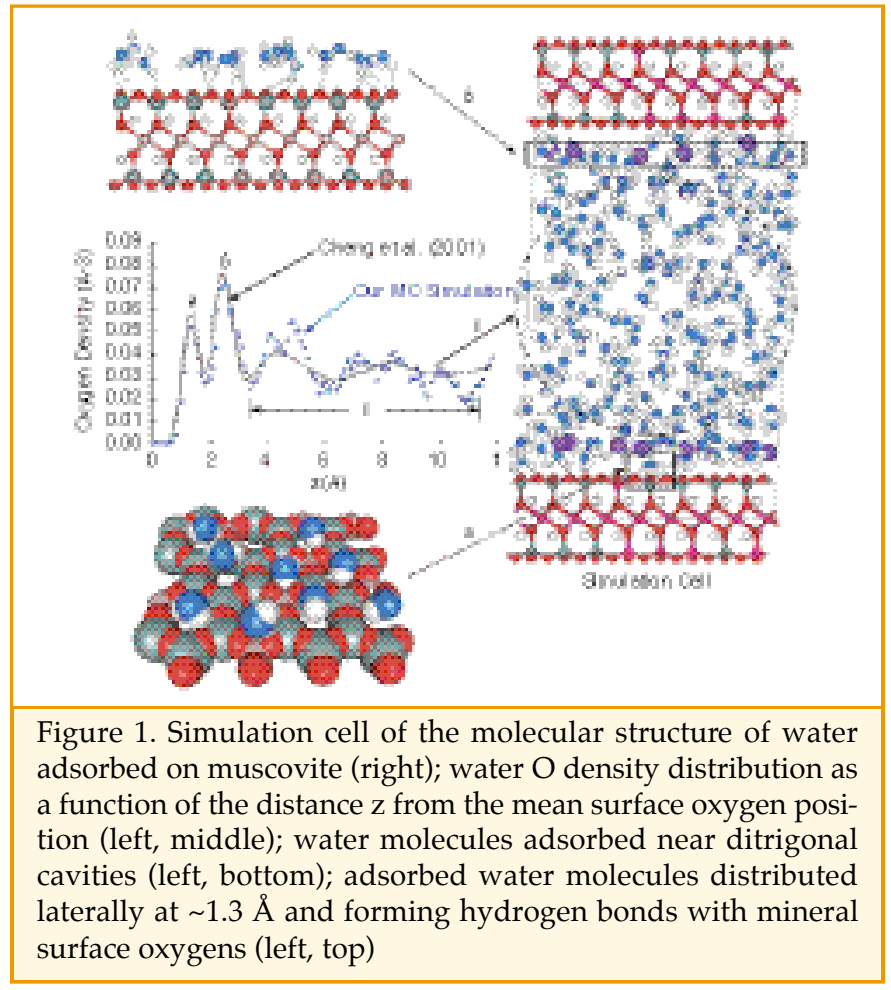

\section{ACKNOWLEDGMENTS}

This work was supported by the Director, Office of Science, Office of Basic Energy Sciences, Division of Chemical Sciences, Geosciences, and Biosciences, of the U.S. Department of Energy under Contract No. DE-AC03-76SF00098. All calculations were performed at the National Energy Research Scientific Computing Center (NERSC). 


\section{Intercomparison of Simulation Codes for Geologic Sequestration of $\mathrm{CO}_{2}$}

Karsten Pruess

Contact: 415/486-6732, k_pruess@lbl.gov

\section{RESEARCH OBJECTIVES}

Mathematical models and numerical simulation tools play an important role in evaluating the feasibility of $\mathrm{CO}_{2}$ storage in subsurface reservoirs, such as brine aquifers, producing or depleted oil and gas reservoirs, and coalbeds. We have designed and performed a code intercomparison study to explore the capabilities of numerical simulators to accurately and reliably model the important physical and chemical processes that would be taking place in $\mathrm{CO}_{2}$ disposal systems. The overall objective of the study is to document and advance the state of the art in modeling $\mathrm{CO}_{2}$ injection into subsurface reservoirs, and to establish credibility for currently available modeling approaches.

\section{APPROACH}

Berkeley Lab designed and directed the code intercomparison study. A set of eight test problems was assembled to examine flow processes during $\mathrm{CO}_{2}$ injection into brine formations, depleted gas reservoirs, and oil reservoirs. Key issues addressed in these problems include (1) the thermodynamics of sub- and supercritical $\mathrm{CO}_{2}$, and PVT properties of mixtures of $\mathrm{CO}_{2}$ with other fluids, including (saline) water, oil, and natural gas; (2) the fluid mechanics of single and multiphase flow when $\mathrm{CO}_{2}$ is injected into aquifers, oil reservoirs, and natural gas reservoirs; (3) coupled hydrochemical effects caused by interactions among $\mathrm{CO}_{2}$, reservoir fluids, and primary mineral assemblages; (4) coupled hydromechanical effects, such as porosity and permeability change, caused by increased fluid pressures from $\mathrm{CO}_{2}$ injection; and (5) space and time discretization effects. The test problems were distributed to interested groups of scientists and engineers, and the Internet was used as a convenient vehicle to help organize this effort.

\section{ACCOMPLISHMENTS}

Ten groups from six countries participated in the study, including Berkeley Lab, Stanford University, Lawrence Livermore National Laboratory, Los Alamos National Laboratory, Pacific Northwest National Laboratory, Alberta Research Council (Canada), Industrial Research Ltd. (New Zealand), CSIRO Petroleum (Australia), University of Stuttgart (Germany), and the Institut Français de Pétrol (France).

In the course of the study, a number of bugs were found and corrected in several simulation codes. Substantial agreement was achieved between results predicted from different simulators, but there exist areas with only fair agreement, as well as some significant discrepancies. Most discrepancies could be traced to differences in fluid property descriptions, an area that will clearly require continuing efforts by code developers to assure that realistic results can be obtained. Some disagreements were caused by effects from space and time discretization, while occasionally discrepancies were noted for which no rational explanation could be found.

A full presentation and discussion of results submitted by all groups are given in a laboratory report (Pruess et al., 2002). A separate report with a more detailed presentation of Berkeley Lab results for the saline-brine-formation problems is also available (Pruess and García, 2002). These reports, as well as other related materials, are available on the Web at http://wwwesd.lbl.gov/GEOSEQ/.

\section{SIGNIFICANCE OF FINDINGS}

Although code development work undoubtedly must continue, this work has shown that codes are available now that can robustly model the complex phenomena accompanying geologic storage of $\mathrm{CO}_{2}$, and with quantitatively similar results.

\section{RELATED PUBLICATIONS}

Pruess, K., and J. García. Solutions of test problems for disposal of $\mathrm{CO}_{2}$ in saline aquifers. Berkeley Lab Report LBNL-51812, 2002.

Pruess, K., J. García, T. Kovscek, C. Oldenburg, J. Rutqvist, C. Steefel, and T. Xu, Intercomparison of numerical simulation codes for geologic disposal of $\mathrm{CO}_{2}$. Berkeley Lab Report LBNL-51813, 2002.

Pruess, K., C.F. Tsang, D. H.-S. Law, and C.M. Oldenburg. Intercomparison of simulation models for $\mathrm{CO}_{2}$ disposal in underground storage reservoirs. Berkeley Lab Report LBNL-47353, 2000.

\section{ACKNOWLEDGMENTS}

This work was supported by the National Energy Technology Laboratory (NETL) of the U.S. Department of Energy under Contract No. DE-AC03-76SF00098. 


\title{
INVESTIGATION OF THE EFFECTS OF EVAPORATION AND INFILTRATION ON VADOSE Zone Pore-Fluid $\delta^{18} \mathrm{O}$ VAlues at Hanford, Using ToughReact
}

\author{
Michael J. Singleton, Eric L. Sonnenthal, Donald J. DePaolo, and Mark E. Conrad \\ Contact: Michael Singleton, 510/486-5241, mjsingleton@lbl.gov
}

\section{RESEARCH OBJECTIVES}

The fraction of rainfall that percolates deep into the vadose zone in arid regions is difficult to predict, but important for understanding groundwater recharge and contaminant transport. At Hanford, where a large amount of radionuclide contamination is present in the vadose zone above the water table, it is especially important to know the water infiltration flux, because this determines how rapidly radionuclides will reach groundwater. This study is aimed at evaluating the use of numerical models in conjunction with water isotope data to measure infiltration flux in arid regions.

\section{APPROACH}

The vadose zone hydrological processes that control infiltration also generate variations in the ratios of stable isotopes (i.e., $18 \mathrm{O} / 16 \mathrm{O}$ and ${ }^{2} \mathrm{H} /{ }^{1} \mathrm{H}$ ) in water and water vapor. A numerical modeling approach is needed to account for the interplay between evapotranspiration, advection, and diffusion. We implemented the temperature-dependent equilibration of stable isotopic species between water and water vapor, and their differing diffusive transport properties, into the thermodynamic database of the reactive transport code TOUGHREACT, developed at Berkeley Lab. This allows for the simulation of stable isotope fractionation in tandem with multiphase unsaturated flow, heat transport, mineral-water-gas reactions, and the transport of other gaseous and aqueous species.

\section{ACCOMPLISHMENTS}

TOUGHREACT simulations with isotope fractionation provide new insights into the behavior of water isotopes in unsaturated zone pore waters in semi-arid climates. Preliminary results (Figure 1) emphasize the effects of alternating wet and dry seasons, which lead to annual fluctuations in moisture content, capillary pressure, and stable isotope compositions in the vadose zone. The effective depths of evaporation and wetting events are primarily controlled by soil properties and infiltration rate. Repeated annual cycles of wet and dry seasons in a semi-arid climate lead to a consistent shift in the isotopic composition of deep vadose zone pore waters, which is proportional to the amount of infiltration.

\section{SIGNIFICANCE OF FINDINGS}

Stable isotope profiles provide a dynamic record of evaporation and infiltration in the unsaturated zone. For the range of infiltration rates measured at the Hanford Site $(5-200 \mathrm{~mm} / \mathrm{yr})$, stable isotope profiles are affected by surface conditions on annual-to-decadal time scales, and therefore can provide a record of recent events such as dumped or spilled waste water, soil removal, and devegetation by brush fires. Numerical simulations of transport and isotope fractionation using TOUGHREACT provide a method to quantitatively interpret the relationship of stable isotope depth profiles to infiltration rate.

\section{RELATED PUBLICATION}

Singleton, M.J., E.L. Sonnenthal, M.E. Conrad, and D.J. DePaolo, Numerical modeling of stable isotope fractionation and multiphase reactive transport of water and water vapor using TOUGHREACT. Proceedings, TOUGH Symposium, Berkeley, California, 2003.

\section{ACKNOWLEDGMENTS}

This work was supported by the U.S. Department of Energy under Contract No.DE-AC06-76RL01830 through the Hanford Science and Technology Program, and by the Assistant Secretary of the Office of Environmental Management, Office of Science and Technology, Environmental Management Science Program, of the U.S. Department of Energy under Contract No. DE-AC03-76SF00098.

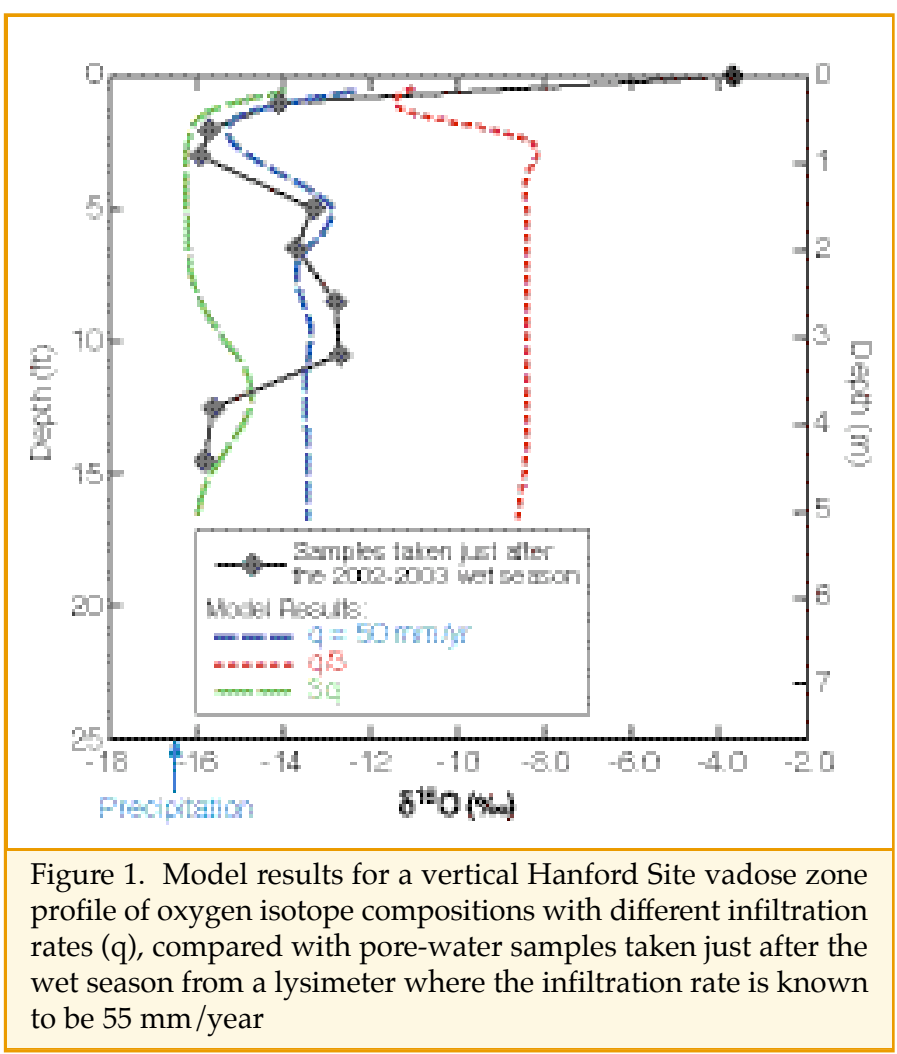




\title{
URANIUM DIFFUSION
}

\author{
Tetsu K. Tokunaga, Jiamin Wan, Jasquelin Pena, Stephen R. Sutton ${ }^{1}$, and Matt Newville ${ }^{1}$ \\ ${ }^{1}$ University of Chicago \\ Contact: Tetsu Tokunaga, 510/486-7176, tktokunaga@lbl.gov
}

\section{RESEARCH OBJECTIVES}

Transport of uranium $(\mathrm{U})$ in contaminated soils and sediments is of great concern. Environments affected by $U$ contamination can be very challenging to understand because extreme disequilibrium is likely in such environments, especially during early stages of waste migration, when solutions are still often either highly acidic or highly alkaline. The impact of diffusion is especially important when large fractions of the subsurface have low hydraulic conductivities relative to a small fraction of interconnected preferential flow paths, and where hydraulic gradients are low. In this study, we are concerned with diffusion of $\mathrm{U}(\mathrm{VI})$ species, since these are commonly much more soluble and mobile than U(IV) species. Because $\mathrm{U}(\mathrm{VI})$ forms a variety of strongly $\mathrm{pH}$-dependent solution complexes and surface complexes, its sorption-and thus its mobility-is strongly $\mathrm{pH}$ dependent. Experiments are being conducted to test various models for predicting transient $\mathrm{U}(\mathrm{VI})$ diffusion.

\section{APPROACH}

Measurements were obtained on U(VI) diffusion into two different soil types, one neutral and the other slightly alkaline. To each of these soil types, we applied U(VI) solutions, one acidic and the other alkaline. Periodic measurements of redox potential profiles within the soil columns, and of $\mathrm{pH}$ and $\mathrm{U}$ concentrations in the boundary reservoirs, were obtained. Profiles of the total $\mathrm{U}$ and $\mathrm{U}(\mathrm{VI})$ distribution in the sediment column were obtained by micro- $x$-ray absorption near-edge structure (micro-XANES) spectroscopy. Measured U profiles were compared with various model predictions.

\section{ACCOMPLISHMENTS}

Micro-XANES analyses confirm that $\mathrm{U}$ remains in oxidized $\mathrm{U}(\mathrm{VI})$ forms within systems having low organic carbon availability. Strong $\mathrm{pH}$-dependent apparent $\mathrm{U}(\mathrm{VI})$ diffusivities are obtained in transient experiments. These apparent diffusivities are in fair agreement with predictions based on aqueous-phase $\mathrm{U}(\mathrm{VI})$ diffusivities, soil porosities, and $\mathrm{pH}$-dependent sorption isotherms. Ongoing sorption studies (Zheng et al., 2003) are being conducted through a related NABIR-supported project.

\section{SIGNIFICANCE OF FINDINGS}

Predicting the mobility of $U$ in soils and sediments requires an understanding of its diffusive transport. Such understanding is being provided in this study, through direct measurements of $\mathrm{U}(\mathrm{VI})$ diffusion profiles and comparisons with $\mathrm{U}(\mathrm{VI})$ sorption isotherms.

\section{RELATED PUBLICATIONS}

Tokunaga, T.K., J. Wan, T.C. Hazen, E. Schwartz, M.K. Firestone, S.R. Sutton, M. Newville, K.R. Olson, A. Lanzirotti, and W. Rao, Distribution of chromium contamination and microbial activity in soil aggregates. J. Environ. Qual. 32, 541-549, 2003.

Zheng, Z., T.K. Tokunaga, and J. Wan, Influence of calcium carbonate on sorption of U(VI) to soils. Environ. Sci. Technol., 2003.

\section{ACKNOWLEDGMENTS}

This project is supported by the Director, Office of Science, Office of Basic Energy Sciences, Division of Chemical Sciences, Geosciences, and Biosciences, of the U.S. Department of Energy under Contract No. DE-AC03-76-SF00098. Use of theAdvanced Photon Source was also supported by the Office of Science, Office of Basic Energy Sciences, of the U.S. Department of Energy.
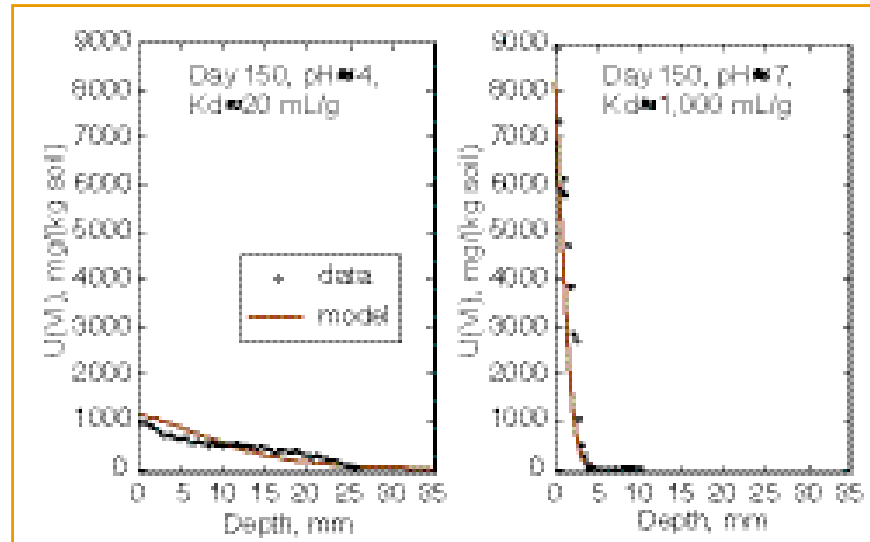

Figure 1. Micro-XANES profiles at day 150, for U(VI) diffusing into Oak Ridge soil from initially acidic (left) and initially alkaline (right) solutions. Neutralization of the alkaline system resulted in strong $\mathrm{U}(\mathrm{VI})$ sorption and retardation of the diffusion front. Model calculations are based on measured porosities, aqueous-phase $\mathrm{U}(\mathrm{VI})$ diffusivities, and $\mathrm{pH}$-dependent $\mathrm{U}(\mathrm{VI})$ sorption. 


\section{Vanishing of Capillary Hysteresis in Porous Media}

Tetsu K. Tokunaga, Keith R. Olson, and Jiamin Wan

Contact: Tetsu K. Tokunaga, 510-486-7176, tktokunaga@lbl.gov

\section{RESEARCH OBJECTIVES}

The degree of water saturation (S) exerts strong influences on water flow, transport of solutes and heat, and mechanical properties of porous media. The monotonic decrease of the matric potential $(\psi)$ with decreased saturation reflects the combination of capillary and adsorptive influences in lowering the free energy of soil water. In the early decades of soil physics, it was assumed that the $S(\psi)$ relation in a given system represented a series of unique equilibrium conditions. Since the classic 1930 paper of Haines, hysteresis in $S(\psi)$ has been regarded as a basic aspect of interactions between water and variably saturated porous media. At any given potential, the equilibrium saturation level obtained by draining a system is greater than or equal to that obtained by wetting an initially dry system to the same potential. In an attempt to gain a better understanding of the hysteresis phenomenon, we consider conditions that lead to its disappearance.

\section{APPROACH}

Capillary models and Miller-Miller unsaturated hydraulic scaling were used to predict conditions necessary for removal of hysteresis. Disappearance of hysteresis was tested through suction plate measurements of drainage and wetting curves for sands and gravels, with grain sizes ranging from 0.2 to 14 $\mathrm{mm}$. The influence of surface tension was tested through measurements of $S(\psi)$ in $7 \mathrm{~mm}$ gravel, with and without a surfactant—sodium dodecylbenzenesulfonate (SDBS).

\section{ACCOMPLISHMENTS}

Calculations based on a simple pore-size model lead to the predicted disappearance of hysteresis in the grain-size range of 8 to $15 \mathrm{~mm}$. A more constrained predicted grain-size limit of $10.4 \pm 0.5 \mathrm{~mm}$ was obtained by applying Miller-Miller scaling to a conceptual model of Haines. More generally, hysteresis is also predicted to depend on surface tension, fluid densities, and acceleration. Laboratory measurements showed that hysteresis loops remain well defined for grain sizes up to $7 \mathrm{~mm}$. At a grain size of $9 \mathrm{~mm}$, hysteresis is barely detectable. For grain sizes equal to or greater than $10 \mathrm{~mm}$, hysteresis is not observed. Measurements of $S(\psi)$ on $7 \mathrm{~mm}$ gravels exhibited hysteresis without SDBS, but did not exhibit hysteresis with it. These results support our general analysis, which predicted elimination of hysteresis based on fluid densities, acceleration, grain size, and surface tension. These parameters combine to yield the dimensionless Haines number, with a critical value of $14.8 \pm 1.4$. Above this value, capillary hysteresis is not possible.

\section{SIGNIFICANCE OF FINDINGS}

The experiments completed in this project support the predicted grain-size and surface-tension dependence of capillary hysteresis, and show that hysteresis is not a fundamental feature of unsaturated porous media. Lack of previous awareness of nonhysteretic $S(\psi)$ appears to result from the fact that the considered combinations of grain size, surface tension, fluid densities, and acceleration were within the realm in which capillary rise is greater than the grain size. Studies on unsaturated media conducted with surfactants and/or in centrifuges may benefit from this work.

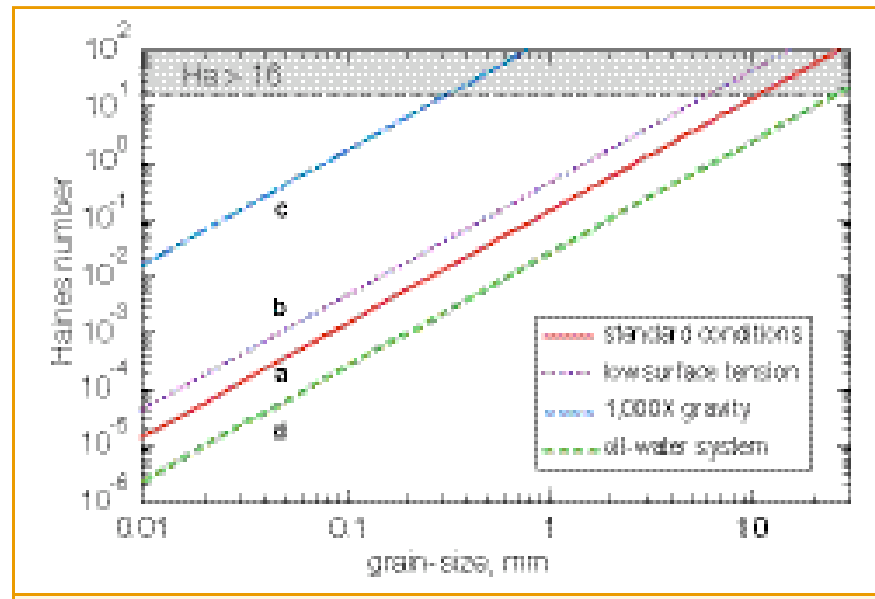

Figure 1. The Haines number is comprised of fluid-fluid density differences and surface tension, acceleration, and grain-size. Grain-size dependence of the Haines number for (a) standard conditions (air-water, ordinary gravity), (b) low surface tension (surfactant solution, ordinary gravity), (c) much higher body force (air-water, 1,000g centrifuge), and (d) an oil-water system conditions (ordinary gravity). The horizontal line at $\mathrm{Ha}=16$ separates systems that do and that do not exhibit hysteresis.

\section{RELATED PUBLICATIONS}

Tokunaga, T.K., J. Wan, and K.R. Olson. Saturation-matric potential relations in gravel. Water Resour. Res. 38(10), 1214, doi:10.1029/2001WR001242, 2002.

Tokunaga, T.K., K.R. Olson, and J. Wan. Moisture characteristics of Hanford gravels: Bulk, grain-surface, and intragranular components. Vadose Zone J., 2003 (in press).

\section{ACKNOWLEDGMENTS}

This project is supported by the Director, Office of Science, Office of Basic Energy Sciences, Division of Chemical Sciences, Geosciences, and Biosciences, of the U. S. Department of Energy under Contract No. DE-AC03-76-SF00098.

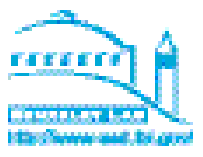




\section{Helium Isotope Ratios in South Sister Volcano Vicinity, Cold Springs}

Matthijs C. van Soest, B. Mack Kennedy, William C. Evans ${ }^{1}$, Robert H. Mariner ${ }^{1}$, and Mariek E. Schmidt ${ }^{2}$

${ }^{1}$ U.S. Geological Survey, Menlo Park, California

${ }^{2}$ Department of Geosciences, Oregon State University, Corvallis, Oregon

Contact: Matthijs C. van Soest, 510/486-5659, mcvansoest@lbl.gov

\section{RESEARCH OBJECTIVES}

As part of a geochemical monitoring project at Oregon's South Sister volcano-a volcano that is undergoing strong uplift (Wicks et al., 2002) — we are carrying out a detailed study of helium isotope ratios in cold and hot springs in the Separation Creek drainage area. Through this study, we hope to determine the occurrence of any changes in spring chemistry that could be related to the ongoing uplift.

\section{APPROACH}

Helium isotope ratios $(3 \mathrm{He} / 4 \mathrm{He})$ in fluids from volcanic areas are useful indicators for the presence of a magmatic component in those fluids. Moreover, in combination with other geochemical indicators, these ratios are indicative of a magma source and subsequent chemical processing of the fluids. The approach of this project was two-fold: (1) to establish a baseline of helium isotope ratios for springs within the zone of uplift and the surrounding area, and (2) establish a chemical and isotopic monitoring program for selected springs within the area.

\section{ACCOMPLISHMENTS}

Helium isotope data from the Three Sisters area are shown in Figure 1a. All the springs in the area, hot or cold, show a significant magmatic helium component. The most remarkable results are that two cold springs with a free gas phase, one close to the center of the uplift zone and the other close to the volcanic edifice itself, gave helium isotope ratios that are indistinguishable from pristine upper-mantle-derived helium ( $8 \pm 1$ times RA, where RA is the ratio in air and used for normalization). For the rest of the area, the data show a general trend of decreasing helium isotope ratios with distance from the zone of uplift (Figure 1b). This trend reflects dilution of the magmatic helium component with crustal fluids that typically are rich in radiogenic ${ }^{4} \mathrm{He}\left({ }^{3} \mathrm{He} /{ }^{4} \mathrm{He} \sim 0.02 \mathrm{RA}\right)$.

During the time this study was conducted, none of the monitored springs showed any significant changes (Figure 1a) in helium isotopic composition. To further understand the system, we are continuing the monitoring program.

\section{SIGNIFICANCE OF FINDINGS}

Geochemical explorations for deep hot fluids, of economic interest as a potential energy source, generally focus on hot springs to the exclusion of nonthermal waters. The surprisingly very high helium isotopic compositions observed in two of the cold springs suggests that cold springs should not be overlooked, because they may contain helium isotope signatures reflecting deep processes, such as magma intrusion, that precede thermal and/or chemical pulses at the surface.

Figure 1(a). Overview map of the Three Sisters area, central Oregon, with sample locations and helium isotope results, using color coding for sampling date and general spring chemistry indication; (b) Plot of helium isotope ratio vs. distance from the volcano, with $\delta^{13} \mathrm{C}$ values next to each data point showing a similar trend.

\section{RELATED PUBLICATIONS}

Wicks, C., Jr., D. Dzurisin, S.E. Ingebritsen, W. Thatcher, Z. Lu, and J. Iversen, Magmatic activity beneath the quiescent Three Sisters volcanic center, central Oregon Cascade Range, Oregon. Geophysical Research Letters, 29, 26-1-26-4, 2002.

\section{ACKNOWLEDGMENTS}

We would like to acknowledge UNOCAL for allowing us access to the data collected during their geothermal exploration studies. The principal author (van Soest) acknowledges Pat Dobson for his assistance with the literature search. This work was supported by the Assistant Secretary for Energy Efficiency and Renewable Energy, Office of Technology Department, Office of Geothermal Technologies, of the U.S. Department of Energy under Contract No. DEAC03-76SF00098.

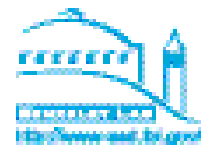




\title{
NANOPARTICles in Subsurface ENVIRONMENTS: Abundance AND Transport of THE Mobile Fraction
}

\author{
Jiamin Wan, Guilin Han, Jasquelin Pena, Xiang-Yun Song, and Tetsu Tokunaga \\ Contact: Jiamin Wan, 510/486-6004, jmwan@lbl.gov
}

\section{RESEARCH OBJECTIVES}

The earth science community has identified environmental nanoscience as an important emerging field. This project provides the first survey of mobile nanoparticle inventories for sediments from a variety of subsurface environments. The research will also provide systematic studies of subsurface nanoparticle transport and its dependence on nanoparticle, sediment, solution, and hydraulic characteristics.

\section{APPROACH}

Quantification of the potentially mobile nanoparticle inventory requires separation of nanoparticle size fractions. In this study, particles in the $<100 \mathrm{~nm}$ size range are defined as nanoparticles. Methods such as flow-through columns, batch extractions in water, and batch extractions with a dispersant (sodium hexametaphosphate) are used. In these ways, operationally defined measures of mass and specific surface areas associated with different particle fractions will be obtained in several sediment types from DOE facilities across the country. Nanoparticle transport quantification will be performed through laboratory column experiments with three types of variables. These are (1) natural versus synthetic (glass bead) sediments, (2) natural versus synthetic (polystyrene latex) particles, and saturated versus unsaturated conditions. Through these experiments, the validity of filtration-theory predictions for nanoparticles will be tested.

\section{ACCOMPLISHMENTS}

Mobile nanoparticle inventories for two types of sediments were studied, one from the Hanford Site and another from Oak Ridge National Laboratory. Our results show that the release of mobile nanoparticles depends strongly on solution chemistry, including $\mathrm{pH}$, ionic strength, and anions. The maximum particle release occurred at the lowest ionic strength condition. Alkaline $\mathrm{pH}$ favors particle release. For example, in the Oak Ridge sediments, the measured nanoparticle fractions $(<0.1$ $\mu \mathrm{m}$ ) were $0.98 \%$ at $\mathrm{pH} 12.0$, and the maximum release obtained with hexametaphosphate solution was $1.72 \%$. The nanoparticle fraction is about $7 \%$ of the total clay fraction $(<2.0 \mu \mathrm{m})$ released in this sediment. We have also discovered that some $\mathrm{U}(\mathrm{VI})$ nanoparticles are relatively stable in the pore solutions of contaminated Hanford sediment (as shown in Figure 1). Uranium(IV) nanoparticles have been found in the mine drainage waters as a result of microbial reduction. This species has previously been considered highly soluble under our test conditions, and thus we did not expect to find $\mathrm{U}(\mathrm{VI})$ nanoparticles in this contaminated Hanford system.

\section{SIGNIFICANCE OF FINDINGS}

This research provides the first survey of mobile nanoparticle inventories for sediments from a variety of subsurface environments. It will also provide systematic studies of subsurface nanoparticle transport and its dependence on nanoparticle, sediment, solution, and hydraulic characteristics. The transport experiments will also be the first to test the validity of filtration theory for nanoparticles in the subsurface.

\section{RELATED PUBLICATIONS}

Wan, J., G. Han, J. Pena, X.Y. Song, and T.K. Tokunaga, The natural abundance of nanoparticles in soils. J. Colloid Interface Sci., 2003 (submitted).

Wan, J., J. Pena, X.Y. Song, Z. Zheng, and T.K.Tokunaga, U(VI) nanoparticles in calcium carbonate-rich subsurface environment. Environ. Sci. Technol., 2003 (submitted).

\section{ACKNOWLEDGMENTS}

This project is supported by the Director, Office of Science, Office of Basic Energy Sciences, Division of Chemical Sciences, Geosciences, and Biosciences, of the U.S. Department of Energy under Contract No. DE-AC03-76-SF00098.

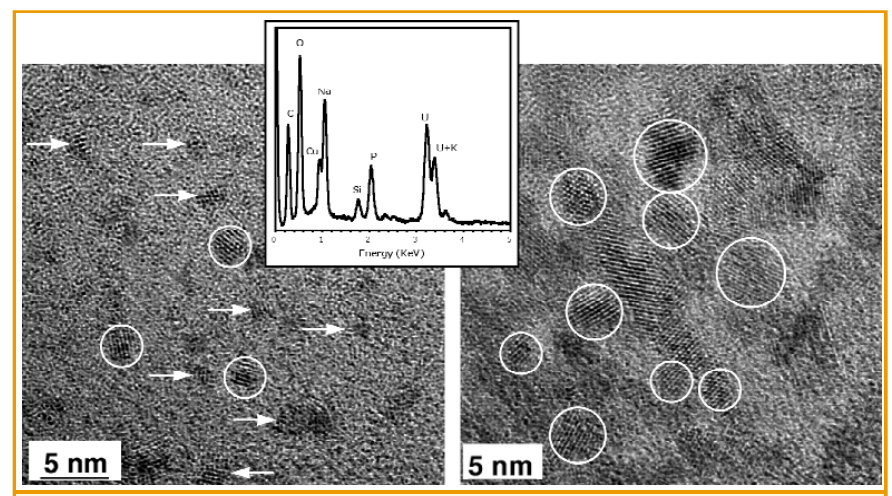

Figure 1. U(VI) nanoparticles (marked by arrows and circles) obtained from a pore solution of $U$ contaminated sediment. Based on lattice fringe (by TEM) and elemental composition (by EDX) analyses, the particles are identified as sodium uranium oxide phosphate hydrate, $\mathrm{Na}_{4} \mathrm{U}_{3} \mathrm{O}_{8}\left(\mathrm{PO}_{4}\right) \cdot 6 \mathrm{H}_{2} \mathrm{O}$ (Wan et al., unpublished).

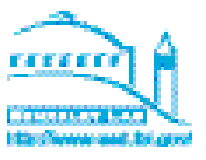




\title{
Comparison of the Wet Hematite and Corundum (0001) Surface Structures DETERMINED BY SYNCHROTRON X-RAY CTR ANALYSIS
}

\author{
Glenn Waychunas, Thomas Trainor ${ }^{1}$, Peter Eng1, and Gordon Brown ${ }^{2}$ \\ ${ }^{1}$ University of Chicago and Advanced Photon Source, Argonne National Laboratory \\ ${ }^{2}$ Stanford University, Stanford, California \\ Contact: Glenn Waychunas, 510/495-2225, gawaychunas@lbl.gov
}

\section{RESEARCH OBJECTIVES}

The surfaces of crystalline minerals generally differ from the bulk structure due to atomic relaxation, expansion, or rearrangement. These changes can have profound effects on the reactivity of the mineral, especially with regard to toxics sorption, catalytic activity, and dissolution. Although modern thermodynamic calculations and structural simulations are now well developed, these still rest on the fundamental underpinning of the experimental determination of the true surface structure. Here we focus on two isostructural phases that behave quite differently in the environment. Hematite is a primary soil mineral with much greater reactivity than corundum. Though itself not found in soils, the corundum (0001) surface structure is a much-used analog for the alumina layers in clays, which also have relatively low reactivity. The aim is to uncover a structural basis for the differences in reactivity.

\section{APPROACH}

We use crystal truncation rod (CTR) surface $\mathrm{x}$-ray diffraction to probe the atomic positions at the surfaces of highly perfect corundum and hematite (0001) crystals under water solutions. Current work utilizes nearneutral water, but will also examine the effect of $\mathrm{pH}$ on surface structure.

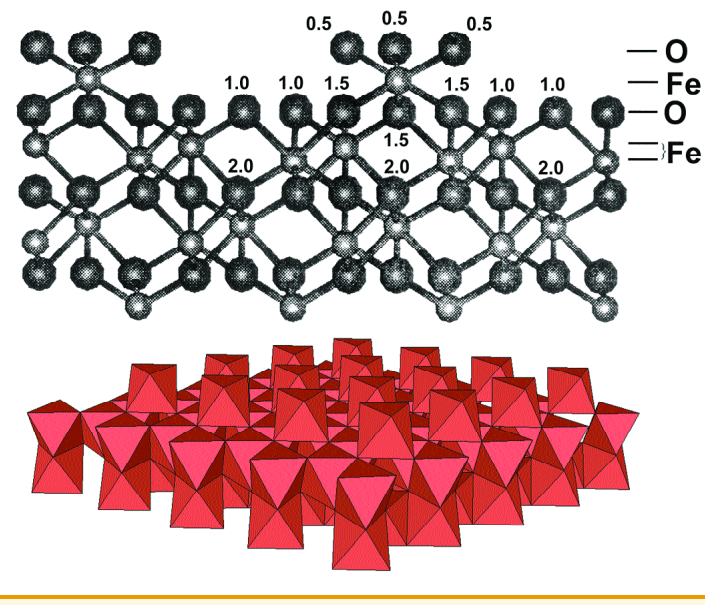

Figure 1. Proposed structure of the hydrated (0001) hematite surface: top: ball and stick structure showing Fe atoms and associated bond valences (inversely related to reactivity); bottom: idealized polyhedral model of the surface. Each octahedron is a $\mathrm{FeO}_{6}$ unit. is also present. Finally, the surface is perfectly terminated by oxygen ions and the water layer. In the hematite (0001) surface, the results are similar (see Figure 1), but individual iron ions with surrounding oxygens form islands on the surface. These islands allow for lower-coordination attachment points for reacting species, unlike the smooth corundum surface that presents only fully coordinated (saturated) metal sites. This sort of result may be a general reason for enhanced reactivity at particular metal oxide mineral surfaces. Analogous work on sorption on the same mineral surfaces using GIXAFS techniques (Waychunas, 2002) supports and confirms our results.

\section{SIGNIFICANCE OF FINDINGS}

Besides the important and fundamental connection of reactivity to structure, the work helps to improve our simulation capability for model-reactivemetal-oxide mineral surfaces. The interatomic potentials used for such simulations-usually molecular dynamicscan be adjusted so that computer results closely approximate the experimental surface structures. Then the simulations can be applied with greater confidence to other mineral-water systems, such as goethite-water.
The technique is based on the fact that the crystal surface termination produces streaks (or "rods") in diffraction space perpendicular to the surface. Though they are of low intensity, equivalent to the scattering of a half-plane of atoms, these rods can be quantitatively measured by synchrotron x-ray diffraction. Small changes in the atomic occupations or positions can have large effects on the rod intensities at different positions in diffraction space, and hence the rod measurements can be refined to reveal the atomic structure of the surface.

\section{ACCOMPLISHMENTS}

Our original CTR analysis of the corundum (0001) surface (Eng et al., 2000) shows considerable relaxations of surface atoms down more than 6 atomic layers. The most important aspect is the shift in the aluminum metal ions near the surface towards the gibbsite $(\mathrm{AlOOH})$ structure. An organized layer of sorbed water

\section{RELATED PUBLICATIONS}

Eng, P.J., T.P. Trainor, G.E. Brown, G.A. Waychunas, M. Newville, S.R. Sutton, and M.L. Rivers, Structure of the hydrated a$\mathrm{Al}_{2} \mathrm{O}_{3}$ (0001) surface. Science, 288, 1029-1033, 2000.

Waychunas, G.A., Grazing-incidence X-ray absorption and emission spectroscopy. Reviews in Mineralogy and Geochemistry, 49, 267-315, 2002.

\section{ACKNOWLEDGMENTS}

This project is supported by the Director, Office of Science, Office of Basic Energy Sciences, Division of Chemical Sciences, Geosciences, and Biosciences, of the U.S. Department of Energy under Contract No. DE-AC03-76SF00098. Synchrotron beam time at the Stanford Synchrotron Radiation Laboratory and Advanced Photon Source is gratefully acknowledged.

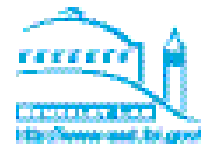




\title{
Manganese Valence and Mineral Surface Structure DeTERMINED WITH IN SITU SOFT X-RAy SPECTROSCOPY
}

\author{
Glenn Waychunas, David Shuh, and Mario Villalobos \\ Contact: Glenn Waychunas, 510/495-2224, gawaychunas@lbl.gov
}

\section{RESEARCH OBJECTIVES}

Manganese (Mn) minerals have high surface reactivity, redox potentials that can either reduce or oxidize adsorbed species, and high surface areas (fine grain sizes). These aspects make them extremely significant players in metal sequestration due to strong sorption and alteration in valence states (and hence solubility products) of solution species. Our goals are to determine how much information about Mn valence states and surface structure (i.e., surface mineral phase) can be extracted from K-edge oxygen and L-edge manganese x-ray fluorescence spectra, measured at the Advanced Light Source (ALS) at Berkeley Lab.

\section{APPROACH}

Experiments are designed to investigate both dry ultrahigh-vacuum (UHV) mineral surfaces and surfaces in equilibrium with ambient water pressures. Fifteen different Mn mineral samples (both synthetic and natural) were examined at ALS Beam Line 9.3.2, using both photon yield and photoelectron yield, allowing simultaneous analysis of bulk and surface $(5 \mathrm{~nm})$ chemistry and structure.

\section{ACCOMPLISHMENTS}

Some representative spectra from our work are shown in Figure 1. Each valence state of $\mathrm{Mn}$ has well-defined features on the L-edge as well as a progressive shift in edge position. Accurate measurement (to about $1 \%$ relative) of valence ratios are possible for these models when two valence states are present. All phases showed the same bulk and surface valences, except for manganite (nominally $\mathrm{Mn}^{3+}$ with composition $\mathrm{MnOOH})$, which has an oxidized surface.

The structure of the Mn phase has less effect on the Mn L spectra than it does on the O K-edge spectra. This is because the Mn L-edge transitions are mainly crystal field transitions, while the $\mathrm{O}$ K-edge transitions include multiple scattering, extended x-ray absorption fine structure (EXAFS), and valence-shell bound state features. This allows the two types of spectra, which can be collected in the same spectroscopy scans, to be used complementarily. For example, the manganite surface coating, less than $5 \mathrm{~nm}$ thick, appears to be mainly ramsdellite-like.

\section{SIGNIFICANCE OF FINDINGS}

These spectroscopy tools can be used to determine the precise chemical reactions at Mn mineral surfaces and whether redox reactions are occurring. Redox reactions can alter the solubility and thus transportability of any surface-sorbed contaminant. In many waste situations, for example at Yucca Mountain, Nevada, small amounts of Mn phases can have large effects on contaminant sequestration. Hence, this type of analysis is crucial to a complete understanding of the ultimate fate of contaminants in Mn mineral-containing environments.

\section{ACKNOWLEDGMENTS}

This work was supported by the Assistant Secretary of the Office of Environmental Management, Office of Science and Technology, Environmental Management Science Program, of the U.S. Department of Energy under Contract No. DE-AC0376SF00098. Synchrotron beam time at the ALS is gratefully acknowledged. A UHV apparatus was loaned by the ALS for these studies.

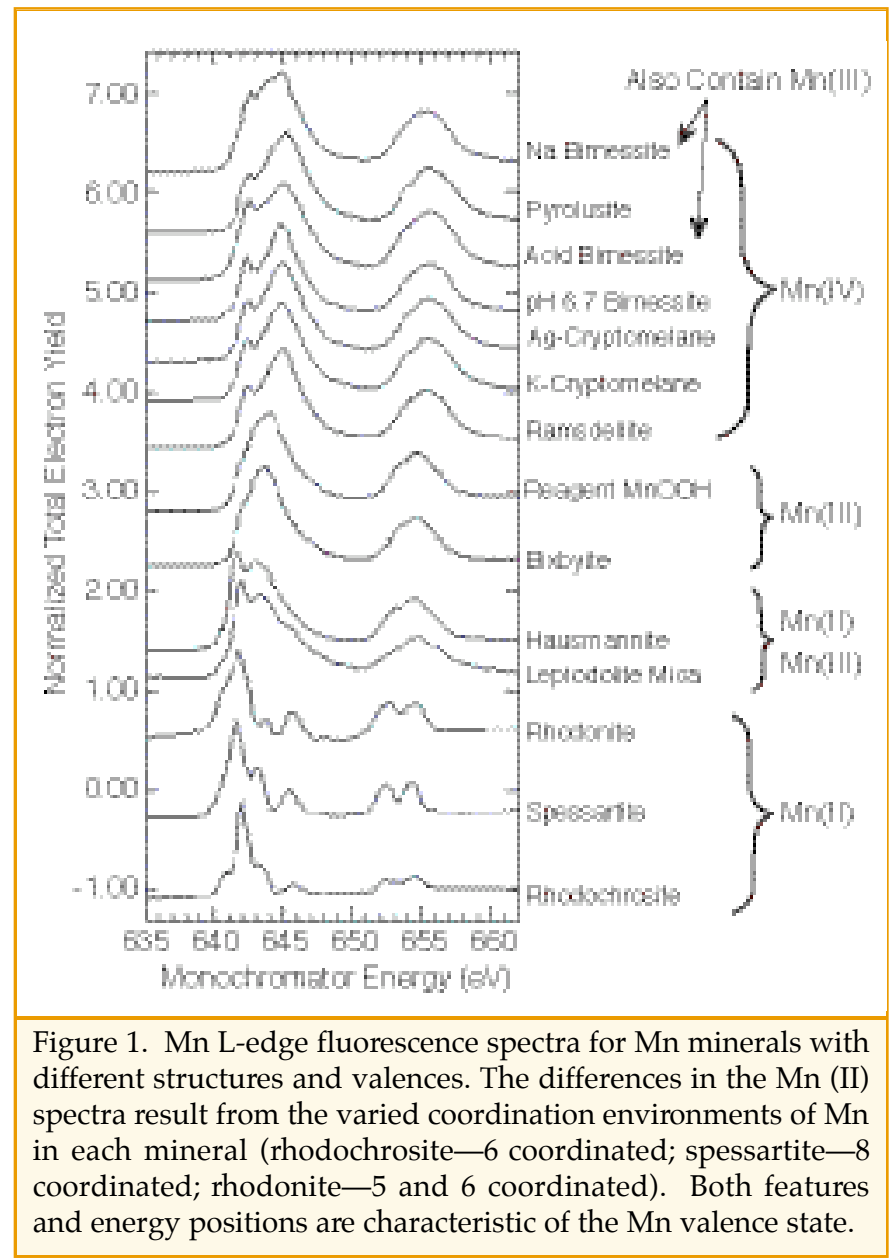

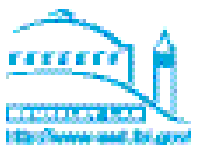




\title{
Sum-Frequency Spectroscopic Studies of Mineral-Water Interfaces
}

\author{
Glenn A Waychunas, Victor Ostroverkhov, and Y. Ron Shen
}

Contact: Glenn A. Waychunas, 510/495-2224, gawaychunas@lbl.gov

\section{RESEARCH OBJECTIVES}

Interactions of water and aqueous solutions with mineral surfaces play an important role in a variety of environmental processes. These processes include soil formation, cycling of chemical elements in nature, mobility of heavy metals and other contaminants as well as nutrients, and surface growth of microorganisms (Brown et al., 1999). Such interactions are affected by solution $\mathrm{pH}$, the presence of dissolved ions, and the surface structure of the solid. The objective of this project is to use available experimental techniques and theoretical approaches to develop a comprehensive microscopic picture of how water and solutes interact with mineral surfaces.

\section{APPROACH}

To study the structure of water at a mineral surface, we use sum-frequency vibrational spectroscopy - a surface-specific technique with monolayer sensitivity that can be applied under ambient conditions (Shen, 1989). The technique is based on sum-frequency generation (SFG), a second-order nonlinear optical process in which two intense input laser beams focused on the medium produce an output beam at the frequency $\omega=\omega 1+\omega 2$. The process is electric-dipole allowed only in noncentrosymmetric media, and thus it is capable of probing the molecular ordering at the interface caused by the breaking of centrosymmetry at the surface. One of the input beam frequencies is tunable in the range of system vibrational resonances (e.g., water molecule vibrations or metal-oxygen stretching vibrations). Hence, spectroscopic information is obtained from the water layer just at the surface, from which the orientational distribution and structural type of molecular species can be extracted.

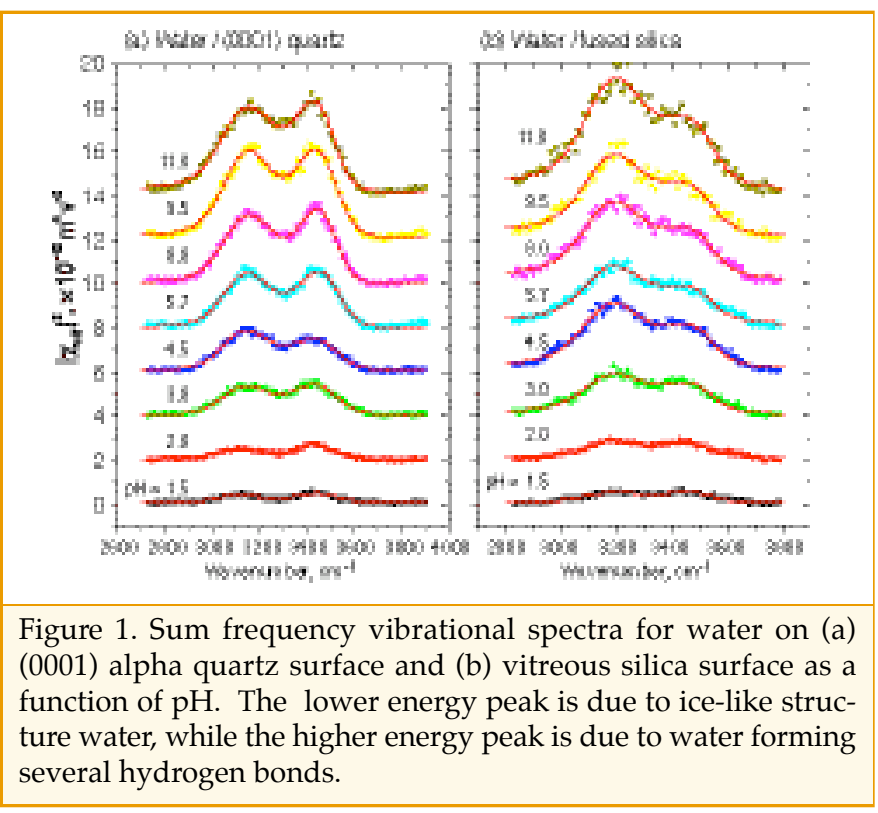

\section{ACCOMPLISHMENTS}

In the past, SFG has been used to observe ice-like ordering of water molecules on a vitreous silica surface (Du et al., 1994). Here, for the first time we implement sum-frequency vibrational spectroscopy to extend the study to the interface of liquid water and a well-characterized surface (0001) of crystalline quartz $\left(\alpha-\mathrm{SiO}_{2}\right)-$ one of the most abundant minerals. We have developed an experimental technique to differentiate a weak SFG signal from a strong background SFG generated in the bulk of quartz crystal (a wellknown nonlinear crystal) by use of special experiment geometry and light polarization combinations. Sets of interface water vibrational spectra as a function of $\mathrm{pH}$ have been obtained (Figure 1). Comparison with the case of vitreous silica shows that the crystallinity of the surface results in a higher degree of ordering in the interfacial layers of water at a given $\mathrm{pH}$. This is shown by a pronounced red-shifting of the peak associated with the symmetrically (ice-like) coordinated species in the hydrogen bond network of water. With increasing $\mathrm{pH}$, this peak also increases in intensity in both series, reflecting increasing surface negative charge. The data suggest that differing crystallographic surfaces may induce specific variations in water structure in the first few layers, as well as modification of response to $\mathrm{pH}$ and sorbing species.

\section{SIGNIFICANCE OF FINDINGS}

The measurements provide important information on the microscopic behavior of water in contact with the surface of $\alpha$ quartz under ambient conditions, and suggest that water on specific mineral surfaces may differ in structural details. This could in part explain the variations of reaction rates on particular mineral surfaces. The study also provides additional constraints for potentials used in molecular-dynamic simulations of water on mineral surfaces, and has allowed enhanced interpretation of sum-frequency spectral features.

\section{RELATED PUBLICATIONS}

Brown, G.E., et al., Metal oxide surfaces and their interactions with aqueous solutions and microbial organisms. Chem. Rev., 99(1), 77-174, 1999.

Shen, Y.R., Surface-properties probed by 2nd-harmonic and sumfrequency generation. Nature, 337, 519-525, 1989.

$\mathrm{Du}$, Q., et al., Vibrational-spectra of water-molecules at quartz water interfaces. Phys. Rev. Lett. 72(2), 238-241, 1994.

\section{ACKNOWLEDGMENTS}

This project is supported by the Director, Office of Science, Office of Basic Energy Sciences, Division of Chemical Sciences, Geosciences, and Biosciences, of the U.S. Department of Energy under Contract No. DE-AC03-76SF00098. The authors are grateful to Ekspla Ltd./ Altos Inc. for use of their laser system.

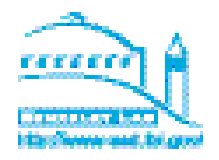




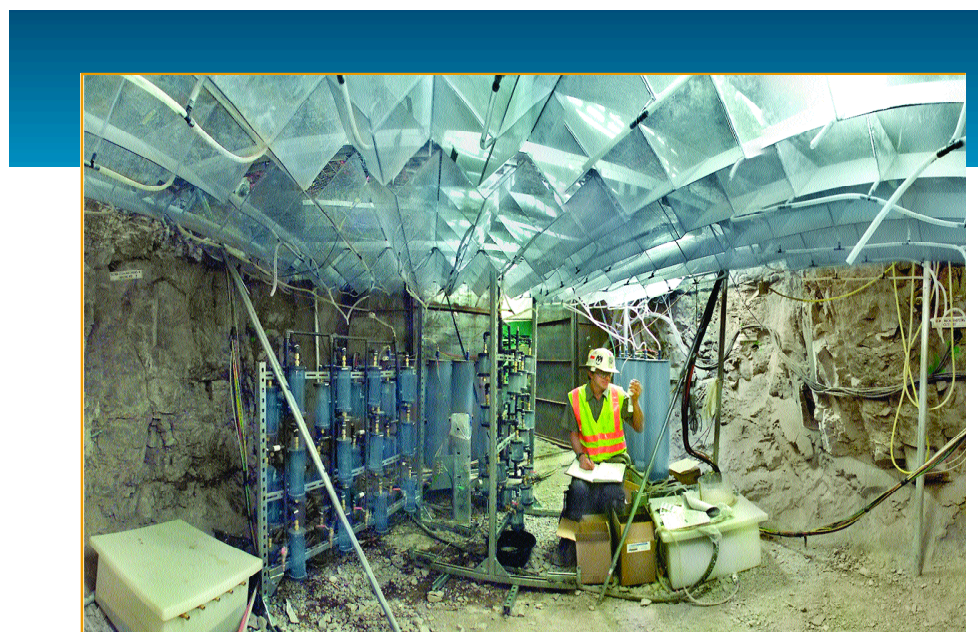

The role of ESD's Nuclear Waste Program (NWP) is to assist the U.S. Department of Energy, the United States, and other countries in solving the problem of the safe disposal of high-level radioactive waste-by means of high-quality scientific analyses and technology development. The major portion of this program involves investigating the feasibility and potential of the Yucca Mountain site in Nevada for permanent storage of high-level nuclear waste. The NWP has also collaborated on nuclear-waste disposal issues with such countries as Japan, Switzerland, Sweden, China, Romania, and others.

The Yucca Mountain site is located about $120 \mathrm{~km}$ northwest of Las Vegas in a semi-arid region. The proposed repository will be located about $350 \mathrm{~m}$ below ground surface within a thick unsaturated zone (UZ). Subsurface rocks at Yucca Mountain consist primarily of fractured volcanic tuffs that vary in degree of welding. To date, a total of about 60 deep surface boreholes have been drilled in the area. In 1996, an $8 \mathrm{~km}$ long underground tunnel, the Exploratory Studies Facility (ESF), was completed at Yucca Mountain to facilitate more extensive subsurface testing.

NWP's work at Yucca Mountain consists of solving many problems related to multiphase, nonisothermal flow and transport through the UZ. Some of the key questions addressed by NWP scientists include:

- How much water percolates through the UZ to the repository at Yucca Mountain?

- What fraction of the water flows in fractures and what fraction flows through the rock matrix blocks?

- How much of this water will seep into the emplacement drifts (tunnels)?

- How will radionuclides migrate from the repository to the water table?

- How will coupled TH (thermal-hydrological), THC (thermal-hydrological-chemical) and THM (thermal-hydrological-mechanical) processes affect flow and transport?
Research Program Nuclear Waste Gudmundur Bodvarsson

510/486-4789 gsbodvarsson@lbl.gov
To address these questions, the NWP is organized into the Ambient Testing, Thermal Testing, and Modeling groups, with support from geophysical studies.

\section{AMBIENT TESTING GROUP}

The Ambient Testing group investigates how water flows through the mountain and how much of this water will seep into the emplacement drifts. This group has performed various tests within the ESF, including fracture-matrix interaction tests, drift-to-drift tests, the Paintbrush unit test (PTn test), and niche (short drift) testing. Fracture-matrix interaction tests are relatively small-scale tests (i.e., covering a few meters) that focus on the components of water flow in fractures and matrix blocks and on the interaction between the two continua. The drift-to-drift tests address the same issues, but on a much larger spatial scale $(10-20 \mathrm{~m})$. The test in the Paintbrush unit, which is an unwelded tuff unit, addresses issues of episodic flow, effects of faults and large-scale features, and lateral continuity of flow and transport. This mostly unfractured unit, directly above the potential repository, is key to dispersing fracture flow from the fractured units above it, and buffering the transient behavior of episodic flow. The niche studies address perhaps the most crucial problem of Yucca Mountain, i.e., determining the fraction of water that will flow into the emplacement drifts. The niche studies are carried out by introducing water into boreholes above the drift opening and measuring what fraction actually seeps into the opening.

\section{THERMAL TESTING GROUP}

The Thermal Testing group works in collaboration with other national laboratories to evaluate the effects of heat on thermodynamic conditions, fluid flow and transport, and permanent property changes in the fractured tuff at and near the emplacement drifts. The Yucca Mountain Project has completed the first in situ heater test, called the Single Heater Test. The project is now conducting a large-scale heater test in a $50 \mathrm{~m}$ long drift. This second test, called the Drift Scale Test (DST), is intended to resemble the actual conditions that would exist 
when the high-level radioactive waste is placed in the emplacement drifts. NWP's roles in the heater tests are to characterize the heater-test rock block (area) prior to testing; to monitor potential changes in fracture and matrix saturations through air injections, tracer testing, and ground-penetrating radar measurements; and to perform predictive $\mathrm{TH}, \mathrm{THC}$, and THM calculations.

The initial characterizations of the heater test areas were performed with air-injection tests that yield the 3D permeability structure of the fracture network. Continued air-injection testing during heating yielded changes that can be attributed to changes in fracture saturations or mechanical effects. Crosshole radar tomography has also yielded very promising results regarding change in global saturations of the system caused by heating. Laboratory scientists are also involved with measurements of the isotopic compositions of gases and condensate water collected in instrumented boreholes. Detailed 3D TH, THC, and THM calculations were used to predict the behavior of the tests.

\section{MODELING GROUP}

Berkeley Lab has the primary responsibility for the development of the UZ Flow and Transport Model. This is a comprehensive, 3D, dual-permeability numerical model that represents the entire UZ at and near Yucca Mountain. The model is intended to integrate, within a single computational framework, all of the relevant geological, hydrological, geochemical, and other observations that have been made at the surface, in boreholes, and in tunnels at Yucca Mountain. The model is calibrated against pneumatic moisture tension, matrix potential, temperature, geochemical, perched water, and other data from the UZ. The model is then used to predict all of these variables in new boreholes and new drifts to be drilled. The degree of agreement between model predictions and subsequent field observations indicates the reliability of the model, and provides guidance as to what additional data need to be collected and incorporated.

A very important submodel of the UZ model is the seepage model, which is on a tens-of-meters scale, versus the UZ model's hundreds-of-thousands-of-meters scale. The seepage model, similar to the UZ model, predicts the results of the niche tests, which are subsequently modified to match the actual observations. Another submodel of the UZ model is the coupled-process THC model, calibrated using the heater test data and used to estimate the chemistry of water and gas entering the drifts. All these models-the UZ model, the seepage model, and the THC model-are key to the Total System Performance Assessment of Yucca Mountain, since performance of the potential repository is only as reliable as these underlying key models.

\section{FUNDING}

The Nuclear Waste Program's Yucca Mountain Project research is supported by the Director, Office of Civilian Radioactive Waste Management, U.S. Department of Energy, through Memorandum Purchase Order EA9013MC5X between Bechtel SAIC Company, LLC, and Berkeley Lab. The support is provided to Berkeley Lab through U.S. Department of Energy Contract No. DE-AC03-76SF00098. 


\section{Evaluation of Seepage During the Thermal Period AT YuCCA MOUNTAIN \\ Jens T. Birkholzer \\ Contact: 510/486-7134, jtbirkholzer@lbl.gov}

\section{RESEARCH OBJECTIVES}

Predicting the amount of water that may seep into waste emplacement tunnels (drifts) is essential for assessing the performance of the geologic nuclear waste repository at Yucca Mountain, Nevada. At ambient temperatures, seepage from the unsaturated fractured tuff into the drifts is reduced by the capillary barrier behavior at the rock-drift interface. In addition, the fractured rock in the drift vicinity will be heated to maximum temperatures of more than $130^{\circ} \mathrm{C}$, caused by the radioactive decay of the nuclear waste, and water percolating down towards the repository will be subject to vigorous boiling during the first several hundred years following waste emplacement. Thus, the superheated fractured rock forms a vaporization barrier that may further limit the potential for seepage. To study the impact of the driftscale thermal-hydrological (TH) perturba-

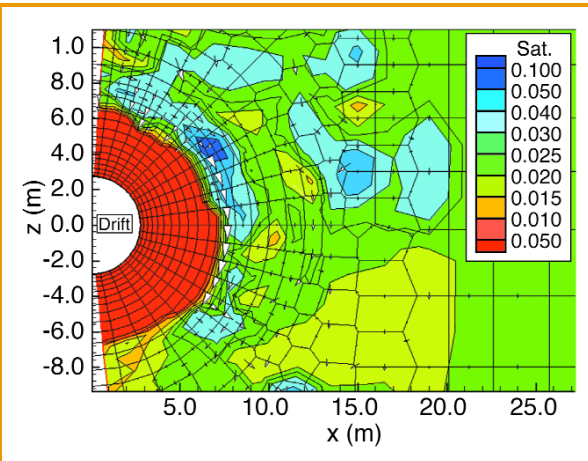

Figure 1. Fracture saturation and liquid flux vectors for a selected simulation case at 100 years of heating tions, a TOUGH2 simulation model was developed for the prediction of "thermal seepage" (i.e., seepage during the time that flow is perturbed due to heating).

\section{APPROACH}

The future TH conditions in the vicinity of waste emplacement drifts at Yucca Mountain are evaluated with a heterogeneous dual-permeability process model. The conceptual framework for describing the TH processes is based on models that accurately represent the thermal response of large in situ heater tests. The specific simulation framework for seepage is consistent with the modeling method employed in ambient seepage studies, which was developed based on model comparisons with liquid-release seepage testing. The key elements in this method-small-scale fracture permeability heterogeneity, relatively weak capillary strength, and the effect of discrete fractures at the drift wall-have all been included in the thermal seepage model. Several simulation cases are performed that cover the expected range of TH conditions at Yucca Mountain. Transient seepage rates during the period of enhanced temperatures are directly calculated from the model and compared to the respective seepage rates at ambient conditions.

\section{ACCOMPLISHMENTS}

Simulation results demonstrate that the thermal perturbation of the flow field-giving rise to increased downward flux from the condensation zone towards the drifts-is strongest during the first few hundred years after waste emplacement, corresponding to the period when rock temperature is highest and the vaporization barrier is most effective (Birkholzer et al., 2003). Even for high percolation fluxes into the model domain, and strong flow channeling as a result of fracture heterogeneity, water is not predicted to penetrate far into the superheated rock during the time that rock temperature is above boiling, and model results show no seepage (Figure 1). At the time when temperature has returned to below-boiling conditions and fractures start rewetting at the drift, the capillary barrier at the drift wall continues to reduce (or prevent) water seepage into the drift. Seepage is predicted to occur for such simulation cases that feature strongly heterogeneous fracture permeability fields, weak fracture capillary strength in the drift vicinity, and high percolation fluxes. In these cases, water starts to seep several hundred to a few thousand years after the rock temperature has returned to below boiling, the delay caused by the slow saturation buildup in fractures. Seepage amounts increase with time and asymptotically approach seepage rates estimated for long-term ambient conditions.

\section{SIGNIFICANCE OF FINDINGS}

The model results consistently demonstrate that (1) seepage does not occur under above-boiling conditions near the drifts, and (2) seepage under below-boiling conditions does not exceed the amount of ambient seepage. These findings are very important for the performance of the nuclear waste repository; they are currently being implemented into the performance assessment supporting the license application process.

\section{RELATED PUBLICATION}

Birkholzer, J., S. Mukhopadhyay, and Y.W. Tsang, Modeling water seepage into heated waste emplacement drifts at Yucca Mountain. Proceedings of the TOUGH Symposium 2003, Berkeley, California, May 12-14, 2003.

\section{ACKNOWLEDGMENTS}

This work was supported by the Director, Office of Civilian Radioactive Waste Management, U.S. Department of Energy, through Memorandum Purchase Order EA9013MC5X between Bechtel SAIC Company, LLC, and the Ernest Orlando Lawrence Berkeley National Laboratory (Berkeley Lab). The support is provided to Berkeley Lab through the U.S. Department of Energy Contract No. DE-AC03-76SF00098.

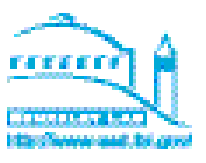




\section{Systematic Hydrological Characterization OF THE TOPOPAH SPRING LOWER LITHOPHYSAL UNIT \\ Paul Cook and Yvonne Tsang \\ Contact: Paul Cook, 510/486-6110, pjcook@lbl.gov}

\section{RESEARCH OBJECTIVES}

Over $80 \%$ of the proposed repository for the permanent disposal of high-level radioactive nuclear waste will be situated in the lower lithophysal unit of the Topopah Spring welded tuff, Yucca Mountain, Nevada. Within the Exploratory Studies Facility at Yucca Mountain, a $5 \mathrm{~m}$ diameter drift (tunnel), called the East-West Cross Drift, traverses this lower lithophysal unit. The welded tuff is intersected by many submeter fractures and interspersed with lithophysal cavities ranging from 15 to $100 \mathrm{~cm}$ in diameter. The size and spacing of both these features (fractures and cavities) varies appreciably. This indicates that hydrological characteristics at one particular location may not be representative of the entire lower lithophysal unit. Therefore, systematic testing at regular intervals, unbiased by the knowledge of specific features, is in progress, with the objective of gaining a greater understanding of the hydrological characteristics and associated heterogeneity of this potential repository unit.

\section{APPROACH}

Liquid-release (seepage) tests determine the ability of the open drift to act as a capillary barrier that diverts water around itself. Seepage into drifts increases the potential for corrosion of waste canisters and subsequent release of radionuclides. Seepage tests through this highly heterogeneous rock are being performed every $30 \mathrm{~m}$ along an $800 \mathrm{~m}$ stretch of the $5 \mathrm{~m}$ diameter drift. Water is released steadily into a series of $20 \mathrm{~m}$ boreholes drilled upward at a $15^{\circ}$ angle along the drift crown. Water that then seeps through the rock is measured by a drip capture system, and evaporation area is estimated using time-lapse photography. Seepage and evaporation are subtracted from the water released to determine how much water has been diverted.

Figure 1 shows a series of time-lapse photos taken of the drift crown as water from a test seeps through. These photos were taken about 6 days apart and show a gradual decrease in the rate of wetting. The photos show the evaporation pan with its white umbrella, which prevents seepage from accidentally filling the pan. The wire mesh (also shown) has a $7.5 \mathrm{~cm} \mathrm{spac}-$ ing, which is used to estimate the size of the wet patch. Multiplying this size by the flux from the pan yields the amount of evaporation from the crown. The photos also help determine when the first seep occurs after initiation of water release and how the flow first intersects the drift, whether it be by fractures, through cavities, or in the matrix itself. In addition, these photos help pinpoint whether a threshold water-release-rate value exists, below which no water enters the drift.

\section{ACCOMPLISHMENTS AND \\ SIGNIFICANCE OF FINDINGS}

Testing has progressed through the fifth of the series of boreholes along the drift. As the systematic hydrological testing progresses, a catalogue of flow characteristics for the drift is being developed. Not only can the various flow characteristics themselves be logged, but the distances for which they persist along the drift can now also be measured. Length scales from 1 to $23 \mathrm{~m}$, with flow characteristics up to $100 \%$ impermeability and 100\% diversion, have now become apparent, because of the expansive coverage of drift that can be tested with the systematic approach.

\section{ACKNOWLEDGMENTS}

This work was supported by the Director, Office of Civilian Radioactive Waste Management, U.S. Department of Energy, through Memorandum Purchase Order EA9013MC5X between Bechtel SAIC Company, LLC, and the Ernest Orlando Lawrence Berkeley National Laboratory (Berkeley Lab). The support is provided to Berkeley Lab through the U.S. Department of Energy Contract No. DE-AC0376 SF00098.

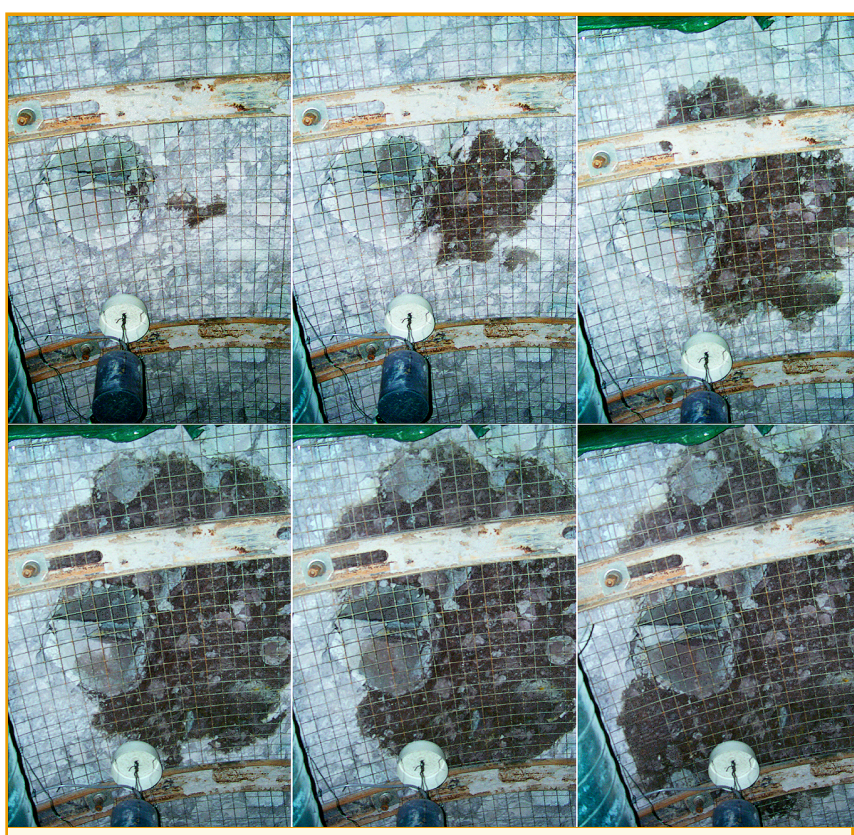

Figure 1. Time-lapse photos of the drift crown under a section of borehole being tested

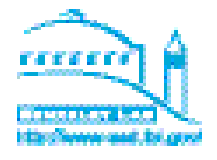




\section{Investigating How the Multiscale Heterogeneity of Hydrogeologic Properties Affects Flow and Transport at Yucca Mountain, Nevada \\ Paul Cook and Joe Wang \\ Contact: Paul Cook, 510/486-6110, pjcook@lbl.gov}

\section{RESEARCH OBJECTIVES}

Much of the exposed rock within the underground tunnels at the proposed repository site for disposal of high-level radioactive nuclear waste at Yucca Mountain, Nevada, has been mapped for fractures and cavities. It is thought that such features (the fractures and cavities) would be the most likely pathways for possible hydrological flow. Yet surface feature mapping gives very little indication as to the capability of these features to transmit fluids. An ongoing effort to dynamically "map" potential hydrological features of this type, using pneumatic testing at the Yucca Mountain Exploratory Studies Facility (ESF), has been under way as part of the systematic testing program there. Systematic testing at regular intervals, the choice of which is unbiased by previous knowledge of specific features (such as large fractures or an extra abundance of fractures/cavities), is in progress. This type of testing is crucial for understanding the overall hydrological characteristics and associated heterogeneity of the proposed repository units.

\section{APPROACH}

Pre-existing $4 \mathrm{~m}$ boreholes, drilled at regular intervals every 5 to $10 \mathrm{~m}$ along a $500 \mathrm{~m}$ "rib" (wall) of the ESF Main Drift, facilitate a series of pneumatic tests utilizing a borehole packer. Using this packer with pneumatic flow control and pressure measurement equipment enables an air-permeability profile to be developed for each of these boreholes. The spatial resolution of these profiles can be adjusted from the length of the whole borehole down to $0.33 \mathrm{~m}$, allowing different scales of features inside the holes to be measured for air permeability. A statistical understanding of the size of impermeable blocks within the holes and of the frequency and spacing of high-flow features is being developed.

\section{ACCOMPLISHMENTS AND SIGNIFICANCE OF FINDINGS}

Testing has progressed through 29 of the series of boreholes. Figure 1 shows the permeability profiles at the $0.33 \mathrm{~m}$ resolution in the 29 boreholes along a $230 \mathrm{~m}$ section of the drift. There is one borehole longer than the others that is thought to intersect the Sundance Fault of Yucca Mountain. A higher permeability at that location (caused by the fault) may account for the higher peak in the profile seen towards the end of that borehole. That some boreholes have extremely low permeability near the rib is somewhat counterintuitive, when considering that the atmospheric boundary at the rib might bias the measurement to a higher value. The presence of the drift itself, however, may cause existing features, particularly if near-horizontal, to close under load, lowering their permeability. As the systematic pneumatic testing progresses, a catalogue of flow characteristics for a growing length of drift is being developed in two dimensions, spanning a range of scales from the $0.33 \mathrm{~m}$ interval length, to borehole scale, to drift scale (obtained from borehole-to-borehole comparisons).

\section{ACKNOWLEDGMENTS}

This work was supported by the Director, Office of Civilian Radioactive Waste Management, U.S. Department of Energy, through Memorandum Purchase Order EA9013MC5X between Bechtel SAIC Company, LLC, and the Ernest Orlando Lawrence Berkeley National Laboratory (Berkeley Lab). The support is provided to Berkeley Lab through the U.S. Department of Energy Contract No. E-AC03-76SF00098.

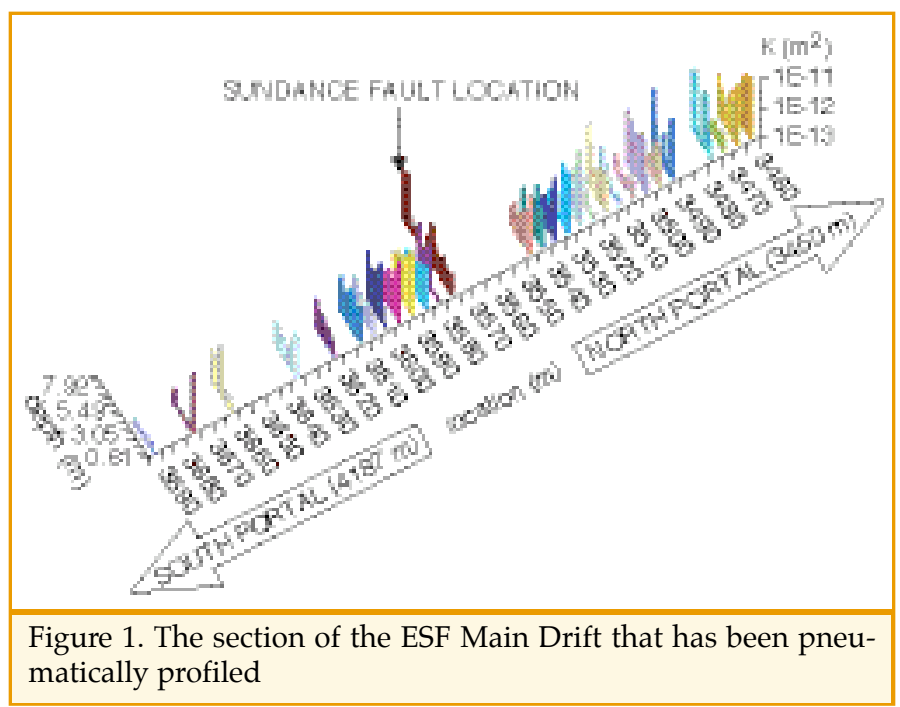

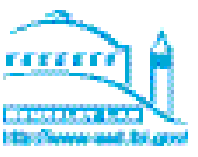




\section{Geothermal Systems as Natural Analogues for Yucca Mountain COUPLED PROCESSES}

Patrick Dobson and Timothy Kneafsey

Contact: Patrick Dobson, 510/486-5373, pfdobson@lbl.gov

\section{RESEARCH OBJECTIVES}

Geothermal systems provide an ideal opportunity for examining the long-term effects of coupled thermal-hydrolog-

ical-chemical (THC) processes expected for the proposed radioactive waste repository at Yucca Mountain, Nevada. Active and fossil geothermal systems provide important insights into the consequences of processes such as boiling, condensation, fluid mixing, and water-rock interaction associated with fluid flow in matrix and fractures, and can be used to test coupled-process models. Geothermal systems also allow observation of the effects of processes over much larger volumes and longer time scales than would be possible in laboratory or field experiments. The objective of this study is to evaluate potential changes in fluid flow resulting from the thermal impacts of storing high-level radioactive waste in fractured ash flow tuffs through characterization of the effects of water-rock interaction in geothermal systems.

\section{APPROACH}

An extensive literature review was performed to identify well-character-

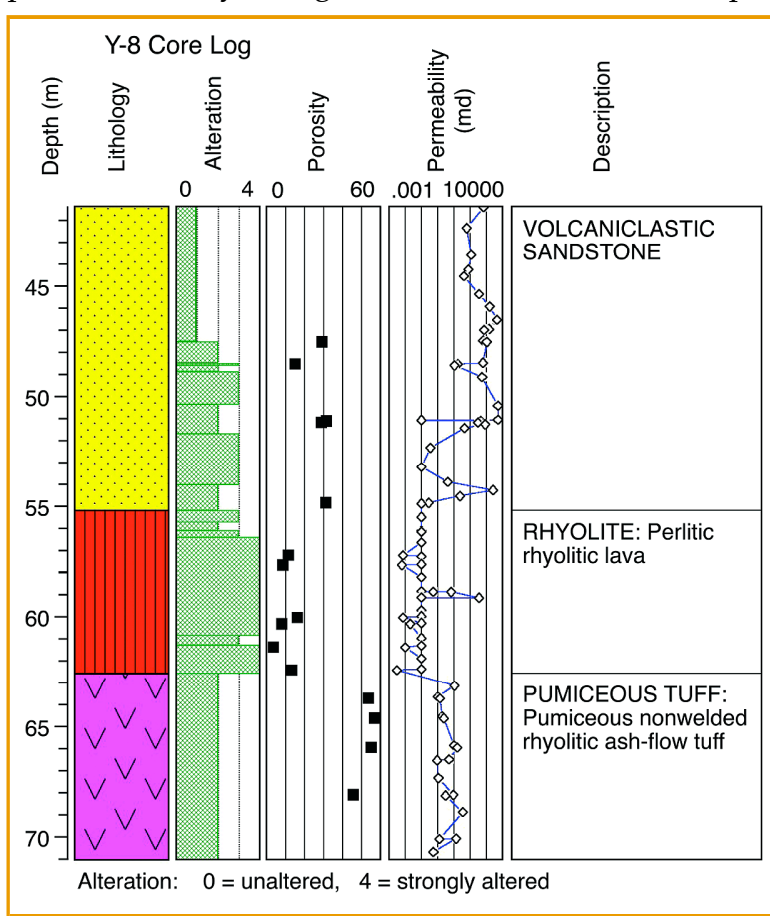

Figure 1. Simplified log of the geology, porosity, and matrix permeability of the Y-8 Yellowstone core. Silicification in the lower portion of the volcaniclastic sandstone unit has resulted in reductions in porosity and permeability, thereby forming an effective seal to the underlying convecting geothermal reservoir. anhydrite, and calcite) occurring within fracture flow pathways can form effective permeability barriers. Self-sealing zones observed in core samples in the Yellowstone geothermal system appear to have resulted from boiling events that led to the development of supersaturated fluids (Figure 1).

\section{SIGNIFICANCE OF FINDINGS}

Effects of THC processes such as boiling, condensation, dissolution, and precipitation for Yucca Mountain's higher-temperature operating mode will be most significant in the near-field environment (near the proposed repository). However, unsaturated conditions, lower temperatures, and the much lower fluid flow rates predicted for the Yucca Mountain system (in comparison to geothermal systems) should result in less extensive waterrock interaction than is observed in geothermal systems. Current THC models for Yucca Mountain predict that while both amorphous silica and calcite will precipitate in the nearfield environment, significant fracture sealing is unlikely. ized examples of THC processes in active and fossil geothermal systems. Special attention was given to processes such as heat and fluid flow, chemical transport, boiling and dryout, condensation and mineral dissolution, and mineral alteration and precipitation. In addition, a detailed examination of core samples from the Yellowstone geothermal system was conducted to evaluate the effects of lithology and hydrothermal alteration on porosity and permeability.

\section{ACCOMPLISHMENTS}

The review identified key THC processes in geothermal systems and evaluated their relevance to Yucca Mountain. Fluid flow in low-permeability rocks (such as the welded tuffs found at Yucca Mountain) occurs predominantly in fractures. Precipitation of minerals can be triggered by boiling, water-rock interaction, heating and cooling of fluids, and fluid mixing. Mineral solubilities, reaction-rate kinetics, and the flux, chemistry, and temperature of circulating fluids control the rates and volumes of mineralization. Mineral precipitation (typically silica, clays, zeolites,

\section{RELATED PUBLICATIONS}

Simmons, A.M., Natural Analogue Synthesis Report. Report TDR-NBS-GS-000027 REV00 ICN 02, Bechtel SAIC Company, Las Vegas, Nevada, 2002.

Dobson, P.F., T.J. Kneafsey, J. Hulen, and A. Simmons, Porosity, permeability, and fluid flow in the Yellowstone geothermal system, Wyoming. J. Volcanol. Geotherm. Res., 123, 313-324, 2003.

\section{ACKNOWLEDGMENTS}

This work was supported by the Director, Office of Civilian Radioactive Waste Management, U.S. Department of Energy, through Memorandum Purchase Order EA9013MC5X between Bechtel SAIC Company, LLC, and the Ernest Orlando Lawrence Berkeley National Laboratory (Berkeley Lab). The support is provided to Berkeley Lab through the U.S. Department of Energy Contract No. DE-AC03-76SF00098.

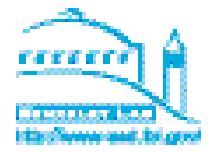




\title{
DeVelopment of Numerical Grids for Unsaturated Zone Flow AND TRANSPORT MODELING
}

\author{
Patrick Dobson, Lehua Pan, Yu-Shu Wu, and Randy Hedegaard \\ Contact: Patrick Dobson, 510/486-5373, pfdobson@lbl.gov
}

\section{RESEARCH OBJECTIVES}

Numerical grid generation is an integral part of the development of numerical models used for simulating unsaturated zone (UZ) flow and transport at Yucca Mountain. Previous studies at Yucca Mountain have generated detailed information on the geologic and hydrological properties of the UZ. Information on the stratigraphy, orientation, and location of faults, presence of vitric and zeolitic subunits, hydrological properties of the different hydrogeologic units, the location of the water table, and the design and location of proposed repository drifts can be used to develop complex 3-D numerical grids. The objective of this work is to construct numerical grids that provide the necessary resolution for subsequent UZ hydrological-property and flow calibration and mountainscale flow and transport simulations for the Yucca Mountain system.

\section{APPROACH}

Numerical grid generation is an iterative process that must achieve a proper balance between desired numerical accuracy (requiring more gridblocks) and short computational time (requiring fewer gridblocks). Fault and stratigraphic contact data obtained from the Yucca Mountain Geologic Framework Model were used in conjunction with hydrogeologic unit definitions to form the basis for the development of numerical grids. Other key input data included the location of calibration boreholes, the proposed repository layout, the water table surface (which forms the lower boundary of the UZ), and the location of zeolitic and vitric tuffs within the Calico Hills nonwelded units. These data were used as input for the WinGridder software package to develop 1-D, 2-D, and 3-D numerical grids (Figure 1). The resulting grids were checked using visual inspection and test simulations to verify the accuracy of the mesh and gridblock connections. Fracture data were used along with the program $2 \mathrm{kgrid} 8$.for to transform the effective-continuum model 3-D grid into the dual-permeability 3-D numerical grid required for conducting flow and transport models in heterogeneous, fractured rocks.

\section{ACCOMPLISHMENTS}

A revised set of 1-D, 2-D, and 3-D numerical grids was generated for use in numerical modeling of UZ flow and transport at Yucca Mountain. These grids incorporated changes made to the Yucca Mountain Geologic Framework Model, the UZ Model area boundaries, the position of the water table, the proposed repository design, and the location of vitric and zeolitic subunits in the Calico Hills nonwelded tuffs. The new grids also contained enhanced vertical resolution in selected units to better resolve processes such as lateral flow.

\section{SIGNIFICANCE OF FINDINGS}

The resulting numerical grids have been used for calibration of hydrogeologic unit properties and flow fields, testing of conceptual models of UZ flow and transport, and simulation of mountain-scale flow and transport behavior for the Yucca Mountain system under a variety of climatic and thermalloading conditions.

\section{RELATED PUBLICATION}

Dobson, P.F., L. Pan, and R. Hedegaard, Development of numerical grids for UZ flow and transport modeling. ANLNBS-HS-0000015 REV01, BSC, Las Vegas, Nevada, 2003.

\section{ACKNOWLEDGMENTS}

This work was supported by the Director, Office of Civilian Radioactive Waste Management, U.S. Department of Energy, through Memorandum Purchase Order EA9013MC5X between Bechtel SAIC Company, LLC, and the Ernest Orlando Lawrence Berkeley National Laboratory (Berkeley Lab). The support is provided to Berkeley Lab through the U.S. Department of Energy Contract No. DE-AC03-76SF00098.

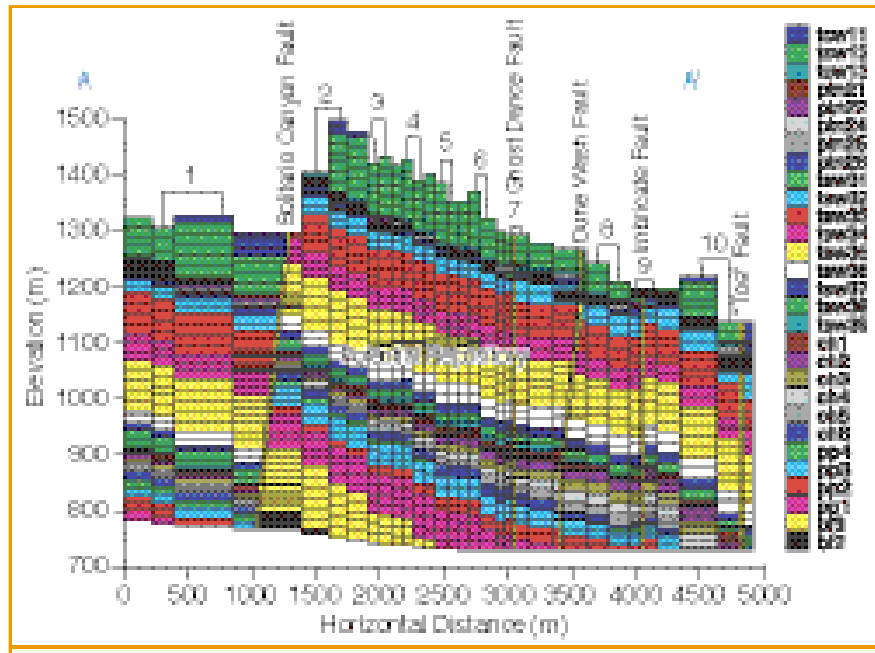

Figure 1. East-west cross section from the UZ Model Grid. Model layers represent hydrogeologic units derived from the Yucca Mountain Geologic Framework Model. Numbered column pairs were used to compare contact elevations obtained from the UZ Model and the Geologic Framework Model.

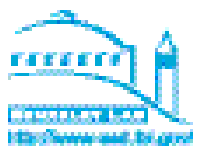




\title{
Scaling and Hierarchy of Models for Flow Processes IN UNSATURATED FRACTURED ROCK
}

\author{
Boris Faybishenko, G.S. Bodvarsson, Jennifer Hinds ${ }^{1}$, and Paul A. Witherspoon \\ ${ }^{1}$ University of Idaho, Moscow, Idaho \\ Contact: Boris Faybishenko, 510/486-4852, bafaybishenko@lbl.gov
}

\section{RESEARCH OBJECTIVE}

The goal of this research is to investigate whether a hierarchy of scales is needed to conduct measurements and develop models for an accurate description of the spatial-temporal behavior of flow and transport processes in unsaturated fractured rock.

\section{APPROACH}

The alternative approach to volume-averaging and scaling in unsaturated fractured rock is to use a hierarchy of scales. This approach is based on a system structure, i.e., the classification of a graded (ranked) series of system parts (subsystems). Each subsystem is dominant over those below it and dependent on those above it.

The concept of a hierarchy of scales in unsaturated fractured rock involves the following scales: elemental-for laboratory cores or a single fracture at a field site; small scale (approximately $0.1-1 \mathrm{~m}^{2}$ ) - for a single fracture, including fracturematrix interaction, film flow, and dripping water phenomena; intermediate scale (approximately 10-100 $\mathrm{m}^{2}$ ) - for flow in the fracture network on a field scale, and large scale-for the fracture and fault network flow. Each of these scales should be investigated on a minimum of three hierarchical levels. For the level of interest, called Level 0, a hierarchy should include at least one hierarchical level above it, called Level +1 , and at least one hierarchical level below it, called Level -1 . The lowfrequency behavior at Level +1 constrains the higher-frequency dynamics of Level 0 and thus determines the system boundary condition, constraining the system behavior over time. Because small-scale intrafracture flow processes are neither physically nor geometrically analogous to large-scale fracturenetwork processes, different conceptual approaches are required for modeling at different scales.

\section{ACCOMPLISHMENTS}

Figure 1 presents an example of a hierarchy of scales for flow processes in fractured tuff at the Yucca Mountain site. If Level 0 investigations are conducted to develop an intermediate-scale model (e.g., flow and transport processes in a fracture network around a tunnel, lateral flow at the interface between the Tiva Canyon and Paintbrush (PTn) hydrogeologic units, dispersion in the PTn unit, and a perched-water zone at the Topopah Spring and Calico Hill interface), Level -1 investigations include the study of small-scale processes taking place in small fractures and lithophysal zones (e.g., seepage, evaporation caused by tunnel ventilation, and intrafracture fingering). Level +1 investigations should be used to assign boundary conditions for the whole TSw unit. We have found that a trace length of $2 \mathrm{~m}$ represents a critical fracture length separating small and intermediate scales. A length of $10 \mathrm{~m}$ represents a critical fracture length separating intermediate and large scales.

\section{SIGNIFICANCE OF FINDINGS}

The concept of a hierarchy of scales and models will improve predictions of both water seepage and chemical transport through unsaturated fractured rocks at different scales, and reduce uncertainty in predictions of such processes.

\section{RELATED PUBLICATION}

Faybishenko, B., G.S. Bodvarsson, P.A. Witherspoon, and J. Hinds, Scaling and hierarchy of models for flow processes in unsaturated fractured rock. In: Scaling Methods in Soil Physics (Y.A. Pachepsky, D.E. Radcliffe and H. M. Selim, eds.), pp. 373-417, CRC Press, LLC, 2003.

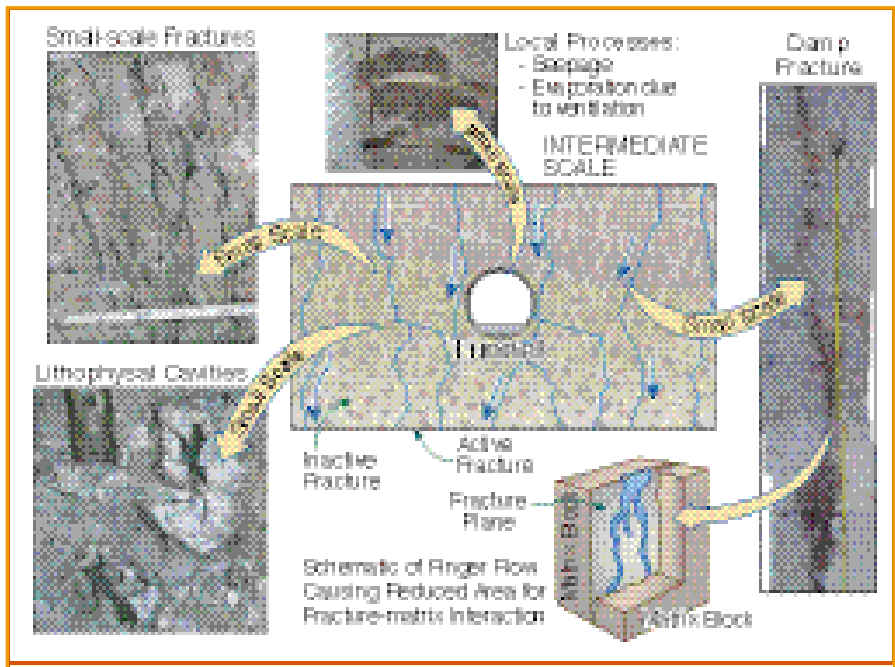

Figure 1. A hierarchy of scales for flow processes in fractured tuff at Yucca Mountain

\section{ACKNOWLEDGMENTS}

This work was supported by the Director, Office of Civilian Radioactive Waste Management, U.S. Department of Energy, through Memorandum Purchase Order EA9013MC5X between Bechtel SAIC Company, LLC, and the Ernest Orlando Lawrence Berkeley National Laboratory (Berkeley Lab). The support is provided to Berkeley Lab through the U.S. Department of Energy Contract No. DE-AC03-76SF00098. This work was also supported by the Director, Office of Science, Office of Basic Energy Sciences, of the Environmental Management Science Program of the U.S. Department of Energy, also under Contract No. DE-AC03-76SF00098.

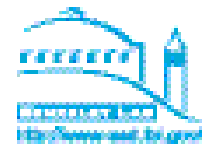




\title{
EVAPORATion From a SEepage Face
}

\author{
Stefan Finsterle, Teamrat A. Ghezzehei, Rob C. Trautz, C.F. (Rick) Ahlers, and Paul J. Cook
}

Contact: Stefan Finsterle, 510/486-5205, safinsterle@lbl.gov

\section{RESEARCH OBJECTIVES}

Dripping of water into waste emplacement drifts may critically affect the integrity of waste packages and the mobilization of radionuclides. To characterize seepage from fractured rocks, we release water from boreholes drilled above an underground opening, and collect it as it drips into the cavity. These seepage data are often influenced by evaporation effects caused by drift ventilation.

The objectives of this research are (1) to understand the evaporation mechanism at a rock surface, (2) to study the coupling between near-surface flow in fractured rock and evaporation, (3) to examine the effect of evaporation on seepage, (4) to develop effective simulation capabilities for unsaturated flow and seepage under evaporative conditions, (5) to analyze evaporation and liquid-release experiments, and (6) to predict seepage into ventilated waste emplacement drifts.

\section{APPROACH}

The research objectives are achieved by (1) monitoring rela-

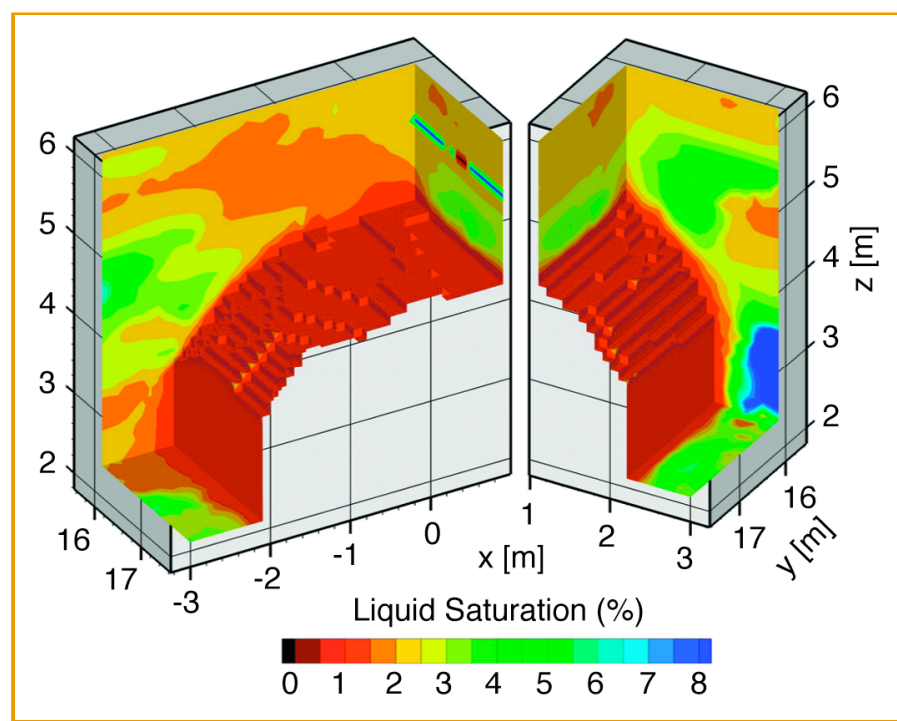

Figure 1. Saturation distribution around a ventilated underground opening, showing the dryout zone caused by evaporation effects relative humidity in the opening), preventing seepage from occurring and affecting the onset of dripping once water is injected from the borehole. The transient release of water f rom the borehole was simulated along with time-dependent changes in relative humidity. Seepage-relevant parameters were estimated by calibrating the model against the cumulative seepage amount observed in the opening. The modeling results indicate that evaporation effects in a ventilated tunnel are significant, i.e., they have to be accounted for during model calibration and p redictive calculations.

\section{SIGNIFICANCE OF} FINDINGS

Compared to previous models that neglected the effect of evaporation, this new approach shows significant improvement in capturing observed seepage fluctuations into ventilated underground openings. Accounting for evaporation effects reduces the potential bias in the estimation of seepagetive humidity and ventilation conditions, (2) measuring evaporation potential, (3) observing wetting patterns at the drift ceiling during liquid-release tests, (4) implementing an evaporation boundary condition into an unsaturated flow simulator, (5) calibrating the model against evaporation and seepage data, and (6) using the calibrated model to estimate total evaporation rates and relating them to other terms affecting seepage.

\section{ACCOMPLISHMENTS}

We incorporated evaporation effects into the numerical simulator by modeling them as a saturation-dependent Fickian diffusion process. The evaporation boundary-layer thickness was then estimated based on data from free-water evaporation experiments conducted under known relative humidity, temperature, and ventilation conditions. A threedimensional, heterogeneous fracture continuum model was developed to simulate liquid-release tests. The figure shows the saturation distribution under natural percolation conditions. Despite continuous downward flow of water, a dryout zone develops around the cavity (caused by the reduced relevant parameters. It also allows for a better understanding of the mass balance during liquid-release tests, and thus provides more confidence in the use of the calibrated model for simulations of seepage under different ventilation conditions.

\section{RELATED PUBLICATION}

Ghezzehei, T., S. Finsterle, and R. Trautz, Evaluating the effectiveness of liquid diversion around an underground opening when evaporation is non-negligible. Proceedings of the TOUGH Symposium 2003, Berkeley, California, May 12-14, 2003.

\section{ACKNOWLEDGMENTS}

This work was supported by the Director, Office of Civilian Radioactive Waste Management, U.S. Department of Energy, through Memorandum Purchase Order EA9013MC5X between Bechtel SAIC Company, LLC, and the Ernest Orlando Lawrence Berkeley National Laboratory (Berkeley Lab). The support is provided to Berkeley Lab through U.S. Department of Energy Contract No. DE-AC03-76SF00098.

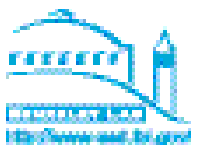




\title{
EfFects of Induced Convection on FAR-Field Groundwater Flow
}

\author{
Kazumasa Ito and Kenzi Karasaki \\ Contact: Kazumasa Ito, 510/486-6985, kito@lbl.gov
}

\section{RESEARCH OBJECTIVES}

In the safety assessment of nuclear waste disposal, the influence of heat convection on the groundwater flow field cannot be neglected. This influence should be estimated by conducting a thermal-hydrological $(\mathrm{TH})$ numerical analysis at the site characterization stage. However, as a first step, it is worthwhile to estimate the influence of heat convection using only the thermodynamic parameters obtained from existing data.

The objective of this research is to estimate the influence of heat convection on the natural groundwater flow system, employing a dimensionless parameter from case studies using a TH coupled model.

\section{APPROACH}

For this sensitivity study, the coupled heat and hydraulic simulation code TOUGH2 is applied to a vertical two-dimensional model with an area 10,000 m long and 3,000 m deep. Induced convection is generated by the hydraulic gradient (0.01) dictated by the assigned topography. The model is saturated with water, with a constant pressure at the upper boundary and impermeable lower and side boundaries. The upper and lower boundaries are set at a constant temperature, while side boundaries are insulated.

In this study, we use representative physical properties of a sedimentary rock. The vertical temperature gradient is set at $0.02^{\circ} \mathrm{C} / \mathrm{m}$. Variable permeabilities within two orders of magnitude are assigned to the model. From the results of case studies, we extract the average velocity along the particle stream traces from six starting points and the maximum vertical velocity in the model, and use them as qualitative indicators to evaluate the relative influence of heat convection. For comparison, we carried out simulations with the same hydraulic properties and the initial temperature distribution without heat transfer as the uncoupled model for each respective case.

\section{ACCOMPLISHMENTS}

To estimate the influence of thermal convection, we used the Peclet number, which denotes the ratio between advection and thermal diffusion. Figure 1 shows representative results from three cases depicting temperature distributions and stream traces. From these results, we can see that when the permeability is large, the recharge zone becomes larger, and the low-temperature area also becomes larger because of the increasing recharge of low-temperature water. Both the average velocity along the stream traces and the maximum vertical velocity increase as the Peclet number increases. However, the velocity ratios of the TH coupled model to the uncoupled model both decrease when the Peclet number exceeds 2.0.
In a high-permeability condition, the flow of cold water from the surface dominates the temperature distribution, and almost the entire area becomes a low-temperature zone. On the other hand, if the Peclet number is less than 0.2 , the velocity ratio is less than 1.1, which means that the error in the uncoupled model is only about $10 \%$.

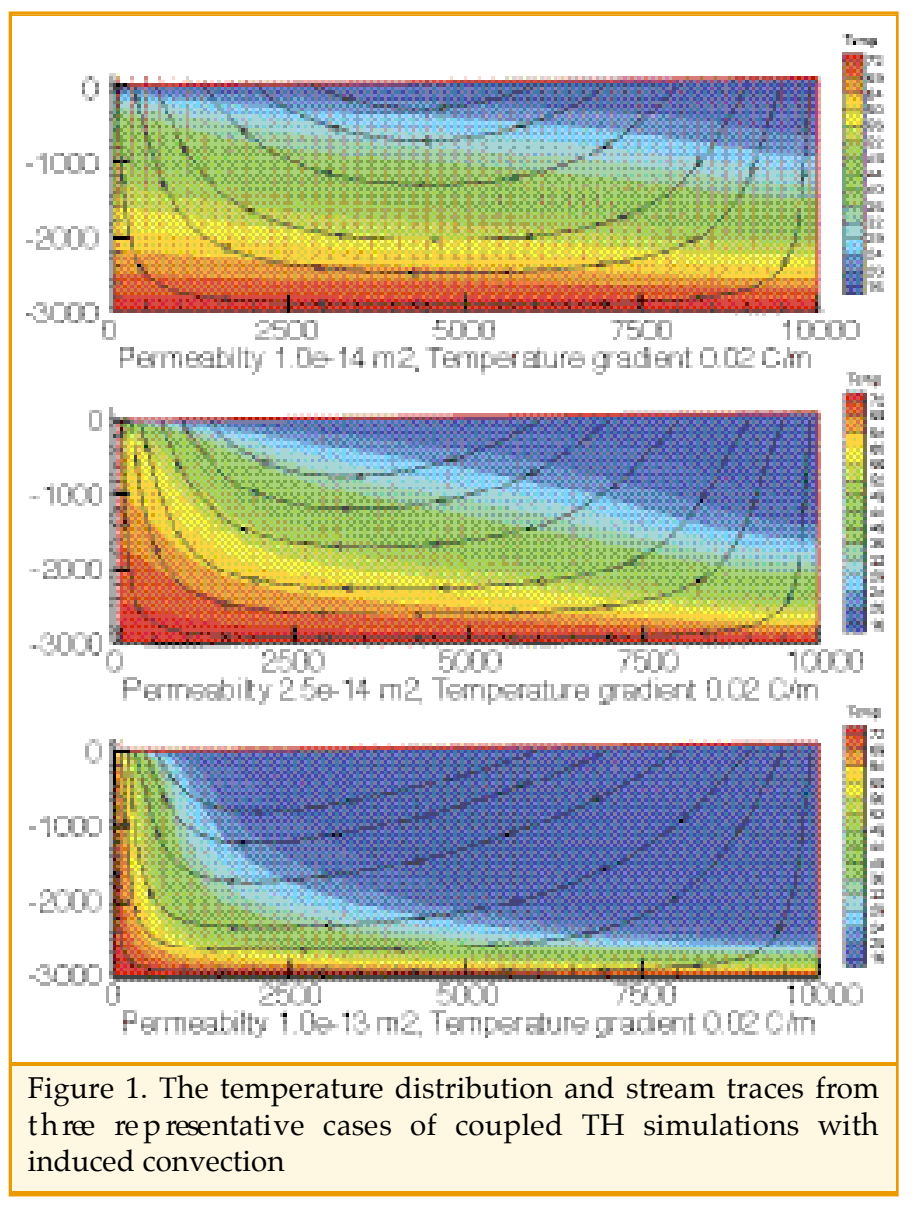

\section{SIGNIFICANCE OF FINDINGS}

It was shown that the Peclet number is a useful indicator for predicting the influence of thermal convection on groundwater flow. When the Peclet number is small, the influence of heat convection is small because of the slow velocity. There is a critical Peclet number (a function of the topography) above which the influence of heat convection becomes significant.

\section{ACKNOWLEDGMENTS}

This work has been supported by Taisei Corporation under U.S. Department of Energy Contract No. DEAC03-76SF00098.

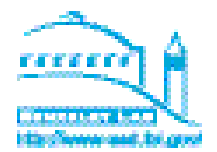




\title{
InVEStigation of UnCertainty in Hydrogeologic Modeling of Flow AND Transport in a Large, Saturated Granitic Rock Mass
}

\author{
Kenzi Karasaki, Christine Doughty, and Kazumasa Ito \\ Contact: Kenzi Karasaki, 510/486-6759, kkarasaki@lbl.gov
}

\section{RESEARCH OBJECTIVES}

The objectives of this project are: (1) to evaluate the uncertainty involved in modeling flow and transport in a large granitic rock mass, and (2) to seek ways of reducing that uncertainty.

\section{APPROACH}

A number of international research organizations are participating in this project. Each has been building a model and conducting simulations of groundwater flow and transport using the same set of information from a site in the Tono area of Gifu, Japan. The base data set is an accumulation of the past several years' field investigations and include geological, hydrological, geophysical, and geochemical data. As a new set of data becomes available, predicted flow rates and particle travel times through the model are compared among the different models. So far, flow rates and travel times differ by three to four orders of magnitude. One focus of the study is to find the cause of these differences among the models. Another focus is to evaluate how much the model improves as new data become available.

In our conceptual model, we use stochastic permeability and porosity distributions to represent fractured rock as an effective continuum. Only large-scale features such as fault zones, lithologic layering, natural boundaries, and surface topography are incorporated deterministically. Because the effective porosity of a large rock mass cannot be measured directly, it has to be estimated indirectly from several different types of data, using scientific judgment. Another large uncertainty stems from the hydraulic properties of faults, although some inferences can be made from measured hydraulic heads.

\section{ACCOMPLISHMENTS}

We have built and continuously updated a model that generally satisfies the observed pressure-head data. We have made use of temperature measurements to distinguish between two plausible boundary conditions for the model. The most recent update to the model was made using large-scale dynamic-pressure-disturbance data, which prompted us to increase the effective porosity value by fifty fold. We also expanded the boundary of our $4 \mathrm{~km} \times$ $6 \mathrm{~km} \times 3 \mathrm{~km}$ model to build a $9 \mathrm{~km} \times 9 \mathrm{~km} \times 2 \mathrm{~km}$ model. The latter appears to better define a hydrological basin. We used an inversion program, iTOUGH2, to estimate the permeability of a major fault by matching the steady-state head distribution.

\section{SIGNIFICANCE OF FINDINGS}

Our findings indicate that the hydraulic structure of the fault likely resembles a sandwich, with a low-permeability core and high-permeability zones on both sides of the core. This structure may generally describe reverse faults in a crystalline rock. Also, borehole temperature data may be used to reduce the uncertainties of a hydrological model. Finally, large-scale pressure disturbance data may be used to infer the effective permeability and porosity of a large fractured rock mass.

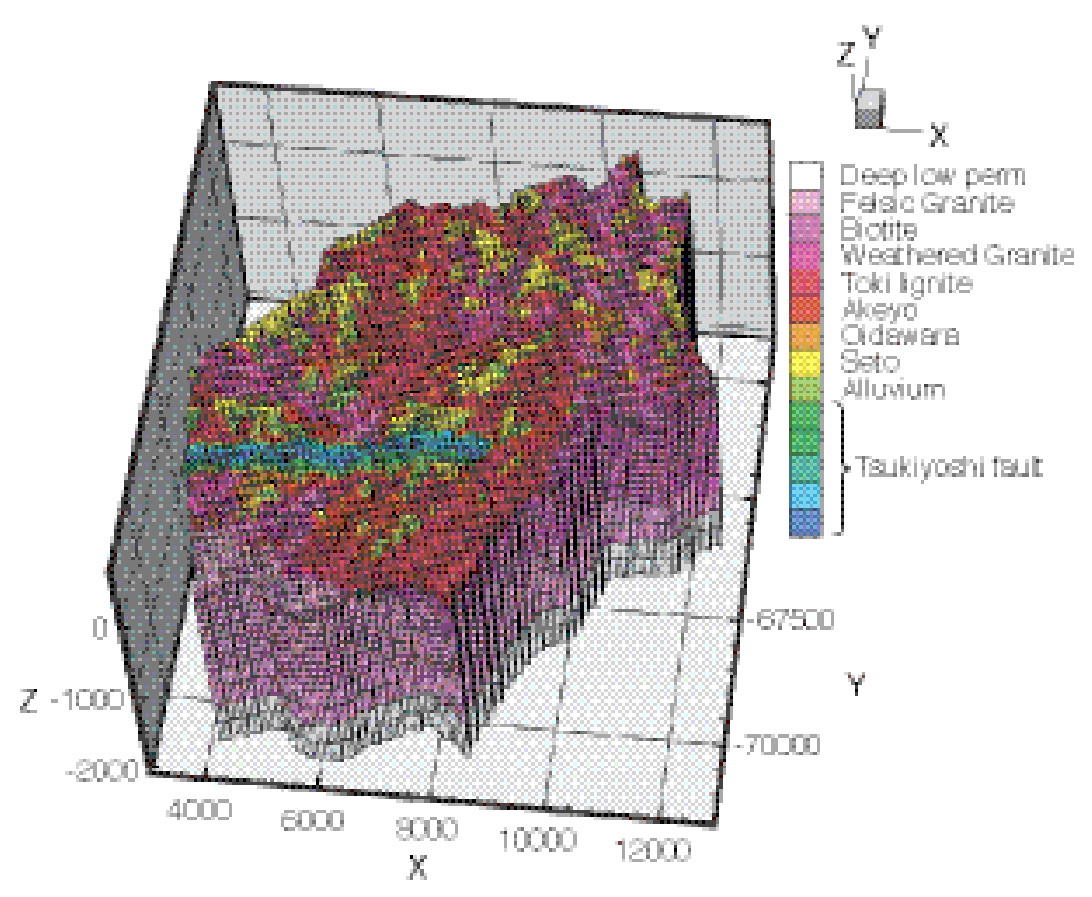

Figure 1. Three-dimensional perspective view of the model used for the TOUGH2 and iTOUGH2 simulations of the $9 \mathrm{~km} \times 9 \mathrm{~km} \times 2 \mathrm{~km}$ region. Material types are color-coded.

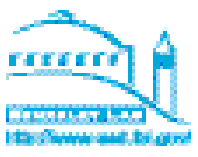

\section{RELATED PUBLICATION}

Doughty, C., and K. Karasaki, Constraining hydrologic models using thermal analysis. In: Proceedings, Rock Mech. Symp., Japan Society of Civil Engineers, Tokyo, Japan, January 23-24, 2003.

\section{ACKNOWLEDGMENTS}

This work was supported by the Japan Nuclear Fuel Cycle Corporation (JNC) and Taisei Corporation of Japan, through the U.S. Department of Energy Contract No. DE-AC03$76 \mathrm{SF} 00098$. 


\section{Fracture Sealing by Mineral Dissolution and Precipitation at Yucca Mountain} Timothy J. Kneafsey, Patrick F. Dobson, Eric L. Sonnenthal, John A. Apps, and Nicolas Spycher Contact: Timothy J. Kneafsey, 486-4414, tjkneafsey@lbl.gov

\section{RESEARCH OBJECTIVES}

The emplacement of heat-generating waste at the proposed Yucca Mountain repository site will induce several processes to occur. Water naturally present in the rock will evaporate or boil, and this vapor will condense at a distance from the proposed repository, where the rock is cooler. The condensate will dissolve the host rock (tuff), and the dissolved constituents will precipitate if the water is boiled away. Mineral precipitation in fractures above the proposed repository could plug flow paths and reduce the probability of water seeping into the repository. Our research objectives are to provide a better understanding of (1) tuff dissolution under conditions expected in the proposed repository, (2) mineral precipitation in fractures, and (3) how these processes might affect the performance of such a proposed repository.

\section{APPROACH}

Our approach was to experimentally and numerically investigate tuff dissolution caused by water condensation in fractures and mineral precipitation in fractures subjected to a thermal gradient with a boiling region. We used anticipated temperature and pressure conditions in the proposed repository.
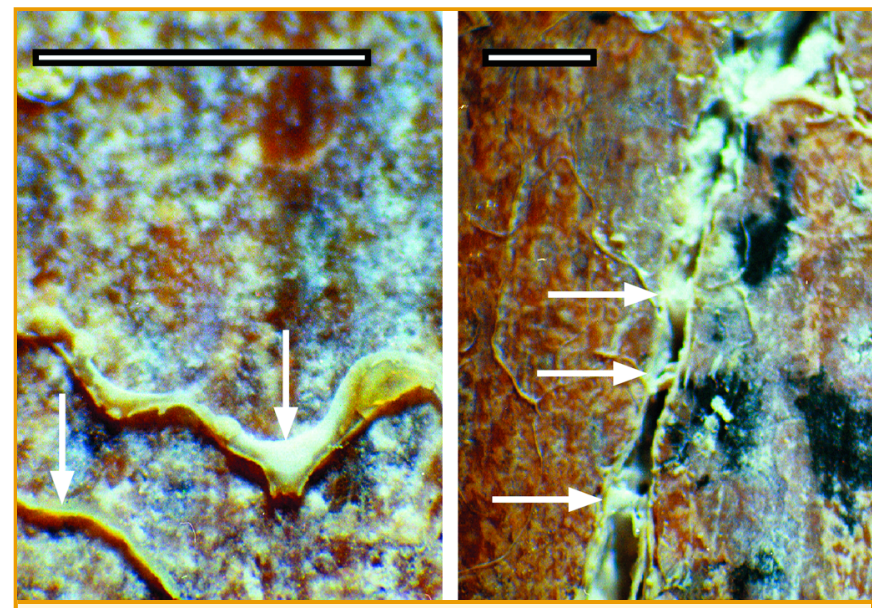

Figure 1. Bridging structures (identified with arrows): (a) extending outward from flat fracture face; (b) spanning aperture in cross-cutting natural fracture. Scale bars are $0.5 \mathrm{~mm}$.

\section{ACCOMPLISHMENTS}

We replicated mineral dissolution by vapor condensate in fractured tuff by flowing water through crushed Yucca Mountain tuff at $94^{\circ} \mathrm{C}$. We monitored the chemistry of the water passing through the crushed tuff to provide information on tuff dissolution. The steady-state fluid composition had a total-dissolved-solids content of about $140 \mathrm{mg} / \mathrm{L}$, and silica was the dominant dissolved constituent. We flowed a portion of this mineral-laden water into a vertically oriented planar (saw cut) fracture in a block of welded Topopah Spring Tuff that was maintained at $80^{\circ} \mathrm{C}$ at the top and $130^{\circ} \mathrm{C}$ at the bottom. In the boiling region, the precipitation of amorphous silica from the water began to seal the fracture within 5 days. Upon opening the fracture, we observed the structure of the precipitate: precipitate coated the fracture walls and formed bridging structures that plugged the aperture. On the right side of Figure 1, we see bridging structures extending out from the fracture wall, and in the cross-cutting fracture shown on the left, both the fracture coating and bridging structures are visible.

A one-dimensional plug-flow numerical model was used to simulate mineral dissolution, and a similar model was developed to simulate the flow of mineralized water through a planar fracture, where boiling conditions led to mineral precipitation. Predicted concentrations of the major dissolved constituents for the tuff dissolution were within a factor of 2 of the measured average steady-state compositions. The mineral precipitation simulations predicted the precipitation of amorphous silica at the base of the boiling front, leading to a greater than 50-fold decrease in fracture permeability in 5 days, consistent with the laboratory experiment. These results help validate the use of a numerical model to simulate thermal-hydrological-chemical processes at Yucca Mountain.

\section{SIGNIFICANCE OF FINDINGS}

The experiment and simulations indicated that precipitation of amorphous silica could cause significant reductions in fracture porosity and permeability on a local scale. However, differences in fluid flow rates and thermal gradients between the experimental setup and anticipated conditions at Yucca Mountain need to be factored into scaling of the results.

\section{RELATED PUBLICATION}

Dobson, P.F., T.J. Kneafsey, E.L. Sonnenthal, N. Spycher, and J.A. Apps, Experimental and numerical simulation of dissolution and precipitation: Implications for fracture sealing at Yucca Mountain, Nevada. Journal of Contaminant Hydrology, 62-63, 459-476, 2003.

\section{ACKNOWLEDGMENTS}

This work was supported by the Director, Office of Civilian Radioactive Waste Management, U.S. Department of Energy, through Memorandum Purchase Order EA9013MC5X between Bechtel SAIC, LLC, and the Ernest Orlando Lawrence Berkeley National Laboratory (Berkeley Lab). The support is provided to Berkeley Lab through the US Department of Energy Contract No. DEAC03- 76SF00098.

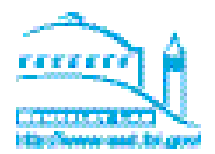




\title{
Scale Dependency of the Effective Matrix Diffusion Coefficient
}

\author{
Hui-Hai Liu, Gudmundur S. Bodvarsson, and Guoxiang Zhang \\ Contact: Hui-Hai Liu, 510/486-6452, hhliu@lbl.gov
}

\section{RESEARCH OBJECTIVES}

The exchange of solute mass (through molecular diffusion) between fluid in fractures and fluid in rock matrix is called matrix diffusion. Owing to the order-of-magnitude slower flow velocity in the matrix compared to fractures, matrix diffusion can significantly retard contaminant transport in fractured rock. The effective matrix diffusion coefficient is an important parameter for describing this matrix diffusion, in that it largely determines overall contaminant transport behavior in fractured rock (in many cases). Such diffusion coefficient values measured from small-scale rock samples in the laboratory have been directly used for modeling largescale radionuclide transport at the proposed Yucca Mountain nuclear waste repository site (and many other sites). However, some preliminary studies have indicated that field-scale matrix diffusion coefficient values are different from local values. The major objective of this work is to determine if a relationship exists between the effective matrix diffusion coefficient and test scales.

\section{APPROACH}

A number of field-scale tracer tests in fractured rocks have been conducted and interpreted by different research groups worldwide. Effective matrix diffusion coefficients, published in the literature and estimated from the relevant tracer tests, were surveyed. To detect the potential scale-dependence of the
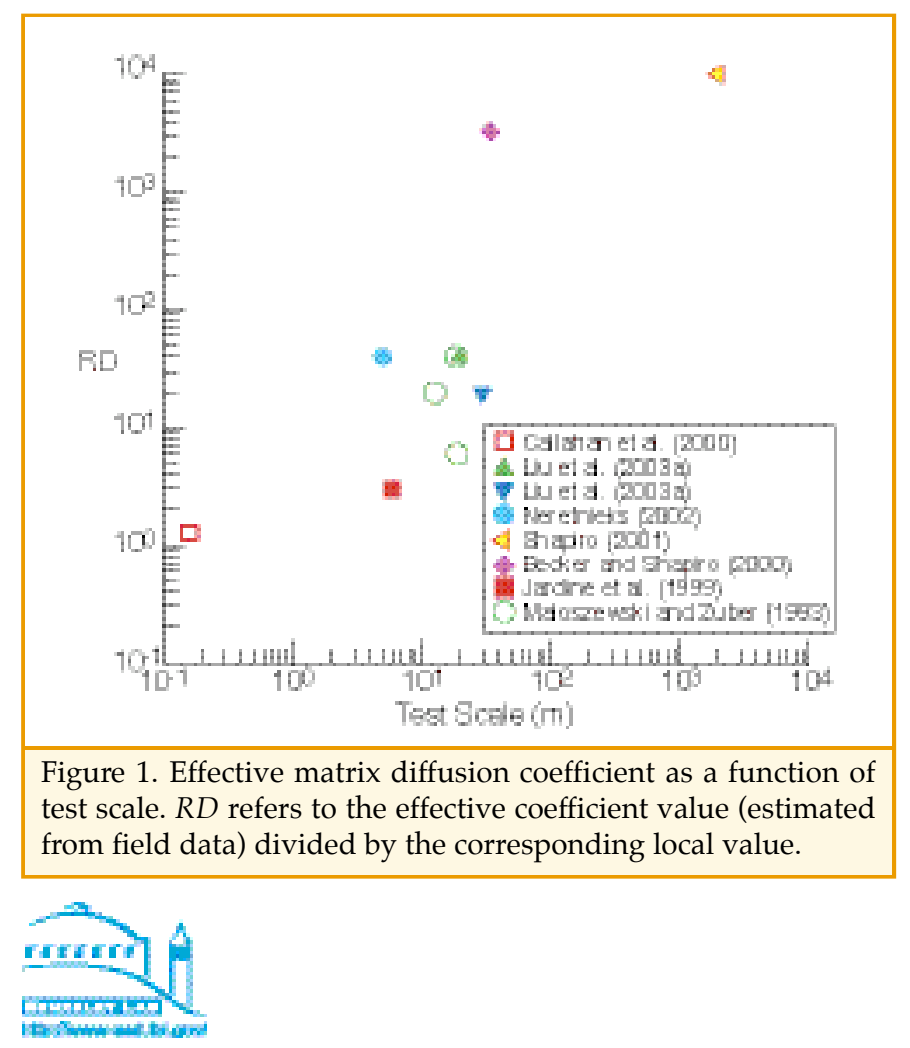

effective matrix diffusion coefficient, we compiled the ratio of an estimated effective matrix diffusion coefficient to its local value (corresponding to a small core sample) as a function of test scale (Figure 1).

\section{ACCOMPLISHMENTS}

As demonstrated in Figure 1, the effective matrix diffusion coefficient may be scale-dependent and generally increases with test scale. The mechanisms behind this surprising scaledependency behavior are not totally clear. We offered a preliminary explanation based on the hypothesis that solute travel paths within a fracture network are fractals (Liu et al., 2003). We believe that the scale dependency of the effective matrix diffusion coefficient actually results from the scale dependency of the fracture-matrix interface area (as a result of fractal solute-travel paths).

\section{SIGNIFICANCE OF FINDINGS}

While the scale dependency of permeability and dispersivity has been known for many years in the subsurface hydrology community, we demonstrate-for the first time- that the effective matrix diffusion coefficient may also be scaledependent, specifically increasing with test scale. This finding has many important implications for problems involving matrix diffusion. For example, the simulated radionuclide travel time within the unsaturated zone of Yucca Mountain may be significantly underestimated when this scale-dependent behavior is not considered. However, more carefully designed field tests and numerical experiments are still needed to confirm this scale-dependent behavior and to develop more rigorous theoretical explanations.

\section{RELATED PUBLICATION}

Liu, H.H., G.S. Bodvarsson, and G. Zhang, Scale dependency of the effective matrix diffusion coefficient. Vadose Zone Journal, 2003 (in press); Berkeley Lab Report LBNL-52824, 2003.

\section{ACKNOWLEDGMENTS}

This work was supported by the Director, Office of Civilian Radioactive Waste Management, U.S. Department of Energy, through Memorandum Purchase Order EA9013MC5X between Bechtel SAIC Company, LLC, and the Ernest Orlando Lawrence Berkeley National Laboratory (Berkeley Lab). The support is provided to Berkeley Lab through the U.S. Department of Energy Contract No. DE-AC03-76SF00098. 


\section{The Active Fracture Model and Fractal Flow Behavior Hui-Hai Liu, Guoxiang Zhang, and Gudmundur S. Bodvarsson \\ Contact: Hui-Hai Liu, 510/486-6452, hhliu@lbl.gov}

\section{RESEARCH OBJECTIVES}

Continuum approaches are commonly used for modeling flow and transport in unsaturated fractured rocks. A traditional continuum approach assumes uniformly distributed flow patterns at a subgrid scale and therefore cannot be used for representing gravity-driven fingering flow and transport in fracture networks. In an effort to incorporate this figuring flow behavior into the continuum approach, Liu et al. (1998) developed the active fracture model (AFM), which assumes that only a portion of fractures in a connected unsaturated fracture network contributes to liquid water flow. The major objective of this work is to provide a further evaluation of the AFM, based on both theoretical arguments and field observations (Liu et al., 2003).

\section{APPROACH}

A flow system exhibits so-called fractal flow behavior when the corresponding flow patterns can be characterized by fractals. Many laboratory and field experiments have shown

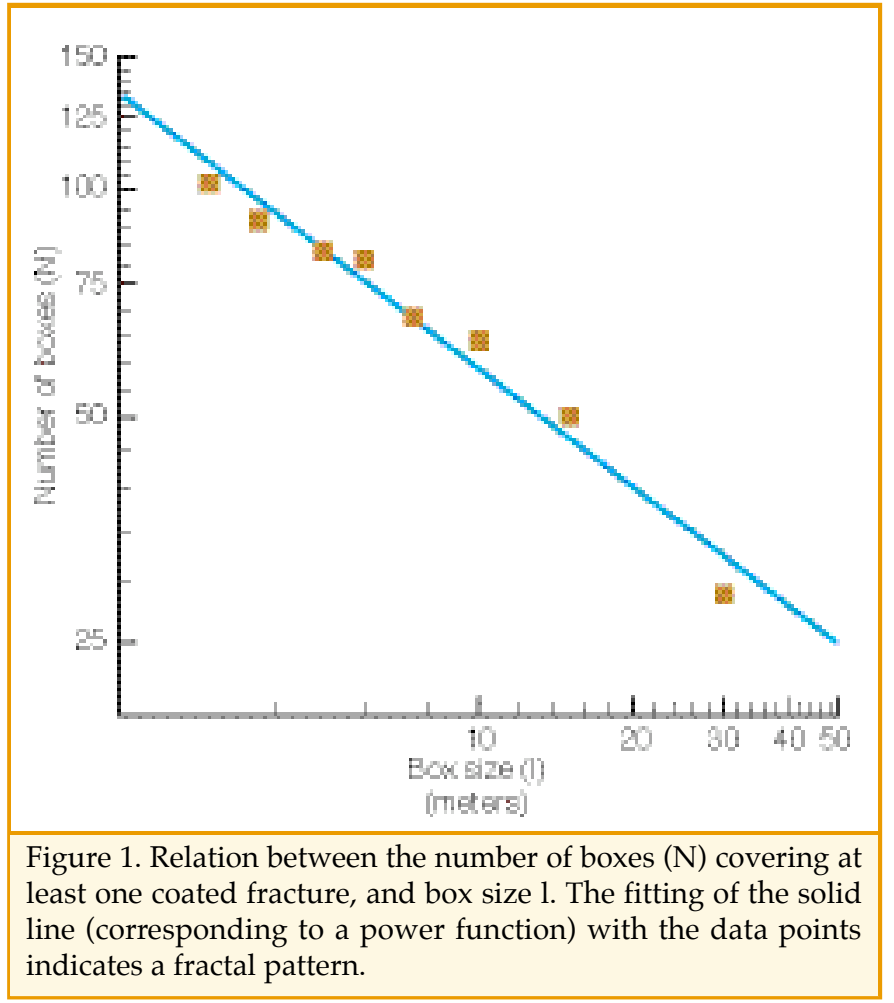

that complex fingering flow patterns in unsaturated porous media are fractal patterns. We used a box-counting approach to detect fractal flow patterns from spatial distributions within coated fractures (a sign of water flow within fractures) in the Yucca Mountain unsaturated zone (Figure 1). The theoretical relationship between the AFM and fractal flow patterns was also explored. AFM-based simulation results were then compared to C-14 and fracture coating data to check the validity of the AFM.

\section{ACCOMPLISHMENTS}

We demonstrated that flow patterns in unsaturated fractured rock, like those in unsaturated porous media, are fractal (Figure 1). While the AFM was initially developed as an empirical model, a rigorous theoretical relation between AFM and the fractal flow pattern was established. Comparisons between model simulations and the relevant field observations support the validity of the AFM.

\section{SIGNIFICANCE OF FINDINGS}

The inadequacy of numerical models in predicting fast flow and transport processes has been a significant problem for many unsaturated systems. In this work, we showed that complex unsaturated flow patterns in both porous media and fractured rock are fractal patterns, and that the AFM can capture this important behavior at the subgrid scale. Because of the relative simplicity of fractal-based characterizations, we believe that the fast flow behavior in unsaturated systems can be successfully captured by the improved large-scale continuum approach. This is partially supported by the consistency between simulation results based on the AFM and field observations from the Yucca Mountain unsaturated zone. Future work will focus on the possibility of extending the AFM to unsaturated porous media.

\section{RELATED PUBLICATIONS}

Liu, H. H., C. Doughty, and G. S. Bodvarsson, An active fracture model for unsaturated flow and transport in fractured rocks. Water Resour. Res., 34, 2633-2646, 1998.

Liu, H.H., G. Zhang, and G.S. Bodvarsson, The active fracture model: Its relation to fractal flow behavior and a further evaluation using field observations. Vadose Zone Journal, 2, 259-269, 2003.

\section{ACKNOWLEDGMENTS}

This work was supported by the Director, Office of Civilian Radioactive Waste Management, U.S. Department of Energy, through Memorandum Purchase Order EA9013MC5X between Bechtel SAIC Company, LLC, and the Ernest Orlando Lawrence Berkeley National Laboratory (Berkeley Lab). The support is provided to Berkeley Lab through the U.S. Department of Energy Contract No. DE-AC03-76SF00098.

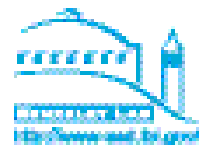




\section{Implications of Halide LeAching on Chlorine-36 Studies at Yucca Mountain Guoping Lu, Eric L. Sonnenthal, and Gudmundur S. Bodvarsson Contact: Guoping Lu, 510/495-2359, gplu@lbl.gov}

\section{RESEARCH OBJECTIVES}

Chlorine-36 generated from worldwide nuclear tests in the 1950s and 1960s has been used to identify fast flow paths at Yucca Mountain, Nevada, the proposed site for a national high-level nuclear waste repository. Fast flow refers to preferential transport of water through faults or fractures in surrounding rock media with relatively low permeability. Bombpulse ${ }^{36} \mathrm{Cl}$ carried into the subsurface by infiltrating rainwater presumably resides along fracture surfaces. However, leaching a rock sample to extract this salt inevitably extracts pore-water chloride $(\mathrm{Cl})$ and rock chloride from the matrix as well. The work described here contributes to the understanding of leaching processes for the ongoing validation study of ${ }^{36} \mathrm{Cl}$ at Yucca Mountain.

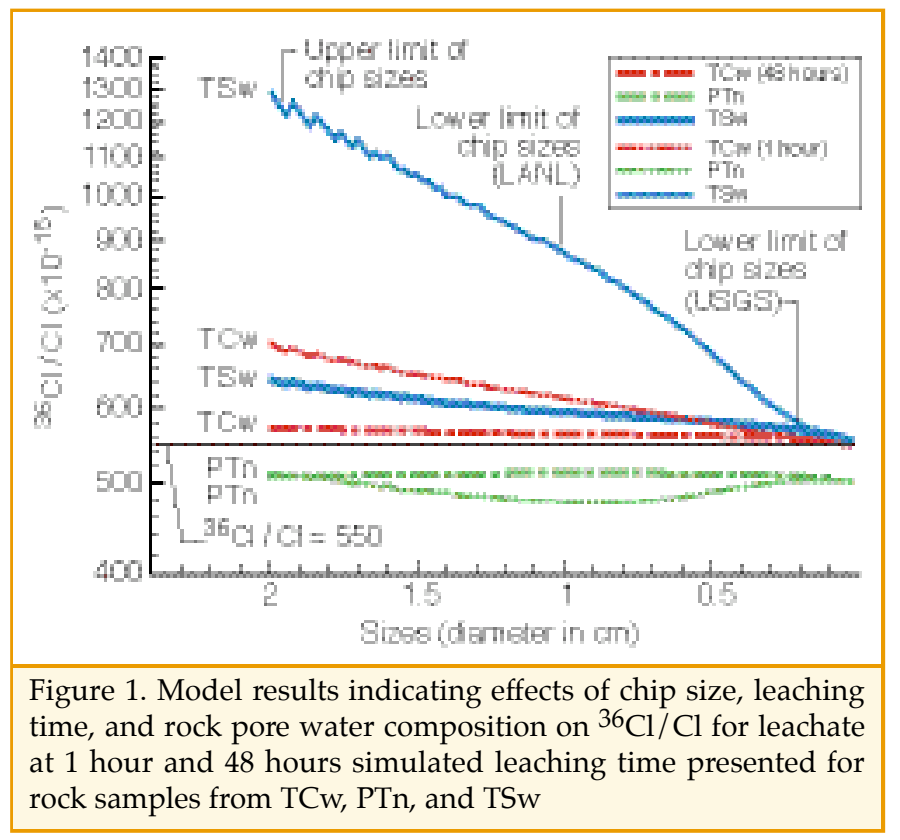

\section{APPROACH}

In this work, we developed both a conceptual and numerical model (as well as a mathematical solution) for leaching processes. First, an analytical solution for diffusion of $\mathrm{Cl}$ and ${ }^{36} \mathrm{Cl}$ in composite media (rock matrix and water) was derived to accommodate variable diffusivity. Second, a leaching model was developed to take into account various $\mathrm{Cl}$ sources, including matrix pore water and less-easily-leached components (isolated fluid inclusion and mineral boundary salts). Third, the leaching model was applied to samples from Yucca Mountain stratigraphic units-the Tiva Canyon welded tuff (TCw), the Paintbrush nonwelded tuff (PTn), and the Topopah Spring welded tuff (TSw).

\section{ACCOMPLISHMENTS}

Our models successfully examined the role of sample leaching in the ${ }^{36} \mathrm{Cl}$ studies at Yucca Mountain. They simulated the effect of leaching time, sample size, and active and passive leaching. Model results show that the probability of detecting a ${ }^{36} \mathrm{Cl} / \mathrm{Cl}$ bomb-pulse signal was severely diminished at longer leaching times and with smaller rock fragment sizes (Figure 1). Bomb-pulse signals in the TSw welded tuff were the least suppressed, because of lower concentrations in the pore water. However, bomb-pulse signals at TCw and PTn were "masked" (had limited detectability) because of higher matrix-pore-water $\mathrm{Cl}$ concentrations. Leaching times of 1 to 10 hours were more likely to reveal detectable bomb-pulse signals (if they were present). Bomb-pulse $36 \mathrm{Cl} / \mathrm{Cl}$ ratios were also more likely to be obtained when pore-water $\mathrm{Cl}$ concentrations were initially low.

\section{SIGNIFICANCE OF FINDINGS}

These research results demonstrate the effects of various factors in leaching experiments and provide much-needed theoretical guidelines for leaching protocols of ${ }^{36} \mathrm{Cl}$ study. The findings are expected to shed a great deal of light on the reproducibility debate in current ${ }^{36} \mathrm{Cl}$ validation studies.

\section{RELATED PUBLICATIONS}

Lu, G., E. L. Sonnenthal, and G. S. Bodvarsson, Implications of halide leaching on chlorine-36 studies at Yucca Mountain, Nevada. Water Resources Research, 2003 (submitted).

\section{ACKNOWLEDGMENTS}

This work was supported by the Director, Office of Civilian Radioactive Waste Management, U.S. Department of Energy, through Memorandum Purchase Order EA9013MC5X between Bechtel SAIC Company, LLC, and the Ernest Orlando Lawrence Berkeley National Laboratory (Berkeley Lab). The support is provided to Berkeley Lab through the U.S. Department of Energy Contract No. DE-AC03-76SF00098. 


\title{
3-D Studies of Mountain-Scale Radionuclide Transport in THE Unsaturated Zone at Yucca Mountain, Nevada
}

\author{
George J. Moridis, Yonkoo Seol, and Yu-Shu Wu \\ Contact: George Moridis, 510/486-4746, gjmoridis@lbl.gov
}

\section{RESEARCH OBJECTIVES}

The U.S. Department of Energy is actively investigating the technical feasibility of permanently disposing high-level nuclear waste in an appropriate repository proposed for the unsaturated zone (UZ) at Yucca Mountain, Nevada. The objectives of this study are to evaluate the transport of radioactive solutes and colloids under ambient conditions, from the proposed repository horizon to the water table, and to determine processes and geohydrological features that significantly affect radionuclide transport.

\section{APPROACH}

The radionuclide transport model considers the site hydrology and spatial distribution effects of hydraulic and transport properties in the Yucca Mountain subsurface. The migration and retardation of radionuclides are analyzed using EOS9nT (Moridis et al., 1999) and T2R3D (Wu et al., 1996), both of which are members of the TOUGH2 family of codes (Pruess, 1991). These models can

tuffs. Diffusion from the fractures into, and subsequent sorption onto, the matrix are the main retardation processes. Arrival times at the water table increase with the sorption dis-

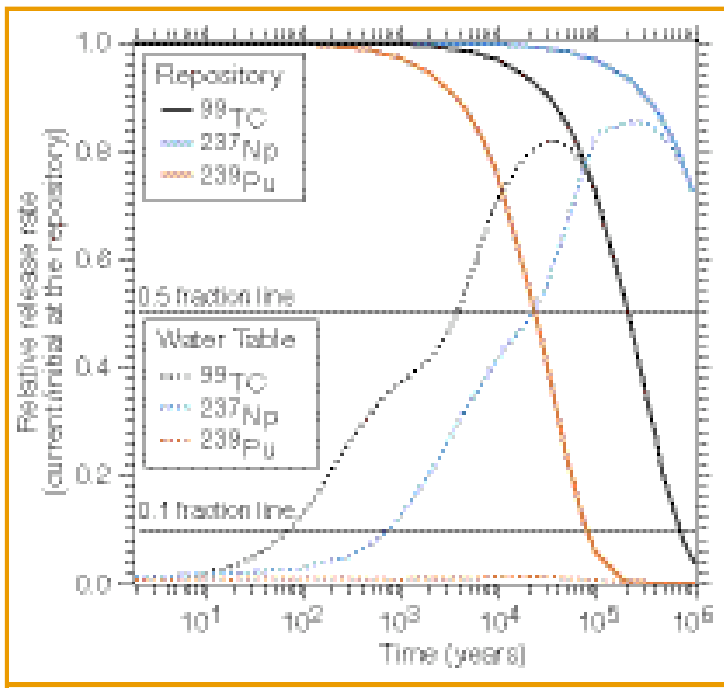

Figure 1. Normalized release rate of ${ }^{99} \mathrm{Tc},{ }^{237} \mathrm{~Np}$ and ${ }^{239} \mathrm{Pu}$ from the repository horizon (for continuous release and mean present-day infiltration) and their subsequent arrival times at the water table tribution coefficients of the various species. For certain radionuclides such as ${ }^{239} \mathrm{Pu}$, the contributions of the decay daughters to the total arrivals at the water table can be very significant. Changes in future climatic conditions can have a significant effect on transport, since increasing infiltration leads to faster transport to the water table. The transport of colloids is strongly influenced by their size (as it affects diffusion into the matrix, straining at hydrogeologic unit interfaces, and transport velocity).

\section{SIGNIFICANCE OF FINDINGS}

Based on these studies, cumulative breakthrough curves for the radionuclides of interest were obtained. Note that because of the extremely conserdescribe the complex processes of flow and transport in the Yucca Mountain subsurface, including advection, diffusion, hydrodynamic dispersion, sorption, radioactive decay and tracking of daughters, colloid straining and physical-chemical filtration, and colloid-assisted solute transport. The mountain-scale grid for these 3-D studies of UZ transport consisted of 245,000 elements. A dual-permeability conceptualization was used to describe the fracture-matrix system in the UZ. The radioactive species were released directly into the fractures of the elements corresponding to the proposed repository. We investigated (a) instantaneous release, describing a single catastrophic event, and (b) continuous release, describing a plausible long-term scenario involving the breaching of the waste-containing canisters and the slow discharge of their contents. A total of eleven instantaneously released radionuclides were investigated, in addition to continuously released radioactive species that included four parents, two chains, and four colloids.

\section{RESULTS}

The results of the study indicate that the most important factors affecting radionuclide transport are the subsurface geology and site hydrology-i.e., the presence of faults (they dominate and control transport), fractures (the main migration pathways), and the relative distribution of zeolitic and vitric vative approach involved in this study, these curves describe the lower bound of arrival times at the water table.

\section{RELATED PUBLICATIONS}

Moridis, G.J., Y.- S. Wu, and K. Pruess, EOS9nT: A TOUGH2 module for the simulation of flow and solute/colloid transport. Berkeley Lab Report LBNL-42351, Berkeley, California, 1999.

Moridis, G.J., Y. Seol, and Y.-S. Wu, Modeling studies of mountainscale radionuclide transport in the unsaturated zone at Yucca Mountain, Nevada. Proceedings of the TOUGH Symposium 2003, May 12-14, 2003; Berkeley Lab Report LBNL-52567, Berkeley, California, 2003.

Wu, Y.-S., C.F. Ahlers, P. Fraser, A. Simmons, and K. Pruess, Software qualification of selected TOUGH2 modules, Berkeley Lab Report LBNL-39490, Berkeley, California, 1996.

\section{ACKNOWLEDGMENTS}

This work was supported by the Director, Office of Civilian Radioactive Waste Management, U.S. Department of Energy, through Memorandum Purchase Order EA9013MC5X between Bechtel SAIC Company, LLC, and the Ernest Orlando Lawrence Berkeley National Laboratory (Berkeley Lab). The support is provided to Berkeley Lab through the U.S. Department of Energy Contract No. DE-AC03-76SF00098.

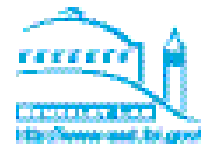




\title{
A Modeling Study of Flow Diversion AND FOCUSING IN UNSATURATED FRACTURED ROCKS
}

\author{
Lehua Pan, Yu-Shu Wu, and Keni Zhang \\ Contact: Lehua Pan, 510/495-2360, lpan@lbl.gov
}

\section{RESEARCH OBJECTIVES}

In a complex subsurface system with multiple layers, faults, and spatially varied alteration of rock properties, flow diversion and focusing are natural phenomena. However, quantitatively describing the magnitude and the spatial patterns of flow diversion and focusing is a challenge for both measurements and modeling. The objective of this study is to develop a systematic modeling approach, taking the Yucca Mountain unsaturated zone (UZ) as an example, to analyze and describe flow diversion and focusing in unsaturated fractured rocks, under ambient steady-state flow conditions.

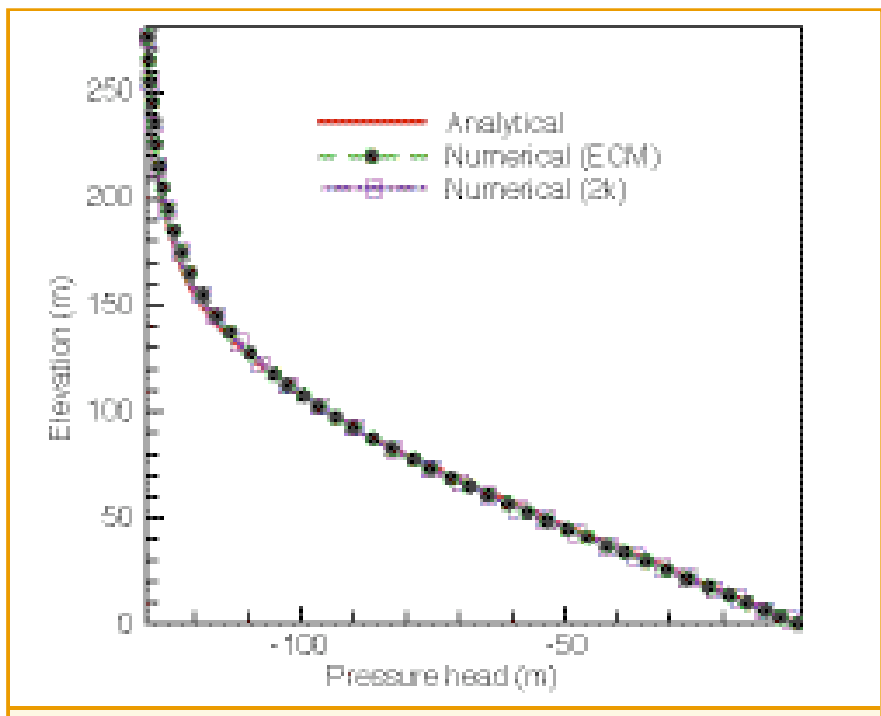

Figure 1. Comparison of pressure-head profiles in the PTn23 layer, calculated using analytical and numerical solutions

\section{APPROACH}

We first approximated the fractured tuffs of Yucca Mountain using the effective continuum model (ECM). For this, we used analytical solutions to identify the critical layers and layer interfaces in terms of flow diversion and to estimate the potential magnitudes of such diversion at typical locations. Then, we approximated the fractured tuffs as dual-permeability media and developed a large 3-D numerical grid (over one million gridblocks) to incorporate the site-specific data (including the knowledge obtained from the analytical solutions). The parallelcomputing version of TOUGH2 was used to perform the numerical modeling, and the 3-D numerical modeling results were partly verified with field measurements.

\section{ACCOMPLISHMENTS}

We extended the analytical solutions of capillary barriers derived by Warrick et al. (1997) for porous media to the case of fractured media (under the ECM approximation) represented by specific geological units (and layers within those units) at Yucca Mountain. The analytical solutions show that, under present-day ambient conditions, capillary diversion occurs primarily within nonwelded units (i.e., units where matrix flow is dominant), like the Paintbrush nonwelded tuff (PTn) unit at Yucca Mountain. Among the critical rock layers within that unit, PTn21, PTn23, and vitric Calico Hills-1 (CH1) conduct the most down-dip diversionary flow, whereas PTn22, PTn24, and vitric CH2 act as capillary barriers to the downward percolation flux. Under dry, ambient conditions, the analytical solutions are good approximations of the capillary barrier system of fractured tuffs (Figure 1).

The 3-D numerical flow model developed in this study is (up to now) the most detailed site-scale model of the Yucca Mountain UZ over several decades of site study. The numerical simulations show that, although the net infiltration rate at the surface depends on various factors, including topography, soil thickness, vegetation, and rock type, the percolation flow patterns are considerably modified during transit through the thick unsaturated zone and are primarily controlled by a few critical rock layers and faults.

\section{SIGNIFICANCE OF FINDINGS}

The results show that:

1. The analysis that combines analytical solutions with largescale numerical modeling is effective for analyzing and describing flow diversion and focusing in unsaturated rock.

2. Large-scale lateral flow could take place in the UZ at Yucca Mountain under ambient conditions. The combined effects of horizontal and vertical barriers result in generally reduced percolation flow through the proposed repository horizon, but also in flow focused downward along penetrating faults.

3. Because lateral flow occurs within a few layers and often turns into focused vertical flow via faults in the models, more detailed information about them is critical to fully understand and describe flow diversion and focusing in the UZ.

\section{RELATED PUBLICATION}

Pan, L., Y.-S. Wu, and K. Zhang, A modeling study of flow diversion and focusing in unsaturated fractured rocks. Vadose Zone Journal, 2002 (submitted); Berkeley Lab Report LBNL49274, 2002.

\section{ACKNOWLEDGMENTS}

This work was supported by the Director, Office of Civilian Radioactive Waste Management, U.S. Department of Energy, through Memorandum Purchase Order EA9013MC5X between Bechtel SAIC Company, LLC, and the Ernest Orlando Lawrence Berkeley National Laboratory (Berkeley Lab). The support is provided to Berkeley Lab through the U.S. Department of Energy under Contract No. DE-AC03-76SF00098. 


\title{
NEW IMPROVEMENTS TO WINGRIDDER: AN INTERACTIVE GRID GENERATOR FOR TOUGH2
}

\author{
Lehua Pan \\ Contact: 510/495-2360, 1pan@lbl.gov
}

\section{RESEARCH OBJECTIVES}

The objective of this study is to enhance the WinGridder software program, which acts as a grid generator for TOUGH2, a software program used worldwide as a simulation code for multiphase, multicomponent flow and heat transfer. The main objectives are (1) to add the capability of handling a repository with multiple subregions and specified drifts, (2) to incorporate an interpolation method (instead of picking the nearest point) in calculating the geological data from a given digital geological model, (3) to add the capability of generating multiple continuum grids (MINC grids), and (4) to enhance searching and other capabilities.

\section{APPROACH}

The following approaches were adopted:

1. Taking advantage of the object-oriented-programming used in WinGridder coding, we modified the REPOSITO object to include subobjects, labeled REGIONS and DRIFTS, to represent subregions and emplacement drifts. In this way, WinGridder could handle a repository with multiple subregions, with each region having specified drifts. As a byproduct, additional grid cells representing any user-specified drifts could be embedded into an existing 3-D grid.

2. A modified bilinear interpolation method (allowing for special treatment in the neighborhood of a fault) has been implemented in the member function of the LAYER object, which calculates the geological data (e.g., layer thickness or elevation).

3. The MINC grid generated by WinGridder is similar in principle to that of the dual-continuum grid. The difference is that the matrix cell in a dual-continuum grid is split into N (a number specified by the user) connected subcells in the corresponding MINC grid. The fracture configurations (e.g., fracture porosity, fracture-matrix interface area per rock volume, fracture aperture and spacing) are provided by the user in a text file. (This functionality is only available in WinGridder V2.1 (beta)).

4. The Save Submesh functionality has been enhanced to save any user-selected subgrid as an independent grid project. Many other tools have been added.

\section{ACCOMPLISHMENTS}

WinGridder V2.0 and V2.1 (beta) have been developed, and WinGridder V2.0 has been qualified for the Yucca Mountain
Project. V2.0 has been successfully used to design and generate 1-D, 2-D, and 3-D meshes for numerical modeling of flow and transport at Yucca Mountain and at the Berkeley Lab site.

\section{SIGNIFICANCE OF FINDINGS}

The main advantages of this grid-generation software are its user-friendly graphical interfaces, flexible grid-design capabilities, efficient grid generation, and powerful searching and postprocessing capability, especially for large size grids (e.g., grids composed of a million grid cells or more). This software has been increasingly applied around the world (so far, multiple users in the U.S., Asia, and Europe).

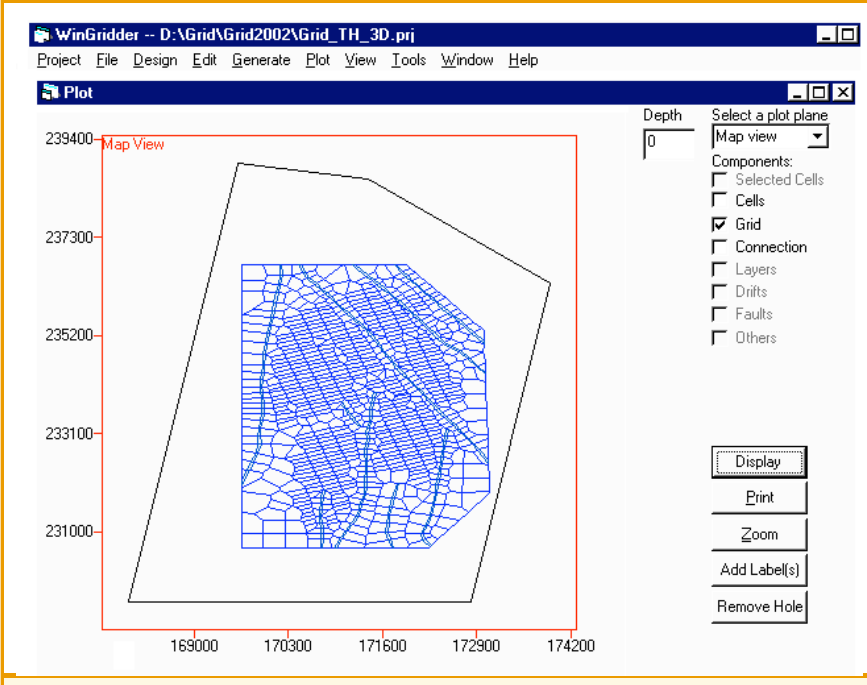

Figure 1. The main window of the WinGridder.

\section{RELATED PUBLICATION}

Pan, L., WinGridder-An interactive Grid Generator for TOUGH2. Proceedings of the TOUGH Symposium 2003. Berkeley, California, May 12-14, 2003; Berkeley Lab Report, LBNL-52422, 2003.

\section{ACKNOWLEDGMENTS}

This work was supported by the Director, Office of Civilian Radioactive Waste Management, U.S. Department of Energy, through Memorandum Purchase Order EA9013MC5X between Bechtel SAIC Company, LLC, and the Ernest Orlando Lawrence Berkeley National Laboratory (Berkeley Lab). The support is provided to Berkeley Lab through the U.S. Department of Energy Contract No. DE-AC03-76SF00098.

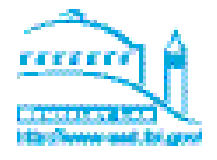




\section{Coupled Thermal-Hydrological-Mechanical Analysis with TOUGH-FLAC Jonny Rutqvist and Chin-Fu Tsang \\ Contact: Jonny Rutgvist, 510/486-5432, jrutqvist@lbl.gov}

\section{RESEARCH OBJECTIVES}

The objective of this work is to develop a numerical simulator for coupled thermal-hydrological-mechanical (THM) analysis of complex geological media under multiphase flow conditions, with possible coupling to reactive transport modeling.

\section{APPROACH}

Two existing computer codes-TOUGH2 and FLAC-3Dwere joined to develop a numerical simulator (named TOUGH-FLAC) for analysis of coupled THM processes in complex geological media under multiphase flow conditions. Both codes are well established and widely used in their respective fields. The TOUGH2 code is designed for geohydrological analysis of multiphase, multicomponent fluid flow and heat transport, whereas the FLAC-3D code is designed for rock and soil mechanics with thermomechanical and hydromechanical interactions. The two codes are executed on two separate meshes and joined with two coupling modules (Figure 1). A set of coupling modules can be exchanged with another set, depending on the type of rock and the studied problem.

\section{ACCOMPLISHMENTS}

A set of TOUGH-FLAC coupling modules has been developed for various applications. Recent applications of the TOUGH-FLAC simulator include:

- A study of caprock hydromechanical changes associated with $\mathrm{CO}_{2}$ injection into a brine formation

- A study of the impact of coupled THM processes on the performance of the proposed nuclear waste repository at Yucca Mountain, Nevada, including drift-scale and mountain-scale coupled THM processes

- Coupled THM analysis of the Yucca Mountain Drift Scale Test

- Analysis of surface uplift during volcanic episodes

- A study of fault slip during underground injection $\mathrm{CO}_{2}$ (ongoing)

\section{SIGNIFICANCE OF FINDINGS}

A coupled THM numerical simulator for multiphase flow conditions has been successfully constructed and its use demonstrated. The results from these simulations will be important for the performance assessments of geological disposal of $\mathrm{CO}_{2}$ and spent nuclear fuel, and are also valuable in other applications (such as geothermal energy extraction and oil and gas reservoir engineering).

\section{RELATED PUBLICATIONS}

Rutqvist, J., Y.-S. Wu, C.-F. Tsang, and G. Bodvarsson, A modeling approach for analysis of coupled multi-phase fluid flow, heat transfer, and deformation in fractured porous rock. Int. J. Rock Mech. Min. Sci., 39, 429-442, 2002.

Rutqvist, J., and C.-F. Tsang, A study of caprock hydromechanical changes associated with $\mathrm{CO}_{2}$ injection into a brine aquifer. Environmental Geology, 42, 296-305, 2002.

Rutqvist, J., and C.-F. Tsang, Analysis of thermal-hydrologicalmechanical behavior near an emplacement drift at Yucca Mountain. J. Contaminant Hydrology, 62-63,1-16, 2003.

\section{ACKNOWLEDGMENTS}

This work was jointly supported by the Director, Office of Science, Office of Basic Energy Sciences, Division of Chemical Sciences, Geosciences and Biological Sciences, of the U.S. Department of Energy, under Contract No. DE-AC03-76SF00098; and by the Director, Office of Civilian Radioactive Waste Management, U.S. Department of Energy, through Memorandum Purchase Order EA9013MC5X between Bechtel SAIC Company, LLC, and the Ernest Orlando Lawrence Berkeley National Laboratory (Berkeley Lab). The support is provided to Berkeley Lab through the U.S. Department of Energy Contract No. DE-AC03-76SF00098.

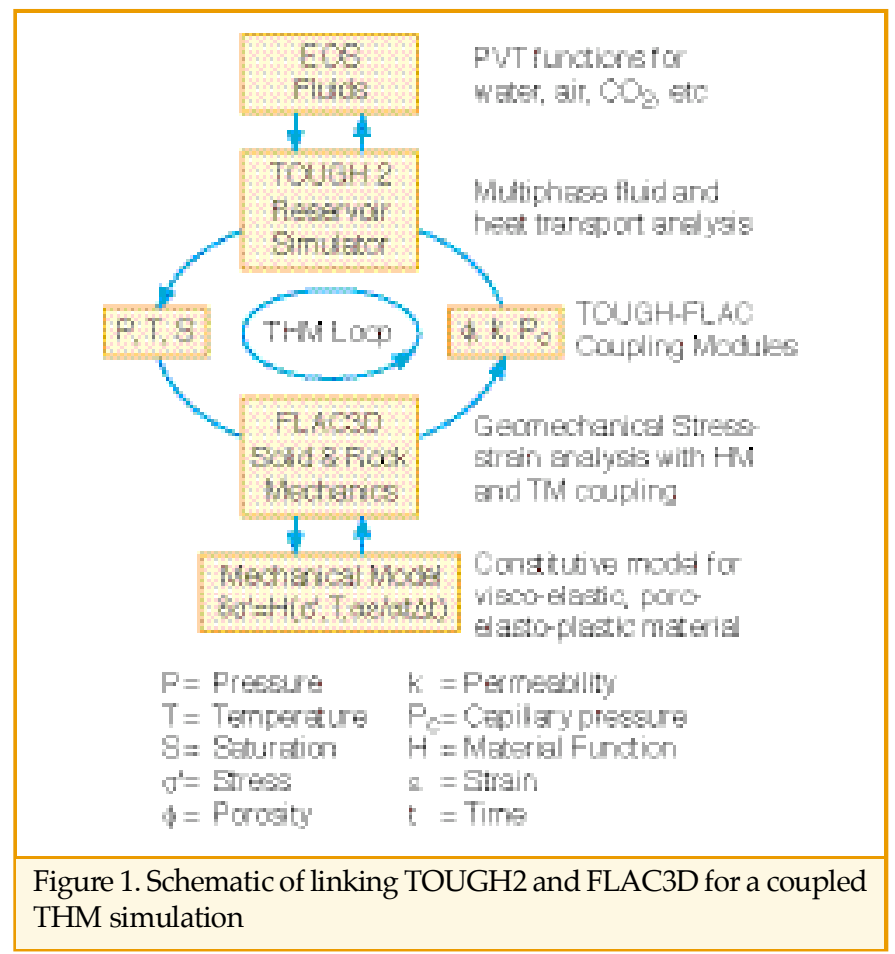

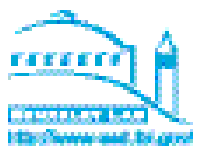




\section{Flow and Transport Through a Fault Embedded in Fractured Rock Rohit Salve, Hui-Hai Liu, Paul Cook, Atlantis Czarnomski, and Joseph S.Y. Wang Contact: Rohit Salve, 510/486-6416, r_salve@lbl.gov}

\section{RESEARCH OBJECTIVES}

The overall objective of this investigation is to study flow and transport through a $20 \mathrm{~m}$ vertical section of a fault located in the fractured welded tuff of the Topopah Spring welded tuff unit at Yucca Mountain, Nevada (Figure 1), the proposed site for a high-level nuclear waste geologic repository.

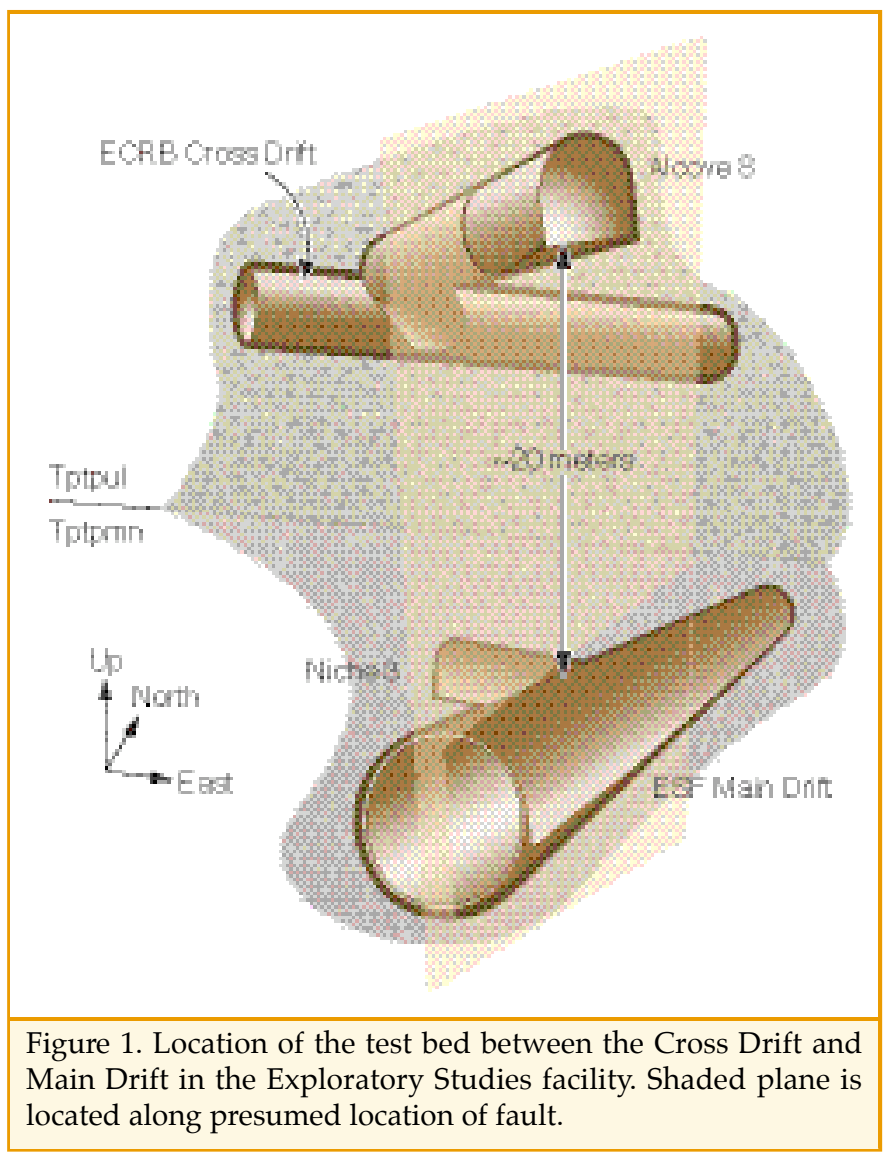

\section{APPROACH}

This investigation involved the release of approximately 82,000 liters of water along a horizontal section of the fault, under ponded conditions over a period of thirteen months and then under reduced fluxes for another six months. When quasi-steady-state seepage was observed at the lower end of the test bed, two tracers with different molecular diffusion coefficients were introduced into the ponded water infiltrating the fault. After tracer-laced water had been released into the fault, more tracer-free water was released. As water was released into the fault, changes in moisture content were monitored in the formation, while a large cavity excavated below the test bed was visually inspected for seepage. Water percolating through the fault and into the excavated cavity was continuously monitored with an automated, remotely accessed water collection system.

\section{ACCOMPLISHMENTS}

We observed that water (introduced along the fault) followed the fault as the primary vertical flow path, while the adjacent fractured matrix served to move water laterally and vertically. Unlike primary flow paths along the fault, flow was not persistent along the secondary flow paths under similar boundary conditions. The field experiment showed the existence of a capillary barrier and confirmed the dynamic nature of flow through the fault. Further, observations of bromide concentrations in seepage water during the early stages of the experiment, and of bromide and pentafluoride benzoic acid (PFBA) concentrations in the seepage water, indicate the significant influence of matrix diffusion on transport through a fault embedded in fractured, nonwelded rock.

\section{SIGNIFICANCE OF FINDINGS}

Field tests involving both flow and transport within a fault under unsaturated conditions are rare. This test has provided insights into mechanisms that come into play when water with tracers is introduced into a fault located in this unsaturated environment. This information is being used to develop conceptual models of flow and transport through Yucca Mountain.

\section{RELATED PUBLICATIONS}

Salve, R., D. Hudson, H. H. Liu, and J. S. Y. Wang, Development of a wet plume following liquid release along a fault. Water Resources Research, 2003 (submitted); Berkeley Lab Report LBNL-52711, 2003.

Liu, H. H., R. Salve, J. S. Y. Wang , G. S. Bodvarsson, and D. Hudson, Field investigation into unsaturated flow and transport in a fault: Model analysis. Journal of Contaminant Hydrology, 2003 (submitted); Berkeley Lab Report LBNL52823, 2003.

Salve, R., A passive-discrete water sampler for monitoring seepage. Groundwater, 2003 (in press); Berkeley Lab Report LBNL-51203, 2002.

\section{ACKNOWLEDGMENTS}

This work was supported by the Director, Office of Civilian Radioactive Waste Management, U.S. Department of Energy, through Memorandum Purchase Order EA9013MC5X between Bechtel SAIC Company, LLC, and the Ernest Orlando Lawrence Berkeley National Laboratory (Berkeley Lab). The support is provided to Berkeley Lab through the U.S. Department of Energy Contract No. DE-AC0376SF00098.

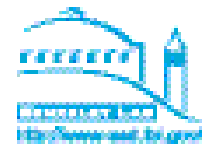




\section{A Numerical Study of Unsaturated Flow and Transport Through a Fractured MeTER-SIZED ROCK BLOCK}

Yongkoo Seol, Timothy J. Kneafsey, Kazumasa Ito, and Stefan Finsterle Contact: Yongkoo Seol, 510/486-4806, yseol@lbl.gov

\section{RESEARCH OBJECTIVES}

Our work involves study of a meter-sized block of fractured rock to obtain experimental evidence in support of the active fracture concept (AFC). This concept assumes that only a portion of fractures in a connected unsaturated fracture network contributes to liquid water flow. Prior to this experimental evaluation, however, we needed to perform a preliminary numerical simulation in which we incorporated the AFC into a dual-continuum model (DCM) to create an enhanced DCM. Through this integration, we intend to identify the most effective way to quantify the AFC parameter in the laboratory.

\section{APPROACH}

The DCM was developed and then compared to a discrete fracture network model (DFNM) representing the meter-sized rock block, to see whether the DCM could accurately simulate flow and transport in the block. The DFNM, which contained an artificially generated 2-D fracture network, is based on statistical information from field observations at Yucca Mountain, Nevada (including fracture density, ranges of aperture and trace length, distribution of orientation, flow rate, and tracer transport data). As a preliminary step, DCM results obtained without incorporating the AFC were calibrated against the DFNM data. The AFC model was then integrated into the DCM to examine whether adding the AFC model could improve DCM predictions of discrete flow behavior.

\section{ACCOMPLISHMENTS}

At transient states, the DFNM showed distinctive preferential flow patterns, such as stepwise increases in water effluent flow rates and high water saturation along predominant flow paths (i.e., fractures). The DCM breakthrough curves did not initially capture the DFNM results because of their conceptual differences. But after the incorporation of the AFC, DCM predictions for flow-rate breakthrough curves were significantly improved. The flow rates from the AFC-enhanced DCM were calibrated against those of the DFNM to estimate the effect of including the AFC parameter.

\section{SIGNIFICANCE OF FINDINGS}

These numerical simulations imply that laboratory experiments incorporating a transient state in the flow field would provide a more sensitive approach for estimating the AFC parameter than steady-state experiments. Additionally, water breakthrough curves at low (rather than high) injection rates may be more appropriate for laboratory tests to determine the AFC parameter. The results also suggest that the DCM-AFC approach improves the pre- diction of unsaturated flow and transport, but may not be well suited for the current two-dimensional meter-scale model. Three-dimensional studies with detailed characterization of fracture networks have been proposed for more accurate estimation of the AFC parameter.

\section{RELATED PUBLICATIONS}

Seol, Y., T.J. Kneafsey, K. Ito, and S. Finsterle, Simulation of unsaturated flow and transport through a fractured metersized model block using the continuum approach. Water Resources Research, 2003 (submitted); Berkeley Lab Report LBNL-52818, 2003.

Ito, K., and Y. Seol, A 3-D discrete fracture network generator to examine fracture-matrix interaction using TOUGH2. Proceedings of the TOUGH Symposium 2003, Berkeley, California, May 12-14, 2003; Berkeley Lab Report LBNL52465, 2003.

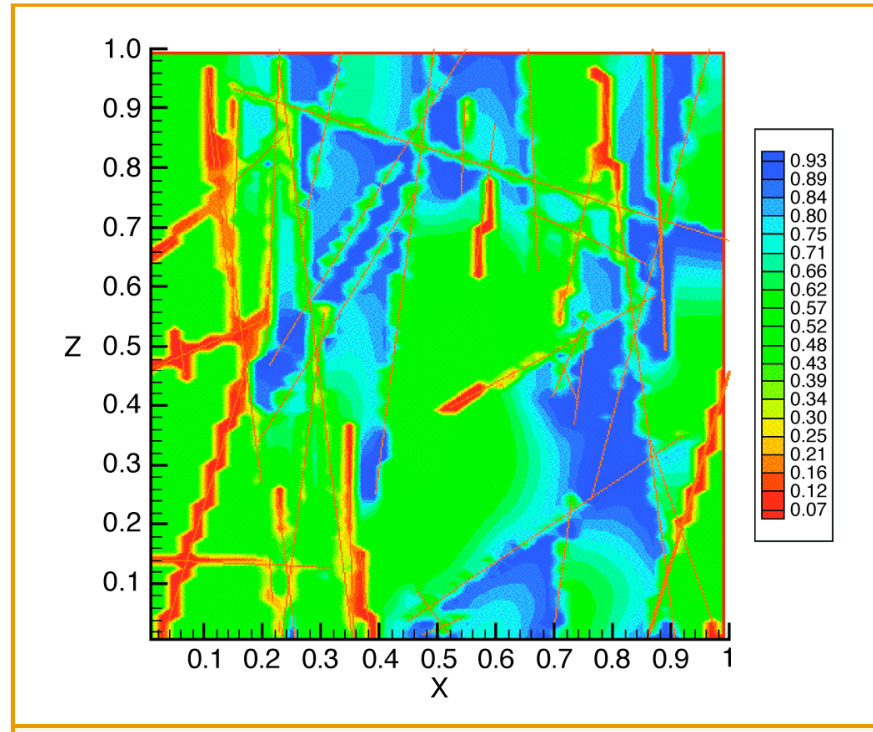

Figure 1. Distribution of water saturation in the DFNM, showing preferential flow patterns developed along major fractures in the transient state of the flow domain.

\section{ACKNOWLEDGMENTS}

This work was supported by the Director, Office of Civilian Radioactive Waste Management, U.S. Department of Energy, through Memorandum Purchase Order EA9013MC5X between Bechtel SAIC Company, LLC, and Berkeley Lab. The support is provided to Berkeley Lab through the U.S. Department of Energy Contract No. DEAC03-76SF00098.

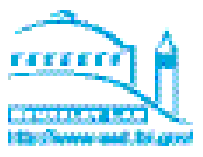




\title{
EFFECTS OF WATER-ROCK INTERACTION OF UNSATURATED FLOW in Heterogeneous Fractured Rock
}

\author{
Eric Sonnenthal, Nicolas Spycher, Charles Haukwa, and Tianfu Xu \\ Contact: Eric Sonnenthal, (510) 486-5866, elsonnenthal@lbl.gov
}

\section{RESEARCH OBJECTIVES}

Evaluation of coupled thermal, hydrological, and chemical processes associated with the proposed high-level nuclear waste repository at Yucca Mountain, Nevada, requires consideration of the effects of permeability heterogeneity on reaction-transport processes. The primary objective of this work is to examine the relationship of fracture flow and fracturematrix interaction to permeability and capillary pressu re modification during mineral precipitation and dissolution in unsaturated fractured tuff under boiling conditions.

\section{APPROACH}

In this analysis, we relate the reactive surface area to the fracture-matrix interaction area, based on a modified form of the Active Fracture Model for flow in unsaturated fractured rock. In most experimental and natural systems, permeability reductions to values near zero occur at porosities significantly greater than zero. This generally is the result of mineral precipitation preferentially closing the narrower interconnecting apertures. The hydraulic aperture, calculated from the fracture spacing and permeability (as determined through air-permeability measurements) assuming a cubic law relation, was used to develop a much stronger relationship between permeability and porosity. Based on air-permeability meas-

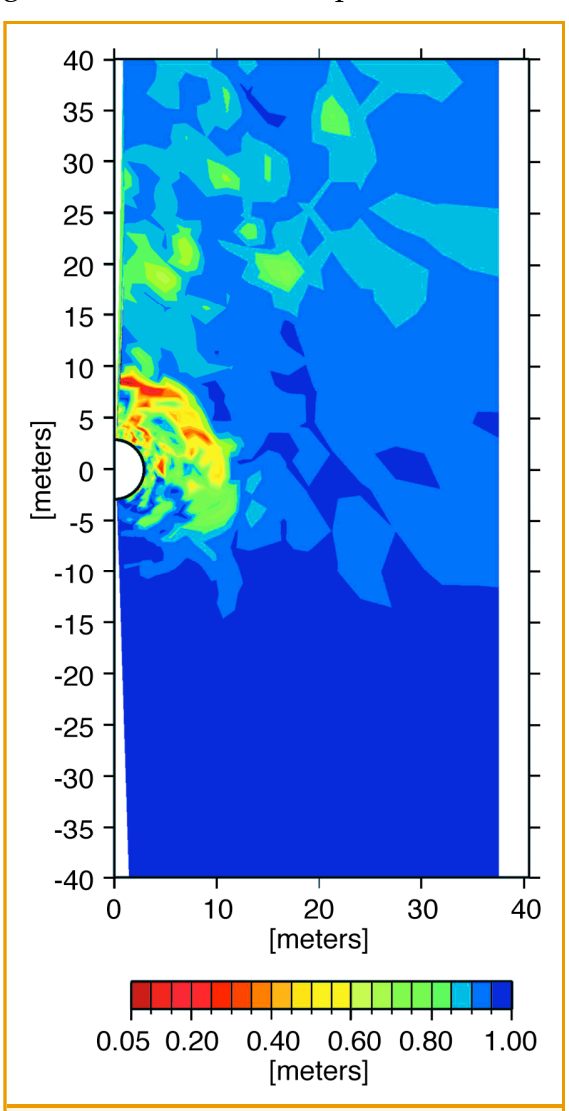

Figure 1. Ratio of fracture permeability at 20,000 years to the initial value tions and evaporative concentration. The net effect of these processes over 20,000 years is a reduction in permeability that is most pronounced in areas of initially low permeability but high liquid fluxes and saturation (Figure 1). The distribution of permeability changes is, however, a combined effect of different minerals precipitating in varying patterns. Amorphous silica, calcite, and gypsum precipitate by evaporative concentration at the boiling front, resulting in a narrow zone of reduced permeability. Calcite also precipitates by degassing of $\mathrm{CO}_{2}$ and heating of percolating fracture water from the surface, thus leading to abundant precipitation well above the boiling zone.

\section{SIGNIFICANCE OF FINDINGS}

Modeling of water-rock interaction in boiling, unsaturated, heterogeneous fractured rock exemplifies the strong feed-backs between water-rock interaction and unsaturated flow. In particular, increased liquid saturation, as a result of higher capillary pressures in smaller aperture fractures, leads to increased rates of reaction and further reductions in permeability. This work indicates that the evolution of preferential flow paths in unsaturated systems undergoing water-rock interaction may progress from the smaller features to the larger ones, in contrast to saturated systems that tend to urements, 2-D heterogeneous fracture permeability fields were generated having a range of four orders of magnitude. Reaction-transport simulations were performed using TOUGHREACT, which included coupling between heat, water, and vapor flow; aqueous and gaseous species transport; and kinetic and equilibrium mineral-water reactions. Changes in unsaturated flow take place through coupling of porosity, permeability, and capillary pressure to mineral precipitation/dissolution.

\section{ACCOMPLISHMENTS}

Simulations demonstrated that in addition to thermodynamic and geochemical parameters, the extent of mineralwater reaction is a function of the fluid flux and the liquid saturation. Liquid saturations, which control reactive surface areas, and fluxes are strongly tied to the permeability and capillary properties. At the edge of the boiling front, mineral precipitation is driven by a combination of mineral-water-reac- start with the most permeable features.

\section{RELATED PUBLICATION}

Sonnenthal, E., N. Spycher, and T. Xu, Linking reaction, transport, and hydrological parameters in unsaturated fractured rock: TOUGHREACT implementation and application. Proceedings of the TOUGH Symposium, Berkeley, California, May 12-14, 2003.

\section{ACKNOWLEDGMENTS}

This work was supported by the Director, Office of Civilian Radioactive Waste Management, U.S. Department of Energy, through Memorandum Purchase Order EA9013MC5X between Bechtel SAIC Company, LLC, and the Ernest Orlando Lawrence Berkeley National Laboratory (Berkeley Lab). The support is provided to Berkeley Lab through the U.S. Department of Energy Contract No. DE-AC03-76SF00098.

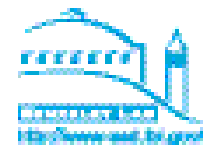




\title{
Yucca Mountain Heater Test Cooling Phase
}

\author{
Yvonne Tsang, Sumit Mukhopadhyay, Jonny Rutqvist, Eric Sonnenthal, and Nicolas Spycher \\ Contact: Yvonne Tsang, 510/486-7047, ytsang@lbl.gov
}

\section{RESEARCH OBJECTIVES}

As part of a multilaboratory team, Berkeley Lab is conducting a large-scale in situ thermal test, the Drift Scale Test (DST), in an underg round facility at Yucca Mountain, Nevada, the site for a proposed national high-level nuclear waste repository. The test is presently in the second year of the natural cooling phase following four years of heating, during which an approximate heating rate of $185 \mathrm{~kW}$ was supplied by nine canister heaters (placed in a drift $47.5 \mathrm{~m}$ in length and $5 \mathrm{~m}$ in diameter) and fifty 11 meter long rod heaters installed in boreholes drilled perpendicular to the drift. The heating thus provided set in motion coupled thermal (T), hydrological $(\mathrm{H})$, chemical $(\mathrm{C})$, and mechanical $(\mathrm{M})$ processes of the type that would be generated from heating in the proposed repository during its postclosure performance period. The objective of this test is to gain an in-depth understanding of THMC coupled processes within fractured welded volcanic tuff situated above the water table.

\section{APPROACH}

The DST has involved a close integration of measurements and numerical modeling. Thousands of sensors installed in nearly 100

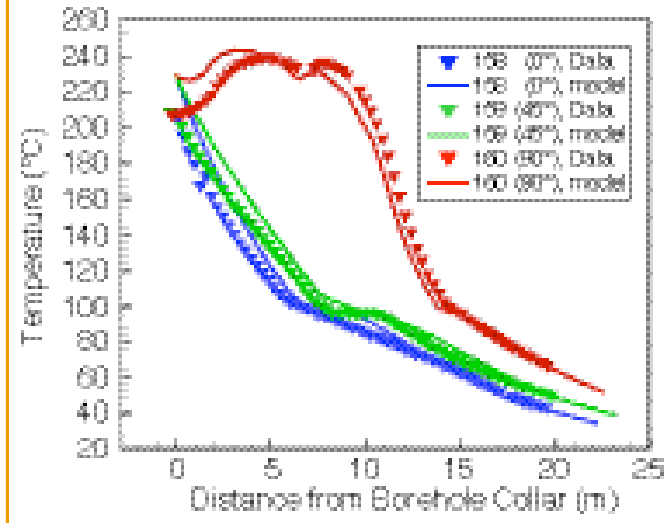

Figure 1. Simulated and measured temperature profiles in boreholes 158, 159, and 160, at (a) 48 months of heating and (b) 6 months of cooling boreholes, within a rock block of $60 \times 60 \times 60 \mathrm{~m}^{3}$, continuously monitor the temperature, relative humidity, and mechanical displacement. Geophysical and air-permeability measurements have been performed at quarterly intervals to track moisture redistribution resulting from boiling, vapor transport, and condensation. Water and gas samples have also been collected periodically from the test block for chemical and isotopic analyses. In addition, $\mathrm{TH}, \mathrm{THC}$, and $\mathrm{THM}$ processes have been simulated using numerical models that realistically incorporate the threedimensional test configuration and the complex multiple processes. Model predictions have been compared to the aforementioned extensive set of measured data.

\section{ACCOMPLISHMENTS}

Manifestations of coupled THMC processes in the rich set of measured data agree well with TH, THC, and THM model predictions. During the heating phase, expanding zones of reduced liquid saturation in the rock matrix around the heaters predicted by TH simulations were consistent with zones of drying shown in neutron logging data, crosshole radar tomograms, and electrical resistivity tomography data. During (the ongoing) cooling, the geophysical data has indicated slow rewetting at the edge of the drying zone, consistent with model predictions. Simulated fracture liquid-saturation has indicated that little water is likely to be collected during the cooling phase, as has been the case. Figure 1 shows the simulated and measured temperatures at the end of the heating phase and after six months of cooling in three boreholes. The plateau at the nominal boiling temperature of $\sim 97^{\circ} \mathrm{C}$ indicates a liquid and vapor two-phase zone that is a good candidate for water collection. Note the disappearance of these measurements confirm modeled predictions of $\mathrm{TH}$ processes two-phase zones during the cooling phase. Air-permeability

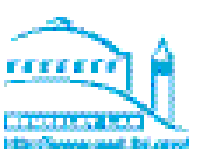

(drying and wetting in fractures) and THM processes (closing and opening of fractures).

\section{SIGNIFICANCE OF FINDINGS}

A close integration of measurements and sophisticated simulations carried out in this large-scale and long-term test has contributed much toward the understanding of THMC coupled processes in fractured rock of the unsaturated zone.

\section{RELATED PUBLICATION}

Birkholzer, J.T., and Y.W. Tsang, Modeling the thermal-hydrological processes in a large-scale underground heater test in partially saturated fractured tuff. Water Resour. Res., 36(6), 1431-1448, 2000.

\section{ACKNOWLEDGMENTS}

This work was supported by the Director, Office of Civilian Radioactive Waste Management, U.S. Department of Energy, through Memorandum Purchase Order EA9013MC5X between Bechtel SAIC Company, LLC, and the Ernest Orlando Lawrence Berkeley National Laboratory (Berkeley Lab). The support is provided to Berkeley Lab through U.S. Department of Energy Contract No. DE-AC03-76SF00098. 


\section{A Mountain-Scale Flow Model FOR The Unsaturated Zone of Yucca Mountain, Nevada \\ Yu-Shu Wu, Guoping Lu, Keni Zhang, and G.S. Bodvarsson \\ Contact: Yu-Shu Wu, 510/486-7291, yswu@lbl.gov}

\section{RESEARCH OBJECTIVES}

Large-scale 3-D flow models have played a critical role in characterizing and assessing the effects of hydrogeologic, ther$\mathrm{mal}$, and geochemical conditions in the unsaturated zone (UZ) at Yucca Mountain, Nevada, the proposed site of the future U.S. nuclear waste repository. Our work involves developing and

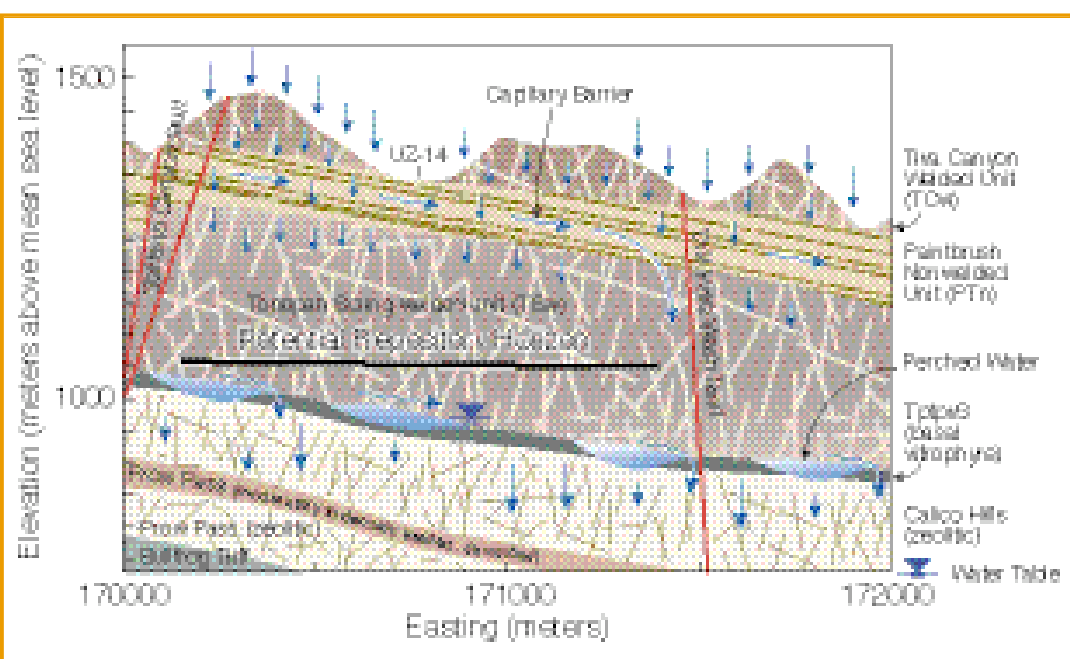

Figure 1. Schematic showing the conceptualized flow processes

refining the current mountain-scale UZ flow model developed for use in the current Total System Performance Assessment for License Application (TSPA-LA) in connection with Yucca Mountain.

\section{APPROACH}

The methodology employed in the ongoing development of the mountain-scale UZ flow model, based on the conceptual model (Figure 1), follows an iterative approach:

- Design a proper 3-D grid that incorporates complicated geological features of the site.

- Incorporate all available field data collected from the UZ.

- Calibrate the model using field-measured hydrological, pneumatic, thermal, and geochemical data.

- Conduct predictive studies and sensitivity analyses.

The modeling approach used in the UZ flow model is a dual-continuum mathematical formulation of coupled multiphase fluid and tracer transport through fractured porous rock, developed with the TOUGH2 code (a simulation code for multiphase, multicomponent flow and heat transfer).

\section{ACCOMPLISHMENTS}

Site-scale UZ flow models and submodels have shown the ability to match various types of field data on the model scale, including matrix liquid saturation and water potential, perched-water elevations, pneumatic data, geothermal gradients, and chloride data. The model has been used to (1) integrate all the available data from the UZ system into a single, comprehensive, and calibrated 3-D model for simulating the hydrological, thermal, and geochemical conditions at Yucca Mountain-for use in predicting system responses to ambient and future climate conditions; (2) quantify the moisture flow through the UZ, under present-day and estimated future climate scenarios; and (3) calculate times of radionuclide transport from the proposed repository level to the water table.

The site-scale UZ model has been successfully used to simulate past, present, and future hydrogeological, geothermal, and geochemical conditions and physical processes within the Yucca Mountain UZ. This model can be used to support various TSPA-LA activities.

\section{SIGNIFICANCE OF FINDINGS}

The mountain-scale UZ flow model generates 18 three-dimensional steady-state UZ flow fields, which have been used in direct calculations of radionuclide transport from the proposed repository to the water table, to support the TSPA-LA efforts. In addition, the UZ model results provide input parameters to various smallscale models and studies, such as drift-scale models, the mountain-scale thermal-hydrological model, and the UZ radionuclide transport model.

\section{RELATED PUBLICATIONS}

Wu, Y. S., L. Pan, W. Zhang, and G. S. Bodvarsson, Characterization of flow and transport processes within the unsaturated zone of Yucca Mountain, Nevada. Journal of Contaminant Hydrology, 54, 215-247, 2002.

Wu, Y. S., G. Lu, K. Zhang, G. Zhang, H.H. Liu, T. Xu, and E. L. Sonnenthal, UZ flow models and submodels. Report MDLNBS-HS-000006 REV01, Lawrence Berkeley National Laboratory, CRWMS M\&O, Berkeley, CA; Las Vegas, Nevada, 2003.

\section{ACKNOWLEDGMENTS}

This work was supported by the Director, Office of Civilian Radioactive Waste Management, U.S. Department of Energy, through Memorandum Purchase Order EA9013MC5X between Bechtel SAIC Company, LLC, and the Ernest Orlando Lawrence Berkeley National Laboratory (Berkeley Lab). The support is provided to Berkeley Lab through the U.S. Department of Energy Contract No. DEAC03-76SF00098.

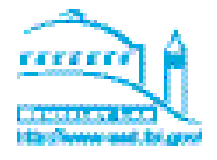




\title{
A Numerical Investigation of Flow Focusing in UnSAturated Fracture Networks
}

\author{
Keni Zhang, Yu-Shu Wu, G. S. Bodvarsson, and Hui-Hai Liu \\ Contact: Keni Zhang, 510/486-7393, kzhang@lbl.gov
}

\section{RESEARCH OBJECTIVES}

The primary objective of this work is to develop numerical models to improve our understanding of discrete flow paths through unsaturated fracture networks. These fracture networks are modeled using fracture data collected from the Topopah Spring welded tuff unit (TSw) of Yucca Mountain, Nevada, the site of the proposed national nuclear waste repository. We try to answer the following questions: How do flow paths develop in the randomly distributed fracture network? How do rock matrix and infiltration rate (on the top boundary) influence flow patterns in the fracture networks? And finally, what is the relation between flow focusing and boundary conditions?

\section{APPROACH}

A two-dimensional fracture network was constructed using field fracture-mapping data, including fracture density, length range, and fracture orientations measured at the site. Each fracture in the network is randomly distributed; however, the random distribution is governed by statistical information derived from field-measured fracture data. Statistically, the generated fracture network should correspond to actual fracture distribution in the study domain. Figure 1 shows a fracture network consisting of those fractures intersecting globally connected paths. Isolated fractures are neglected in the simulation. The simulation domain is considered to be combined media, consisting of a fracture network superimposed on a porous matrix.

\section{ACCOMPLISHMENTS}

Five simulation cases were run with different matrix rock permeabilities and different infiltration rates. These cases may reflect the influence of matrix rock on flow focusing and the influence of infiltration rate on the flow pattern of the fracture network. The modeling results demonstrate that focused flow paths through fractures are generally vertical (Figure 1). Simulation results suggest that the average spacing between flow paths in a layered system tends to increase with depth as long as flow is gravity-driven. In addition, flow paths are found to consist primarily of long trace fractures in lower fracture-density domains. In higher fracture-density domains, long and short trace fractures both contribute to the development of flow paths.

\section{SIGNIFICANCE OF FINDINGS}

The majority of fluxes along flow paths have low normalized fluxes (ranging from 0 to 2 ). The higher normalized flux is caused by the higher degree of focusing into several fracture paths. Simulation results indicate that lower matrix-rock permeability will lead to a larger flow-focusing phenomenon. Flow focuses into only a few fractures and forms two main flow paths. Each flow path spreads over a range of several meters. Simulation results thus indicate that the impact of infiltration rate on flow focusing may be insignificant for unsaturated flow in a fracture network.

\section{RELATED PUBLICATIONS}

Zhang, K., Y.S. Wu, G.S. Bodvarsson, and H.H. Liu, Flow focusing in unsaturated fracture networks: A numerical investigation. Vadose Zone Hydrology, 2003 (in press); Berkeley Lab Report LBNL-52819, 2003.

Zhang, K., Y.S. Wu, G.S. Bodvarsson, and H.H. Liu, Determination of unsaturated flow paths in a randomly distributed fracture network. Proceedings for Probabalistic Approaches and Groundwater Modeling Symposium, World Water and Environmental Resources Congress, Philadelphia, Pennsylvania, 2003.

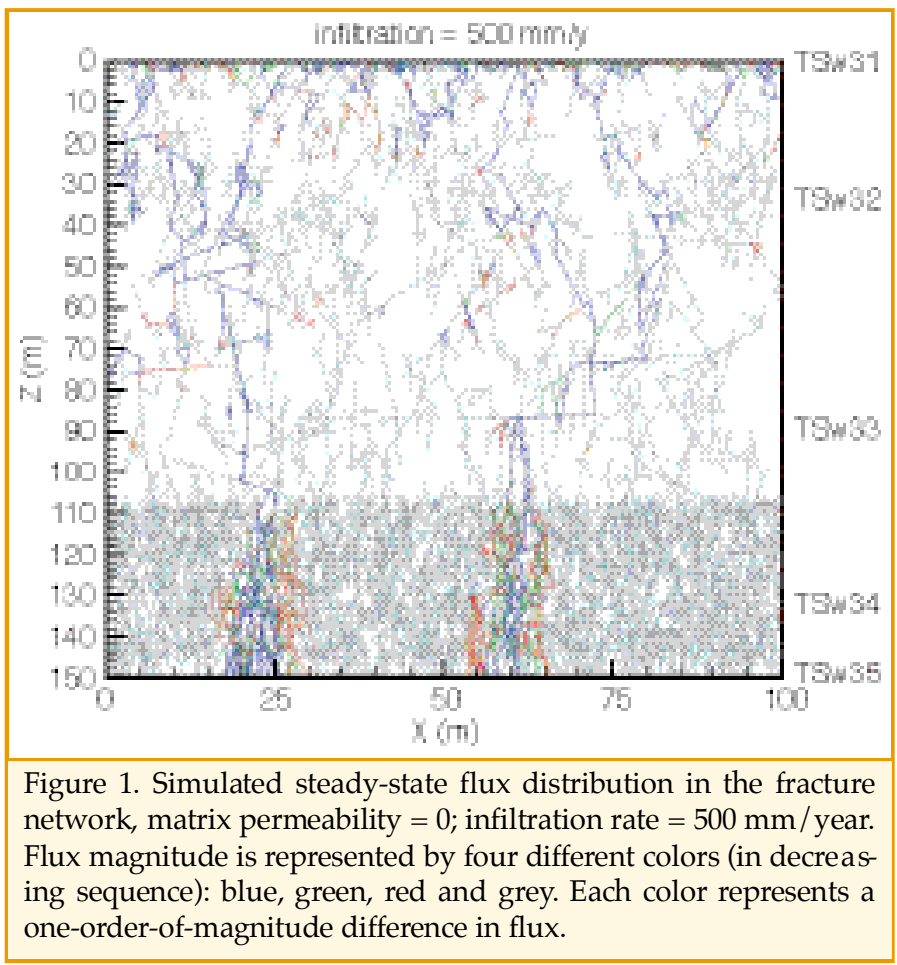

\section{ACKNOWLEDGMENTS}

This work was supported by the Director, Office of Civilian Radioactive Waste Management, U.S. Department of Energy, through Memorandum Purchase Order EA9013MC5X between Bechtel SAIC Company, LLC, and the Ernest Orlando Lawrence Berkeley National Laboratory (Berkeley Lab). The support is provided to Berkeley Lab through the U.S. Department of Energy Contract No. DE-AC03-76SF00098. 


\section{Multiscale Heterogeneity Effects at Yucca Mountain \\ Quanlin Zhou, Hui-Hai Liu, Gudmundur S. Bodvarsson, and Curtis M. Oldenburg \\ Contact: Quanlin Zhou, 510/486-5344, qlzhou@lbl.gov}

\section{RESEARCH OBJECTIVES}

The objectives of this work are to characterize the multiscale variability of fracture and matrix hydrogeological properties, and to investigate the effects of multiscale heterogeneity on unsaturated flow and transport at Yucca Mountain, Nevada, the proposed site for the national high-level nuclear waste repository.

\section{APPROACH}

We developed a model for the Yucca Mountain unsaturated zone that represented complex heterogeneity at two different scales: (1) layer scale, corresponding to geological layering, and (2) local scale, corresponding to measurement scale. The horizontal variability of layer-scale properties was calibrated based on the available measurements collected in multiple deep boreholes. Vertical and horizontal correlation lengths were obtained using local-scale permeability and porosity data. Random fields of the three most sensitive hydrogeologic properties for a two-dimensional, vertical cross section of the site were generated by combining the average layer-scale matrix and fracture properties with local-scale perturbations (generated using a stochastic simulation method).

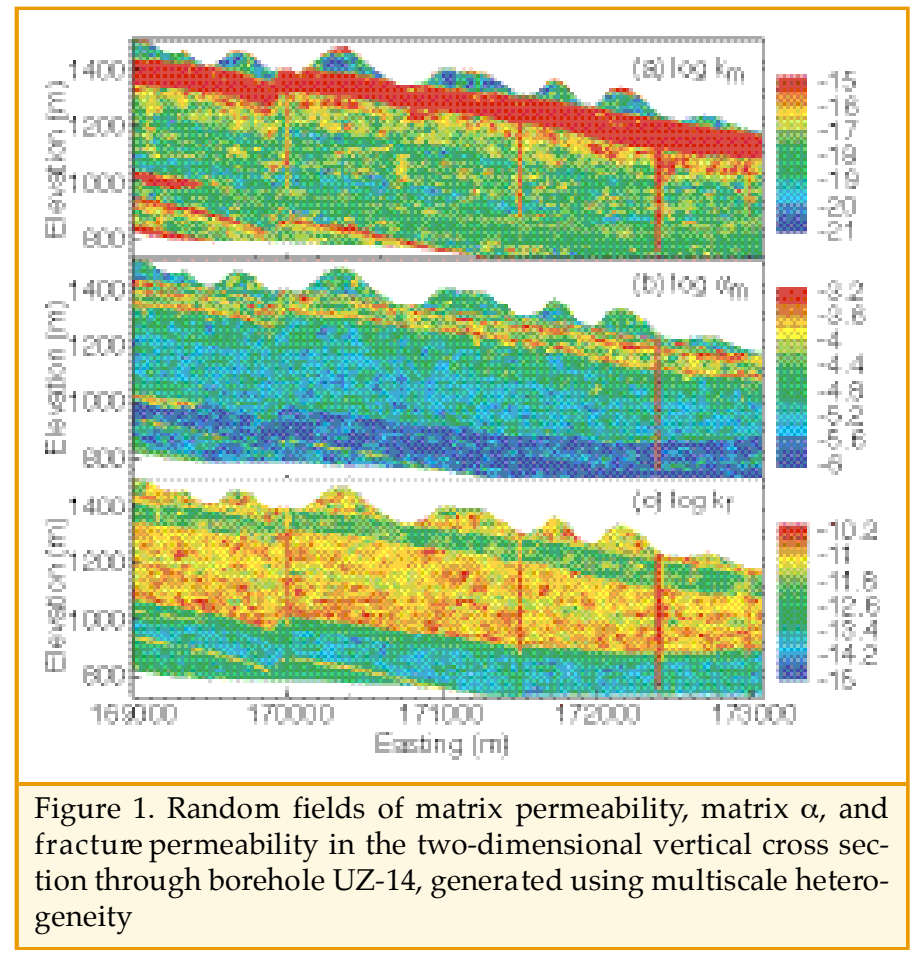

Unsaturated water flow and conservative tracer transport were simulated throughout the cross section. The effects of multiscale heterogeneity were investigated by comparison to the homogeneous layer-wise rock properties used for mountain-scale flow and transport modeling at Yucca Mountain.

\section{ACCOMPLISHMENTS}

In addition to local-scale perturbations, the Yucca Mountain multiscale heterogeneity characterization captured the significant lateral and vertical variability in layer-scale matrix and fracture properties. This indicates that the multiscale heterogeneity of matrix and fracture properties has a considerable effect on unsaturated flow processes, leading to fast flow paths in fractures and the matrix. These paths shorten the travel time of a conservative tracer from a source (repository horizon) in the unsaturated zone to the water table. As a result, multiscale heterogeneity would seem to have a significant effect on local and global tracer-transport processes, especially for the early arrival of tracer mass. However, the effect on global transport is not significant at later times-for example, after $20 \%$ of tracer mass reaches the water table.

\section{SIGNIFICANCE OF FINDINGS}

This work has produced a useful approach for characterizing subsurface heterogeneity at different scales. It showed that multiscale heterogeneity has a significant effect on local and global flow and transport. Consequently, it improves and confirms our conceptual understanding of how rock heterogeneity affects nuclear waste disposal.

\section{RELATED PUBLICATION}

Zhou, Q., H.H. Liu, G.S. Bodvarsson, and C.M. Oldenburg,

Flow and transport in unsaturated fractured rock: Effects of multiscale heterogeneity of hydrologic properties. Journal of Contaminant Hydrology, 60, 1-30, 2003.

\section{ACKNOWLEDGMENTS}

This work was supported by the Director, Office of Civilian Radioactive Waste Management, U.S. Department of Energy, through Memorandum Purchase Order EA9013MC5X between Bechtel SAIC Company, LLC, and the Ernest Orlando Lawrence Berkeley National Laboratory (Berkeley Lab). The support is provided to Berkeley Lab through the U.S. Department of Energy Contract No. DE-AC03-76SF00098. 


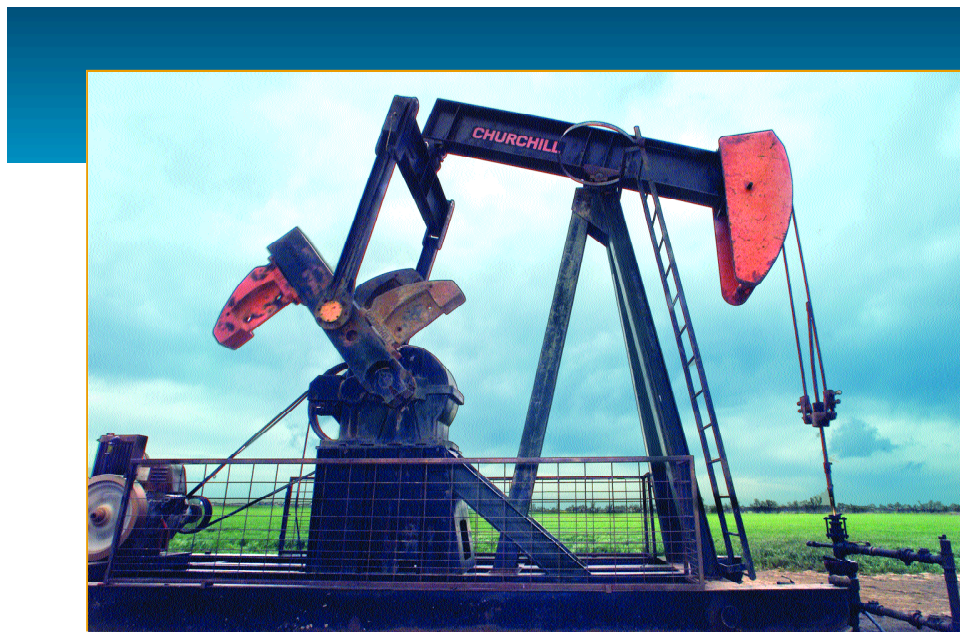

Research Program ENERGy RESOURCES

The Energy Resources Program (ER) is responsible for two major program areas: Oil and Gas Exploration and Development, and Geothermal Energy Development.

\section{OIL AND GAS EXPLORATION AND DEVELOPMENT}

Multidisciplinary research is being conducted in reservoir characterization and monitoring, optimization of reservoir performance, and environmental protection. Using basic research studies as a source of innovative concepts, ER researchers seek to transform these concepts into tangible products of use to industry within a time-frame consistent with today's rapid growth in technology. Reservoir characterization and monitoring involve development of new seismic and electromagnetic techniques focused at the inter-well scale. Field acquisition, laboratory measurements, and numerical simulation play important roles in the development activities. Optimization of reservoir performance is focused on simulation-based methods for enhancing reservoir management strategies. Emphasis is placed on the integration of geophysical data, production data, and reservoir simulation. The next major step in research will focus on methods to optimize performance through integration of monitored geophysical data, production data, and reservoir simulation.

International and national concern about the variable climatic effects of greenhouse gases produced by burning of fossil fuels is increasing, while it is also recognized that these fuels will remain a significant energy source well into the next century. In response to these concerns, ER has initiated research focused on development of technologies that will minimize the impact of fossil-fuel usage on the environment. Methane hydrates constitute a huge potential fuel source with lower carbon emissions than coal or oil. ER researchers are developing and evaluating possible methods for producing gas from such deposits. Geophysical data acquisition and inversion methods developed in the ER program are also being applied in a new project on geologic sequestration of $\mathrm{CO}_{2}$ carried out in the Climate Variability and Carbon Management Program within the Earth Sciences Division.

Principal research activities include:

- Development of single-well and crosswell seismic technology, including instrumentation, acquisition and processing

- Applications of seismic methods for characterization of fractured reservoirs

- Laboratory measurement of the seismic properties of poorly consolidated sands

- Development of efficient 3D elastic-wave propagation codes

- Improved inversion methods for reservoir characterization, with a focus on combining production and geophysical data

- Application of x-ray CT and NMR imaging to study multiphase flow processes

- Pore-to-laboratory-scale study of physical properties and processes, with a focus on controlling phase mobility, predicting multiphase flow properties and drilling efficiency

- Development of reservoir process-control methods

- Development of new methods to mitigate environmental effects of petroleum refining and use

- Enhancement of refining processes using biological technologies

- Numerical simulation of subsurface methane hydrate systems

Since 1994, the major part of the Oil and Gas Exploration and Development program has been funded through the Natural Gas and Oil Technology Partnership Program. Begun in 1989, the partnership was expanded in 1994 and again in

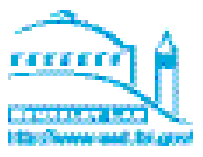


1995 to include all nine Department of Energy multiprogram laboratories, and has grown over the years to become an important part of the DOE Oil and Gas Technologies program for the national laboratories. Partnership goals are to develop and transfer to the domestic oil industry the new technologies needed to produce more oil and gas from the nation's aging, mature domestic oil fields, while safeguarding the environment.

Partnership technology areas are:

- Oil and gas recovery technology

- Diagnostics and imaging technology

- Drilling, completion, and stimulation

- Environmental technologies

- Downstream technologies

Projects are typically multiyear, are reviewed and reprioritized annually by industry panels, and are collaborations between national laboratories and industry

\section{GEOTHERMAL ENERGY DEVELOPMENT}

The main objective of ER's geothermal energy development program is to reduce uncertainties associated with finding, characterizing, and evaluating geothermal resources. The ultimate purpose is to lower the cost of geothermal energy for electrical generation or direct uses (e.g., agricultural and industrial applications, aquaculture, balneology). The program encompasses theoretical, laboratory, and field studies, with an emphasis on a multidisciplinary approach to solving the problems at hand. Existing tools and methodologies are upgraded, and new techniques and instrumentation are developed for use in the areas of geology, geophysics, geochemistry, and reservoir engineering. Cooperative work with industry, universities, and government agencies draws from Berkeley Lab's 25 years of experience in the area of geothermal research and development.

In recent years, DOE's geothermal program has become more industry-driven, and the Berkeley Lab effort has been directed toward technology transfer and furthering our understanding of the nature and dynamics of geothermal resources under production, such as The Geysers geothermal field in northern California, which has begun to show the effects of overexploitation.

At present, the main research activities of the program include:

- Geothermal Reservoir Dynamics: development and enhancement of computer codes for modeling heat and mass transfer in porous and fractured rocks, with specific projects such as modeling the migration of phase-partitioning tracers in boiling geothermal systems; modeling of mineral dissolution and precipitation during natural evolution, production, and injection operations; and geophysical-signature prediction of reservoir conditions and processes

- Isotope Geochemistry: identification of past and present heat and fluid sources, development of natural tracers for monitoring fluids re-injected into geothermal reservoirs, better understanding of the transition from magmatic to geothermal production fluids, and enhancement of reservoir-simulation methods and models by providing isotopic and chemical constraints on fluid source, mixing, and flow paths

- Multicomponent 3D Seismic Imaging: development and implementation of 3D surface and borehole methods for defining permeable pathways in geothermal reservoirs

- Geochemical Baseline Studies: documentation of geothermal-fluid behavior under commercial production and injection operations (e.g., field case studies), with specific emphasis on The Geysers field

- Electromagnetic Methods for Geothermal Exploration: development of efficient numerical codes for mapping highpermeability zones, using single-hole electromagnetic data

Future research will concentrate on the development of innovative techniques for geothermal exploration and assisting in a reassessment of geothermal power potential in the U.S. The emphasis will be on expanding existing fields, prolonging their productive life, and finding new "blind" geothermal systems, i.e., those that do not have any surface manifestations, such as hot springs, fumaroles, etc., that suggest the presence of deeper hydrothermal systems.

\section{FUNDING}

Within ER, The Oil and Gas Exploration and Development program receives support from the Assistant Secretary for Fossil Energy, Office of Natural Gas and Petroleum Technology, through the National Energy Technology Laboratory, the National Petroleum Technology Office, and the Natural Gas and Oil Technology Partnership, under U.S Department of Energy Contract No. DE-AC03-76SF00098. Support is also provided from industry and other sources through the Berkeley Lab Work for Others program. Industrial collaboration is an important component of DOE Fossil Energy projects.

The Geothermal Energy Development program receives support from the Assistant Secretary for Energy Efficiency and Renewable Energy, Office of Power Technologies, Office of Wind and Geothermal Technologies, of the U.S. Department of Energy. 


\title{
Fractured Reservoir Modeling: Coupled Seismic and Fluid Response
}

\author{
Thomas M. Daley, Michael Schoenberg, Jonny Rutqvist, and Kurt Nihei \\ Contact: Thomas M. Daley, 510/486-7316, tmdaley@lbl.gov
}

\section{RESEARCH OBJECTIVES}

Fractured reservoirs are more difficult to model and typically less well understood than porous reservoirs. These problems lead to greater expense in resource exploration/exploitation and in environmental characterization and cleanup. We are coupling state-of-the-art fractured-media modeling codes to allow investigation of the seismic response to fluid-induced changes in reservoir properties, such as pore pressure and permeability. This research could lead to improvements in remote sensing and time-lapse monitoring of dynamic processes in fractured reservoirs.

\section{APPROACH}

We have coupled two previously independent modeling codes, a hydromechanical finite-element code and a 3-D seismic finite-difference, elastic, anisotropic modeling code. In both codes, fractures are defined by their mechanical stiffness, which is in turn linked to permeability and seismic response by recently developed theoretical relationships. Using the hydromechanical code, we simulate injecting fluid into or withdrawing fluid from a reservoir for a length of time. This creates fluid-pressure gradients that act to change the fracture stiffness. Conceptually, the spatially variable fluid pressure causes fractures to open or close inhomogeneously. In a dynamic process, as fracture stiff-

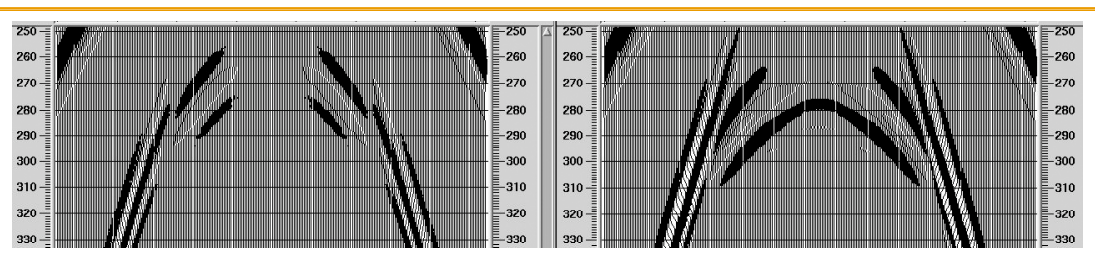

Figure 1. Surface seismic shot gather for the three-layer model described in the text. Pre-injection (left) and post-injection (right) comparison shows a substantial change in the event between 270 and $310 \mathrm{~ms}$. This change in seismic reflection response is caused by fluid pressure changes in the reservoir due to injection. minute over the $60 \mathrm{~m}$ thick reservoir. A 3-D, three-component surface seismic survey was modeled at various times. Figure 1 shows the response at pre-injection (left) and at 2 months postinjection (right). A distinct change is seen in reservoir seismic reflectivity. This change is most evident in the amplitude and time of a P- to S-wave converted reflection polarized normal to the fractures. This change in seismic response is caused by the fluid injection changing fracture stiffness.

\section{SIGNIFICANCE OF FINDINGS}

Understanding fractured reservoirs is important for many problems facing the U.S. Department of Energy (and the U.S. in general), including resource development (oil and gas production), underg round storage of high-level waste, remediation of ness changes, fracture permeability and fluid pressure distribution change, which then influence the next change in fracture stiffness.

At any given time, we can apply spatially variable fracturestiffness values to model the seismic response of the reservoir. These stiffness values are used to calculate anisotropic elastic constants, which control seismic wave propagation. In general, the reservoir has a unique set of elastic constants for each finiteelement cell or finite-difference grid point. The seismic response of the reservoir can be used to spatially map the variations in elastic constants, which can then be related to variations in fracture stiffness and, in turn, to pore-pressure and permeability variations in the reservoir. In this manner, time-lapse seismic surveys can monitor reservoir changes.

\section{ACCOMPLISHMENTS}

We have successfully coupled the hydromechanical and wave-propagation modeling codes. The initial study considered a 3-D vertically fractured reservoir layer sandwiched between two homogeneous, relatively impermeable nonfractured layers. The layer is assumed to have a single dominant fracture direction. For two months, fluid is injected into the center of the reservoir via a vertical well at 80 liters per

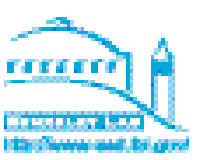

contaminated aquifers, geologic sequestration of $\mathrm{CO}_{2}$, and groundwater exploration and storage. Currently, fluid flow modeling and seismic imaging are considered separately. Linking these fields through a consistent conceptual and theoretical framework will allow improved understanding of coupled processes, and may lead to improved monitoring of reservoir conditions.

\section{RELATED PUBLICATION}

Schoenberg, M., K. Nihei, T. Daley, J. Rutqvist, and E.L. Majer,

Fractured reservoirs: An analysis of coupled elasto-dynamic and permeability changes due to pore pressure variation. Presented at the Society of Exploration Geophysicists' Pore Pressure Workshop, May 2002; Berkeley Lab Report LBNL50697, 2002.

\section{ACKNOWLEDGMENTS}

This work was supported by the Assistant Secretary for Fossil Energy, Federal Energy Technology Center (FETC). Processing was performed at the Center for Computational Seismology, which is supported by the Director, Office of Science, Office of Basic Energy Sciences, Division of Engineering and Geosciences, of the U.S. Department of Energy under Contract No. DE-AC03- 76SF00098. 


\section{A Portable X-Ray Computed Tomography Sysytem \\ Barry M. Freifeld, Timothy J. Kneafsey, Jacob Pruess, and Liviu Tomutsa \\ Contact: Barry Freifeld, 510/486-4381, bmfreifeld@lbl.gov}

\section{RESEARCH OBJECTIVES}

Drilling boreholes is an expensive activity, whether conducted for environmental monitoring, resource extraction, or scientific purposes. Retrieving geologic samples (core) from the ground adds significantly to this expense, potentially doubling or tripling drilling costs. Beyond a geologist's visual inspection, much of the core often goes untouched. Frequently, core is subsampled for use in subsequent tests (such as oil/gas/water relative permeability). Some samples, such as those containing gas hydrates, change rapidly upon retrieval. In these cores, on-site core examination and evaluation is critical. Our objective in developing a portable x-ray computed tomography (CT) system is to (1) provide personnel in the field with a real-time comprehensive picture of core structure and (2) provide a tool for selecting subsamples.

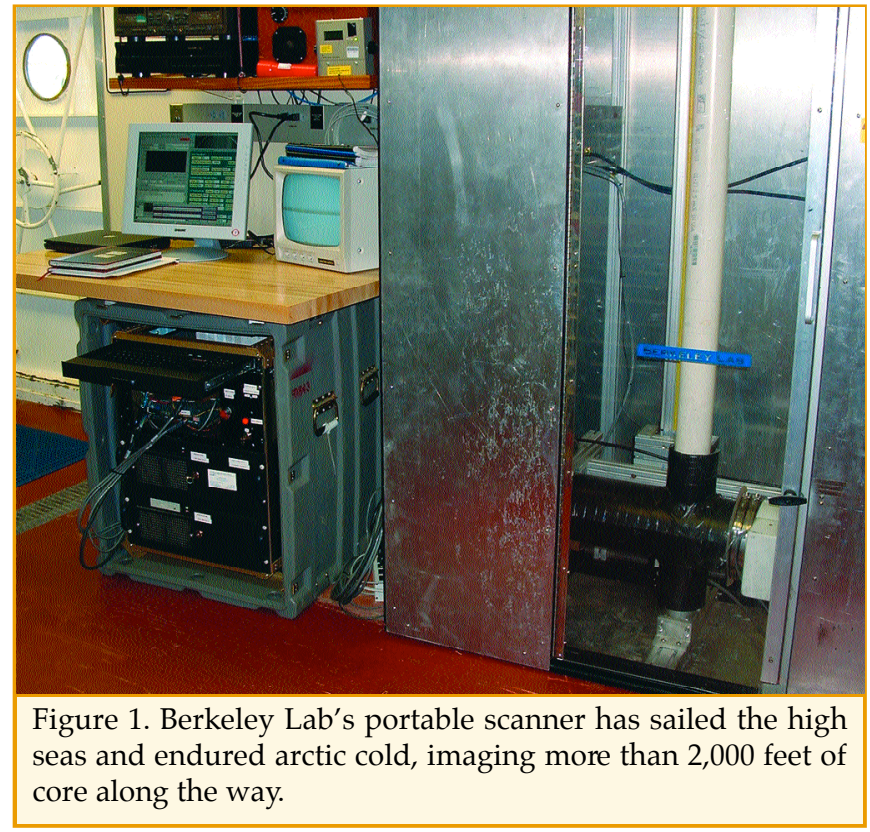

\section{APPROACH}

Soil scientists and petroleum engineers have used x-ray CT to perform measurements on recovered core. The bulk of this work has been conducted using large medical scanners designed for imaging humans. These large, immobile systems, often costing a million dollars or more, are used in a laboratory and require water-cooling systems and air-conditioned lead-lined rooms. Our portable system had to be rugged, compact, lightweight, and fast. We were able to eliminate most of the weight by producing a novel multicomponent lead-shielding arrangement that reduced the footprint of the system and eliminated the need for a dedicated room. Special collimators and filters, optimized for geologic core, enabled us to use offthe-shelf industrial imagers and obtain results that rivaled the performance of expensive scientific instruments. As a result, our final product costs significantly less than the baseline medical technology that we set our sights on.

\section{ACCOMPLISHMENTS}

This unique portable x-ray CT scanner was fabricated in July 2002. Its first deployment was on Ocean Drilling Program (ODP) Leg 204 off the Oregon Coast, a research cruise to investigate methane-hydrate-bearing cores retrieved from Cascadia Ridge. Afterwards, the scanner was transported to the ODP Gulf Coast Core Repository, where it was used for follow-up studies. It was briefly back at Berkeley Lab to image hydrate dissociation experiments, before heading off for two months (March-April, 2003) to the Alaskan North Slope to image permafrost cores in another hydrate researh project. The scanner will be used next for ODP Leg 210, a cruise to study the Newfoundland half of the Newfoundland-Iberia nonvolcanic rift.

\section{SIGNIFICANCE OF FINDINGS}

A portable x-ray CT system can provide geologists in the field with detailed information (such as density and macroporosity distribution) from recovered drill core. Additionally, subsamples can be selected knowing not just what is on the surface, but also the structure throughout the core. As a result of CT imaging, detailed structural information can be obtained quickly, and an electronic record can be generated. Ultimately, information will be extracted from recovered core quicker, with more precision, and at a lower cost.

\section{RELATED PUBLICATION}

Freifeld, B.M., T.J. Kneafsey, L. Tomutsa, and J. Pruess, Development of a portable x-ray computed tomographic imaging system for drill-site investigation of recovered core. Proceedings of the 2003 International Symposium of the Society of Core Analysts, Pau, France, September 21-24, 2003.

\section{ACKNOWLEDGMENTS}

This work was supported by the Assistant Secretary for Fossil Energy, Office of Natural Gas and Petroleum Technology, through the National Energy and Technology Laboratory, of the U.S. Department of Energy under Contract No. DEAC03-76SF00098.

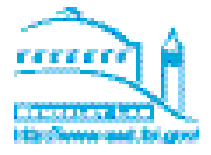




\title{
Joint Crosswell and Single-Well Seismic Studies of $\mathrm{CO}_{2}$ InJeCtion IN AN OIL Reservoir at Lost Hills, California
}

\author{
Roland Gritto, Thomas M. Daley, and Larry R. Myer \\ Contact: Roland Gritto, 510/486-7118, rgritto@lbl.gov
}

\section{RESEARCH OBJECTIVES}

The objective of this research is to study whether crosswell and single-well seismic techniques can be applied to monitor the sequestration of $\mathrm{CO}_{2}$ in oil reservoirs. The advantage of injecting $\mathrm{CO}_{2}$ into oil reservoirs is two-fold: (1) it offers one method of geologic carbon sequestration, while it (2) enhances the recovery of difficult-to-extract oil, which otherwise would remain locked in place.

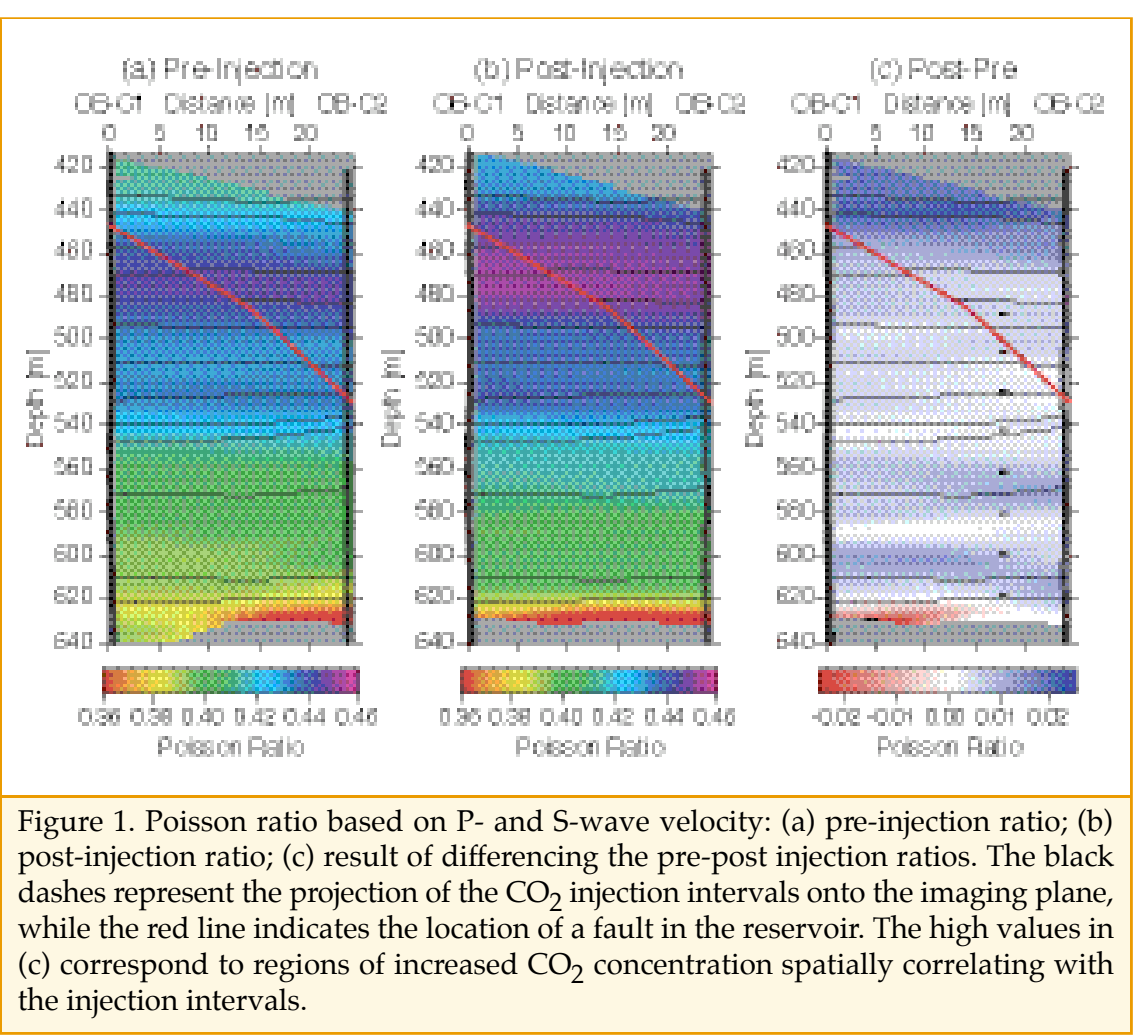

difference image of the two. The pre- and post-injection tomograms show the stratification and compaction of the reservoir rock with depth (decreasing Poisson values). The difference tomogram shows an increase in Poison ratio throughout the imaged area, indicating an increase in pressure in the reservoir. This information, in conjunction with the $\mathrm{P}$ - and S-wave results, led to the conclusion that the injected $\mathrm{CO}_{2}$ dissolved into the liquid phase, which was corroborated by in situ pressure measurements and reservoir simulations. The seismic single-well supported the crosswell results.

\section{ACCOMPLISHMENTS}

The experiment has shown that seismic crosswell time-lapse P- and S-wave data can be used to successfully monitor $\mathrm{CO}_{2}$ injection and migration in oil reservoirs, and to determine the state of the injected gas. Single-well seismic measurements provide independent data that are useful in corroborating crosswell results without adding much data acquisition time in the field.

\section{SIGNIFICANCE OF FINDINGS}

The analysis of the $\mathrm{CO}_{2}$ injection experiment revealed that both P-and S-wave data sets are essential in determining the migration and state of the injected gas in the reservoir, because one data set by itself would yield inconclusive results. The availability of time-lapse data reduces the effect of reservoir heterogeneity, which would be difficult to estimate in an absolute sense. Poisson ratio can be applied to determine whether the injected gas has dissolved into the liquid phase or remained in gas form. It also appears that seismic crosswell data are useful in delineating the structural features of the reservoir, whereas single-well seismic data are applicable in determining the location and possibly the properties of a hydrofracture zone.

\section{ACKNOWLEDGMENTS}

This work was supported by the Assistant Secretary for Fossil Energy, Office of Coal and Power Systems and the Office of Natural Gas and Petroleum Technology, through the National Energy Technology Laboratory (NETL), of the U.S. Department of Energy under Contract No. DE-AC03-76SF00098. Support was also provided by Chevron USA Production Co. and the National Petroleum Office under Contract No. DE-FC2295BC14938, Class III Field Demonstration Project. ratio before and after injection, as well as a 


\section{JoINT GEOPHYSICAL IMAGING \\ G. Michael Hoversten \\ Contact: 510/486-5085, gmhoversten@lbl.gov}

\section{RESEARCH OBJECTIVES}

The objective of the Joint Geophysical Imaging project is to ultimately develop formal joint geophysical imaging algorithms for simultaneously inverting different types of geophysical data - to find a common, self-consistent earth model. The initial stages of this work have concentrated on demonstrating a methodology for combining time-lapse changes in electric conductivity and compressional- and shear-wave velocity with a detailed rock-properties model, to produce quantitative estimates of the change in reservoir pressure and fluid saturations.

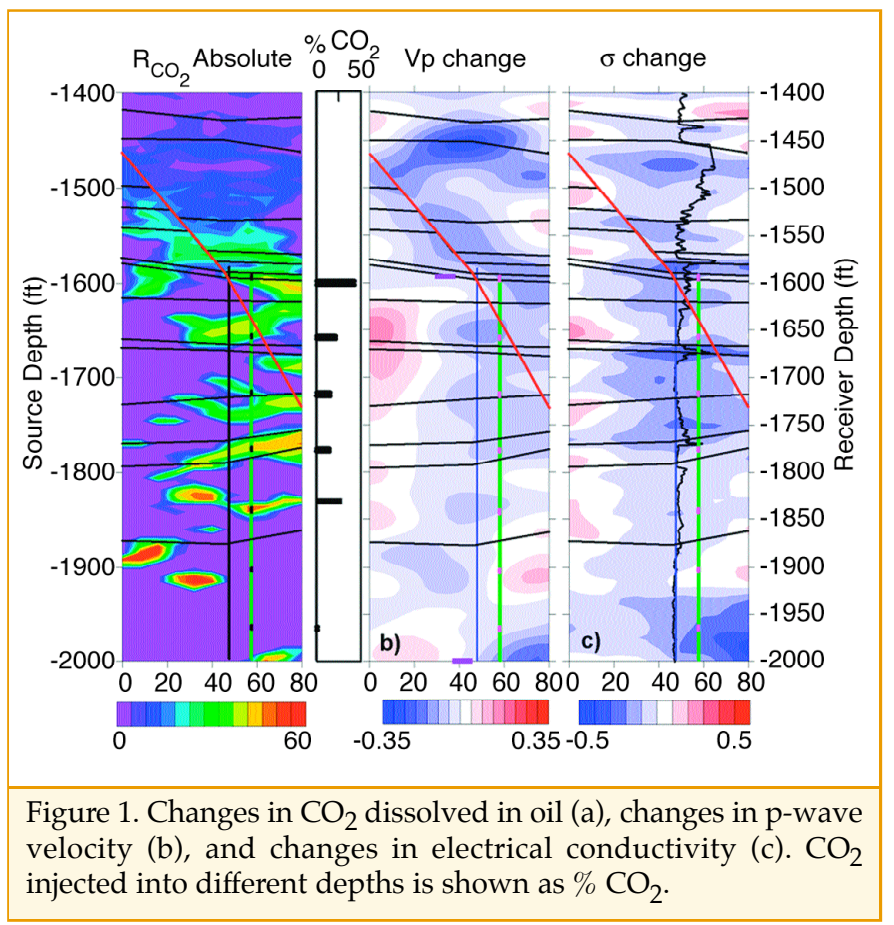

\section{APPROACH}

Crosswell electromagnetic (EM) and seismic data were acquired during $\mathrm{CO}_{2}$ injection into the Lost Hills Oil field. Data were recorded before and during $\mathrm{CO}_{2}$ injection. From well log data, a detailed rock-properties model was developed that related changes in the electrical and seismic properties of the reservoir to changes in pressure and fluid saturations. The rock-properties model was used to constrain inversion of the time-lapse data sets to produce time-lapse changes in the seismic compressional, shear, and electrical conductivity as $\mathrm{CO}_{2}$ was injected.
These time-lapse changes in geophysical parameters were combined with the rock-properties model to produce changes in reservoir pressure and fluid saturations (including changes in hydrocarbon gas, water, and $\mathrm{CO}_{2}$ saturations).

A critical step was to first remove the effects of the reservoirpressure and water-saturation changes by combining the EM and shear-wave velocity changes. Once the effects of reservoir pressure and water saturation changes were stripped off, the changes in acoustic velocity were used to map $\mathrm{CO}_{2}$ saturation changes within the reservoir.

\section{ACCOMPLISHMENTS/ SIGNIFICANCE OF FINDINGS}

The newly developed procedure for unraveling the combined effects of reservoir pressure and fluid saturation changes produced a predicted change in $\mathrm{CO}_{2}$ content in the reservoir oil. This change in $\mathrm{CO}_{2}$ content is substantially better that that which can be obtained by traditional predictions (based on changes in geophysical parameters alone). Figure 1 shows the changes in $\mathrm{CO}_{2}$ dissolved in oil compared to the changes in compressional velocity and electrical conductivity between the two observations wells used in the survey. There is a clear improvement in spatial resolution, along with accurate quantitative prediction of the $\mathrm{CO}_{2}$ volume in place.

\section{RELATED PUBLICATIONS}

Hoversten, G.M., P. Milligan, J. Byun, J. Washbourne, L.C. Knauer, and P. Harness, Crosswell electromagnetic and seismic imaging: An examination of coincident surveys at a steam flood project. Geophysics, 2003 (in press); Berkeley Lab Report LBNL-48703.

Hoversten, G.M., R. Gritto, J. Washbourne, and T.M. Daley, Pressure and fluid saturation prediction in a multicomponent reservoir, using combined seismic and electromagnetic imaging. Geophysics, 2003 (in press); Berkeley Lab Report LNBL-51281.

\section{ACKNOWLEDGMENTS}

Support for this work was provided by the Assistant Secretary for Fossil Energy, Office of Coal and Power Systems, Office of Oil, Gas, and Shale Technologies, through the National Energy Technology Laboratory, under U.S. Department of Energy Contract No. DE-AC03-76SF00098. 


\section{Gas-Hydrate Imaging Using X-Ray COMPUTed TOMOgRaPHY \\ Timothy J. Kneafsey, Barry Freifeld, Liviu Tomutsa, and Jacob Pruess \\ Contact: Timothy J. Kneafsey, 510/486-4414, tjkneafsey@lbl.gov}

\section{RESEARCH OBJECTIVES}

Gas hydrates are ice-like crystalline solids formed from a mixture of water and natural gas at high pressures and temperatures near freezing. They are abundant in deep oceans and underlie vast stretches of permafrost. There is general scientific agreement that naturally occurring hydrates contain significantly more energy than is stored in traditional fossil fuel reserves. While gas-hydrate dissociation (the process of hydrate separating to gas and water or ice) is well understood, there is very little known about hydrate behavior in oceanic sediments or porous media. Our objective was to develop a technique capable of observing gas-hydrate dissociation in oceanic sediments or porous media, so that we may eventually extract the natural gas as an economic resource.

\section{APPROACH}

We used x-ray computed tomography (CT), coupled with physical measurements of temperature, pressure, and volume, to observe hydrate dissemination and monitor dissociation of synthetic samples. We compared the results from the physical measurements to the $\mathrm{x}$-ray $\mathrm{CT}$ scanning to examine the effectiveness of using $\mathrm{x}$-ray CT scanning in quantifying hydrate dissociation.

\section{ACCOMPLISHMENTS}

We have performed several experiments to accomplish our objective. In one experiment, we used a modified medical $x$ ray CT scanner to observe the changes in a hydrate/silica sand sample. The sample contained two different mixtures of hydrate and sand. We measured the temperature at the bottom of the sample, as well as the volume and composition of the produced gas. The sample warmed from top to bottom, and as dissociation occurred, methane gas was produced. Simultaneously, changes in x-ray attenuation were observed in the top of the sample. The location where the hydrate was dissociating was identifiable in the $\mathrm{x}$-ray images as a horizontal front, and we were able to track the front from the sample top to the bottom. As expected, gas production ceased when the front reached the sample bottom.

We conducted another experiment using the Berkeley Lab portable x-ray CT scanner. In this experiment, we measured the pressure change and temperature as the sample, consisting of clean $1 \mathrm{~mm}$ sand as well as chunks of hydrate and ice (Figure 1), warmed from $-196^{\circ} \mathrm{C}$. As in the first experiment, the x-ray CT images clearly show changes in the hydrate as dissociation occurs.

\section{SIGNIFICANCE OF FINDINGS}

We have shown that $\mathrm{x}$-ray CT scanning is a valuable tool in examining samples containing hydrates, and can be used to track hydrate dissociation. The use of $\mathrm{x}$-ray CT scanning at remote locations can be performed using the Berkeley Lab portable x-ray CT scanner, allowing examination of natural samples in their most representative condition. The x-ray CT results, combined with pressure and temperature measurements, provide clear indications of hydrate changes in samples.

\section{RELATED PUBLICATION}

Freifeld, B.M., T.J. Kneafsey, L. Tomutsa, L.A. Stern, and S.H. Kirby, Use of $\mathrm{x}$-ray computed tomographic data for analyzing the thermodynamics of a dissociating porous sand/hydrate mixture. Proceedings of the Fourth International Conference on Gas Hydrates, pp. 750-755, Yokohama, Japan, May 19-23, 2002.

\section{ACKNOWLEDGMENTS}

This work was supported by the Assistant Secretary for Fossil Energy, Office of Natural Gas and Petroleum Technology, through the National Energy Technology Laboratory, of the U.S. Department of Energy under Contract No. DE-AC03-76SF00098.

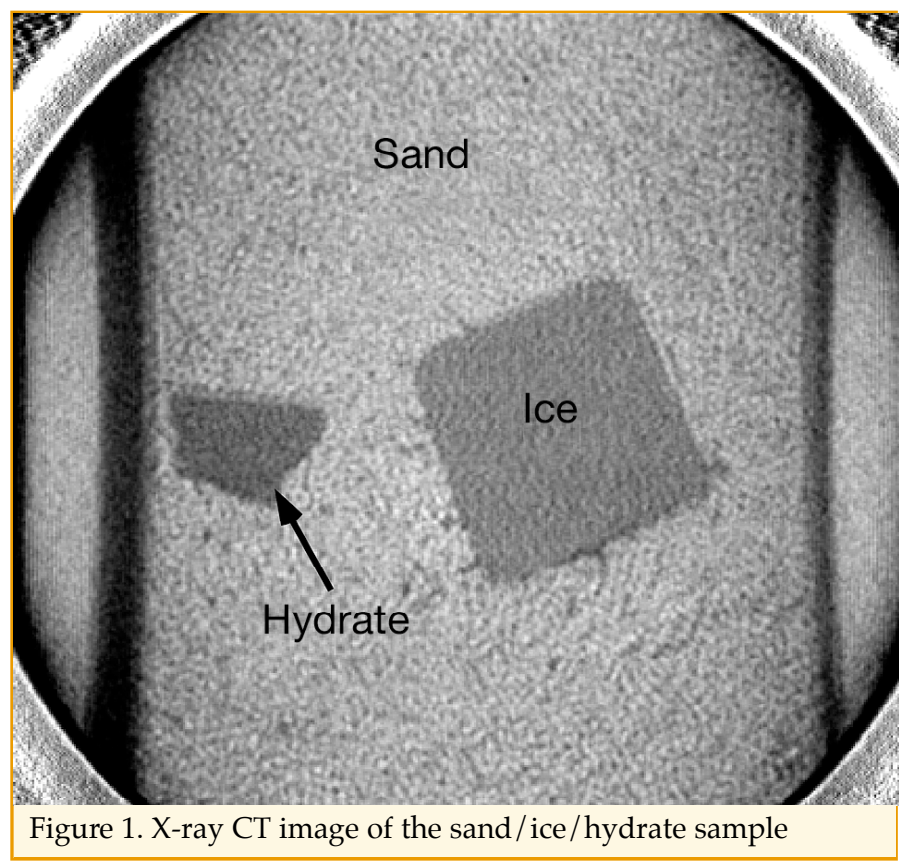

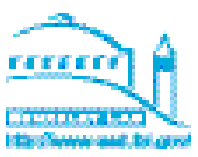




\section{Fracture Quantification in Naturally Fractured Gas Reservoirs \\ Ernest L. Majer \\ Contact: 510/486-6709, elmajer@lbl.gov}

\section{OBJECTIVE}

The objective for this work is to apply high-resolution seismic-imaging fracture-identification methods (logging, singlewell vertical seismic profiling [VSP]) to naturally fractured gas reservoirs, and to integrate the results with three-dimensional (3-D) surface imaging. The goal is to determine the optimum technique for not only locating fractures, but also quantifying their properties in a manner that allows the fractures controlling flow to be identified.

\section{APPROACH}

As part of the U.S. Department of Energy's Natural Gas Program, Berkeley Lab is leading a multiinstitutional project to develop methods for mapping the fractures that control flow in naturally fractured gas reservoirs. This project strives to extend surface information with current borehole methods (VSP, crosswell, and singlewell seismic) to quantify fracture characteristics. The work has pro-

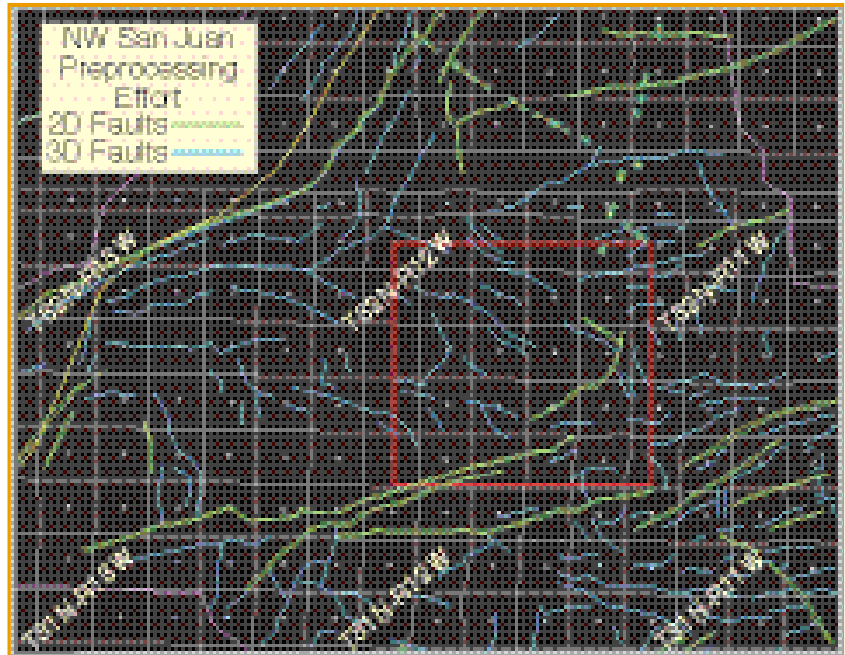

Figure 1. Study area (red box) in relation to the fault structure as determined by 2-D and 3-D seismic imaging
- Multi-offset (approximately 70 source points per well) 3D, 9-C VSP at $20 \mathrm{ft}$ spacing (10 to $100 \mathrm{~Hz}$ )

- Single well with three component receivers at $10 \mathrm{ft}$ spacing, using orbital source (50 to $400 \mathrm{~Hz}$ )

- Single well with hydrophones at $5 \mathrm{ft}$ spacing, using piezoelectric source (200 to $4,000 \mathrm{~Hz}$ )

- FMI and dipole sonic (4,000 to $8,000 \mathrm{~Hz}$ )

Together with the reprocessed seismic data, this information will form the basis of a unique multiscale data set to process for fracture properties. To check the predictions, each well will be put on production after the seismic studies are completed.

\section{SIGNIFICANCE OF FINDINGS}

Overall, the project has made the anticipated progress towards the goal of developing and testing seismic methods for fracture quantification. The drilling of the well by ConocoPhillips (an over- $\$ 1.5$ gressed from lab studies to controlled field studies, and now to a full-scale application in the San Juan Basin in New Mexico.

\section{ACCOMPLISHMENTS}

The project effort during 2002 focused on three areas: (1) modeling seismic wave propagation in fractured media, (2) acquisition of an extensive set of VSP data, well logs, and single-well data, and (3) initial processing of the field data.

The thrust of the modeling effort has been to model the actual field data that was processed in both 2-D and 3-D. Existing 3-D data from the 20-square-mile target area was reprocessed to apply processing that would enhance interpretation for fracture and fault identification. The result was an analysis of predicted well performance across the 20-squaremile area.

The objective of the field tests was to augment the existing data sets at both the borehole scale (logging and single-well seismic) and VSP scale. The objective of the interpretation and processing effort has been (and will be) to derive images that are indicative of fracture characteristics. Each method (surface seismic, VSP, crosswell, single well) has a different image produced at a different scale. The following data have been compiled: million investment alone) and the acquisition of the field data sets mark a significant milestone in this work-and in general a significant scientific contribution to the discipline of fracture imaging. The final phase of the project will involve additional work in modeling, data processing, and reservoir simulation.

\section{RELATED PUBLICATIONS}

Majer, E.L., J.E. Peterson, T. Daley, B. Kaelen, J.L. Myer, J. Queen, P. D'Onfro, and W. Rizer, Fracture detection using crosswell and single well surveys. Geophysics, 62(2), 495-504, 1997.

Daley, T.M., T. Nihei, L.R. Myer, E.L. Majer, J.H. Queen, M. Fortuna, J. Murphy, and R.T. Coates, 2002, Numerical modeling of scattering from discrete fracture zones in a San Juan Basin gas reservoir. In Proceedings of the SEG Annual Meeting, Salt Lake City, Utah, 2002.

\section{ACKNOWLEDGMENTS}

This work was funded by the Assistant Secretary for Fossil Energy, Department of Natural Gas Exploration, Production, and Storage, through the National Energy Technology Laboratory, of the U.S. Department of Energy under Contract No. DE-AC03-76SF200098. 


\section{Classification of Gas Hydrate Deposits and Corresponding Production Strategies \\ George J. Moridis \\ Contact: 510/486-4746, gjmoridis@lbl.gov}

\section{RESEARCH OBJECTIVES}

Gas hydrates are solid (ice) crystalline compounds, inside the lattices of which gas molecules can be encased. Vast amounts of hydrocarbons are thus trapped in hydrate deposits. The objective of this study is the analysis and development of appropriate strategies for gas production from a wide range of natural hydrate accumulations. These strategies involve the three main hydrate dissociation mechanisms (depressurization, thermal stimulation, inhibitor effects), either individually or in combination. Selection of the appropriate strategy is strongly influenced by the geological setting and the conditions prevailing in the hydrate accumulation.

\section{APPROACH}

The TOUGH2 general-purpose simulator with the EOSHYDR2 module was used for the analysis. EOSHYDR2 models the nonisothermal gas release, phase behavior, and flow in binary hydratebearing porous and fractured media (involving methane and another hydrateforming gas) by solving the coupled equations of mass and heat balance. This model can describe any combination of

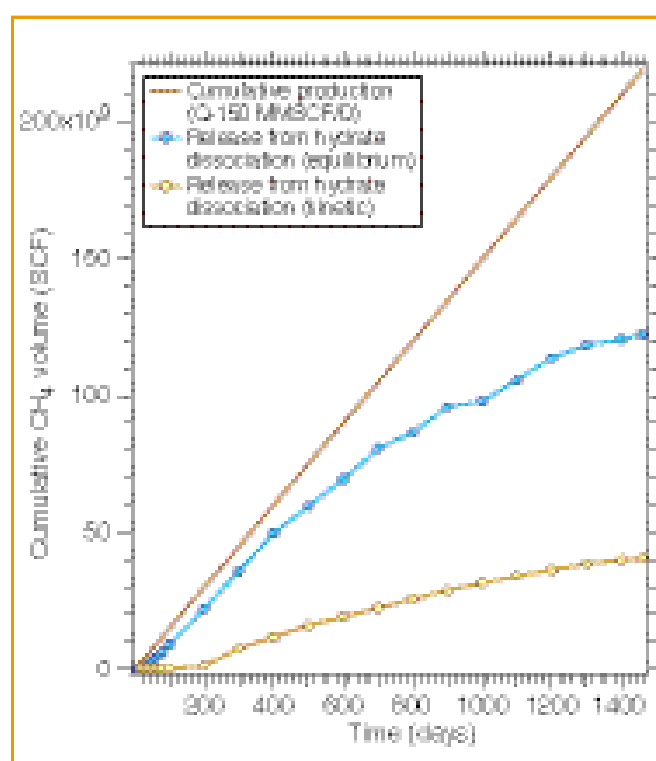

Figure 1. Cumulative release of $\mathrm{CH}_{4}$ from hydrate dissociation during gas production from a Class 1 hydrate in the North Slope of Alaska
The numerical simulations indicate that, in general, the appeal of depressurization decreases from Class 1 to Class 3 , while that of thermal stimulation increases. Thus, simple depressurization appears to enjoy an advantage over other production strategies in Class 1 hydrate deposits. The most promising production strategy for Class 2 hydrates involves combinations of depressurization and thermal stimulation, and is clearly enhanced by multi-well production-injection systems (e.g., a five-spot configuration). Because of the very low permeability of hydrate-bearing sediments, the effectiveness of depressurization in Class 3 hydrates is limited, and thermal stimulation through single well systems seems to be the strategy of choice in such deposits (and especially so in high-hydrate-saturation regimes).

\section{SIGNIFICANCE OF FINDINGS}

This is the first-ever (a) classification of gas hydrate deposits and (b) development of general principles for gas production strategies based on the hydrate deposit classification. hydrate dissociation mechanisms - and can also account for up to four phases (gas phase, liquid phase, ice phase, and hydrate phase $)$ and up to seven components $\left(\mathrm{CH}_{4}\right.$-hydrate, water, native methane, dissociated methane, native and dissociated components of a second hydrate-forming gas, salt, water-soluble inhibitors, and heat).

\section{ACCOMPLISHMENTS}

In terms of production strategy and behavior, hydrate accumulations are divided into three main classes. In Class 1, the permeable formation includes two zones: the hydrate interval and an underlying two-phase fluid zone with free (mobile) gas. In this class, the bottom of the hydrate stability zone occurs above the bottom of the permeable formation. Class 2 features a hydrate-bearing interval overlying a mobile water zone (e.g., an aquifer). Class 3 is characterized by the absence of a hydrate-free zone, and the permeable formation is thus composed of a single zone, the hydrate interval. In Classes 2 and 3, the entire hydrate interval may be well within the hydrate stability zone (i.e., the bottom of the hydrate interval does not necessarily indicate hydrate equilibrium).

\section{RELATED PUBLICATIONS}

Moridis, G.J., Numerical studies of gas production from methane hydrates. SPE Paper 75691, SPE Journal, 2003 (in press); Berkeley Lab Report LBNL-49765.

Moridis, G.J., Numerical simulation studies of thermally induced gas production from hydrate accumulations with no free gas zones at the Mallik Site, Mackenzie Delta, Canada. SPE Paper 77861, SPE 2002 Asia Pacific Oil and Gas Conference and Exhibition, Melbourne, Australia, October 8-10, 2002; Berkeley Lab Report LBNL-50256.

Moridis, G.J. and T. Collett, Strategies for gas production from hydrate accumulations under various geologic conditions. Berkeley Lab Report LBNL-52568, 2003.

\section{ACKNOWLEDGMENTS}

This work was supported by the Assistant Secretary for Fossil Energy, Office of Natural Gas and Petroleum Technology, through the National Energy Technology Laboratory, under U.S. Department of Energy Contract No. DE-AC03-76SF00098.

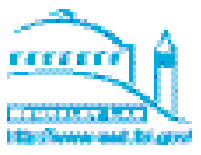




\title{
Anisotropic Properties of Compacted Clay-Rich Rocks
}

\author{
Kurt T. Nihei, F. Reverdy, and Larry R. Myer
}

Contact: Kurt T. Nihei, 510/486-5349, ktnihei@lbl.gov

\section{RESEARCH OBJECTIVES}

The principal objective of this work is to characterize the elastic anisotropic properties of clay-rich rocks for consolidation conditions simulating compaction at depth. A novel consolidation cell containing sets of ultrasonic transducers and a phased array has been designed to allow measurement of the five transverse isotropy (TI) elastic constants of a rock sample during compaction. During the testing phase of this project, we will conduct a series of laboratory anisotropy tests on clayrich rock samples provided by our industry partners from basins worldwide.

\section{APPROACH}

The standard laboratory ultrasonic transmission method for measuring the five elastic constants of rock with TI requires a minimum of three oriented cores taken parallel, perpendicular, and at an angle to the bedding. This method is unsuitable for measuring the stress-induced TI elastic constants of clayrich rocks during compaction because: (1) the process of unloading-recoring-reloading is time consuming, and (2) it is difficult to realize the same stress state in the sample cored at an angle to the bedding. The apparatus developed in this project utilizes a P-wave phased array and three sets of polarized ultrasonic transducers to recover the five TI constants during uniaxial strain consolidation.

\section{ACCOMPLISHMENTS}

A series of ultrasonic tests on clay-rich rocks provided by ChevronTexaco were performed to determine the attenuation of $\mathrm{P}$ - and S-waves in the $200 \mathrm{kHz}$ to $2 \mathrm{MHz}$ range. These tests were carried out on clay samples compacted under drained, uniaxial strain conditions to axial stresses of $2.5 \mathrm{MPa}$. Based on these results, the design of the compaction cell, the P-wave phased array, and the ultrasonic P- and S-wave transducers were finalized.

A schematic of the compaction cell, including the locations of the phased array and the ultrasonic transducers, is shown in Figure 1a. The cell accommodates an approximately $2 \mathrm{~cm}$ thick clay sample in a slot with the geometry and dimensions given in Figure 1b. A pair of $1 \mathrm{MHz}$ P-wave transducers are used to directly measure $\mathrm{c}_{11}-\mathrm{P}\left(0^{\circ}\right)$ in Figure 1b. Two sets of $40 \mathrm{kHz}$ S-wave transducers with polarizations parallel and perpendicular to the bedding direction- $\mathrm{SH}\left(0^{\circ}\right)$ and $\mathrm{SV}\left(0^{\circ}\right)$, respectively, in Figure $1 \mathrm{~b}$-provide direct measurements of $\mathrm{c}_{44}$ and $\mathrm{c}_{66}$. A 1 $\mathrm{MHz}$, 32-element $\mathrm{P}$-wave phased array and a P-wave pinducer (Figure 1a) are used to obtain $c_{33}$ and $c_{13}$ from plane P-wave measurements made over a range of angles $\left(0^{\circ}\right.$ to approximately $\left.60^{\circ}\right)$.

\section{SIGNIFICANCE OF FINDINGS}

The apparatus developed in this project utilizes a pair of P-wave transducers, two pairs of polarized S-wave transducers, and a P-wave phased array to recover the five TI constants during uniaxial strain consolidation. Because the measurements are performed during consolidation without the need for unloading-recoring-reloading, the apparatus can be used to investigate the development of stress-induced anisotropy in geomaterials such as clay-rich rocks and benthic sands. We anticipate that this apparatus will prove useful in investigations of the anisotropic properties of soft sediments relevant for oil and gas imaging in sedimentary basins, and for the characterization of the shallow sea floor.

\section{ACKNOWLEDGMENTS}

This work was supported by the Assistant Secretary for Fossil Energy, Office of Natural Gas and Petroleum Technology, through the National Petroleum Technology Office, Natural Gas and Oil Technology Partnership, of the U.S. Department of Energy under Contract No. DE-AC0376SF00098.

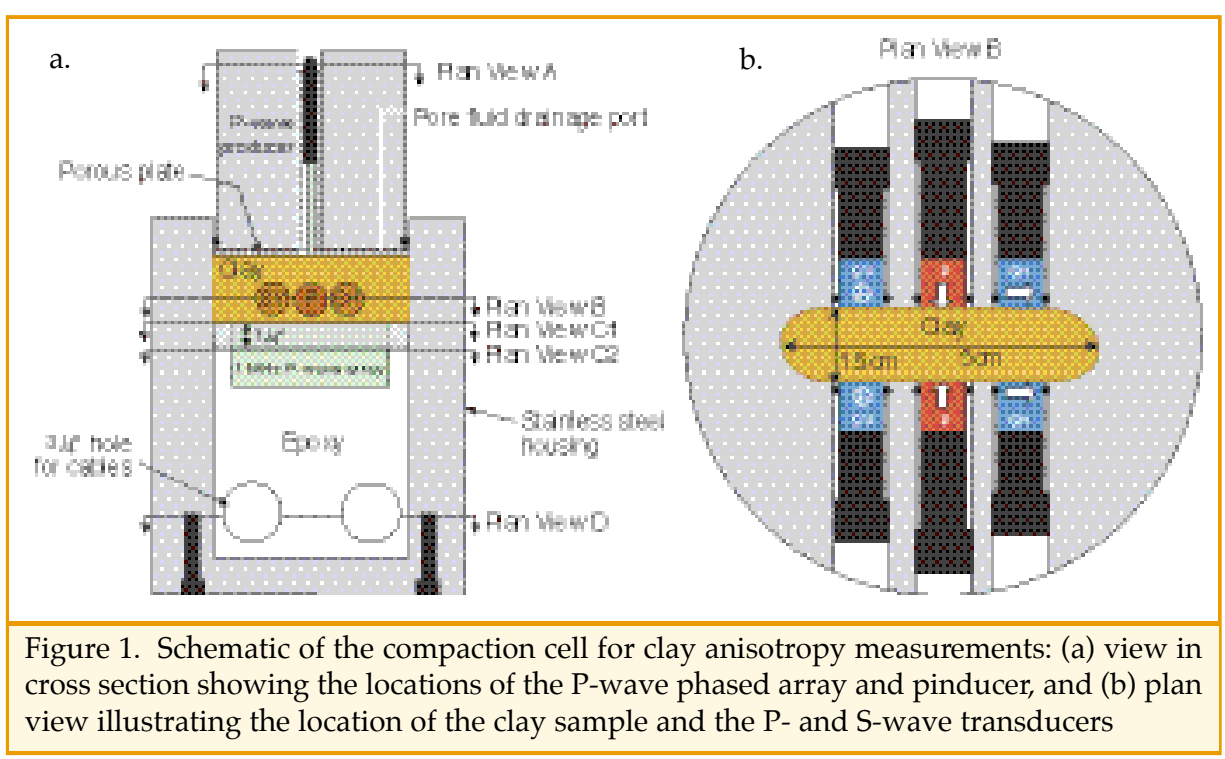

Figure 1. Schematic of the compaction cell for clay anisotropy measurements: (a) view in view illustrating the location of the clay sample and the P- and S-wave transducers

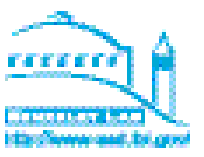




\section{Simulation of Partitioning Tracers \\ Chao Shan and Karsten Pruess \\ Contact: Chao Shan, 510-486-5718, c_shan@lbl.gov}

\section{RESEARCH OBJECTIVES}

Noble gases widely exist in nature, and except for radon, they are stable. Modern techniques can detect noble gases to relatively low concentrations and with great precision. In addition, different noble gases have different transport properties. These factors suggest that noble gases can be useful partitioning tracers for subsurface characterization. Previous research has shown that the solubility and dispersivity of a gas have strong temperature dependency, and that the dependency is gas-specific. We wanted to develop a numerical code that both simulates the transport of noble gases in the subsurface and also accounts for how temperature affects gas properties.

\section{APPROACH}

We base our code development on TOUGH2, a simulation code for multiphase, multicomponent, and heat flow. Among the many TOUGH2 modules, EOS7R specifically simulates two-phase, five-component flow and transport problems. The two phases are water and gas, and the five components are water, brine, air, and two radionuclides (Oldenburg and Pruess, 1995). For our studies, we added two subroutines to EOS7R and slightly modified the original code.

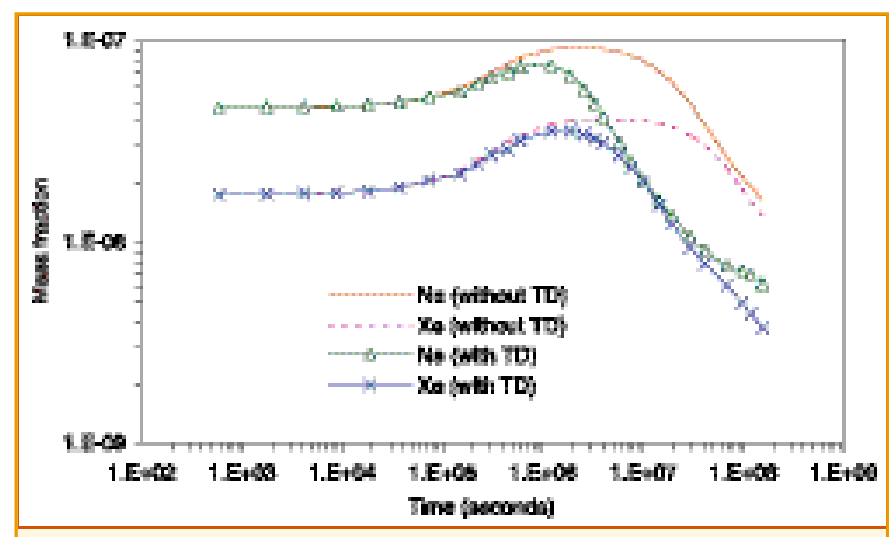

Figure 1. Noble gas mass fractions at the discharge face for example calculation.
One subroutine, called NOHEN, uses the laboratory-experiment-based Crovetto et al. (1982) model to calculate the Henry's law coefficient; the other, called GASDIF, uses the theoretical model given by Reid et al. (1987) to calculate noble gas diffusivity in the gas phase. At every time step and iteration, the program substitutes the most current temperature/pressure data to the two new subroutines to update the two coefficients for the next step of simulation.

\section{ACCOMPLISHMENTS}

A new fluid property module, EOSN, was developed for TOUGH2 to simulate transport of noble gases in the subsurface. Like most other sister modules, TOUGH2/EOSN can simulate nonisothermal multiphase flow and fully coupled transport in fractured porous media. In applying the new module, users need only to give the names of the two selected gases; all required thermodynamic properties are provided in an internal data bank. There are, however, options for users to overwrite internal molecular weights for modeling specific isotopes. Currently, six user-selectable gases are available: helium, neon, argon, krypton, xenon, and carbon dioxide. Radon may be added in the future; a capability to model radioactive decay by means of a half-life is already included in EOSN.

\section{SIGNIFICANCE OF FINDINGS}

Preliminary TOUGH2/EOSN simulations have shown that the temperature effect may play an important role in gas diffusion-dominant processes and in fluid exchange between matrix blocks and surrounding fractures. The difference in solubility and diffusivity between two different noble gases leads to a difference in resulting noble gas mass fractions (see Figure 1), which may provide additional information for subsurface studies. Vaporization and condensation of water may greatly affect mass fractions of gases, which is a factor to be considered in data analyses. The study of noble gases may be extended to any other noncondensable gases or even volatile organic chemicals (commonly referred to as VOCs).

\section{RELATED PUBLICATIONS}

Oldenburg, C. M., and K. Pruess, EOS7R: Radionuclide transport for TOUGH2. Berkeley Lab Report LBL-34868, 1995.

Shan, C., and K. Pruess, EOSN: A TOUGH2 module for noble gases. Berkeley Lab Report LBNL-52379, 2003.

\section{ACKNOWLEDGMENTS}

This work was supported by the Assistant Secretary for Energy Efficiency and Renewable Energy, Office of Technology Development, Office of Geothermal Technologies, of the U.S. Department of Energy under Contract No. DE-AC0376SF00098. 


\section{Physics-Based Reconstruction of Sedimentary Rocks \\ Dmitriy Silin and Tad Patzek \\ Contact: Dimitriy Silin, 510/495-2215, dsilin@lbl.gov}

\section{RESEARCH OBJECTIVES}

The relative permeability and capillary pressure functions define how much oil can be recovered from a reservoir. These parameters are the key input data for any reservoir simulation. The objective of this project is to develop methods of estimating the absolute permeability, capillary pressure, and relative permeability functions by analyzing 3-D images of the rock.

\section{APPROACH}

High-resolution images of rock are obtained both by electron-scanning microscopy of cores and by physics-based computer simulation of the sedimentary-rock formation process [Jin et al., 2003]. In either case, the geometry of the pore space is studied by applying methods of mathematical morphology to the digital images [Silin and Patzek, 2003; Silin et al., 2003].

\section{ACCOMPLISHMENTS}

A general approach for process-based reconstruction of sedimentary rocks has been developed [Jin et al., 2003]. The procedure includes dynamic grain sedimentation and compaction, followed by diagenesis. The results are confirmed by statistical comparison of computer-generated and natural images of sandstone cores. The mechanical properties of the natural rock, such as stress-strain curve, are also well reproduced in the computer-generated rock. Computer simulations provide an insight into rock-damage propagation as a system of coalescing microcracks.

A new, robust approach to studying the pore-space morphology of rocks from their 3-D digital images has been developed. An efficient and stable algorithm, which distinguishes between the pore bodies and pore throats and establishes their respective volumes and connectivity, has been proposed and tested. The output of this algorithm has been used to compute a dimensionless drainage-capillary-pressure curve, which simulates mercury injection. This curve is a robust descriptor of the pore-space geometry that can be used to determine the quality of natural-rock computer reconstruction (see Figure 1). An appropriate scaling of this image-analysis-based curve should enable prediction of the rock capillary pressure.

\section{SIGNIFICANCE OF FINDINGS}

Our approach provides a practical, inexpensive, and fast alternative to tedious core-flood experiments and allows the investigator to run many "what-if" scenarios. The predictive capability of the pore-scale calculations is especially important for imbibition experiments in mixed-wet rocks and in multiple drainage-imbibition cycles with two or three fluids present. For unconsolidated reservoir rock, analysis of computer-generated images, based on the known grain-size distribution, is virtually the only way to get insight into rock transport properties.

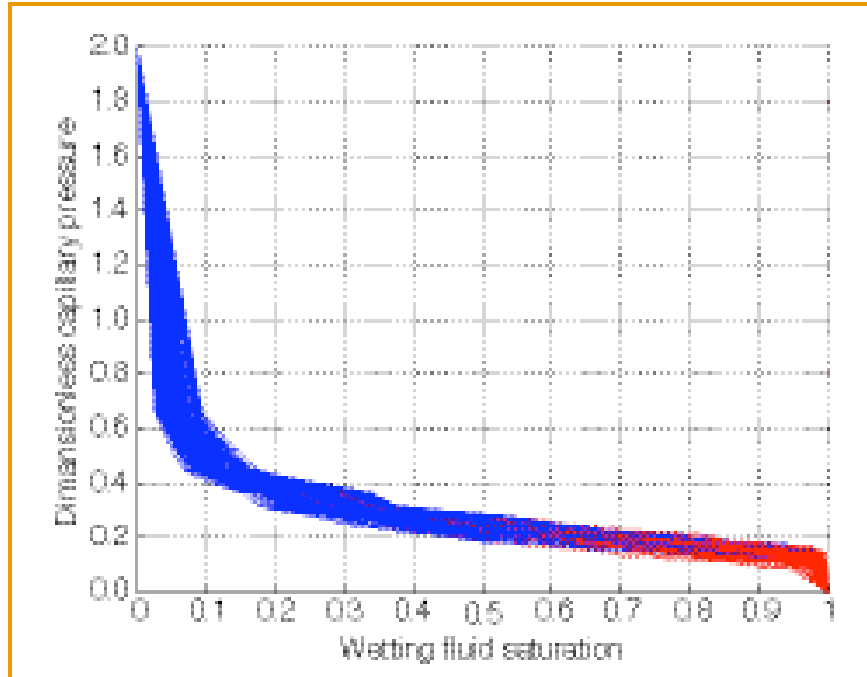

Figure 1 . These $800+$ dimensionless capillary pressurecurves have been obtained for images of Fontainebleau sandstone. The porosity of the imaged rock samples varies between $11 \%$ and $22 \%$.

\section{RELATED PUBLICATIONS}

Jin, G., T. Patzek, and D. Silin. Physics-based reconstruction of sedimentary rocks. SPE Paper 83587 presented at SPE Western Regional/AAPG Pacific Section Joint Meeting. Long Beach, California, 2003; Berkeley Lab Report LBNL-52966, 2003.

Silin, D., and T. Patzek, An object-oriented cluster search algorithm. Berkeley Lab Report LBNL-51599, 2003.

Silin, D., G. Jin, and T. Patzek, Robust determination of the porespace morphology in sedimentary rocks. SPE Paper 84296 presented at SPE Annual Technical Conference and Exhibition, Denver, Colorado, 2003; Berkeley Lab Report LBNL-52942, 2003.

\section{ACKNOWLEDGMENTS}

This research was supported by the Assistant Secretary for Fossil Energy, Office of Natural Gas and Petroleum Technology, through the National Petroleum Technology Office, Natural Gas and Oil Technology Partnership, under U.S. Department of Energy Contract No. DE-AC03-76SF00098. Partial support was also provided by gifts from ChevronTexaco and ConocoPhillips to UC Oil, Berkeley. Synchrotron images of Fontainebleau sandstone were provided by Schlumberger.

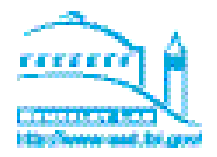




\section{Nanoscale Three-Dimensional Rock Imaging Using Focussed Ion Beam}

Liviu Tomutsa (ESD) and Velimir Radmilovic (NCEM)

Contact: Liviu Tomutsa, 510/486-5635, 1tomutsa@1bl.gov

\section{RESEARCH OBJECTIVES}

Computation of effective flow properties of fluids in porous media based on three-dimensional (3-D) pore-structure information has become more successful in the last few years, due to improvements in both input data and network models. Computed x-ray microtomography has been successful in 3-D pore imaging at micron scale, which is adequate for many sandstones. For other rocks of economic interest, such as chalk and diatomite, nanoscale resolution is needed to resolve the 3-Dpore structure. To achieve such resolution, a new method of pore imaging using Focussed Ion Beam (FIB) technology is being developed.

\section{APPROACH}

To directly access the pore structure at nanoscale scale, the FIB is used to mill successive layers of the rock material. FIB mills layers as wide as 50 micrometers and as thin as 10 nanometers by sputtering of atoms from the sample surface. The FIB, consisting of gallium ions $(\mathrm{Ga}+)$ accelerated by potentials of up to $30 \mathrm{kV}$ and currents up to 20,000 pA, yields very clean, flat surfaces in which the pore-grain boundaries appear in high contrast. No distortion of the pore boundaries caused by ion milling is apparent. After each milling step, as a new surface is exposed, a 2-D image of the surface is obtained using either the ion beam or the electron beam. While epoxy impregnation improves the contrast in the images, unimpregnated samples can yield excellent images (Figure 1). The high pore-matrix contrast is used next to binarize the 2-D images and, by stacking them, to reconstruct the 3-D structures of the pore space.

\section{ACCOMPLISHMENTS}

The FIB method was used to generate, for the first time, 3-D images of the pore spaces of Belridge diatomite and North Sea Chalk. Both these rocks have pores and pore throats in the tens to hundreds of nanometer range.

\section{SIGNIFICANCE OF FINDINGS}

Large oil reserves are present in both diatomite and chalk formations. By obtaining the 3-D pore structure of these rocks, we accomplished the first step in generating the input data needed for pore-network simulators. The
3-D pore images of complex fragile rocks, such as diatomite and chalk, are essential for the construction of idealized pore networks and the subsequent simulations of flow experiments for various displacement processes (drainage, imbibition, water-alternating gas, secondary drainage, etc.). Such experiments would be extremely difficult, if not impossible, to perform in the laboratory. The calculations provide scientific understanding of the pore-scale flow phenomena of mixedwet rocks, which control large-scale hydrocarbon or carbon dioxide flow.

\section{RELATED PUBLICATION}

Tomutsa, L., and V. Radmilovic, Focussed ion beam assisted three-dimensional rock imaging at submicron scale. Proceedings of the 2003 International Symposium of the Society of Core Analysts, Pau, France, September 21-24, 2003.

\section{ACKNOWLEDGMENTS}

This work was supported by the Assistant Secretary for Fossil Energy, Office of Natural Gas and Petroleum Technology, through the National Energy Technology Laboratory; and the Director, Office of Science, Office of Basic Energy Sciences, Materials Science Division, of the U.S. Department of Energy under Contract No. DE-AC3-76SF00098
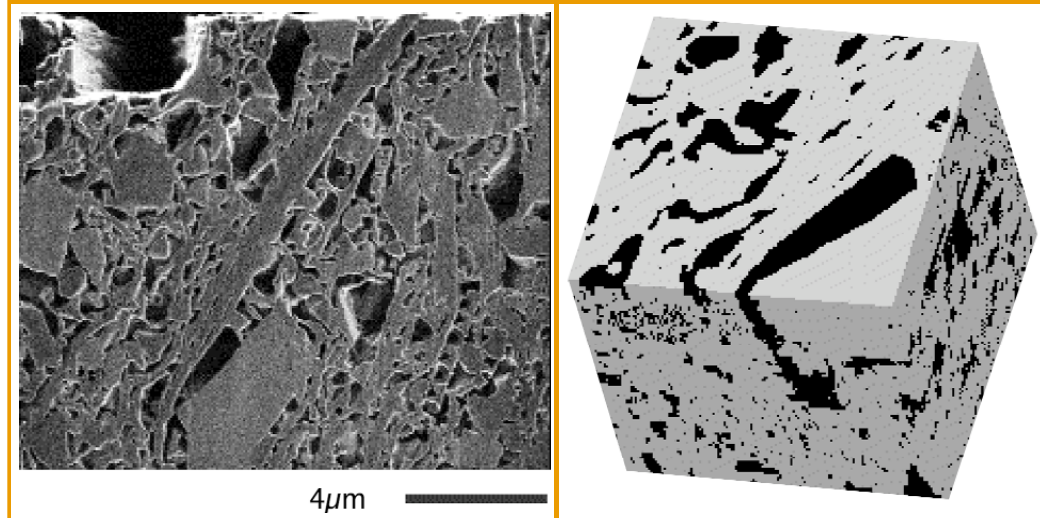

Figure 1. (a) Ion-beam image of diatomite at 20,000x magnification, (b) Diatomite volume reconstructed from binarized successive images spaced at 0.2 micron intervals. The pore space is dark . 


\title{
Finite-Difference Modeling of 3-D Anisotropic Wave Propagation USING VARIABLE GRID SPACING
}

\author{
Aoife Toomey and G. M. Hoversten
}

Contact: Aoife Toomey, 510/486-6091, actoomey@lbl.gov

\section{RESEARCH OBJECTIVES}

Finite-difference modeling is routinely carried out to aid interpretation of seismic data acquired during hydrocarbon exploration. Most hydrocarbon reservoirs are overlain by lowvelocity sediments, whose effects on the wavefield must be considered in order to successfully image deeper structures. However, the computational expense associated with finitedifference modeling is greater for low-velocity materials than for high-velocity materials. Including the effects of anisotropy on the seismic wavefield further increases the computational expense. Three-dimensional anisotropic finite-difference modeling has thus been restricted to small-scale models, unrealistic velocity structures, or long wavelengths due to its demand on computer time and memory. This research overcomes these limitations by using parallel computation and improved computational algorithms, enabling larger and more realistic geological models to be tackled.

\section{APPROACH}

We are using a fourth-order staggered-grid finite-difference (FD) solution to the wave equation. In a fourth-order scheme, the wavefield must be sampled with at least five gridpoints per seismic wavelength to avoid numerical dispersion. Geological models containing low-velocity zones require fine discretization, and hence a large number of gridpoints, because of the shorter seismic wavelengths in these zones. When a uniform grid is used, oversampling of the wavefield occurs in high-velocity zones. Using variable grid spacing improves the efficiency of the FD method by partially avoiding this oversampling. We are using the variable-gridding scheme developed by Pitarka (1999). The grid spacing is adapted to the velocity structure using spatial differential operators designed for grids with nonuniform spacing. The coefficients to the spatial differential operators depend on the spacing between gridpoints and are calculated at the beginning of the simulation.

\section{ACCOMPLISHMENTS}

We have implemented the 3-D variable-gridding anisotropic FD code to run on a 30-processor Beowulf cluster using message passing interface (MPI) . Pentium III processors with 2 GB RAM and speeds ranging between $1 \mathrm{GHz}$ and 1.4 $\mathrm{GHz}$ were used. On a single processor machine, model sizes were limited to $200 \times 200 \times 200$ gridpoints. This has increased to $620 \times 620 \times 620$ on the cluster (a 30-fold increase).

The accuracy of the variable-gridding code was tested for a homogeneous anisotropic model with the elastic properties of shale (a transversely isotropic material). We used a mesh with a constant grid spacing of $6 \mathrm{~m}$ in the two horizontal directions. The vertical grid spacing decreased abruptly from 6 $\mathrm{m}$ to $3 \mathrm{~m}$ within a $300 \mathrm{~m}$ thick layer. A $20 \mathrm{~Hz}$ Ricker wavelet was used as a pressure source. Figure 1 shows a snapshot of the wavefield showing quasi-P- and -S-waves and a pure $\mathrm{SH}$ wave. Horizontal black lines mark the change in grid spacing, which clearly has no effect on the wavefield.

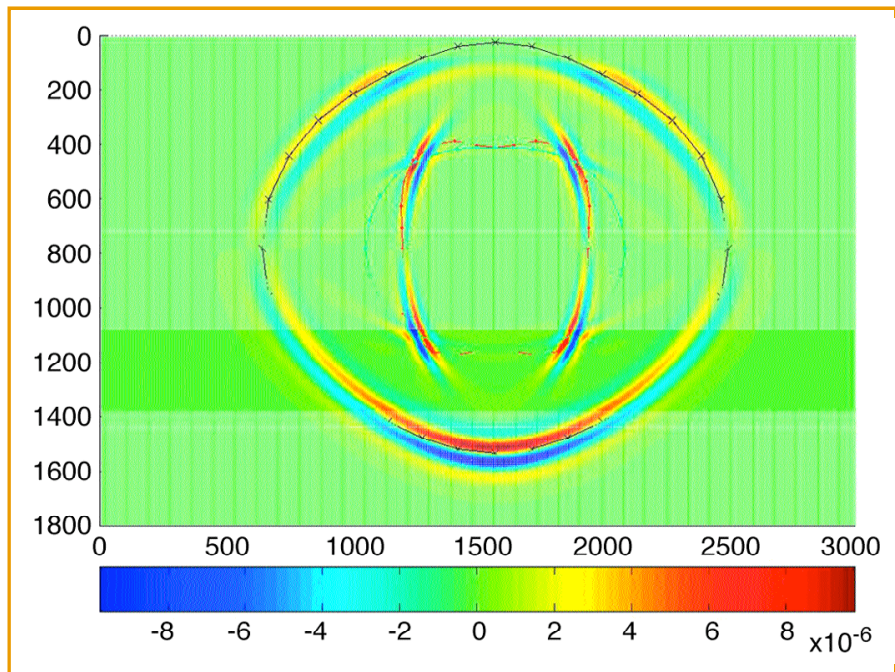

Figure 1. Snapshot of the wavefield in a homogeneous VTI model with vertical variations in grid-spacing indicated by thick black lines. Quasi-P and -S waves and a pure SH wave are unaffected by the change in grid-spacing.

\section{SIGNIFICANCE OF FINDINGS}

Our results show that variable-gridding and parallel computation can be used to reduce the computational expense associated with finite-difference modeling without any sacrifice in accuracy. These tools will enable us to incorporate more realistic velocity structure and geological complexity in largescale 3-D anisotropic finite-difference modeling.

\section{RELATED PUBLICATION}

Pitarka, A., 3-D elastic finite-difference modeling of seismic motion using staggered grids with nonuniform spacing. Bull. Seism. Soc. Am., 89(1), 54-68, 1999.

\section{ACKNOWLEDGMENTS}

This work was supported by the Assistant Secretary for Fossil Energy, Office of Natural Gas and Petroleum Technology, through the National Petroleum Technology Office, Natural Gas and Oil Technology, of the U.S. Department of Energy under Contract No. DE-AC3-76SF00098. 


\title{
Changes in Noncondensable Gases in Steam from the Cerro Prieto Geothermal Field
}

\author{
Alfred H. Truesdale, Marcelo J. Lippmann, M. H. Rodriguez ${ }^{1}$, and A. Perez ${ }^{1}$ \\ ${ }^{1}$ Comisión Federal de Electricidad, Mexico \\ Contact: Marcelo Lippmann, 510/486-5035, mjlippmann@lbl.gov
}

\section{RESEARCH OBJECTIVES}

Changes in $\mathrm{CO}_{2}$ content and nitrogen/argon $\left(\mathrm{N}_{2} / \mathrm{Ar}\right)$ weight ratios in the steam produced by wells from the eastern parts of the Cerro Prieto geothermal field of Baja California, Mexico, were studied to determine the effects of the main active processes in the reservoir (i.e., boiling, condensation, groundwater recharge, and mixing) on the gases contained in the steam.

\section{APPROACH}

Comprehensive data sets have been collected on this $>300^{\circ} \mathrm{C}$ liquid-dominated geothermal field since the beginning of the exploration phase of the project in the late 1950s. Electricity began to be produced in 1973. Chemical and production data for the period 1990-2000 were analyzed and plotted to determine changes in the distribution of $\mathrm{CO}_{2}$ concentrations and $\mathrm{N}_{2} / \mathrm{Ar}$ values with time. Only the physical aspects of the reservoir gases were studied, mainly in connection with earlier work on solute chemistry and enthalpy of well discharges.

\section{ACCOMPLISHMENTS}

The results of this study agree in general with our earlier understanding of the response of the Cerro Prieto reservoir to pressure drawdown due to large mass extraction rates. (About 14,000 tons/hour are extracted and some 3,500 tons/hour are injected back into the reservoir.) In areas of boiling, production enthalpy increased greatly, and $\mathrm{CO}_{2}$ content in steam increased two to three times. Nitrogen/argon ratios remained near that of air-saturated surface waters, but were lower in areas where boiling decreased and where production originated from gas-depleted brines residual to boiling. Newly drilled deeper wells also produced steam that was low in gas and $\mathrm{N}_{2} / \mathrm{Ar}$ ratios, suggesting that these zones were also affected by boiling and gas loss. Injection of highly evaporated, air-equilibrated brine seemed to have little effect on the gases in the steam. There is evidence of a 1990 short-term, high $\mathrm{N}_{2} / \mathrm{Ar}$ anomaly in the eastern part of the field (Figure 1), possibly from injection of air with the residual brine. There is also evidence that in 1995 and 1996, the northeastern region of the field produced steam with much higher $\mathrm{N}_{2} / \mathrm{Ar}$ ratios, perhaps reflecting a bubble of altered magmatic gas that entered the system at depth.

\section{SIGNIFICANCE OF FINDINGS}

The results show that it is possible to identify reservoir processes by studying the chemical and physical response of wells to large-scale exploitation. These studies are valuable for anticipating changes in fluid production behavior. The information helps design appropriate changes in the field management plan that may reduce any future negative impact on the field's energy output. This is especially true at Cerro Prieto, since its electricity output satisfies the needs of about a million people (the present installed capacity is $720 \mathrm{MW}$ ). The work also seems to indicate that bubbles of magmatic gas are injected periodically into the geothermal reservoir as part of the recharge mechanism of the system. This hypothesis warrants further study.

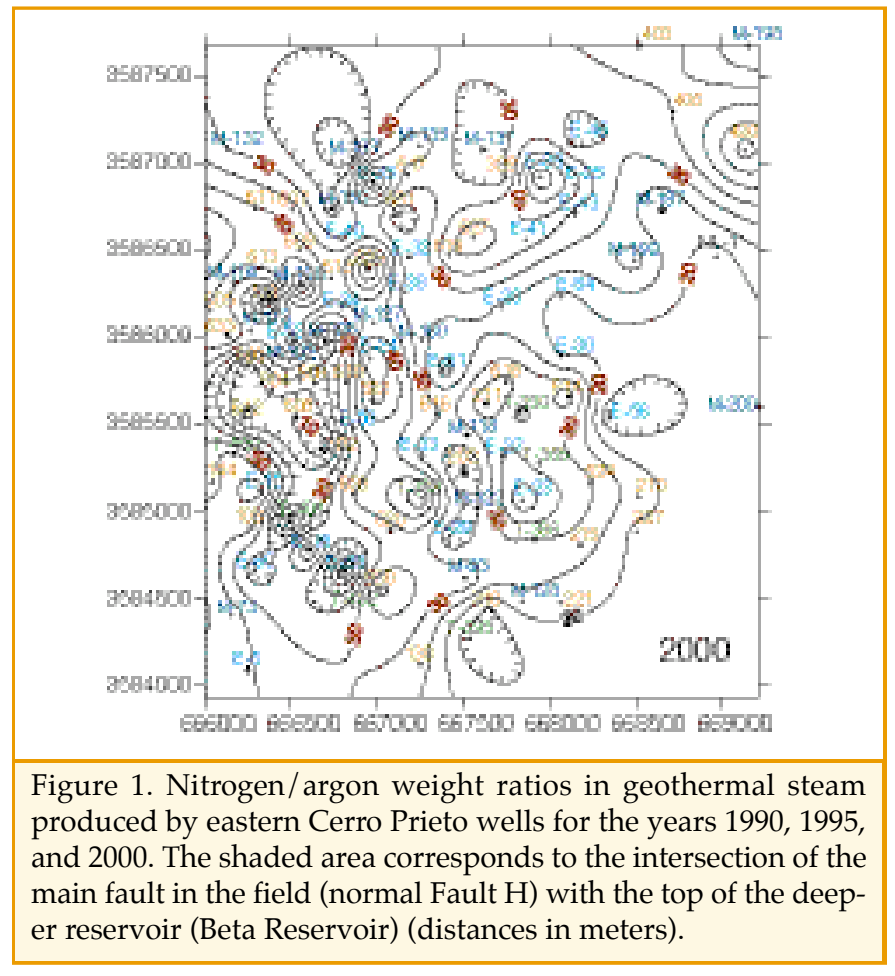

\section{RELATED PUBLICATIONS}

Lippmann, M.J., A.H. Truesdell, M.H. Rodríguez, and A. Pérez, Response of Cerro Prieto II and III to exploitation. Geothermics, 2003 (in press).

Truesdell, A.H., M.J. Lippmann, M.H. Rodríguez, and A. Pérez, Influence of reservoir processes on gas in Cerro Prieto steam. Geothermal Resources Council Trans., 27, 2003 (in press); Berkeley Lab Report LBNL-53499.

\section{ACKNOWLEDGMENTS}

Most of this work was supported by the Assistant Secretary for Energy Efficiency and Renewable Energy, Office of Technology Development, Office of Geothermal Technologies, of the U.S. Department of Energy under Contract No. DE-AC0376SF00098. The rest of the support came from the Comision Federal de Electricidad of Mexico. 


\section{3-D Resistivity Imaging of Single-Hole EM Data \\ Hung-Wen (Ocean) Tseng and Ki Ha Lee \\ Contact: Hung-Wen Tseng, 510/486-5502, hwtseng@lbl.gov}

\section{RESEARCH OBJECTIVES}

Traditionally, electromagnetic (EM) induction logging has been widely used for directly measuring the formation conductivity surrounding uncased wells. Such a logging tool primarily consists of a magnetic dipole transmitter and a receiver in a coaxial configuration, in line with the borehole axis. As a result of this cylindrically symmetric nature of source and receiver, induction logging data offer no information about the 3-D conductivity distribution in the vicinity of the borehole. We can only characterize the 3-D conductivity structure surrounding a borehole if we can acquire multiple components of the magnetic fields resulting from various source polarizations. However, 3-D interpretations using such single-hole EM data are difficult because of the richness and complexity of the data and the very large number of discretized conductivity elements needed to construct a realistic earth model. Taking advantage of the computing efficiency of an algorithm based on a modified extended Born approximation (MEBA), we have developed an algorithm for simulating and interpreting EM data acquired in a single-hole environment.

\section{APPROACH}

Successful 3-D interpretation of geophysical EM singlehole data depends on the efficiency of a fast forward simulation as well as a sound inversion strategy. For EM simulations, scattered magnetic field at observing locations can be calculated, provided the total electric field in a confined conductivity inhomogeneity is known. This electric field can be derived using the integral equation method. However, this method quickly becomes impractical if the number of discretized cells making up the anomalous region exceeds a certain limit. Based on an approximation approach, the MEBA technique avoids this problem by calculating the total electric field in the electrical conductivity anomaly without solving any huge matrix equation. This methodology also provides an efficient way to calculate the Jacobian matrix for a 3-D inversion, which is based on a least-squares criteria and uses a conjugate gradient method for solving the system matrix equation.

\section{ACCOMPLISHMENTS}

We have verified the algorithm with simulation data. A set of single-hole data collected at a site for a pilot $\mathrm{CO}_{2}$ injection project in southern California was used for inversion. The inverted conductivity structure around a borehole is displayed in Figure 1. Electrical conductivity variation within $8 \mathrm{~m}$ around the borehole is clearly indicated-this could never have been achieved with logging data. The results conform well to induction logging data and a crosshole section.

\section{SIGNIFICANCE OF FINDINGS}

With multicomponent magnetic data, 3-D interpretation of geophysical EM single-hole data is now practical on PC-based computing platforms. Weightings of the data must be carefully selected because of the strong transmitter-receiver coupling between the transmitting and receiving units for coaxial and co-planar components.

\section{RELATED PUBLICATION}

Tseng, H.-W., K.H. Lee, and A. Becker, 3-D interpretation of electromagnetic data using a modified extended Born approximation. Geophysics, 68, 127-137, 2003.

\section{ACKNOWLEDGMENTS}

This work was supported by the Assistant Secretary for Energy Efficiency and Renewable Energy, Office of Technology Development, of the U.S. Department of Energy under Contract No. DE-AC03-76SF00098. We are also grateful for financial support and field data offered by Electromagnetic Instruments, Inc.

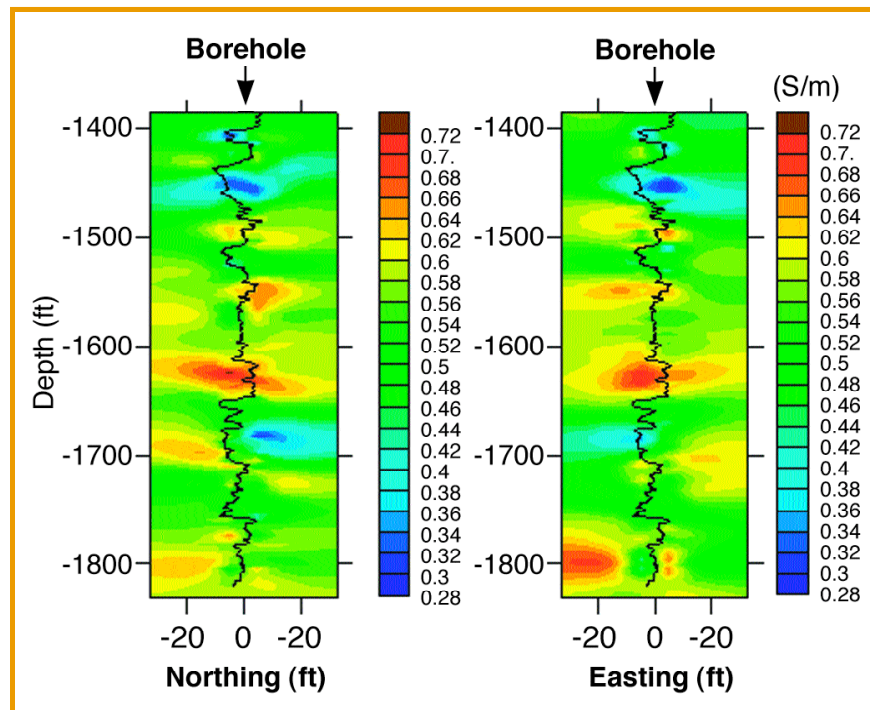

Figure 1. Inverted conductivity structure centered at a borehole in the $\mathrm{CO}_{2}$ injection project site. Transmitter-receiver separation was $5 \mathrm{~m}$; transmitter operating frequency was $6 \mathrm{kHz}$. Because of a vertical source, all three magnetic-field components were used for the inversion. The induction logging data is also displayed at the center of each panel for comparison.

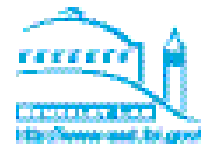




\section{RAPID IMAgING OF INTERWEll Fluid SATURATIONS Using Seismic and Multiphase Production Data \\ Don Vasco and Akhil Datta-Gupta ${ }^{1}$ \\ ${ }^{1}$ Texas A \& M University \\ Contact: Don Vasco, 510/486-5206,dwvasco@lbl.gov}

\section{RESEARCH OBJECTIVES}

Seismic imaging is a very powerful tool for obtaining highresolution views of the subsurface. The current goal of this research project is to use seismic and fluid flow observations to estimate reservoir flow properties such as porosity and permeabilities.

\section{APPROACH}

This year, we have developed a method that maps estimates of reservoir pressure change, obtained from geophysical observations, into interwell permeability variations. This technique allows us to obtain high-resolution images of reservoir permeability in a reliable fashion. The method derives from the fact that if we fix the pressure in the equation for fluid flow, we have a linear first-order partial differential equation for permeability. Thus, we use the time-lapse data to estimate pressure variations in the reservoir. We then substitute these pressures in the flow equation and solve for permeability.

\section{ACCOMPLISHMENTS}

We have applied the imaging technique to a set of crosswell seismic and electromagnetic data gathered at the Lost Hills oil field. Time-lapse crosswell data were collected before and after the injection of $\mathrm{CO}_{2}$. The data were first mapped into water and $\mathrm{CO}_{2}$ saturation changes and pressure changes between the wells (Figure 1a). Based upon these changes, we then inferred reservoir permeability variations (Figure 1b).

\section{SIGNIFICANCE OF FINDINGS}

The results are significant because they enable us to estimate permeability directly from geophysical observations. Note specifically that reservoir simulation is not required in this approach. Furthermore, the inverse problem for permeability is linear in nature, and consequently the solution is more robust and less sensitive to an initial reservoir model. Also, we can estimate permeability in regions that have undergone pressure changes. Thus, we can estimate permeability for portions of the reservoir that have not yet been produced.

\section{RELATED PUBLICATIONS}

Vasco, D.W., K. Karasaki, and K. Kishida, A coupled inversion of pressure and surface displacement. Water Resour. Res., 37, 3071-3089, 2001.

Vasco, D.W., A. Datta-Gupta, R. Behrens, P Condon, and J. Rickett, J., 2003. Seismic imaging of reservoir flow properties: Time-lapse amplitude changes. Geophysics 2003 (submitted).

Vasco, D.W., Seismic imaging of reservoir flow properties: Timelapse pressure changes. Geophysics, 2003 (submitted).

\section{ACKNOWLEDGMENTS}

This work was supported by the Assistant Secretary for Fossil Energy, Office of Oil Gas and Shale Technologies, of the U.S. Department of Energy under Contract No. DE-AC0376SF00098. All computations were carried out at the Center for Computational Seismology of Berkeley Lab.
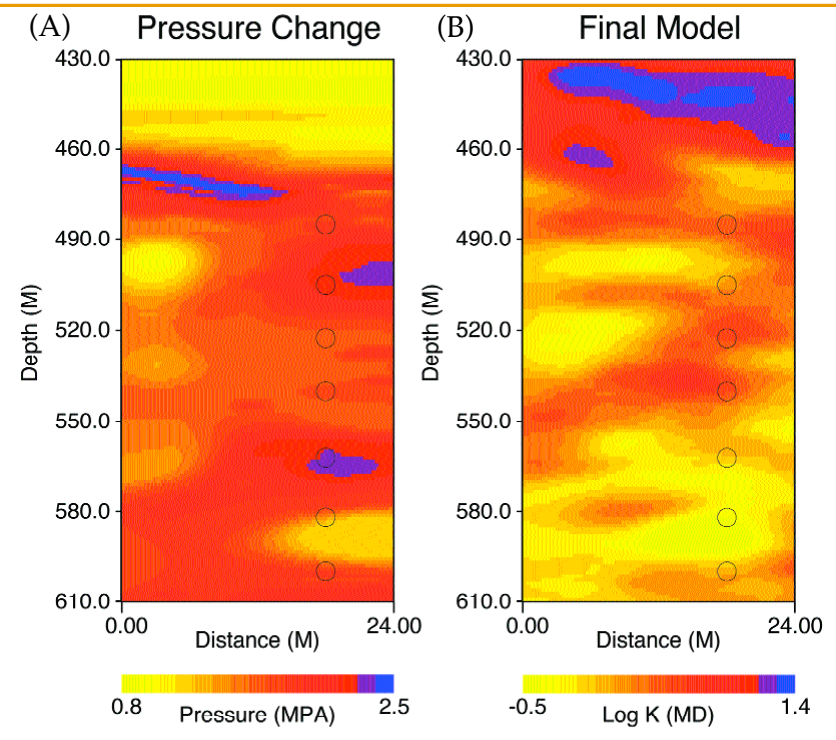

Figure 1. (A) Pore pressure changes due to the injection of $\mathrm{CO}_{2}$. (B) Estimates of reservoir permeabilities in the interwell region. 



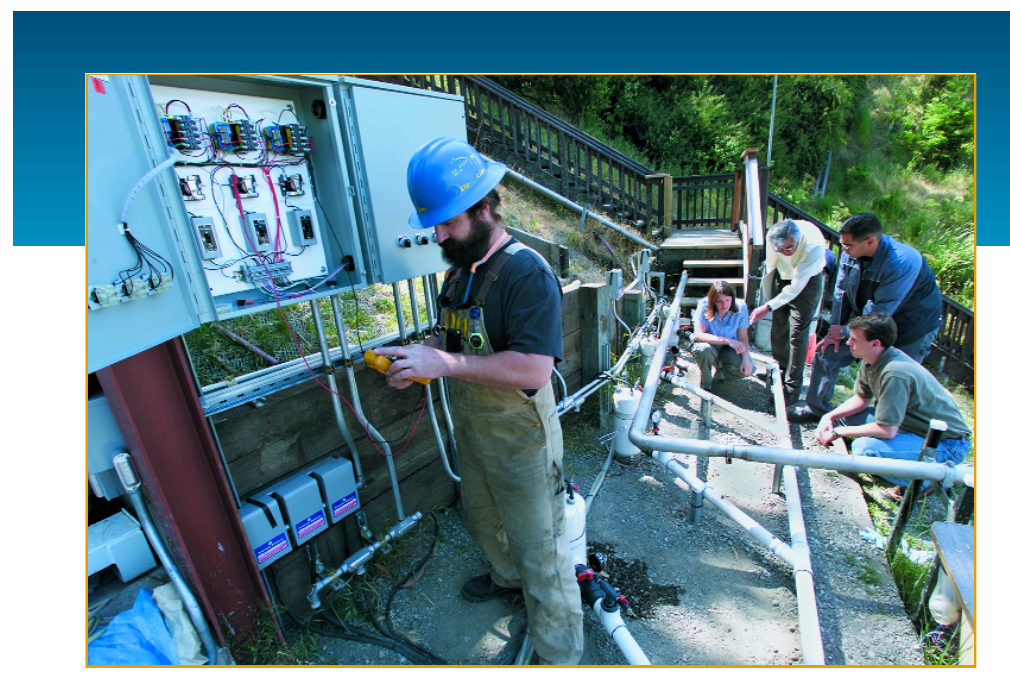

Research Program ENVIRONMENTAL REMEDIATION TECHNOLOGY

The Environmental Remediation Technology Program (ERTP) conducts multidisciplinary environmental research on characterization, monitoring, modeling, and remediation technologies. This research is directed primarily at U.S. Department of Energy and Department of Defense waste site problems, as well as pollution problems in California-especially those targeted by the CALFED program for the San Francisco Bay/Delta. Since many of the contaminants or closely related compounds found at these sites are also dominant at industrial waste sites, much of this research is also applicable to problems faced by the private sector and other government agencies. These projects are both basic and applied, and include everything from molecular studies to full-scale field deployments in all types of media (gas, water, sediment), in all types of environments (wetlands to deserts). This year's major customers have been DOE Office of Environmental Management, DOE Office of Science, DOE National Nuclear Security Administration Chemical and Biological NonProliferation Program NN-22, Work for Others-DOD, Work for Others-USEPA, Work for Others-CALFED, and Work for Others (Industry and Other Government Agencies).

\section{DEMONSTRATIONS AND DEPLOYMENT}

ERTP supports DOE's Office of Environmental Management (EM) in both the areas of Environmental Restoration and the Office of Science and Technology. Berkeley Lab ESD scientists directly supervise characterization, remediation, and monitoring, and provide regulatory and permitting support to Berkeley Lab's Environmental Health and Safety Department for all environmental problems on site. During this past year, the program demonstrated and deployed technologies for thermally enhanced vapor extraction of volatile organic compounds (VOCs), constant-head well testing for characterization of low-yield porous materials, and groundwater flow models for complex geological structures.

This past year, ERTP has developed a new method, implemented in a code called ODA, to analyze the operation pumping rates for underground injection of liquid wastes for the U.S. Environmental Protection Agency. This represents a significant safety enhancement over normal injection practices. ERTP scientists have also shown how strontium isotopes can be used to determine vadose zone infiltration flux and how carbon isotopes can be used to measure biodegradation rates of buried waste by carbon dioxide analyses of soil gas. At DOE waste sites, they have also demonstrated how uranium isotope analysis can be used to determine source histories and migration rates. In addition, ERTP scientists have field-demonstrated a new crosswell high-frequency seismic method for determining nonaqueous-phase liquid (NAPL) contamination in groundwater aquifers. Since NAPL is the hardest contaminant source to detect and remediate, this method could save both time and money in characterization and monitoring during and after remediation.

ERTP also supports EM with technical expertise via the International Programs in Russia, Ukraine, and Argentina; Environmental Laboratory Council, EM Technical Assistance Program, the multi-agency DNAPL Technology Advisory Group, and the Hanford Vadose-Groundwater-River Integrated Program.

\section{FIELD AND LABORATORY STUDIES}

DOE's Office of Science provides funding for several ERTP projects. The basic research projects funded in this area take advantage of the unique facilities at Berkeley Lab, such as the Advanced Light Source, where researchers look at the interactions between contaminants, water, and minerals at the microscale. ERTP scientists have also shown how humic acid

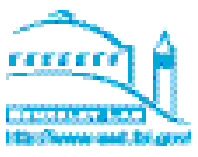


accelerates biodegradation of organic contaminants using synchrotron IR methods. Further, ERTP is conducting a project (funded by the Natural and Accelerated Bioremediation Research [NABIR] program) that looks at mesoscale biotransformation dynamics as the basis for predicting core-scale reactive transport of chromium and uranium. The Environmental Management Science Program (EMSP) funds projects on the geochemical evolution of highly alkaline and saline tank waste plumes in vadose zone sediments at DOE waste sites. DOE's Initiatives for Proliferation Prevention program also funds ERTP for bioprospecting in the extreme environments of the Kamchatka Peninsula in Russia.

ERTP efforts have recently achieved numerous scientific breakthroughs and advancement in knowledge. ERTP scientists showed this year that biological treatment of mixed wastes represents a safer alternative to incineration. Using a drip-feed bioreactor, ERTP scientists were able to degrade mixed wastes containing acetonitrile and tritium, so that only the radioactive component remained without dilution. ERTP scientists also developed a new module for the TOUGH2 simulator that models landfill biodegradation processes - to allow landfill management of optimal biodegradation rates for faster and safer closure. Moreover, using EMSP funding, ERTP scientists have developed a new high-frequency electromagnetic impedance measurement system for characterization, monitoring, and verification for buried waste and landfills. ERTP scientists have also demonstrated new techniques for measuring microbial backgrounds in air, using DNA microarrays that can determine variations in community structure from site to site. The effects that perturbations might have on key organisms can thus be determined, as can the reliability of various detection systems.

\section{DEMONSTRATIONS AND TECHNICAL ASSISTANCE FOR INDUSTRY/ OTHER AGENCIES}

ERTP has researched selenium transport in the Grassland Water District, California, for many years. Recent research has focused on better methods for compliance monitoring and management. The U.S. Bureau of Reclamation has sponsored this work in an effort to better manage selenium loading in the agricultural wastewater of the San Luis Drain. ERTP scientists showed that real-time management of dissolved oxygen in the San Joaquin River Deep Water Ship Channel was possible. The Sonoma County Water Agency has also funded ERTP scientists to model hydraulic conductivities along the Russian River in northern California, using groundwater temperature profiles. ERTP scientists have also developed a real-time sensor that can monitor suspended sediment loads and streams, and thus improve watershed management.

ERTP also provides technical consultation to private industry and other government agencies on implementing Berkeley Lab- and DOE-patented technologies at private and government-owned sites. Private industry must have a license to the technology for use at private sites, and all ERTP expenses are reimbursed by the company or another agency. Several contracts this year were executed for consultation regarding bioremediation and characterization.

\section{NABIR PROGRAM OFFICE}

ERTP continued to be the Natural and Accelerated Bioremediation Research (NABIR) Program Office for the Office of Science. The NABIR Program Office maintains the dynamic NABIR Web home page (www.lbl.gov/NABIR/) with links to investigators, program element managers, science team leaders, recent publications, annual meeting registration, calls for proposals, review documents, and other Web sites. In addition, the NABIR Program Office also organizes the NABIR annual investigators meeting, with more than 150 participants and sessions for posters, presentations, and breakout sessions. Moreover, the NABIR Program Office is producing a new NABIR bioremediation primer that will be available to the public in print or electronically on the NABIR home page. The NABIR program office also assisted DOE-HQ in reviewing and evaluating field-project implementation at the Field Research Center for the NABIR program at Oak Ridge National Laboratory.

\section{PARTNERS AND FUNDING}

ERTP receives support from DOE programs in the Offices of Science and Environmental Management. The EM programs include the Environmental Management Science Program (now in the Office of Science); the Subsurface Contaminants Focus Area; and the Characterization, Monitoring, and Sensor Technology Crosscutting Program. The Office of Science funds the NABIR Program Office at Berkeley Lab, and the Office of Science, Office of Biological and Environmental Research funds two environmental remediation projects. The DOE IPP and NN22 also fund two biological monitoring and bioprospecting projects. Support is also provided by the Department of Defense, Cal-EPA, other DOE Labs, DHS, UC Berkeley, and the U.S. Bureau of Land Management. 


\title{
DNA Microarrays For Characterization of Microbial Backgrounds
}

\author{
Gary Andersen, Todd DeSantis, and Sonya Murray
}

Contact: Gary Andersen, 510/495-2795, glandersen@lbl.gov

\section{RESEARCH OBJECTIVES}

The primary goal of this project is to understand the quantity and composition of background microorganisms in the environment and to define and predict their ability to interfere with DNA-based pathogen detection systems. By providing baseline knowledge of bacterial organisms in urban aerosols and other environmental samples, this work will make it possible to predict the sensitivity, accuracy, and reliability of DNA-based detection schemes under "real world" conditions. Characterization of bioaerosols is also important for determining the long-term effects of introducing engineered microorganisms for biopesticides and bioremediation on downwind environments.

\section{APPROACH}

Sequence variation within the $16 \mathrm{~S}$ rRNA gene was used to provide an effective method for the identification of bacteria in environmental samples without the need for their cultivation. Taking advantage of the fact that all bacteria possess a $16 \mathrm{~S}$ rRNA gene, we developed a high-density oligonucleotide microarray for simultaneous identification of all bacterial components in any complex environmental sample. Multiple, sequence-specific probes target sections of the gene that are unique to each species. The combinatorial power of multiple probes increases the confidence of correct species identification. Our latest design has 500,000 probes arrayed on a $1.3 \mathrm{~cm}^{2}$ surface. The unique discriminatory power of this microarray allows, for the first time, a high-throughput method for finescale microbial species composition measurements. Thus, it is

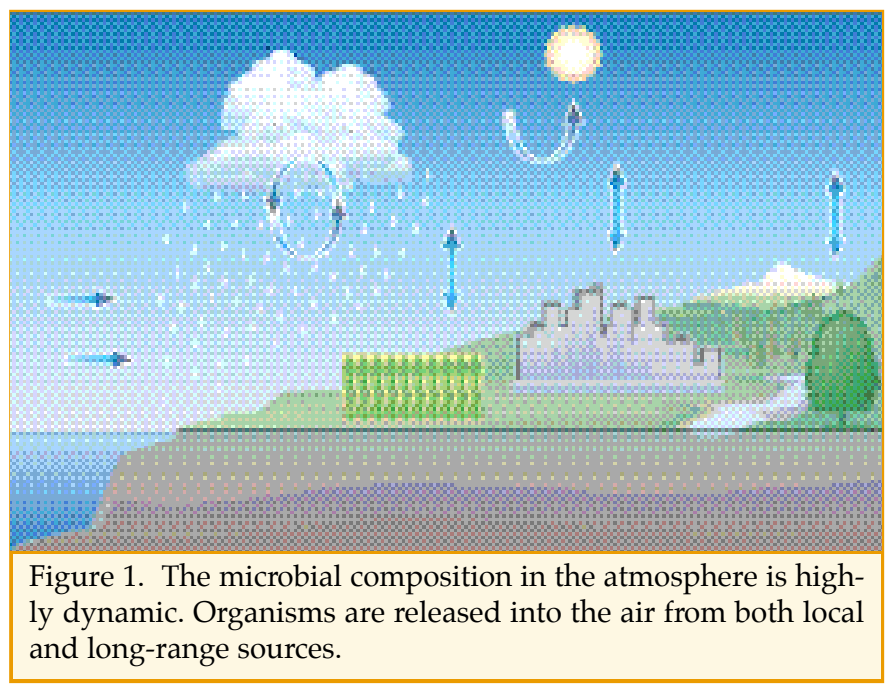

possible to measure, over time, the fate of hundreds of different species in a complex microbial community subject to meteorological or other variations.

\section{ACCOMPLISHMENTS}

We collected replicated aerosol samples from two biosurveillance studies targeting 12 U.S. cities and from an eight-site longitudinal transect comparing urban and rural bacterial community composition. Changes in microbial community composition were observed from city to city and from urban to rural areas. Information on bacterial species composition and relative amounts as determined by the strength of the hybridization interaction is being placed on a database. An information retrieval network is being established that will allow researchers to identify predominant organisms for specific cities, seasons, or other user-defined variables.

\section{SIGNIFICANCE OF FINDINGS}

Variations from site to site suggest that local reservoirs play a significant role in bacterial community composition. The increased diversity of urban sites over rural sites further strengthens this observation, with a greater number of distinctive habitats in the urban areas. The sequence-specific hybridization of $16 \mathrm{~S}$ rRNA to a microarray allows the gathering of detailed information on microbial composition and diversity for any environmental sample. By comparing the microbial species composition before and after an environmental perturbation, key organisms may be identified.

\section{RELATED PUBLICATIONS}

Wilson, K. H., W.J. Wilson, , J.L. Radosevich, T. Z. DeSantis, V. S. Viswanathan, T.A. Kuczmarski, and G.L. Andersen, High density microarray of small subunit ribosomal DNA probes. Appl. Env. Micro., 68 (5), 2535-2541, 2002.

DeSantis, T. Z., I. Dubosarskiy, and G.L. Andersen, Comprehensive aligned sequence construction for automated design of effective probes (CASCADE-P) using $16 \mathrm{~S}$ rDNA. Bioinformatics, 19 (July 2003 issue).

\section{ACKNOWLEDGMENTS}

This work was supported by the National Nuclear Security Administration (NNSA) Chemical and Biological NonProliferation Program, NN-22, for the U.S. Department of Energy under Contract No. DE-AC03-76SF00098.

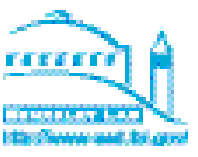




\section{SMART StORAge OF LANDFilled WASTE}

Sharon E. Borglin, Terry C. Hazen, Curtis M. Oldenburg, and Peter T. Zawislanski

Contact: Sharon E. Borglin, 510/486-7515, seborglin@lbl.gov

\section{RESEARCH OBJECTIVES}

Although Subtitle D landfills are permitted to contain only nonhazardous municipal solid waste (MSW), in fact they often include substances such as metals, solvents, halogenated organics and mercury. Currently, most landfills are "dry tombs" because moisture and air exposure are restricted, slowing biodegradation of the waste and increasing the time required for landfill stabilization. The time period over which the waste presents itself as a risk for contamination of air and water extends to decades, severely limiting land reuse options. In addition, landfill costs have more than doubled in the last 15 years, as the requirements for stabilization and containment of waste have become increasingly stringent, and obtaining a permit for a new landfill site has become more costly.

Smart Storage is the active control of the waste containment environment for accelerated degradation and stabilization of landfill waste. Smart Storage provides a framework for managing landfilled waste that includes long-term, cost-effective, and environmentally sustainable solutions based on bioreactor technology. Extreme heterogeneity and the large scale of landfills make comparison between the technologies difficult. This study directly compares identical MSW samples in controlled laboratory conditions to give rela-

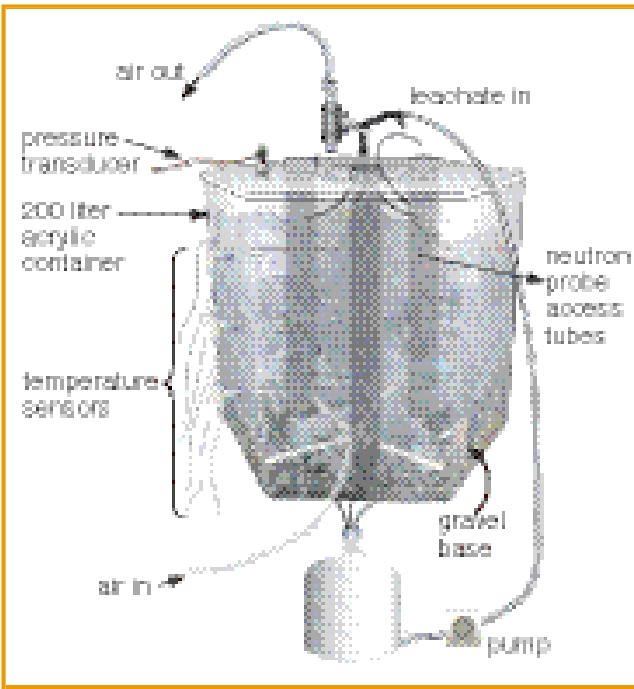

Figure 1. Schematic of the laboratory landfill bioreactor tive rates of settlement, gas production, and leachate quality to support the decision-making process concerning aerobic and anaerobic strategies.

\section{APPROACH}

Mesoscale laboratory reactor systems (see Figure 1) filled with MSW were used to measure respiration rates, methane and carbon dioxide generation rates, subsidence, and leachate quality. Three treatments were applied to the bioreactors: (1) aerobic landfill (air injection with water addition and leachate recirculation), (2) anaerobic landfill (no air injection, water addition and leachate recirculation) and (3) no treatment (no air injection or leachate recirculation), which was converted to a wet, aerobic landfill (air injection with water addition and leachate recirculation).

\section{ACCOMPLISHMENTS}

Measurements of leachate quality and gas production clearly demonstrate that aerobic treatment of MSW creates a more stable and environmentally benign waste mass over a shorter treatment time than does anaerobic waste treatment. Comparison of carbon production from both aerobic and anaerobic reactors shows that in the 400-day test period, the aerobic tank produced $6 \mathrm{~mol} \mathrm{C} / \mathrm{kg}$ MSW, whereas the anaerobic bioreactor produced $4 \mathrm{~mol} \mathrm{C} / \mathrm{kg}$ waste. Thus, the aerobic tank was 50\% more stabilized than the anaerobic bioreactor. Additionally, methane production was slowed in the anaerobic tank by excess ammonia production, potentially requiring an additional treatment step for removal. Elevated levels of several metals and biochemical oxygen demand were measured in the anaerobic leachate. These leachate quality issues associated with the anaerobic system would require additional investigation.

\section{SIGNIFICANCE OF FINDINGS}

This study directly compared identical MSW samples in controlled laboratory conditions to give relative rates of settlement, gas production, and leachate quality to support the decision-making process concerning aerobic and anaerobic strategies. The study shows that although both aerobic and anaerobic treatment is superior to dry-tomb landfill management, the aerobic treatment is a more sustainable and environmentally friendly solution.

\section{RELATED PUBLICATION}

Borglin, S.E., T.C. Hazen, C.M. Oldenburg, and P.T. Zawislanski, Comparison of aerobic and anaerobic biotreatment of municipal solid waste. Journal of the Air and Waste Management Association, June 2003 (submited).

\section{ACKNOWLEDGMENTS}

This work has been supported by Laboratory Directed Research and Development (LDRD) funding from Berkeley Lab, provided by the Director, Office of Science, of the U.S. Department of Energy under Contract No. DE-AC03-76SF00098. 


\title{
Real-time Sensor to Monitor Suspended Sediment Loads in Streams
}

\author{
Chris G. Campbell \\ Contact: 510/495-2953, cgcampbell@lbl.gov
}

\section{RESEARCH OBJECTIVES}

Throughout California and worldwide, water quality is negatively impacted by suspended sediments in surface water bodies. Not only is sediment itself a major pollutant, but additional contaminants in these environments, including heavy metals and organic compounds like polychlorinated biphenyls, dioxins, and pesticides, are likely to be adsorbed to suspended sediments. Unfortunately, current methods to measure the total mass of suspended sediment mobilized in storm water runoff are inadequate. As a result, it is impossible to accurately estimate the total load of either sediment or associated contaminants transported with sediments during storms.

In response to this challenge, our project developed a fiberoptic in-stream technology (FIT) for continuous measurements of suspended sediment load in surface waterways. Our research objectives were to:

(1) Assemble and test the FIT for light absorbance measurements in suspended sediment solutions.

(2) Address calibration issues.

(3) Compare measurements to a commercially available turbidity probe.

(4) Examine portable and stationary field measurement designs.

\section{APPROACH}

The FIT is based on optical light absorbance occurring between two linear fiber-optic arrays. Suspended sediment moving between the source and detector decreases the total light intensity reaching the detector. Light in the red spectra (around $680 \mathrm{~nm}$ ) was selected to focus on sediment particles. Commercially available turbidity probes measure light scattering at a $90^{\circ}$ angle, which is extremely sensitive to sediment geometry (e.g., particle size and shape). The increased sampling size, linear arrangement, and uniquely paired source and detectors make the FIT a superior device for estimating sediment loads.

\section{ACCOMPLISHMENTS}

Our proof-of-concept studies examined using a low-energy light source, a red light-emitting diode (LED), connected to a linear fiber-optic array, to measure suspended sediments in a specially designed storm water simulator. Tests examined sediment loads ranging from 1 to $10 \mathrm{~g} / \mathrm{L}$, with five particle size classes from 45 to $1,000 \mathrm{~mm}$. We also compared the FIT to a commercially available turbidity probe. Applications of the FIT were successful, with a high signal-to-noise ratio. By adjusting the source-detector spacing, we showed that the linear measurement range may be optimized for a 1 to $10 \mathrm{~g} / \mathrm{L}$ load (Figure 1). This linear relationship allows for simple device-calibration procedures.

The turbidity probe also measured a linear response to the suspended sediment, but reached a maximum measurement at $3.0 \mathrm{~g} / \mathrm{L}$ (Figure 1). This maximum may be insufficient in streams that commonly reach maximum loads of $10 \mathrm{~g} / \mathrm{L}$ during large storms. The variability in turbidity measurements is also much larger than the FIT, because of turbidity's sensitivity to sediment geometry.

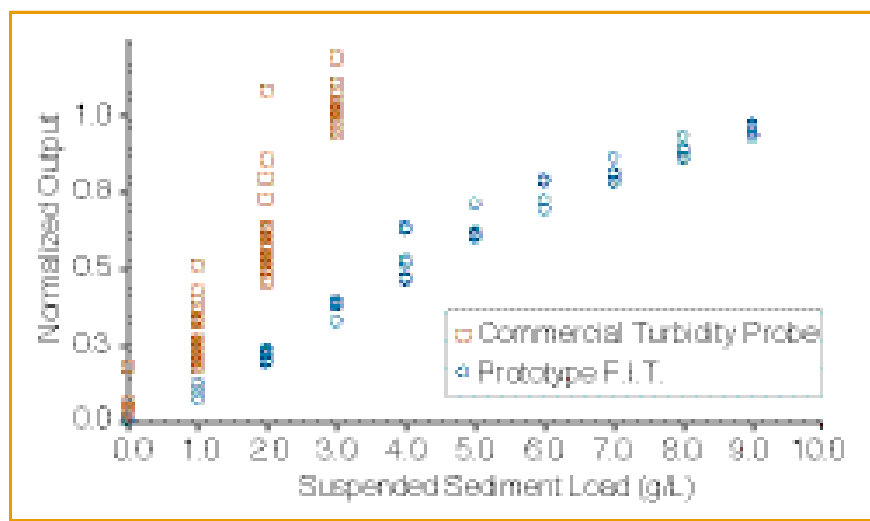

Figure 1. Measurements collected from the prototype FIT (circles) and a commercially available turbidity probe (squares) for suspended sediment loads of 1.0 to $10.0 \mathrm{~g} / \mathrm{L}$ and for 5 different particle size classes. Data were collected in the laboratory using a specially designed storm water simulator. The Y-axis is the measurement value normalized between 0 and 1 .

\section{SIGNIFICANCE OF FINDINGS}

The FIT is an accurate, simple to calibrate, inexpensive, and reliable alternative to turbidity measurements for real-time measurements of suspended sediment loads in streams. The application of devices like the FIT could provide information that would ultimately improve stream water quality.

\section{ACKNOWLEDGMENTS}

The author would like to thank Danny Laycak, Jim Richards, and Bill Hoppes of Lawrence Livermore National Laboratory. A portion of this work was performed under the auspices of the U.S. Department of Energy by the University of California Lawrence Livermore National Laboratory under Contract No. W-7405-Eng-48, funded by the Laboratory Directed Research and Development Program (LDRD), provided by the Director, Office of Science, of the U.S. Department of Energy under Contract No. DE-AC03-76SF00098.

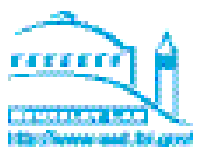




\title{
A Stochastic Integrated Approach to Parameter Estimation Using GEOPHYSICAL DATA
}

\author{
Jinsong Chen, Susan Hubbard, Michael G. Hoversten, and Ernest Majer \\ Contact: Jinsong Chen, 510/486-6842, jchen@lbl.gov
}

\section{RESEARCH OBJECTIVES}

Subsurface investigations often require characterizing hydrogeological and geochemical parameters. Well-log or core methods for collecting these data are invasive and laborious, and are therefore rarely acquired at a sufficient spacing for describing field conditions. Integrated approaches, which combine multiple sources of information such as wellbore and geophysical measurements, offer great potential for improved, minimally invasive, and cost-effective characterization. Deterministic integration methods, however, are limited because of their inability to solve for a large number of unknown parameters, or to find a global optimal solution, or to describe the uncertainty associated with those parameters. We have developed a stochastic integrated approach that overcomes these limitations, based on the Markov chain Monte Carlo (MCMC) method. This approach has been applied to two different data sets in order to demonstrate the benefits of the method for integrating multiple sources of information.

\section{APPROACH}

Our integration framework is based on a Bayesian estimation approach. Within this framework, all unknown quantities are considered as random variables, and observable parameters are considered as data with measurement errors. The unknown variables and the known data are linked by geophysical forward models, rock physical relationships, and the site-specific cross correlations between all the parameters. Those variables, data, and relationships together define a joint conditional probability function (or posterior probability function). Our goal was to obtain the marginal posterior probability function for each unknown variable by conditioning on all the available information. Since analytical methods are not tractable when the joint probability function includes such a large number of unknown variables and when the relationships are very complicated, we use the MCMC method to obtain many samples for each unknown random variable. Using the generated samples, the mean, variance, prediction intervals, and posterior probability function of the unknown variable can be calculated.

\section{ACCOMPLISHMENTS}

We employed the developed stochastic model with crosshole ground-penetrating radar attenuation data to estimate sediment geochemical parameters at the South Oyster Bacterial Transport Site in Virginia (Figure 1). We also employed the method with crosshole seismic and electromagnetic data to estimate reservoir parameters, such as porosity and water saturation. Results from the two case studies showed that the developed method was more accurate, flexible, and efficient than deterministic approaches for integrating

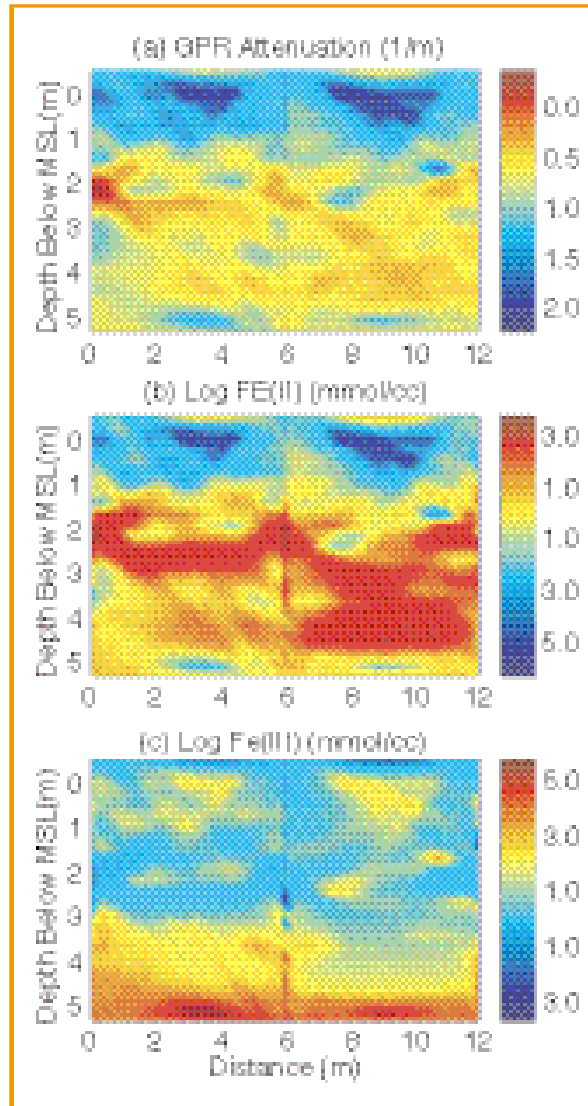

Figure 1. An example illustrating the use of our stochastic integration approach for geochemical parameter estimation. In this study, ground penetrating radar attenuation tomographic data (a) and other types of wellbore data were used to estimate logarithmic extractable $\mathrm{Fe}(\mathrm{II})$ (b) and $\mathrm{Fe}(\mathrm{III})$ (c) concentrations along a twodimensional cross section. multiple sources of parameter-estimation information.

\section{SIGNIFICANCE OF FINDINGS}

We have developed a general framework that can be used to integrate various types of data sets for parameter estimation. This is the first effort to use minimally invasive and cost-effective geophysical data to aid in estimation of field-scale geochemical parameters. The methodology is particularly advantageous for use with data sets involving a large number of variables and complicated relationships between the variables.

\section{RELATED PUBLICATIONS}

Chen, J., S. Hubbard, Y. Rubin, C. Murray, E. Roden, and E. Majer, Geochemical characterization using geophysical data: A case study at the South Oyster Bacterial Transport Site in Virginia. Water Resources Research, 2003 (in press).

Chen, J., and M.G. Hoversten, Joint stochastic inversion of geophysical data for reservoir parameter estimation. 73rd Annual International Meeting, Society of Exploration Geophysics, 2003 (submitted).

\section{ACKNOWLEDGMENTS}

This study was supported by the Assistant Secretary for Energy Research, Office of Biological and Environmental Research, of the U.S. Department of Energy under Contract No. DE-AC03-765SF00098, by NSF Grant EAR 9628306, and by the Assistant Secretary for Fossil Energy, National Petroleum Office, of the U.S. Department of Energy, also under Contract No. DE-AC03-76SF00098.

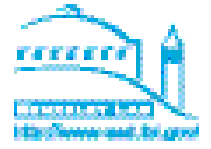




\title{
IdENTIFying The Sources of Subsurface Uranium Contamination at THE HANFORD SITE, WASHINGTON
}

\author{
John N. Christensen, P. Evan Dresel ${ }^{1}$, Mark Conrad, Kate Maher, and Donald J. DePaolo \\ ${ }^{1}$ Pacific Northwest National Laboratory (PNNL) \\ Contact: John N. Christensen, 510/486-6735, jnchristensen@lbl.gov
}

\section{RESEARCH OBJECTIVES}

In the mid-1990s, a groundwater plume of uranium (U) and other contaminants was recognized in monitoring wells in the BBX-BY Waste Management Area (WMA) at the Hanford Site in Washington. This area had been used since the late 1940s to store high-level radioactive waste and other products of $U$ fuel-rod processing. Consequently, within a small area there are a number of potential sources for contamination. Some records exist of inadvertent waste spills, and several locations of vadose zone contamination had been identified. Two of these plumes were cored in an effort to understand the extent and nature of the contamination. However, the pattern of $U$ concentration in these cores did not fully resolve the source issue. We undertook a study of the variation in $\mathrm{U}$ isotopic composition within the vadose zone and groundwater $\mathrm{U}$ plumes to better understand the source and history of contamination, as well as its transport in the subsurface.

\section{APPROACH}

The isotopic composition of natural $U$ contrasts with the variable isotopic composition of $U$ from processed fuel rods. This variation can be used as a tracer and fingerprint of contamination. We applied a new technique using MC-ICP-MS to provide high-precision isotopic measurements of small $\mathrm{U}$ samples, generating ${ }^{234} \mathrm{U} / 238 \mathrm{U}, 235 \mathrm{U} / 238 \mathrm{U}$, and ${ }^{236} \mathrm{U} / 238 \mathrm{U}$ ratios. Samples were provided from two cores (E33-45 and E33-46; see inset to Figure 1) through vadose zone plumes of $U$ contamination near two single-shelled tanks in the B-BX-BY WMA. Uranium from pore waters in the sediment samples were separated and analyzed for isotopic composition. Aliquots of groundwater samples taken from wells in the area groundwater samples. In addition, the isotopic variation of the groundwater samples can be explained by mixing between natural background $U$ and the E33-45 contamination U. The vadose zone plume in the E33-46 core was probably not a significant source of groundwater contamination.

\section{SIGNIFICANCE OF FINDINGS}

A comparison of the $\mathrm{U}$ isotopic data to model histories of fuel rod isotopic compositions demonstrates that the E33-45 contamination is consistent with a large spill event in 1951, as had been suspected from historical records. The locus of this spill is about $150 \mathrm{~m}$ from the core of the groundwater plume, suggesting significant horizontal displacement of the contamination before it encountered the water table. Over 50 years separates the vadose zone spill and the groundwater contamination detected in the mid-1990s, indicating a continuing large potential for contamination. Between 1993 and 2001, it appears that the groundwater $\mathrm{U}$ contamination migrated at an average of $\sim 0.7 \mathrm{~m} /$ day. High-precision $\mathrm{U}$ isotopic measurements provide an improved tool for tracing and understanding the behavior of $U$ contamination in the subsurface and groundwater.

\section{ACKNOWLEDGMENTS}

This work was supported by the Assistant Secretary of the Office of Environmental Management, Office of Science and Technology, Environmental Management Science Program, of the U.S. Department of Energy under Contract No. DE-AC0376SF00098 to Berkeley Lab and Contract No. DE-AC0676RL01830 to Pacific Northwest National Laboratory. (see inset to Figure 1) were also analyzed. These samples cover the known extent of the groundwater $U$ contamination plume. The results of the isotopic analyses are evaluated and compared to each other to identify sources and the extent of mixing with background $\mathrm{U}$.

\section{ACCOMPLISHMENTS}

Twenty-five samples from the two cores were analyzed, along with nine groundwater samples. The results of the analyses are displayed in Figure 1. The isotopic signature of the E33-45 core contamination plume matches the most contaminated

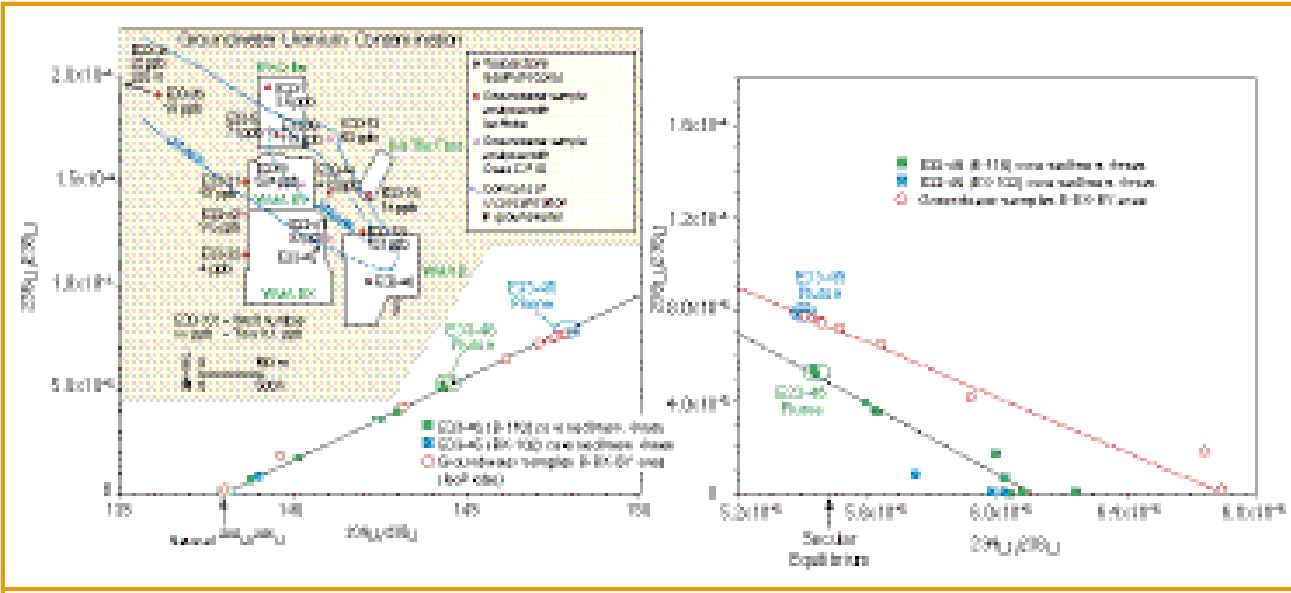

Figure 1. Uranium isotopic data for groundwater (red circles) samples, and sediment pore water from cores E33-45 (blue squares) and E33-46 (green squares). Left panel ${ }^{238} \mathrm{U} /{ }^{235} \mathrm{U}$ vs. ${ }^{236} \mathrm{U} /{ }^{238} \mathrm{U}$ and right panel ${ }^{234} \mathrm{U} /{ }^{238} \mathrm{U}$ vs. ${ }^{236} \mathrm{U} /{ }^{238} \mathrm{U}$. Inset in left panel is a map of analyzed sample well and core locations in the B-BX-BY Waste Management Area. 


\title{
Estimation of Natural Biodegradation Rates of Organics in BURIED WASTE AT INEEL
}

\author{
Mark Conrad and Donald J. DePaolo \\ Contact: Mark Conrad, 510/486-6141, msconrad@lbl.gov
}

\section{RESEARCH OBJECTIVES}

Radioactive waste resulting from U.S. Department of Energy activities is buried in shallow pits in the Subsurface Disposal Area (SDA) at the Radioactive Waste Management Complex (RWMC) of the Idaho National Engineering and Environmental Laboratory (INEEL). In addition to the radionuclides, the waste drums also contain significant amounts of chlorinated solvents mixed with lubricating oils. Leakage from the drums has resulted in a plume of vaporphase contaminants in the vadose zone. The main objective of this study was to use measurement concentrations and isotopic compositions of $\mathrm{CO}_{2}$ from the SDA to assess the potential for bioremediation of the organic contaminants at the site.

\section{APPROACH}

Over a 2-year period, pore gas samples were collected from monitoring wells in and around the RWMC site. Gas sampling ports within the monitoring wells were designed for sampling discrete depth intervals. Sampling depths ranged from $<1 \mathrm{~m}$ to $180 \mathrm{~m}$. For each sample, the $\mathrm{CO}_{2}$ concentration and stable carbon isotope ratios ( $\delta^{13} \mathrm{C}$ values) were measured. In addition, the ${ }^{14} \mathrm{C}$ contents of a subset of these samples were also measured.

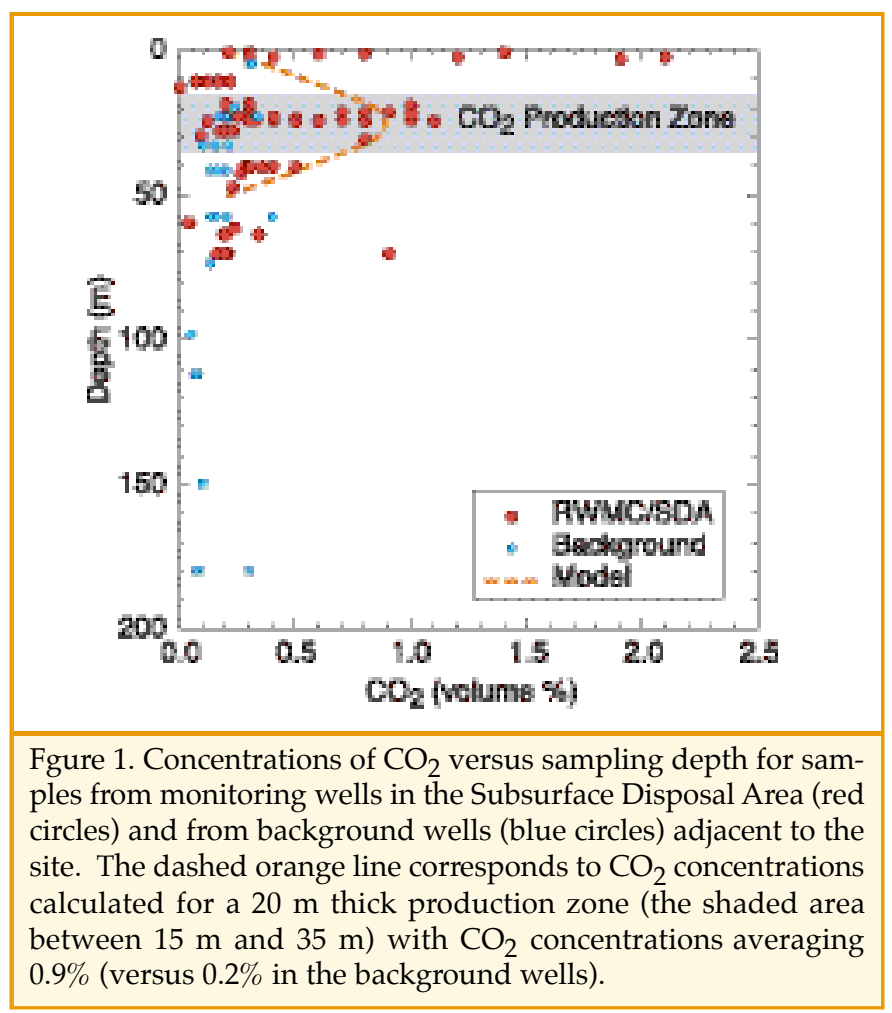

\section{ACCOMPLISHMENTS}

Carbon dioxide concentrations in pore gas samples from monitoring wells in the vicinity of the disposal pits were 3 to 5 times higher than the concentrations in nearby background wells. The $\delta^{13} \mathrm{C}$ values of $\mathrm{CO}_{2}$ from the disposal pits averaged $2.4 \%$ less than $\mathrm{CO}_{2}$ from the background wells, indicating that the elevated $\mathrm{CO}_{2}$ concentrations around the pits were derived from source materials with $\delta^{13} \mathrm{C}$ values in the range of $-24 \%$ to $-29 \%$. These $\delta^{13} \mathrm{C}$ values are typical of lubricating oils, but higher than most solvents. The radiocarbon $\left({ }^{14} \mathrm{C}\right)$ contents of $\mathrm{CO}_{2}$ across most of the site were significantly elevated above modern concentrations because of reactor blocks buried in a subsurface vault at the site. However, several samples collected from the high- $\mathrm{CO}_{2}$ zone on the far side of the RWMC from the reactor blocks had very low ${ }^{14} \mathrm{C}$ contents (less than 0.13 times modern), confirming production from lubricating oils manufactured from fossil hydrocarbons.

\section{SIGNIFICANCE OF FINDINGS}

The key aspects of the data collected for this project include the following:

- The higher concentrations of $\mathrm{CO}_{2}$ in the pore gas samples from the vicinity of the disposal pits indicate elevated levels of subsurface microbial activity.

- The lower $\delta^{13} \mathrm{C}$ values of the $\mathrm{CO}_{2}$ in the disposal area suggest that the source of the elevated $\mathrm{CO}_{2}$ concentrations is organic carbon.

- ${ }^{14} \mathrm{C}$ contents of less than $13 \%$ of modern indicate that biodegradation of fossil hydrocarbon compounds in the waste material is the primary source of the $\mathrm{CO}_{2}$.

A simple 1-dimensional production-diffusion model of the $\mathrm{CO}_{2}$ anomaly observed at the site is consistent with intrinsic biodegradation rates on the order of 0.5 to 2.0 metric tons of carbon per year. This represents degradation of approximately $1 \%$ per year of the lubricating oils buried in the disposal pits.

\section{RELATED PUBLICATION}

Conrad, M.E., and D.J. DePaolo, Carbon isotopic evidence for biodegradation of organic contaminants in the shallow vadose zone of the Radioactive Waste Management Complex. The Vadose Zone Journal, 2003 (in press).

\section{ACKNOWLEDGMENTS}

This work was supported by the Director, Office of Science, Office of Basic Energy Sciences, Environmental Management Science Program, of the U.S. Department of Energy under Contract No. DE-AC03-76SF00098.

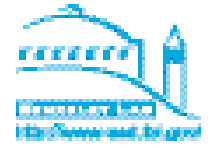




\title{
DOE Environmental Management International Projects Highlights
}

\author{
Boris Faybishenko \\ Contact: 510/486-4852, bafaybishenko@lbl.gov
}

\section{BACKGROUND AND OBJECTIVES}

Berkeley Lab is involved in eight projects with Russia, Ukraine, and Argentina. The projects with Russia are conducted according to a "Memorandum of Cooperation in the Areas of Environmental Restoration and Waste Management" between DOE and the Ministry of Atomic Energy for the Russian Federation. The projects with Argentina are being conducted according to the "Implementing Arrangement" between DOE and the National Atomic Energy Commission of the Argentine Republic. The collaboration with Ukraine is provided in accordance with the agreement between the U.S. and Ukraine governments concerning the International Radioecology Laboratory of the International Chernobyl Center.

The overall goal of these projects is to assess and improve the capability of the DOE's fate and transport models in predicting future environmental and human impacts of radioactive contaminant releases. The international sites chosen will benefit from application of the latest U.S. models, while DOE will benefit from access to long-term and detailed monitoring data sets of contaminant transport in a variety of contaminant, climatic, and geological settings.

\section{APPROACH AND ACCOMPLISHMENTS}

The projects with Russia include predictions of transport of radionuclides $\left({ }^{90} \mathrm{Sr},{ }^{137} \mathrm{Cs},{ }^{238} \mathrm{U}\right.$, and $\left.{ }^{239} \mathrm{Pu}\right)$ and nitrates in the groundwater at the Mayak and the Lake Karachay sites (which are among the most radioactively contaminated sites in the world). Models for deep well injection of liquid radiation waste have been developed for the Tomsk site. In addition, conceptual and numerical models have been developed for vadose zone flow and transport at two field sites (NovoVoronezh and Tomsk), as well as comparison of modeling and experimental data for calibrating the numerical models.

The International Radioecology Laboratory in Ukraine provides services to researchers from Texas Tech University and the Savannah River Ecology Laboratory to conduct their research in the Chernobyl Exclusion Zone. A Special Issue of the International Journal of Environmental Sciences and Pollution Research (ESPR) devoted to problems arising from the Chernobyl Nuclear Power Plant accident of 1986 is being edited and prepared for publication, including manuscripts submitted from Ukraine, Canada, U.S., and Russia.

The projects with Argentina include: (1) numerical modeling and characterization of groundwater flow and contaminant transport at the Ezeiza nuclear waste disposal site, with recommendations for appropriate monitoring technologies; and (2) investigations of the physics of liquid flow and contaminant transport to develop improved conceptual and mathematical modeling for unsaturated fractured-porous media.

\section{SIGNIFICANCE OF FINDINGS}

These projects will allow DOE researchers, engineers, and managers to use international scientific resources to test and build confidence in DOE's fate and contaminant transport models and remediation technologies, and to reduce the costs and increase the predictability of remediation technologies during long-term stewardship of DOE sites.

\section{ACKNOWLEDGMENTS}

This work was supported by the Assistant Secretary of the Office of Environmental Management, Office of Science and Technology, Environmental Management Science Program, of the U.S. Department of Energy under Contract No. DE-AC0376SF00098. The aforementioned projects are managed by the Joint Coordinating Committee for Environmental Restoration and Waste Management (JCCEM) of DOE and the Institute for International Cooperative Environmental Research of Florida State University. 


\title{
NAPL CONTAMINANT LOCATION WITH High-Frequency Crosswell Seismic Methods
}

\author{
Jil T. Geller, Ernest L. Majer, Jonathan Ajo-Franklin, Kenneth H. Williams, and John E. Peterson \\ Contact: Jil T. Geller, 510/486-7313, jtgeller@lbl.gov
}

\section{RESEARCH OBJECTIVES}

Our objectives are to develop, demonstrate, and evaluate,

before beginning a demonstration of six-phase heating remediaat appropriate field sites, the utility of high-frequency seismic imaging methods to detect and characterize nonaqueous-phase liquid (NAPL) contamination in groundwater aquifers.

\section{APPROACH}

This work is a new application of Berkeley Lab's high-frequency crosswell seismic imaging system. Crosshole seismic data is obtained at sites known to have NAPL contamination to map the distribution of P-wave velocities and amplitudes between boreholes (tomograms). Several approaches are tested to distinguish anomalies arising from the presence of NAPL from those arising from lithological heterogeneities, including: (1) time-lapse measurements before and after remediation, (2) comparison of tomograms from the contaminated location with nearby clean locations, (3) calibration of field data with laboratory measurements on cores from the site with varying amounts of NAPL, and (4) constraint of seismic data with crosswell radar data.

\section{ACCOMPLISHMENTS}

We obtained baseline crosswell data (before remediation) at two contaminated sites where remediation is currently in progress. We also measured P-wave transmission on cores from one of the sites, as a function of NAPL/water saturation. At the northeast site of the former DOE Pinellas Plant in Florida, NAPL trichloroethylene

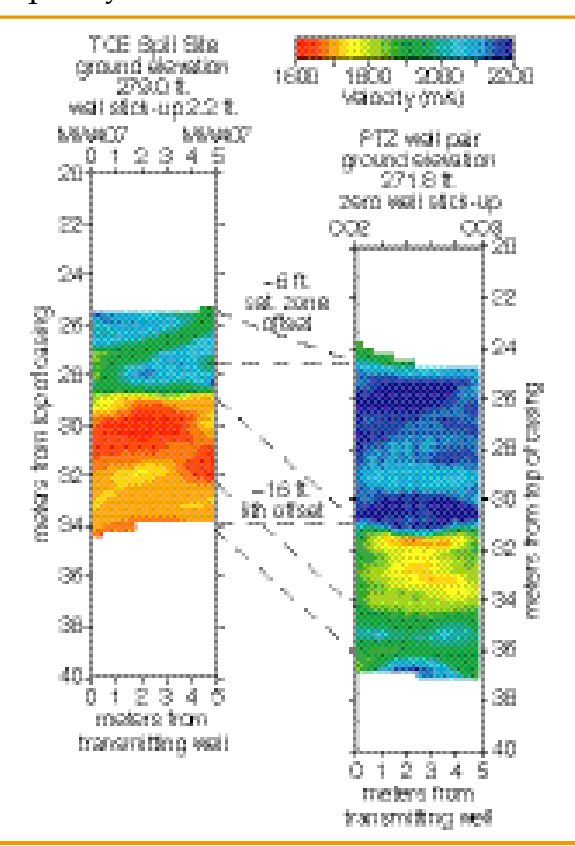

Figure 1. Velocity distributions between survey wells at the Paducah Gaseous Diffusion Plant before the onset of remediation. The tomogram on the left is at the site of the TCE spill. The right hand image is from wells outside the Plant boundary where there is no dense nonaqueous-phase liquid (DNAPL) TCE. The same lithological contrasts occur at each site, and the offsets between the layers are consistent. Changes in these distributions in postremediation surveys will indicate whether the lower velocities at the TCE spill site are caused by DNAPL. sistent lithology, with measurable differences, compared to the contaminated site.

\section{SIGNIFICANCE OF FINDINGS}

The contrast in the acoustic velocities of many NAPL contaminants (such as TCE and toluene) in water significantly affect P-wave attributes in natural-aquifer core samples tested in the lab. Possible locations of NAPL areas were identified from comparing Pwave attributes in a nearby uncontaminated zone, but these are uncertain because of the unknown contribution of well-completion and lithology variations. Postremediation surveys will be essential to determine the visibility of NAPL contrasts with water and their signature at the field scale, as well as the efficacy of crosswell seismic imaging for monitoring the remediation of NAPL-contaminated sites.

\section{RELATED PUBLICATIONS}

Geller, J.T., J.B. Ajo-Franklin, and E.L. Majer, Effect of immiscible liquid contaminants on $\mathrm{P}$-wave transmission through natural aquifer samples. In Proceedings of the 2003 Symposium on the Application of Geophysics to Engineering and Environmental Problems (SAGEEP), Environmental and Engineering Geophysical Society (EEGS), San Antonio, Texas, pp. 1059-1077, April 6-10, 2003; Berkeley Lab Report LBNL-52131.
(TCE), toluene, methylene chloride, weathered oils, and resins all contaminate the $30 \mathrm{ft}$ deep surficial aquifer. In laboratory tests on core from selected survey boreholes, NAPL TCE and toluene caused significant reductions in P-wave velocity and increases in $\mathrm{P}$-wave attenuation relative to water-saturated conditions. Our crosswell seismic and radar surveys, within and outside of the area identified as having NAPL, reveal continuous sedimentary layers where NAPL could be trapped. Regions of anomalously high P-wave attenuation occur throughout the surveyed region, which may arise from lithology, biogenic gas, NAPL, or a combination of these. At the Paducah Gaseous Diffusion Plant in Kentucky, we collected crosswell seismic data at the location of a historic TCE spill, estimated to be as large as 500,000 gallons,
Ajo-Franklin, J.B., J.T. Geller, E.L. Majer, J.E. Peterson, K.H. Williams, and J.M. Harris, Preliminary characterization of a NAPL-contaminated site using borehole geophysical techniques. In 2003 SAGEEP Proceedings. EEGS, San Antonio, Texas, pp. 202-220, April 6-10, 2003.

\section{ACKNOWLEDGMENTS}

This work was funded by the Assistant Secretary of the Office of Environmental Management, Subsurface Contamination Focus Area Program, of the U.S. Department of Energy, under Contract No. DE-AC03-76SF00098.

http: / / www-esd.lbl.gov / ERT / projects/map_dnapl.html 


\section{Biological Treatment of Irrigation Drainage for Selenium Removal}

Franklin Bailey Green, Sharon E. Borglin, Clement Hsieh, Rick Y.C. Huang, Tryg J. Lundquist, Nigel W.T. Quinn, Archana Sudame, Mathew G. Takata, and William J. Oswald

Contact: F. Bailey Green, 510/495-2612 ; fb gree@lbl.gov

\section{RESEARCH OBJECTIVES}

Much of the subsurface agricultural drainage in the western San Joaquin Valley (SJV) is contaminated with selenate $(50-1200 \mathrm{mg} / \mathrm{L}$ as Se) and nitrate $(20-120 \mathrm{mg} / \mathrm{L}$ as N), in addition to high total dissolved solids and boron. This water is currently either discharged to sloughs that drain into the San Joaquin River and then to the San Joaquin Delta, or it is evaporated in terminal ponds. These means of disposal are problematic, since Se is a teratogen that bioaccumulates in the aquatic food web, and nitrate contaminates groundwater supplies and promotes eutrophication of surface waters. Nitrate also interferes with the reduction and removal of selenate $\mathrm{SeO}_{4}{ }^{-2}$, the most abundant form of Se found in western SJV drainage. Our objective is to develop reliable and economical treatment methods to remove these contaminants.

\section{APPROACH-PILOT FACILITY}

We have developed the algal-bacterial selenium removal (ABSR) Process to remove nitrate and selenium from drainage. A $75 \mathrm{~m}^{3}$ / day pilot-scale ABSR Facility has been used to study the mechanisms and rates of selenium and nitrate removal (Figure 1). Subsurface drainage is dosed with a carbon and energy source for bacteria (usually animal feed-grade molasses) and then injected into a baffled and covered anoxic reduction pond. In the reduction pond, bacteria denitrify and reduce selenate to selenite, elemental Se, and bacterial-associated organic Se. Much of the reduced Se settles in the pond. Settled bacterial biomass in the reduction pond undergoes anaerobic decomposition, so that the volume of solid residues increases very slowly. Removal of the selenium-containing solids should not be required for many years, possibly not even decades.

\section{ACCOMPLISHMENTS}

\section{Selenium Removal}

Over two years, the ABSR Facility at Panoche, California, removed $95 \%$ of the influent nitrogen load and $80 \%$ of the influent soluble selenium load. The addition of physical-chemical flotation and filtration processes to remove particulate Se has increased total Se removal to $87 \%$. Dozens of bacterial species have been isolated from the ABSR Facility and identified by 16S rRNA sequencing, including the prevalent Acinetobacter Johnson II/genospecies 7, Pseudomonas mendocina, and Xanthomonas maltophilia. Pure cultures of several of these bacteria have been proven to reduce selenite in the laboratory.

\section{Brine Treatment}

Planned "zero discharge" drainage management in the SJV will create brines that require treatment. The high salt concentration of brines may inhibit bacterial Se reduction. We have found that denitrification and selenate reduction are unaffected by $\mathrm{NaCl}$ concentrations augmented up to $22 \mathrm{~g} / \mathrm{L}$. Higher concentrations and other potential inhibitors such as sulfate will be studied during 2003-2004.

\section{SIGNIFICANCE OF FINDINGS}

With the ABSR facility at the Panoche Drainage District, we have demonstrated a promising, cost-effective process that will be used in planning full-scale facilities to remove nitrate and selenium from irrigation drainage.

\section{RELATED PUBLICATION}

Green, F.B., T.J. Lundquist, N.W.T. Quinn, M.A. Zárate, I.X. Zubieta, and W.J. Oswald, Selenium and nitrate removal from agricultural drainage using the AIWPS ${ }^{\circledR}$ Technology. Fifth International Water Association Specialist Conference on Waste Stabilization Ponds, Pond Technology for the New Millennium, Auckland, New Zealand, April 2-5, 2002; Water Science and Technology, 2003 (in press).

\section{ACKNOWLEDGMENTS}

We are grateful to the U.S. Bureau of Reclamation (CALFED Bay-Delta Program), Department of Water Resources, and the Panoche Drainage District for their support.

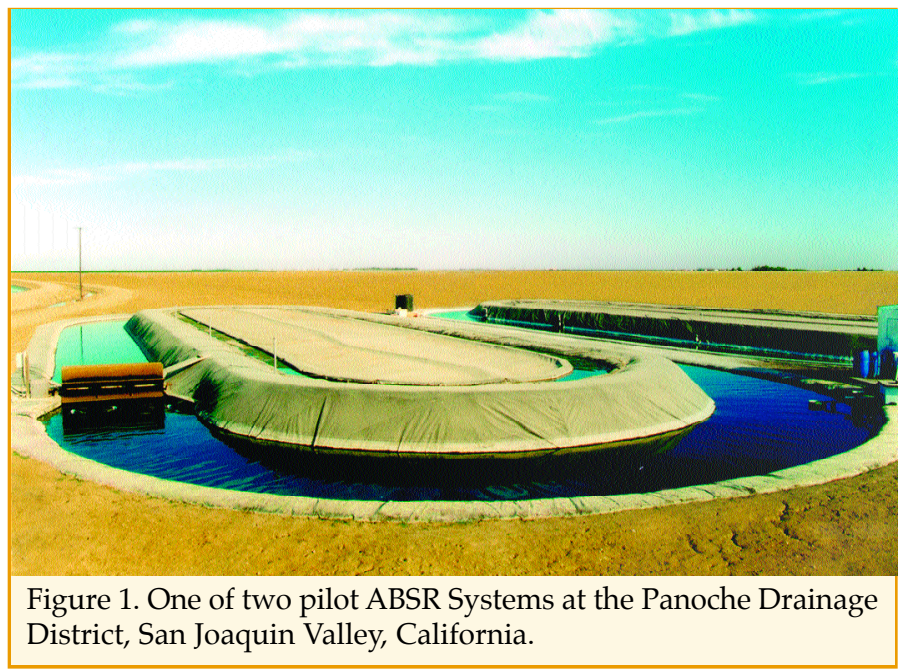

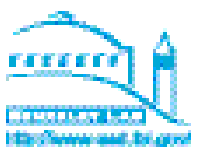




\section{Accelerated Biodegradation of Organic Contaminants by Humic Acid Hoi-Ying Holman, K. Nieman ${ }^{1}$, D.L. Sorenson ${ }^{1}$, C.D. Miller ${ }^{1}$, and R.C. Sims ${ }^{1}$ \\ ${ }^{1}$ Utah State University, Logan, Utah \\ Contact: Hoi-Ying Holman, 510/486-5943, hyholman@lbl.gov}

\section{RESEARCH OBJECTIVES}

The role of humic acid (HA) in the biodegradation of toxic polycyclic aromatic hydrocarbons (PAHs) has been the subject of controversy in the design of bioremediation strategy for polluted sites, particularly in unsaturated environments. To solve this controversy, we utilized our novel synchrotron infrared (SIR) spectromicroscopy technique to monitor, in situ and over time, the influence of HA on the degradation of pyrene (a model PAH) by a bacterial colony on a magnetite surface.

\section{APPROACH AND ACCOMPLISHMENTS}

The pyrene-degrading bacterium used for this study is Mycobacterium sp. JLS, a gram-positive, rod-shaped bacterium recently isolated from PAH-contaminated soil at the Libby

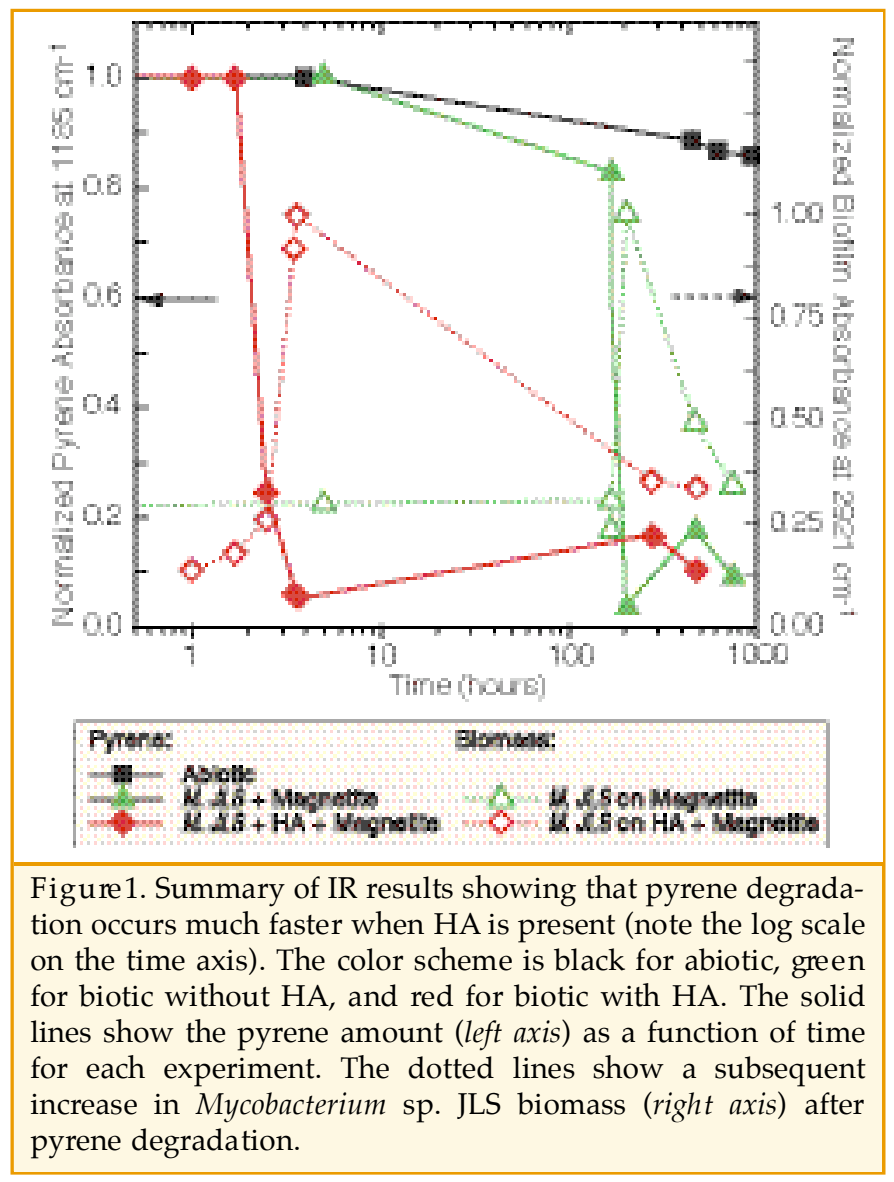

Groundwater Superfund Site in Libby, Montana. We took time-course "snap shots" of actions of M. sp. JLS at the same location on each pyrene-coated sample over more than a month. For comparison, we conducted similar experiments in the absence of either Elliott Soil Humic Acid (ESHA) or bacteria (i.e., abiotic experiments). We summarize in Figure 1 the time-course of pyrene degradation under different experimental conditions over more than a month. We found that, with only slow removal mechanisms, pyrene remains on the mineral surface. For samples occupied by M. sp. JLS, ESHA dramatically shortens the onset time for pyrene biodegradation from 168 to 2 hours. Further analysis of spectral fingerprints showed that in the absence of ESHA, it takes the bacteria about 168 hours to produce sufficient glycolipids to solubilize pyrene and make it available for biodegradation. It is likely that the increased bioavailability of pyrene by HA accelerates bacteriainduced degradation.

\section{SIGNIFICANCE OF FINDINGS}

This is the first study that provides direct evidence that HA can accelerate PAH biodegradation through the mechanism of enhanced bioavailability, which will have significant implications for bioremediation of contaminated soils. We can obtain this type of important biogeochemical information because of our novel and powerful SIR spectromicroscopy technique. This technique enabled research to assess, in real time, the interactions between multiple constituents in contaminated soils.

\section{RELATED PUBLICATION}

Holman, H.-Y. N., K. Nieman, D.L. Sorensen, C.D. Miller, M.C. Martin, T. Borch, W.R. McKinney, and R.C. Sims, Catalysis of PAH biodegradation by humic acid shown in synchrotron infrared studies. Environmental Science \& Technology, 36(6), 1276-1280, 2002.

\section{ACKNOWLEDGMENTS}

This work was partly supported by the Director, Office of Science, Office of Basic Energy Sciences, of the U.S. Department of Energy under Contract No. DE-AC0376SF00098. 


\title{
Application of Thermally Enhanced Vapor Extraction at Berkeley Lab
}

\author{
Iraj Javandel and Barry Freifeld \\ Contact: Iraj Javandel, 510/486-6106, ijavandel@lbl.gov
}

\section{OBJECTIVE}

A plume of contaminated groundwater was found near the site of the first Berkeley Lab cyclotron. Detailed investigations have identified the source area and determined the vertical and lateral extent of the contamination in the subsurface. The contaminants are chlorinated hydrocarbons consisting mainly of perchloroethene, trichloroethene, and carbon tetrachloride. The source area is located within heterogeneous geological materials consisting of both volcanic and sedimentary rocks. The hydraulic conductivity of these materials varies between $10^{-5}$ and $10^{-9} \mathrm{~m} / \mathrm{s}$. Various technologies are being tested to study their applicability for cleaning the source area. The objective of this study was to examine the effectiveness of thermally enhanced vapor extraction in removing contaminants from the source area.

\section{APPROACH}

In a pilot-scale test, we used a combination of soil heating and vapor extraction techniques to remove the chlorinated hydrocarbons from very-low-permeability geological materials of the source area. Three heaters, each of approximately 5.3 kilowatts capacity, were placed in three wells at 20 to $40 \mathrm{ft}$ depth. Heater wells were drilled $6 \mathrm{ft}$ apart, at the apexes of an equilateral triangle. Resistive heating raised soil temperature to a maximum of $200^{\circ} \mathrm{C}$. Both liquid and vapor were extracted from a well at the center of the triangle. Two instrumented wells were installed within $5 \mathrm{ft}$ of one of the heaters. Temperatures were measured along the heater well casings, the extraction well, and at various depths in the instrumented wells. In addition, soil gas probes and vacuum lysimeters were installed at various depths in the instrument wells. Soil vapor and soil water from all sampling points were collected and tested periodically, while flow rate and chemical composition of soil gas samples collected at the top of the extraction well were measured. The test continued for about 18 months.

\section{ACCOMPLISHMENTS}

More than $500 \mathrm{~kg}$ of perchloroethene, trichloroethene, and carbon tetrachloride were removed from the source area. This estimate is based on the measured flow rates and concentrations of contaminants in the extracted air. Note that the total mass of dissolved chlorinated hydrocarbons in the groundwater plume before this experiment was estimated to be about 7 kilograms.

\section{SIGNIFICANCE OF FINDINGS}

- Thermally enhanced vapor extraction proves to be an excellent technique for removing dispersed nonaqueousphase liquids from very-low-permeability heterogeneous geological materials.

- If the test were not properly designed, some of the chemicals volatilized may diffuse and condense into areas that were previously clean.

\section{ACKNOWLEDGMENTS}

This work is part of Berkeley Lab's Environmental Restoration Program, supported by the DOE Office of Environmental Management, under U.S. Department of Energy Contract No. DE-AC03-76SF00098.

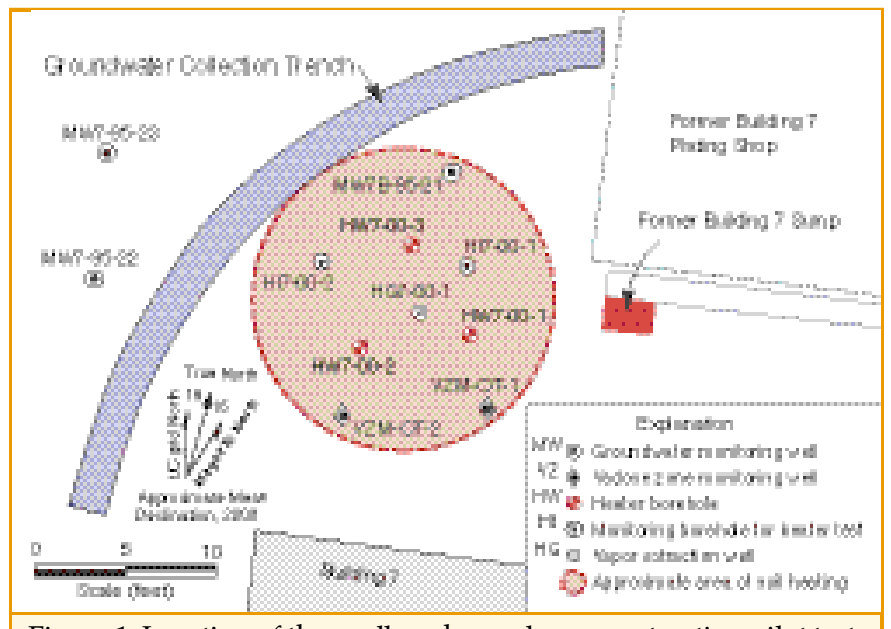

Figure 1. Location of thermally enhanced vapor extraction pilot test.

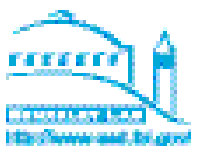




\title{
High-Frequency Electromagnetic Impedance Measurements for Characterization, MONITORING, AND Verification EFFORTS
}

\author{
Ki Ha Lee, Alex Becker, and Hung-Wen Tseng \\ Contact: Ki Ha Lee, 510/486-7468, khlee@lbl.gov
}

\section{RESEARCH OBJECTIVES}

Noninvasive, high-resolution imaging of the shallow subsurface is needed for delineation of buried waste, detection of unexploded ordinance, verification and monitoring of containment structures, and other environmental applications. Electromagnetic (EM) measurements at frequencies between 1 and $100 \mathrm{MHz}$ are important for such applications, because the induction number of many targets is small and the ability to determine the dielectric constant (in addition to the electrical conductivity) of the subsurface is possible. Earlier investigators were successful in developing systems for detecting anomalous areas, but no quantifiable information was accurately determined. For high-resolution imaging, accurate measurements are necessary, so that field data can be mapped into the space of the subsurface parameters. The objective of this project is to develop a noninvasive method for accurately mapping the electrical conductivity and dielectric constant of the shallow subsurface, using the EM impedance.

\section{APPROACH}

EM impedance, the ratio of electric to magnetic field, can be used to map subsurface electrical properties without the exact knowledge of the transmitter signal. A prototype $30 \mathrm{MHz}$ high-frequency impedance (HFI) system was originally assembled using off-the-shelf components, including a magnetic dipole transmitter as well as electric and magnetic antennae. The system was tested in known areas against theoretical predictions (Lee and Becker, 2001), thereby verifying the utility of the EM impedance for shallow subsurface application. The test was focused on mapping only the electrical conductivity because the frequency was limited to $30 \mathrm{MHz}$. To improve data quality and to include the capability of mapping dielectric constants, we began modifying the HFI system by miniaturizing the transmitter and receiver electronics and implementing fiber optics communication.

\section{ACCOMPLISHMENTS}

Success in achieving the overall objective of the HFI system depends on the accuracy of field measurements, especially in the electric field. All electronic components have been miniaturized and repackaged, and communication is now done via optical fibers. The other important improvement for the acquisition system has been the replacement of the lock-in amplifier with the HP network analyzer. This allows much wider operating bandwidth for the HFI system, well beyond $100 \mathrm{MHz}$ with greatly improved efficiency (Lee et al., 2002). Along with the hardware, we developed a one-dimensional inversion scheme, INVEM1D, in which the electrical conductivity and dielectric constant of an N-layered earth are simultaneously inverted. The key development has been the successful implementation of the analytically evaluated sensitivity function to the inversion code.

\section{SIGNIFICANCE OF FINDINGS}

The improved HFI system can be used to map shallow subsurface electrical conductivity and the dielectric constant simultaneously.

\section{RELATED PUBLICATIONS}

Lee, K.H., and A. Becker, High-frequency electromagnetic impedance measurements for characterization, monitoring and verification efforts. Interim Report, Project \#60328, U.S. DOE, 2001.

Lee, K.H., A. Becker, and H.-W. Tseng, High-frequency electromagnetic impedance measurements for characterization, monitoring and verification efforts. Annual Report, Project \#73776, U.S. DOE, 2002.

\section{ACKNOWLEDGMENTS}

This work was supported by the Assistant Secretary of the Office of Environmental Management, Office of Science and Technology, Environmental Management Science Program, of the U.S. Department of Energy under Contract No. DE-AC0376SF00098. 


\title{
The Role of Biogeochemical Dynamics in the Formation of U(VI) Solid Phases
}

\author{
Tracy E. Letain, Terry C. Hazen, and Heino Nitsche
}

Contact: Tracy E. Letain, 510/486-6612, teletain@lbl.gov

\section{RESEARCH OBJECTIVES}

To assist the U.S. Department of Energy with long-term stewardship issues associated with bioremediation of uranium $(\mathrm{U})$, we seek to define the mechanisms by which microorganisms facilitate the formation of $\mathrm{U}(\mathrm{VI})$ solid phases. Under anaerobic conditions, microbial reduction of $\mathrm{U}(\mathrm{VI})$ to $\mathrm{U}(\mathrm{IV})$ can potentially decrease groundwater $\mathrm{U}$ contamination by lowering solubility and by slowing migration through the soil. However, such biological alteration must be considered temporary unless long-term anaerobicity can be maintained. When aerobic conditions return, U(IV) will likely re-oxidize to $\mathrm{U}(\mathrm{VI})$, which is generally more soluble and potentially more mobile. The transformation to $\mathrm{U}(\mathrm{VI})$-phosphate solids is of particular interest, since the $\mathrm{U}(\mathrm{VI})$ phosphates are the least soluble of the $\mathrm{U}(\mathrm{VI})$ solids found in nature.

\section{APPROACH}

Bacteria present in soils may play a role in the formation of $\mathrm{U}(\mathrm{VI})$-phosphate solid phases, both because they serve as an available phosphate source and because the cell surface may act as a nucleation site for the reprecipitation of $\mathrm{U}$. We are investigating the ability of some model microorganisms, such as the Gram-positive bacterium, Bacillus sphaericus, to complex with $\mathrm{U}(\mathrm{VI})$. Ability of B. sphaericus to sorb $\mathrm{U}(\mathrm{VI})$ has been tested for a wide $\mathrm{pH}$ range ( $\mathrm{pH} 3-\mathrm{pH} 7)$, with special attention to the sorption behavior at low concentrations of $\mathrm{U}$, such as would be commonly found in contaminated waste sites. The cell surface group responsible for $\mathrm{U}(\mathrm{VI})$ complexation is identified by both laser-induced fluorescence spectroscopy (LiFS) and x-ray absorption spectroscopy (XAS).

\section{ACCOMPLISHMENTS}

We find B. sphaericus can remove even trace amounts of $\mathrm{U}(\mathrm{VI})$ from solution (to below the detection limit of 10-8 moles/L U(VI). Isotherm modeling of $\mathrm{U}(\mathrm{VI})$ sorbed onto $B$. sphaericus at pH 5 suggests the presence of greater than one bacterial cell surface site available for $U$ complexation. Both LiFS and XAS yield data that are consistent with the cell surface organic phosphate functional group, called teichoic acid, being the dominant site for $\mathrm{U}(\mathrm{VI})$ complexation. $\mathrm{U}(\mathrm{VI})$ sorption by B. sphaericus is somewhat $\mathrm{pH}$-dependent, with $\mathrm{U}(\mathrm{VI})$ sorption capacity increasing initially with increasing $\mathrm{pH}$ (from $\mathrm{pH} 3$ to $\mathrm{pH} 5$ ), and similar sorption capacity seen for $\mathrm{pH}$ 5-7.

\section{SIGNIFICANCE OF FINDINGS}

Up to this time, no other group has been able to determine $\mathrm{U}(\mathrm{VI})$ sorption onto bacteria at the very low and environmentally relevant concentrations of both $\mathrm{U}(\mathrm{VI})$ and bacteria used in this study (over 100-fold lower than previous studies). We are the only group testing $\mathrm{U}(\mathrm{VI})$ sorption at $\mathrm{pH}$ values greater than 5, partly due to the low solublity of $\mathrm{U}(\mathrm{VI})$ at higher $\mathrm{pH}$ values. Additionally, using a combination of LiFS and XAS to determine the cell surface functional group has led to the strongest evidence to date of organic phosphate serving as the dominant group responsible for $\mathrm{U}(\mathrm{VI})$ complexation.

\section{RELATED PUBLICATIONS}

Letain, T.E., J.A. Warner, D.K. Shuh, and H. Nitsche, EXAFS study of pH-dependent uranyl adsorption to bacteria. In preparation for Geochimica et Cosmochimica Acta, 2003.

Letain, T.E., T.C. Hazen, and H. Nitsche, Bacillus sphaericus surface interactions with uranium (VI) at environmentally relevant concentrations. Appl. Environ. Microbiol., 2003 (submitted).

\section{ACKNOWLEDGMENTS}

This work was supported by the Director, Office of Science, Office of Biological and Environmental Research, Natural and Accelerated Bioremediation Research Program, of the U.S. Department of Energy under Contract No. DE-AC0376SF00098. 


\title{
Use of Sr Isotopes to Determine Long-Term Average Vadose Zone INFILTRATION FLUX AT HANFORD 200W AREA
}

\author{
Katharine Maher, Donald J. DePaolo, and Mark S. Conrad \\ Contact: Katharine Maher, 510/642-9524, kmaher@eps.berkeley.edu
}

\section{RESEARCH OBJECTIVES}

Infiltration rates are an important variable in assessing contaminant transport at the Hanford Site, where the majority of the contaminants are contained in the upper $30 \mathrm{~m}$ of a thick $(\sim 70 \mathrm{~m})$ vadose zone. The transit time to the aquifer for a given contaminant largely determines the remediation action, especially for mobile radioactive contaminants. Efforts to quantify infiltration rates at the Hanford Site have been hindered by the complexity of the hydrogeologic setting, the thick vadose zone, and recent anthropogenic disturbances. Independent estimates of infiltration rates range from $0.01 \mathrm{~mm} / \mathrm{yr}$ to 200 $\mathrm{mm} / \mathrm{yr}$, depending on the method and surface cover.

Using variations in the natural strontium (Sr) isotopic compositions of vadose zone pore waters and sediments, the infiltration flux can be quantified using a simple one-dimensional reactive transport model. The strontium isotope ratio $\left.{ }^{87} \mathrm{Sr} /{ }^{86} \mathrm{Sr}\right)$ of pore water is a very sensitive indicator of interaction with the rock matrix. Because of the relatively low concentration of $\mathrm{Sr}$ in the pore water relative to the sediments, even minor exchange between the solid and fluid phases will quickly shift the pore-water $\mathrm{Sr}$ isotope ratio towards that of the rock. The pore water ${ }^{87} \mathrm{Sr} /{ }^{86} \mathrm{Sr}$ value is thus controlled by a balance between the infiltration flux and weathering of the sediments.

\section{APPROACH}

Strontium isotope ratios were measured in the pore water, acid extracts, mineral separates, and sediments of a $70 \mathrm{~m}$ vadose zone core in the 200W Area of the Hanford / DOE complex in eastern Washington State. Using an estimate of the bulk weathering rate for the sediments, the steady-state reactive transport model for $\mathrm{Sr}$ in the vadose zone was inverted to solve for the infiltration rate (see Maher et al., 2003). This method is currently being applied to other locations around the Hanford Site.

\section{ACCOMPLISHMENTS}

Given a range of weathering rates based on sediment mineralogy, the infiltration flux for the 200W Area is constrained at between $7 \pm 3 \mathrm{~mm} / \mathrm{yr}$ (Figure 1). Non-steady-state models spanning the last $15 \mathrm{kyr}$ reveal that the profile is very close to steady state; therefore, these infiltration flux values are applicable over at least this time span. The transit time for meteoric water to percolate from surface to the water table is in the range of $\sim 1,200$ years.

\section{SIGNIFICANCE OF FINDINGS}

The method of inferring infiltration rates using $\mathrm{Sr}$ isotopes provides a novel method for quantifying fluid flow in the vadose zone. This method is advantageous in that it does not require disturbance of the site prior to measurement (e.g., lysimeters), it does not rely ab initio on assumptions regarding atmospheric and geochemical parameters (e.g., $\mathrm{Cl}$ mass balance), it can be applied to deep heterogeneous vadose zones, and it provides a long-term ( 1-10 kyr) average of the infiltration flux.

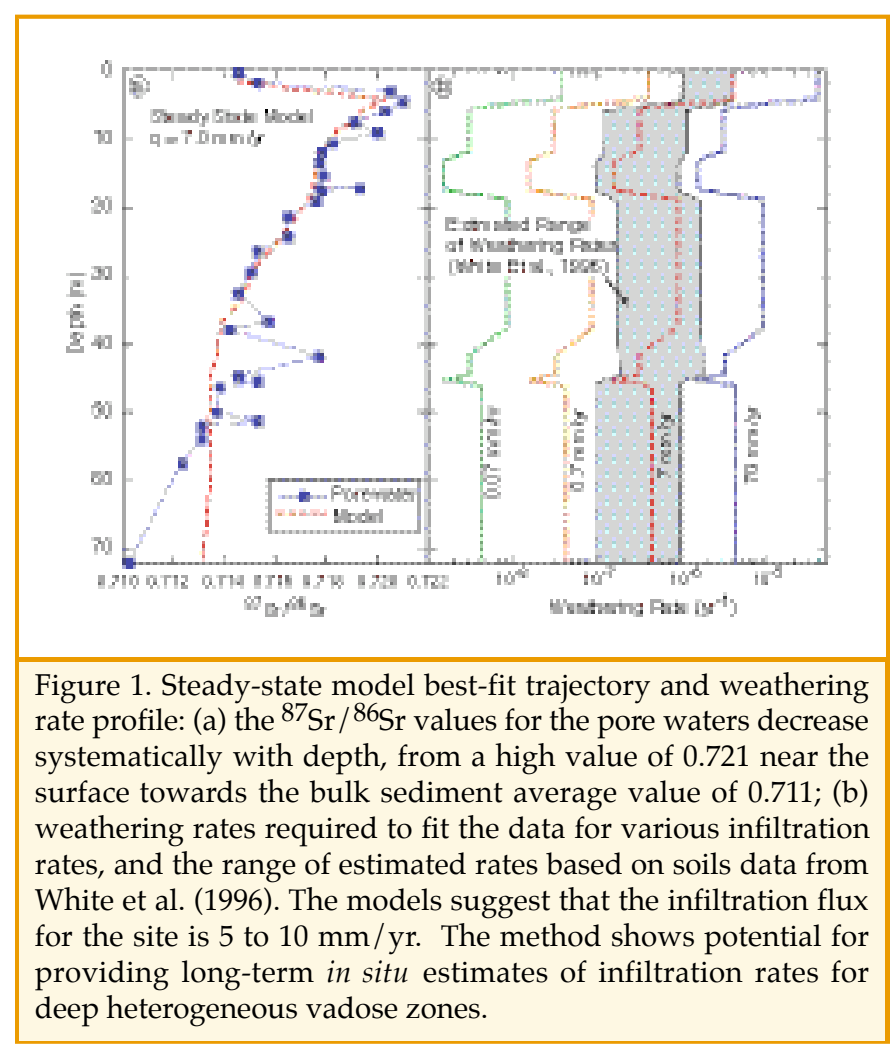

\section{RELATED PUBLICATIONS}

Maher, K., D.J. DePaolo, and M.E. Conrad, Vadose zone infiltration rate at Hanford, Washington, inferred from Sr isotope measurements. Water Resources Research 39 (8), 1204, 2003.

DePaolo, D.J., M.E. Conrad, and K. Maher, Oxygen and hydrogen isotopes in pore fluids from a $70 \mathrm{~m}$ thick vadose zone. Vadose Zone Journal, 2003 (submitted).

\section{ACKNOWLEDGMENTS}

Funding was provided by the Department of Energy under Contract No. DE-AC06-76RL01830 through the Hanford Science and Technology Program, and by the Director, Office of Science, Office of Basic Energy Sciences, Division of Chemical Sciences, Geosciences, and Biosciences, of the U.S. Department of Energy under Contract No. DEAC03-76SF00098. 


\section{Simulating Landfill Biodegradation Processes With T2LBM}

Curtis M. Oldenburg, Sharon E. Borglin, and Terry C. Hazen

Contact: Curtis M. Oldenburg, 510/486-7419, cmoldenburg@lbl.gov

\section{RESEARCH OBJECTIVES}

We have developed T2LBM, a module for the TOUGH2 simulator that implements a Landfill Bioreactor Model. This model can simulate processes of aerobic or anaerobic biodegradation of municipal solid waste (MSW) and the associated flow and transport of gas and liquid. We present an example study to verify the code against a laboratory experiment carried out in a parallel effort. The overall objective of our MSW landfill research is to investigate the advantages and disadvantages of different landfill treatment approaches.

\section{APPROACH}

We have enhanced an existing numerical reservoir simulator to include additional chemical components and biodegradation processes relevant to MSW. Our approach assumes that a single substrate component (acetic acid, $\mathrm{CH}_{3} \mathrm{COOH}$ ) serves as a proxy for all of the biodegradable fractions in MSW. T2LBM includes six chemical components $\left(\mathrm{H}_{2} \mathrm{O}, \mathrm{CH}_{3} \mathrm{COOH}\right.$, $\mathrm{CO}_{2}, \mathrm{CH}_{4}, \mathrm{O}_{2}, \mathrm{~N}_{2}$ ) and heat distributed in gaseous and aqueous phases with partitioning by Henry's law. This approach further assumes, implicitly, that hydrolysis reactions occur to produce acetic acid. Gas and liquid containing the chemical components flow through the MSW refuse mass as governed by Darcy's law. The focus of the process model is on biodegradation with nonisothermal effects and the associated gas production, along with liquid- and gas-phase flow through the refuse mass.

\section{ACCOMPLISHMENTS}

We have carried out tests of T2LBM and compared results against published studies of biodegradation. In addition, we have compared T2LBM results to the laboratory experiment of MSW biodegradation carried out in parallel with model development. Shown in Figure 1 are the volume fractions of oxygen $\left(\mathrm{O}_{2}\right)$ from the experiment and from a T2LBM simulation over a 40-day period. The event being examined is a respiration test in a system where air is blown into the MSW for 28 days to keep it aerobic, and then (for a short period) the air is turned off and the system is shut in. Over the period of shut in, we can observe the rate of $\mathrm{O}_{2}$ consumption, i.e., respiration. During the shut-in period, the $\mathrm{O}_{2}$ was rapidly consumed, and the system became anaerobic. At $t=31$ days, the fan was turned back on, air addition continued, and the system became aerobic again. As shown in Figure 1, T2LBM was able to match the observed $\mathrm{O}_{2}$ volume fraction data fairly well, using kinetic biodegradation parameters from the literature. We also plot the T2LBM CO $\mathrm{CO}_{2}$ curve to show its relation to the transition from aerobic to anaerobic conditions.

\section{SIGNIFICANCE OF FINDINGS}

Our preliminary testing of T2LBM suggests that the simulator is capable of modeling fundamental aspects of MSW biodegradation processes. Further development and testing are needed to elucidate the capabilities and limitations of the model for simulating laboratory experiments and actual MSW landfills.

\section{RELATED PUBLICATION}

Oldenburg C.M., T2LBM: Landfill Bioreactor Model for TOUGH2, Version 1.0. Berkeley Lab Report LBNL-47961, 2001.

\section{ACKNOWLEDGMENTS}

This work was supported by Laboratory Directed Research and Development (LDRD) funding from Berkeley Lab, provided by the Director, Office of Science, of the U.S. Department of Energy under Contract No. DE-AC03-76SF00098.

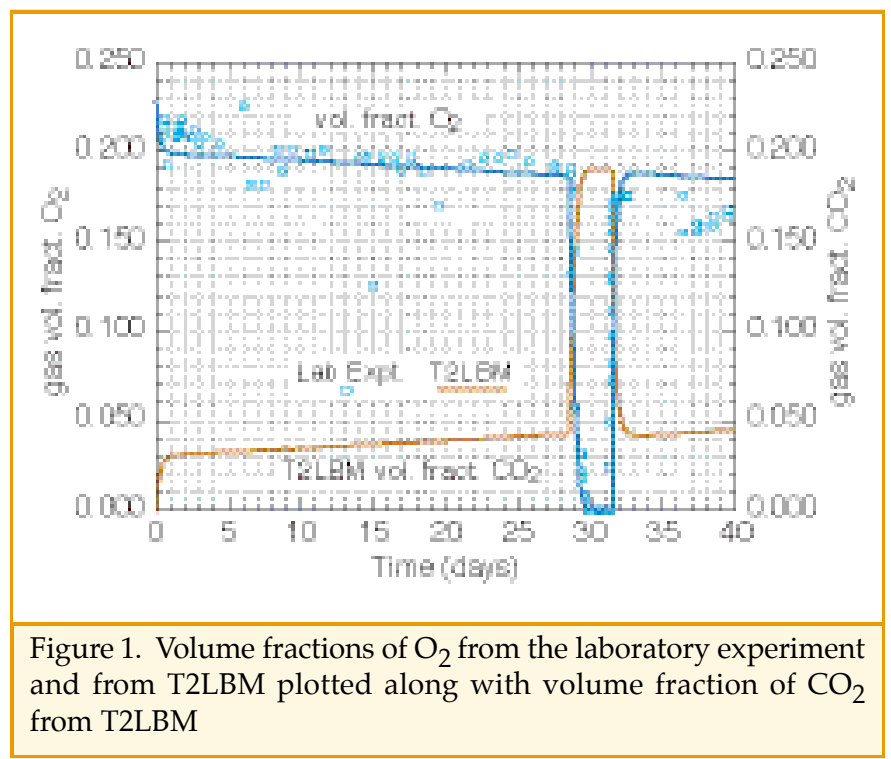

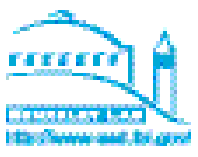




\section{TMVOC, A Simulator for Multiple Volatile Organic Chemicals \\ Karsten Pruess and Alfredo Battistelli ${ }^{1}$ \\ ${ }^{1}$ Aquater S.p.A., Italy \\ Contact: Karsten Pruess, 510/486-6732, k_pruess@lbl.gov}

\section{RESEARCH OBJECTIVES}

Many environmental contamination problems involve volatile organic chemicals (VOCs), such as crude oil, gasoline, diesel, and/or organic solvents. When spilled into the unsaturated zone, these chemicals may form a separate nonaqueous phase, giving rise to three-phase flow of water, soil gas, and a nonaqueous phase liquid (NAPL). Such flows can be modeled with T2VOC, but that code is limited to conditions in which the VOC is a pure, single-component fluid. However, in many cases of interest, nonaqueous fluids released into the subsurface may consist of a multicomponent mixture of several different chemicals. TMVOC is designed for three-phase flows in which the NAPL consists of a general multicomponent mixture of organic fluids. In addition, one or several noncondensable gases (NCGs) may be present.

\section{APPROACH}

TMVOC is based on the M2NOTS code that was developed by Adenekan (1992) as part of his Ph.D. project at the University of California, Berkeley. It is implemented as a specialized module for Berkeley Lab's general multipurpose simulator TOUGH2 and retains its general process-modeling capabilities and user features.

\section{ACCOMPLISHMENTS}

In the TMVOC formulation, the multiphase system is assumed to be composed of water, NCGs, and water-soluble VOCs. The number and nature of NCGs and VOCs can be specified by the user. Organic chemicals with critical temperatures below ambient, such as methane or ethane, can be modeled as NCGs. There are no intrinsic limitations to the number of NCGs or VOCs. Thermophysical property data for individual VOCs must be provided by the user. TMVOC uses a very general formulation to obtain thermophysical and PVT (pressure-volumetemperature) properties for mixtures of VOCs and NCGs. The fluid components may partition (volatilize and/or dissolve) among gas, aqueous, and NAPL phases. Any combination of the three phases may be present, and phases may appear and disappear in the course of a simulation.

Flows can be nonisothermal, and may involve advective, diffusive, phase-partitioning, and sorptive processes. A simple model for biodegradation is provided as well. Chief applications for which TMVOC is designed include analysis of NAPL spills and remediation alternatives in the vadose zone and below the water table.

A detailed self-contained user's guide is available that provides a technical reference to the TMVOC formulation and includes seven sample problems to illustrate code applications:

1. Demonstrating initialization of different phase conditions

2. One-dimensional Buckley-Leverett flow

3. Diffusion

4. Steam displacement of TCE

5. Steam displacement of a benzene-toluene mixture

6. Air displacement of NAPL

7. NAPL spill in the unsaturated zone

TMVOC is upwardly compatible with T2VOC; that is, T2VOC input files can be executed with TMVOC.

\section{SIGNIFICANCE OF FINDINGS}

The TMVOC code is available through DOE's Energy Science and Technology Software Center (see http://wwwesd.lbl.gov/TOUGH2/tmvoc.html).

\section{RELATED PUBLICATIONS}

Adenekan, A.E., Numerical modeling of multiphase transport of multicomponent organic contaminants and heat in the subsurface. PhD thesis, University of California at Berkeley, 1992.

Pruess, K. and A. Battistelli. TMVOC, a numerical simulator for three-phase non-isothermal flows of multicomponent hydrocarbon mixtures in saturated-unsaturated heterogeneous media. Berkeley Lab Report LBNL-49375, 2002.

\section{ACKNOWLEDGMENTS}

This work was supported, in part, by the Director, Office of Science, Office of Basic Energy Sciences, Division of Chemical Sciences, Geosciences, and Biosciences, of the U.S. Department of Energy under Contract No. DE-AC03-76SF00098. Partial support was also provided by a grant from Aquater S.p.A. (ENI Group) to Berkeley Lab in the frame of the REPIS project, sponsored by the ENI Research Fund. 


\section{ReAl-Time Management of Dissolved OXYGen IN THE SAN JoAQuin River DeEP-WATER SHIP CHANNEL}




\title{
Biological Treatment of Mixed Wastes: A Safer Alternative to Incineration
}

\author{
William T. Stringfellow, Tatsuyuki Komada, and Li-Yang Chang
}

Contact: Will Stringfellow, 510/486-7903, wstringfellow@lbl.gov

\section{RESEARCH OBJECTIVES}

The objective of this research was to develop a biological treatment process that could serve as an alternative to incineration for the treatment of mixed wastes. Mixed wastes are wastes that contain both radioactive materials and hazardous chemicals. Radioactive wastes are regulated under the Atomic Energy Act and are most safely disposed of in a secure landfill where the radioactivity is excluded from the biosphere. Hazardous wastes are regulated under the Resource Conservation and Recovery Act (RCRA) and are prohibited from disposal in landfills. Hazardous waste regulations take priority, and mixed wastes are typically incinerated. During incineration, radioactivity is released directly to the biosphere.

The advantage of biological treatment is that radioactivity can be contained during treatment of the hazardous waste component. Once the hazardous waste component is treated biologically, the waste is no longer regulated under RCRA, and the radioactivity can be kept from the biosphere.

\section{APPROACH}

To meet the objective of a completely contained treatment process, we developed a "Drip-Feed Bioreactor" (Figure 1). Unlike conventional biological treatment systems, in the dripfeed system the waste stream flows into the reactor, but no waste flows out. In the reactor, the waste is contacted with specially prepared bacterial cultures that completely destroy the hazardous waste to carbon dioxide and water. The radioactive waste is not treated by the bacteria, but is contained in the reactor for recovery and safe disposal.

\section{ACCOMPLISHMENTS}

The Drip-Feed Bioreactor was tested for the treatment of a mixed waste containing acetonitrile (the hazardous waste) and tritium (the radioactive waste). This type of waste is generated during biomedical researh at universities and hospitals throughout the nation. Under the RCRA regulations, the acetonitrile must be reduced to below $1.0 \mathrm{mg} / \mathrm{L}$ before the waste is no longer considered hazardous. A surrogate (nonradioactive) waste was tested that contained acetonitrile at a concentration of approximately $10 \%$ by volume. Results of this trial are as follows: influent acetonitrile concentration, 88,000 $\mathrm{mg} / \mathrm{L}$; final acetonitrile concentration, less than $0.1 \mathrm{mg} / \mathrm{L}$.

\section{SIGNIFICANCE OF FINDINGS}

This study demonstrated that the Drip-Feed Bioreactor could be used to treat mixed wastes containing acetonitrile to concentrations below $1.0 \mathrm{mg} / \mathrm{L}$, the land disposal restriction for this compound. This study showed that mixed wastes can be treated without releasing radioactivity and that incineration should not be considered the only alternative for treatment of mixed wastes.

This study represents the first time that a highly concentrated hazardous waste has successfully been treated biologically without excessive dilution. The robust nature of the DripFeed Bioreactor suggests that this reactor could be used to treat other concentrated hazardous or toxic wastes, including scintillation cocktail and chemical agents.

\section{RELATED PUBLICATION}

Chang, L.-Y., A. Proctor, and W.T. Stringfellow, Kinetic parameters for the biological treatment of mixed wastes containing acetonitrile and methanol. Berkeley Lab Formal Report LBID-2433, 2002.

\section{ACKNOWLEDGMENTS}

This project was partially supported by the Assistant Secretary of the Office of Environmental Management (EM) and Office of Science (OS) through Department of Energy Contract No. DE-AC03-76SF00098. The High Pressure Liquid Chromatography (HPLC) waste compositions were kindly provided by Dr. Philip Williams and Chit Than of the National Tritium Labeling Facility of Berkeley Lab. This research was also partially supported by the Center for Science and Engineering Education at Berkeley Lab. Special thanks to Jeremy Hanlon for his assistance on this project.

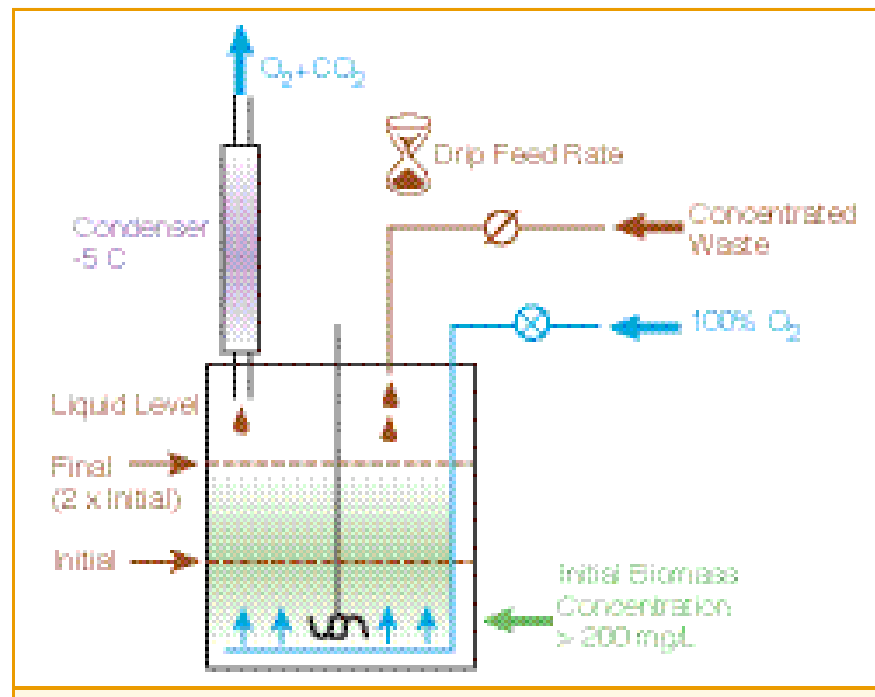

Figure 1. Drip-feed bioreactor schematic 


\section{Estimates of Hydraulic Conductivities Along the Russian River Using Groundwater Temperature Profiles}

Grace W. Su, James Jasperse ${ }^{1}$, Donald Seymour ${ }^{1}$, and Jim Constantz ${ }^{2}$

${ }^{1}$ Sonoma County Water Agency, Santa Rosa, CA, 95406

${ }^{2}$ U.S. Geological Survey, Menlo Park, CA, 94025

Contact: Grace Su, 510/495-2338, gwsu@lbl.gov

\section{RESEARCH OBJECTIVES}

Quantifying surface-groundwater exchanges has become an important component of water resources management, resulting from the increase in the conjunctive use of water resources. Reducing uncertainty in models used to select optimal operation management alternatives requires proper identification of the spatial and temporal variations in physical parameters, such as the hydraulic conductivity.

Recently, heat as a tracer has been demonstrated to be a robust method for quantifying surface-groundwater exchanges. Groundwater temperatures and water levels are routinely monitored in observation wells near streams, but temperature data are generally considered a water-quality parameter and are not used as an environmental tracer to characterize hydraulic parameters. The objective of this study is to quantify the spatial and temporal variations of the alluvial aquifer hydraulic conductivites along the middle reaches of the Russian River in Sonoma County, California, by analyzing groundwater temperature profiles and water levels measured in six observation wells.

\section{APPROACH}

Stream temperatures, groundwater temperatures, and well water levels recorded from June 2000 through October 2000 were used to develop two-dimensional groundwater flow and heat transport simulations of the region from the

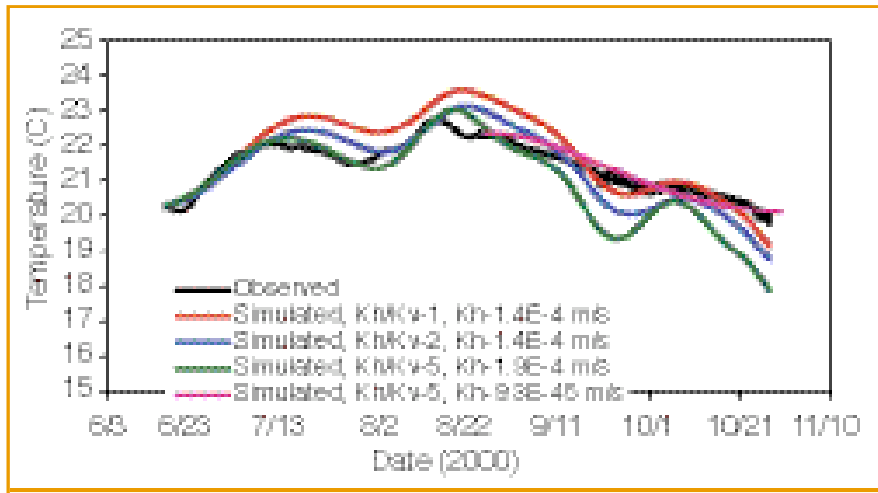

Figure 1. Groundwater temperatures recorded between June and October 2000 in an observation well close to a dam and the best fit simulated temperature profiles at different anisotropies $(\mathrm{Kh} / \mathrm{Kv})$. After mid-August, a smaller conductivity is necessary to obtain a good fit. river to each observation well. Different values for the hydraulic conductivity were used in the simulations, and the value resulting in the smallest difference between the simulated and observed temperatures was considered the best estimate. Simulations were performed under isotropic conditions and with anisotropy (horizontal-to-vertical hydraulic conductivity) values of 2 and 5 .

\section{ACCOMPLISHMENTS}

Estimated hydraulic conductivities varied by almost two orders of magnitude over the six locations analyzed, from 1.7 $\times 10^{-5} \mathrm{~m} / \mathrm{s}$ to $2.3 \times 10^{-3} \mathrm{~m} / \mathrm{s}$. The simulated temperature profiles generally fit the observed ones best when an anisotropy of 5 was used. In some locations, a change in the observed temperature profile occurred through the summer and fall, most likely caused by deposition of fine-grained sediment and organic matter plugging the streambed. A reasonable fit to this change in the temperature profile was obtained by decreasing the hydraulic conductivity in the simulations. The most significant decrease in conductivity occurred in the region closest to an inflatable dam, where the conductivity decreased by about one-half after mid-August, as shown in Figure 1.

\section{SIGNIFICANCE OF FINDINGS}

The results of this study demonstrate that groundwater temperatures and water levels monitored in observation wells can provide an effective means of estimating alluvial aquifer hydraulic conductivities. The temporal and spatial estimates in hydraulic conductivities will be incorporated into a threedimensional groundwater model of this study area currently under development.

\section{RELATED PUBLICATION}

Su, G.,W., J. Jasperse, D. Seymour, and J. Constantz, Analysis of water levels and temperatures in wells to estimate alluvial aquifer hydraulic conductivities. Ground Water, 2003 (submitted).

\section{ACKNOWLEDGMENTS}

This work was supported by the Sonoma County Water Agency (SCWA), through U.S. Department of Energy Contract No. DE-AC03-76SF00098. 


\section{Unsaturated Hydraulic Properties of Gravels}

Tetsu K. Tokunaga, Keith R. Olson, and Jiamin Wan

Contact: Tetsu Tokunaga, 510/486-7176, tktokunaga@lbl.gov

\section{RESEARCH OBJECTIVES}

Gravels can make up large fractions of the subsurface, including vadose zones. The extensiveness of some gravel deposits is evident from the fact that they serve as major aquifers that supply groundwater for agricultural, industrial, and municipal use. Because some gravel deposits do occur in the vadose zone, understanding unsaturated flow and transport in such settings requires knowledge of their hydraulic properties. Some gravel deposits occur in heavily contaminated vadose zones such as the Hanford Site in Washington State, where radioactive wastes have leaked. Gravels are also an important component in engineered capillary barriers for subsurface waste isolation. However, relatively little information is available on the unsaturated hydraulic properties of gravels. In a recent study (Tokunaga et al., 2002), the levels of residual saturation in Hanford gravels were found to be high, in the range of 0.1 to 0.2 . The present work addresses a much broader range of matric (capillary) potentials and saturations in Hanford gravels, and includes characterization of intragranular porosity and water film thicknesses on external grain surfaces.

\section{APPROACH}

To cover a wide range of matric potentials (0 to $-300 \mathrm{MPa}$ ), water-retention measurements were made using suction plate, pressure plate, and vapor-pressure methods (Figure 1). Average water film thicknesses on external surfaces of gravel grains were obtained with a synchrotron $x$-ray microprobebased suction plate technique (Tokunaga et al., 2003). External grain surfaces were also characterized with a laser profilometer, atomic force microscope, and scanning electron microscope. Intragranular surface area was determined with adsorption isotherms (water vapor and krypton gas).

\section{ACCOMPLISHMENTS}

External surfaces of these gravels have root mean-square roughnesses in the $\mu \mathrm{m}$ range, with sparsely distributed deep (hundreds of $\mu \mathrm{m}$ ) pits. Water films on these external surfaces are volumetrically insignificant at matric potentials less than about $-2 \mathrm{kPa}$. Residual water in these gravels occurs in intragranular pores, accounts for about $10 \%$ of the total porosity, and is effectively hydraulically immobile. The insignificant advective access to this intragranular domain was established from measurements that show less than $2 \%$ change in saturation over the matric potential interval of $-10 \mathrm{kPa}$ to $-10 \mathrm{MPa}$. The intragranular domain in Hanford gravels also has a large specific surface area of about $11 \mathrm{~m}^{2} \mathrm{~g}^{-1}$.

\section{SIGNIFICANCE OF FINDINGS}

The high specific surface area and porosity associated with interior regions of Hanford gravel grains largely explain why exchanges of solutes (including contaminants) in these sediments are significant and strongly diffusion-limited.

\section{RELATED PUBLICATIONS}

Tokunaga, T.K., J. Wan, and K.R. Olson, Saturation-matric potential relations in gravel. Water Resour. Res. 38(10), 1214, doi:10.1029/2001WR001242, 2002.

Tokunaga, T.K., K.R. Olson, and J. Wan, Moisture characteristics of Hanford gravels: Bulk, grain-surface, and intragranular components. Vadose Zone J. accepted June 2, 2003.

\section{ACKNOWLEDGMENTS}

This project is supported by the Assistant Secretary of the Office of Environmental Management, Office of Science and Technology, of the U.S. Department of Energy under Contract No. DE-AC03-76-SF00098.

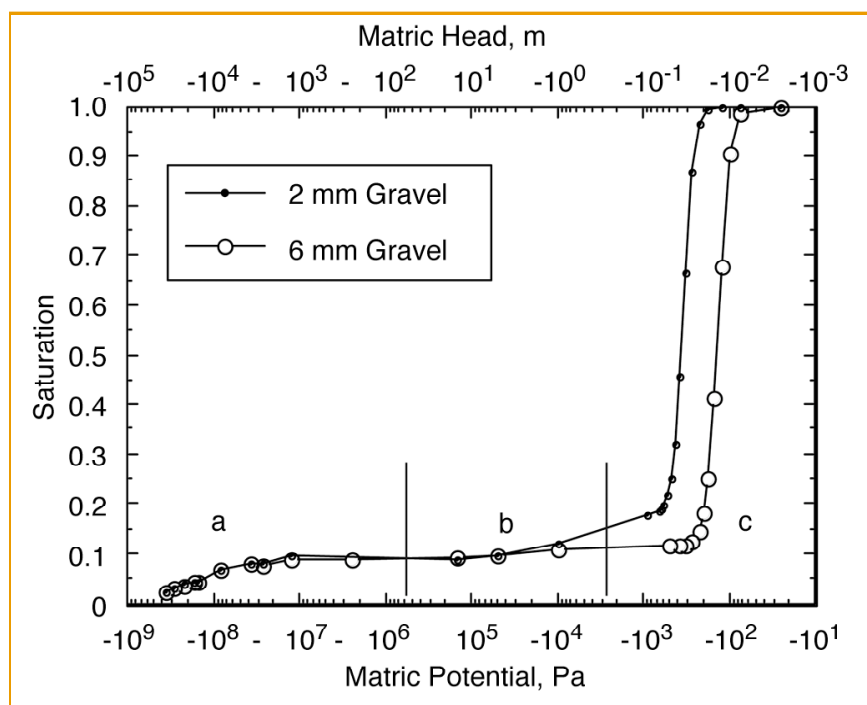

Figure 1. Moisture retention in 2 and $6 \mathrm{~mm}$ Hanford gravels, over a wide range of matric (water) potentials. Measurement methods used are indicated along the $\mathrm{x}$-axis as (a) vapor-pressure regulation, (b) pressure plate, and (c) suction plate. The vapor-pressure equilibration region data were obtained in adsorption mode. The suction plate and pressure plate data were obtained in drainage mode. 


\section{BIOPROSPECTING IN EXTREME ENVIRONMENTS \\ Tamas Torok, Center for Environmental Biotechnology \\ Contact: 510/486-5808 ttorok@lbl.gov)}

\section{RESEARCH OBJECTIVES AND SIGNIFICANCE}

Extremophilic microorganisms are adapted to survive in such ecological niches as high temperatures, extremes of $\mathrm{pH}$, high salt concentrations, and high pressures. Therefore, extremophilic microorganisms represent a challenging scientific opportunity, not only for those interested in microbial diversity and the evolution of life, but for researchers searching for clues to extraterrestrial life. Also, extremophiles produce unique biocatalysts that function under extreme conditions comparable to those prevailing in various industrial processes. Bioprospecting for extremophiles with potential immediate use in the food, chemical, and pharmaceutical industries-and in environmental biotechnology - is therefore highly relevant.

In fulfilling the national security and biological nonproliferation missions of the U.S. Department of Energy, the main objective of this research is to establish a multiyear bioprospecting program for novel biotechnology applications in the extreme environments of the Newly Independent States (NIS) of the former Soviet Union. In previous years, the program collected environmental samples in the exclusion zone of the failed nuclear power plant in Chernobyl, around Lake Baikal in Siberia, and on the Kamchatka peninsula. Currently, we are expanding our research to the deserts and hot springs in Uzbekistan, the Caucasus mountain sites in Georgia, and the former nuclear test site in Kazakhstan.

\section{APPROACH AND RESULTS}

Structure of the microbial community in an ecological niche is characteristic for the ongoing biogeochemical processes. We use a polyphasic approach to microbial community characterization-i.e., both culture-based and alternative, nonculture-based techniques. We have isolated several thousand new microbial strains and detected novel restriction enzymes (as well as unique combinations thereof). Isolated microorganisms are then grown under proprietary, secondary metabolite-producing conditions, and the resulting natural products are screened for innovative crop protection and biomedical application in collaboration with our biotech industry partners. Lead molecules are chemically characterized. Nucleic acid sequences of interest extracted from extreme environmental samples are used in recombinant technologies and lead to novel biocatalysts and biologically active molecules, with a wide range of applications in industry, agriculture, and medicine. Microorganisms and their natural products are being protected by joint patent disclosures. Berkeley Lab is licensing the cultures to the industrial partners. Royalties and other benefits are equitably shared with the NIS researchers.

\section{ACKNOWLEDGMENTS}

This program has been supported by DOE's Initiatives for Proliferation Prevention (IPP) program. The author wishes to express his deepest appreciation for the support he received from colleagues at the International Institute of Cell Biology, Kiev, Ukraine; the State Research Center of Virology and Biotechnology, "VECTOR", Koltsovo, Novosibirsk region; the Institute of Volcanology, Petropavlovsk-Kamchatsky, a member of the Far East Branch of the Russian Academy of Sciences (RAS); the Institute of Geochemistry of the RAS, Irkutsk; and the Buryat Institute of Geology in Ulan Ude, Russia. Special thanks are due to the Baikal Drilling Project and the members of the Russian drilling crew for their professional understanding and support. Special thanks are extended to G. Dahlbacka, Berkeley Lab's ILAB representative. Without his active support, this program could not have achieved its goals.

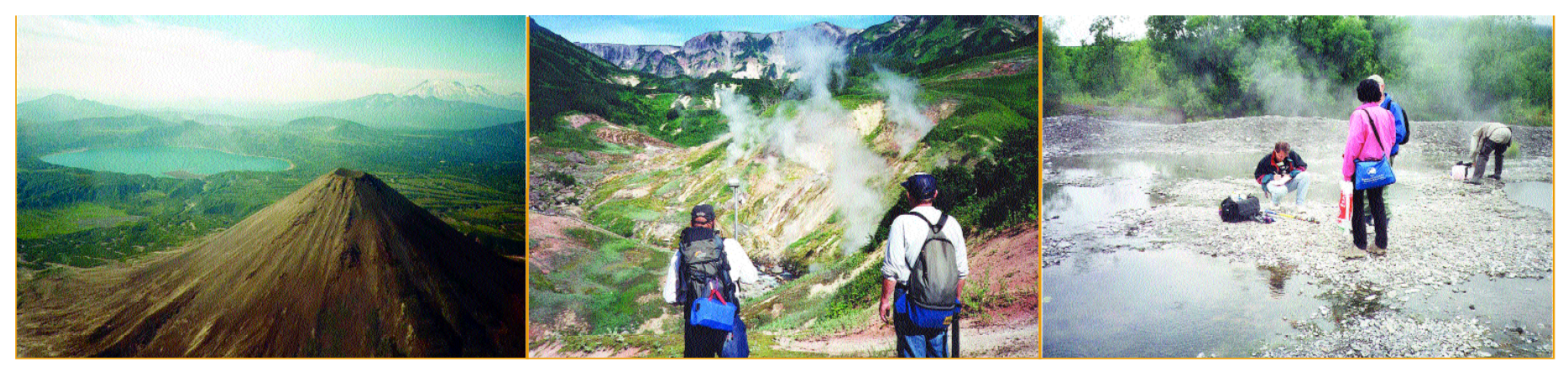




\section{Constant-Head Well Testing in Support of Environmental Remediation \\ Robert C. Trautz, Iraj Javandel, and Preston D. Jordan \\ Contact: Rob Trautz, 510/486-7954, rctrautz@lbl.gov}

\section{RESEARCH OBJECTIVES}

Groundwater contamination resulting from improper waste disposal and accidental releases of chemicals to the environment is a significant problem faced by many communities. Numerous technologies have been developed over the past two decades to treat contaminated groundwater. Selection of the best-available technology for a given site is based on the treatment technology's ability to either remove or immobilize the contaminant and the cost of implementing the treatment. Both criteria are typically evaluated in light of contaminant travel times, which influence the groundwater treatment time and cost, thus potentially affecting the final cleanup method selected. This article describes a constant-head test method and equipment used in the field to estimate relatively low hydraulic conductivities (K), an important hydrological property of the contaminated water-bearing zone used to estimate travel times.

\section{APPROACH}

A variety of methods are employed to measure $\mathrm{K}$ in the field. During a typical pumping test, groundwater is pumped from a well penetrating the desired zone at a constant rate, and the change in water levels is monitored in nearby wells. Alternatively, during a slug test, groundwater may be quickly added to or removed from a well, and the water level in the test well is monitored as it returns to its original level. Both techniques have their advantages and disadvantages. Pumping tests are difficult to perform in low

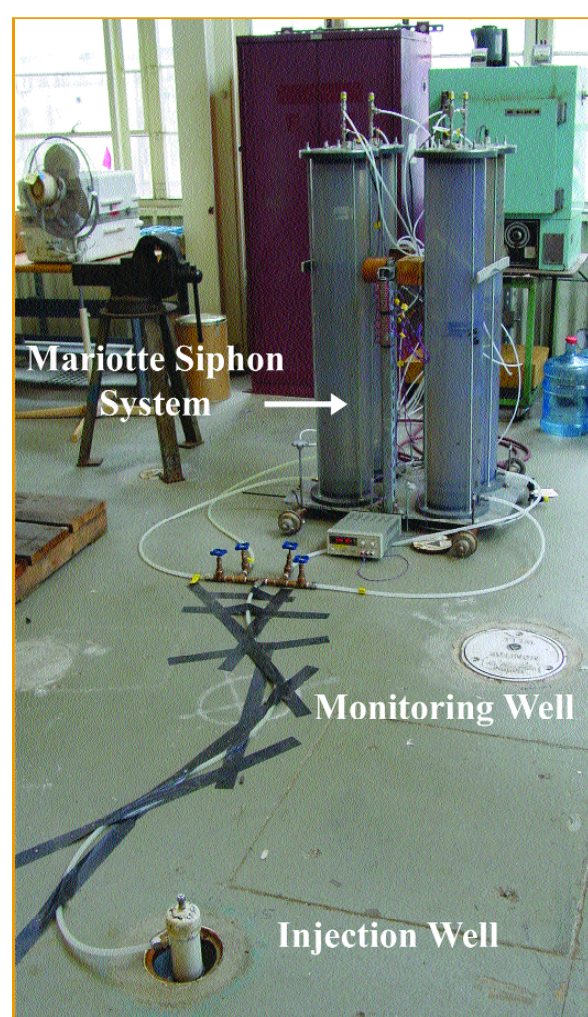

Figure 1. Photo of pressurized Mariotte siphon system and constant-head test configuration well during water injection. Observed changes in flow rate and water levels are used to estimate $\mathrm{K}$.

\section{ACCOMPLISHMENTS}

Our equipment (Figure 1) differs from what is typically employed, which includes disc and Guelph permeameters, in that the test vessel is constructed to withstand higher working pressures and, therefore, can be operated at pressures exceeding one atmosphere (zero gauge pressure). This allows the test operator to deliver water to the well at a constant positive head up to 3 atmospheres (gauge) by connecting compressed air to the bubble tube instead of leaving it open to the atmosphere.

\section{SIGNIFICANCE OF FINDINGS}

The test equipment was successfully used to conduct a constant-head injection test lasting 60 days in duration. During this time period, water levels in adjacent observation wells, located up to $4.6 \mathrm{~m}$ from the injection point, increased by 0.3 to $1 \mathrm{~m}$ because of the $5.2 \mathrm{~m}$ injection head. Analysis of the test results produced estimates of $\mathrm{K}$ comparable to those produced from baseline slug tests conducted on the same wells. Constant-head tests have an advantage over pump tests in that they can be used to characterize lowyield porous materials. Compared to slug tests, this method stresses a much larger volume of the zone of interest, producing estimates of $\mathrm{K}$ that are less susceptible to error caused by wellbore damage and, therefore,

$\mathrm{K}$ formations because the pumping rate may exceed the yield of the aquifer, causing the well to be pumped dry. The stress applied to the aquifer during a slug test typically penetrates only a short distance into the adjacent formation, suggesting the measured $\mathrm{K}$ may be influenced by conditions near the borehole (e.g., formation damage caused by drilling). The method presented here employs a specially designed Mariotte siphon system (Figure 1) to maintain a constant-hydraulic head on the test more representative of the formation.

\section{ACKNOWLEDGMENTS}

This work is part of Berkeley Lab's Environmental Restoration Program, supported by the Assistant Secretary of the Office of Environmental Management, Office of Science and Technology, of the U.S. Department of Energy, under Contract No. DE-AC03-76-SF00098. 


\section{Studies Related to Deep WAste InJection Chin-Fu Tsang and Dmitriy B. Silin \\ Contact: Chin-Fu Tsang, 510/486-5782, cftsang@lbl.gov}

\section{RESEARCH OBJECTIVES}

The main purpose of the Underground Waste Injection project at Berkeley Lab is to develop new scientific approaches and methods related to underground injection of liquid wastes and to advise EPA on scientific aspects of injection regulation and permit process. In 2003, under the project an international symposium on Underground Injection Science and Technology will be organized, with attendees from 15 countries. One technical development in 2003 is the demonstration of a new pressure analysis method that allows the possibility of estimating the formation's hydraulic properties using regular operations data, to replace the currently-required annual shut-in tests. It is discussed below.

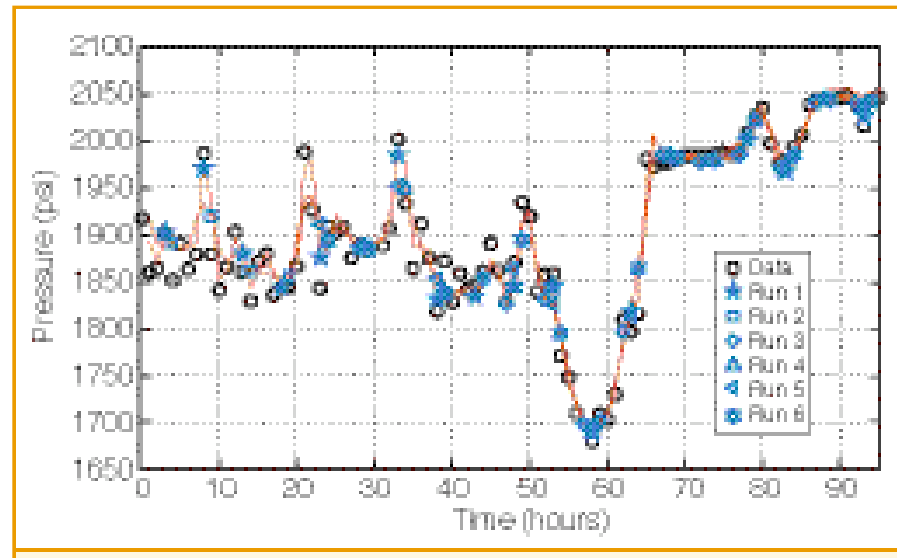

Figure 1. Hourly injection pressures from a deep injection well at an Ohio EPA site. Besides measured pressures (circles), the plot includes six matching curves obtained using ODA on different data intervals. All six curves practically collapse. Outside of the data matching intervals, the calculated curves provide accurate pressure predictions.

\section{APPROACH}

We have developed a new method, implemented in a code, ODA, to analyze the operations pumping rates and pumping pressure data (Silin and Tsang, 2002; 2003). To demonstrate its capability, first, the formation parameters are estimated from the regular injection operations data using the ODA code. Then, these results are compared with the results obtained independently from conventional analyses of fall-off tests.

\section{RESULTS}

The developed method has been applied to analyze several regular injection data sets obtained from four deep injection wells at an Ohio EPA site. The injection intervals are approximately $300 \mathrm{ft}$ long and mostly consist of sandstone formations.

The data fitting has been performed on various data intervals. The resulting estimates of the key hydraulic parameters are stable with respect to the selected data interval. Figure 1 shows the results of six different runs of the code on different matching intervals. In cases where the matching interval was significantly shorter than the whole data set, the extension of the calculated curve beyond this interval provides an accurate prediction of the actually measured pressures. In some cases, averaging of the data over a running time window helps to improve the quality of fitting. The smoothing of the data by such an averaging does not significantly affect the estimated values of the hydraulic parameters. Comparison of the results of analysis of conventional pressure fall-off tests obtained by our method with results obtained independently, using standard methods, shows that in most cases our estimates of the skin factor are significantly lower. We explain this by the fact that our approach rigorously accounts for the impact of pre-test pumping. Such an impact is neglected by the standard methods. The stability of our estimates makes them more credible than those of the standard methods, where the estimates strongly depend on the selection of the analyzed data interval.

\section{SIGNIFICANCE OF FINDINGS}

We have demonstrated that by applying the methods we have developed to regular operations data, we can obtain robust estimates of formation hydraulic properties. It implies that interruptions for conducting transient pressure well tests, which are required by regulations governing deep waste injection, can be significantly reduced or entirely replaced by regular data analysis. In addition to the consequent cost reduction, our method makes possible continuous monitoring of the formation properties, which means a significant safety enhancement with regard to timely detection of possible leakage or breakthrough of the liquid injectant.

\section{RELATED PUBLICATIONS}

Silin, D.B. and C.F. Tsang, Estimation of formation hydraulic properties accounting for pre-test injection or production operations. Journal of Hydrology, 265, 1-14, 2002.

Silin, D.B. and C.F. Tsang, A well-test analysis method accounting for pre-test operations. SPE Journal, 8(1), 22-30, 2003.

\section{ACKNOWLEDGMENTS}

This research has been supported by the U.S. Environmental Protection Agency, Office of Ground Water and Drinking Water, Underg round Injection Control Program, under an Interagency Agreement with the US Department of Energy under Contract No. DE-AC03-76SF00098.

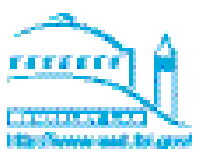




\section{UraniUm Transformations in CONTAMINATEd SEDIMENTS}

Jiamin Wan, Tetsu K. Tokunaga, Terry Hazen, Mary Firestone ${ }^{1}$, Zuoping Zheng,

Jasquelin Pena, Joern Larsen, and Eoin Brodie ${ }^{1}$

${ }^{1}$ University of California, Berkeley

Contact: Jiamin Wan, 510/486-6004, jmwan@lbl.gov

\section{RESEARCH OBJECTIVES}

Biogeochemical heterogeneity in the subsurface occurs because of transport limitations at many length scales. The question arises, when micro-environmental conditions vary significantly at the millimeter scale, where do specific biogeochemical processes occur, and how are they coupled? Within much of the subsurface, the spectrum of micro-environments is coupled through diffusive mass transfer. Thus, diffusion-limited domains are the simplest systems within which the full range of transformations can occur. Furthermore, such systems cannot be understood through characterization of bulk, volume-averaged properties because key gradients in chemical components and microbial communities are overlooked. In this research, we are investigating the biogeochemistry of uranium $(\mathrm{U})$ and nitrate $\left(\mathrm{NO}_{3}{ }^{-}\right)$ in diffusion-limited domains in order to understand the integrated effects of transport and biogeochemical reactions on transformations of these contaminants. Uranium and $\mathrm{NO}_{3}{ }^{-}$often occur as co-contaminants, and the reduction of soluble $\mathrm{U}(\mathrm{VI})$ to insoluble U(IV) in sediments is being considered as a strategy for in situ remediation. Pathways for $\mathrm{U}$ reoxidation need to be understood for us to critically evaluate reductive in situ remediation strategies. Our studies address three main segments of the subsurface U contamination cycle: (1) transport (sorption-release, diffusion, advection), (2) biogeochemistry of reduction (as influenced by $\mathrm{NO}_{3}{ }^{-}$), and (3) reoxidation.

\section{APPROACH}

Many studies are being conducted to evaluate both the individual aspects and integrated effects of the $U$ cycle in contaminated sediments. Individual components under investigation include $\mathrm{U}(\mathrm{VI})$ sorption and release in batch systems, nitrate and $\mathrm{U}(\mathrm{VI})$ reduction in batch systems, and $\mathrm{U}(\mathrm{IV})$ reoxidation to $\mathrm{U}(\mathrm{VI})$. Column studies permit assessment of sorption-release and reduction-oxidation on overall $\mathrm{U}$ and $\mathrm{NO}_{3}{ }^{-}$transport. Experiments are also being done on historically contaminated and pristine soils from the NABIR Field Research Center at Oak Ridge, Tennessee.

\section{ACCOMPLISHMENTS}

The importance of calcite in suppressing $\mathrm{U}(\mathrm{VI})$ sorption into soils has been predicted and demonstrated (Zheng et al., 2003). Overall bacteria diversity in historically U-contaminated soils appeared to increase in response to lactate and $\mathrm{NO}_{3}{ }^{-}$additions, although the high diversity in $n i$ ir genes decreased. Lactate infusion into U-contaminated soils resulted in reduction to U(IV) within 30 days and was well reflected in redox potential measurements.

\section{SIGNIFICANCE OF FINDINGS}

The effect of calcite on suppressing U(VI) sorption was previously overlooked when standard experimental procedures were applied to slightly calcareous sediments. The sorption envelopes help explain the transient $\mathrm{U}(\mathrm{VI})$ diffusion measurements obtained in a related BES-supported study.

\section{RELATED PUBLICATIONS}

Tokunaga, T.K., J. Wan, T.C. Hazen, E. Schwartz, M.K. Firestone, S.R. Sutton, M. Newville, K.R. Olson, A. Lanzirotti, and W. Rao, Distribution of chromium contamination and microbial activity in soil aggregates. J. Environ. Qual., 32, 541-549, 2003.

Zheng, Z., T.K. Tokunaga, and J. Wan, Influence of calcium carbonate on sorption of U(VI) to soils, Environ. Sci. Technol., 2003 (submitted).

\section{ACKNOWLEDGMENTS}

This project is supported by the Director, Office of Science, Office of Biological and Environmental Research, Natural and Accelerated Bioremediation Research (NABIR) Program, of the U. S. Department of Energy under Contract No. DE-AC0376-SF00098. Use of the Advanced Photon Source was supported by the DOE, Office of Science, Office of Basic Energy Sciences, under the same DOE contract number.

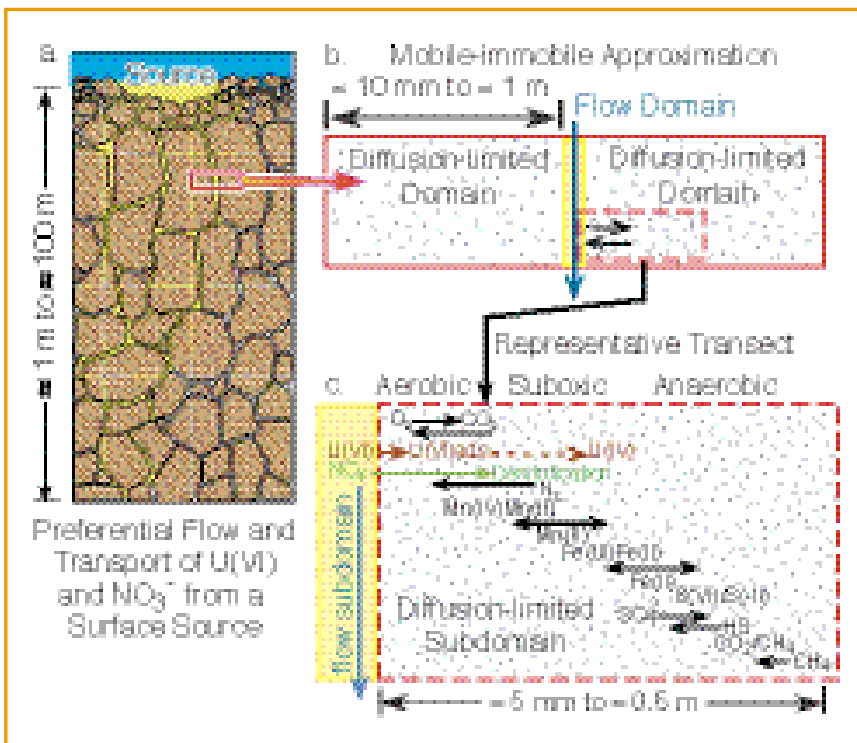

Figure 1. (a) Preferential flow and transport in the subsurface; (b) mobile-immobile approximation; (c) redox zonation within diffusion-limited domains 


\title{
Geochemical Evolution of Highly Alkaline and Saline Tank Waste Plumes During Seepage Through Vadose Zone Sedments
}

\author{
Jiamin Wan, Tetsu K. Tokunaga, Joern T. Larsen, and Zuoping Zheng \\ Contact: Jiamin Wan, 510/486-6004, jmwan@lbl.gov
}

\section{RESEARCH OBJECTIVES}

Leakage of highly saline and alkaline radioactive waste solutions from storage tanks into underlying sediments is a serious problem at the Hanford Site in Washington State. Although it was found from field samples that $\mathrm{pH}$ values of the initially highly alkaline $(\mathrm{pH} 14)$ waste plumes dramatically decreased (to $\mathrm{pH} 10-7$ ), understanding of the neutralization process was lacking. Since $\mathrm{pH}$ is a master geochemical variable, the behavior of waste plume contaminants, including their speciation, sorption, solubility, precipitation, and transport, can be reliably predicted only when the evolution of the $\mathrm{pH}$ profile is understood. This study focuses on the geochemical evolution of major geochemical parameters including $\mathrm{pH}$, and addresses how $\mathrm{pH}$ evolved as the plumes propagated.

\section{APPROACH}

We designed a plume profiling method to obtain spatially and temporally direct measurements of plume geochemistry profiles. The influences of waste solution $\mathrm{pH}$, ionic strength, and sediment type were also studied. To maximize the relevance of this laboratory study for understanding real field problems, most of

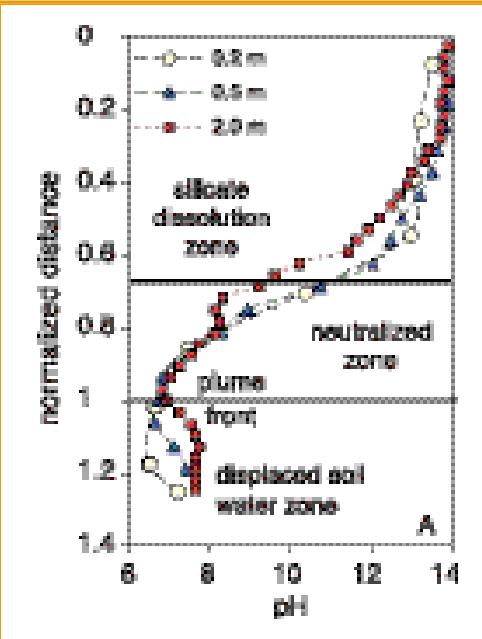

Figure 1. The $\mathrm{pH}$ profile along the $0.2,0.5$, and $2.0 \mathrm{~m}$ tall columns, with the distance axis normalized to the predicted plume front position the experiments involved infusion of synthetic waste solutions into sediment columns, thereby integrating the influences of reactions and transport.

\section{ACCOMPLISHMENTS}

This study revealed that while the plume is connected to an actively leaking source, its profile spans the very broad range from $\mathrm{pH} 14$ (influent waste $\mathrm{pH}$ ) within the near-source region, down to $\mathrm{pH} 6.5$ (lower than that of the initial soil solution) at the plume front (Figure 1). The plume can be divided into two zones: the Silicate Dissolution Zone (SDZ, pH 14-10), and Neutralized Zone (NZ, pH 10-7). After the plume source became inactive and the plume aged, $\mathrm{pH}$ values within the SDZ continued to decrease at a decreasing rate and eventually reached equilibrium at around $\mathrm{pH} 10$ - whereas the $\mathrm{pH}$ values in the original neutralized zone remained relatively unchanged. The major reactions responsible for the $\mathrm{pH}$ evolution of the waste plumes were identified, along with specific regions within the plumes where they occur.

\section{SIGNIFICANCE OF FINDINGS}

This laboratory study provides information on how $\mathrm{pH}$ evolved as tank waste plumes propagated. As a master geochemical variable, $\mathrm{pH}$ needs to be understood in order to predict the fate and transport of contaminants carried by waste plumes.

\section{RELATED PUBLICATIONS}

Wan, J., T.K. Tokunaga, J.T. Larsen, and R.J. Serne, Geochemical evolution of highly alkaline and saline tank waste plumes during seepage through vadose zone sediments. Geochim. Cosmochim. Acta, 2003 (in press).

Wan, J., J.T. Larsen, T.K. Tokunaga, and Z. Zheng, pH neutralization and zonation in alkaline-saline tank waste plumes. Environ. Sci. Technol., 2003 (submitted).

\section{ACKNOWLEDGMENTS}

This project is supported by the Assistant Secretary of the Office of Environmental Management, Office of Science and Technology, Environmental Management Science Program, of the U.S. Department of Energy under Contract No. DE-AC0376-SF00098.

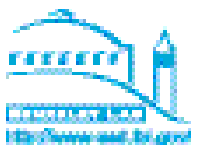




\section{Modeling Geochemical Reactive Transport of Concentrated Aqueous SOlUTIONS IN VARIAbly SATURATED MEDia}

Guoxiang Zhang, Zuoping Zheng, and Jiamin Wan

Contact: Guoxiang Zhang, 510/486-4980, gxzhang@lbl.gov

\section{RESEARCH OBJECTIVE}

Concentrated aqueous solutions (CAS) occur in many natural and contaminated environments, such as in the leakage of highly concentrated $\mathrm{NaNO}_{3}$ electrolytes stored at DOE's Hanford site. They are generally considered as solutions with ionic strength larger than $1 \mathrm{M}$ and can be more than $10 \mathrm{M}$. The main objectives in this paper are (1) to develop a model that can simulate the coupled geochemical and transport processes of CAS by developing a Pitzer ion-interaction module and incorporating it into a previously developed computer code, BIO-CORE2D॰, (2) to verify the developed module and the implementation into $\mathrm{BIO}-\mathrm{CORE}^{2 \mathrm{D} \odot}$, and (3) to validate the developed model through simulating laboratory experiments.

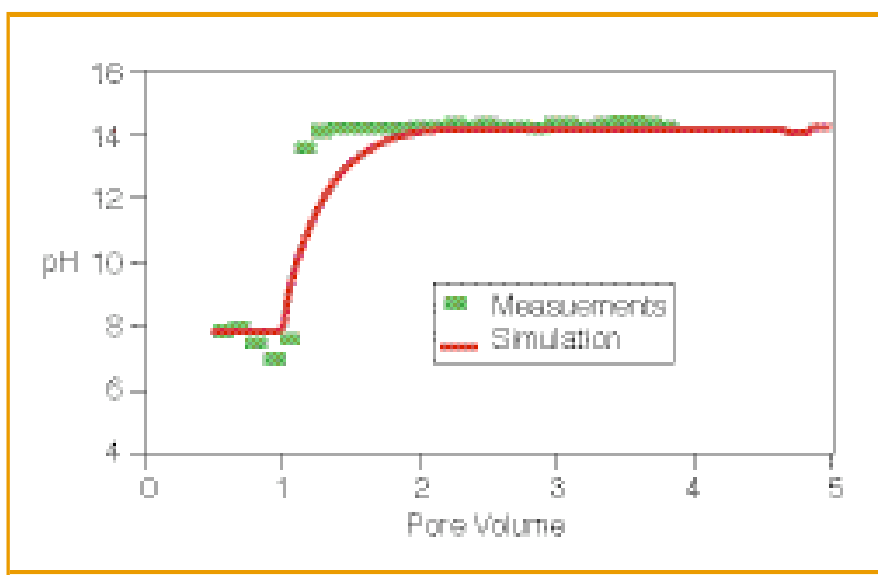

Figure.1. Simulated $\mathrm{pH}$ and measured $\mathrm{pH}$ of the effluent fluid during the injection of a highly alkaline-saline solution into a column filled with unsaturated sediments from the Hanford Site

\section{APPROACH}

The Pitzer ion-interaction model is considered the best representation of the ionic activity within CAS. In this study, a module of the Pitzer ion-interaction model is developed and implemented in a previously existing geochemical and microbiological reactive transport computer code, BIO-CORE $2 \mathrm{D} \odot$ (Zhang, 2001). This code solves saturated-unsaturated flow, heat transfer, and solute transport coupled with chemical and microbial processes. A database storing Pitzer ion-interaction parameters was also developed. All parameters are temperature-dependent.

\section{ACCOMPLISHMENTS}

Several reported cases in the literature are used to verify the implementation of the Pitzer model. One of them calculates the activity coefficient of hydrochloric acid in a concentrated $\mathrm{HCl}-\mathrm{NaCl}-\mathrm{KCl}-\mathrm{H}_{2} \mathrm{O}$ system $(298.15 \mathrm{~K})$, at ionic strengths of $4,5,6$, and $7 \mathrm{~mol} / \mathrm{kg}$, respectively, as a function of $\mathrm{KCl}$ concentration. We compared model results to the experimental data. Another case reports calculation of the activity coefficient of $\mathrm{NaCl}$ in a concentrated aqueous $\mathrm{NaCl}-$ $\mathrm{Na}_{2} \mathrm{SO}_{4}-\mathrm{H}_{2} \mathrm{O}$ system-at ionic strengths of 2, 3, 4, and 6; and at $298.15 \mathrm{~K}$ and $318.15 \mathrm{~K}$, respectively, as a function of $\mathrm{Na}_{2} \mathrm{SO}_{4}$ concentration. The results show that the activity coefficients calculated by BIO-CORE $2 \mathrm{D} \odot$ are fairly close to the measurements. Wan et al. (2002) carried out a column experiment to understand the chemical interactions taking place in sediments from the Hanford Site during leakage of highly alkaline-saline solutions. In this experiment, highly alkaline-saline solution was injected into a column filled with unsaturated sediments from the Hanford Site. The experiment was modeled using BIO-CORE $2 \mathrm{D} \odot$, and the results match the measured chemical composition of the effluent water. Figure 1 shows that the simulated $\mathrm{pH}$ matches the measured $\mathrm{pH}$ well. This result helps to improve our understanding of mineral precipitation and cation exchange processes during leakage of the tank waste solutions into sediments.

\section{SIGNIFICANCE OF FINDING}

The Pitzer phenomenological theory, as a basis for calculating ionic activities in concentrated aqueous solutions, is adequate for modeling high-ionic-strength problems. The Pitzer-type model generally reproduces the observed concentration trends for the Hanford case in which highly alkalinesaline solutions have leaked into sediments. Discrepancies could be attributed to uncertainties in cation exchange coefficients, surface areas, kinetics, and other thermodynamic data used in the model, as well as measurement errors.

\section{RELATED PUBLICATIONS}

Wan, J., T.K. Tokunaga, and J.T. Larsen, 2002, Evolution of REDOX tank waste plumes in Hanford vadose zone: A conceptual model developed through reactive transport studies, 2002 (submitted).

Zhang, G., 2001, Nonisothermal hydrobiogeochemical models in porous media. Ph.D. dissertation, University of La Coruña, Spain.

\section{ACKNOWLEDGMENTS}

This research is provided by the Assistant Secretary of the Office of Environmental Management, Office of Science and Technology, Environmental Management Science Program, of the U.S. Department of Energy under Contract No. DE-AC0376SF-00098. 


\title{
Berkeley Lab Site Modeling
}

\author{
Quanlin Zhou, Jens T. Birkholzer, Iraj Javandel, and Preston D. Jordan \\ Contact: Quanlin Zhou, 510/486-5344, qlzhou@lbl.gov
}

\section{RESEARCH OBJECTIVES}

In the late 1980s, groundwater contamination was detected at the original site of Berkeley Lab (Old Town Area). A detailed investigation was conducted to locate the source and extent of the contamination. Interim corrective measures were initiated where appropriate and required, typically directed towards removing the source of contamination and installing groundwater collection trenches downstream of the plumes, limiting further spreading of contaminants. To provide a basis for predicting the fate of contaminants, we developed a transient groundwater flow model for the complex hydrogeological situation in this area. The objective of this work is to improve our understanding of flow patterns and contaminant transport in the Old Town Area, to support the decisionmaking processes for remediation measures.

\section{APPROACH}

In addition to the complex hydrogeology_featuring several geologic units with strongly varying thicknesses, slopes, and properties-groundwater flow is strongly affected by seasonal patterns, by local recharge from leaking storm drains, and by significant water recharge from steep hills located in the upstream direction. A hydrogeologic model was developed from geologic information obtained from more than 100 boreholes and outcrop maps. Boundary conditions

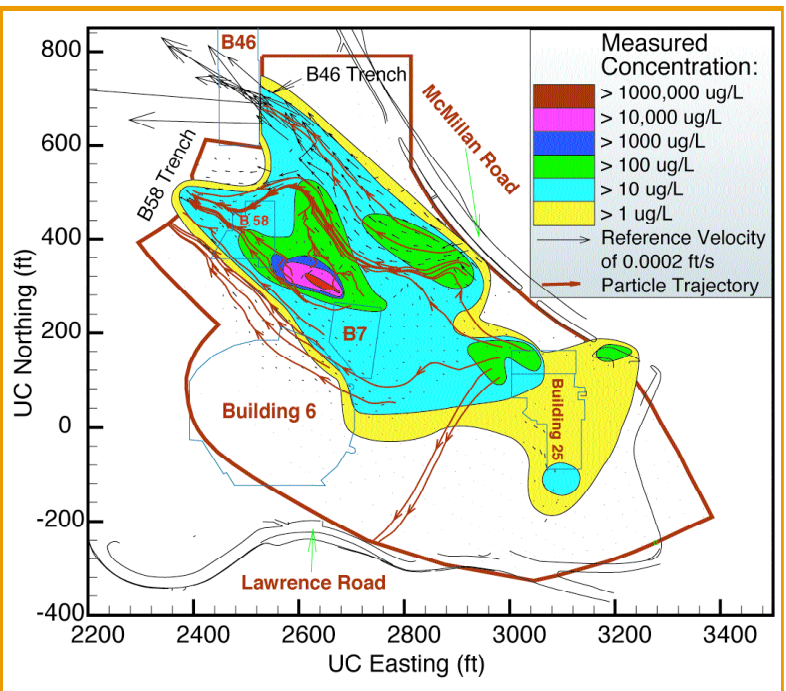

Figure 1. Simulated particle trajectories originating from contaminant plumes at steady-state flow rate (April 1998)

\section{ACCOMPLISHMENTS}

The calibrated hydrogeologic properties and recharge rates produced good agreement between the simulated and measured water table at about 40 observation wells and the flow rate at two water collection trenches. The calibrated "effective" porosity, which is much smaller than the actual physical porosity, represents the bulk effect of thin layers of relatively high hydraulic conductivity and large porosity, found in the mixed unit within bedrock of otherwise very low conductivity and porosity. This effective porosity thus leads to fast responses to water table changes with strong seasonal fluctuations. The validation results indicate that the developed model can accurately predict the complex groundwater flow at the Berkeley Lab site. Figure 1 shows the simulated velocity field and particle trajectories at July 1998, together with measured concentration contours. The simulated advective transport patterns and the measured extent of the plume are in good agreement.

\section{SIGNIFICANCE OF FINDINGS}

The developed model predicts g roundwater flow in complex geological structures (ones with sharp changes in interfaces and water table gradients). It can improve our understanding of contaminant transport at the Berkeley Lab site and help us for this model were established from water levels collected from a large set of monitoring wells, subdrains, and deep trenches. Distribution of hydraulic conductivity was initially assigned based on the data compiled from single- and multiwell pumping tests. Recharge to groundwater was initially estimated from the type of land surface coverage (i.e., paved, under the building, or irrigated areas). Subsurface utility maps were also employed to locate and estimate potential leakage from corroded storm drains. Subsequently, some of the input data were adjusted, using calibration techniques enabling a very accurate hydrography of a large set of monitoring wells. Calibration was performed based on 1994-1996 water levels. The calibrated flow model was validated using a blind model prediction conducted for the period of July 1996-June 2000. A refined model was subsequently developed for the central area of the main contaminant plume. This refined model will be used as a tool to analyze and improve the current hydraulic measures conducted for contaminant remediation. make better decisions about remediation measures for the Berkeley Lab Remediation Project.

\section{RELATED PUBLICATIONS}

Javandel, I., RCRA Facility Investigation Report, Module B, Lawrence Berkeley National Laboratory, Berkeley, California, 2000.

Zhou, Q., J. T. Birkholzer, I. Javandel, and P. D. Jordan, Simulation of Groundwater Flow at the LBNL site Using TOUGH2, LBNL-52512, Proceedings of TOUGH Symposium 2003, Berkeley, California, 2003.

\section{ACKNOWLEDGMENTS}

This work is part of Berkeley Lab's Environmental Restoration Program, supported by the Assistant Secretary of the Office of Environmental Management, Office of Science and Technology, of the U.S. Department of Energy under Contract No. DE-AC03-76SF00098. 



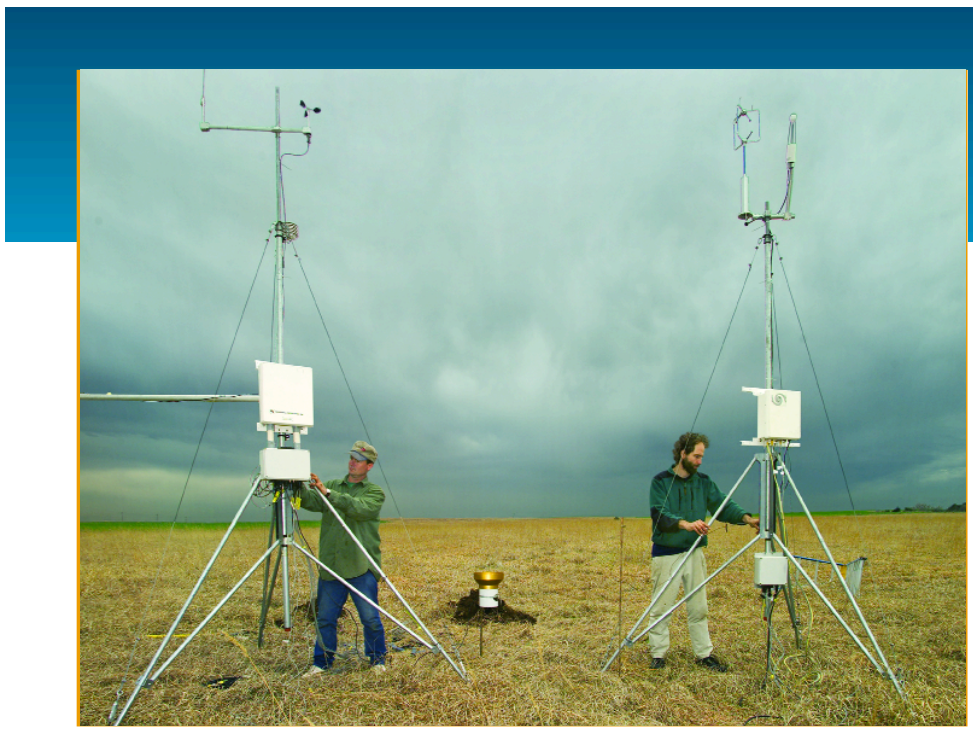

Climate Variability and Carbon Management is a growing interdisciplinary research program in the Earth Sciences Division. The program's main focus is on conducting research to increase the scientific foundation for prediction, impact assessment, and prevention of climate change. In addition, increased understanding of the earth's biogeochemical cycles and climate is needed for many other pressing issues under the purview of DOE and other public agencies, such as stewardship of water resources and the environmental effects of energy use and land use. To that end, we have active projects on climate and hydrology, climate change, a variety of ecological systems and biogeochemical cycles, and carbon sequestration in geologic, oceanic, and terrestrial systems.

One of the strengths of the Climate Variability and Carbon Management Program is its active partnerships with universities, industry, and other research laboratories. A prominent example of such partnerships is our strong link to research activities on the UC Berkeley campus, including the Berkeley Atmospheric Sciences Center.

Last year (2002), within the Program, more than a dozen PIs led projects that included four divisions and more than 62 people at Berkeley Lab. This year (2003), the Program joined with three other divisions (Energy and Environmental Technologies, Engineering, and National Energy Research and Scientific Computing) in developing a proposal for a Lab-wide climate change initiative.

\section{RECENT ACCOMPLISHMENTS}

To illustrate a few recent accomplishments by the Climate Variability and Carbon Management Program, below we describe the new regional carbon sequestration alliance we have joined and the advanced research we are doing in the areas of regional climate studies, terrestrial carbon cycling, oceanic carbon cycling, and geologic carbon sequestration.
Research Program

Climate Variability and Carbon Management

Margaret S. Torn

510/486-2223

mstorn@lbl.gov

\section{CARBON SEQUESTRATION PARTNERSHIP}

A major new development this year was the establishment of the West Coast Regional Carbon Sequestration Partnership, in which ESD is playing a central role. This is one of seven partnerships recently established by the DOE to evaluate $\mathrm{CO}_{2}$ capture, transport, and sequestration technologies best suited for different regions of the country. The West Coast Region comprises Arizona, California, Nevada, Oregon, Washington, and the North Slope of Alaska. This partnership constitutes a consortium of over 35 organizations, including state natural resource and environmental protection agencies; national labs and universities; private companies working on $\mathrm{CO}_{2}$ capture, transportation, and storage technologies (CS\&T); utilities; oil and gas companies; nonprofit organizations; and policy / governance coordinating organizations. In an 18-month Phase I project, this partnership will evaluate both terrestrial and geologic sequestration options. There are five major tasks. The first task is to collect data to characterize major $\mathrm{CO}_{2}$ point sources, the transportation options, and the terrestrial and geologic sinks in the region. These data will be compiled and organized via a geographic information system (GIS) database.

Another task is to address key issues affecting deployment of CS\&T technologies, including storage site permitting and monitoring, injection regulations, and health and environmental risks. As part of this, we will conduct public outreach and maintain an open dialogue with stakeholders in carbon CS\&T technologies through public meetings, joint research, and education work. At this point, the data and information from the above tasks can be integrated and analyzed to develop supply curves and cost-effective, environmentally acceptable sequestration options, both near- and long-term. Finally, the partnership will identify appropriate terrestrial and geologic demonstration projects consistent with the options defined above, and create action plans for their safe and effective implementation. If suitable demonstration projects can be identified and are approved by DOE, they will be carried out as a Phase II of the Partnership program.

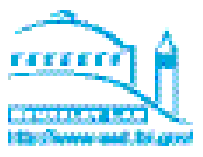




\section{REGIONAL CLIMATE AND WATER RESOURCES}

Berkeley Lab's California Water Resources Research Center investigates regional and local hydroclimates for multiple state and federal agencies. A number of regional climate models tend to overestimate precipitation in California, making it difficult to predict water resources and flooding, or to evaluate climate change impacts with confidence. Berkeley Lab analyses showed that these biases arise because models do not represent snow accurately. Simulating the snow pack also has great practical significance, since snow packs store $80 \%$ of California's water supply. A climate change analysis for the year 2100 performed by the Lab projects a significant reduction in snow pack for six major watersheds in the state. The related changes in snowmelt and stream flow suggest there will be higher flow, and thus greater flood danger, in the winter, while summer flows, when demand is greatest, will be lower.

\section{TERRESTRIAL BIOSPHERE CARBON CYCLE}

Soils contain twice as much carbon as the atmosphere and exchange carbon with the atmosphere at ten times the rate of fossil fuel emissions. We are using advanced isotopic techniques to study the poorly understood rate-controlling processes hidden underground. Berkeley Lab documentation that fine tree roots live five times longer than previously thought is leading to changes in forest ecosystem models and estimates of the amount of carbon pumped belowground by root growth. One of the focal points of carbon cycle research is the vast range of scales-from a single leaf to an entire continent-that must be bridged with measurements and models. Berkley Lab has implemented a coordinated suite of carbon concentration, isotope, and flux measurements in the Southern Great Plains, as part of the DOE Atmospheric Radiation Measurement (ARM) Program. Data streams began flowing to the ARM archives this year. Simultaneously monitoring from crop fields, tall towers, and aircraft, this facility is possibly the best-instrumented site for regional carbon studies in the world.

\section{OCEAN BIOGOECHEMISTRY}

Oceans contain more carbon than any other dynamic reservoir on earth, and thus pose a great observational challenge. The pulses of biological productivity are episodic and rapid, and the areas are vast. As a result, we lack understanding of what controls ocean productivity and the export of carbon from the productive photic zone to deeper waters, where it can be stored for long periods. Berkeley Lab has developed the Carbon Explorer, an autonomous float that uses satellite telemetry to report its observations from distant oceans. Last year, Carbon Explorers were deployed as part of the Southern Ocean Iron Experiment to test the effect of iron fertilization. The results suggest that the impact of iron was greater than expected in waters where other essential elements were deficient. These results were made possible by the continuous observations of the Carbon Explorers over an entire year, a data record that would not have been possible with conventional research ships.

\section{GEOLOGIC CARBON SEQUESTRATION}

Geologic sequestration of $\mathrm{CO}_{2}$ below the earth's surface is one of the most promising options for reducing atmospheric $\mathrm{CO}_{2}$ over the next several decades, because the technologies to capture and store $\mathrm{CO}_{2}$ are readily available. Berkeley Lab has been exploring a possible new technology_carbon sequestration with enhanced gas recovery, whereby $\mathrm{CO}_{2}$ is injected into mature natural gas reservoirs to enhance $\mathrm{CH}_{4}$ recovery while simultaneously storing $\mathrm{CO}_{2}$ in the reservoir. Simulations suggest that the method is both technically and economically feasible in many cases. Berkeley Lab was also active during the year in leading an international comparison of numerical codes that predict the fate of $\mathrm{CO}_{2}$ in storage reservoirs, to better understand human health and environmental impacts. We also demonstrated the first use of seismic imaging between two horizontal wells for detailed characterization of a storage reservoir, and the first use of joint electromagnetic and seismic imaging to quantitatively map the saturation of $\mathrm{CO}_{2}$ in the subsurface for monitoring and verification.

\section{FUNDING AND PARTNERSHIPS}

The Climate Variability and Carbon Management Program is funded by a variety of federal and state agencies, and international collaborations. These include the U.S. Department of Energy's Office of Basic Energy Sciences, Office of Fossil Energy, Office of Geological and Environmental Research, and Office of Biological and Environmental Research; the National Aeronautics and Space Administration; the National Science Foundation; the National Oceanographic and Atmospheric Administration; and the Office of Naval Research, as well as the California Energy Commission and CAL-FED. 


\title{
UNDERSTANDING AND ASSESSING Global Ocean Carbon Sequestration
}

\author{
James K. Bishop \\ Contact: 510/486-2457, jkbishop@lbl.gov; http://www-ocean.lbl.gov
}

\section{RESEARCH OBJECTIVES}

Over the past century and a half, atmospheric $\mathrm{CO}_{2}$ concentrations have risen by over $30 \%$ from pre-industrial levels. The increase is approximately half the cumulative emission as a result of human activity, with the oceans acting as a major repository for the anthropogenic carbon. This rapid increase in the atmospheric $\mathrm{CO}_{2}$ has contributed in some measure to the recent warming trends observed worldwide. Understanding the processes that maintain and change the carbon cycle, and developing strategies for managing carbon fluxes and inventories, are national priorities. The following questions are critical: How does the ocean naturally sequester carbon? How will this change in the future? Could purposeful enhancement of carbon storage in the ocean be an effective way to manage $\mathrm{CO}_{2}$ in the atmosphere and are such actions safe?

Biological transformations of carbon in the sea have an important impact on the atmosphere. Marine phytoplankton, whose biomass is renewed entirely every 1 to 2 weeks, consume $\mathrm{CO}_{2}$ through photosynthesis at a rate of $\sim 50 \mathrm{Pg} \mathrm{C} \mathrm{yr}^{-1}$ and transport $\sim 10 \mathrm{Pg} \mathrm{C}$ $\mathrm{yr}^{-1}$ from the surface layer to the deep sea. These fast biological and equally fast physical processes alter the $\mathrm{CO}_{2}$ distribution in the surface ocean and atmosphere. If we were to disable the "biological carbon pump," then levels of atmospheric $\mathrm{CO}_{2}$ would rise by $30 \%$. The challenge is to follow such fast processes on a global scale.

\section{APPROACH}

The international project, Argo, is seeding the ocean with thousands of low-cost, long-lived autonomous profiling floats for studying the variability of heat, salinity, and mid-depth circulation of the ocean. Four years ago, we initiated a collaborative effort with Argo scientists to create the first robotic Carbon Explorer-a fully robotic telemetry- and sensor-enhanced version of an Argo float - carrying new optical sensors for characterizing the distribution and fate of marine biology products.

Under Berkeley Lab leadership, Carbon Explorers controlled to cycle between the surface and kilometer depths have been deployed in the subarctic North Pacific (April 2001, February 2003) and in the Southern Ocean surrounding Antarctica (January 2002), where they have remained operational for more than one year in notoriously stormy seas. Three more have just begun observations in the North Atlantic (June 2003).

\section{ACCOMPLISHMENTS}

Our North Pacific Carbon Explorers documented the response of marine biota to an iron-deposition event associated with a massive dust storm originating in northeast Asia (Bishop, Davis, and Sherman, 2002).

In the Southern Ocean, Carbon Explorers have quantified an immediate biomass enhancement in response to deliberate i ron amendment (Bishop et al., 2002). Also, for the first time, they have documented carbon exported from such experiments into the deep sea. Results have been submitted for publication.

\section{SIGNIFICANCE OF FINDINGS}

The development of the Carbon Explorer has truly revolutionized the study of ocean biogeochemistry, by opening an entirely new path for ocean carbon cycle understanding. We have proven an inexpensive method for following biological processes in the ocean, on daily time scales, for the greater part of one year. No limitation prevents implementation of sensors for other carbon components and fluxes on the Carbon Explorer.

The Explorers are inexpensive enough for wide deployment in the oceans to follow the natural carbon cycle. They can also perform observations during small-scale experiments, such as those designed to study ocean ecosystem response to ocean fertilization.

\section{RELATED PUBLICATIONS}

Bishop, J.K.B., R.E. Davis, and J.T. Sherman, Robotic observations of dust storm enhancement of carbon biomass in the North Pacific. Science, 298, 817-821, 2002.

Bishop, J.K.B., T.J. Wood, and J.T. Sherman, Carbon Explorer assessment of carbon biomass variability and carbon flux systematics in the upper ocean during SOFeX. EOS Trans Am Geophys Union, 83(47), F799, 2002.

\section{ACKNOWLEDGMENTS}

This research is supported by grants from ONR (National Oceanographic Partnership Program), the National Oceanic and Atmospheric Administration (NOAA), Office of Global Programs, and the DOE Office of Science, Office of Biological and Environmental Research, KP1202030.

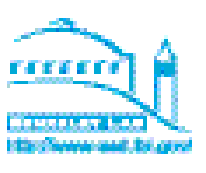




\title{
Modeling Supercritical $\mathrm{CO}_{2}$ InJection in Brine-Bearing Formations
}

\author{
Christine Doughty, Karsten Pruess, and Sally M. Benson
}

Contact: Christine Doughty, 510/486-6453, cadoughty@lbl.gov

\section{RESEARCH OBJECTIVES}

Geologic sequestration of $\mathrm{CO}_{2}$ in brine-bearing formations has been proposed as a means of reducing the atmospheric load of greenhouse gases. Numerous brine-bearing formations have been identified as having potential for geologic sequestration of $\mathrm{CO}_{2}$. One promising setting is the fluvial/deltaic Frio formation in the upper Texas gulf coast, which is the site of an upcoming pilot test of $\mathrm{CO}_{2}$ sequestration. The objective of this research is to investigate the physical processes controlling the behavior and ultimate fate of $\mathrm{CO}_{2}$ in the subsurface, to help design the pilot test and to gain a broader understanding of the issues accompanying $\mathrm{CO}_{2}$ sequestration in brine-bearing formations.
$S_{g r}$, the plume is compact and does not move much under buoyancy forces, because much of the gas is immobile. In contrast, for relative permeability functions with small $S_{\mathrm{gr}}$, the plume is more diffuse. It moves and spreads significantly over time, allowing a much larger fraction of the $\mathrm{CO}_{2}$ to dissolve in the brine.

\section{SIGNIFICANCE OF FINDINGS}

The ability to numerically simulate the complex multiphase flow processes involved in $\mathrm{CO}_{2}$ injection is critical to developing a good experimental design for the pilot test, just as it will ultimately be for designing successful sequestration operations.

To evaluate $\mathrm{CO}_{2}$ sequestration scenarios, we use the numerical simulator TOUGH2, which considers all flow and transport processes relevant for a two-phase (liquid-gas), three-component $\left(\mathrm{CO}_{2}\right.$, water, dissolved $\mathrm{NaCl}$ ) system. In the subsurface, supercritical $\mathrm{CO}_{2}$ forms an immiscible gas-like phase and partially dissolves in the brine.

A three-dimensional numerical model is developed of the pilot test site, a $450 \mathrm{~m} \times 450 \mathrm{~m}$ dipping fault block containing several wells that penetrate the $12 \mathrm{~m}$ thick brine-saturated sand near the top of the Frio that is our sequestration target. Under the planned sequestration conditions ( $\mathrm{P}=150$ bars, $\mathrm{T}$ $=66^{\circ} \mathrm{C}$ ), supercritical $\mathrm{CO}_{2}$ is strongly buoyant compared to the native brine.

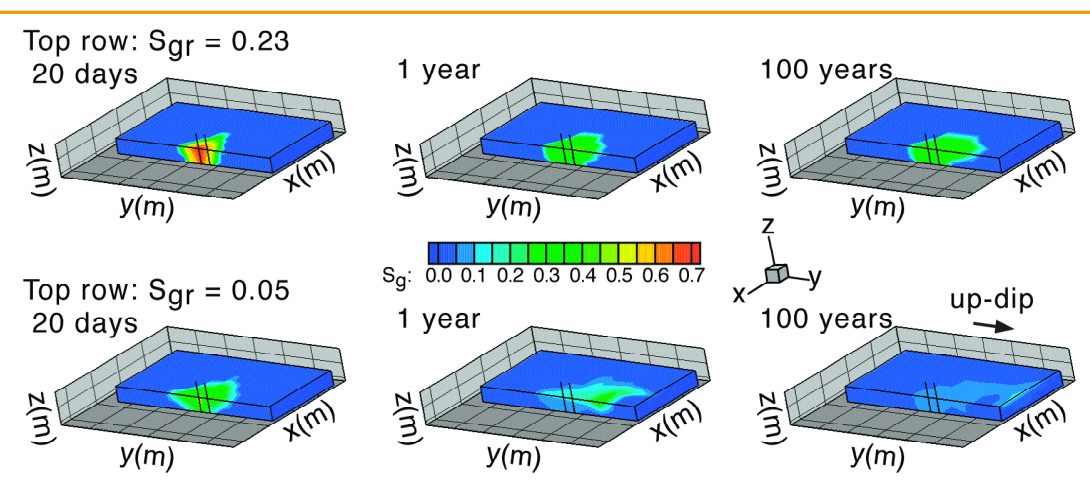

Figure 1. Modeled gas saturation distribution after 20 days of injection of supercritical $\mathrm{CO}_{2}$ into a brine-saturated formation, for two different values of residual gas saturation $\mathrm{S}_{\mathrm{gr}}$. The injection and monitoring wells are shown as black lines.

\section{ACCOMPLISHMENTS}

We have simulated a number of alternative scenarios for the pilot test, varying three types of model parameters:

- Operational parameters such as injection and monitoring well locations and injection schedule

- Geological features such as the continuity of shale layers, the connectivity of sand channels, and the permeability of faults

- Multiphase flow properties such as relative permeability curves

Simulations show that relative permeability functions have a strong effect on $\mathrm{CO}_{2}$ plume development. Because most of our knowledge and experience concerning relative permeability for the Frio comes from petroleum reservoirs, in which liquid phases displace a pre-existing gas phase, how to choose appropriate relative permeability functions for supercritical $\mathrm{CO}_{2}$ injection into a brine-saturated formation is still an open question. Snapshots of the simulated supercritical $\mathrm{CO}_{2}$ plume (Figure 1) show the impact of relative permeability. For relative permeability functions with large residual gas saturation

The residual gas saturation used in the relative permeability functions is a key factor controlling the development of the $\mathrm{CO}_{2}$ plume. Future laboratory and field work will be directed toward determining appropriate values of $\mathrm{S}_{\mathrm{gr}}$ for $\mathrm{CO}_{2}$ injection into brine-bearing formations.

\section{RELATED PUBLICATIONS}

Doughty, C., and K. Pruess, Modeling supercritical $\mathrm{CO}_{2}$ injection in heterogeneous porous media. Presented at TOUGH Symposium 2003, Berkeley Lab., Berkeley, California, May 12-14, 2003.

Related web site: http: / / www-esd.lbl.gov/GEOSEQ/index.html

\section{ACKNOWLEDGMENTS}

This work was supported by the Assistant Secretary for Fossil Energy, Office of Coal and Power Systems and Office of Natural Gas and Petroleum Technology, through the National Energy Technology Laboratory, of the U.S. Department of Energy under Contract No. DE-AC03-76SF00098. 


\section{Tracking Stable Isotopes In a Regional Climate Model \\ Prudence N. Foster, Norman L. Miller, and Don DePaolo \\ Contact: Norman L. Miller, 510/495-2374, nlmiller@lbl.gov}

\section{RESEARCH OBJECTIVES}

The ability to track isotopes through the water cycle in a climate model offers the opportunity to test the climate model itself, as well as to learn more about the water cycle. While several global climate models currently have isotope-tracking subroutines, there is to date no regional climate model with isotope tracing. Well-recognized advantages of a regional climate model, over a global one, include the ability to study the natural variability of local water budgets on scales of interest to water planning and ecological impact analyses. Adding tracing routines to the regional model will allow us to study the source of local rainfall and to better understand its sensitivity to climate and land surface changes. Moreover, isotope tracking throughout the water cycle will allow an unprecedented ability to test numerical precipitation schemes. Currently, climate models compare their precipitation predictions based primarily on the amount of rainfall. Since rain can develop in a variety of ways, simply getting the amount correct is not a guarantee that the model is actually simulating reality. By comparing the isotopic content of both deuterium and $18 \mathrm{O}$ in the rainfall to observations on the scales at which observations can actually be extensively done (i.e., the regional scale), we will have much greater confidence in our rainfall schemes. Such intensive observations are already under way at the DOE Atmospheric Radiation Measurement-Cloud and Radiation Testbed (ARM-CART) site in Kansas (Machavaram et al., 2003), and we plan to make comparisons between our model and these observations.

\section{APPROACH}

Our approach has been to add isotope tracers to the community regional climate model MM5 (fifth generation
Mesoscale Model). First of all, we have added a set of tracers that exactly copy the water cycle itself. Now, we are working on tracking "colored water"; for example, red water only enters the grid from the water surface of the Gulf of Mexico. We are testing various schemes for tracking the colored water through the processes of surface evaporation, mixing in the planetary boundary layer and cloud physics. The colored water will allow us to understand where water is coming from over the ARM/CART site. Once we have some assurance that these schemes are redistributing the colored water in a manner that we expect, adding the fractionation associated with various phase changes should be trivial. We will then be in a position to validate the model predictions against the observations of precipitation and vapor isotopic values measured in June 2000 at the ARM/ CART site.

\section{ACCOMPLISHMENTS}

To date, we have completed a map of the water cycle in MM5. We have reproduced the water cycle with an additional vector that can exactly follow the treatment of water or can be manipulated to test code development. We have also prepared the fractionation subroutines that will be needed when the code is ready to address the issue of isotopes.

\section{ACKNOWLEDGMENTS}

This project is sponsored by the DOE Water Cycle Pilot Study through the Office of Science, Office of Biological and Environmental Research, under U.S. Department of Energy Contract No. DE-AC03-76F00098. 


\title{
Performance Requirements for Geological Storage of $\mathrm{CO}_{2}$
}

\author{
Robert P. Hepple and Sally M. Benson \\ Contact: Robert P. Hepple, 510/486-5989, rphepple@1bl.gov
}

\section{RESEARCH OBJECTIVES}

The probability that long-term geologic storage or sequestration of $\mathrm{CO}_{2}$ will become an important climate change mitigation strategy depends on a number of factors, namely (1) public acceptance, (2) the cost of geologic storage compared to other climate change mitigation options, and (3) the availability, capacity, and location of suitable sites. Whether or not a site is suitable will be determined by establishing that it can meet a set of performance requirements for safe and effective geologic storage. Establishing effective requirements must start with an evaluation of how much $\mathrm{CO}_{2}$ might be stored, and how long the $\mathrm{CO}_{2}$ must remain underground, to meet goals for controlling atmospheric $\mathrm{CO}_{2}$ concentra tions. These requirements then provide a context for addressing the issue of what is an "acceptable" surface seepage rate.

\section{APPROACH}

To address the question, "How much $\mathrm{CO}_{2}$ might be stored underground and for how long?" we developed zeroth-order estimates for the annual amount of $\mathrm{CO}_{2}$ that would need to be sequestered to meet atmospheric stabilization targets of 350, 450, 550, 650, and 750 ppmv. We assumed geologic sequestration would be used as a bridging technology, allowing for the gradual phase-out of fossil fuels over a period of up to 300 years. We also assumed that geologic storage constitutes the only mitigation outside of the climate-forcing parameters included in the emissions scenarios (e.g., parameters such as the rates of technology and economic development, and the strength of the movement toward global environmental and sustainability ethics.)

To address a second important question, "What would be an acceptable surface seepage rate?" we first calculated the rate at which $\mathrm{CO}_{2}$ might seep back to the surface and then compared the calculated seepage to the allowable emissions for atmospheric $\mathrm{CO}_{2}$ stabilization at each of the five targets. We assumed that the amount of seepage would be proportional to the total amount of $\mathrm{CO}_{2}$ stored underground at any given time.

\section{ACCOMPLISHMENTS}

Figure 1 shows the range of projected storage amounts across the potential stabilization targets, which average between 900 and 2,500 $\mathrm{GtC}$, and it includes estimated storage capacity for comparison. For an annual seepage rate of $0.01 \%$ or $10^{-4}$ /year, the maximum annual seepage never exceeds 0.5 $\mathrm{GtC} /$ year for any of the projected sequestration scenarios and would ensure that at least $90 \%$ remained effectively sequestered after 1,000 years. For comparison, the total estimated worldwide volcanic and magmatic degassing is estimated to be 0.07 to $0.13 \mathrm{GtC} /$ year. Because seepage rates less than $0.01 \%$ per year meet several criteria for all scenarios, this may be a reasonable long-term global performance requirement for surface seepage.

Figure 1. Total target sequestration in Gigatonnes of Carbon (GtC) for each scenario across the range of potential atmospheric stabilization targets in parts per million (ppm) of carbon dioxide.

\section{SIGNIFICANCE OF FINDINGS}

According to the results presented here, geologic storage could be an effective method to ease the transition away from a fossil-fuel-based economy over the next several decades to centuries, even if large amounts of $\mathrm{CO}_{2}$ are stored and some small fraction seeps from storage reservoirs back into the atmosphere.

\section{RELATED PUBLICATIONS}

Benson, S.M., R. Hepple, J. Apps, C.-F. Tsang, and M. Lippmann, Lessons learned from natural and industrial analogues for storage of carbon dioxide in deep geological formations. Berkeley Lab Report LBNL-51170, 2002.

Hepple, R.P. and S.M. Benson, Geologic storage of carbon dioxide as a climate change mitigation strategy: performance requirements and the implications of surface seepage. Env. Sci. Tech., 2003 (submitted).

\section{ACKNOWLEDGMENTS}

This work was supported by Laboratory Directed Research and Development (LDRD) funding from Berkeley Lab, provided by the Director, Office of Science, of the U.S. Department of Energy under Contract No. DE-AC03-76SF0009. 


\section{A Mesoscale Analysis of the Impact of Snowpack on Climate Variability IN THE SiERra NeVAda REgION \\ Jiming Jin and Norman L. Miller \\ Contact: Jiming Jin, 510/486-7551, jimingjin@lbl.gov}

\section{RESEARCH OBJECTIVE}

Greater than $70 \%$ of the annual streamflow in the western United States is derived from snowpack. Hence, accurately forecasting snowpack is essential to this region's economy and well-being, and numerical models are necessary (and powerful) tools for this purpose. The objectives of this study were to evaluate the snow scheme with an advanced mesoscale model, using observational evidence, and to investigate the impact of snowpack on climate variability in the Sierra Nevada region.

\section{APPROACH}

The model used is the fifth-generation Mesoscale Model (MM5) developed by the Pennsylvania State University/National Center for Atmospheric Research. This model was used to generate $12 \mathrm{~km}$ resolution results that account for complex topography in the Sierra Nevada. The observed Snow Water Equivalent (SWE) depths for this region were assimilated into MM5 to allow for an investigation into snow evolution and its related processes. This investigation was an approach toward correcting the identified model deficiencies caused in part by the simple snow physics in the land-surface model coupled to MM5. The observed daily SWEs were measured through the automated Snowpack Telemetry system during the snowmelt season from April 1998 to June 1998.

\section{ACCOMPLISHMENTS}

Comparison of observed and simulated SWEs (Figure 1a) indicates that at the $12 \mathrm{~km}$ resolution, MM5 poorly represents the snowpack over the Sierra Nevada region during the snowmelt season. At the same time, with the misrepresented snowpack, the model produces a strong warm bias at the near surface (Figure 1b) and exaggerated precipitation (Figure 1c). Subsequently, the observed SWEs (red line in Figure 1a) were incorporated into the model to improve its climate-simulation performance. After the SWE assimilation, the simulated $2 \mathrm{~m}$ height air temperature was in very good agreement with observations. In the model, because the assimilated SWE consumes a large amount of energy on account of the melting process, the surface skin temperature was reduced, which decreases the upward sensible heat flux. The decreased sensible heat flux supplied less energy to the near surface air and alleviated the warm bias in the $2 \mathrm{~m}$ height air temperature. Furthermore, SWE assimilation caused a lowered sensible heat flux as well as a colder surface, leading to weaker outgoing long-wave radiation, reduced air temperature in the lower troposphere, and a stabilizing of the atmosphere. The more stable atmosphere restricted atmospheric convections and thus decreased the amplified precipitation.

\section{SIGNIFICANCE OF FINDINGS}

This study (Jin and Miller, 2003) indicates that snowpack has a significant effect on near-surface air and precipitation over the Sierra Nevada. Our findings provide a substantial advancement in our understanding of climate variability in the Sierra Nevada region, as well as direction for future model development.

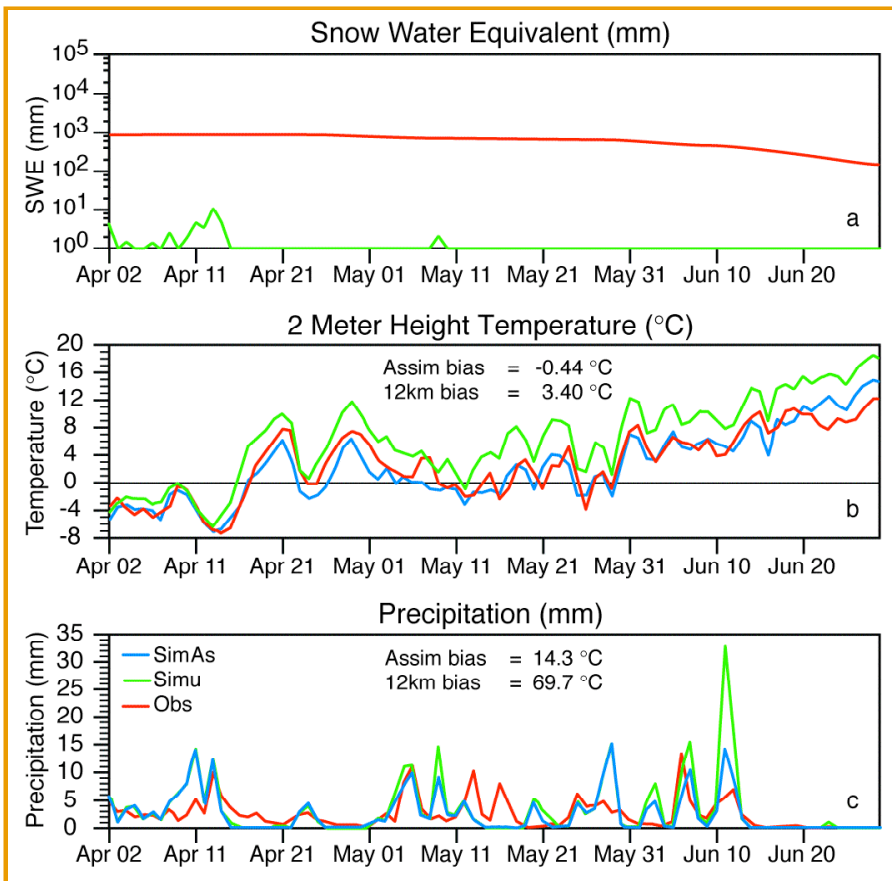

Figure 1. Comparison of simulations and observations averaged over the Sierra Nevada region for the period of April 2-June 30, 1998: (a) Snow water equivalent (mm); (b) $2 \mathrm{~m}$ height air temperature $\left({ }^{\circ} \mathrm{C}\right)$; (c) Precipitation $(\mathrm{mm})$. Obs is observations, Simu is the $12 \mathrm{~km}$ resolution simulation with no SWE assimilation, and SimuAs is the $12 \mathrm{~km}$ resolution simulation with SWE assimilation.

\section{RELATED PUBLICATIONS}

Jin, J., and N.L. Miller, A mesoscale analysis of snowpack on climate variability and snowmelt mechanisms in the Sierra Nevada Region. Presented at the PACLIM Conference, April 2003, Pacific Grove, California; J. Hydrometeorology, September, 2003 (submitted).

Jin, J., and N.L. Miller, An analysis of climate variability and snowmelt mechanisms in mountainous regions. J. Hydrometeorology, September, 2003 (submitted).

\section{ACKNOWLEDGMENTS}

Support is provided by the NASA Regional Earth Science Applications Center Program under Grant NS-2791.

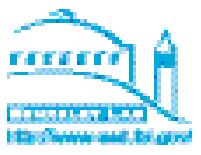




\section{IMPACT OF THE ENSO SNOWPACK ON THE WESTERN UNITED STATES: A Global Climate Model Study}

Jiming Jin and Norman L. Miller

Contact: Jiming Jin, 510/486-7551, jimingjin@lbl.gov

\section{RESEARCH OBJECTIVE}

Snowpack is a major water resource in the western U.S.. An accurate forecast of snow amount is essential to water allocation in this region. The objectives of this study are to examine the relationship between El Niño Southern Oscillation (ENSO) and snowpack over this region and to investigate-by comparing observations to simulations from a state-of-the-art global climate model (GCM)- how ENSO affects snow accumulations.

\section{APPROACH}

The GCM used in this study is the Community Climate Model Version 3 (CCM3) developed by the National Center for Atmospheric Research (Kiehl et al., 1996). To accurately represent the snowpack in the model, a Snow-Atmosphere-Soil Transfer (Jin et al., 1999) land-surface model with sophisticated snowpack processes was coupled to CCM3. A 45.5-year simulation from December 1949 to May 1995 was generated from this coupled model, which was forced by observed global sea surface temperature (SST) data with year-to-year variations. The observed Snow Water Equivalent (SWE) depths were collected from more than 300 snow-course locations in the western U.S.

\section{ACCOMPLISHMENTS}

Figure 1 illustrates the correlation between observed Niño-3.4 SSTs averaged over $120^{\circ} \mathrm{W}-170^{\circ} \mathrm{W}$ and $5^{\circ} \mathrm{S}-5^{\circ} \mathrm{N}$, and SWEs from the model output and observations during winter and early spring for 1950 to 1994 . This figure indicates that sig-

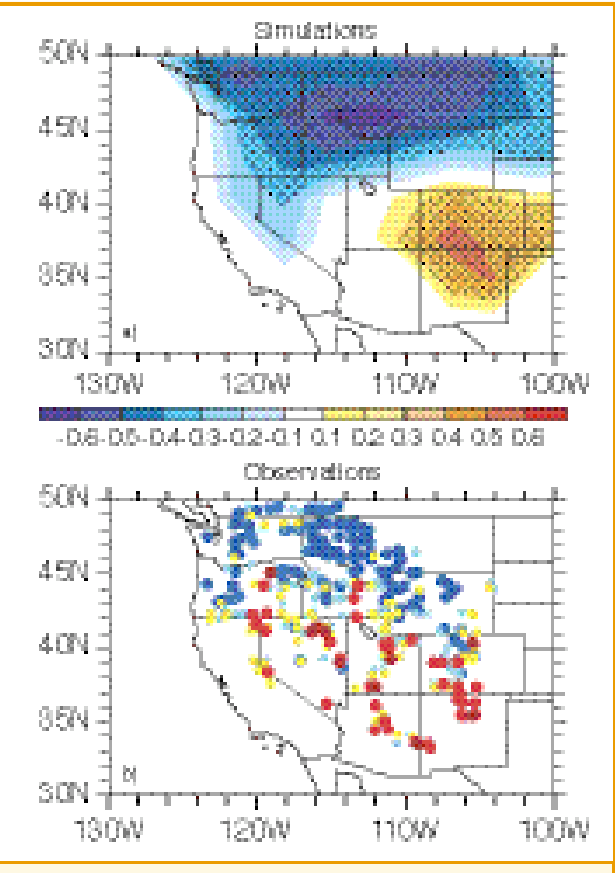

Figure 1. Correlation coefficients between Niño-3.4 and (a) SWEs from the CCM3 output and (b) observed snowcourse data in the western U.S. Values in stippled areas pass the 95\% significance Student's $t$ test.

\section{SIGNIFICANCE OF FINDINGS}

This study clarifies how the ENSO affects snowpack in the western U.S. and improves our understanding of the mechanism of snow anomalies. The modeled atmosphere in the mid-latitudes incorrectly responds to the tropical Pacific SSTs and shifts the way the air mass gets transported over the Northwest (compared to observations). These findings will greatly benefit climate and water- resources forecasts and future model development.

\section{RELATED PUBLICATIONS}

Jin, J., X. Gao, Z. Yang, R.C. Bales, S. Sorooshian, R.E. Dickinson, S. Sun, and G. $\mathrm{Wu}$, One-dimensional snow water and energy balance model for vegetated surfaces. Hydrological Processes, 13, 2467-2482, 1999.

Jin, J., N.L. Miller, S. Sorooshian, and X. Gao, 2003: Impact of ENSO snowpack in the western U.S.: A GCM Study. Presented at the American Meteorological Society Conference, Long Beach, California, Feb. 2003; Journal of Climate, 2003 (manuscript in final preparation).

Kiehl, J.T., J.J. Hack, G.B. Bonan, B.A. Boville, B.P. Briegleb, D.L. Williamson, and P.J. Rasch, Description of the NCAR Community Climate Model (CCM3). NCAR Tech. Note, NCAR/TN-420+STR [Available from the National Center for Atmospheric Research, Boulder, Colorado], 1996.

\section{ACKNOWLEDGMENTS}

Support was provided by the NASA Regional Earth Science Applications Center Program under Grant No. NS-2791.

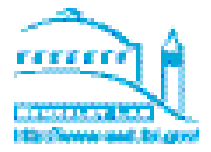




\section{Geostatistical Modeling of Climate Variables at Regional Scales}

Phaedon C. Kyriakidis and Norman L. Miller

Contact: Phaedon Kyriakidis, 805/893-2266, phaedon@geog.ucsb.edu

\section{RESEARCH OBJECTIVES}

The objective of this research is to develop, and illustrate the application of, a novel geostatistical framework for stochastic modeling of climate variables at regional scales. The developed approach allows for assessing explicitly the uncertainty in hydrological and environmental model predictions due to uncertain climate forcing, with wide applications to risk analysis in related impact assessment studies.

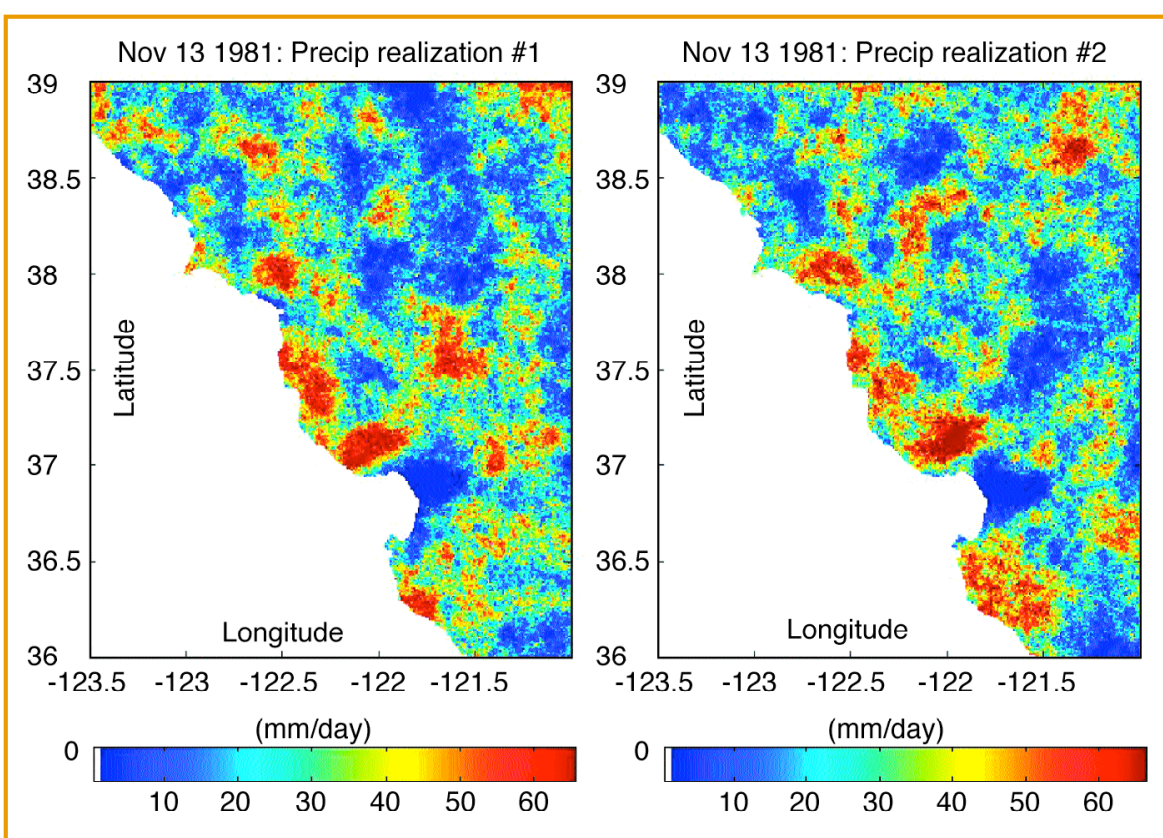

Figure 1 . Two alternative simulated realizations of daily precipitation, at $1 \mathrm{~km}$ resolution, over the San Francisco Bay Area, for November 13, 1981

\section{APPROACH}

The developed geostatistical framework is based on stochastically assimilating (fusing) direct measurements of climate-related variables obtained at monitoring stations, and on ancillary (indirect) information provided by (1) terrain elevation and its derived products (e.g., slope, aspect) and (2) coarse-resolution predictions of climate variables obtained from dynamical downscaling, using a regional climate model. A novel adaptation of stochastic simulation in a space-time context enables the generation of realistic, fine-resolution, alternative synthetic realizations of climate variables at regional scales. These realizations are consistent with (i.e., reproduce exactly) the information available at coarser resolutions available in the form of dynamically downscaled predictions.

\section{ACCOMPLISHMENTS}

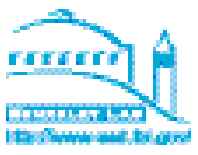

The development and application of the geostatistical framework for modeling daily precipitation over a region near the San Francisco Bay Area in a space-time context (Case 2 in the Approach section above) is showcased in Kyriakidis et al. (2003). Simulated precipitation realizations at a $1 \mathrm{~km}$ resolution were constrained by the available rain-gauge measurements and ancillary terrain-related information. They were shown to reproduce (a) the rain-gauge measurements and their histogram, and (b) a model of their spatiotemporal correlation. Two such simulated realizations are shown in Figure 1. The theoretical proof of mass preservation for the geostatistically derived fine-resolution predictions-that is, the exact reproduction of data available at a coarser resolution (Case 2 above) - is given in Kyriakidis (2003). Current work is focused on a case study illustrating how to apply stochastic simulation of fine-resolution daily precipitation subject to such coarser-resolution data constraints.

\section{SIGNIFICANCE OF FINDINGS}

The developed geostatistical framework constitutes a novel approach for the stochastic generation of realistic fine-resolution climate predictions, which can be used in a Monte Carlo setting for risk analysis in environmental and hydrological modeling. When coupled with regional climate model forecasts under future climate change scenarios, the geostatistical framework provides a novel approach to downscaling climate predictions at finer resolutions for more realistic impact assessment studies. The explicit account of the different data supports (i.e., the different volume informed by different types of measurements: rain gauge data versus regional climate model predictions) is a novel modeling characteristic not shared by any of the currently available statistical downscaling methods.

\section{RELATED PUBLICATIONS}

Kyriakidis, P.C., N.L. Miller, and J. Kim, A spatial time series framework for modeling daily precipitation at regional scales. Journal of Hydrology, 2003 (in press).

Kyriakidis, P.C., The geostatistical solution of the area-to-point spatial interpolation problem. Geographical Analysis, 2003 (in press).

\section{ACKNOWLEDGMENTS}

Support is provided by the NASA Office of Earth Science/Earth Science Applications Research Program (OES/ESARP) under Grant No. NS-2791. 


\title{
Isotopic VARiations in Atmospheric Moisture in the Great Plains Region
}

\author{
Madhav V. Machavaram, Mark E. Conrad, and Norman L. Miller \\ Contact: Madhav V. Machavaram, 510/486-5026, mvmachavaram@lbl.gov
}

\section{RESEARCH OBJECTIVES}

The stable isotopic composition of atmospheric water vapor at a given region is determined by its source and subsequent admixture and condensation processes. The most dynamic changes in the water cycle occur in the atmospheric part of the cycle. Thus, the variation in the stable isotope ratios of atmospheric vapor provides critical information about the locally evapo-transpired moisture. In our work, we analyzed atmospheric vapor samples to improve predictability, in part by integrating stable isotope variations into climatological models.

\section{APPROACH}

To understand the response of regional hydrology to climatic variations, it is important to quantify the influence of local moisture on precipitation. The deuterium excess $(\delta-$ excess)-a measure of the abundance of deuterium ( $\mathrm{\delta D}$ ) over 18-oxygen $\left(\delta^{18} \mathrm{O}\right)$ - is a valuable tool for estimating the contribution of secondary moisture sources to atmospheric moisture. The $d$-excess in the atmospheric vapors is determined primarily

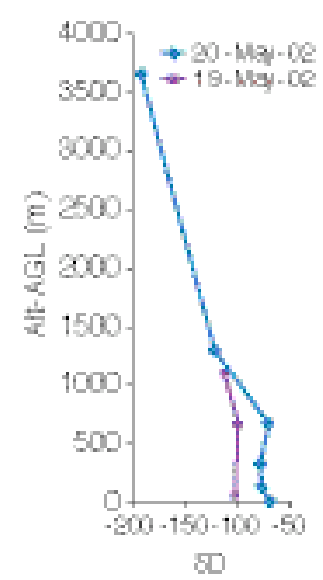

Figure 1. Isotopic variation in the atmospheric vapor samples at various altitudes

be considered as the atmospheric moisture originating from the Gulf of Mexico.

Assuming that the samples above and below the ABL represent two end members on a linear mixing line, we performed a mixing calculation using the d-excess values, which indicated that approximately $75 \%$ of the moisture within the ABL is derived from local sources through evapo-transpiration.

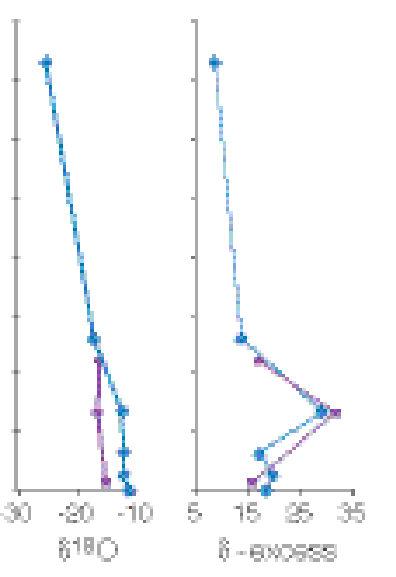

Although the contribution of secondary moisture may change diurnally and seasonally, the overall effect of locally derived moisture on precipitation is believed to remain significant over time.

\section{SIGNIFICANCE} OF FINDINGS

Understanding the influence of locally derived moisture on the water cycle is valuable for improving climatological models. When monitored over longer time scales, such information is extremely useful in documenting the hydrological changes of a region through man-made causes, such as agriculture and urbanization. at the oceanic source and altered by admixture of secondary moisture derived through evapo-transpiration. Thus, by measuring the $d$-excess in atmospheric vapors, we can estimate the influence of land-derived moisture.

\section{ACCOMPLISHMENTS (DATA DISCUSSION)}

Samples of atmospheric vapor between the earth surface and 3,500 $\mathrm{m}$ altitude were cryogenically collected during a flight operation. The stable isotope data for the vapor samples are presented in Figure 1. The samples that were collected below $700 \mathrm{~m}$ exhibited much smaller isotopic variation than those from above. The top of the Atmospheric Boundary Layer $(\mathrm{ABL})$ was determined to be at $1,000 \mathrm{~m}$ from the surface during the sampling time. The height of the ABL marks the altitude above which the turbulence of the lower troposphere is negligible. Thus, the sample collected at 3,660 m height could

\section{RELATED PUBLICATIONS}

Machavaram, M.V., M.E. Conrad, and N.L. Miller, The deuterium excess in precipitation and atmospheric moisture in the southern Great Plains region of USA. AGU Conference, San Francisco, California, December 6-10, 2002.

Machavaram, M.V., D.O. Whittemore, M.E. Conrad, and N.L. Miller, Precipitation induced stream flow: An event based study in a small stream from the Great Plains region of the USA, 2003 (to be submitted to Journal of Hydrology).

\section{ACKNOWLEDGMENTS}

This work was supported by the Director, Office of Science, Office of Basic Energy Sciences, Division of Chemical Sciences, Geosciences, and Biosciences, of the U.S. Department of Energy under Contract No. DE-AC03-76SF00098. 


\section{Crosswell and Vertical Seismic Imaging at The Weyburn $\mathrm{CO}_{2}$ Project

\author{
Ernest L. Majer, Dale Cox, Roland Gritto, and Thomas M. Daley \\ Contact: Ernest L. Majer, 510/486-6709, elmajer@lbl.gov
}

\section{RESEARCH OBJECTIVE}

This work is part of a comprehensive time-lapse seismic monitoring program for monitoring a massive $\mathrm{CO}_{2}$ flood in a thin fractured carbonate reservoir in EnCana's Weyburn field, located in the Williston Basin, southeast Saskatchewan, Canada. There are two goals to this project: (1) develop and deploy costeffective technology that could track the detailed changes in $\mathrm{CO}_{2}$ content as a function of time and (2) aid in the interpretation, validation, and integration of surface seismic data (from 3-C 3-D and 9-C 3-D surface and vertical seismic profiles [VSP]) to obtain an overall understanding of monitoring technologies for $\mathrm{CO}_{2}$.

\section{APPROACH}

An extensive long-term $\mathrm{CO}_{2}$ miscible injection is being operated by EnCana in its Weyburn field. The first phase of $\mathrm{CO}_{2}$ injection started in September 2000. The flooding project is expected to expand over the Weyburn field area in the next several years. To determine applicability as well as refine the methods, a comprehensive plan for using geophysical methods for

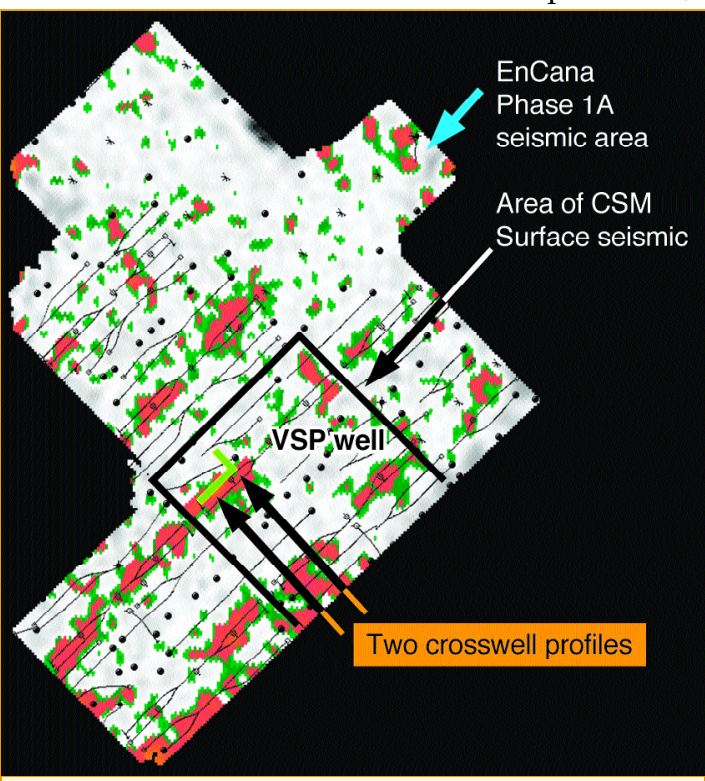

Figure 1. Location of the two vertical crosswell profiles and the VSP acquired in the fall of 2002, relative to the EnCana surface seismic and the CSM surface seismic mapping fluid migration and dynamics is being carried out. In addition to the baseline and repeat 3-C 3-D and 9-C 3-D surface seismic and VSP surveys acquired by EnCana and the Colorado School of Mines (CSM) Reservoir Characterization Project, Berkeley Lab is carrying out high-resolution crosswell studies. The higher-resolution borehole data will be integrated with the surface seismic and reservoir engineering models to provide an overall understanding of reservoir definition and the dynamics of fluid migration. The crosswell seismic survey is intended to provide tomographic images of changes in reservoir properties at a meter scale or less. Integrated with the surface seismic survey and VSP, these data will provide proper scaling relationships for understanding overall flow behaviors of the $\mathrm{CO}_{2}$ fluid at the reservoir dimensions. We will closely study the trade-off between the spatial resolution and spatial coverage of surface methods and borehole methods.

\section{ACCOMPLISHMENTS}

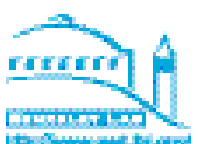

The main activities during the last year were a successful implementation of the vertical crosswell and VSP program. We planned and carried out two crosswell seismic profiles in three vertical wells surrounding one of the injection patterns (see Figure 1 for location relative to surface seismic and relative to the injection wells and producers). These profiles provided data parallel and perpendicular to the injector. The objective was to acquire high-resolution crosswell seismic images by using downhole seismic sources and receivers in separate vertical wells, as well as data with sufficient resolution (estimated at a scale of 1 to $2 \mathrm{~m}$ ) to monitor $\mathrm{CO}_{2}$ flood front movement and sequestration within the Midale reservoir zones and (most importantly) possible migration from the reservoir into other formations. After the completion of the crosswell, a VSP was run in the center well at the two offsets used for the crosswell. The source was an I/O multi-component vibrator used in the CSM surface seismic work.

\section{SIGNIFICANCE}

Both EnCana's and CSM's 4-D results have shown strong seismic anomalies that effectively correlate with the performance in the $\mathrm{CO}_{2}$ flood front movements and conformance efficiency (supported largely by information such as production data and tracer study). However, EnCana's 4-D surface seismic has also produced some unexpected results. For example, the patterns of the subject VSP and crosswell have so far behaved quite abnormally. It has not yet generated any production response, even after it had received 3.4 billion $\mathrm{ft}^{3} \mathrm{CO}_{2}$ (or equivalently 12.3\% HCPV [hydrocarbon pore volume], an amount that would have made a normal pattern yield good production response). EnCana's 4-D data further show significant time delay at and below the reservoir layers and seismic energy attenuation, both indicating a significant amount of $\mathrm{CO}_{2}$ gas accumulated near or above the reservoir. With all the information combined, we believe that a large portion (or even all) of the injected volume may have migrated into the overlying rocks and sequestered there. This likelihood indicates that monitoring this (and other) phenomena using high-resolution crosswell seismic technology may be required to detect zones of uncertainty in $\mathrm{CO}_{2}$ floods.

\section{ACKNOWLEDGMENTS}

This work was supported by the Petroleum Technology Research Center in Regina, Saskatchewan, Canada. 


\section{UnCertainty Analysis of California Streamflow Using Multiple Climate Change Scenarios}

Norman L. Miller, Kathy E. Bashford, and Eric Strem

Contact: Norman Miller, 510/486-2374, nlmiller@lbl.gov

\section{RESEARCH OBJECTIVES}

The objectives of this study are to determine the potential upper and lower bounds of future streamflow response in California, based on a range of climate projections.

\section{APPROACH}

Analysis of the range of hydrological response is based on two Global Climate Model (GCM) projections: the Hadley Centre's HadCM2, a warm and wet projection; and the National Center for Atmospheric Research Parallel Climate Model (PCM-B06.06), a cool and dry projection. Three future periods (2010-2039, 2050-2079, 2080-2099) were analyzed. Future watershed mean-area temperature (precipitation) sensitivities were derived from the temperature (precipitation) difference (ratio) between the projected and baseline (1961 to 1990) climatologies. Specified perturbations with increasing temperature $(\mathrm{T})$ and precipitation (P) were also used. Hydrology was simulated using the Sacramento Soil Moisture Accounting Model, for a set of representative basins (Smith, Sacramento, Feather, American, Merced, Kings).

\section{ACCOMPLISHMENTS}

Streamflow was analyzed with his-

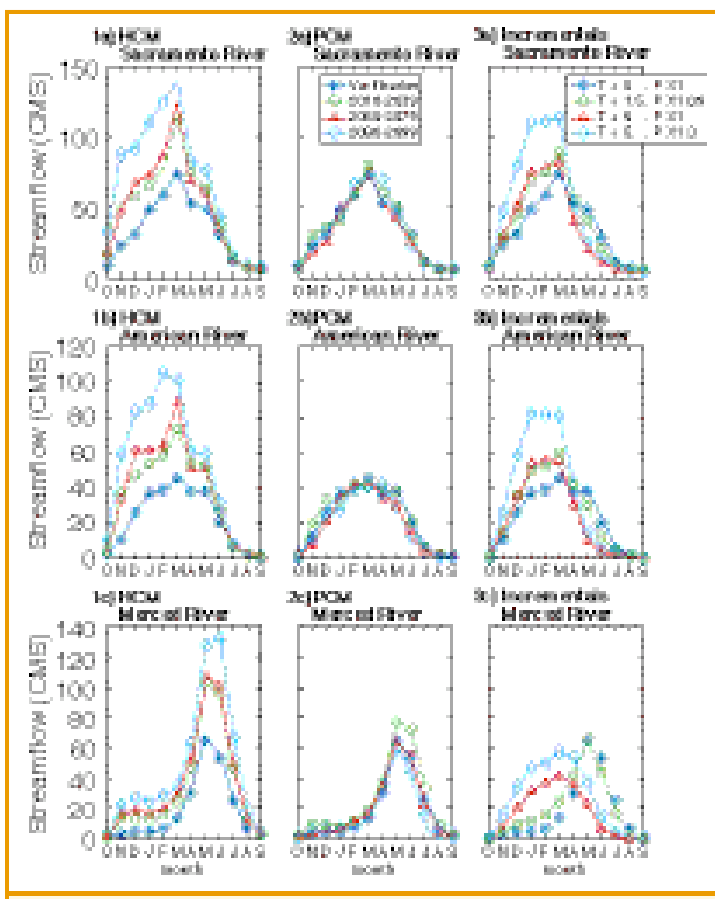

Figure 1. Climatological monthly streamflow at the (a) Sacramento, (b) American, and (c) Merced watersheds for GCM projections: (1) warm-wet and (2) cool-dry. Incremental temperature $\left(0^{\circ}\right.$ to $\left.5^{\circ} \mathrm{C}\right)$ and precipitation ( 0.7 to $1.30 \%$ ) are specified for each watershed as well.
American shows a peakflow one month earlier, while the timing of the other two watersheds remains consistent with the historical peakflow timing.

The uniform perturbations bracket projected temperature uncertainties. The $1.5^{\circ} \mathrm{C}$ increase and $9 \%$ precipitation increase do not change peakflow timing, but increase the October to February peakflow magnitude and slightly decrease the magnitude during the snowmelt period. The peakflow magnitude is higher for the Sacramento (3a) and American (3b), but not for the highelevation Merced (3c). The Merced peakflow decreases and occurs three months earlier. The extreme scenario represents a high likelihood of more flood events and decreased snowmelt runoff.

\section{SIGNIFICANCE OF FINDINGS}

California Sierra Nevada peakflow will likely occur earlier and with increased magnitude. Summer season flow will likely decrease. High-elevation basins are less sensitive to warming, but show a peakflow shift under the incremental changes. The range of outcomes suggests that peakflow magnitudes can shift from $100 \%$ increases to $50 \%$ decreases.

These results have been applied to torical and HadCM2- and PCM-perturbed time series, and specified increments (see Figure 1). During 2010-2039, HadCM2-forced peakflow occurs during the same month with increased peakflow magnitude for the Sacramento (1a), American (1b), and Merced (1c). Peakflow timing during the 2080-2099 period for the American is a month, while the Sacramento timing remains unchanged. The higher elevation Merced has peakflow one month later than the historical, and a secondary peakflow. This secondary high flow results from increased early season snowmelt and a higher snowline, caused by increased temperature.

The relatively cool-dry PCM-forced streamflow significantly decreases during the March-to-July melt season. Peakflow remains close to the historical amount for the Sacramento (2a) and American (2b) for all projected periods, but the Merced (2c) shows an increase during 2010-2039, and then decreases during 2050-2079 and 2080-2099. For these projections, the water demand and agro-economic analyses (Brekke et al. 2003).

\section{RELATED PUBLICATIONS}

Brekke, L.D., N.W.T. Quinn, N.L. Miller, and J.A. Dracup, Climate Change Impacts Uncertainty for San Joaquin River Basin. J. American Water Resources Association (in press), Berkeley Lab Report LBNL-51393, 2003.

Miller, N.L., K.E. Bashford, and E. Strem, Potential impacts of climate change to California hydrology. LBNL-51313, J. American Water Resources Association, August 2003.

\section{ACKNOWLEDGMENTS}

This project was supported by a NASA Grant NS-2791 and a California Energy Commission Grant. Work at the Department of Energy is under Contract No. DE-AC03-76F00098. 


\title{
The California Water Resources Research and Applications Center
}

\author{
Norman L. Miller, K.E. Bashford, G. Brimhall, W.E. Dietrich, J.A. Dracup, \\ J. Jin, J. Kim, P. C. Kyriakidis, X. Liang, and N.W.T. Quinn \\ Contact: Norman Miller, 510/495-2374, nlmiller@lbl.gov
}

\section{RESEARCH OBJECTIVES}

The California Water Resources Research and Applications Center is a NASA-sponsored center designed around a set of integrated activities focusing on California water resources and related impacts. The objectives are to advance our understanding of California hydroclimate variability and change. Core projects include building research partnerships that focus on analysis and educational outreach of hydroclimate impacts on natural systems, society, and infrastructure.

\section{APPROACH}

The Center uses dynamical and statistical downscaling schemes within our Regional Climate System Model framework. We produce hydroclimate simulations at short-term, seasonal, and long-term time scales for weather and river flow forecasts, climate change analyses, uncertainty estimates, landslide modeling, water quality monitoring, and climate change assessments of water resources, agriculture, and natural hazards.

Our applications projects include:

- Runoff contaminant monitoring and real-time waterquality monitoring in the San Joaquin Basin

- Contaminant identification and monitoring from Sierra Foothills mine sites

- Development of a dynamic sediment transport and landslide hazards prediction system

- Snow cover area and water equivalent for California using remotely sensed data and model assimilation

- Geostatistical uncertainty analysis of precipitation and streamflow simulations

- Contributions to impact assessment reports

\section{ACCOMPLISHMENTS}

Our Center became a member of the Earth Science Information Partnership, providing value-added climate, weather, streamflow, and impact information to the broad user community, the U.S. National Assessment, and the Intergovernmental Panel on Climate Change reports. We have completed a series of seasonal and multiyear regional climate and streamflow simulations, developed a new statistical downscaling technique for estimating the limits of uncertainty (Kyriakidis et al., 2003), and have used our results as input to the applications listed above. Recent analysis of projected climate and streamflow analysis has been published (Kim et al., 2002) and received national media coverage.

\section{SIGNIFICANCE OF FINDINGS}

The climate change and streamflow analyses indicate that the likelihood of extreme weather events will increase, and that night-time temperature will increase at a faster rate than the daytime temperature. An important finding is that warm-wet and cool-dry future climate projections both indicate a 50\% decrease in snowpack toward the end of this century. Based on our accomplishments, we received new support from the California Energy Commission, CALFED, and DOE, The California Water Resources Research and Applications Center has become a voice in California climate change assessments, increasing the awareness of potential water resource problems in California and the United States.

\section{RELATED PUBLICATIONS}

Brekke, L.D., N.L. Miller, N.W.T. Quinn, and J.D. Dracup, Climate change impacts uncertainty for San Joaquin River Basin. LBNL-51393, 2003. J. American Water Resources Assoc., 2003 (in press).

Casadei, M., W.E. Dietrich, and N.L. Miller, Testing a model for predicting the timing and location of debris flow initiation in soil mantled landscape. Earth Surface Processes, 2003 (in press).

Kim, J., T. Kim, R. Arritt, and N.L. Miller, Impacts of increased atmospheric $\mathrm{CO}_{2}$ on the hydroclimate of the western United States. J. Climate, 15, 1926-1942, 2002.

Kyriakidis, N.L. Miller, and J. Kim, A spatial time series framework for modeling daily precipitation at regional scales. Journal of Hydrology, 2003 (in press).

\section{ACKNOWLEDGMENTS}

Support is provided by the NASA Regional Earth Science Applications Center Program under Grant NS-2791. Work for the Director, Office of Science, Office of Biological and Environmental Research, is under Department of Energy Contract No. DE-AC03-76SF00098. 


\title{
The DOE Water Cycle Pilot Study: Modeling and Analysis of Seasonal and EVent Variability at the WALNUT RIVER WATERSHED
}

\author{
Norman L. Miller, Kathy E. Bashford, Mark S. Conrad, Prudence N. Foster, and Madhav V. Machavaram \\ Contact: Norman L. Miller, 495-2374, nlmiller@lbl.gov
}

\section{RESEARCH OBJECTIVES}

The DOE Water Cycle Pilot Study is designed to develop the use of water isotopic data $\left(\delta \mathrm{D}, \delta^{18} \mathrm{O}\right)$ to constrain hydroclimate models and test process descriptions and their sensitivity at multiple scales, to better understand water cycle variability. The research objectives are to: (1) evaluate predictions of components of the water budget for several study periods, using a set of nested models with different spatial resolutions, along with archived and new field data from the Walnut River Watershed (WRW); (2) evaluate multiscale water isotope modeling as a means of tracing sources and sinks within and external to the WRW and the Atmospheric and Radiation Measurements Program Southern Great Plains (ARM SGP) site, a representative global climate model grid cell; and (3) identify water-budget-model improvements and data needs over a range of scales.

\section{APPROACH}

Water isotopic measurements of precipitation, surface water, soils, plants, and atmospheric water vapor were collected every three months and during the DOE Intensive Observing Period, April 1 to June 30, 2002 (Machavaram et al., this volume). Land-surface modeling compared $1 \mathrm{~km}$ fluxes for different modes and for a 50-year simulation. Different wetting and drying conditions caused by different controls were investigated. The Penn State/NCAR Mesoscale Model version 5 (MM5) was advanced with the implementation of water-isotope mass-conservation equations (Foster and Miller, this volume). Multiscale atmospheric simulations using the MM5 and radar-based data have been analyzed and are discussed below.

\section{ACCOMPLISHMENTS}

The MM5 6-hour precipitation slightly underestimates for WRW using $4 \mathrm{~km}$ resolution during March 1-30, 2000 (Figure 1a). MM5 lags between radar-precipitation onset at March 3. MM5 exhibits considerable accuracy in predicting precipitation occurrences, but shows less accuracy in predicting the precipitation amount. When the $4 \mathrm{~km} \mathrm{MM} 5$ results are compared to radar precipitation over the entire ARM CART site (Figure 1b), accuracy is improved. MM5 may be underestimating the precipitation in the WRW, but overestimating it in the larger ARM/CART area. This allows for compensating errors, whereas the smaller WRW domain is less forgiving. At $12 \mathrm{~km}$ resolution, the MM5 model shows remarkable accuracy in forecasting the total precipitation. At $48 \mathrm{~km}$, the size of the comparison domain becomes important; the precipitation in the WRW is significantly underestimated, while it is well represented over the entire ARM/CART site. MM5 underestimates the amount of precipitation at $4 \mathrm{~km}$, because it represents the observed variability in precipitation from point-to-point.

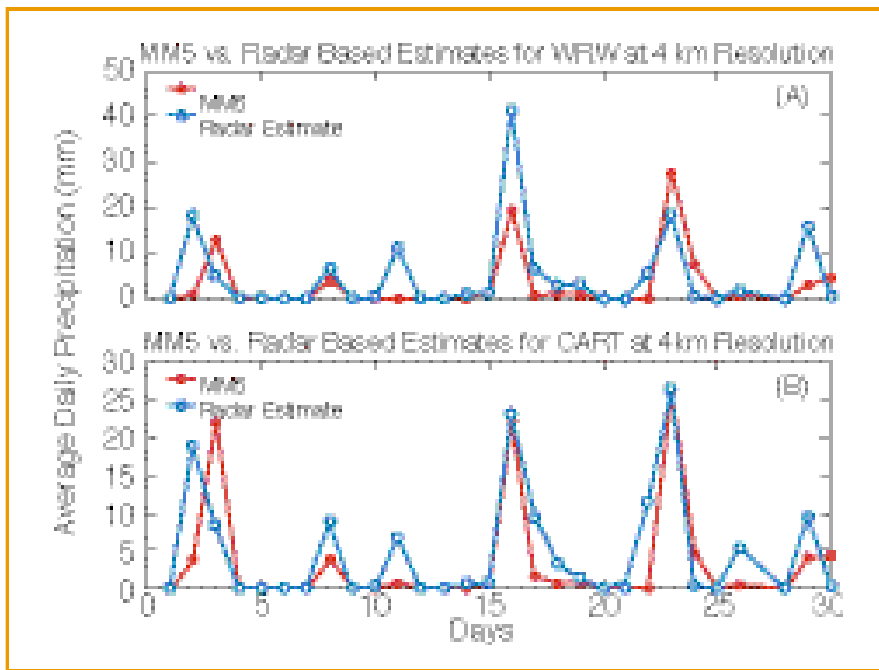

Figure 1. MM5-simulated $4 \mathrm{~km}$ precipitation and WSR-88D radar-derived precipitation during March 2000 for (A) WRW domain and (B) the ARM/CART domain.

\section{SIGNIFICANCE OF FINDINGS}

During March 2000, there was no convective precipitation, and hence MM5 simulations did not require use of the convective parameterization. The nonconvective precipitation scheme is inadequate at $4 \mathrm{~km}$ resolution. It performs better at $12 \mathrm{~km}$, but significantly overestimates variability. This suggests that MM5 may be used during nonconvective situations to predict the amount of precipitation over small watersheds (tens of kilometers) in the U.S. Southern Great Plains during early spring-as long as the resolution is $12 \mathrm{~km}$. Attempts to resolve local-scale precipitation features with MM5 are likely to be biased toward underestimation of precipitation amount.

\section{ACKNOWLEDGMENTS}

This work is supported by the DOE Water Cycle Initiative Pilot Study through the Director, Office of Science, Office of Biological and Environmental Research, Atmospheric and Radiation Measurements Program, under U.S. Department of Energy Contract No. DE-AC-03-76F00098. 


\title{
The GEO-SEQ Project
}

\author{
Larry R. Myer and Sally M. Benson
}

Contact: Sally Benson, 510/486-5875, smbenson@lbl.gov

\section{RESEARCH OBJECTIVES}

The GEO-SEQ Project is a public-private applied R\&D partnership, founded with the goal of developing the technology and information needed to enable safe and cost-effective geologic sequestration of $\mathrm{CO}_{2}$ by the year 2015. The goals of the project are to:

- Lower the cost of geologic sequestration by (1) developing innovative optimization methods for sequestration technologies, with collateral economic benefits such as enhanced oil recovery (EOR), enhanced gas recovery (EGR), and enhanced coalbed-methane production, and (2) understanding and optimizing trade-offs between $\mathrm{CO}_{2}$ separation and capture costs, compression and transportation costs, and geologic-sequestration alternatives.

- Lower the risk of geologic sequestration by (1) providing the information needed to select sites for safe and effective sequestration, (2) increasing confidence in the effectiveness and safety of sequestration by identifying and demonstrating cost-effective monitoring technologies, and (3) improving performance-assessment methods to predict and verify that long-term sequestration practices are safe, effective, and do not introduce any unintended environmental impact.

- Decrease the time to implementation by (1) pursuing early opportunities for pilot tests with our private sector partners and (2) gaining public acceptance.

\section{APPROACH}

The GEO-SEQ Project consists of four coordinated and interrelated tasks carried out by a multidisciplinary team from eight research organizations: Berkeley Lab, Lawrence Livermore National Laboratory, Oak Ridge National Laboratory, Stanford University, Texas Bureau of Economic Geology, Alberta Research Council, and NITG-TNN, The Netherlands.

The research is conducted with the participation, advice, and cooperation of DOE's National Energy Technology Laboratory and five industry partners: Chevron, Texaco, Pan Canadian Resources, British Petroleum, and Statoil. In addition, through ongoing collaborations and our advisory committee, the team extends to include other universities and a number of public and private research organizations.

\section{ACCOMPLISHMENTS}

Highlights of the research conducted to date include:

- Screening criteria for selection of oil reservoirs that could be candidates for co-optimizing $\mathrm{CO}_{2}$-EOR and $\mathrm{CO}_{2}$ sequestration were developed.

- Engineering approaches have been developed to increase $\mathrm{CO}_{2}$ storage, while at the same time enhancing oil recovery.

- Numerical simulations have been carried out to show changes in mineralogy and porosity in a brine-saturated sandstone formation resulting from injection of $\mathrm{CO}_{2}$ waste streams that are impure (i.e., that contain $\mathrm{SO}_{2}, \mathrm{NO}_{2}$, and $\mathrm{H}_{2} \mathrm{~S}$ ).

- Numerical reservoir simulations have shown that it is technically feasible to enhance recovery of gas while at the same time sequestering $\mathrm{CO}_{2}$; the market conditions needed to make the process economical have also been evaluated.

- Software tools have been developed to evaluate the sensitivity of candidate geophysical monitoring methods.

- Effects of hydrocarbons and clay on isotopic compositions need to be taken into account in using isotopic tracers for monitoring reservoir processes.

- State-of-the-art coalbed-methane numerical simulators have been compared, using a set of benchmark problems incorporating increasing levels of complexity.

- An international comparison study of reservoir simulators for oil, gas, and brine formations has been completed.

- Combined crosswell seismic and electromagnetic (EM) surveys were used to quantitatively map gas saturation in a $\mathrm{CO}_{2}$ EOR pilot in Lost Hills, California.

- The concept of a capacity factor, which could be used to quantitatively compare the sequestration capacity of specific sites, has been developed.

- A pilot brine formation $\mathrm{CO}_{2}$ injection experiment is being conducted in collaboration with the Texas Bureau of Economic Geology.

\section{SIGNIFICANCE OF FINDINGS}

The climate of the earth is affected by changes in radiative forcing caused by several sources, including greenhouse gases $\left(\mathrm{CO}_{2}, \mathrm{CH}_{4}, \mathrm{~N}_{2} \mathrm{O}\right)$. Energy production and the burning of fossil fuels are substantially increasing the atmospheric concentrations of $\mathrm{CO}_{2}$. One of several proposed strategies to reduce atmospheric emissions is to capture $\mathrm{CO}_{2}$ from fossil-fuel final power plants and sequester it deep underground. Results from the GEO-SEQ Project are providing methods and information to enable safe and cost-effective geologic sequestration.

\section{RELATED PUBLICATIONS}

Publications of the GEO-SEQ Project can be found at http:/ / esd.lbl.gov/GEOSEQ/.

\section{ACKNOWLEDGMENTS}

Support for this work was provided by the Assistant Secretary for Fossil Energy, Office of Coal and Power Systems and Office of Natural Gas and Petroleum Technology, through the National Energy Technology Laboratory; and by the Director, Office of Science, Office of Basic Energy Sciences, of the U.S. Department of Energy under Contract No. DE-AC03-76SF00098. 


\section{Carbon Dioxide for Enhanced Gas Recovery and as Cushion Gas Curtis M. Oldenburg \\ Contact: 510/486-7419, cmoldenburg@lbl.gov}

\section{RESEARCH OBJECTIVES}

Natural gas reservoirs are obvious targets for carbon sequestration by direct carbon dioxide $\left(\mathrm{CO}_{2}\right)$ injection, because of their proven record of gas production and integrity against gas escape. Carbon sequestration in depleted natural gas reservoirs can be coupled with enhanced gas production by injecting $\mathrm{CO}_{2}$ into the reservoir as it is being produced, a process called Carbon Sequestration with Enhanced Gas Recovery (CSEGR). In this process, supercritical $\mathrm{CO}_{2}$ is injected deep in the reservoir while methane $\left(\mathrm{CH}_{4}\right)$ is produced at wells some distance away. The active injection of $\mathrm{CO}_{2}$ causes repressurization and $\mathrm{CH}_{4}$ displacement to allow the acceleration and enhancement of gas recovery relative to water-drive or depletion-drive reservoir operations. Carbon dioxide undergoes a large change in density as $\mathrm{CO}_{2}$ gas passes through the critical pressure at temperatures near the critical temperature. This feature makes $\mathrm{CO}_{2}$ a potentially effective cushion gas for gas storage reservoirs. Thus at the end of the CSEGR process when the reservoir is filled with $\mathrm{CO}_{2}$, additional benefit of the reservoir may be obtained through its operation as a natural gas storage reservoir. The objective of this research is to demonstrate by numerical simulation the potential sequestration-related uses of $\mathrm{CO}_{2}$ in natural gas reservoirs.

\section{APPROACH}

We have developed a new module called TOUGH2 / EOS7C for simulating natural gas reservoirs under $\mathrm{CO}_{2}$ injection. TOUGH2/EOS7C considers five mass components (water, brine, $\mathrm{CO}_{2}$, gas tracer, $\mathrm{CH}_{4}$ ) and heat. For the gas mixture properties, new real gas mixture subroutines were developed to calculate density and enthalpy departure in the system $\mathrm{H}_{2} \mathrm{O}-\mathrm{CO}_{2}$ $\mathrm{CH}_{4}$ using the Peng-Robinson equation of state and an accurate gas mixture viscosity model. We use this new module to carry out numerical simulations of $\mathrm{CO}_{2}$ injection and $\mathrm{CH}_{4}$ production in model natural gas reservoirs.

\section{ACCOMPLISHMENTS}

We have carried out numerous simulations of $\mathrm{CO}_{2}$ injection, $\mathrm{CH}_{4}$ production, and natural gas storage with $\mathrm{CO}_{2}$ as a cushion gas. We present here simulation results for a comparison of native gas $\left(\mathrm{CH}_{4}\right)$ and $\mathrm{CO}_{2}$ cushion gases in a model gas storage reservoir. In Figure 1, we show a schematic of a natural gas storage reservoir showing cushion gas which is not produced, but which compresses upon injection of the working gas $\left(\mathrm{CH}_{4}\right)$, and which expands to help produce the working gas $\left(\mathrm{CH}_{4}\right)$ upon $\mathrm{CH}_{4}$ withdrawal. As shown in the pressure vs. time part of the figure, the pressure rise in the reservoir for a given $\mathrm{CH}_{4}$ injection rate is lower with the $\mathrm{CO}_{2}$ cushion gas than for a native gas cushion. If the $\mathrm{CH}_{4}$ injection rate is cut to $70 \%$ of the original rate, the pressure rise with a native gas cushion is comparable to the full $\mathrm{CH}_{4}$ injection rate with $\mathrm{CO}_{2}$ as cushion gas. In short, more working gas can be injected using a $\mathrm{CO}_{2}$ cushion than for a native gas cushion. The reason for this is the extreme compressibility of $\mathrm{CO}_{2}$ around the critical pressure in the $40^{\circ} \mathrm{C}$ reservoir.

\section{SIGNIFICANCE OF FINDINGS}

These simulation results show that $\mathrm{CO}_{2}$ could be a very effective cushion gas for natural gas storage. Such a use of the reservoir would follow active $\mathrm{CO}_{2}$ injection that could be used for enhanced gas recovery in a depleting gas reservoir. Our simulations over the last few years show that $\mathrm{CO}_{2}$ may be a potentially useful gas for both enhancing gas recovery in depleted gas reservoirs, and for use as a cushion gas once the reservoir is filled with $\mathrm{CO}_{2}$.

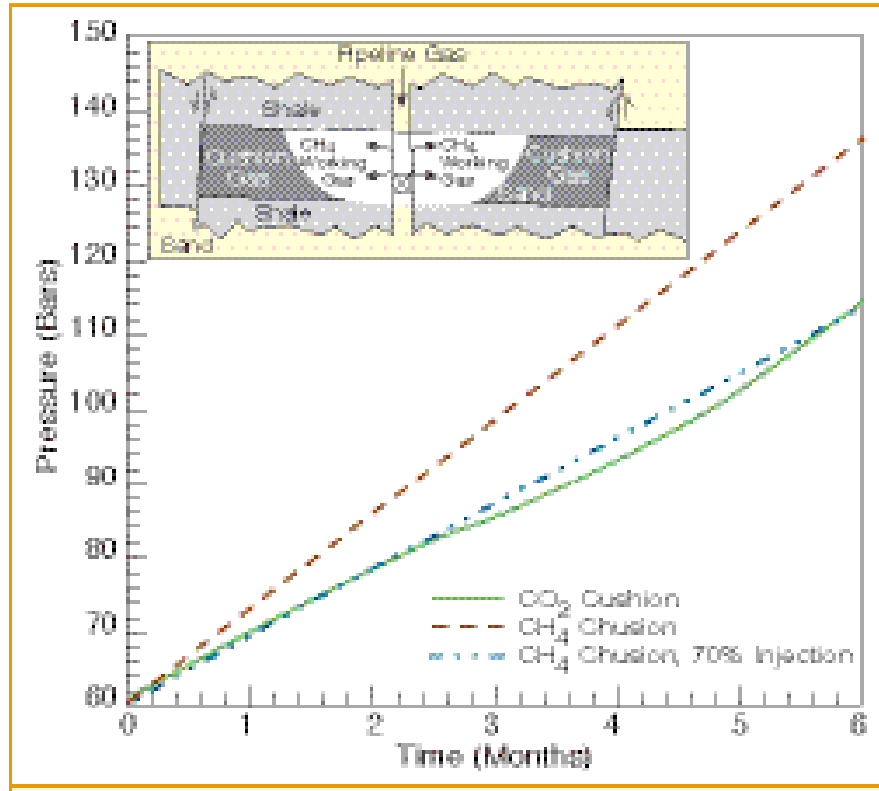

Figure 1. Schematic of natural gas storage and pressure vs. time for one cycle of $\mathrm{CH}_{4}$ injection with various cushion gases showing the lower pressure rise for $\mathrm{CO}_{2}$ cushion gas relative to a native $\mathrm{CH}_{4}$ gas cushion.

\section{RELATED PUBLICATIONS}

Oldenburg, C.M., Carbon dioxide as cushion gas for natural gas storage, Energy and Fuels, 17(1), 240-246, 2003.

Oldenburg, C.M., S.H. Stevens, and S.M. Benson, Economic feasibility of carbon sequestration with enhanced gas recovery (CSEGR), Energy, 2003 (in press).

\section{ACKNOWLEDGEMENT}

This work was supported by the Assistant Secretary for Fossil Energy, Office of Coal and Power Systems through the National Energy Technology Laboratory, and by Lawrence Berkeley National Laboratory under Department of Energy Contract No. DE-AC03-76SF00098. 


\section{Coupled Model for $\mathrm{CO}_{2}$ Leakage and Seepage \\ Curtis M. Oldenburg and André J.A. Unger \\ Contact: Curtis M. Oldenburg, 510/486-7419, cmoldenburg@lbl.gov}

\section{RESEARCH OBJECTIVES}

Geologic carbon sequestration involves the direct injection of large quantities of carbon dioxide $\left(\mathrm{CO}_{2}\right)$ into deep geologic formations, such as depleted oil and gas reservoirs, saline aquifers, and unminable coal seams. The accumulation of vast quantities of $\mathrm{CO}_{2}$ in the deep subsurface entails the risk that $\mathrm{CO}_{2}$ will leak from the target formation and seep out of the ground. Leakage is $\mathrm{CO}_{2}$ migration away from the primary target formation, whereas seepage is $\mathrm{CO}_{2}$ migration across an interface such as the ground surface. The objective of this research is to investigate the leakage, seepage, and dispersion of $\mathrm{CO}_{2}$.

\section{APPROACH}

We have developed a simulation capability called T2CA (TOUGH2 for $\mathrm{CO}_{2}$ and Air) that is an enhancement of the TOUGH2 reservoir simulator. T2CA includes both subsurface and atmospheric surface layer regions. The approach for the subsurface follows the standard multicomponent and multiphase methods in TOUGH2. For the surface layer, we assume a logarithmic velocity profile to represent time-averaged winds. For atmospheric dispersion, we use the PasquillGifford dispersion curves and Smagorinski Model to estimate dispersivities. The logarithmic velocity profile is specified by setting suitable permeabilities and pressure boundary conditions and setting porosity equal to one. In this way, T2CA can handle coupled subsurface-surface-layer flow and transport. This approach is valid for the case in which $\mathrm{CO}_{2}$ concentrations in the surface layer are low and mixing is passive. This appears to be a reasonable assumption for the leakage rates expected in geologic sequestration.

\section{ACCOMPLISHMENTS}

We have simulated cases of subsurface, surface layer, and coupled flow and transport using T2CA. For the subsurface, we have carried out a sensitivity analysis where various properties of a thick unsaturated zone were varied. In the surface layer, we have carried out verification studies in which we compared our approach with a commercial fluid-dynamics code and observed good agreement. In Figure 1, we present coupled flow results for wind speed equal to $1 \mathrm{~m} \mathrm{~s}^{-1}$ at a height of $2 \mathrm{~m}$.

\section{SIGNIFICANCE OF FINDINGS}

As shown in Figure 1, $\mathrm{CO}_{2}$ concentrations can reach high levels in the subsurface, but are quickly diluted in the surface layer. This result has significance in two important areas of carbon sequestration research: (1) $\mathrm{CO}_{2}$ sequestration monitoring and verification; and (2) health, safety, and environmental (HSE) risk assessment. For monitoring and verification, our results show that detection is more likely if instruments are placed in the subsurface or in trenches. For HSE risk assessment, our results point to the potentially significant risks of subsurface enclosed spaces, such as basements.

\section{RELATED PUBLICATION}

Oldenburg, C.M., and A.J.A. Unger, On leakage and seepage from geologic carbon sequestration sites: Unsaturated zone attenuation. Vadose Zone Journal, 2(3), 287-296, 2003; Berkeley Lab Report LBNL-51928.

\section{ACKNOWLEDGMENT}

This work was supported in part by the Director, Office of Science, U.S. Department of Energy under Contract No. DEAC03-76SF00098, and by a Cooperative Research and Development Agreement (CRADA) between BP Corporation North America, as part of the $\mathrm{CO}_{2}$ Capture Project (CCP) of the Joint Industry Program (JIP), and the U.S. Department of Energy (DOE) through the National Energy Technologies Laboratory (NETL).

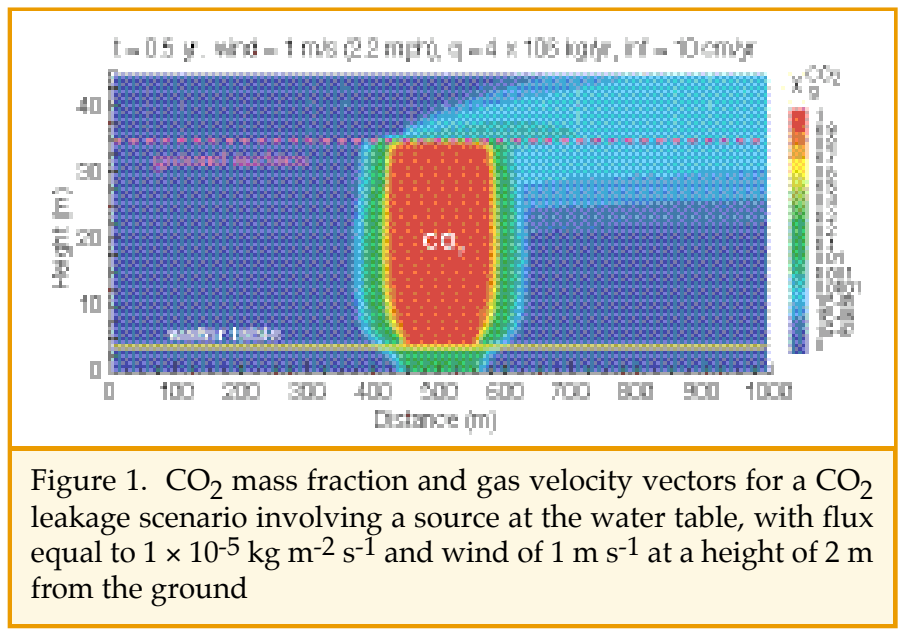

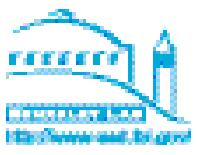




\title{
Nonisothermal EfFects During $\mathrm{CO}_{2}$ Leakage From a GeOlogic Disposal Reservoir
}

\author{
Karsten Pruess \\ Contact: 510/486-6732, k_pruess@lbl.gov
}

\section{RESEARCH OBJECTIVES}

There is general consensus in the scientific community that geologic disposal of $\mathrm{CO}_{2}$ into saline aquifers would be made at supercritical pressures, $\mathrm{P}>$ Pcrit $=73.82$ bars. However, $\mathrm{CO}_{2}$ escaping from a storage reservoir may migrate upwards towards regions with lower temperatures and pressures, where $\mathrm{CO}_{2}$ would be in subcritical conditions. An assessment of the fate of leaking $\mathrm{CO}_{2}$ requires the capability to model not only supercritical but also subcritical $\mathrm{CO}_{2}$, as well as phase changes between liquid and gaseous $\mathrm{CO}_{2}$ in subcritical conditions.

\section{APPROACH}

A new fluid property module was written for the generalpurpose TOUGH2 simulator to represent mixtures of brine and $\mathrm{CO}_{2}$ in all possible phase states, including gaseous, liquid, and supercritical $\mathrm{CO}_{2}$, as well as an aqueous phase and solid precipitate. This was applied to a study of leakage behavior in a simplified hypothetical model system.

\section{ACCOMPLISHMENTS}

Starting from a typical geothermal gradient of $30^{\circ} \mathrm{C} / \mathrm{km}$ in continental crust and hydrostatic pressures, the response to leaking $\mathrm{CO}_{2}$ entering a vertical channel with elevated permeability at $1,000 \mathrm{~m}$ depth

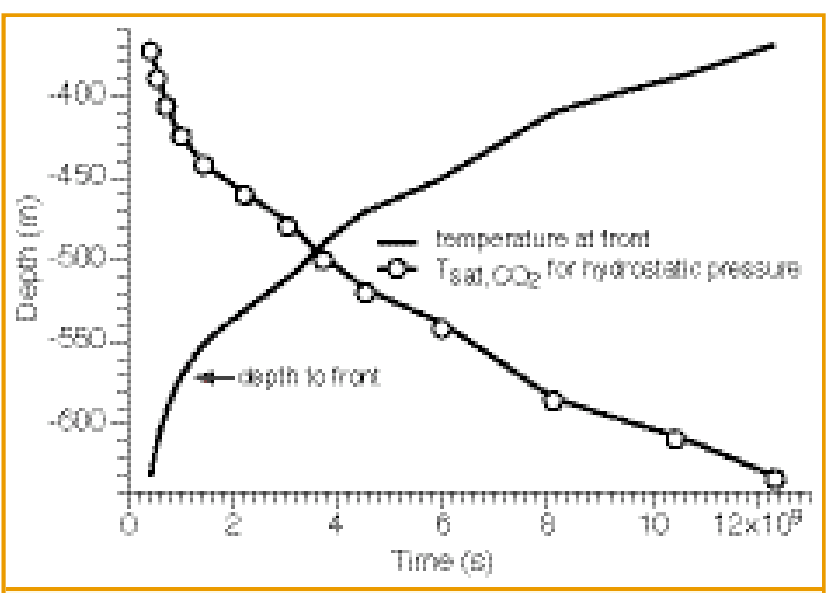

Figure 1. Advancement of liquid front, and frontal temperature, as a function of time three-phase zone became several hundred meters thick. Upflow across the three-phase zone was impeded by interference between the phases. As a consequence, $\mathrm{CO}_{2}$ discharge at the land surface was more dispersed than it otherwise would have been.

The simulation stopped after 391.2 years as freezing conditions were approached. This stoppage occurred because the fluid-property treatment adopted here has no provisions to deal with phase change from liquid water to ice or solid hydrate phases.

Another simulation was run for a larger land-surface temperature of $15^{\circ} \mathrm{C}$, in which the initial T,P-profile did not intersect the $\mathrm{CO}_{2}$ saturation line. Although the rising $\mathrm{CO}_{2}$ was not subject to phase change, there were nevertheless strong cooling effects because specific enthalpy of $\mathrm{CO}_{2}$ increases upon depressurization. Over time, temperatures declined and a three-phase zone evolved, similar to what was observed for lower land-surface temperature.

\section{SIGNIFICANCE OF FINDINGS}

Upward migration of $\mathrm{CO}_{2}$ from a geologic disposal reservoir is accompanied by strong heat-transfer effects and gives rise to the evolution of a thick and broad threephase zone. was simulated in 2-D cylindrical geometry. A first simulation case was run with an average land surface temperature of $5^{\circ} \mathrm{C}$. In this case, the initial T,P-profile intersected the $\mathrm{CO}_{2}$ saturation line, suggesting that liquid $\mathrm{CO}_{2}$ will boil as it rises.

The system behavior observed in the simulation can be summarized as follows. Some of the $\mathrm{CO}_{2}$ dissolved in water, but most of it formed a separate liquid phase. The liquid rose and started vaporizing at about a $630 \mathrm{~m}$ depth. Vaporization was partial and gave rise to evolution of a three-phase zone: aqueousliquid $\mathrm{CO}_{2}-$ gaseous $\mathrm{CO}_{2}$. Latent heat transfer during phase change caused considerable cooling of the rock, which allowed the liquid front to advance upward (see Figure 1). Over time, the

\section{RELATED PUBLICATION}

Pruess, K., Numerical simulation of $\mathrm{CO}_{2}$ leakage from a geologic disposal reservoir, including transitions from superto subcritical conditions, and boiling of liquid $\mathrm{CO}_{2}$. SPE Journal, 2003 (submitted). Berkeley Lab Report LBNL52423.

\section{ACKNOWLEDGMENTS}

This work was supported by the Director, Office of Science, Office of Basic Energy Sciences, of the U.S. Department of Energy under Contract No. DE-AC03-76SF00098. 


\title{
Effect of Wheat Harvest on Regional Clmate: Experiments With the COUPLED MM5-ISOLSM MODEL
}

\author{
William Riley, Heather S. Cooley ${ }^{1}$, and Margaret S. Torn \\ ${ }^{1}$ University of California, Berkeley \\ Contact: William Riley, 510/486-5036, wjriley@lbl.gov
}

\section{RESEARCH OBJECTIVES}

Surface energy and water fluxes are tightly coupled with $\mathrm{CO}_{2}$ exchanges between the ecosystem and atmosphere. Other surface-to-atmosphere trace-gas exchanges of interest in climate change research are also strongly impacted by surface energy exchanges. Further, land-use change has considerable impact on the surface energy balance and therefore the exchanges of these trace gases. To investigate these issues at the regional scale, we have coupled the meteorological model MM5 with ISOLSM (Riley et al., 2002; 2003), a land-surface model that, in addition to simulating the surface energy balance, predicts gaseous and aqueous fluxes of climatically relevant species within the soil and between the ecosystem and atmosphere.

\section{APPROACH}

Here we describe a modeling investigation of the impact of the winter wheat harvest on surface fluxes, air temperatures, and regional climate in the Southern Great Plains Atmospheric Radiation Measurement-Cloud and Radiation Testbed (ARM-CART) region (Cooley et al., 2003). We chose to study the winter wheat harvest because wheat accounts for about $20 \%$ of the ARMCART land area, and the fields are typically harvested within a two-week peri-

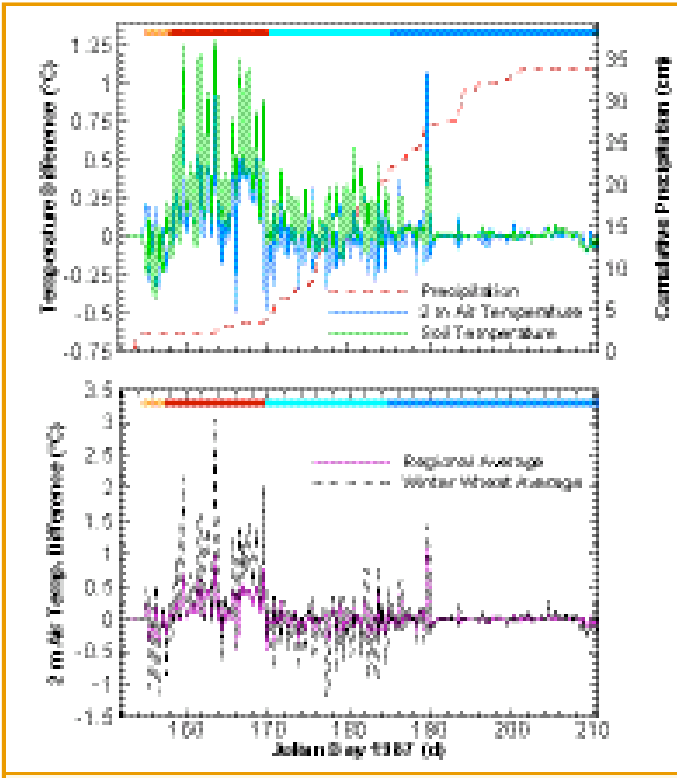

Figure 1. (a) Differences (relative to the late harvest scenario) in cumulative precipitation and in $2 \mathrm{~m}$ air and soil temperatures averaged over the ARM-CART region show four distinct time periods (solid bars at top). (b) Differences in $2 \mathrm{~m}$ air temperature in the harvested area and averaged over the entire region. Air temperatures were substantially higher in the harvested area. od. Two harvest dates, bracketing the interannual range in the region, were simulated and compared: "early harvest" on June 4 and "late harvest" on July 5.

\section{ACCOMPLISHMENTS}

Differences in latent and sensible heat fluxes, $2 \mathrm{~m}$ air and soil temperatures, and precipitation varied over the two-month simulation. During the first three days after harvest, midday latent heat fluxes increased substantially, and much of the near-surface soil moisture was lost via evaporation. Over about the next two weeks, midday latent heat fluxes decreased, as transpiration was eliminated and evaporation was sharply reduced in the harvested area. The concurrent increase in sensible heat fluxes resulted in midday air-temperature increases of about $1^{\circ} \mathrm{C}$. After the second harvest, air temperature and soil moisture and temperature levels rapidly converged between the two scenarios, indicating that the system has relatively little memory of the early harvest.

Changes within the harvested areas are substantially larger than the regionally averaged results (Figure 1); further, there are some edge effects. For example, latent heat fluxes increased and sensible heat fluxes decreased in areas adjacent to the harvest because of the drier air being advected from the harvested region.

\section{SIGNIFICANCE OF FINDINGS}

Simulations of the winter wheat harvest in the ARM-CART region indicate that coherent harvesting substantially impacts regionally averaged and local surface conditions and climate. These findings highlight the importance of land use change on climate; in the near future we will use the model to study interactions between land use changes and the changing global climate.

\section{RELATED PUBLICATIONS}

Cooley, H.S., W.J. Riley, and M.S. Torn, Effect of harvest on regional climate and soil moisture and temperature, in Chapman Conference on Ecosystem Interactions with Land Use Change, Santa Fe, NM, 2003.

Riley, W.J., C.J. Still, M.S. Torn, and J.A. Berry, A mechanistic model of $\mathrm{H}_{2}{ }^{18} \mathrm{O}$ and $\mathrm{C}^{18} \mathrm{OO}$ fluxes between ecosystems and the atmosphere: Model description and sensitivity analyses, Global Biogeochemical Cycles, 16, 1095-1109, 2002.

Riley, W.J., C.S. Still, B.R. Helliker, M. Ribas-Carbo, S. Verma, and J.A. Berry, Measured and modeled $\delta^{18} \mathrm{O}$ in $\mathrm{CO}_{2}$ and $\mathrm{H}_{2} \mathrm{O}$ above a tallgrass prairie, Global Change Biology, 2003 (in press).

\section{ACKNOWLEDGMENTS}

This work was supported by Laboratory Directed Research and Development funding from Berkeley Lab, provided by the Director and by the Atmospheric Radiation Measurement Program, Office of Science, of the U.S. Department of Energy under Contract No. DE-AC03-76SF00098.

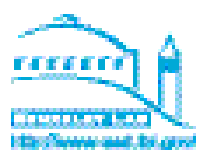




\section{Using 18 O TO PARTition Ecosystem CARbon ExChANGes: IMPACT OF THE NeAR-SuRface $\mathbf{8} 180$ VAlue OF SOIL Water ON The $\mathbf{0} 18 \mathrm{O}$ Value OF The Soil-Surface $\mathrm{CO}_{2}$ FluX \\ William J. Riley \\ Contact: 510/486-5036, wjriley@lbl.gov}

\section{RESEARCH OBJECTIVES}

The ${ }^{18} \mathrm{O}$ content of atmospheric $\mathrm{CO}_{2}$ has been proposed as a means to partition site-level measured net ecosystem carbon fluxes into component gross fluxes and, at the global scale, to estimate the regional distribution of $\mathrm{CO}_{2}$ fluxes. However, these approaches require accurate prediction of the $\delta^{18} \mathrm{O}$ value of the soil-surface $\mathrm{CO}_{2}$ flux $\left(\delta \mathrm{F}_{\mathrm{s}}\right)$. This work aims to better characterize and to improve the computational efficiency of models used in global and regional simulations.

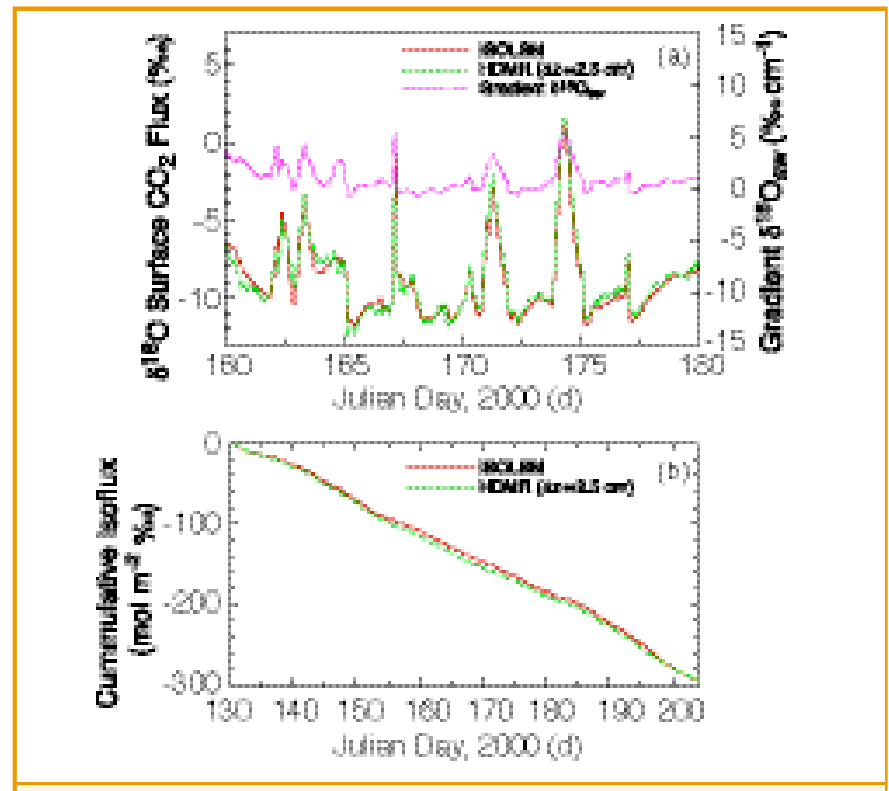

Figure 1 (a) $\delta \mathrm{F}_{\mathrm{S}}$ as predicted by ISOLM and the HDMR approach. Also shown is the gradient in $\delta_{\mathrm{sw}}$ over the top $15 \mathrm{~cm}$. (b) Cumulative isoflux from the soil to the atmosphere for the two approaches. The error the three-month growing season was $0.2 \%$.

\section{APPROACH}

The net $\mathrm{C}^{18} \mathrm{OO}$ surface flux depends, nonlinearly, on the depth-dependent $\delta^{18} \mathrm{O}$ value of soil water $\left(\delta_{\mathrm{sw}}\right)$, soil moisture and temperature, soil $\mathrm{CO}_{2}$ production, and the $\delta^{18} \mathrm{O}$ value of above-surface $\mathrm{CO}_{2}$ (Riley, 2003a). We developed ISOLSM (Riley et al., 2002; Riley et al., 2003b) to simulate these processes within an established land surface model (LSM1). ISOLSM simulates the $18 \mathrm{O}$ content of canopy water vapor, leaf water, and vertically resolved soil water; leaf photosynthetic $\mathrm{C}^{18} \mathrm{OO}$ fluxes; $\mathrm{CO}_{2}$ oxygen isotope exchanges with soil and leaf water; soil $\mathrm{CO}_{2}$ and $\mathrm{C}^{18} \mathrm{OO}$ diffusive fluxes (including abiotic soil exchange); and ecosystem exchange of $\mathrm{H}_{2}{ }^{18} \mathrm{O}$ and $\mathrm{C}^{18} \mathrm{OO}$ with the atmosphere. Since ISOLSM is a computationally expensive model, we applied a high-dimension model representation (HDMR) technique to efficiently predict $\delta F_{s}$.

\section{ACCOMPLISHMENTS}

Our results indicate that the HDMR approach is very accurate and about 100 times faster than the full numerical solution of the $\mathrm{C}^{18} \mathrm{OO}$ surface flux, making it appropriate for regional and global simulations. We successfully tested the HDMR approach over a growing season at a $\mathrm{C}_{4}$-dominated tallgrass prairie site, and then used the model to investigate the factors important in determining $\delta \mathrm{F}_{\mathrm{s}}$. The top panel of the figure shows comparisons between the full numerical model and the HDMR approach for a 20-day period. The bottom panel shows comparisons of the cumulative isoflux from the soil surface over the full season; the error over the growing season was less than $0.2 \%$. The largest changes in $\delta \mathrm{F}_{\mathrm{S}}$ occur when gradients in the top $5 \mathrm{~cm}$ are large. These conditions typically occur when soil evaporation is large, i.e., following precipitation.

\section{SIGNIFICANCE OF FINDINGS}

Simulation results indicate that $\delta F_{S}$ is dependent on the $\delta^{18} \mathrm{O}$ value of soil water in the top few centimeters of soil. These results indicate that recent approaches to estimating global distributions of the surface $\mathrm{C}^{18} \mathrm{OO}$ flux are problematic and demonstrate the importance of accurately resolving nearsurface $\delta_{\mathrm{sw}}$. Also, the development of the HDMR approach allows for accurate and computationally affordable simulations of regional and global distributions.

\section{RELATED PUBLICATIONS}

Riley, W.J., Impact of the near-surface $\delta^{18} \mathrm{O}$ value of soil water on the $\delta^{18} \mathrm{O}$ value of the soil-suface $\mathrm{CO}_{2}$ flux: Application of a high-dimension model representation technique. GRL, 2003a (submitted).

Riley, W.J., C.J. Still, M.S. Torn, and J.A. Berry, A mechanistic model of $\mathrm{H}_{2}{ }^{18} \mathrm{O}$ and $\mathrm{C}^{18} \mathrm{OO}$ fluxes between ecosystems and the atmosphere: Model description and sensitivity analyses. Global Biogeochemical Cycles, 16, 1095-1109, 2002.

Riley, W.J., C.S. Still, B.R. Helliker, M. Ribas-Carbo, S. Verma, and J.A. Berry, Measured and modeled $\delta^{18} \mathrm{O}$ in $\mathrm{CO}_{2}$ and $\mathrm{H}_{2} \mathrm{O}$ above a tallgrass prairie. Global Change Biology, $2003 b$ (in press).

\section{ACKNOWLEDGMENTS}

This work was supported by Laboratory Directed Researh and Development funds at Berkeley Lab provided by the Director and by the Atmospheric Radiation Measurement Program, Office of Science, of the U.S. Department of Energy under Contract No.

DE-AC03-76SF00098. 


\section{A Noniterative Model to Compute $\mathrm{CO}_{2}-\mathrm{H}_{2} \mathrm{O}$ Mutual Solubilities at $12-100^{\circ} \mathrm{C}$ AND UP TO 600 BAR \\ Nicolas Spycher and Karsten Pruess \\ Contact: Nicolas Spycher, 510/495-2388, nspycher@lbl.gov}

\section{RESEARCH OBJECTIVES}

Evaluating the feasibility of $\mathrm{CO}_{2}$ geologic sequestration requires intensive numerical simulations of multiphase fluid flow. These simulations require the calculation of pressuretemperature-composition (P-T-X) data for mixtures of $\mathrm{CO}_{2}$ and $\mathrm{H}_{2} \mathrm{O}$ under moderate pressures and temperatures at which a $\mathrm{CO}_{2}$-rich phase (gas or liquid) and an $\mathrm{H}_{2} \mathrm{O}$-rich liquid coexist. The objective of this study is to develop correlations to calculate efficiently and accurately the composition of these phases at equilibrium, for implementation into numerical simulations of water- $\mathrm{CO}_{2}$ flows.

\section{APPROACH}

We compiled a large number of published experimental data on the mutual solubility of $\mathrm{CO}_{2}$ and $\mathrm{H}_{2} \mathrm{O}$ over our $\mathrm{P}-\mathrm{T}$ range of interest into a database (403 data points). We then developed a solubility model, based on equating chemical potentials, and used a modified Redlich-Kwong (RK) equation of state to calculate fugacity coefficients for $\mathrm{CO}_{2}$ and $\mathrm{H}_{2} \mathrm{O}$ in the compressed gas phase. The mixing rules implemented in this model have a standard form but assume infinite $\mathrm{H}_{2} \mathrm{O}$ dilution in

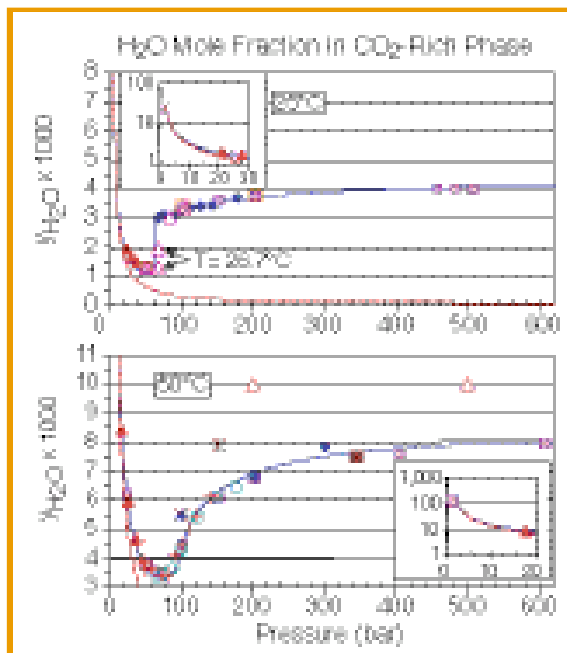

\section{SIGNIFICANCE OF FINDINGS}

Other $\mathrm{CO}_{2}-\mathrm{H}_{2} \mathrm{O}$ solubility models have been published in the literature. However, these models either do not cover our entire P-T range of interest or involve complex correlations the $\mathrm{CO}_{2}$-rich phase. This allowed the use of a noniterative algorithm for computing mutual solubilities at given pressures and temperatures. RK parameters for pure $\mathrm{CO}_{2}$ were obtained by fitting the equation of state to reference P-T data. Inverse modeling (PEST-ASP v5.0) was then used to calibrate the solubility model to the entire database of experimental P-T-X data, yielding RK parameters for the mixture, as well as aqueous solubility constants for gas and liquid $\mathrm{CO}_{2}$ as functions of temperature and pressure. Water fugacities needed in the model were taken directly from literature sources.

\section{ACCOMPLISHMENTS}

A new model was developed to compute the mutual solubilities of $\mathrm{CO}_{2}$ and $\mathrm{H}_{2} \mathrm{O}$ at $12-100^{\circ} \mathrm{C}$ and up to 600 bar. The solubility model uses an efficient noniterative algorithm and reproduces experimental data typically within a few percent (Figure 1). The solubility model can be easily extended to moderately saline solutions, using existing activity coefficient models.

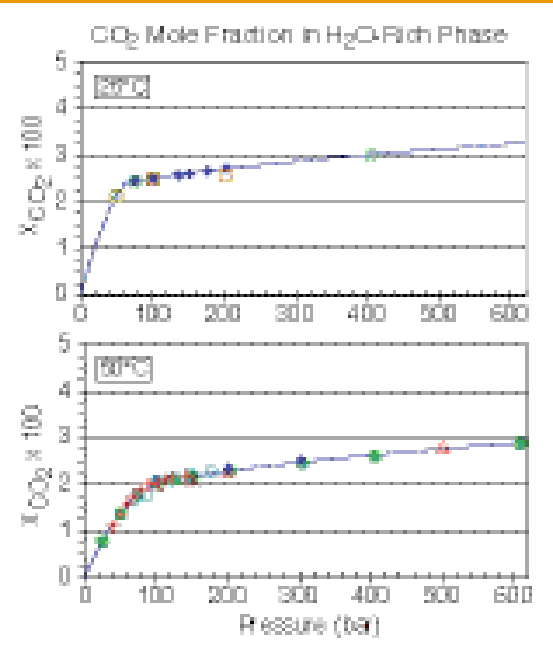

Figure 1. Calculated mutual solubilities of $\mathrm{CO}_{2}$ and $\mathrm{H}_{2} \mathrm{O}$ in this study (solid lines) and experimental data from the literature (symbols, with different shapes or colors for each different set of data). Dotted lines assume ideal mixing. Letters $y$ and $x$ refer to mole fractions in the compressed gas and aqueous phases, respectively.

requiring an iterative solution. Also, these models rely on a much smaller number of experimental data points. The noniterative procedure developed in this study reproduces experimental mutual solubilities of $\mathrm{CO}_{2}$ and $\mathrm{H}_{2} \mathrm{O}$ with sufficient accuracy for the study of geologic $\mathrm{CO}_{2}$ disposal and enough simplicity to avoid degrading the performance of numerical fluid-flow simulations.

\section{RELATED PUBLICATION}

Spycher, N., K. Pruess, and J. Ennis-King, $\mathrm{CO}_{2}-\mathrm{H}_{2} \mathrm{O}$ mixtures in the geological sequestration of $\mathrm{CO}_{2}$. I. Assessment and calculation of mutual solubilities from 12 to $100^{\circ} \mathrm{C}$ and up to 600 bar. Geochimica et Cosmochimica Acta, 2003 (in press); Berkeley Lab Report LBNL-50991, 2002.

\section{ACKNOWLEDGMENTS}

This work was supported by the Director, Office of Science, Office of Basic Energy Sciences, under U.S. Department of Energy Contract No. DE-AC03-76SF00098. 


\title{
Carbon Cycling in the Southern Great Plains: The ARM/LBNL CARbon PROJECT
}

\author{
Margaret S. Torn, M.L. Fischer, William J. Riley, I. Pesenson, and J. Berry \\ Contact: Margaret S. Torn, 510/495-2223, mstorn@lbl.gov
}

\section{RESEARCH OBJECTIVES}

One of the challenges in carbon cycle research is the vast range of scales, from plants to continents, that must be bridged with measurements and models. The Atmospheric and Radiation Measurement (ARM)/ LBNL Carbon Project is making a coordinated suite of carbon concentration, isotope, and flux measurements to support a range of scaling and integration exercises, including those proposed for the North American Carbon Program:

- Quantify the regional atmospheric $\mathrm{CO}_{2}$ budget.

- Predict carbon fluxes, and the effect of land use and climate on them.

- Link local processes to regional and global models.

\section{APPROACH}

We are working at the DOE ARM Southern Great Plains testbed, a GCMgrid sized area centered in Northern Oklahoma. The carbon cycle data streams that our group produces are centered at the $60 \mathrm{~m}$ tower of the ARM Central Facility and include: precise $\mathrm{CO}_{2}$ concentration profiles; carbon eddy covariance fluxes; National Oceanic and Atmospheric Administration-Climate Monitoring Diagnostics Laboratory (NOAA-CMDL) flasks in the mixed layer and free troposphere and diurnal profiles of ${ }^{13} \mathrm{C}$ and ${ }^{18} \mathrm{O}$ in $\mathrm{CO}_{2}$. In the next year, we are adding continuous $\mathrm{CO}$ measurements and flask sampling for ${ }^{14} \mathrm{CO}_{2}$ to assist with source attribution.

\section{ACCOMPLISHMENTS}

The continuous precise $\mathrm{CO}_{2}$ measurements and the NOAA flask sampling tie the ARM testbed to the global atmospheric network. We observe that $\mathrm{CO}_{2}$ concentrations are higher than global average for the latitude, reflecting continental sources. The diurnal cycle also shows the influence of continental atmospheric and terrestrial processes. At night (as seen in Figure 1), soil respiration and stable conditions lead to large buildups in $\mathrm{CO}_{2}$, especially near the surface. During the day- time, the atmosphere is well mixed and photosynthesis reduces atmospheric $\mathrm{CO}_{2}$ concentrations. The highest concentrations of $\mathrm{CO}_{2}$ are on nights of low wind speed and low mixing height. Our flux studies indicate that land use is the most important driver of spatial heterogeneity in fluxes in the study
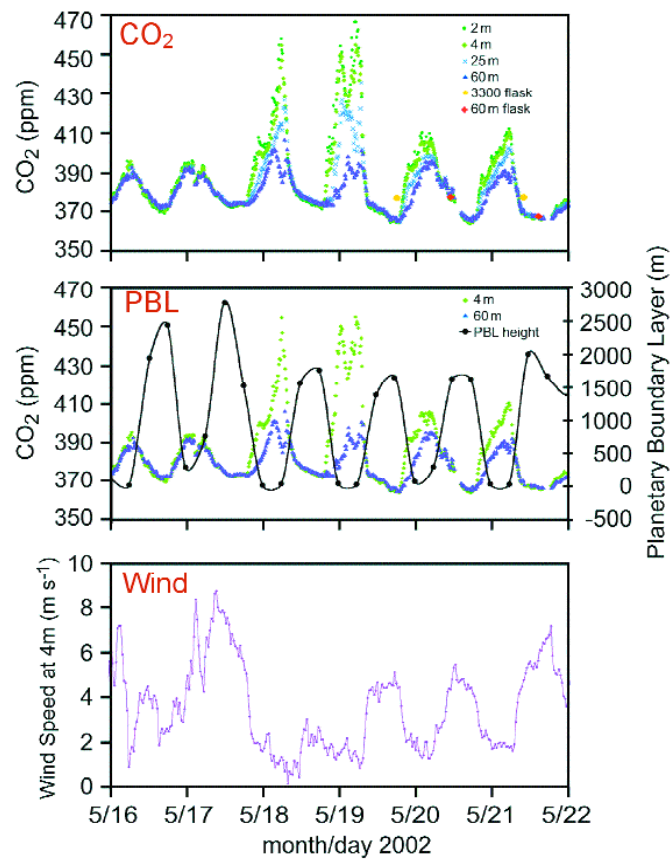

Figure 1. Diurnal cycle of $\mathrm{CO}_{2}$, PBL height, and wind speed, May 16-22, 2002. Data were collected at the ARM Central Facility: $\mathrm{CO}_{2}$ concentrations are from the continuous precise system at $60 \mathrm{~m}$ tower; red and yellow symbols are NOAA-CMDL flask data. PBL height was estimated from radiosonde profiles. Windspeed was measured at $4 \mathrm{~m}$ at the base of tower. area. Using these results, regionalscale estimates of carbon fluxes based on "top-down" (atmospheric concentrations) and "bottom up" (distributed modeling and eddy flux measurements) approaches are in progress.

SIGNIFICANCE OF FINDINGS

Observations of Atmospheric $\mathrm{CO}_{2}$ concentrations can improve estimates of surface fluxes, source types, and total atmospheric $\mathrm{CO}_{2}$ stocks. However, the diurnal cycle of $\mathrm{CO}_{2}$ concentration at continental sites reflects not only net ecosystem exchange, but also atmospheric mixing (planetary boundary layer) advection from surface winds, and anthropogenic carbon sources. Thus, interpreting atmospheric concentrations also requires understanding atmospheric processes and anthropogenic activity.

The isotopic and molecular composition of atmospheric samples creates fingerprints of fossil, biomass burning, and biogenic sources of carbon cycle gases. Our ongoing research efforts are focused on joining models of isotopic and atmospheric processes with land use patterns, and testing output against data covering multiple spatial and temporal scales.

\section{RELATED PUBLICATION}

ARM Carbon Web Site: http:/ / esd.lbl.gov/ ARMCarbon/

\section{ACKNOWLEDGMENTS}

This work was supported by the U.S. Department of Energy Atmospheric Radiation Measurement Program, Office of Science, of the U.S. Department of Energy under Contract No. DE-AC03-76SF00098.

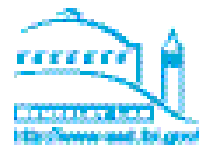




\title{
The Importance of Belowground Plant Allocation for Terrestrial Carbon Sequestration
}

\author{
Margaret S. Torn, T.E. Dawson ${ }^{1}$, J.A. Bird, J. Gaudinski, and D.E. Williard \\ ${ }^{1}$ University of California, Berkeley \\ Contact: Margaret S. Torn, 510/495-2223, mstorn@lbl.gov
}

\section{RESEARCH OBJECTIVES}

One strategy proposed for sequestering carbon in terrestrial ecosystems is to increase allocation of carbon to roots, on the assumption that root inputs are efficiently converted to stable soil organic matter (SOM). We are conducting research to fill critical gaps in understanding belowground carbon cycling and sequestration in soils of temperate forests, by characterizing:

- The lifetime of fine roots and implications for belowground net primary productivity

- Decomposition dynamics of root and needle/leaf $C$ inputs

- Total residence time of belowground $\mathrm{C}$, including SOM

\section{APPROACH}

The total residence time of root $C$ in the ecosystem depends on how long roots live, the decay rate of root litter, the fraction of $\mathrm{C}$ inputs humified rather than lost as $\mathrm{CO}_{2}$, and the stability of decomposition products. We are characterizing these aspects of residence time with field experiments and isotopebased approaches, including: (1) Natural abundance ${ }^{14} \mathrm{C}$ to determine fine-root lifetimes; (2) Litterbags and in situ incubations of ${ }^{13} \mathrm{C}$-labeled litter to estimate litter decay rates; (3) ${ }^{13} \mathrm{C}$ labeled litter to track root and needle decay into soil-respired $\mathrm{CO}_{2}$, microbial biomass, and soil organic fractions.

We are conducting the full suite of measurements at a mature ponderosa pine forest (Blodgett, California), measuring roots and litter decay at Harvard Forest, Massachusetts, and focusing on fine-root lifetime at additional forests in the U.S. and Europe. We report here the first year's results on litter decomposition.

\section{ACCOMPLISHMENTS}

Several lines of evidence indicate that roots decompose more slowly than leaves or needles in the first year of decay. First, the litter bags had greater mass loss of needles compared to roots at Blodgett (75\% versus $90 \%$ mass remaining, respectively) and leaves compared to roots at Harvard Forest (65\% versus $90 \%$ mass remaining, respectively). Second, for the ${ }^{13} \mathrm{C}$-labeled litter, recovery of fine-root $\mathrm{C}$ exceeded that of needles (77\% versus 52\%, respectively). Third, after one year, more of the needle material had been reduced to a smaller size class ( $<2 \mathrm{~mm}$ ) than had the roots ( $42 \%$ and $24 \%$, respectively), see figure 1 . Finally, the loss of $\mathrm{C}$ as respired $\mathrm{CO}_{2}$ was greater for needles than for roots.

Decay rates may vary because of chemical quality or the depth of placement, with the latter affecting both microclimate and soil mineral composition. We saw little or no significant effect on decay rates between two depths ( $\mathrm{O}$ and $\mathrm{A}$ horizons), for either the litter bag or the ${ }^{13} \mathrm{C}$ label experiments. In contrast, we did find a greater proportion of $\mathrm{C}$ compounds associated with recalcitrance, such as acid-soluble $C$ and lignin, in roots compared to needles and leaves. Preliminary results suggest that chemical quality, rather than timing or depth of input to soil, was responsible for the differences in decay rates.

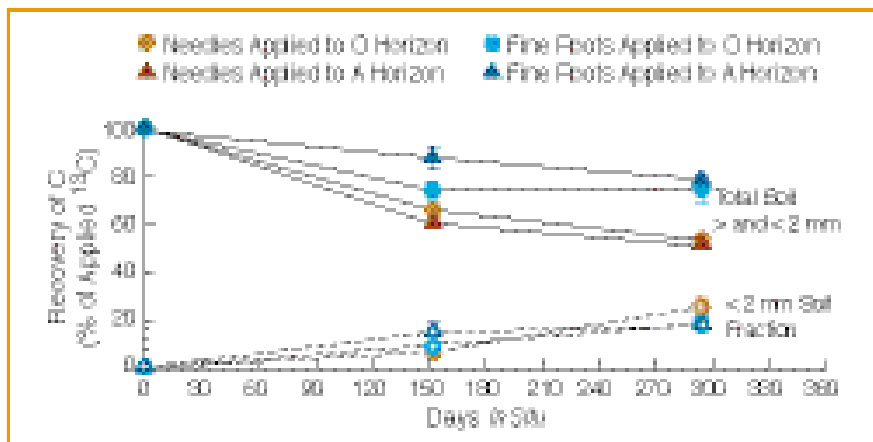

Figure 1. Percent $C$ recovery from needle and root litter after 10 months in situ. Litter was applied to the top of the $\mathrm{O}$ horizon or 2-5 cm below the $\mathrm{O} / \mathrm{A}$ interface in the $\mathrm{A}$ horizon during November 2001. Shown are total $C$ recovery in the whole soil (solid lines) and the $<2 \mathrm{~mm}$ fraction (dashed lines). Means $(\mathrm{n}=4)$ and standard errors are shown.

\section{SIGNIFICANCE OF FINDINGS}

Although roots live longer and decay more slowly than leaves or needles in these temperate forests, estimating the long-term sequestration potential will require a second phase of research on the humification pathways and stabilization of root inputs.

\section{RELATED PUBLICATION}

Torn, M.S., S. Davis, J.A. Bird, M.R. Shaw, and M.E. Conrad, Automated analysis of ${ }^{13} \mathrm{C} /{ }^{12} \mathrm{C}$ ratios in $\mathrm{CO}_{2}$ and dissolved inorganic carbon for ecological and environmental applications. Rapid Communications in Mass Spectrometry, 2003 (in press). Berkeley Lab Report LBNL53147.

\section{ACKNOWLEDGMENTS}

This work was supported by the Director, Office of Science, Office of Biological and Environmental Research, under U.S. Department of Energy Contract No. DE-AC03-76SF00098. We appreciate the use of the Blodgett Experimental Forest, California, and Harvard Forest, Massachusetts.

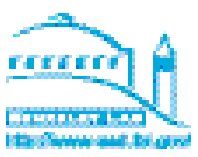




\title{
A Whole-Forest Pulse-Label Study of Microbial DYNAMics AND RoOT TURNOVER
}

\author{
Margaret S. Torn, J. Gaudinski, K. Treseder ${ }^{1}$, J. Westbrook, D. Joslin ${ }^{2}$, and C. Swanston ${ }^{3}$ \\ ${ }^{1}$ University of Pennsylvania, Philadelphia, PA \\ ${ }^{2}$ Belowground Forest Research, Oak Ridge, TN \\ ${ }^{3}$ Lawrence Livermore National Laboratory, Livermore, CA \\ Contact: Margaret S. Torn, 510/495-2223, mstorn@lbl.gov
}

\section{RESEARCH OBJECTIVES}

In the summer of 1999, there was a large atmospheric release of ${ }^{14} \mathrm{CO}_{2}$ near the Oak Ridge Reservation (ORR), Tennessee, from a local incinerator. The rapid photosynthetic uptake of the ${ }^{14} \mathrm{CO}_{2}$ created a pulse label for studying carbon (C) cycling through the ORR forests. Several institutions (four DOE labs, two UC campuses, the U.S. Forest Service, and a private firm) are utilizing this whole-ecosystem isotopic label to address unresolved issues in terrestrial carbon cycling. At Berkeley Lab, we are investigating (1) the longevity of fine roots, and (2) the pathways from leaf and root inputs to microbial biomass and soil organic matter. Here, we summarize the first year's results.

\section{APPROACH}

The ORR team used enriched and near-background leaf litter to create four treatments, depending on plant ${ }^{14} \mathrm{C}$ inputs: enriched roots, enriched leaf litter, both enriched leaves and roots, and no enrichment. We determined fine-root longevity by tracing the radiocarbon label through live and dead root populations. New root growth was isolated by harvesting roots that grew through a screen in the soil. For fungal dynamics, ectomycorrhizae were hand-picked from freshly harvested roots. For microbial biomass, chloroform fumigation-extracts of soils were freeze-dried and combusted for graphitization. Radiocarbon content was measured at Lawrence Livermore National Laboratory by accelerator mass spectrometry.

\section{ACCOMPLISHMENTS AND SIGNIFICANCE}

New root growth contains about $10-20 \%$ of the ${ }^{14} \mathrm{C}$ signature from the previous year's growth (Figure 1), showing that roots grow from a mixture of recent photosynthate and $\mathrm{C}$ storage from the previous year. This result is helping us parameterize root models and estimate fine-root turnover based on atmospheric trends in ${ }^{14} \mathrm{CO}_{2}$. Our data from this and other forests show no correlation in root lifetimes between different root-diameter size classes; we believe that the diameter-lifetime correlation observed by minirhizotron studies may only be valid for roots living less than 1 year.

The only plots in which ectomycorrhizal fungi were ${ }^{14} \mathrm{C}$ enriched were those with trees that had enriched roots. This shows that the fungi were not receiving carbon from decom- position of organic matter, but rather from the live roots they colonized.

Microbial biomass was enriched in all treatments and depths. The rapid enrichment ( $\sim 500 \%$ in 2002$)$ is consistent with conceptual models of microbes as an active carbon pool that decomposes roots, litter, and dissolved organic material. The similarity to heterotrophic respiration values ( 400-600\%) suggests that we may be able to use microbial biomass ${ }^{14} \mathrm{C}$ to estimate the season-integrated signature soil-respired ${ }^{14} \mathrm{CO}_{2}$. We are using results from these studies to improve models of forest $\mathrm{C}$ cycling and sequestration.

\section{RELATED PUBLICATION}

Enriched Background Isotope Study (EBIS) Workshop Report, January 2003; www.esd.ornl.gov/programs/WBW/ EBISwkshp2003.htm.

\section{ACKNOWLEDGMENTS}

This work was supported by the Director, Office of Science, Office of Biological and Environmental Research, U.S. Department of Energy under Contract No. DE-AC0376SF00098. EBIS is led by Paul Hanson, Oak Ridge National Laboratory.

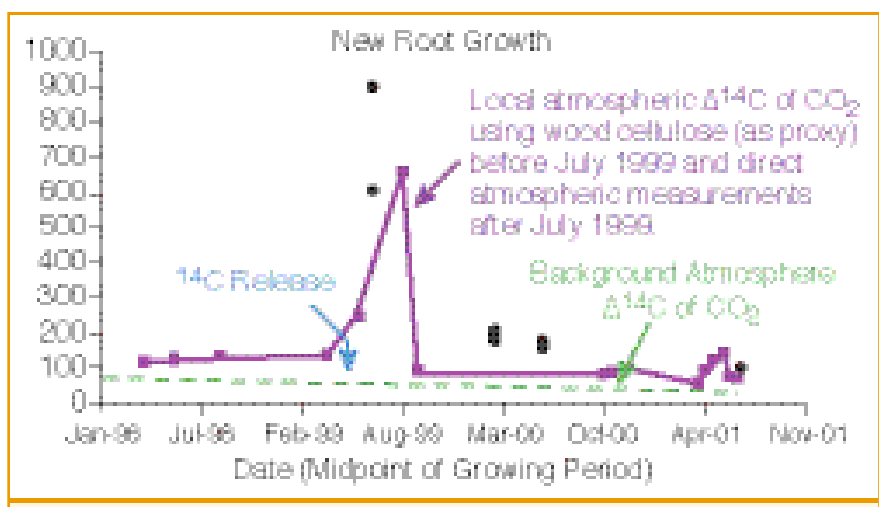

Figure 1 . The change in $\Delta^{14} \mathrm{C}$ of new root growth (black circles) over time at Walker Branch, Oak Ridge, TN. The purple line shows atmospheric ${ }^{14} \mathrm{CO}_{2}$ at Oak Ridge, with the major ${ }^{14} \mathrm{C}$ release in 1999, based on wood cellulose before July 1999 and direct atmospheric measurements after July 1999. The dashed green line is background atmospheric $\Delta^{14} \mathrm{CO}_{2}$. 


\title{
TOUGHREACT Simulation STUdies for Mineral Trapping Following $\mathrm{CO}_{2}$ Disposal in Deep Saline AQuifers
}

\author{
Tianfu Xu, John A. Apps, and Karsten Pruess \\ Contact: Tianfu Xu, 510/486-7057, tianfu_xu@lbl.gov
}

\section{RESEARCH OBJECTIVES}

A reactive fluid flow and geochemical transport numerical model TOUGHREACT has been developed for evaluating long-term $\mathrm{CO}_{2}$ disposal in deep geologic formations. The model is needed because alteration of the aluminosilicate minerals in the predominant host rock is very slow and not amenable to laboratory experiment under ambient deep-formation conditions. Using this model, we performed: (1) batch geochemical modeling analysis with three rock types (glauconitic sandstone from the Canada Alberta Sedimentary Basin, a sediment from the United States Gulf Coast, and a dunite); (2) reactive transport simulations of a 1-D radial-well region under $\mathrm{CO}_{2}$ injection conditions to analyze $\mathrm{CO}_{2}$ immobilization through carbonate precipitation in Gulf Coast sandstone of the Frio formation (Texas); and (3) reactive transport simulations of $\mathrm{CO}_{2}$ sequestration in bedded sandstone-shale sequences.

\section{APPROACH}

TOUGHREACT was developed by introducing reactive chemistry into the framework of the existing multiphase fluid and heat flow code TOUGH2. The code can be applied to one, two-, or three-dimensional porous and fractured media with physical and chemical heterogeneity, and can accommodate any number of chemical species present in liquid, gas, or solid phases. A wide range of subsurface thermal-physical-chemical processes is considered, including (1) redox processes that could be important in deep subsurface environments; (2) the presence of organic matter; (3) the kinetics of chemical interactions between the host rock minerals and the aqueous phase; and (4) $\mathrm{CO}_{2}$ solubility dependence on pressure, temperature, and salinity of the system.

\section{ACCOMPLISHMENTS}

We evaluated the geochemical evolution under both natural background and $\mathrm{CO}_{2}$ injection conditions. Changes in porosity were monitored during the simulations. Under favorable conditions, the amount of $\mathrm{CO}_{2}$ that may be sequestered by precipitation of secondary carbonates is comparable to (and can be larger than) the effect of $\mathrm{CO}_{2}$ dissolution in pore waters. The addition of $\mathrm{CO}_{2}$ mass as secondary carbonates (Figure 1) to the solid matrix decreases porosity, and a small porosity decrease can result in a significant decrease in permeability. The mass-transfer pattern of aqueous chemical components under high $\mathrm{CO}_{2}$ pressure conditions is different from that under natural conditions-most $\mathrm{CO}_{2}$ sequestration occurs in the sandstone. Simulation results of mineral alteration under natural conditions agree well with field observations. The limited information currently available for the mineralogy of high-pressure $\mathrm{CO}_{2}$ reservoirs is also generally consistent with our simulation. More details are given in Xu et al. (2003a, b, c).

\section{RELATED PUBLICATIONS}

$\mathrm{Xu}, \mathrm{T}, \mathrm{J}$. A. Apps, and K. Pruess, Numerical simulation to study mineral trapping for $\mathrm{CO}_{2}$ disposal in deep aquifers. Applied Geochemistry, 2003 (in press).

$\mathrm{Xu}, \mathrm{T}$, J.A. Apps, and K. Pruess, Reactive geochemical transport simulation to study mineral trapping for $\mathrm{CO}_{2}$ disposal in deep arenaceous formations. Journal of Geophysical Research, 108 (B2), 2071, doi:10.1029/ 2002JB001979, 2003.

$\mathrm{Xu}, \mathrm{T}, \mathrm{J} . \mathrm{A}$. Apps, and K. Pruess, Mass transfer, mineral alteration, and $\mathrm{CO}_{2}$ sequestration in a sandstone-shale system. Chemical Geology, 2003 (submitted).

\section{ACKNOWLEDGMENTS}

This work was supported by the Director, Office of Science, Office of Basic Energy Sciences, of the U.S. Department of Energy under Contract No. DE-AC03-76SF00098.

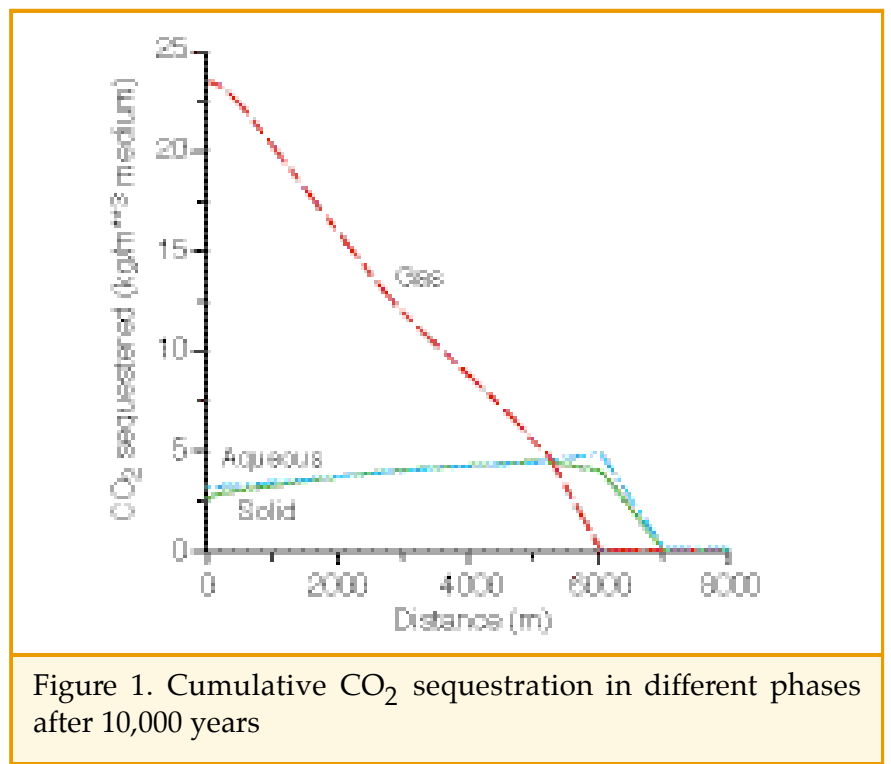

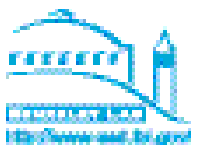





\section{Earth Sciences Division Publications 2002-2003}

Abuladze, M.K., N.V. Asatiani, N.G. Bakradze, T.M. Kartvelishvili, H.-Y.N Holman, T.L. Kalabegishvili, L.M. Mosulishvili, A.N. Rcheulishvili, N.A. Sapojnikova, and N.Y. Tsibakhashvili, Effect of chromium action on the protein composition of $A$. oxydans. Fresenius Environmental Bulletin, 11(9A), 562-567, 2002. Berkeley Lab Report LBNL50929.

Aciego, S., B.M. Kennedy, D.J. DePaolo, J.N. Christensen, and I. Hutcheon, U-Th/He age of phenocrystic garnet from the 79 A.D. eruption of Mt. Vesuvius. Earth and Planetary Science Letters (in press), 2003. Berkeley Lab Report LBNL-53622.

Ádámkovics, M., and K.A. Boering, Photochemical formation rates of organic aerosols through time-resolved in situ laboratory measurements. Berkeley Lab Report LBNL-51908, 2002.

Agron, P.G., M. Macht, L. Radnedge, E.W. Skowronski, W. Miller, and G.L. Andersen, Use of subtractive hybridization to survey comprehensively prokaryotic genome differences. Fems Microbiology Reviews, 211(2), 175-182, 2002.

Agron, P.G., P. Sobecky, and G.L. Andersen, Establishment of uncharacterized plasmids in Escherichia coli by in vitro transposition. Fems Microbiology Letters, 217(2), 249-254, 2002.

Ahlers, C. F., T. Ghezzehei, and S. Finsterle, Development and testing of a method for efficient simulation of evaporation from a seepage face. In: Proceedings of the TOUGH Symposium 2003, On CD, Berkeley, California, May 12-14, 2003. Berkeley Lab Report LBNL-52502.

Ahlers, C.F., R.C. Trautz, P.J. Cook and S. Finsterle, Testing and modeling of seepage into underground openings in a heterogeneous fracture system at Yucca Mountain, Nevada. In: Proceedings of the International Groundwater Symposium: Bridging the Gap between Measurement and Modeling in Heterogeneous Media, pp. 563-567, Berkeley, California, March 25-28, 2002. Berkeley Lab Report LBNL-48911.

Ajo-Franklin, J.B., J.T. Geller, E.L. Majer, J.E. Peterson, K.H. Williams, and J.M. Harris, Preliminary characterization of a NAPL-contaminated site using borehole geophysical techniques. In: 2003 SAGEEP Proceedings. EEGS, pp. 202-220, San Antonio, Texas, April 6-10, 2003. Berkeley Lab Report LBNL-50689.

Arehart, G.B., A.M. Chakurian, D.R. Tretbar, J.N. Christensen, B.A. McInnes, and R.A. Donelick, Review of radioisotope dating of Carlin-type deposits in the Great Basin, western North America and implications for deposit genesis. Economic Geology, 98, 235-248, 2003. Berkeley Lab Report LBNL-51210.
Asner, G.P., A.R. Townsend, W.J. Riley, J.C. Neff, P.A. Matson, and C.C. Cleveland, Physical and biogeochemical controls over terrestrial ecosystem responses to nitrogen deposition. Biogeochemistry, 54, 1-39, 2002. Berkeley Lab Report LBNL48494.

Bakradze, N., V. Sokhadze, M. Abuladze, N.V. Asatiani, N.A. Sapojnikova, T.L. Kartvelishvili, N.Y. Tsibakhashvili, E. Namchevadze, L. Tabatadze, L. Lejava, and H.-Y.N. Holman, A caloriemetric characterization of $\mathrm{Cr}(\mathrm{VI})$-reducing Arthro bacter oxydans at different phases of cell growth cycle. The Scientific World Journal, 3, 432-442, 2003. Berkeley Lab Report LBNL-53388.

Balser, T.C., J.W. Kirchner, and M.K. Firestone, Methodological variability in microbial community level physiological profiles. Soil Science Society of America Journal, 66(2), 519-523, 2002.

Barenblatt, G.I., T.W. Patzek, and D.B. Silin, The mathematical model of non-equilibrium effects in water-oil displacement. In: Proceedings of the SPE/DOE 13th Symposium on Improved Oil Recovery, On CD, Tulsa, Oklahoma, April 13-17, 2002. Berkeley Lab Report LBNL-49484.

Barenblatt, G.I., T. W. Patzek, V. M. Prostokishin and D. B. Silin, Oil deposits in diatomites: A new challenge for subterranean mechanics. In: Proceedings of the SPE/DOE 13th Symposium on Improved Oil Recovery, On CD, Tulsa, Oklahoma, April 13-17, 2002. Berkeley Lab Report LBNL-49509.

Baxter, E., and D.J. DePaolo, Field measurement of high temperature bulk reaction rates I: Theory and technique. American Journal of Science, 302, 442-464, 2002.

Baxter, E., and D.J. DePaolo, Field measurement of high- temperature bulk reaction rates II: Interpretation of results from a field site near Simplon Pass, Switzerland. American Journal of Science, 302, 465-515, 2002.

Baxter, E, and D.J. DePaolo, Can metamorphic reaction rates proceed faster than bulk strain? Contributions to Mineralogy and Petrology (in press), 2003.

Benson, S., R. Hepple, J. Apps, C.F. Tsang, and M. Lippmann, Comparative evaluation of risk assessment, management and mitigation approaches for deep geological storage of $\mathrm{CO}_{2}$. Berkeley Lab Report LBNL-51170, 2002.

Bessinger, B., N.G.W. Cook, L. Myer, S. Nakagawa, K. Nihei, P. Benito, and R. Suarez-Rivera, The role of compressive stresses in jointing on Vancouver Island, British Columbia. Journal of Structural Geology, 25(6), 983-1000, 2002. Berkeley Lab Report LBNL-51104. 
Bhatt, D., J. Newman, and C.J. Radke, Molecular simulations of disjoining-pressure isotherms for free liquid, Lennard-Jones thin films. Journal of Physical Chemistry B, 106(25), 6529-6537, 2002.

Bhupathiraju, V. K., P. Krauter, H.-Y.N. Holman, M.E. Conrad, P.F. Daley, A.S. Templeton, J.R. Hunt, M. Hernandez, and L. Alvarez-Cohen, Assessment of in-situ bioremediation at a refinery waste-contaminated site and an aviation gasoline contaminated site. Biodegradation, 13(2), 79-90, 2002. Berkeley Lab Report LBNL-50048.

Billesbach, D.P., M.L. Fischer, M.S. Torn, and J.A. Berry, A portable eddy covariance system for the measurement of ecosystem-atmosphere exchange of $\mathrm{CO}_{2}$, water vapor, and energy. The Journal of Atmospheric and Oceanic Technology (in press), 2003. Berkeley Lab Report LBNL48953.

Bird, J.A., C. van Kessel, and W.R. Horwath, Stabilization of ${ }^{13} \mathrm{C}$-carbon and immobilization of ${ }^{15} \mathrm{~N}$-nitrogen from rice straw in humic fractions. Soil Science Society of America Journal, 67, 2003.

Birkholzer, J., Penetration of liquid fingers into superheated fractured rock. Water Resources Research, 39(4), 9-1 to 9-21, 2003. Berkeley Lab Report LBNL-50042.

Birkholzer, J.T., Abstraction of drift seepage. MDL-NBS-HS000019REV00, BSC, Las Vegas, Nevada, 2003. Berkeley Lab Report LBID-2475.

Birkholzer, J.T., TH_PULSE: Program for calculating infiltration of episodic liquid fingers in superheated rock fracturesTheory, user's manual and sample applications. Berkeley Lab Report LBNL/ PUB-3277, 2002.

Birkholzer, J., and C.K. Ho, A probabilistic analysis of episodic preferential flow into superheated fractured rock. Journal of Hydrology (in press), 2003. Berkeley Lab Report LBNL-51893.

Birkholzer, J., S. Mukhopadhyay, and Y. Tsang, Analysis of the vaporization barrier above waste emplacement drifts. In: Proceedings of the Tenth International High-Level Radioactive Waste Management Conference, On CD, Las Vegas, Nevada, March 30-April 3, 2003. Berkeley Lab Report LBNL-51539.

Birkholzer, J.T., S. Mukhopadhyay, and Y. Tsang, Modeling water seepage into heated waste emplacement drifts at Yucca Mountain. In: Proceedings of the TOUGH Symposium 2003, On CD, Berkeley, California, May 12-14, 2003. Berkeley Lab Report LBNL-52500.
Birkholzer, J.T., S. Mukhopadhyay, and Y. Tsang, Drift-scale coupled processes (DST and TH seepage) models. MDL-NBS-HS000015 REV00, BSC, Las Vegas, Nevada, 2003. Berkeley Lab Report LBID-2469.

Bishop, J. K. B., R.E. Davis, and J.T. Sherman, Robotic observations of dust storm enhancement of carbon biomass in the North Pacific. Science, 298(5594), 817-821, 2002. Berkeley Lab Report LBNL-50120.

Bishop, J.K.B., T.J. Wood, and J.T. Sherman, Carbon Explorer assessment of carbon biomass variability and carbon flux systematics in the upper ocean during SOFeX. EOS Transactions of the American Geophysical Union, 83(47), F799, 2002.

Bodvarsson, G.S., J.T. Birkholzer, S. Finsterle, H.H. Liu, J. Rutqvist, and Y.-S. Wu, The use of TOUGH2/ITOUGH2 in support of the Yucca Mountain Project: Successes and limitations. In: Proceedings of the TOUGH Symposium 2003, On CD, Berkeley, California, May 12-14, 2003. Berkeley Lab Report LBNL-52594.

Bodvarsson, G., C. Ho, and B. Robinson, Preface for a special issue of the Journal of Contaminant Hydrology. Journal of Contaminant Hydrology, 62-63, 1-2, 2003. Berkeley Lab Report LBNL-42846.

Bodvarsson, G.S., E. Kwicklis, C. Shan, and Y.-S. Wu, Estimation of percolation flux from borehole temperature data at Yucca Mountain, Nevada. Journal of Contaminant Hydrology, 62-63, 3-22, 2003. Berkeley Lab Report LBNL-41866.

Bodvarsson, G.S., Y.-S. Wu, and K. Zhang, Development of the discrete flow paths in unsaturated fractures at Yucca Mountain, Nevada. Journal of Contaminant Hydrology, 62-63, 23-42, 2003. Berkeley Lab Report LBNL-49863.

Borglin, S., T. Hazen, C. Oldenburg, and P. Zawislanski, Comparison of aerobic and anaerobic biotreatment of municipal solid waste. Journal of the Air and Waste Management Association, June 2003 (submitted). Berkeley Lab Report LBNL-50576, 2002.

Bowling, L. C., D.P. Lettemaier, B. Nijssen, L. P. Graham, D.B. Clark, M. El Maayar, R. Essery, S. Goers, F. Habets, B. van den Hurk, J. Jin, D. Kahan, D. Lohmann, S. Mahanama, D. Mocko, O. Nasonova, P. Samuelsson, A.B. Shmakin, K. Takata, D. Verseghy, P. Viterbo, Y. Xia, X. Ma, Y. Xue, and Z.-L. Yang, Simulation of high latitude hydrological processes in the Torne-Kalix basin: PILPS Phase 2e 1: Experiment description and summary intercomparisons. Global and Planetary Change, 38, 1-30, 2003.Brekke, L.D., N.L. Miller, K.E. Bashford, 
N.W.T. Quinn, and J.A. Dracup, Climate change uncertainty impacts for the San Joaquin River Basin water resources. Journal of American Water Resources Association (in press), 2003. Berkeley Lab Report LBNL-51393.

Brink, J.L., T.W. Patzek, D.B. Silin, and E.J. Fielding, Lost Hills field trial-Incorporating new technology for reservoir management. SPE77646. In: Proceedings of SPE Annual Technical Conference and Exhibition, San Antonio Texas, 9/29-10/2, 2002, On CD, 2002. Berkeley Lab Report LBNL-50562.

Brumbaugh, T., C. Williams, M. Alemi, and N.W.T. Quinn, A conceptual salt budget for characteristic water districts in the western San Joaquin Valley. In: Proceedings of the 2002 USCID/EWRI Conference: Energy, Climate, Environment and Water, pp. 23-34, San Luis Obispo, California, July 9-12, 2002.

Byun, J., J.W. Rector, and T. Nemeth, Postmap migration of crosswell reflection seismic data. Geophysics, 67(1), 135-146, 2002.

Campbell, C.G., and F. Garrido, Spatial and temporal variability of soil processes: Implications for methods selection and characterization studies. In: Soil-Water Solute Process Characterization: An Integrated Approach, J. AlvarezBenedi and R. Munoz-Carpena, eds., CRC Press (in press), Boca Raton, Florida, USA, 2003. Berkeley Lab Report LBNL53569.

Campbell, C.G., F. Garrido, and M. Ghodrati, Leaf litter and solute transport in a woodland hillslope soil. Soil Science (in press), 2003. Berkeley Lab Report LBNL-52522, 2003.

Campbell, J., D. Antoine, R. Armstrong, K. Arrigo, W. Balch, R. Barber, M. Behrenfeld, R. Bidigare, J. Bishop, M.-E. Carr, W. Esaias, P. Falkowski, N. Hoepffner, R. Iverson, D. Kiefer, S. Lohrenz, J. Marra, A. Morel, J. Ryan, V. Vedernikov, K. Waters, C. Yentsch, and J. Yoder, Comparison of algorithms for estimating ocean primary production from surface chlorophyll, temperature and irradiance. Global Biogeochemical Cycles, 16(3), 10.1029, 2002. Berkeley Lab Report LBNL-48412.

Cappa, C.D., M.B. Hendricks, D.J. DePaolo, and R.C. Cohen, Isotopic fractionation of water during evaporation. Journal of Geophysical Research, 108, 4525, 2003. Berkeley Lab Report LBNL-54025.

Casadei, M., W.E. Dietrich, and N.L. Miller, Testing a model for predicting the timing and location of debris flow initiation in soil mantled landscape. Earth Surface Processes (in press), 2003. Berkeley Lab Report LBNL-51314.
Cascão-Pereira, L.G., A. Hickel, C.J. Radke, and H.W. Blanch, Interfacial reaction versus mass transfer limited enzymatic cleavage of mandelonitrile by hydroxynitrile lyase in a biphasic system. Biotechnology and Bioengineering, 83(4), 498-501, 2003.

Cascão Pereira, L.G., O. Theodoly, H.W. Blanch, and C J. Radke, Dilatational rheology of BSA conformers at the air/water interface. Langmuir, 19, 2349-2356, 2003.

Chang, L.-Y., A. Proctor, and W.T. Stringfellow, Kinetic parameters for the biological treatment of mixed wastes containing acetonitrile and methanol. Berkeley Lab Formal Report LBID2433, 2002.

Chen, J., S. Hubbard, Y. Rubin, C. Murray, E. Roden, and E. Majer, Geochemical characterization using geophysical data: A case study at the South Oyster Bacterial Transport Site in Virginia. Water Resources Research, DOI: 10.1029, 2003. Berkeley Lab Report LBNL-51980, 2003.

Chen, J., and Y. Rubin, An effective Bayesian model for lithofacies estimation using geophysical data. Water Resources Research, 39(5), 1118, 2002. Berkeley Lab Report LBNL52817.

Christenson, B.W., E.K. Mroczek, B.M. Kennedy, T. van Soest, M.K. Steward, and G. Lyon, Ohaaki reservoir chemistry: Characteristics of an arc-type hydrothermal system in the Taupo Volcanic Zone, New Zealand. Journal of Volcanology \& Geothermal Research, 115(1-2), 53-82, 2002. Berkeley Lab Report LBNL-48570.

Conrad, M.E., and D.J. DePaolo, Carbon isotopic evidence for biodegradation of organic contaminants in the shallow vadose zone of the Radioactive Waste Management Complex. The Vadose Zone Journal (in press), 2003. Berkeley Lab Report LBNL-53748.

Constantz, J., M.H. Cox, and G.W. Su, Comparison of heat and bromide as tracers of stream exchanges with shallow ground water along the Santa Clara River, California. Ground Water, 41(5), 647-656, 2003. Berkeley Lab Report LBNL-52974.

Cook, P.J., R. Salve, B.M. Freifeld, and Y.T. Tsang, A measurement system for systematic hydrological characterization of unsaturated fractured welded tuff in a mined underground tunnel. Ground Water, 41(4), 449-457, 2003. Berkeley Lab Report LBNL-48163.

Daley, T., R. Gritto, E. Majer, and P. West, Tube-wave suppression in single-well seismic acquisition. Geophysics, 68(3), 863-869, 2002. Berkeley Lab Report LBNL-49769. 
Daley, T.M., R. Gritto, and E.L. Majer, Single-well seismic imaging of a gas-filled hydrofracture. Berkeley Lab Report LBNL-53601, 2003.

Daley, T.M., E.L. Majer, and J.E. Peterson, Crosswell seismic imaging in a contaminated basalt aquifer. Geophysics (in press), 2003. Berkeley Lab Report LBNL-45533.

Daley, T.M., K. Nihei, L.R. Myer, E.L. Majer, J.H. Queen, M. Fortuna, J. Murphy, and R.T. Coates, Numerical modeling of scattering from discrete fracture zones in a San Juan Basin gas reservoir. In: Proceedings of the SEG International Exposition and 77nd Annual Meeting, pp. 1-4, Salt Lake City, Utah, October 6-11, 2002. Berkeley Lab Report LBNL53754 .

Das, K., A. Becker, and K.H. Lee, Experimental validation of the wavefield transformation of electromagnetic data. Geophysical Prospecting, 50, 441-451, 2002. Berkeley Lab Report LBNL47466.

DePaolo, D.J., M.E. Conrad, K. Maher, and G.W. Gee, Evaporation effects on $\mathrm{O}$ and $\mathrm{H}$ isotopes in deep vadose zone pore fluids at Hanford, Washington: Implications for recharge and horizontal fluid movement. Vadose Zone Journal (in press), 2003.

DePaolo, D.J., and M. Manga, Deep origin of hotspots-The mantle plume model. Science, 300(5621), 920-921, 2003. Berkeley Lab Report LBNL-54017.

DeSantis, T.Z., I. Dubosarskiy, and G.L. Andersen, Comprehensive aligned sequence construction for automated design of effective probes (CASCADE-P) using $16 \mathrm{~S}$ rDNA. Bioinformatics, 19, 2003. Berkeley Lab Report LBNL-52352.

Dobson, P.F., T.J. Kneafsey, J. Hulen, and A. Simmons, Porosity, permeability, and fluid flow in the Yellowstone geothermal system, Wyoming. Journal of Volcanology and Geothermal Research, 123(3-4), 313-324, 2003. Berkeley Lab Report LBNL-50044.

Dobson, P.F., T.J. Kneafsey, E.L. Sonnenthal, N. Spycher, and J. Apps, Experimental and numerical simulation of dissolution and precipitation: Implications for fracture sealing at Yucca Mountain, Nevada. Journal of Contaminant Hydrology, 62-63, 459-476, 2003. Berkeley Lab Report LBNL-48872.

Dobson, P., L. Pan, and R. Hedegaard, Development of numerical grids for UZ flow and transport modeling, ANL-NBSHS-000015 REV01, BSC, Las Vegas, Nevada, 2003. Berkeley Lab Report LBID-2468.
Dobson, P., S. Salah, N. Spycher, and E. Sonnenthal, Simulation of water-rock interaction in the Yellowstone Geothermal System using TOUGHREACT. In: Proceedings of the TOUGH Symposium 2003, On CD, Berkeley, California, May 12-14, 2003. Berkeley Lab Report LBNL-52550.

Doughty, C., S.M. Benson, and K. Pruess, Capacity investigation of brine-bearing sands for geologic sequestration of $\mathrm{CO}_{2}$. Presented at GHGT-6, Kyoto, Japan, 2002. Berkeley Lab Report LBNL-51333.

Doughty, C., and K. Karasaki, Flow and transport in hierarchically fractured rock. Journal of Hydrology, 263(1-4), 1-22, 2002. Berkeley Lab Report LBNL-47030.

Doughty, C., and K. Karasaki, Modeling flow and transport in saturated fractured rock to evaluate site characterization needs. IAHR Journal of Hydraulics (in press), 2003. Berkeley Lab Report LBNL-49045.

Doughty, C., and K. Karasaki, Constraining hydrologic models using thermal analysis. In: Proceedings of the Rock Mech. Symp., Japan Society of Civil Engineers, Tokyo, Japan, January 23-24, 2003. Berkeley Lab Report LBNL-53828.

Doughty, C., and K. Karasaki, Evaluation of uncertainties due to hydrogeological modeling and groundwater flow analysis: Steady flow, transient flow, and thermal studies. Berkeley Lab Report LBNL-51894, 2002.

Doughty, C., and K. Pruess, Modeling supercritical $\mathrm{CO}_{2}$ injection in heterogneous porous media. In: Proceedings of the TOUGH Symposium 2003, On CD, Berkeley, California, May 12-14, 2003. Berkeley Lab Report LBNL-52527.

Doughty, C., R. Salve, and J.S.Y. Wang, Liquid-release tests in unsaturated fractured welded tuffs: II. Numerical modeling. Journal of Hydrology, 256(1-2), 80-105, 2002. Berkeley Lab Report LBNL-47530.

Doughty, C. and C.-F. Tsang, Signatures in flowing wellbore electrical-conductivity logs. Berkeley Lab Report LBNL-53011, 2003.0

Doughty, C. and C.-F. Tsang, Inflow and outflow signatures in flowing wellbore electrical conductivity logs. Berkeley Lab Report LBNL-51468, 2002.

Downing, J.B., E. Bracco, F.B. Green, A.Y. Ku, T.J. Lundquist, I.X. Zubieta, and W.J. Oswald, Low cost wastewater reclamation using the advanced integrated wastewater pond system technology and reverse osmosis. Water Science and Technology, 45(1), 117-125, 2002. 
Engelhardt, I., and S. Finsterle, Thermal-hydrologic experiments with backfill material and estimation of effective parameters by inverse modeling. Applied Clay Science, 23, 111-120, 2003. Berkeley Lab Report LBNL-52837.

Engelhardt, I., S. Finsterle, and C. Hofstee, Experimental and numerical investigation of flow phenomena in nonisothermal, variably saturated bentonite/crushed rock mixtures. Vadose Zone Journal, 2, 239-246, 2003. Berkeley Lab Report LBNL-52838.

Evans, W.C., R.H. Mariner, S.E. Ingebritsen, M.C. van Soest, B.M. Kennedy, and M.A. Huebner, Report of hydrologic investigations in the Three Sisters area of central Oregon, Summer 2001. Berkeley Lab Report LBNL-50649, 2002.

Faybishenko, B., Chaotic dynamics in flow through unsaturated fractured media. Advances in Water Resources, 25(7), 793-816, 2002. Berkeley Lab Report LBNL-46958.

Faybishenko, B., Introduction to modeling of hydrogeologic systems using fuzzy differential equations. In: Fuzzy Partial Differential Equations and Relational Equations, M. Nikravesh, L.A. Zadeh, and V. Korotkikh, eds. (in press), Physica-Verlag, Springer, in the series "Studies in Fuzziness and Soft Computing," 2003. Berkeley Lab Report LBNL52170.

Faybishenko, B., Nonlinear dynamics in flow through unsaturated fractured-porous media: Status and perspectives. Reviews of Geophysics (in press), 2003. Berkeley Lab Report LBNL-51779, 2002.

Faybishenko, B., G.S. Bodvarsson, J. Hinds, and P.A. Witherspoon, Scaling and hierarchy of models for flow processes in unsaturated fractured rock. In: Scaling Methods in Soil Physics, Y.A. Pachepsky et al, ed., CRC Press, pp. 373-417, 2003. Berkeley Lab Report LBNL-51543.

Faybishenko, B., G.S. Bodvarsson, and R. Salve, On the physics of unstable infiltration, seepage, and gravity drainage in partially saturated tuffs. Journal of Contaminant Hydrology, 62-63, 63-87, 2003. Berkeley Lab Report LBNL-49864.

Feineman, M., and D.J. DePaolo, Steady-state ${ }^{226} \mathrm{Ra} /{ }^{230} \mathrm{Th}$ disequilibrium in mantle minerals: Implications for melt transport rates in Island Arcs. Earth Planet. Sci. Lett. 215(3-4), 339-355, 2003.

Finsterle, S., C.F. Ahlers, R.C. Trautz, and P.J. Cook, Inverse and predictive modeling of seepage into underground openings. Journal of Contaminant Hydrology, 62-63, 89-109, 2003. Berkeley Lab Report LBNL-48914.
Finsterle, S., J.T. Fabryka-Martin, and J.S.Y. Wang, Migration of a water pulse through fractured porous media. Journal of Contaminant Hydrology, 54(1-2), 37-57, 2002. Berkeley Lab Report LBNL-46747.

Finsterle, S., T. Ghezzehei, R.C. Trautz, and P. Cook, Seepage calibration model and seepage testing data. MDL-NBS-HS000004 REV02, BSC, Las Vegas, Nevada, 2003. Berkeley Lab Report LBID-2470.

Finsterle, S., G.J. Moridis, C.M. Oldenburg, and Y.-S. Wu, Proceedings of the TOUGH Symposium 2003, On CD, Berkeley, California, May 12-14, 2003. Berkeley Lab Report LBNL-52494.

Flay, R.B. and T.N. Narasimhan, Managing groundwater quality and quantity in the San Joaquin Valley, California: Integrated strategies for protecting groundwater in arid regions. M.S. Thesis, University of California, at Berkeley, 2002. Berkeley Lab Report LBNL-51655.

Flint, A., L. Flint, E. Kwicklis, G.S. Bodvarsson, and J. FabrykaMartin, Estimating recharge at Yucca Mountain, Nevada: A case study. Hydrology Journal, 10, 180-204, 2002. Berkeley Lab Report LBNL-50724.

Frangos, W., A. Becker, and K.H. Lee, High-frequency and very-highfrequency above-ground electromagnetic impedance measurements. Berkeley Lab Report LBNL-51672, 2002.

Freer, E.M., T. Svitova, and C.J. Radke, The role of interfacial rheology in reservoir mixed wettability. Journal of Petroleum Science and Engineering, 39(1-2), 137-158, 2003.

Freifeld, B., T. Kneafsey, J. Pruess, P. Reiter, and L. Tomutsa, X-ray scanner for ODP Leg 204: Drilling gas hydrates on Hydrate Ridge, Cascadia Continental Margin. Berkeley Lab Report LBNL-51327, 2002.

Freifeld, B.M., T.J. Kneafsey, L. Tomutsa, L.A. Stern, and S.H. Kirby, Use of x-ray computed tomographic data for analyzing the thermodynamics of a dissociating porous sand/hydrate mixture. In: Proceedings of the Fourth International Conference on Gas Hydrates, Yokohama, Japan, pp. 750-755, May 19-23, 2002. Berkeley Lab Report LBNL-49859.

Freifeld, B.M., T.J. Kneafsey, L. Tomutsa, and J. Pruess, Development of a portable x-ray computed tomographic imaging system for drill-site investigation of recovered core. Proceedings of the 2003 International Symposium of the Society of Core Analysts, Pau, France, September 21-24, 2003. Berkeley Lab Report LBNL-52088. 
Fried, J.S., M.S. Torn, and E. Mills, The impact of climate change on wildfire severity: a regional forecast for Northern California. Climatic Change (in press), 2003. Berkeley Lab Report LBNL-53273.

Garcia, J.E., and K. Pruess, Flow instabilities during injection of $\mathrm{CO}_{2}$ into saline aquifers. In: Proceedings of the TOUGH Symposium 2003, On CD, Berkeley, California, May 12-14, 2003. Berkeley Lab Report LBNL-52717.

Gasperikova, E., N. Cuevas, and H.F. Morrison, Natural fieldinduced polarization for mapping of deep mineral deposits: A case study from Arizona. Berkeley Lab Report LBNL-52485, 2003.

Gasperikova, E., G.M. Hoversten, M.P. Ryan, J.P. Kauahikaua, G.A. Newman, and N. Cuevas, Magnetotelluric investigations of Kilauea Volcano, Hawaii, Part I: Experiment design and data processing. Berkeley Lab Report LBNL-53341 Part II, 2003.

Geller, J.T., J.B. Ajo-Franklin, and E.L. Majer, Effect of immiscible liquid contaminants on $\mathrm{P}$-wave transmission through natural aquifer samples. In Proceedings of the 2003 Symposium on the Application of Geophysics to Engineering and Environmental Problems (SAGEEP), Environmental and Engineering Geophysical Society (EEGS), pp. 1059-1077, San Antonio, Texas, April 6-10, 2003. Berkeley Lab Report LBNL-52131.

Ghezzehei, T.A., R.C. Trautz, and S. Finsterle, Evaluating the effectiveness of liquid diversion around an underground opening when evaporation is non-negligible. In: Proceedings of the TOUGH Symposium 2003, On CD, Berkeley, California, May 12-14, 2003. Berkeley Lab Report LBNL-52499.

Ghezzehei, T.A., and D. Or, Stress-induced shrinkage of isolated pores in a wet soil matrix. Water Resources Research, 39(3), 1067, doi:10.1029/2001WR001137, 2003.

Ghezzehei, T.A., and D. Or, Pore space dynamics in soil aggregate bed under steady external load. Soil Science Society of America Journal, 67(1), 12-19, 2003.

Glascoe, L.G., A.J. Olson, G. Lu, M.A. McGraw, P.C. Lichtner, and A.V. Wolfsberg, Radionuclide transport from an underground nuclear test in the presence of residual heat and colloids. In: Proceedings of the XIII International Conference on Computational Methods of Water Research. Calgary, Canada, pp. 357-364, 2002.

Glassley, W.E., A. Simmons, and J.R. Kercher, Small-scale porosity and minerological heterogeneity effects on reactive transport models. Applied Geochemistry, 17, 699-708, 2002. Berkeley Lab Report LBNL-46487.
Goloshubin, G.M., V.A. Korneev, and V.M. Vingalov, Seismic lowfrequency effects from oil-saturated reservoir zones. In: Proceedings of SEG International Exposition and Annual Meeting. Salt Lake City, Utah, pp. 1813-1816, October 6-11, 2002. Berkeley Lab Report LBNL-50638.

Green, F.B., T.J. Lundquist, N.W.T. Quinn, M.A. Zarate, I.X. Zubieta, and W.J. Oswald, Selenium and nitrate removal from agricultural drainage using the AIWPS $^{\circledR}$ technology. Fifth International Water Association Specialist Conference on Waste Stabilization Ponds, Pond Technology for the New Millennium, Auckland, New Zealand, April 2-5, 2002. Water Science and Technology (in press), 2002.

Gritto, R., Subsurface void detection using seismic tomographic imaging. In: Proceedings of the Conference on Geophysical Technologies for Detecting Underground Coal Mine Voids, Lexington, Kentucky, July 28-30, 2003. Berkeley Lab Report LBNL-53227.

Gritto, R., T.M. Daley, and E.L. Majer, Integrated seismic studies at the Rye Patch Geothermal Reservoir, Nevada. In: Proceedings of the GRC Annual Meeting, Reno, Nevada, 2002. Berkeley Lab Report LBNL-50590.

Gritto, R., T.M. Daley, and E.L. Majer, Estimating subsurface topography from surface-to-borehole seismic studies at the Rye Patch Geothermal Reservoir. Geothermics, 32(3), 275-295, 2003. Berkeley Lab Report LBNL-50490.

Gritto, R., T.M. Daley, and L.R. Myer, Joint cross well and single well seismic studies at Lost Hills, California. Geophysical Prospecting (in press), 2003. Berkeley Lab Report LBNL-50651, 2002.

Gritto, R., T.M. Daley, and L.R. Myer, Imaging of $\mathrm{CO}_{2}$ injection during an enhanced-oil-recovery experiment. Underground Injection Science and Technology Symposium, Berkeley, California, October 22-25, 2003. Berkeley Lab Report LBNL52626.

Gritto, R., V.A. Korneev, T.M. Daley, M.A. Feighner, E.L. Majer, and J.E. Peterson, Surface-to-tunnel seismic tomography studies at Yucca Mountain, Nevada. Journal of Geophysical Research (in press), 2003. Berkeley Lab Report LBNL-50470, 2002.

Gritto, R., and E.L. Majer, Seismic methods for resource exploration in enhanced geothermal systems. Geothermal Resources Council Trans., 27, 2003. Berkeley Lab Report LBNL-52967.

Gritto, R., A.E. Romero, and T.M. Daley, VSP analysis at Long Valley Caldera, California. Geophysical Research Letters (submitted), 2003. Berkeley Lab Report LBNL-52488, 2003.. 
Grote, K., S. Hubbard, and Y. Rubin, Field-scale estimation of volumetric water content using GPR groundwave techniques. Water Resources Research, 39 (11), 1321, 2003. Berkeley Lab Report LBNL-50347.

Grote, K., S. Hubbard, and Y. Rubin, GPR monitoring of volumetric water content in soils applied to highway construction and maintenance. The Leading Edge of Exploration, 21(5), 482-485, 2002. Berkeley Lab Report LBNL-49383.

Guay, C. K., and J.K.B. Bishop, A rapid birefringence method for measuring suspended $\mathrm{CaCO}_{3}$ concentrations in seawater. Deep-Sea Research, 49, 197-210, 2002. Berkeley Lab Report LBNL-46895.

Haukwa, C. B., Y.W. Tsang, Y.-S. Wu, and G.S. Bodvarsson, Effect of heterogeneity in fracture permeability on the potential for liquid seepage into a heated emplacement drift of the potential repository. Journal of Contaminant Hydrology, 62-63, 509-527, 2003. Berkeley Lab Report LBNL-51355.

Haukwa, C.B., Y.-S. Wu, and G.S. Bodvarsson, Modeling thermalhydrological response of the unsaturated zone at Yucca Mountain, Nevada, to thermal load at a potential repository. Journal of Contaminant Hydrology, 62-63, 529-552, 2003. Berkeley Lab Report LBNL-49950.

Hazen, T., SCFA lead lab technical assistance at Lawrence Berkeley National Laboratory: Baseline review of three groundwater plumes. Berkeley Lab Report LBNL-51386, 2002.

Hazen, T., Technical assistance to Ohio closure sites: Technologies to address elachate from the on-site disposal facility at Fernald Environmental Management Project, Ohio. Berkeley Lab Report LBNL-51387, 2002.

Hazen, T., SCFA lead lab technical assistance at Oak Ridge Y-12 national security complex: Evaluation of treatment and characterization alternatives of mixed waste soil and debris at disposal area remedial action (DARA) solids storage facility (SSF). Berkeley Lab Report LBNL-51389, 2002.

Hazen, T., Technical assistance to Ohio closure sites: Recommendations to address contaminated soils, concrete, and corrective action management unit/groundwater contamination at Ashtabula, Ohio. Berkeley Lab Report LBNL-51388, 2002.

Hazen, T.C., A. Tien, A. Worsztynowicz, D.J. Altman, K. Ulfig, and T. Manko, Biopiles for remediation of petroleum-contaminated soils: A Polish case study. In: Proceedings of the NATO Advanced Research Workshop on the Utilization of Bioremediation to Reduce Soil Contamination: Problems and Solutions. Prague, Czech Republic, 19, pp. 229-246, 2003. Berkeley Lab Report LBNL-46445.
Hepple, R.P. and S.M. Benson, Geologic storage of carbon dioxide as a climate change mitigation strategy: Performance requirements and the implications of surface seepage. Berkeley Lab Report LBNL-51267, 2002.

Hickman, R.G., P.F. Dobson, M. van Gerven, B. Sagala, and R.P. Gunderson, Tectonic and stratigraphic evolution of the Sarulla Graben region, North Sumatra, Indonesia. Journal of Asian Earth Sciences (in press), 2003. Berkeley Lab Report LBNL51196.

Hidalgo, H.G., L.D. Brekke, N.L. Miller, N.W.T. Quinn, J. Keyantash, and J.A.Dracup, Assessment of the impacts of climate change on the water allocation, water quality and salmon production in the San Joaquin River Basin. In: Climate Change and Variability: Consequences and Responses, Matthias Ruth, Kieran Donaghy, and Paul Kirshen, eds. (in press), 2003.

Hinds, J., G.S. Bodvarsson, and G. Nieder-Westermann, Conceptual evaluation of the potential role of fractures in unsaturated processes at Yucca Mountain. Journal of Contaminant Hydrology, 62-63, 111-132, 2003. Berkeley Lab Report LBNL-48950.

Hoch, G., A. Chauhan, and C. J. Radke, Permeability and diffusivity for water transport through hydrogel membranes. J. Membrane Sci., 214(2), 199-209, 2003.

Holman, H.-Y., K. Bjornstad, M.P. McNamara, M.C. Martin, W.R. McKinney, and E.A. Blakely, Synchrotron infrared spectromicroscopy as a novel bioanalytical microprobe for individual living cells: Cytotoxicity considerations. Journal of Biomedical Optics, 7(3), 417-424, 2002. Berkeley Lab Report LBNL-50240.

Holman, H.Y.N., R. Goth-Goldstein, D. Aston, M. Yun, and J. Kengsoontra, Evaluation of gastrointestinal solubilization of petroleum hydrocarbon residues in soil using an in vitro physiologically based model. Environmental Science \& Technology, 36(6), 1281-1286, 2002. Berkeley Lab Report LBNL-48401.

Holman, H.-Y.N., M.C. Martin, and W.R. McKinney, Tracking chemical changes in a live cell: Biomedical applications of SRFTIR spectromicroscopy. In: Proceedings of the First International Conference on Biomedical Spectroscopy: From Molecules to Meneds, Cardiff, Wales, 2002. Berkeley Lab Report LBNL-51337.

Holman, H.-Y.N., M.C. Martin, and W.R. McKinney, Synchrotronbased FTIR spectromicroscopy: Cytotoxicity and heating considerations. Journal of Biological Physics, 2002. Berkeley Lab Report LBNL-51900. 
Holman, H.Y.N., K. Nieman, D.L. Sorensen, C.D. Miller, M.C. Martin, T. Borch, W.R. McKinney, and R.C. Sims, Catalysis of PAH biodegradation by humic acid shown in synchrotron infrared studies. Environmental Science \& Technology, 36(6), 1276-1280, 2002. Berkeley Lab Report LBNL-50239.

Houseworth, J.E., S. Finsterle, and G.S. Bodvarsson, Flow and transport in the drift shadow in a dual-continuum model. Journal of Contaminant Hydrology, 62-63, 133-156, 2003. Berkeley Lab Report LBNL-49868.

Hoversten, G.M., E. Gasperikova, G.A. Newman, J.P. Kauahikaua, M.P. Ryan, and N. Cuevas, Magnetotelluric investigations of Kilauea Volcano, Hawaii. Part II. Numerical modeling and data interpretation. Berkeley Lab Report LBNL-53341, 2003.

Hoversten, G.M., R. Gritto, J. Washbourne, and T. Daley, Pressure and fluid saturation prediction in a multi-component reservoir using combined seismic and electromagnetic imaging. Geophysics 68, 1580-91, 2003. Berkeley Lab Report LBNL-51408.

Hoversten, G.M., P. Milligan, J. Byun, J. Washbourne, L.C. Knauer, and P. Harness, Crosswell electromagnetic and seismic imaging: An examination of coincident surveys at a steam flood project. Geophysics (in press), 2003. Berkeley Lab Report LBNL-48703.

Hovorka, S.D., C. Doughty, S.M. Benson, K. Pruess, and P.R. Knox, Assessment of the impact of geological heterogeneity on $\mathrm{CO}_{2}$ storage in brine formations: A case study from the Texas Gulf Coast. In: Geological Storage for Emissions Reduction: Technology, S.J. Baines, J. Gale, and R.H. Worden, eds., Geological Society (London) Special Publication (in press), 2003. Berkeley Lab Report LBNL-51390.

Hu, M.Q., T.J. Kneafsey, R.C. Trautz, and J.S.Y. Wang, Tracer penetration into welded tuff matrix from the flowing fracture. Vadose Zone Journal, 1 (1), 102-112, 2002. Berkeley Lab Report LBNL-46400.

Hubbard, S., K. Grote, and Y. Rubin, Estimation of near-subsurface water content using surface GPR ground wave data. The Leading Edge of Exploration, 21(6), 482-485, 2002. Berkeley Lab Report LBNL-49386.

Hubbard, S., K. Grote, and Y. Rubin, Mapping the volumetric soil water content of a California vineyard using high-frequency GPR ground wave data. The Leading Edge of Exploration, 21(6), 552-559, 2002. Berkeley Lab Report LBNL-50487.

Hubbard, S., and Y. Rubin, Hydrogeophysics: State of the discipline. EOS, 83(51), 602 and 606, 2002. Berkeley Lab Report LBNL-51326.
Hubbard, S., P. Zhang, P. Monteiro, J. Peterson, and Y. Rubin, Detection of rebar corrosion using nondestructive geophysical techniques. American Concrete International (in press), 2003. Berkeley Lab Report LBNL-48454.

Huisman, J.A., S. Hubbard, J.D. Redman, and A.P. Annan, Measuring soil water content with ground penetrating radar: A review. Vadose Zone Journal (in press), 2003. Berkeley Lab Report LBNL-52357.

Ito, K., and Y. Seol, A three-dimensional discrete fracture network generator to examine fracture-matrix interaction using TOUGH2. In: Proceedings of the TOUGH Symposium 2003, On CD, Berkeley, California, May 12-14, 2003. Berkeley Lab Report LBNL-52465.

Jackson, W.E., G.E. Brown Jr., G.A. Waychunas, M. Yaeger, P. Marburg, and E. Solomon, The coordination environment of $\mathrm{Fe}^{2+}$ in $\mathrm{Na}_{1.5} \mathrm{Ca}_{0.5} \mathrm{Fe}_{0.75} \mathrm{Si}_{3} \mathrm{O}_{8}$ composition glass: An EXAFS, Mossbauer, optical absorption, magnetic circular dichroism, and x-ray scattering study. Geochimica et Cosmochimica (submitted), 2003.

Jellinek, A.M., and D.J. DePaolo, A model for the origin of large silicic magma chambers: Precursors of caldera-forming eruptions. Bulletin of Volcanology, 65(5), 363-381, 2002. Berkeley Lab Report LBNL-54020.

Jin, G., T.W. Patzek, and D.B. Silin, Physics-based reconstruction of sedimentary rocks. In: Proceedings of the SPE Western Regional/AAPG Pacific Section Joint Meeting, Long Beach, California, 2003. Berkeley Lab Report LBNL-52966.

Jin, J., and N.L. Miller, A mesoscale analysis of snowpack on climate variability and snowmelt mechanisms in the Sierra Nevada Region. Presented at the PACLIM Conference, Pacific Grove, California, April 2003; Journal of Climate (in press), 2003.

Jin, J., X. Gao, and S. Sorooshian, Impact of model calibration on high-latitude land-surface processes: PILPS Phase 2e calibration/validation experiments. Global and Planetary Change, 38,73-80, 2003.

Jin, J. and N.L. Miller, An analysis of climate variability in mountainous regions. J. Hydrometeorology. Berkeley Lab Report LNBL-53845, 2003.

Jin, J., N.L. Miller, S. Sorooshian, and X. Gao, Impact of ENSO snowpack in the western U.S.: A GCM study. Presented at the American Meteorological. Society Conference, Long Beach, California, Feb. 2003; Journal of Climate (in press), 2003. 
Johnson, L.R., and R.M. Nadeau, Asperity model of an earthquake-Dynamic problem. Bulletin of the Seismological Society of America, 92(2), 672-686, 2002. Berkeley Lab Report LBNL-52630.

Juanes, R., and T. Patzek, Analytical solution to the Riemann problem of three-phase flow in porous media. Transport in Porous Media (in press), 2003. Berkeley Lab Report LBNL-51558.

Juanes, R., and T. Patzek, Strictly hyperbolic models of co-current three-phase flow with gravity. Berkeley Lab Report LBNL51845, 2002.

Juanes, R., and T.W. Patzek, Relative permeabilities for strictly hyperbolic models of three-phase flow in porous media. Berkeley Lab Report LBNL-51442, 2002.

Juanes, R., and T.W. Patzek, Multi-scale stabilized finite elements for the simulation of tracer injections and waterflood. Berkeley Lab Report LBNL-50383, 2002.

Juanes, R., and T.W. Patzek, Stabilized numerical solutions of three-phase porous media flow using a multiscale finite element formulation. Computer Methods in Applied Mechanics and Engineering (in press), 2003. Berkeley Lab Report LBNL51603.

Juanes, R., and T.W. Patzek, Three-phase displacement theory. Berkeley Lab Report LBNL-50845, 2002.

Juanes, R., J. Samper, and J. Molinero, A general and efficient formulation of fractures and boundary conditions in the finite element method. International Journal for Numerical Methods in Engineering, 54(12), 1751-1774, 2002.

Kahle, M., M. Kleber, M.S. Torn, and R. Jahn, Carbon storage in coarse and fine clay fractions of illitic soils. Soil Science Society of America Journal (in press), 2003. Berkeley Lab Report LBNL-537924.

Kalabegishvili, T.L., N.Y. Tsibakhashvili, and H.-Y.N. Holman, Electron spin resonance (ESR) study of chromium (V) formation and decomposition by basalt-inhabiting bacteria. Environmental Science \& Technology (in press), 2003. Berkeley Lab Report LBNL-53383.

Karasaki, K., Rethinking geothermal energy as a renewable energy source (1). Geothermal Energy, 27(2), 113-119, 2002. Berkeley Lab Report LBNL-51374.

Karasaki, K., Rethinking geothermal energy as a renewable energy source (2). Geothermal Energy, 27(3), 245-251, 2002. Berkeley Lab Report LBNL-51375.
Karraker, K.A., and C.J. Radke, Disjoining pressures, zeta potentials and surface tensions of aqueous non-ionic surfactant/electrolyte solutions: Theory and comparison to experiment. Advances in Colloid and Interface Science, 96(1-3), 231-264, 2002.

Keers, H., L. Johnson, and D. Vasco, Poroelastic waveform inversion of crosswell data. Berkeley Lab Report LBNL-51179, 2002.

Kennedy, B.M., and T. Torgersen, Multiple atmospheric noble gas components in hydrocarbon reservoirs: A study of the northwest shelf, Delaware Basin, SE New Mexico. Geochimica Cosmochimica Acta, 66, 2807-2822, 2002. Berkeley Lab Report LBNL-47387.

Kim, H.J., K.H. Lee, and M. Wilt, Efficient imaging of crosshole electromagnetic data. In: Proceedings of the $6^{\text {th }}$ SEGJ International Symposium-Imaging Technology, pp. 322-327, Tokyo, Japan, January 22-24, 2003. Berkeley Lab Report LBNL-51439.

Kim, H.J., K.H. Lee, and M. Wilt, A fast inversion method for interpreting borehole electromagnetic data. Earth Planets Space, 55, 249-254, 2003. Berkeley Lab Report LBNL-52292.

Kim, H.J., Y. Song, K.H. Lee, and J. Wilt, Efficient crosswell EM tomography using localized nonlinear approximation. Berkeley Lab Report LBNL-53451, 2003.

Kim, J., T.-K. Kim, R.W. Arritt, and N.L. Miller, Impacts of increased $\mathrm{CO}_{2}$ on the hydroclimate of the western United States. Journal of Climate, 15, 1926-1942, 2002. Berkeley Lab Report LBNL-47986.

Kim, J., F.W. Schwartz, J. Shi, and T. Xu, Modeling the coupling between flow and transport developed by chemical reactions and density differences using TOUGHREACT. In: Proceedings of the TOUGH Symposium 2003, On CD, Berkeley, California, May 12-14, 2003. Berkeley Lab Report LBNL-52424.

Kiryukhin, A., Numerical modeling as a tool in understanding TH (thermo-hydrodynamic) processes in geothermal systems (Kamchatka and Kurile islands examples). In: Proceedings of the International Groundwater Symposium, Berkeley, California, 2002. Berkeley Lab Report LBNL-51240.

Kiryukhin, A., T. Xu, K. Pruess, J. Apps and I. Slovtsov, Thermalhydrodynamic-chemical (THC) modeling based on geothermal field data. Geothermics (in press), 2003. Berkeley Lab Report LBNL-51293.

Kneafsey, T.J., and J.R. Hunt, The effect of vertical non-aqueous liquid film spreading in the vadose zone on soil vapor extraction. Journal of Contaminant Hydrology (in press), 2003. Berkeley Lab Report LBNL-46519, 2000. 
Kneafsey, T.J., K. Pruess, M.J. O'Sullivan, and G.S. Bodvarsson, Geothermal reservoir simulation to enhance confidence in predictions for nuclear waste disposal. Berkeley Lab Report LBNL-48124, 2001.

Korneev, V., Tube wave effects in crosswell seismic data. Berkeley Lab Report LBNL-53006, 2003.

Korneev, V.A., R.M. Nadeau, and T.V. McEvilly, Seismological studies at Parkfield IX: Fault zone imaging using guided wave attenuation. Bulletin of Seismological Society of America (in press), 2003. Berkeley Lab Report LBNL-48524, 2001.

Koury, D., A.L. Johnson, D.L. Perry, and J.W. Farley, Investigation of corrosion of steel by lead bismuth eutectic. In: Proceedings of the American Nuclear Society Topical Meeting on Accelerated Applications, 2002.

Kovscek, A.R., and C.J. Radke, Pressure-driven capillary snap-off of gas bubbles at low wetting liquid content. Colloids and Surfaces A: Physicochemical and Engineering Aspects, 212(2-3), 99-108, 2003

Kowalsky, M.B., S. Finsterle, and Y. Rubin, Estimating flow parameter distributions using ground-penetrating radar and hydrological measurements during transient flow in the vadose zone. Advances in Water Resources (in press), 2003. Berkeley Lab Report LBNL-53786, 2003.

Kowalsky, M.B., S. Finsterle, and Y. Rubin, Estimating flow parameters using ground-penetrating radar and hydrological data during transient flow in the vadose zone. In: Proceedings of the TOUGH Symposium 2003, On CD, Berkeley, California, May 12-14, 2003. Berkeley Lab Report LBNL-52504.

Kowalsky, M.B., Y. Rubin, and P. Dietrich, The use of ground-penetrating radar in sediments undergoing transient variably saturated flow. In: Aquifer Characterization Using Sedimentology and Geophysics, SEPM SP 80 (ISBN 1-56576-107-3) (in press), J. Bridge and D. Hyndman, eds., 2003. Berkeley Lab Report LBNL-53790.

Kyriakidis, P.C., A geostatistical solution of the area-to-point spatial interpolation problem. Geographical Analysis (in press), 2003.

Kyriakidis, N.L. Miller, and J. Kim, A spatial time series framework for simulating daily precipitation at regional scales. Journal of Hydrology (in press), 2003. Berkeley Lab Report LBNL-49156.

Lee, E.-S., Y. Seol, Y.C. Fang, and F.W. Schwartz, Destruction eff iciencies and dynamics of reaction fronts associated with the permanganate oxidation of cloroethylene. Environmental Science and Technology, 37(11), 2540-2546, 2003. Berkeley Lab Report LBNL-52163.
Lee, K.H., 3-D full waveform inversion of seismic data: Part I. Theory. Presented at the SEG International Exposition and 72nd Annual Meeting, Dallas, Texas. Berkeley Lab Report LBNL-52665, 2003.

Lee, K.H., and H.J. Kim, Source-independent full waveform inversion of seismic data. Geophysics (in press), 2003. Berkeley Lab Report LBNL-49934.

Lee, K.H., H.J. Kim, and M. Wilt, Efficient imaging of single-hole electromagnetic data. Geothermal Energy-The Baseload Renewable Resource, 26, 399-404, 2002. Berkeley Lab Report LBNL-50010.

Li, G., Tracer mixing at fracture intersections. Environmental Geology, 42, 137-144, 2002. Berkeley Lab Report LBNL-48531.

Li, G., and E.L. Majer, High-resolution crosswell seismic imaging between horizontal wells. CSEG Recorder, 27, 18-22, 2002. Berkeley Lab Report LBNL-51692.

Li, G., and E.L. Majer, Coiled tubing deployment makes crosswell seismic surveying successful in horizontal wells. The Leading Edge, 22(5), 454-458, 2003. Berkeley Lab Report LBNL-53005.

Li, G., and C.-F. Tsang, Seepage into drifts with mechanical degradation. Journal of Contaminant Hydrology, 62-63, 157-172, 2002. Berkeley Lab Report LBNL-49869.

Li, L., I. Yolcubal, S. Snyder, Q. Hu, and M. Brusseau, Biodegradation during contaminant transport in porous media-Apparent condition-dependency of growth-related coefficients. Journal of Contaminant Hydrology, 50(3-4), 209-223, 2002. Berkeley Lab Report LBNL-50300.

Lippmann, M., Electrical systems and geothermal development in the Central American Isthmus. Geothermal Resources Council Trans., 26, 37-42, 2003. Berkeley Lab Report LBNL51844.

Lippmann, M., Geothermal and the electricity market in Central America. Geothermal Resources Council Trans, 26, 37-42, 2002. Berkeley Lab Report LBNL-50931.

Lippmann, M., and S. Benson, Relevance of underground natural gas storage to geologic sequestration of carbon dioxide. In: Proceedings of the Sixth International Conference on Greenhouse Gas Control Technologies (GHGT-6), Kyoto, Japan, 2002. Berkeley Lab Report LBNL-51294.

Lippmann, M., A.H. Truesdell, M.H. Rodríguez, and A. Pérez, Response of Cerro Prieto II and III to exploitation. Geothermics (in press), 2004. Berkeley Lab Report LBNL-51748. 
Liu, H.-H., A constitutive-relationship model for film flow on rough fracture surfaces. Hydrogeology (in press), 2003. Berkeley Lab Report LBNL-51201, 2002.

Liu, H.-H., C.F. Ahlers, S. Mukhopadhyay, R. Hedegaard, J. Houseworth, G. Zhang, and Y.-S. Wu, Analysis of hydrologic properties data. MDL-NBS-HS-000014 REV00, BSC, Las Vegas, Nevada, 2003. Berkeley Lab Report LBID-2471.

Liu, H.-H., C.F. Ahlers, L. Pan, and Y.-S. Wu, Calibrated properties model. MDL-NBS-HS-000003 REV01, BSC, Las Vegas, Nevada, 2003. Berkeley Lab Report LBID-2472.

Liu, H.--H., G. Bodvarsson, and G. Zhang, Scale dependency of the effective matrix diffusion coefficient. Vadose Zone Journal (in press), 2003. Berkeley Lab Report LBNL-52824.

Liu, H.-H., G.S. Bodvarsson, and L. Pan, Reply to Hassan for comments on paper by Liu et al., 2000. Water Resources Research, 38(11), 3-1-3-3, 2003.

Liu, H.-H., and G.S. Bodvarsson, Upscaling of constitutive relations in unsaturated heterogeneous porous media with large air entry values. Journal of Hydrology, 276, 198-209, 2003. Berkeley Lab Report LBNL-47237.

Liu, H.-H., G.S. Bodvarsson, and S. Finsterle, A note on unsaturated flow in two-dimensional fracture networks. Water Resources Research, 38(9), 1176, 2002. Berkeley Lab Report LBNL-48970.

Liu, H.-H., G.S. Bodvarsson, and D. Hudson, Large-scale constitutive relationships for unsaturated flow in fractured rocks. Berkeley Lab Report LBNL-50449, 2002.

Liu, H.-H., G.S. Bodvarsson, S. Lu, and F.J. Molz, A corrected and generalized successive random-additions algorithm for simulating fractional levy motions. Mathematical Geology (in press), 2003. Berkeley Lab Report LBNL-50448.

Liu, H.-H., C.B. Haukwa, C.F. Ahlers, G.S. Bodvarsson, A.L. Flint, and W.B. Guertal, Modeling flow and transport in unsaturated fractured rock: An evaluation of the continuum approach. Journal of Contaminant Hydrology, 62-63, 173-188, 2003. Berkeley Lab Report LBNL-51621.

Liu, H.-H., R. Salve, J.S.Y. Wang, G. Bodvarsson, and D. Hudson, Field investigation into unsaturated flow and transport in a fault: Model analyses. Berkeley Lab Report LBNL-52823, 2003.

Liu, H.-H., G. Zhang, and G. Bodvarsson, The active fracture model: Its relation to fractal flow patterns and a further evaluation using field observations. Vadose Zone Journal, 2, 259-269, 2003. Berkeley Lab Report LBNL-52822.
Liu, H.H., Q. Zhou, J. Rutqvist, and G.S. Bodvarsson, Understanding the impact of upscaling THM processes on performance assessment. Presented at the GEOPROC International Conference on "Coupled T-H-M-C Processes in Geosystems: Fundamentals, Modeling, Experiments and Applications," October 13-15, 2003. Berkeley Lab Report LBNL-50447.

Liu, J., G.S. Bodvarsson, and Y.-S. Wu, Analysis of flow behavior in fractured lithophysal reservoirs. Journal of Contaminant Hydrology, 62-63, 189-211, 2003. Berkeley Lab Report LBNL49870.

Liu, J., E.L. Sonnenthal, and G.S. Bodvarsson, Calibration of Yucca Mountain unsaturated zone flow and transport model using porewater chloride data. Journal of Contaminant Hydrology, 62-63, 213-235 2003. Berkeley Lab Report LBNL-49871.

Lo, W.-C., G. Sposito, and E.L. Majer, Immiscible two-phase flows in deformable porous media. Advances in Water Resources, 25, 1105-1117, 2002. Berkeley Lab Report LBNL-50624.

Lu, G., E.L. Sonnenthal, and G.S. Bodvarsson, Implications of halide leaching on chlorine-36 studies at Yucca Mountain, Nevada. Water Resources Research, 39(12), 3-1 to 3-15, 1361, 2003. Berkeley Lab Report LBNL-50465.

Lu, G., and D. Zhang, Nonstationary stochastic analysis of flow in a heterogeneous semiconfined aquifer. Water Resources Research, 38(8), 30-1 to 30-11, 2002. Berkeley Lab Report LBNL-49754.

Lu, G., and C. Zheng, Natural attenuation of fuel hydrocarbon contaminants: Hydraulic conductivity dependency of biodegradation rates in a field case study. In Modlfow and More 2003: Understanding through Modeling, Golden, Colorado, 2003. Berkeley Lab Report LBNL-53443.

Lu, G., C. Zheng, and A. Wolfsberg, Effect of uncertain hydraulic conductivity on the fate and transport of BTEX compounds at a field site. Berkeley Lab Report LBNL-50464, 2002.

Lu, S., F.J. Molz, and H.-H. Liu, An efficient, three-dimensional, anisotropic, fractional Brownian motion and truncated factional Levy motion simulation algorithm based on successive random additions. Computers and Geosciences, 29, 15-25, 2003. Berkeley Lab Report LBNL-52537.

Machavaram, M.V., M.E. Conrad, and N.L. Miller, The deuterium excess in precipitation and atmospheric moisture in the southern Great Plains region of USA. Presented at the American Geophysical Union Conference, San Francisco, California, December 10-14, 2002. 
Maddalena, R.L., T.E. McKone, and W.J. Riley, Is there a "forest filter effect" for organic pollutants? Stochastic Environmental Research and Risk Assessment (in press), 2003. Berkeley Lab Report LBNL-51882.

Maher, K., D.J. DePaolo, M.E. Conrad, and R.J. Serne, Vadose zone infiltration rate at Hanford, Washington, inferred from Sr isotope measurements. Water Resources Research, 39(8), 1204, 2003. Berkeley Lab Report LBNL-53747.

Majer, E., 3-D Seismic methods for geothermal reservoir exploration and assessment. Berkeley Lab Report LBNL-49881, 2002.

Majer, E., L. Slater, A. Ward, D. Lesmes, S. Hubbard, and R. Cumbest, Verification: Airborne and surface geophysical methods. Berkeley Lab Report LBNL-52460, 2003.

Majer, E., J. Queen, T. Daley, J. Murphy, M. Fortuna, H.B. Lynn, R.T. Coates, P. Eike, J. Sinton, D. Cox, L. Myer, K. Nihei, and S. Nakagawa, Scaling between logs, single well, VSP and surface seismic for fracture quantification in naturally fractured gas reservoirs. In: Proceedings of the 72nd Annual Meeting of the SEG International Expo., pp. 2381-2384, Salt Lake City, Utah, 2002. Berkeley Lab Report LBNL-50699.

Majer, E., K. Williams, J.E. Peterson Jr., and T. Daley, Application of high resolution crosswell radar and seismic for mapping flow in the vadose zone. Presented at the SEG International Expo \& Annual Meeting, Salt Lake City, Utah, 2002. Berkeley Lab Report LBNL-50701.

Malkovsky, V.I., A.A. Pek, and C.-F. Tsang, Dynamic stabilization of heat-generating liquid waste plume in slope aquifer. Journal of Hydrology, 258, 69-82, 2002. Berkeley Lab Report LBNL-45957.

Manga, M., E.E. Brodsky, and M. Boone, Response of streamflow to multiple earthquakes and implications for the origin of postseismic discharge changes. Geophysical Research Letters, 30(5), 18-1-18-4, 2003.

Marshall, J.D., W.J. Riley, T.E. McKone, and W.W. Nazaroff, Intake fraction of primary pollutants: Motor vehicle emissions in the South Coast Air Basin. Atmospheric Environment, 37, 3455-3468, 2003. Berkeley Lab Report LBNL-51854.

Mays, D.C., B.A. Faybishenko, and S. Finsterle, Information entropy to measure temporal and spatial complexity of unsaturated flow in heterogeneous media. Water Resources Research, 38(12), 1313, DOI 10.1029/2001WR001185, 2002. Berkeley Lab Report LBNL-49181.

Miller, N.L., California climate change, hydrologic response, and flood forecasting. Berkeley Lab Report LBNL-54041, 2003.
Miller, N.L., A.W. King, M.A. Miller, E.P. Springer, M.L. Wesely, et al., The DOE water cycle pilot study. Bull. Amer. Meteorological Soc. (in press), 2003. Berkeley Lab Report LBNL53826.

Miller, N.L., K.E. Bashford, and E. Strem, Potential impacts of climate change on California hydrology. JAWRA, August 2003, pp. 771-784. Berkeley Lab Report LBNL-51313.

Miller, K.L., K.A. Polse, and C.J. Radke, Fenestrations enhance tear mixing under silicone-hydrogel contact lenses. Investigative Opthalmology and Vision Science, 44(1), 60-67, 2003.

Molinero, J., J. Samper, and R. Juanes, Numerical modeling of the transient hydrogeological response produced by tunnel construction in fractured bedrocks. Engineering Geology, 64(4), 369-386, 2002.

Moridis, G., Semianalytical solutions of radioactive or reactive solute transport in variably fractured layered media. Water Resources Research, 38(12), 46-1 to 46-24, 1310, 2002.

Moridis, G., Radioactive or reactive tracer transport in flowing fracture-matrix systems. Berkeley Lab Report LBNL-47951, 2002.

Moridis, G., EOS9nT V2.0 User's Manual-A Fortran 90 simulator of water flow and solute/colloid transport in the subsurface, 2003. Berkeley Lab Report LBNL-52826, 2003.

Moridis, G., Evaluation of gas production from Class 1 deposits of hydrates. Journal of Petroleum Science and Engineering (submitted), 2003. Berkeley Lab Report LBNL-52827, 2003.

Moridis, G., Numerical studies of hydrate preservation in cores and of gas production from permafrost hydrate accumulations. Berkeley Lab Report LBNL-52828, 2003.

Moridis, G., Numerical studies of gas production from methane hydrates. SPE Journal, 32(8), 2003. Berkeley Lab Report LBNL-50256.

Moridis, G., and T. Collett, Strategies for gas production from hydrate accumulations under various geologic conditions. In: Proceedings of the TOUGH Symposium 2003, On CD, Berkeley, California, May 12-14, 2003. Berkeley Lab Report LBNL-52568.

Moridis, G., T. Collett, S.R. Dallimore, T. Satoh, S. Hancock, and B. Weatherhill, Numerical studies of gas production from several $\mathrm{CH}_{4}$-hydrate zones at the Mallik Site, McKenzie Delta, Canada. Journal of Petroleum Science and Engineering (in press), 2002. Berkeley Lab Report LBNL50257. 
Moridis, G., Y. Seol, and Y.-S. Wu, Modeling studies of mountain-scale radionuclide transport in the unsaturated zone at Yucca Mountain, Nevada. In: Proceedings of the TOUGH Symposium 2003, On CD, Berkeley, California, May 12-14, 2003. Berkeley Lab Report LBNL-52567.

Moridis, G., Q. Hu, Y.S. Wu, and G.S. Bodvarsson, Preliminary 3$\mathrm{D}$ site-scale studies of radioactive colloid transport in the unsaturated zone at Yucca Mountain, Nevada. Water Resources Research, 60(3-4), 251-286, 2003. Berkeley Lab Report LBNL-45876.

Mukhopadhyay, S., and Y.W. Tsang, Uncertainties in coupled thermal-hydrological processes associated with the Drift Scale Test at Yucca Mountain, Nevada. Journal of Contaminant Hydrology, 62-63, 595-612, 2003. Berkeley Lab Report LBNL-49872.

Mukhopadhyay, S., and Y.W. Tsang, Understanding the anomalous temperature data from the Large Block Test at Yucca Mountain, Nevada. Water Resources Research, 38(10), 281-28-12, 2002. Berkeley Lab Report LBNL-49124.

Myer, L.R., Geomechanical risks in coal bed carbon dioxide sequestration. Berkeley Lab Report LBNL-53250, 2003.

Myer, L.R., S.M. Benson, C. Byrer, D. Cole, C.A. Doughty, W. Gunter, G.M. Hoversten, S. Hovorka, J.W. Johnson, K.G. Knauss, A. Kovscek, D. Law, M.J. Lippmann, E.L. Majer, B. van der Meer, G. Moline, R.L. Newmark, C.M. Oldenburg, J. Orr, Franklin M, K. Pruess, and C.-F. Tsang, The GEO-SEQ project: A status report. In GHGT-6, Kyoto, Japan, 2002. Berkeley Lab Report LBNL-51278.

Nadeau, R., and T. McEvilly, Periodic pulsing of the San Andreas Fault. Berkeley Lab Report LBNL-53593, 2003.

Nakagawa, S., K.T. Nihei, and L.R. Myer, Elastic wave scattering of a fracture with non-uniform stiffness distribution. EOS Transactions, 83(47), AGU Fall Meeting, Abstract S61B-1141, 2002.

Nakagawa, S., K.T. Nihei, and L.R. Myer, Elastic wave propagation along a set of parallel fractures. Geophysical Research Letters, 29(16), 31-34, 2002. Berkeley Lab Report LBNL-49623.

Nakagawa, S., K.T. Nihei, and L.R. Myer, Plane wave method for elastic wave scattering by a heterogeneous fracture. Berkeley Lab Report LBNL-52207, 2003.

Nakagawa, S., K.T. Nihei, L.R. Myer, and E.L. Majer, Three-dimensional elastic wave scattering by a layer containing vertical periodic fractures. Journal of Acoustical Society of America, 113, 3012-3023, 2002. Berkeley Lab Report LBNL-50241.
Narasimhan, T.N., A finite world, earth sciences, and public trust. Ground Water, 41(1), 11-14, 2002. Berkeley Lab Report LBNL51757.

Nelson, J.L., S. Paradis, J.N. Christensen, and J. Gabites, Canadian cordilleran Mississippi Valley-type deposits: A case for Devonian-Mississippian backarc hydrothermal origin. Economic Geology, 97(5), 1013-1036, 2002. Berkeley Lab Report LBNL51209.

Newman, G.A., G.M. Hoversten, and D.L. Alumbaugh, Three-dimensional magnetotelluric modeling and inversion: Application to sub-salt imaging. In: Three-Dimensional Electromagnetics: Proceedings of the Second International Symposium, Michael S. Zhdanov, ed., pp. 127-152, Elsevier Science, 2002. Berkeley Lab Report LBNL48528.

Nihei, K.T., L.R. Myer, and E.L. Majer, Fracture imaging with elastic waves. In: Proceedings of the $5^{\text {th }}$ International Workshop on the Application of Geophysics in Rock Engineering, Inter. Soc. Rock Mech., pp. 20-24, Toronto, Canada, 2002. Berkeley Lab Report LBNL-50789.

Nihei, K.T., S. Nakagawa, L.R. Myer, and E.L. Majer, Finite difference modeling of seismic wave interactions with discrete, finite fractures. Soc. Expl. Geophys. $72^{\text {nd }}$ Annual Meeting, pp. 1963-1966, Salt Lake City, Utah, 2002.

Nijssen, B., L.C. Bowling, L. C., D. P. Lettemaier, L.P. Graham, D.B. Clark, M. El Maayar, R. Essery, S. Goers, F. Habets, B. van den Hurk, J. Jin, D. Kahan, D. Lohmann, S. Mahanama, D. Mocko, O. Nasonova, P. Samuelsson, A.B. Shmakin, K. Takata, D. Verseghy, P. Viterbo, Y. Xia, X. Ma, Y. Xue, and Z.L. Yang, Simulation of high latitude hydrological processes in the Torne-Kalix basin: PILPS Phase 2e 2: Comparison of model results with observations. Global and Planetary Change, 38, 31-53, 2002.

Oldenburg, C.M., Carbon dioxide as cushion gas for natural gas storage. Energy and Fuels, 17, 240-246, 2002. Berkeley Lab Report LBNL-51053.

Oldenburg, C.M., Foreword to the special issue on strongly coupled density-dependent flow in porous media. Transport in Porous Media, 47(2), 123-124, 2002. Berkeley Lab Report LBNL-49076.

Oldenburg, C.M., Carbon sequestration in natural gas reservoirs: Enhanced gas recovery and natural gas storage. In: Proceedings of the TOUGH Symposium 2003, On CD, Berkeley, California, May 12-14, 2003. Berkeley Lab Report LBNL-52476. 
Oldenburg, C.M., P.F. Daley, B.M. Freifeld, J. Hinds, and P.D. Jordan, Three-dimensional groundwater flow, aquifer response and treatment system monitoring at Site OU 1, former Fort Ord, California, 2002. Berkeley Lab Report LBNL-49586, 2002.

Oldenburg, C.M., D.H.-S. Law, Y. LeGallo, and S.P. White, Mixing of $\mathrm{CO} 2$ and $\mathrm{CH} 4$ in gas reservoirs: Code comparison studies. In: Greenhouse Gas Control Technologies, pp. 443-448, J. Gale and Y. Kaya, eds., Proceedings of the $6^{\text {th }}$ International Conference on Greenhouse Gas Control Technologies, pp. 443-448, Elsevier, 2003. Berkeley Lab Report LBNL-49763.

Oldenburg, C.M., T.E. McKone, R.P. Hepple, and A.J.A. Unger, Health risk assessment for leakage and seepage from geologic carbon sequestration sites: Requirements and design of a coupled model. Berkeley Lab Report LBNL-51131, 2002.

Oldenburg, C.M., S.H. Stevens, and S.M. Benson, Economic feasibility of carbon sequestration with enhanced gas recovery (CSEGR). Energy (in press), 2003. Berkeley Lab Report LBNL-49762.

Oldenburg, C.M., and A.J.A. Unger, Coupled modeling framework for $\mathrm{CO}_{2}$ leakage and seepage risk assessment. Berkeley Lab Report LBNL-53009, 2003.

Oldenburg, C.M., and A.J.A. Unger, Coupled subsurface-surface layer gas transport and dispersion for geologic carbon sequestration seepage simulation. In: Proceedings of the TOUGH Symposium 2003, On CD, Berkeley, California, May 12-14, 2003. Berkeley Lab Report LBNL-52477.

Oldenburg, C.M., and A.J.A. Unger, On leakage and seepage from geologic carbon sequestration sites: unsaturated zone attenuation. Vadose Zone Journal, 2(3), 287-296, 2003. Berkeley Lab Report LBNL-51928.

Oldenburg, C., A. Unger, and R.P. Hepple, On atmospheric dispersion of $\mathrm{CO}_{2}$ seepage from geologic carbon sequestration. Berkeley Lab Report LBNL-51734, 2002.

Oldenburg, C.M., A.J.A. Unger, R.P. Hepple, and P.D. Jordan, On leakage and seepage from geological carbon sequestration sites. Berkeley Lab Report LBNL-51130, 2002.

Oldenburg, C.M., S.W. Webb, K. Pruess, and G.J. Moridis, Mixing of stably stratified gases in subsurface reservoirs: A comparison of diffusion models. Transport in Porous Media, 54, 323334, 2004. Berkeley Lab Report LBNL-51545.
Ontoy, Y., P. Molling, T. Xu, N. Spycher, M. Parini, and K. Pruess, Scaling of hot brine injection wells: Supplementing field studies with reactive transport modeling. In: Proceedings of the TOUGH Symposium 2003, On CD, Berkeley, California, May 12-14, 2003. Berkeley Lab Report LBNL-52513.

Oswald, W.J., My sixty years in applied algology. Journal of Applied Phycology, 15, 99-106, 2003.

Pan, L., WinGridder-An interactive grid generator for TOUGH2. In: Proceedings of the TOUGH Symposium 2003, On CD, Berkeley, California, May 12-14, 2003. Berkeley Lab Report LBNL-52422.

Pan, L., and G.S. Bodvarsson, Modeling transport in fractured porous media with random-walk particle method: The transient activity range and the particle transfer probability. Water Resources Research, 38(6), 2002. Berkeley Lab Report LBNL-48042.

Pan, L., Y.-S. Wu, and K. Zhang, A modeling study of flow diversion and focusing in unsaturated fractured rocks. Vadose Zone Journal, 2002 (in press). Berkeley Lab Report LBNL49274 .

Park, S.-H., and G. Sposito, Do montmorillonite surfaces promote methane hydrate formation?: Monte Carlo and molecular dynamics simulations. Journal of Physical Chemistry B, 107, 2281-2290, 2003. Berkeley Lab Report LBNL-52712.

Park, S.-H. and G. Sposito, Molecular modeling of clay structure and surface chemistry. In: Layered Materials for Catalytic and Other Applications, S.A. Auerbach, K.A. Carrado, and P.K. Dutta, eds., Marcel Dekker: New York (in press), 2003.

Park, S.-H. and G. Sposito, Monte Carlo simulations of hydration of mono- and divalent cation exchanged (SWy-1 and SAz-1) montmorillonite. EOS. AGU Transactions 83 (47). 2002. Berkeley Lab Report LBNL-48579.

Park, S.-H., K. Refson, and G. Sposito, Density functional theory on the structure of montmorillonite. In: Proceedings of the American Chemical Society National Meeting, AM CHEM S 223, p. 153, 2002. Berkeley Lab Report LBNL48577.

Park, S.-H., K. Refson, and G. Sposito, Ab initio computational crystallography of 2:1 clay minerals: I. Pyrophyllite 1-Tc. J. Phys. Chem. B. (in press), 2003. 
Park, S.-H., and G. Sposito, Structure of water absorbed on a mica surface. Physical Review Letters, 89, 2002. Berkeley Lab Report LBNL-49660.

Park, S.-H., G. Sposito, R. Sutton, and J. Greathouse, Formation and stability of methane hydrates in clay interlayers. Berkeley Lab Report LBNL-50312, 2002.

Parra, J.O., C.L. Hackert, A.W. Gorody, and V. Korneev, Detection of guided waves between gas wells for reservoir characterization. Geophysics, 67(1), 38-49, 2002. Berkeley Lab Report LBNL-48523.

Patzek, T.W., D.B. Silin, S.M. Benson, and G.I. Barenblatt, On vertical diffusion of gases in a horizontal reservoir. Transport in Porous Media, 51, 141-156, 2003. Berkeley Lab Report LBNL48909.

Perry, D.L., M.K. Firestone, G.L. Molnar, Z. Kasztovszky, R. Gatti, and P. Wilde, Neutron-induced prompt gamma activation analysis (PGAA) of metals and non-metals in ocean floor geothermal vent-generated samples. Journal of Analytical Atmospheric Spect., 17, 32, 2002. Berkeley Lab Report LBNL48424.

Pfiffner, S.M., A.V. Palumbo, T.J. Phelps, J.J. Beauchamp, D.B. Ringelberg, H.C. Pinkart, D.C. White, and T.C. Hazen, Microbial monitoring as a measure of success for in situ TCE bioremediation. Berkeley Lab Report LBNL-45232.

Pride, S.R., J.M. Harris, D.L. Johnson, A. Mateeva, K.T. Nihei, R.L. Nowack, J.W. Rector, H. Spetzler, R. Wu, T. Yamamoto, J.G. Berryman, and M. Fehler, Permeability dependence of seismic amplitudes. The Leading Edge, 22(6), 518-525, 2003. Berkeley Lab Report LBNL-53683.

Pride, S.R., J.M. Harris, D.L. Johnson, A. Mateeva, K.T. Nihei, R.L. Nowack, J.W. Rector, H. Spetzler, R. Wu, T. Yamomoto, J.G. Berryman, and M. Fehler, Erratum: Acquisition/processing-Permeability dependence of seismic amplitudes. The Leading Edge, 22(7), 698, 2003. Berkeley Lab Report LBNL-53735.

Pruess, K., Numerical simulation of multiphase tracer transport in fractured geothermal reservoirs. Geothermics, 31, 475-499, 2002. Berkeley Lab Report LBNL-48657.

Pruess, K., Numerical simulation of $\mathrm{CO}_{2}$ leakage from a geologic disposal reservoir, including transitions from super- to subcritical conditions, and boiling of liquid of $\mathrm{CO}_{2}$. In: Proceedings of the TOUGH Symposium 2003, On CD, Berkeley, California, May 12-14, 2003. Berkeley Lab Report LBNL-52423.
Pruess, K., Numerical simulation of $\mathrm{CO}_{2}$ leakage from a geologic disposal reservoir, including transitions from super- to subcritical conditions, and boiling of liquid $\mathrm{CO}_{2}$. Berkeley Lab Report LBNL-52423, 2003.

Pruess, K., Mathematical modeling of fluid flow and heat transfer in geothermal systems-An introduction in five lectures. Berkeley Lab Report LBNL-51295, 2002.

Pruess, K., A composite medium approximation for unsaturated flow in layered sediments. Journal of Contaminant Hydrology (in press), 2003. Berkeley Lab Report LBNL-49609.

Pruess, K. The TOUGH codes-A family of simulation tools for multiphase flow and transport processes in permeable media. Vadose Zone Journal (in press), 2003. Berkeley Lab Report LBNL-53630, 2003.

Pruess, K., and A. Battistelli, TMVOC, A simulator for multiple volatile organic chemicals. In: Proceedings of the TOUGH Symposium 2003, On CD, Berkeley, California, May 12-14, 2003. Berkeley Lab Report LBNL-52400.

Pruess, K., and A. Battistelli, TMVOC, a numerical simulator for three-phase non-isothermal flows of multicomponent hydrocarbon mixtures in saturated-unsaturated heterogeneous media. Berkeley Lab Report LBNL-49375, 2002.

Pruess, K., and A. Battistelli, TMVOC, A simulator for multiple volatile organic Ch. In: Proceedings of the TOUGH Symposium 2003, On CD, Berkeley, California, May 12-14, 2003. Berkeley Lab Report LBNL-52400.

Pruess, K. and J. García, Multiphase flow dynamics during $\mathrm{CO}_{2}$ injection into saline aquifers. Environmental Geology, 42, 282-295, 2002. Berkeley Lab Report LBNL-46793.

Pruess, K., and J. Garcia, Solutions of test problems for disposal of $\mathrm{CO}_{2}$ in saline aquifers. Berkeley Lab Report LBNL-51812, 2002.

Pruess, K., J. Garcia, T. Kovscek, C. Oldenburg, J. Rutqvist, C. Steefel, and T. Xu, Code intercomparison builds confidence in numerical simulation models for geologic disposal of $\mathrm{CO}_{2}$. Energy (in press), 2003. Berkeley Lab Report LBNL-52211.

Pruess, K., T. Xu, J. Apps and J. García, Numerical modeling of aquifer disposal of $\mathrm{CO}_{2}$, SPE Journal, 49-60, 2003. Berkeley Lab Report LBNL-47135.

Pruess, K., S. Yabusaki, C. Steefel and P. Lichtner, Fluid flow, heat transfer, and solute transport at nuclear waste storage tanks in the Hanford vadose zone. Vadose Zone Journal, 1(1-2), 68-88, 2002. Berkeley Lab Report LBNL-49215. 
Quinn, N.W.T., L.D. Brekke, N.L. Miller, T. Heinzer, H. Hidalgo, and J.A. Dracup, Model integration for assessing future hydroclimate impacts on water resources, agricultural production and environmental quality in the San Joaquin Basin, California. Environmental Modeling and Software (in press), 2003. Berkeley Lab Report LBNL-51708.

Quinn, N.W.T., C.W. Chen, and W. Stringfellow, A decision support system for real-time management of dissolved oxygen in the Stockton deep water ship channel. Environmental Information and Decision Support. In $9^{\text {th }}$ International Symposium on Environmental Software Systems, D.A.S. Gerald Schimak, Robert Argent, and Nigel Quinn, eds., Kluwer Academic Publishers, Massachusetts, Austria, 2003. Berkeley Lab Report LBNL-53394.

Quinn, N.W.T., and M.C.S. Eacock, Real-time water quality modeling and management in the San Joaquin River. In: Proceedings of the U.S. Committee on Irrigation and Drainage, pp. 73-86, San Luis Obispo, California, July 9-12, 2002. Berkeley Lab Report LBNL-51167.

Quinn, N.W.T., and M.W. Hanna, Real-time management of seasonal wetland drainage as an alternative for compliance with salinity TMDL objectives in California's Grasslands Basin. In: Proceedings of the U.S. Committee on Irrigation and Drainage, TMDL, Sacramento, California, 2002. Berkeley Lab Report LBNL-51168.

Quinn, N.W.T., and W.M. Hanna, A decision support system for adaptive real-time management of seasonal wetlands in California. Environmental Modeling and Software, 18(6), 503-511, 2003. Berkeley Lab Report LBNL-49206.

Quinn, N.W.T., C.Y. Jacquemin, and T. Heinzer, WESTSIM: A GISbased application of the integrated GW surface water model (IGSM) to the western San Joaquin Basin for conjunctive use planning and drainage prediction. In $23^{\text {rd }}$ Biennial Groundwater Conference, Sacramento, California, 2002. Berkeley Lab Report LBNL-50315.

Quinn, N.W.T and A.T. Tulloch, San Joaquin River diversion data assimilation, drainage estimation and installation of diversion monitoring stations. Final Report. CALFED Bay-Delta Program, Sacramento, California, 2002.

Radnedge, L., P.G. Agron, P.L. Worsham, and G.L. Andersen, Genome plasticity in Yersinia pestis. Microbiology Sgm., 148(6), 1687-1698, 2002.
Radosevich, J.L., W.J. Wilson, J.H. Shinn, T.Z. DeSantis, and G.L. Andersen, Development of a high-volume aerosol collection system for the identification of airborne micro-organisms. Letters in Applied Microbiology, 34(6), 162-167, 2002.

Ragot, F., S. Belin, V. Ivanov, D.L. Perry, M. Ortega, T.V. Ignatova, I.G. Kolobov, E.A. Masalitin, G.V. Kamarchuk, A.V. Yeremenko, Y.P. Molinie, J. Wery, and E. Faulques, Electronic and magnetic dynamic properties of imidazolate complexes. Material Science, 20, 13, 2002.

Ragot, F., V. Ivanov, J. Wery, A. Garcia, D.L. Perry, J. Ouvrard, and E. Faulques, Spectroscopy of a Eu(III)-imidazole complex. Synthetic Metals, 120(773), 2002. Berkeley Lab Report LBNL-50319.

Richardson, R.E., V.K. Bhupathiraju, D.S. Song, T. Goulet, and L. Alvarez-Cohen, Phylogenetic characterization of microbial communities that reductively dechlorinate TCE based upon a combination of molecular techniques. Environmental Science and Technology, 36(12), 2652-2662, 2002.

Richter, F.M., A.M. Davis, D.J. DePaolo, and E.B. Watson, Isotope fractionation by chemical diffusion between molten basalt and rhyolite. Geochimica et Cosmochimica Acta, 67(20), 39053923, 2003.

Riley, W.J., T.E. McKone, and E. Hubal-Cohen, Exposure and dose models for intermittent dermal contact. Risk Analysis (in press), 2003. Berkeley Lab Report LBNL-53020.

Riley, W.J., C.J. Still, B.R. Helliker, M. Ribas-Carbo, and J.A. Berry, Measured and modeled ${ }^{18} \mathrm{O}$ in $\mathrm{CO}_{2}$ and $\mathrm{H}_{2} \mathrm{O}$ above a tallgrass prairie. Global Change Biology (in press), 2003. Berkeley Lab Report LBNL-53019.

Riley, W.J., C.J. Still, M. Torn, and J.A. Berry, A mechanistic model of $\mathrm{H}_{2}{ }^{18} \mathrm{O}$ and $\mathrm{C}^{18} \mathrm{OO}$ fluxes between ecosystems and the atmosphere Model description and sensitivity analyses. Global Biogeochemical Cycles, 16, 1095-1109, 2002. Berkeley Lab Report LBNL-51234.

Roberts, P.M., I.B. Esipov, and E.L. Majer, Elastic wave stimulation of oil reservoirs: Promising EOR technology? The Leading Edge, 22(5), 448-453, 2003. Berkeley Lab Report LBNL-52234.

Roberts, P.M., S.A. Kostrove, W.O. Wooden, E.L. Majer, and T.M. Daley, Laboratory and field observations of stress-wave induced changes in oil flow behavior. In SEG Annual Meeting, Austin, Texas, 2002. Berkeley Lab Report LBNL-50633. 
Rutqvist, J., and O. Stephansson, The role of hydromechanical coupling in fractured rock engineering. Hydrogeology Journal, 11, 7-40, 2003. Berkeley Lab Report LBNL-52224.

Rutqvist, J., and C.-F. Tsang, Analysis of thermal-hydrologicalmechanical behavior near an emplacement drift at Yucca Mountain. Journal of Contaminant Hydrology, 62-63, 637-652, 2003. Berkeley Lab Report LBNL-49951.

Rutqvist, J., and C.-F. Tsang, A study of caprock hydromechanical changes associated with $\mathrm{CO}_{2}$ injection into a brine aquifer. Environmental Geology, 42, 296-305, 2002. Berkeley Lab Report LBNL-48145.

Rutqvist, J., Y.-S. Wu, C.-F. Tsang, and G. Bodvarsson, A modeling approach for analysis of coupled multiphase fluid flow, heat transfer, and deformation in fractured porous rock. Int. Journal of Rock Mechanics and Mining Sciences, 39, 429-442, 2002. Berkeley Lab Report LBNL-50138.

Salve, R., An automated tunnel evaporation measurement system for confined spaces. Hydrological Processes, 16, 1101-1109, 2002. Berkeley Lab Report LBNL-48157.

Salve, R., A passive-discrete water sampler for monitoring seepage. Groundwater (in press), 2003. Berkeley Lab Report LBNL-51203, 2002.

Salve, R., C. Doughty, and J.S.Y. Wang, Measuring and modeling flow in welded fractured tuffs. In: Proceedings of the International Groundwater Symposium: Bridging the Gap between Measurement and Modeling in Heterogeneous Media, pp. 393-397, Lawrence Berkeley National Laboratory, Berkeley, California, March 2002. Berkeley Lab Report LBNL-51205.

Salve, R., D. Hudson, H.-H. Liu, and J.S.Y. Wang, Development of a wet plume following liquid release along a fault. Berkeley Lab Report LBNL-52711, 2003.

Salve, R., H. H. Liu, Q. Hu, D. Hudson, P. Cook, and A. Czarnomski, Unsaturated Flow and transport through a fault embedded in fractured welded tuff. Water Resources Research (in press), 2003. Berkeley Lab Report LBNL-53632, 2003.

Salve, R., C. M. Oldenburg and J.S.Y. Wang, In situ flow experiments in nonwelded tuff: Conceptual models and implications for flow in the PTn. Journal of Contaminant Hydrology, 2003, 62-63, 269-286, 2003. Berkeley Lab Report LBNL-48869.

Salve, R., J.S.Y. Wang, and C. Doughty, Liquid-release tests in unsaturated fractured welded tuffs: I. Field investigations. Liquid flow in unsaturated fractured welded tuffs. Journal of Hydrology, 256(1-2), 60-79, 2002. Berkeley Lab Report LBNL-50334.
Seol, S.J., J.H. Suh, Y. Song, H.J. Kim, and K.H. Lee, The potential of fracture imaging using high-frequency, single-hole electromagnetic data. Geophysics, 67(4), 1087-1094, 2002. Berkeley Lab Report LBNL-52236.

Seol, Y., T.J. Kneafsey, K. Ito, and S. Finsterle, Simulation of unsaturated flow and transport through a fractured meter-sized model block using continuum approach. Berkeley Lab Report LBNL-52818, 2003.

Seol, Y., and L.S. Lee, Coupled effects of treated effluent irrigation and wetting/drying cycles on transport of atrazine and prometryn through unsaturated laboratory columns. Journal of Environmental Quality, 30, 1644-1652, 2002. Berkeley Lab Report LBNL-50337.

Seol, Y., and L.S. Lee, Effect of dissolved organic matter from treated effluents on sorption of atrazine and prometryn by soils. Soil Science Society of America Journal, 64(6), 1976-1983, 2002. Berkeley Lab Report LBNL-50338.

Seol, Y., H.H. Liu, and G.S. Bodvarsson, Effects of dry fractures on matrix diffusion in unsaturated fractured rocks. Geophysical Research Letters, 30(2), 1075, 2002. Berkeley Lab Report LBNL-49437.

Seol, Y., and F.W. Schwartz, Phase-transfer-catalyst applied to oxidation of trichloroethylene by potassium permanganate. Journal of Contaminant Hydrology, 44(2), 185-201, 2002. Berkeley Lab Report LBNL-50336.

Seol, Y., H. Zhang, and F.W. Schwartz, A review of in situ chemical oxidation and heterogeneity. Environmental and Engineering Geoscience, 6(1), 39-51, 2003. Berkeley Lab Report LBNL-52146.

Shan, C., and K. Pruess, EOSN-A new TOUGH2 module for simulating transport of noble gases in the subsurface. In: Proceedings of the TOUGH Symposium 2003, On CD, Berkeley, California, May 12-14, 2003. Berkeley Lab Report LBNL-52431.

Shan, C., and G. Bodvarsson, An analytical solution for estimating percolation rate by fitting temperature profiles in the vadose zone. Journal of Contaminant Hydrology, 25, 2003. Berkeley Lab Report LBNL-52351.

Shan, C., and K. Pruess, Numerical simulation of noble gases as natural tracers for injection returns and reservoir processes in vapor dominated systems. In: Proceedings of the $28^{\text {th }}$ Workshop on Geothermal Reservoir Engineering, pp. 286-293, Stanford, California, 2003. Berkeley Lab Report LBNL-52110. 
Shaughnessey, D., H. Nitsche, C.H. Booth, D.K. Shuh, G.A. Waychunas, R. Wilson, K. Cantrell, and R.J. Serne, Complexation and redox interactions between aqueous plutonium and manganese oxide interfaces. Journal of Nuclear Science Technology (in press), 2003. Berkeley Lab Report LBNL-47777.

Sheridan, C.C., D.C. Lee, S.G. Wakeham, and J.K.B. Bishop, Suspended particle organic composition and cycling in surface and midwaters of the equatorial Pacific Ocean. Deep Sea Research Part I-Oceanographic Research Papers, 49, 1983-2008, 2002. Berkeley Lab Report LBNL-50751.

Shevenell, L., L. Garside, G.B. Arehart, M.C. van Soest, and B.M. Kennedy, Geochemical sampling of thermal and nonthermal waters in Nevada to evaluate the potential for resource utilization. Geothermal Resources Council Transactions, 26, 501-505, 2002. Berkeley Lab Report LBNL-50647.

Shvidler, M., and K. Karasaki, Exact averaging of stochastic equations for transport in random velocity field. Transport in Porous Media, 50(3), 223-241, 2003. Berkeley Lab Report LBNL-46310.

Shvidler, M., and K. Karasaki, Probability density functions for solute transport in random fields. Transport in Porous Media, 50(3), 243-266, 2003. Berkeley Lab Report LBNL-46309.

Silin, D., and T. Patzek, On the Barenblatt model of spontaneous countercurrent imbibition. Transport in Porous Media (in press), 2003. Berkeley Lab Report LBNL-51373.

Silin, D., and T. Patzek, An object-oriented cluster search algorithm. Berkeley Lab Report LBNL-51599, 2003.

Silin, D., and T. Patzek, Robust determination of the pore space morphology in sedimentary rocks. In: Proceedings of the 2003 SPE Annual Technical Conference and Exhibition, On CD, Denver, Colorado, October 5-8, 2003. Berkeley Lab Report LBNL-52942.

Silin, D.B., and C.-F. Tsang, Estimation of formation hydraulic properties accounting for pre-test injection or production operations. Journal of Hydrology, 265, 1-14, 2002. Berkeley Lab Report LBNL-45079.

Silin, D.B. and C.-F. Tsang, A well-test analysis method accounting for pre-test operations. SPE Journal, 8(1), 22-30, 2003. Berkeley Lab Report LBNL-53012.
Silin, D., C.F. Tsang, and H. Gerrish, Replacing annual shut-in well tests by analysis of regular injection data: Field case feasibility study. In: Proceedings of the Second International Symposium on Underground Injection Science and Technology, On CD, Berkeley, California, 2003. Berkeley Lab Report LBNL-52941.

Silin, D.B., V.A. Korneev, and G.M. Goloshubin, Pressure diffusion waves in porous media. SEG 2003 73 ${ }^{\text {rd }}$ Annual Meeting, 2003. Berkeley Lab Report LBNL-52536.

Simmons, A.M., Natural analogue synthesis report. Report TDRNBS-GS-000027 REV00 ICN 02, Bechtel SAIC Company, Las Vegas, Nevada, 2002. Berkeley Lab Report LBNL-53065.

Singleton, M.J., E.L. Sonnenthal, M.E. Conrad, and D.J. DePaolo, Numerical modeling of stable isotope fractionation and multiphase reactive transport of water and water vapor using TOUGHREACT. In: Proceedings of the TOUGH Symposium 2003, On CD, Berkeley, California, May 12-14, 2003.

Singleton, M.J., E.L. Sonnenthal, M.E. Conrad, D.J. DePaolo, and G.W. Gee, Multiphase reactive transport modeling of stable isotope fractionation of infiltrating unsaturated zone pore water and vapor using TOUGHREACT. Vadose Zone Journal (in press), 2003. Berkeley Lab Report LBNL-54052, 2003.

Smith, J.T., and H.F. Morrison, Estimating equivalent dipole polarizabilities for the inductive response of isolated conductive bodies. IEEE Transactions on Geoscience and Remote Sensing (in press), 2003. Berkeley Lab Report LBNL51573.

Smith, J.T., H.F. Morrison, and A. Becker, Resolution depths for some transmitter receiver configurations. IEEE Transactions on Geoscience and Remote Sensing (in press), 2003. Berkeley Lab Report LBNL-51574.

Smith, J.T., H.F. Morrison, and A. Becker, Depths of equivalent dipole polarizability resolution for some transmitter receiver configurations. In UXO/Countermine Forum 2002, Orlando, Florida, 2002. Berkeley Lab Report LBNL-50636.

Song, D.L., M.E. Conrad, K.S. Sorenson, and L. Alvarez-Cohen, Stable carbon isotope fractionation during enhanced in situ bioremediation of trichloroethene. Environmental Science \& Technology, 36(10), 2262-2268, 2002. Berkeley Lab Report LBNL-50047. 
Song, Y., H.J. Kim, and K. Lee, High-frequency EM impedance for subsurface imaging. Geophysics, 67(2), 501-510, 2002. Berkeley Lab Report LBNL-50139.

Song, Y., H.J. Kim, and K.H. Lee, An integral equation representation of wide-band electromagnetic scattering by thin sheets. Geophysics, 67 (3), 746-754, 2002. Berkeley Lab Report LBNL50488.

Sonnenthal, E., N. Spycher, and J. Apps, A conceptual and numerical model for thermal-hydrological-chemical processes in the Yucca Mountain Drift Scale Test. Presented at the GEOPROC International Conference on "Coupled T-H-M-C Processes in Geosystems: Fundamentals, Modeling, Experiments and Applications," October 13-15, 2003.

Sonnenthal, E., N. Spycher, and T. Xu, Linking reaction, transport, and hydrological parameters in unsaturated fractured rock: TOUGHREACT implementation and application. In: Proceedings of the TOUGH Symposium 2003, On CD, Berkeley, California, May 12-14, 2003.

Sonnenthal, E., G. Lu, L. Han, I. McClung, and N. Spycher, Software qualification of TOUGHREACT V3.0. Berkeley Lab Report LBNL-53246, 2003.

Spiller, E., and D.L. Perry, A facile wet synthesis of nanoparticles of Litharge, the tetragonal form of $\mathrm{PbO}$. Proceed. Mater. Res. Soc., 704, 117, 2002. Berkeley Lab Report LBNL-51015.

Spycher, N., K. Pruess, and J. Ennis-King, $\mathrm{CO}_{2}-\mathrm{H}_{2} \mathrm{O}$ mixtures in the geologic sequestration of $\mathrm{CO}_{2}$. I. Assessment and calculation of mutual solubilities from 12 to $100^{\circ} \mathrm{C}$ and up to $600 \mathrm{bar}$. Geochimica et Cosmochimica Acta, 67(16), 3015-3031, 2003. Berkeley Lab Report LBNL-50991.

Spycher, N.F., E.L. Sonnenthal, and J.A. Apps, Fluid flow and reactive transport around potential nuclear waste emplacement tunnels at Yucca Mountain, Nevada. Journal of Contaminant Hydrology, 62-63, 653-674, 2003. Berkeley Lab Report LBNL-49875.

Spycher, N., E. Sonnenthal, P. Dobson, J. Apps, S. Salah, T.J. Kneafsey, and C. Haukwa, Drift-scale coupled processes (DST and THC Seepage) models. MDL-NBS-HS-000001 REV02, BSC, Las Vegas, Nevada, 2003. Berkeley Lab Report LBID-2473.

Starzec, P., and C.-F. Tsang, Use of fracture-intersection density for predicting the volume of unstable blocks in underground openings. Int. Journal of Rock Mechanics and Mining Sciences, 39, 807-813, 2002. Berkeley Lab Report LBNL-48475.
Still, C.J., W.J. Riley, B.A. Helliker, and J.A. Berry, Simulation of ecosystem ${ }^{18} \mathrm{O} \mathrm{CO}_{2}$ isotope fluxes in a tallgrass prairie: Biological and physical controls. In: Stable Isotopes and Biosphere-Atmosphere Interactions, L.B. Flanagan, J.R. Ehleringer, and D.E. Pataki, eds., Elsevier Academic Press, Physiological Ecology Series, 2002.

Strawn, D., H. Doner, M. Zavarin, and S. McHugo, Microscale investigation of the geochemistry of arsenic, selenium, and iron soil developed in pyritic shale materials. Geoderma, 108, 237-257, 2002.

Stringfellow, W.T., Applying co-metabolic biological reactions for the ex-situ treatment of methyl tert-butyl ether contaminated groundwater. In: Oxygenates in Gasoline: Environmental Aspects ACS Symposium Series 799, A.F.D. Drogos, ed., pp. 243-256, American Chemical Society, 2002. Berkeley Lab Report LBNL-46417.

Stringfellow, W.T., L. Chand, and A. Proctor, Kinetic parameters for the biological treatment of mixed wastes containing acetonitrile and methanol. Berkeley Lab Report LBID-2433, 2002.

Stringfellow, W.T., and K.-C. Oh, Influence of gasoline hydrocarbons on methyl tert-butyl ether biotreatment in fluidized bed bioreactors. Water Science and Technology, 2(2), 223-228, 2002. Berkeley Lab Report LBNL-51024.

Stringfellow, W.T., and K.-C. Oh, Initiation of MTBE biotreatment in fluidized-bed bioreactors. Journal of Environmental Engineering, 128(9), 852-861, 2002. Berkeley Lab Report LBNL-51023.

Stringfellow, W.T., and N.W.T. Quinn, Discriminating between west-side sources of nutrients and organic carbon contributing to algal growth and oxygen demand in the San Joaquin River. CALFED Bay-Delta Program, Sacramento, California, 2002. Berkeley Lab Report LBNL-51166.

Su, G., J.T. Geller, J.R. Hunt, and K. Pruess, Small-scale features of gravity-driven flow in unsaturated fractures. Vadose Zone Journal (in press), 2003. Berkeley Lab Report LBNL-50691.

Su, G.W., J. Jasperse, D. Seymour, and J. Constantz, Analysis of temperatures and water levels in wells to estimate alluvial aquifer hydraulic conductivities. Berkeley Lab Report LBNL53167, 2003.

Su, G.W., J.R. Nimmo, and M.I. Dragila, Effect of isolated fractures on accelerated flow in unsaturated porous rock. Water Resources Research (in press), 2003. Berkeley Lab Report LBNL-53788. 
Sudame, A., S. Lee, H. Lee, T. Lundquist, P. Muller, K. Hida, H. Ng, P.F. Strom, and T. Leighton, Selenite reducing bacteria of Panoche Algal Bacterial Selenium Removal (ABSR) Facility, California. In: Proceedings of $34^{\text {th }}$ Mid-Atlantic Industrial and Hazardous Waste Conference, pp. 159-172, September 2002.

Sutton, R., and G. Sposito, Animated molecular dynamics simulations of hydrated caesium-smectite interlayers. Geochemical Transactions, 3(9), 73-80, 2002. Berkeley Lab Report LBNL-50650.

Svitova, T., O. Theodoly, S. Christiano, R.M. Hill, and C.J. Radke, Wetting behavior of silicon oils on solid substrates immersed in aqueous electrolyte solutions. Langmuir, 18(18), 6821-6829, 2002.

Svitova, T. F., M. J. Weatherbee, and C. J. Radke, Dynamics of surfactant sorption at the air/water interface: Continuous flow tensiometry. J. Colloid and Interface Science, 261, 170-179, 2003.

Todaka, N., C. Akasaka, T. Xu, and K. Pruess, Modeling of geochemical interactions between acidic and neutral fluids in the Onikobe Geothermal Reservoir. In: Proceedings of the $28^{\text {th }}$ Workshop on Geothermal Reservoir Engineering, pp. 128-135, Stanford, California, 2003. Berkeley Lab Report LBNL-52002.

Todaka, N., C. Akasaka, T. Xu, and K. Pruess, Reactive geothermal transport simulation to study the formation mechanism of the impermeable barrier between acidic and neutral fluid zones in the Onikobe Geothermal Field, Japan. Berkeley Lab Report LBNL-52493, 2003.

Todesco, M., J. Rutqvist, G. Chiodini, K. Pruess, and C.M. Oldenburg, Modeling of recent volcanic episodes at Phlegrean Fields (Italy): Geochemical variations and ground deformation. Geothermics (in press), 2003. Berkeley Lab Report LBNL-53603.

Tokunaga, T.K., K.R. Olson, and J. Wan, Moisture characteristics of Hanford gravels: Bulk, grain-surface, and intragranular components. Vadose Zone Journal, 2, 322-329, 2003. Berkeley Lab Report LBNL-52691.

Tokunaga, T.K., J. Wan, M.K. Firestone, T.C. Hazen, K.R. Olson, D.J. Herman, S.R. Sutton, and A. Lanzirotti, In situ reduction of $\mathrm{Cr}(\mathrm{VI})$ in heavily contaminated soils through organic carbon amendment. Journal of Environmental Quality, 32, 541-549, 2003. Berkeley Lab Report LBNL-52528.

Tokunaga, T.K., J. Wan, T.C. Hazen, E. Schwartz, M.K. Firestone, S.R. Sutton, M. Newville, K.R. Olson, A. Lanzirotti, and W. Rao, Distribution of chromium contamination and microbial activity in soil aggregates. Journal of Environmental Quality, 32, 541-549, 2003. Berkeley Lab Report LBNL-48562.
Tokunaga, T.K., J. Wan, and K.R. Olson, Saturation-matric potential relations in gravel. Water Resources Research, 32(10), 1242, 2002. Berkeley Lab Report LBNL-49644.

Tomutsa, L., B. Freifeld, T.J. Kneafsey, and L.A. Stern, X-ray computed tomography observation of methane hydrate dissociation. In: Proceedings of the Society of Petroleum Engineers (SPE) Gas Technology Symposium, On CD, Calgary, Alberta, Canada, 2002. Berkeley Lab Report LBNL-49580.

Tomutsa, L., and V. Radmilovic, Focussed ion beam assisted threedimensional rock imaging at submicron scale. Proceedings of the 2003 International Symposium of the Society of Core Analysts, Pau, France, September 21-24, 2003. Berkeley Lab Report LBNL-52648.

Torn, M.S., S. Davis, J.A. Bird, M.R. Shaw, and M.E. Conrad, Automated analysis of ${ }^{13} \mathrm{C} /{ }^{12} \mathrm{C}$ ratios in $\mathrm{CO}_{2}$ and dissolved inorganic carbon for ecological and environmental applications. Rapid Communications in Mass Spectrometry (in press), 2003. Berkeley Lab Report LBNL-53147.

Torn, M., A.G. Lapenis, A. Timofeev, M. Fischer, I. Babikov, and J. Harden, Organic carbon and carbon isotopes in modern and 100-year-old soil archives of the Russian steppe. Global Change Biology, 8(10), 941-953, 2002. Berkeley Lab Report LBNL-48540.

Torn, M., C. Masiello, I. Basile-Doelsch, N. Bijoor, and R. Sutton, Mineral control of carbon storage in Andisols: Case studies and applications to other soils. In: Proceedings of the Conference on Mineralogy-Related Features and Processes Common to European Andosols, M. Kleber, P. Bartoli, and O. Arnalds, eds., pp. 7-8; COST ACTION 622: "Soil Resources of European Volcanic Systems," Manderscheid, Germany, April 24-28, 2002. Berkeley Lab Report LBNL-53797.

Trautz, R.C., and J.S.Y. Wang, Seepage into an underground opening constructed in unsaturated fractured rock under evaporative conditions. Water Resources Research, 38(10), 1188, 2002. Berkeley Lab Report LBNL-47006.

Truesdell, A.H., M.J. Lippmann, M.H. Rodríguez, and A. Pérez, Influence of reservoir processes on gas in Cerro Prieto steam. Geothermal Resources Council Trans., 27 (in press), 2003. Berkeley Lab Report LBNL-52642.

Trumbore, S.E., and M.S. Torn, Soils and the global carbon cycle. In: Soils and Global Change, E.A. Holland, ed., NATO Advanced Study Institute, 2003. Berkeley Lab Report LBNL44910. 
Tsang, C.-F., and C. Doughty, Multi-rate flowing wellbore electric conductivity logging method. Water Resources Research (in press) 2003. Berkeley Lab Report LBNL-52518.

Tsang, C.-F., and C. Doughty, A particle-tracking approach to simulating transport in complex fractures. Water Resources Research, 39(7), 1174, 2003. Berkeley Lab Report LBNL-50537.

Tsang, C.-F., and V.M. Shestakov, Introduction to the Special Issue: "Subsurface flow and transport: From theoretical studies to actions at field sites." Environmental Geology, 42(2-3), 125-126, 2002.

Tseng, H.-W., and K.H. Lee, Application of joint inversion for mapping fluid parameters. In: Proceedings of the $6^{\text {th }}$ SEGJ International Symposium: Imaging Technology, pp. 328-333, Tokyo, Japan, January 22-24, 2003. Berkeley Lab Report LBNL-51494.

Tseng, H.-W., K.H. Lee, and A. Becker, 3-D interpretation of electromagnetic data using a modified extended Born approximation. Geophysics, 68, 127-137, 2003. Berkeley Lab Report LBNL-51061.

Tsibakhashvili, N.Y., N.V. Asatiani, M.K. Abuladze, B.G. Birkaya, N.A. Sapojnikova, L.M. Mosulishvili, and H.Y.N. Holman, Capillary electrophoresis of $\mathrm{Cr}(\mathrm{VI})$ reducer Arthrobacter oxy dans. Biomedical Chromatography, 16(5), 327-331, 2002. Berkeley Lab Report LBNL-50927.

Tsibakhashvili, N.Y., L.M. Mosulishvili, T.L. Kalabegishvili, T.I. Kirkesali, M.V. Frontasyeva, E.V. Pomyakkushina, S.S. Pavlov, and H.-Y.N. Holman, Epithermal neutron activation analysis (ENAA) studies of chromium uptake by Arthrobacter oxydans. Journal of Radioanalytical and Nuclear Chemistry (in press), 2003. Berkeley Lab Report LBNL-53385.

Tsibakhashvili, N.Y., L.M. Mosulishvili, T.L. Kalabegishvili, D.T. Pataraya, M.A. Gurielidze, G.S. Nadareishvili, and H.Y.N. Holman, Chromate-resistant and reducing-microorganisms in Georgia basalts: Their distribution and characterization. Fresenius Environmental Bulletin, 11(10), 352-361, 2002. Berkeley Lab Report LBNL-50911.

Unger, A., S. Finsterle, and G. Bodvarsson, Mechanisms controlling radon gas concentrations in the exploratory studies facility and implications on the operation of the ventilation system. Journal of Contaminant Hydrology (in press), 2003. Berkeley Lab Report LBNL-51308, 2002.

Unger, A.J.A., B. Faybishenko, G.S. Bodvarsson, and A. Simmons, Simulating infiltration tests in fractured basalt at the Box Canyon Site, Idaho. Vadose Zone Journal (in press), 2003. Berkeley Lab Report LBNL-53047.
Unger, A.J.A., S. Finsterle, and G. Bodvarsson, Transport of radon gas into a tunnel at Yucca Mountain-Estimating large-scale fractured tuff hydraulic properties and implications for the operation of the ventilation system. Journal of Contaminant Hydrology, 20, 2003. Berkeley Lab Report LBNL-52577.

Urzua, L., T. Powell, W.B. Cumming, and P. Dobson, Apacheta, a new geothermal prospect in Northern Chile. Geothermal Resources Council Tran. 26, 65-69, 2002. Berkeley Lab Report LBNL-50457.

van Soest, M.C., D.R. Hilton, C.G. MacPherson, and D.P. Mattey, Resolving sediment subduction and crustal contamination in the Lesser Antilles Island arc: A combined He-O-Sr isotope approach. Journal of Petrology, 43(1), 143-170, 2002. Berkeley Lab Report LBNL-50641.

van Soest, M.C., B.M. Kennedy, W.C. Evans, and R.H. Mariner, Mantle helium and carbon isotopes in Separation Creek Geothermal Springs, Three Sisters area, Central Oregon: Evidence for renewed volcanic activity or a long-term steadystate system. In: GRC Meeting, Reno, Nevada, 2002. Berkeley Lab Report LBNL-50646.

Vasco, D.W., Seismic imaging of reservoir flow properties: Timelapse pressure changes. Geophysics (in press), 2003. Berkeley Lab Report LBNL-52486.

Vasco, D.W., A. Datta Gupta, R. Bechrens, P. Condon, and J. Rickett, Seismic imaging of reservoir flow properties: Timelapse amplitude changes. Berkeley Lab Report LBNL-52354.

Vasco, D.W., and S. Finsterle, Numerical trajectory calculations for the efficient inversion of flow and transport observations. Water Resources Research (in press) 2003. Berkeley Lab Report LBNL-51181.

Vasco, D.W., L. Johnson, and O. Marques, Resolution, uncertainty, and whole Earth tomography. Journal of Geophysical Research, 108(B1), 2022, 2003. Berkeley Lab Report LBNL51177.

Vasco, D.W., K. Karasaki, and O. Nakagome, Monitoring reservoir production using surface deformation at the Hijiori test site and the Okuaizu geothermal field, Japan. Geothermics, 31, 303-342, 2002. Berkeley Lab Report LBNL-51174.

Vasco, D.W., H. Keers, J.E. Peterson Jr., and E. Majer, Zeroth order asymptotics: Wave form inversion of the lowest degree. Geophysics, 68(2), 614-628, 2003. Berkeley Lab Report LBNL48685 . 
Vasco, D., J. Wicks, C., K. Karasaki, and O. Marques, Geodetic imaging: High resolution reservoir monitoring using satellite interferometry. Geophysical Journal International, 149, 555-571, 2002. Berkeley Lab Report LBNL-46464.

Victorov, A.I., C.J. Radke, and J.M. Prausnitz, Molecular thermodynamics for swelling of bicontinuous gel. Molecular Physics, 100(14), 2277-2297, 2002.

Viswanthan, H.S., A.V. Wolfsberg, P.W. Reimus, D.W. Ware, and G. Lu, Colloid facilitated transport in fractured rocks: Parameter estimation and comparison with experimental data. In: Proceedings of the $10^{\text {th }}$ International High-Level Radioactive Waste Management Conference, Las Vegas, Nevada, pp. 1337-1343, 2003. Berkeley Lab Report LBNL52268 .

Wagner, R., Y. Tsang, T. Vogt, W. Lin, J. Case, M. Conrad, L. DeLoach, B. Freifeld, F. Homuth, R. Jones, S. Levy, B. Marshall, J.E. Peterson, S. Sobolik, and K. Williams, Thermal testing measurements report. ANL-NBS-HS-000041 REV00, BSC, Las Vegas, Nevada, 2002. Berkeley Lab Report LBID2474.

Wan, J., and T.K. Tokunaga, Partitioning of clay colloids at airwater interfaces. Journal of Colloid and Interface Science, 247(1), 54-67, 2002. Berkeley Lab Report LBNL-49155.

Wan, J., T.K. Tokunaga, J.T. Larsen, and R.J. Serne, Geochemical evolution of highly alkaline and saline tank waste plumes during seepage through vadose zone sediments. Geochim. Cosmochim. Acta (in press), 2003.

Wan, J., T.K. Tokunaga, E. Saiz, K.R. Olsen, and J.T. Larsen, Colloid formation resulting from highly alkaline and saline waste tank solution leaking into sediments at the Hanford site, 2002. Berkeley Lab Report LBID-2446, 2002.

Wan, J., J.T. Larsen, T.K. Tokunaga, and Z. Zheng, pH Neutralization and zonation in alkaline-saline tank waste plumes. Environmental Science and Technology (in press), 2003. Berkeley Lab Report LBNL-53646, 2003.

Wang, J.S.Y., and G.S. Bodvarsson, Evolution of the unsaturated zone testing at Yucca Mountain. Journal of Contaminant Hydrology, 62-63, 337-360, 2003. Berkeley Lab Report LBNL-49876.

Watanabe, T., K.T. Nihei, S. Nakagawa, and L.R. Myer, Viscoacoustic waveform inversion and reverse-time reflection imaging of laboratory crosshole data. In: Proceedings of the $6^{\text {th }}$ International Symposium on Recent Advances in Exploration Geophysics, pp. 41-46, Kyoto, Japan, 2002.
Watanabe, T., K.T. Nihei, S. Nakagawa, and L.R. Myer, Imaging of crosshole laboratory data using visco-acoustic waveform inversion and reverse-time imaging. In: Proceedings of the 72 nd Annual Meeting of the Society of Exploration Geophysics, pp. 870-873, Salt Lake City, Utah, 2002.

Waychunas, G.A., Grazing incidence x-ray spectroscopy of mineral surfaces. Reviews in Mineralogy and Geochemistry, 49, 267-315, 2002. Berkeley Lab Report LBNL-50277.

Waychunas, G.A., Apatite luminescence. Reviews in Mineralogy and Geochemistry, 48, 701-742, 2002. Berkeley Lab Report LBNL-50278.

Waychunas, G.A., Applications of grazing incidence x-ray spectroscopy for mineralogical and geochemical analysis. European Journal of Mineralogy, 2003.

Waychunas, G.A., and C.C. Fuller, Surface complexation and precipitate geometry for aqueous $\mathrm{Zn}$ (II) sorption on Ferrihydrite: I. EXAFS analysis. Geochimica Cosmochimica Acta, 66, 1119-1137, 2002. Berkeley Lab Report LBNL-48552.

Waychunas, G.A., C.C. Fuller, J.A. Davis, and J.J. Rehr, Surface complexation and precipitate geometry for aqueous $\mathrm{Zn}$ (II) sorption on ferrihydrite: II. XANES analysis. Geochmica et Cosmochimica Acta (in press), 2003. Berkeley Lab Report LBNL-48561.

Webb, S.W., and K. Pruess, The use of Fick's law for modeling trace gas diffusion in porous media. Transport in Porous Media, 51(3), 327-341, 2003. Berkeley Lab Report LBNL-51363.

Wilkinson, T.J., D.L. Perry, M.C. Martin, W.R. McKinney, and M.C. Martin, Use of synchrotron reflectance infrared spectromicroscopy as a rapid, direct nondestructive method for the study of inks on paper. Applied Spectroscopy, 56, 800, 2002. Berkeley Lab Report LBNL-50162.

Wilkinson, T.J., D.L. Perry, W.R. McKinney, and M.C. Martin, Physics and forensics. Physics World, 15, 43, 2002. Berkeley Lab Report LBNL-50163.

Williams, K.H., M.B. Kowalsky, and J.E. Peterson, High resolution imaging of vadose zone transport using surface and crosswell ground penetrating radar methods. Berkeley Lab Report LBNL-53151.

Wilson, K.H., W.J. Wilson, J.L. Radosevich, T.Z. DeSantis, V.S. Viswanathan, T.A. Kuczmarski, and G.L. Andersen, Highdensity microarray of small-subunit ribosomal DNA probes. Applied and Environmental Microbiology, 68(5), 2535-2541, 2002. 
Wilson, W.J., C.L. Strout, T.Z. DeSantis, J.L. Stilwell, A.V. Carrano, and G.L. Andersen, Sequence-specific identification of 18 pathogenic microorganisms using microarray technology. Molecular and Cellular Probes, 16(2), 119-127, 2002.

Wu, Y.-S., An approximate analytical solution for non-Darcy flow in fractured media. Water Resources Research, 38(3), 5-1-5-7, 2002. Berkeley Lab Report LBNL-48197.

$\mathrm{Wu}, \mathrm{Y}$.-S., Numerical simulation of single-phase and multiphase non-Darcy flow in porous and fractured reservoirs. Transport in Porous Media, 49(2), 209-240, 2002. Berkeley Lab Report LBNL-45855.

$\mathrm{Wu}, \mathrm{Y}$.-S., Non-Darcy flow behavior near high-flux injection wells in porous and fractured formations. Presented at the International Symposium on Underground Injection, Berkeley, California, October 2003. Berkeley Lab Report LBNL-52541.

$\mathrm{Wu}$, Y.-S., and J. Liu, Integration of perched water and chloride data in modeling flow processes within the unsaturated zone of Yucca Mountain, Nevada. In: Proceedings of the 2002 IAHR International Groundwater Symposium (in press), Berkeley, California, 2003. Berkeley Lab Report LBNL-48702.

Wu, Y.-S., H.-H. Liu, and G. Bodvarsson, Effect of small-scale fractures on flow and transport processes at Yucca Mountain, Nevada. Presented at the 2003 International High-Level Radioactive Waste Management Conference, Las Vegas, Nevada, 2003. Berkeley Lab Report LBNL-51848.

Wu, Y.-S., G. Lu, K. Zhang, and G.S. Bodvarsson, Modeling unsaturated flow and transport processes in fractured tuffs of Yucca Mountain. In: Modflow and More: Understanding through Modeling, Golden, Colorado, September 2003. Berkeley Lab Report LBNL-53439.

Wu, Y. S., G. Lu, K. Zhang, G. Zhang, H.H. Liu, T. Xu, and E. L. Sonnenthal, UZ flow models and submodels. Report MDLNBS-HS-000006 REV01, Berkeley, CA, Lawrence Berkeley National Laboratory, Las Vegas, Nevada, CRWMS M\&O, 2003. Berkeley Lab Report LBID-2330.

Wu, Y.-S., and L. Pan, Special relative permeability functions with analytical solutions for transient flow into unsaturated rock matrix. Water Resources Research, 39(4), 2002. Berkeley Lab Report LBNL-50443.
Wu, Y. S., L. Pan, W. Zhang, and G. S. Bodvarsson, Characterization of flow and transport processes within the unsaturated zone of Yucca Mountain, Nevada. Journal of Contaminant Hydrology, 54, 215-247, 2002. Berkeley Lab Report LBNL-46572.

Wu, Y.-S., K. Zhang, and K. Pruess, Massively parallel simulation of flow and transport in porous in variably saturated porous and fractured media. Computational Methods in Water Resources, 1, 289-296, 2002. Berkeley Lab Report LBNL-49407.

Wu, Y.-S., W. Zhang, L. Pan, J. Hinds, and G.S. Bodvarsson, Modeling capillary barriers in unsaturated fractured rock. Water Resources Research, 38(11), 35-1 to 35-12, 2002. Berkeley Lab Report LBNL-47469.

Wu, Y.S., K. Zhang, C. Ding, K. Pruess, E. Elmroth and G.S. Bodvarsson, An efficient parallel-computing method for modeling nonisothermal multiphase flow and multicomponent transport in porous and fractured media. Adv. Wat. Resour., 25, 243-261, 2002. Berkeley Lab Report LBNL-47937.

Wuy, L., DOE-NABIR PI Workshop: Abstracts 2002. Berkeley Lab Report LBNL-49242.

Wuy, L., DOE-NABIR PI Workshop: Abstracts 2003. Berkeley Lab Report LBNL-51925.

Xu, T., E. Sonnenthal, N. Spycher, and K. Pruess, TOUGHREACT: A new code of the TOUGH family for nonisothermal multiphase reactive geochemical transport in variably saturated geologic media. In: Proceedings of the TOUGH Symposium 2003, On CD, Berkeley, California, May 12-14, 2003. Berkeley Lab Report LBNL-52342.

Xu, T., J. Apps, and K. Pruess, Mass transfer, mineral alteration, and $\mathrm{CO}_{2}$ sequestration in a sandstone-shale system. Berkeley Lab Report LBNL-52566, 2003.

Xu, T., J. Apps, and K. Pruess, Reactive geochemical transport simulation to study mineral trapping for $\mathrm{CO}_{2}$ disposal in deep arenaceous formations. Journal of Geophysical Research, 108(B2), 2071, doi:10.1029/2002JB001979, 2003. Berkeley Lab Report LBNL-50089.

$\mathrm{Xu}$, T., J.A. Apps, and K. Pruess, $\mathrm{CO}_{2}$ sequestration in bedded sandstone-shale sequences. Presented at the Second Annual Carbon Sequestration Conference, Alexandria, Virginia, 2003. Berkeley Lab Report LBNL-52616. 
Xu, T., J.A. Apps, and K. Pruess, Numerical simulation to study mineral trapping for $\mathrm{CO}_{2}$ disposal in deep aquifiers. Applied Geochemistry (in press), 2003. Berkeley Lab Report LBNL-48399.

Xu, T., K. Pruess, and G. Brimhall, Modeling reactive geochemical transport in natural fractured rock systems over geological time. 2002 International Groundwater Symposium, Berkeley, California, March 25-28, 2002. Berkeley Lab Report LBNL-49062.

Xu, T., E. Sonnenthal, and G. Bodvarsson, A reaction-transport model for calcite precipitation and evaluation of infiltrationpercolation fluxes in unsaturated fractured rock. Journal of Contaminant Hydrology, 64(1-2), 113-127, 2003. Berkeley Lab Report LBNL-48282.

Yaros, H.D., J. Newman, and C.J. Radke, Evaluation of DLVO theory with disjoining-pressure and film-conductance measurements of common-black films stabilized with sodium dodecyl sulfate. Journal of Colloid and Interface Science, 262, 442-455, 2003.

Yoon, S., A. Datta-Gupta, D.W. Vasco, and G.A. Pope, Inverse modeling of partitioning interwell tracer tests: A streamline approach. Water Resources Research, 38(6), 10.1029, 2002. Berkeley Lab Report LBNL-51178.

Zavarin, M., and H.E. Doner, Interpretation of heterogeneity effects in synchrotron $x$-ray fluorescence microprobe data. Geochemical Transactions, 3, 51-55, 2002.

Zawislansi, P.T., S.M. Benson, R. TerBerg and S. Borglin, Selenium speciation, solubility, and mobility in land-disposed dredged sediments. Environmental Science and Technology, 37(11), 2415-2420, 2003. Berkeley Lab Report LBNL-48714.

Zhang, K., and A.D. Woodbury, A Krylov finite-element approach for multi-species containment transport in discretely fractured porous media. Advances in Water Resources, 25, 705-721, 2002.

Zhang, K., Y.-S. Wu, G. Bodvarrson, and H.-H. Liu, Determination of unsaturated flow paths in a randomly distributed fractured network. Presented at the 2003 World Water and Environmental Congress, American Society of Civil Engineers, Philadelphia, Pennsylvania, 2003. Berkeley Lab Report LBNL52192.
Zhang, K., Y.S. Wu, G.S. Bodvarsson, and H.H. Liu, Flow focusing in unsaturated fracture networks: A numerical investigation. Vadose Zone Hydrology (in press), 2003. Berkeley Lab Report LBNL-52819, 2003.

Zhang, K., Y.-S. Wu, and G.S. Bodvarsson, Massively parallel computing simulation of fluid flow in the unsaturated zone of Yucca Mountain, Nevada. Journal of Contaminant Hydrology, 62-63, 381388-399, 2003. Berkeley Lab Report LBNL-48883.

Zhang, K., Y.-S. Wu, C. Ding, and K. Pruess, TOUGH2_MP: A parallel version of TOUGH2. In: Proceedings of the TOUGH Symposium 2003, On CD, Berkeley, California, May 12-14, 2003. Berkeley Lab Report LBNL-52508.

Zhang, Y., and G. Pinder, Latin-hypercube lattice-samples selection strategy for correlated random hydraulic-conductivity fields. Water Resources Research, 39(8), 1226, doi:10.1029/ 2002WR001822, 2003. Berkeley Lab Report LBNL-53043.

Zhang, Y., G. Pinder, and G. Herrera, Enabling technology for the least-cost design of groundwater quality monitoring networks: 1. Methodology. Berkeley Lab Report LBNL-53046, 2003.

Zhang, Y., G. Pinder, and G. Herrera, Enabling technology for the least-cost design of groundwater quality monitoring networks: 2. Field application. Berkeley Lab Report LBNL-53044, 2003.

Zheng, Z., T.K. Tokunaga, and J. Wan, Influence of calcium carbonate on sorption of U(VI) to soils. Environ. Science Technology (in press), 2003.

Zhou, Q., J.T. Birkholzer, I. Javandel, and P.D. Jordan, Simulation of groundwater flow at the LBNL site using TOUGH2. In: Proceedings of the TOUGH Symposium 2003, On CD, Berkeley, California, May 12-14, 2003. Berkeley Lab Report LBNL-52512.

Zhou, Q., G.S. Bodvarsson, H.H. Liu, and C.M. Oldenburg, Characterization of spatial variability of hydrogeologic properties for unsaturated flow in the fractured rocks at Yucca Mountain, Nevada. Berkeley Lab Report LBNL50505, 2002.

Zhou, Q., H.-H. Liu, G.S. Bodvarsson, and C.M. Oldenburg, Flow and transport in unsaturated fractured rock: Effects of multiscale heterogeneity of hydrogeologic properties. Journal of Contaminant Hydrology, 60(1-2), 2002. Berkeley Lab Report LBNL-50503. 


\section{EARTH ScIENCES Division StAFF 2002-2003}

\section{DIVISION DIRECTOR}

Gudmundur S. Bodvarsson

\section{SCIENTISTS/ENGINEERS}

\section{Hydrogeology AND} RESERVOIR DYNAMICS

Birkholzer, Jens

Campbell, Christopher

Doughty, Christine

Faybishenko, Boris

Finsterle, Stefan

Freifeld, Barry

Haukwa, Charles

$\mathrm{Hu}$, Qinhong (Max)

Javandel, Iraj

Karasaki, Kenzi

Kim, Jeongkon

Kiryukhin, Alexey

Kneafsey, Timothy

Li, Guomin

Lippmann, Marcelo

Liu, Hui-Hai

Liu, Jianchun

Moridis, George

Mukhopadhyay, Sumit

Oldenburg, Curtis *

Onishi, Tiemi

Pan, Lehua

Pruess, Karsten

Rutqvist, Jonny

Salve, Rohit

Seol, Yongkoo

Silin, Dmitriy

$\mathrm{Su}$, Grace

Tokunaga, Tetsu

Truesdell, Alfred

Tsang, Chin-Fu

Tsang, Yvonne

Unger, Andre

Wan, Jiamin

Wang, Joseph

Wu, Yu-Shu

$\mathrm{Xu}$, Tianfu

Zhang, Keni

Zhou, Quanlin

Zimmerman, Robert
GEOPHYSICS AND

GEOMECHANICS

Gasperikova, Erika

Goldstein, Norman

Gritto, Roland

Haught, Ramsey

Hoversten, Michael

Hubbard, Susan

Korneev, Valeri

Lee, Ki Ha

Majer, Ernest

Myer, Larry

Nakagawa, Seiji

Nihei, Kurt *

Pride, Steven

Smith, Torquil

Tseng, Ocean

Tomutsa, Liviu

Vasco, Donald

\section{GEOCHEMISTRY}

Apps, John

Bishop, James

Christensen, John Neil

Conrad, Mark

DePaolo, Donald *

Dobson, Patrick

Gates, Lydia

Guay, Christopher

Kennedy, M. Burton

$\mathrm{Lu}$, Guoping

Miller, Norman

Myneni, Satish

Park, Sung-Ho

Perry, Dale

Riley, William

Simmons, Ardyth

Sonnenthal, Eric

Spycher, Nicolas

Torn, Margaret

Waychunas, Glenn
Microbial Ecology AND ENVIRONMENTAL ENGINEERING

Andersen, Gary

Borglin, Sharon

Hazen, Terry *

Holman, Hoi-Ying

Quinn, Nigel

Stringfellow, William
* Department Head 


\section{FACULTY}

\section{HYDROLOGY AND RESERVOIR DYNAMICS}

Manga, Michael Narasimhan, T.N. Patzek, Tadeusz Radke, Clayton Witherspoon, Paul

\section{GEOPHYSICS AND GEOMECHANICS}

Becker, Alex

Cooper, George

Doyle, Fiona

Dreger, Doug

Glaser, Steven

Johnson, Lane

Morrison, H. Frank

Rector, James

Romanowicz, Barbara

Rubin, Yoram

\section{GEOCHEMISTRY}

Banfield, Jillian

Boering, Kristie

Brimhall, George

Fung, Inez

DePaolo, Donald

Dietrich, William

Doner, Harvey

Ingram, B. Lynn

Kyriakidis, Phaedon

Sposito, Garrison
Microbial Ecology AND ENVIRONMENTAL ENGINEERING

Alvarez-Cohen, Lisa

Buchanan, Bob

Coates, John

Firestone, Mary

Leighton, Terrance

Oswald, William

\section{POSTDOCTORAL FELLOWS}

\section{HYDROLOGY AND \\ RESERVOIR DYNAMICS}

Ghezzehei, Teamrat

Ito, Kazumasa

Krutilla, Kendra

Lewicki, Jennifer

Zhang, Yingqi

Zheng, Zuoping

\section{GEOPHYSICS AND}

GEOMECHANICS

Chen, Jinsong

Lo, Wei-Cheng

Toomey, Aoife

Tseng, Hung-Wen

\section{GEOCHEMISTRY}

Bashford, Kathy

Kemball-Cook, Susan

Salah, Sonia

Singleton, Michael

Zhang, Guoxiang
Microbial Ecology AND ENVIRONMENTAL ENGINEERING

Letain, Tracy

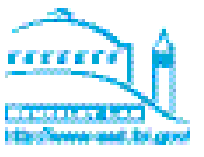




\section{RESEARCH ASSOCIATES, SPECIALISTS, AND TECHNICIANS}

\section{HYDROLOGY AND \\ RESERVOIR DYNAMICS}

Ahlers, C. Fredrik

Borelli, Robert

Cook, Paul J.

Czarnomski, Atlantis

Flexser, Steven

Gonzalez, Jr., Emilio

Hedegaard, Randall F.

Hinds, Jennifer

Jordan, Preston

Larsen, Joern

Menendez-Barreto, Melani

Morales, Alejandro

Olson, Keith

Pena, Jasquelin

Shan, Chao

Trautz, Robert

\section{GEOPHYSICS AND}

GEOMECHANICS

Daley, Thomas

Geller, Jil

Hepple, Robert

Hoffpauir, Cecil

Lippert, Donald
Nandi, Papia

Peterson, John

Solbau, Ray

Sell, Russell

Williams, Kenneth

\section{GeocheMistry}

Alusi, Thana

Biraud, Sebastien

Brooks, Kindra

Cooley, Heather

Cox, Dale

Downs, Kindra

Finnin, Lawrence

Foster, Prudence

Gatti, Raymond

Jin, Jiming

Kong, Jonas

Lindvall, Rachel

Machavaram, Madhav

Macomber, Tara

Olness, Charles

Owens, Thomas

Pesenson, Igor
Zhang, Yongkai

Smith, Donna

van Soest, Matthijs

Vonguyen, Lien

Westbrook, Jessica

Williard, Deb

Wood, Todd

Woods, Katharine

Zhao, Wenguang

\section{Microbial Ecology AND}

ENVIRONMENTAL ENGINEERING

DeSantis, Todd

Hanlon, Jeremy

Huang, Rick

Joyner, Dominique

Komada, Tatsuyuki

Leonardson, Rebecca

Lin, Zhang (Jenny)

Lundquist, Tryg

Moberg, Jordan

Murray, Sonya

Oh, Keun-Chan

Zubieta, Ingrid

\section{GRADUATE STUDENT RESEARCH ASSISTANTS}

\section{HYDROGEOLOGY AND RESERVOIR DYNAMICS}

Al-Futaisi, Ahmed

Benito, Pascual

Cheng, Lily

Chhabra, Mahendra

Duff, Elizabeth

Fornasiero, Francesco

Freer, Eric

Garcia, Julio

Green, Christopher

Halecky, Nicholaus

Howes, Andrew

Jin, Guodon

Juanes, Ruben

Mays, David

Payne, Mark

Reynolds, Benedict

Rowland, Joel

Saar, Martin

Van Amstel, Wouter
GEOPHYSICS AND

GEOMECHANICS

Anderson, Heidi

Aristilde, Ludmilla

Bhatt, Divesh

Choi, Youngki

Cassassuce, Florence

Hildenbrand, Keary

Kowalsky, Michael

Pandit, Tarun

Sutton, Rebecca

Yang, Jeong-Seok

Zhang, Linbin

Zhang, Yongkai

\section{GEOCHEMISTRY}

Asiego, Sarah

Berhe, Asmeret

Hammersley, Lisa

Jin, Ling

Lam, Phoebe

Maher, Katharine

Stanley, Mary

Yaros, Heather
Microbial Ecology and

ENVIRONMENTAL ENGINEERING

Ju, Kou-San

Wozei, Eleanor 


\section{TECHNICAL, ADMINISTRATIVE, AND MANAGEMENT STAFF}

Aden-Gleason, Nancy

Atkinson, Maria

Bruce, John

Burton, Terry

Datta, Robin

Denn, Walter

Dotterer, Marlene

Fissekidou, Vassiliki

Gruol, Victor

Han, Lijie
Harris, Stephen

Hawkes, Daniel

Houseworth, James

Kramer, Bridget

Kurtzer, Greg

Lau, Peter K.

Lucido, Nina

McClung, Ivelina

Miller, Grace

Morales, Alejandro
Nieder-Westermann, Gerald

Nodora, Donald

Persoff, Peter

Pfeiffer, Joyce

Seybold, Sherry

Swantek, Diana

Taliaferro, Carol

Terberg, Robert

Valladao, Carol

Villavert, Maryann

Wuy, Linda 


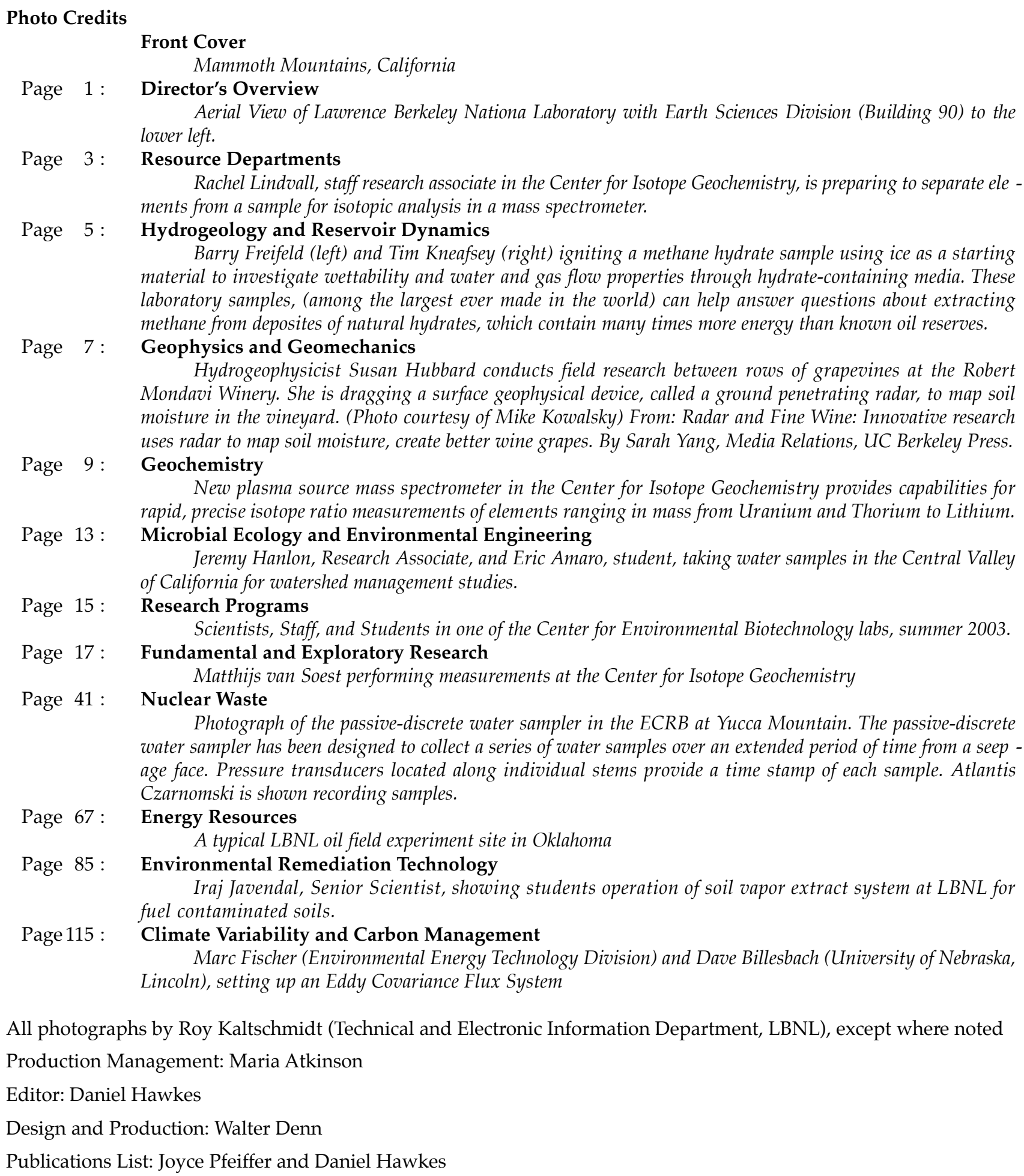
water sampler has been designed to collect a series of water samples over an extended period of time from a seep age face. Pressure transducers located along individual stems provide a time stamp of each sample. Atlantis Czarnomski is shown recording samples.

Page 67: Energy Resources A typical LBNL oil field experiment site in Oklahoma

Page 85: $\quad$ Environmental Remediation Technology Iraj Javendal, Senior Scientist, showing students operation of soil vapor extract system at LBNL for fuel contaminated soils.

Page 115 : Climate Variability and Carbon Management Marc Fischer (Environmental Energy Technology Division) and Dave Billesbach (University of Nebraska, Lincoln), setting up an Eddy Covariance Flux System

All photographs by Roy Kaltschmidt (Technical and Electronic Information Department, LBNL), except where noted Production Management: Maria Atkinson

Editor: Daniel Hawkes

Design and Production: Walter Denn

Publications List: Joyce Pfeiffer and Daniel Hawkes 


\section{2-2003}

\section{EARTH SCIENCES DIVISION RESEARCH SUMMARIES}

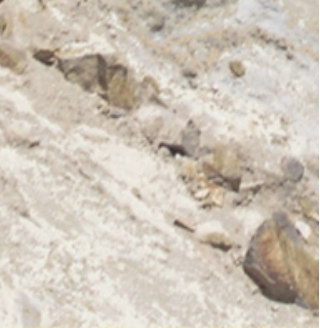

